
$E-1$ 



\section{ANATOMIE DES KANINCIENS}

IN

TOPOGRAPHISCHER UND OPERATIVER RÜCKSICHT

BEARBEITET

VON

\section{W. KRAUSE}

DR. MED. ET ZOOL, PROFESSOR IN GÖTTINGEN.

ZWEITE AUFLAGE.

MIT 161 FIGUREN IN HOLZSCHNITT.

\section{LEIPZIG}

VERLAG VON WILHELM ENGELMANN

1884. 
Alle Rechte vorbehalten. 
C. L U D W I G

GE WID MET. 



\section{Mein verehrter Lehrer und Fremnd!}

Wenn Sie die zweite Auflage dieser Monographie durchblattern, so werden Sie eine Anzahl von Verinderungen finden, welche ich längst vornehmen zu können gewuinscht hätte. Sorgfiltigeres Priiparieren hat manche thmen wahrscheinlich nicht ganz unbekannte Maingel beseitigen helfen und die Figuren sind stimtlich neu geschnitten.

Sie werden bemerken, daß ich auf dem neuen Titelhlatt mich als Dr. zool. (rect. philos.) bezeichnen konnte. Ich dankie dies der nachsichtigen Beurteilung meiner vergleichend-anatomischen und histologischen Arbeiten seitens threr geehrten Kollegen von der kgl. philosophischen Fakultait zu Leipzig, insbesondere Herm Geh. Hofrallh Leuckart.

Was an der vorliegenden Arbeit Brauchbares sein mag, verdanke ich wesentlich Ihnen. Ihr Vorbild und Ihre Anregung erfültten mich nicht nur indirelit mit dem Mut, mich einer wissenschaftlichen Thatigkeit ibberhaupt zu widmen, sondern ich habe auch meine ganze Richtung wesentlich dem frischen geistigen Luftzug zu danken, welcher schon lhr kleines Laboratorium in Zuirich durchwehte. Gestatten Sie deshalb, daß ich die vorstehende Widmung mit dem Ausdruck solchen Dankes und der Erimnerung an jene goldenen Tage verbinde.

Göttingen, den 15 . November 1883.

\section{W. Krause.}





\section{Inhalts - Verzeichnis.}

Allgemeine Anatomie.

Einleitung. Seite

Naturgeschichte .............

Rassen des Kaninchens . . . . . . 7

Unterschiede des Hasen u. Kaninchens ...... $241 \quad 12$

Krankheiten . . . . . . . 21

Plan der Darstellung . . . . . .

Technik der Operationen. . . 30

Allgemeine Osteologie . . . . . 3 36

Allgemeine Syndesmologie . . . . 47

Mechanik der Gelenke. . . . 47

Allgemeine Myologie . . . . . . . . 49

Allgemeine Splanchnologie . . . . $\quad 57$

Allgemeine Angiologie . . . . . . . 63

Allgemeine Neurologie . . . . . $6 \mathrm{~s}$

\section{Spezielle Anatomie.}

\section{Osteologie u. Syndesmologie.}

\section{Kopf .}

Schädelknochen . . . . . . 75

Os occipitis . . . . . . . . . . 75

Os interparietale . . . . . . 78

Os sphenoideum posterius . . . 80

Os sphenoideum anterius . . . . 89

Ossa temporum a....... Sit

Ossa parietalia . . . . . . . 88

Os frontis . . . 89

Os ethmoideum ....... 91

Gesichtsknochen . . . . . . 9.3

Ossa maxillaria superiora . . . . 93

Os intermaxillare. .... 93

Os maxillare superius proprium 94

Ossa zygomatica . . . . . . 96

Ossa palatina . . . . . . 96

Ossa nasi . . . . . . . . . 98

Ossa lacrymalia . . . . . . . 98

Conchae anteriores. . . . . . . 99

Vomer ........ . 100

Maxilla inferior . . . 100

Kiefergelenk . . . 102

Os hyoideum . . . . . 103
Wirbelsinule ........ 10'

llalsteil. . . . . 104

Riickenteil . . . . . 106

Lendenteil. . . . . . 107

Kreuzteil . . . . . 108

Schwanzteil . . . . . 109

Ligamente der Wirbelsäule . . 110

Ligamente zwischen Os occipitis, Atlas u. Epistropheus. . . 111

Ligamente des Schwanzes . . . . 111

Gelenkverlindungen der Wirbel. 112

Thorax. 112

Costae . . . . . . 112

Sternum . . . . . 113

Ligamente der Rippen . . 114

Gelenkverbindungen des Thorax 114

Obere Extremitiit _... 115

Clavicula ....... 115

Scapula . . . . . . . 116

Humerus ... 117

Schultergelenk ... 117

Knochen des Vorderarmes . . 118

Radius 118

Ulua .... 119

Ellbogengelenk . . . . 119

knochen der Hand . . . . . . . 119

Os carpi radiale . . . 120

Os carpi intermedium. . . . 120

Os carpi ulnare . . . . . . . 120

Os pisiforme, . . . . 120

Os carpale 1. . . . . 120

Os carpale II . . . . . . . . 120

os centrale . . . . . 120

Os carpale III . . . . . . . . 120

Os carpale IV . . . . . . . . . 120

Ossa metacarpi . . . . . . 120

Phalanges. . . . . . . 120

Gelenke der Hand. . . . . . 121

Untere Extremitait . . . . . . . 122

Os coxae . . . . . 122

Os ilium ........ 122

Os ischii . . . 123

Os acetabuli . . . . . . 124 


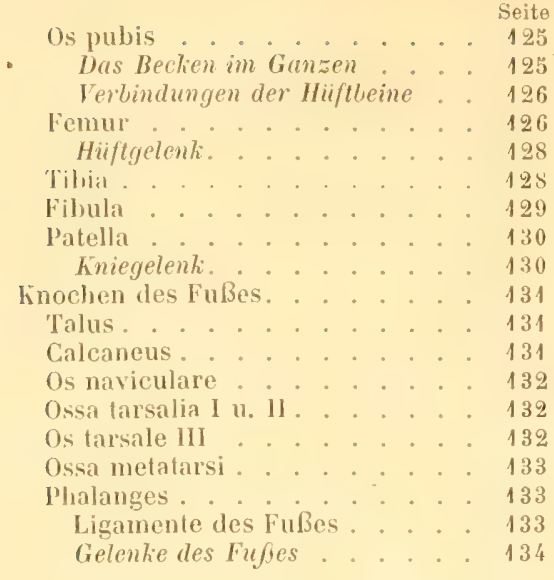

\section{Myologie.}

Muskelı des Kopfes

Muskeln des Gesichtes

M. zygomalicus major

II. zygomaticus minor

11. levator labii superioris.

il. levator nasi.

il. levator anguli oris.

M. dentalis superior

M. buccinator

11. depressor labii inferioris . . 137

Kaumuskeln ........ 137

11. massefer. . . . 137

M. temporalis ....... 137

11. pterygoideus internus . . . 137

M. pterygoideus externus ... 137

Eigentliche Kopfmuskeln . . . . 137

11. rectus capilis posticus superficialis

11. rectus capitis posticus minor

M. rectus capitis posficus major .

1. obliquus capitis major . . . 138

11. obliquus capitis minor . . 138

11. reclus capitis lateralis . . . 138

MIuskelu des Halses . . . . 138

ll. sternomastoideus . . . . 138

II. sternuliyuideus. . . . 138

II. sternothyreoideus . . . . 138

II. Hereoligoideus. . . . . 138

1i. stylohyoideus major . . . . 139

M. mandibulae . . . . . . 139

M. stylohyoideus minor. . . 139

II. mylohyoideus. . . . . 139

11. geniohyoideus . . . . 139

Muskeln d. Seitengegend des Halses 139

M. scalenus anticus . . . . 139

M. scalenus medius . . . . . 139

1I. scalenus posticus . . . . 139

M. longus atlantis . . . . . 139

II. longus colli. . . . . . 140

II. rectus capitis anticus major . 140

11. rectus capitis anticus minor . 140
Muskeln des Rickens ..... 140

Breite Ruickenmuskeln . . . . , 140

M. serratus posticus ..... 140

M. splenius capitis et colli. . . 141

Lange Rückenmuskeln . . . . 141

II. sacrospinalis . . . . 141

M. iliocostalis . . . . 141

11. longissimus dorsi . . . 141

M. spinalis ........ 142

Kurze Riickenmuskeln . . . . . . 142

M. multifidus ........ 142

$\mathbf{M m}$. intertransversarii und interspinales ........ 142

Muskelu des Schwanzes ..... 143

M. extensor caudae medialis . $143 \quad 171$

M. extensor caudae lateralis . . 143

M. abductor caudae posticus . . 143

II. abductor caudae anticus .. 144

1I. flexor caudae . . . . . 144

Mm. intertransversarii und interspinales........ 144

Muskeln der Brust . . . . . . 144

Mm. intercostales externi . . . 144

Mm. intercostales interni ... 144

Mm. levatores costarum. . . . 145

Diaphragma . . . . . . 145

Muskeln der oberen Extremität 145

Muskeln vom Rumpf zur ob. Extrem. 145

11. cleidomastoideus ..... 145

M. basiohumeralis . . . . 146

M. levator scapulae major . . 146

II. cucullaris ....... 140

M. latissimus dorsi . . . . 146

M. rhomboideus cervicalis . . 146

M. rhomboideús dorsalis . . . 146

M. levator anguli scapulae . . 447

I. pectoralis superficialis. . . 147

I. pectoralis major. . . . . 147

M. pectoralis minor. . . . . 147

II. serratus anticus major . : 147

Muskeln am Oberarm . . . . . 148

11. deltoideus ....... 148

11. abductor brachii superior . 148

11. abductor brachii inferior. . 148

M. supraspinatus. ...... 148

II. infraspinatus ...... 148

II. teres minor. . . . . . . . 148

M. teres major . . . . . . 148

M. subscapularis. . . . . 149

M. coracobrachialis. ..... 149

Streckmuskeln des Vorderarmes . . 149

II. extensor antibrachii parvus . 149

M. triceps brachii . . . . . 149

M. anconaeus longus . . . . 149

II. anconaeus lateralis ... . 149

M. anconaeus medialis . . 149

M. anconaeus minimus . . . 150

Beugemuskeln des Vorderarmes . 450

M. gleno-ulnaris ...... 450

M. brachialis internus. . . . 150

Muskeln des Vorderarmes . . . . 151

An der Dorsalseite . . . . 151 
M. extensor carpi radialis longus Seite

II extensor carpi radialis brevis

M. abductor pollicis . . . . . 151

M. extensor pollicis (et indicis) . 151

II. extensor digitorum communis 152

11. extensor digiti quarti proprius 153

II. extensor digiti minimi proprius 153

M. extensor carpi ulnaris . . . 153

An der Volarseite . . . . . 153

M. pronator teres. . . . . . 153

M. flexor carpi radialis . . . 154

MI. flexor digitorum profundus . . 154

II. palmaris ....... 154

II. flexor digitorum sublimis . . 154

II. flexor carpi ulnaris . . . 154

Muskeln der Hand . . . . . . 155

II. flexor digiti minimi . . . . 155

Mm. lumbricales . . . . . 15:

Mm. interossei metacarpi . . . 155

Physiologie der Muskeln der oberen Extremitit. . . . . . . $15 \%$

Muskelu des Bauches.

M. obliquus abdominis externus 157

M. obliquus abdominis internus . $\quad 157$

II. cremaster . . . . 157

M. transversus abdominis . . . 1.88

M. rectus abdominis . . . . . 458

M. quadratus lumborum . . . 158

Mnskeln der unteren Extremitit . 159

Muskeln der Hüfte . . . . . . . 159

Äußere Hiuftmuskeln . . . . . . 159

II. gluteus maximus . . . . . 159

M. gluteus medius . . . . . 159

M. gluteus minimus . . . . . . 159

M. pyriformis ....... 160

M. tensor fasciae latae . . . . 160

M. obturator internus. . . . . 160

Mm. gemelli ........ 160

M. quadratus femoris . . . . 160

M. obturator externus. . . . 160

Innere Hüftmuskeln . . . . . . 161

M. iliopsoas . . . . . . . 161

M. psoas major . . . . . . 161

M. iliacus . . . . . 161

M. psoas minor . . . . . . 161

Muskeln am Oberschenkel .... 161

Muskeln an der medialen Seite des Oberschenkels . . . . . 161

M. gracilis. . . . . . 161

M. sartorius . . . . . . . 162

II. pectineus. . . . . . . 162

M. adductor brevis . . . . . 162

M. adductor longus . . . . . . 162

M. adductor magnus ..... 162

Muskeln an der vorderen Seite des Oberschenkels . . . . . 162

II. quadriceps femoris . . . 162

M. rectus femoris . . . . 162

M. vastus lateralis .... 163

M. vastus medialis . . . . . 163

M. cruralis ....... 163

Mm. subcrurales . . . . . 163
Muskeln an der hinteren Seite des Oberschenkels . . . . . . 164

11. biceps femoris . . . . 164

M. tensor fasciae cruris. . . . 164

II. semimembranosus. . . . 164

M. semitendinosus . . . . 165

Muskeln des Unterschenkels . . . . $16 \%$

Muskeln an der medialen und vorderen Seitedes Unterschenkels. 16:;

M. extensor digiti primi pedis proprius ......... $166^{\circ}$

II. tibialis anticus . . . . . 165

M. extensor digitorum pedis longus $\mathbf{1 6 0}$

Muskeln an der lateralen Seite des Unterschenkels. . . . . . . 166

II. peronaeus longus . . . . . 166

II. peronaeus brevis . . . . . 166

II. peronaeus tertius . . . . . 166

II. peronaeus quartus. . . . . . 166

- Muskeln an der hinteren Seite des Unterschenkels. . . . . 167

M. triceps surae . . . . . 167

M. gastrocnemius medialis . . 167

M. gastrocnemius lateralis. . . 167

M. soleus . . . . . . 167

M. plantaris . . . . . . . . 167

II. popliteus . . . . . . 167

M. flexor digitorum pedis longus. 168

Muskeln am Fuße . . . . . . . $16 \mathrm{~s}$

Muskeln der Fußsohle . . . . . 168

Mm. Iumbricales . . . . . . 168

Mm. interossei metatarsi . . . $16 \mathrm{~s}$

\section{Splanchnologie.}

\section{Simes-Apparate.}

Haut.

Muskeln der Haut . . . . . . 170

M. cutaneus maximus. . . . . . 170

M. subcutaneus faciei. . . . . 170

M. orbicularis oris . . . . . 170

M. depressor alae nasi ... 170

M. depressor septi mobilis narium 170

M. submentalis ...... 170

M. platysma ...... 170

M. extensor caudae medialis . $143 \quad 171$

Pathologische Anatomie der Haut. . 171

Parasiten der Haut. . . . . . . 171

Überzichen der Haut . . . . . . 172

Ohr . . . . . . . . . . . 173

Äußeres Ohr. . . . . . . . 173

Knorpel des äußeren Ohres . . . 173

Ligamente des äußeren Ohres . . 174

Muskeln des äußeren Ohres . . 175

M. intermedius scutulorum . . $17: 3$

N. frontoscutularis . . . 175

M. cervicoscutularis .... 175

II. scutulo-auricularis superior anticus ........ $17:$

II. scutulo-auricularis superior posticus. . . . . . . 
is forior

II. parotideo-auricularis antict

11. parotideo-auricularisposticus 175

M. maxillo-auricularis . . 175

M. temporo-auricularis . . . 176

MI. cervico-auricularis. . . . 176

II. occipilo-auricularis . . . 176

II. helico-occipitalis . . . . 176

11. transversus auriculac . . 176

II. tragicus major . . . . . 176

11. tragicus minor . . . . . 176

1I. tragiens minimus . . . . . 176

M. helicis superior . . . . . 176

M. helicis inferior . . . . . 176

Wirkungen der Mnskeln des itußoren Ohres . . . . . . . 176

Pathologische Anatomie des änßeren Ohres .

Parasiten des änßeren Ohres

Blutlauf im inßeren Obr.

Mitlleres Ohr

Tympanum . . . . . . . . 177

Ossicula auditus...... 180

Malleus....... 180

Incus . . . . . . . 180

Os lenticulare..... 180

Stapes ....... 180

Muskeln des mittleren Ohres. . 180

M. mallei ....... 180

M. stapedius. . . . 180

Tuba Eustachii. . . . . . . 180

Parasiten des mittleren 0hres . . 180

Inneres Ohr. . . . . . . . 181

Vestibulum ........ . 181

Canales semicirculares . . . . 181

Eröffurng des Vestibuluem. . . . 181

Verletzung der Canales scmicirculares.

Cochlea. . . . . . . .

Aquaeductus cochleae und vestibuli

Ange.

Orbita . . . . . . . 183

Augenlider . . . . . . . 184

M. depressor palpebrae inferioris 184

Thränenwege . . . . . . . 184

H. zygomaticolacrymalis . . . 185

Anlegung einer Thränenfistel . 156

Bulbus oculi. . . . . . 186

Sclera . . . . . . . 186

Cornea ......... 186

Durchschncidung der Hornzhant-

Ätzung der Comea

Chorioidea . . . . . . 186

Corpus ciliare . . . . . . . . 187

Iris. . . . . . . 187

M. dilatator iridis . . . . 187

Erweiterung der Pupille. . 187

Retina ....... . . 188

Linse. . . . . . . . . 189

Glaskörper . . . . . . 189
Blutgefäße des Bulbus . . . . 1 s9

Augenmuskeln'. . . . . . . . 190

M. orbicularis . . . . . . . 190

M. levator palpebrae superioris . 190

Mm. recti oculi . . . . . . 190

M. obliquus oculi superior. . . 190

M. obliquus oculi inferior . . . . 190

M. retractor bulbi . . . . . 190

Wirkungen der Augenmuskeln . . 191

Motorische Endplatten. . . . 191

Drüsen der Augenhöhle. . . . . . 191

Gl. lacrymalis . . . . . . 191

Gl. Harderiana. . . . . . . 191

Gl. infraorbitalis...... . 202

Nase ........ 193

Cartilago narium . . . . . . 193

Cavum nasi . . . . . . . . 193

Septum narium cartilagineum . 194

Ductus nasopalatinus . . . . 194

Jacobson'sches Organ. . . . 195

Nasenschleimhaut . . . . 195

Hintere Muscheln . . . . 196

Knorpelinseln. . . . . . $19 \%$

Pathologische Anatomie . . . . I!Mi

Nasenkatarrh . . . . . . . 196

Vordere Muschel . . . . . . 196

Mundhöhle. . . . . . . . 196

Lippen . . . . . . . . 196

Zaihne . . . . . . . . 197

Schneidezähne. . . . . . 197

Pathologische Anatomie . . . $1 ! 17$

Backenzahne . . . . . . 19s

Zahnwechsel . . . . . . . 15

Milehgebiß . . . . . . . . 19

Gaumen. ......... 199

Velum palatinum. . . . . . . 200

M. glossopalatinus . . . . 200

M. pharyngopalatinus. . . . 200

Tonsillen........ . 200

H. levator veli palatini . . . 200

M. tensor veli palatini. . . . . 200

Zunge .......... . . 200

Nerven der Zunge . . . . 201

Muskeln der Zunge. . . . . . . 201

M. hyoglossus . . . . . . . 201

M. genioglossus . . . . „201

1I. styloglossus. . . . . . 201

Processus styloideus . . . . 7202

M. lingualis . . . . . . 202

Speicheldrüsen ....... $20 y$

Glandula infraorbitalis . . . . 202

Glandulae buccales superiores . . 203

Glandula buccalis inferior . . . 203

Glandula mandibularis superficialis . . . . . . 203

Glandula parotis . . . . . 203

Nerven der Gl. parotis . . . . 201

Aufsuchung des Ductus parotideus. 
Glandula submaxillaris ....

Tubulöser T'eil der GL. submaxillaris. . . . . . . 205

Nerven der Gl. submaxillaris . . 207

Aufsuchung des Ductus submaxillaris. . . . . . . . 207

Glandula sublingualis..... 208

Nerven der Gl. sublingualis . . . 201

Pathologische Anatomie der Speieheldrüsen

205

\section{Respirations-Apparat.}

Kehlkopf ......... 208

Knorpel des Kehlkopfes . . . . . 208

Ligamente des Kehlkopfes . . . . . 209

Muskeln des Kehlkopfes. . . . . 210

II. cricothyreoideus . . . 210

M. crico-arytaenoideus posticus . 210

M. crico-arytaenoideus ilateralis . 210

M. thyreo-arytaenoideus 210

II. thyreo-epiglotticus . . . 240

N. arytaenoideus transversus . 210

II. glosso-epiglotticus .... 211

Gl. thyreoidea ........ 211

Luftröhre . . . . . . . 212

Tracheotomie , . . . . 212

Lungen ... . . . . . . . 213

Nerven der Lunge. . . . . . . 213

Pathologische Anatomie . . . . 213

Parasiten der Lunge. . . . . . 214

Pleura ............ 214

Pathologische Anatomie . . . . 214

Eröffnung der Pleurahöhle. . . 214

Exstirpationen der Lunge . . . 211

Lungeabewegung. . . . . . 215

Thymus. .......... 215

\section{Digestions-Apparat.}

Pharynx

M. stylopharyngeus. . . . . . . 215

Oesophagus ........... 216

Nerven des Oesophagus . . . 216

Unterbindung des Oesophagus . . 216

Magen . . . . . . . 216

Nerven des Magens . . . . . . 217

Pathologische Anatomie . . . . 217

Parasiten des Magens . . . . 217

Anlegung einer Magenfistel . . . 217

Injektionen in den Magen . . . 217

Darmkanal .......... 217

Dimensionen des Darmkanales . $\quad 60217$

Lymphfollikel . . . . . . . . 218

Nerven des Darmkanales . . . . 219

Pathologische Anatomie . . . . 21:

Parasiten des Darmkanales . . . 219

Lage des Darmkanales . . . . . 220

Leber. . . . . . . . . 221

Parasiten der Leber. . . . . . 22\%

Exstirpation von Stücken d. Leber 222
Ductus ebeite

222

Gallenblase. . . . . . . 22.2

Pathologische Anatomie . . . . 22:2

Aufsuchung des Duchus cholcilochus 22.

Anlegung einer Gallenfistel . . 2.2:3

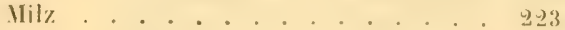

Septicämie . . . . . . 221

Exstirpation der Milz . . . . . 221

Pankreas . . . . . . . . . 294

Nerven des Pankreas . . . . . 2.)

Aufsuchung des Inctus pancrertticus. . . . . . 22,

Peritoncum .. . . . . . . . 220

Omentum majus . . . . . . . 227

Pathologische Anatomie des Peritoneum, Eisisicke

Parasiten des Peritoneum.

Injektionen in die Bauchlöhle . $\quad 227$

\section{Harn-Apparat.}

Nieren .......... . 9兄

Nierenbecken . . . . . .

Pathologische Anatomie der Nieren Exstirpation der Niercns. Unterbindung der Aa.renales.

Ureleren . . . . . . . . . . 229

Unterbindung der Ureteren s. Unterbindung der Aa. renales . . 2.2!y

Ilarnblase. . . . . . . . . . $2 \geq 9$

Nerven der Harnblase . . . . . 2:0

Harn . . . . . . . . 2:01

Pathologische Anatomie . . . 2:31

Nebennieren ......... . 2 . 230

Exstirpation der Nebenniercn . . $2: 31$

\section{Geschlechts-Apparat.}

Maimuliche Geschlechtsorgane . . 231

Hoden . . . . . . . . 231

Epididymis . . . . . . . 231

Ovarium masculinum . . . . 231

Samenfüden. . . . . . 2 231

Kastration . . . . . . . . . 231

Lage der Hoden . . . . . . 232

Canalis inguinalis . . . . . . . 232

II. cremaster . . . . . . 157

Vasa deferentia . . . . . . 232

Aufsuchung des Vas deforenes. . 232

Vesicula prostatica . . . . . 233

Prostata. . . . . . . . 234

Nerven der Prostata. . . . . 234

Pathologisehe Anatomie . . . . 234

Vesiculae seminales . . . . . 234

Harnröhre. . . . . . . . . 234

Penis . . . . . . . . . $23 \%$

Glandulae Cowperi . . . . . . 23:;

Glandulae praeputiales . . . . 235

Glandulae anales. . . . . . . 235 
Weibliche Geschlechtsorgane . Seite

Eierstöcke. . . . . . . 236

Exstirpation des Ovarium. . . 236

Gebärmutter. . . . . . 236

Reizung des_Uterus. . . . . . 237

Superfötation . . . . . 238

Künstliche Befruchtung von Eicm. 238

Verschließung cines Cormu utcri. 235

Exstivpation eines Cornu uteri . 238

Muttertrompeten........ 238

Scheide........ 239

Verschließung ciner Stelle der Vagina.

Exstirpation eines Stiuckes der Vagina. . . . . . . 239

Mesometria . . . . . . . 240

Ligamentum uteri rotundum. . . 240

Außere Geschlechtsteile. . . . 241

Labia . . . . . . . . . 241

Clitoris ........ 241

M. retractor praeputii clitoridis 241

Urethra ......... 241

Begattungsversuche. . . . . 241

Glandulae Cowperi . . . . . 241

Glandulae praeputiales .... 241

Glandulae anales. ..... 241

Mamma .......... . 241

Milch . . . . . . . 242

Muskeln am Beckenansgange. . 242

Perinaeum ........ 242

M. pubocavernosus . . . . 242

M. ischiocavernosus ..... 242

M. bulbocavernosus . . . . 242

M. constrictor pudendi ... . 242

M. levator ani . . . . . . 242

M. rectococcygeus. . . . . 242

M. sphincter ani ...... 243

\section{Angiologie.}

\section{Herz.}

Pericardium ....... 244

Herz .......... 244

Nerven des Herzens. . . . . . 245

Jatgr des Herzens . . . . . . 245

Lymphgefäße . . . . . . . 245

Pathologisehe Anatomie . . . . 245

Einführengeiner Nadel in das Horg 245

Bloßlegung des Herzens. . . . . 245

\section{Arterien des grofsen Kreislaufes.}

Aorta adscendens . . . . . 246

Aa. coronariae cordis . . . 246

Arcus aortae. . . . . . . 246

Truncus anonymus . . . . . . 247

Unterbindung des Truncus anonymus . . . . . . . . . 247

A. carotis communis ..... 248

A. thyreoidea superior ... 248
A. laryngea inferior . . . . 248

A. pharyngea adscendens . . . 248

Unterbindung der A. carotis communis s. N.vagus . . . . . 318

A. carotis externa . . . . . 249

A. laryngea (superior) . . . 249

A. occipitalis . . . . . . 249

A. lingualis . . . . . . 249

A. maxillaris externa .... 249

A. temporalis superficialis. . . 249

A. maxillaris interna . . . . 251

A. carotis interna . . . . . 252

A. communicans posterior . 252

A. ophthalmica superior. . . 252

A. cerebri anterior ...... 253

А. cereliri media. . . . . . 253

A. subclavia . . . . . . . . 253

Unterbindung der A. subclavia . . 253

Truncus cervicovertebralis . . 253

A. vertebralis ...... 254

A. cervicalis superficialis . . 254

A. mammaria interna. . . . 254

Unterbindung der A. mammaria interna . . . . . . 255

A. intercostalis suprema . . . 255

A. cervicalis profunda .. . . 255

1. transversa colli ...... 255

A. axillaris . . . . . . . 255

A. thoracico-acromialis . . . . 255

A. thoracica longa...... 255

A. subscapularis ...... 255

A. circumflexa humeri anterior . 256

A. circumflexa humeri posterior . 256

A. profunda brachii . . . . 236

A. brachialis. . . . . . . . 256

A. radialis. . . . . . 256

A. ulnaris . . . . . . . 257

Arcus volaris . . . . . . 257

Aorta descendens thoracica . . . . 257

Aa. intercostales...... . 258

Aa. phrenicae superiores . . . 258

Aorta descendens abdominalis . . . 258

Unterbindung der Aorta abdominalis, Stenson'scher Versuch . . 258

A. coeliaca . . . . . . . 259

Unterbindung der A. coeliaca . . 259

A. coronaria ventriculi sinistra $\quad 259$

A. lienalis ........ 959

A. hepatica . . . . . 260

Unterbindung der $A$. hepatica s. Aufsuchung des Ductus choledochus....... . 222

A. mesenterica superior . . . 260

Unterbindung der A. mesenterica supcrior . . . . . . 261

Aa. renales . . . . . . . 261

Unterbindung der Aa.renales . . 261

Aa. lumbales communes I-VI . . 262

Aa. spermaticae . . . . . . 262

A. mesenterica inferior . . . . 263

A. sacralis media. . . . . . 263 
A. iliaca communis. ..... Seite 263

Unterbindung der A. iliaca communis

A. iliolumbalis ....... 263

A. vesicalis snperior . . . . 263

A. uterina. . . . . . 264

Unterbindung der A. uterina. . . 261

A. iliaca interna . . . . . . 264

A. haemorrhoidalis media. . . 264

A. obturatoria . . . . . 264

A. ischiadica ...... 264

A. sacralis lateralis . . . . 265

A. pudenda interna . . . . . 265

A. iliaca externa. . . . . . 263

Unterbindung der $\Delta_{\text {, iliaca cxtcma }}$ s. Unterbindung der A. iliaca communis. ..... .

A. epigastrica inferior . . . . 265

A. cruralis ......... 265

Unterbindung der A. cruralis . . 265

A. profunda femoris . . . . 266

A. circumflexa femoris lateralis . 266

A. circumflexa abdominis . . . 266

A. articularis genu superficialis . 266

A. saphena magna ..... 266

Unterbindung derA.saphenamugna 267

A. tibialis posterior. .... 267

Arcus plantaris . . . . 267

A. poplitea ....... 267

A. saphena parva. . . . . 267

A. tibialis anterior ..... 267

A. peronaea....... . . 268

Unterbindung $d$. A. nutritia tibiae 265

\section{Venen des grolsen Kreislaufes.}

V. cava superior dextra . . . 268

V. azygos ........ 268

V. intercostalis suprema dextra . 269

V. phrenica superior dextra. . 269

V. cava superior sinistra . . . . 269

V. coronaria cordis dextra. . . 269

V. coronaria cordis media . . 269

V. posterior ventriculi cordis sinistri. 269

V. coronaria cordis magna . . 269

V. phrenica superior sinistra . . 269

V. intercostalis suprema sinistra . 270

Kleinere Aste d. Vv. cav. superiores 270

V. mammaria interna. . . . . 270

Unterbindung der V. memmaria interna.

V. threoidea inferior.

V. jugularis interna . . . . . . . . . . . 970

Unterbindung der Y. jugularis interna. s. N. vagus

V. lingualis

318

270

Sinus transversus . . . . . 270

Sinus longitudinalis anterior. . 270

Sinus longitudinalis posterior . . 271

Confluens sinuum ..... . 271

V. cerebri magna. . . . . 271
V. collateralis cerebri..... 271

Sinus cavernosus. . . . . . 271

V. ophthalmica superior. . . 271

V. jugularis externa...... 271 Unterbindung der V. jugularis $e x$ terna . . . . . . . 272

V. facialis anterior ..... 272

V. maxillaris externa . . . . 272

V. maxillaris interna . . . . 273

V. facialis posterior . . . . 273

V. temporalis superficialis. . 274

V. ophthalmica externa . . 274

V. vertebralis mediana . . . 275

V. transversa scapulae .... 275

I. subclavia. . . . . . . . 275

V. axillaris . . . . . . . 275

V. cephalica ....... 275

V. brachialis ..... 276

V. basilica. . . . . . 276

V. cava inferior ...... . 276

Vv. phrenicae inferiores . . . 276

Vv. renales ........ 276

Unterbindung der Vv, renales s. Unterbindung der Aa, renales. 261

Vv. suprarenales . . . . . . 277

Vv. spermaticae internae . . . . 277

Vv. lumbales I-VI. . . . . . 277

V. iliaca interna communis . . . . 277

V. iliaca interna ... . . . . 278

V. sacralis media. . . . . 278

V. haemorrhoidalis externa . . 278

V. obturatoria . . . . . . $27 \mathrm{~s}$

V. ischiadica ...... . 278

V. pudenda interna. . . . 278

V. tibialis anterior...... . . . 78

V. sacralis lateralis. . . . .

V. iliaca externa . . . . . . 279

V. iliolumbalis. . . . . . 279

V. vesicalis superior . . . . . 279

V. uterina . . . . . . 279

V. epigastrica inferior. . . . . 279

V. cruralis . . . . . . . . . 279

Unterbindung der V. cruralis . . 279

V. profunda femoris . . . . . 279

V. circumflexa abdominis . . . 279

V. saphena magna ..... . 280

V. tibialis posterior..... 280

V. poplitea ...... 280

V. sapliena parva . . . . 280

V. portarum . . . . . . 280

Unterbindung der V. portarum . . 250

V. coronaria ventriculi superior . . 281

V. mesenterica superior. . . . . 281

V. mesenterica inferior .... 281

Yv. hepaticac....... . . 281

\section{Arterien und Venen des Lungen- kreislaufes.}

A. pulmonalis ........ 281

Vv. pulmonales . . . . . 281 


\section{Lymphgelïil'ssystem.}

Lymphgefälse . . . . . . . 282

Ductus thoracicus . . . . . 282

Truncus lymphaticus communis dexter . . . . . . . 282

Trunci lymphatici jugulares . . 282

Lymphdrüsen . . . . . . . . . 282

Glandula facialis . . . . . 282

Glandulae cervicales superficiales 282

Glandula cervicalis profunda . . 282

Glandula masseterica . . . . . 282

Glandulae axillares . . . . . 282

Glandula scapularis. . . . . . 282

Glandulae bronchiales . . . . 282

Glandulae mesentericae superiores 282

Glandulae mesentericae inferiores 283

Glandulae hypogastricae . . . 283

Glandula inguinalis superior. . . 283

Glandula inguinalis inferior . . 283

Glandula ischiadica. . . . . 283

Glandula poplitea . . . . . 283

\section{Neurologie.}

\section{Zentrales Nervensystem.}

\section{Riickenmark}

Operationeni am Rückenmark . .

Durchschneidung des Rückenmarkes

Partielle Durchschneidung des Rïckenmarkes

Zerstörung des Lumbaltciles. . .

Reizuny des Cervicalteiles. - Mikroskopischo Anatomio des Ruckenmarkes . . . . . . 301

Subencephalon

Medulla oblongata

7.uckerstich.

Nocul vital.

Durchschneidung der Pyramidenstränge ,

Pons Varolii .

Pathologische Anatomie .

Durchschneidung d. Pons Varolii

Eminentia quadrigemina

Cerebellum.

Hemisphären

Zerstörung der Flocke des Cerebellun

Vermis .
Crura cerebelli.
Exstirpation des Corebellum .
Durchschncidung des Crus cercbelli
ad pontem. . . . . . . . .

Vela medullaria . . . . . . . 294

Cerebrum

Pedunculi cerebri

Durchschneidung des I'colnculus cerebri

Manzègebenterentg-Operations.

Evilep'sie.
254

251

284

285

285

285

301

286

247

288

2ss

289

259

289

289

289

290

290

290

291

291
Substantia perforata media

Seite

'Tuber cinereum . . . . .

293

Hypophysis cerebri. . . . . . 293

Chiasma opticum. . . . . . . . 293

'Iractus optici . . . . . . . 293

Substantiae perforatae laterales . 294

Trigona olfactoria . . . . . . 294

Ventriculus tertius : . . . . . . 294

Thalami optici . . . . . . . . 294

Corpora striata . . . . . . . 294

Commissura posterior. . . . . 295

Conarium . . . . . . . 295

Commissura mollis . . . . . . 296

Commissura anterior . . . . . . 296

Fornix ........ . . 296

Bulbi fornicis . . . . . . . . 296

Septum pellucidum. . . . . . 296

Corpus callosum . . . . . . . 296

Ventriculi laterales. . . . . 297

Corpora medullaria hemisphaer.

cerebri. . . . . .. 297

Oberfläche der Hemisphären . . 297

Lobus frontalis . . . . . 297

Lobus olfactorius. . . . . . 298

Lobus temporalis. . . . . . 298

Lobus parietalis . . . . . . . 299

Lobus occipitalis. . . . . . 299

Betrachtung des Gehirnes von oben 299

Betrachtung des Gehirnes von unten 300

Mikroskopische Anatomie des GeGehirnes . . . . 300

Pathologische Anatomio des Gehirnes . . . . . . . . 302

Parasiten des Gehirnes. . . . 302

Exstirpation der Grophimihemisphären. . . . . . . 302

Blutlauf in lebenden Gekirn. . . 302

Operationen an der Grophimrinde 303

Hảute des Gehirnes und Rückenmarkes . . . . . . . 303 Entleerung von Cerebrospinalfliissigkeit .

\section{Peripherisches Nervensystem.}

\section{Hirunerven . . . . . . 304}

N. olfactorius ....... 304

Durchschneidung des $N$. olfactorius 301

N. opticus . . . . . . 304

Durchschneidung des N. opticus. . 304

N. oculomotorius . . . . . 305

Durchschneidung des $N$, oculomotorius. . . . . . 305

N. trochlearis ...... 306

N. trigeminus . . . . . 306

N. ophthalmicus . . . . . 306

N. maxillaris superior . . . . 307

Durchschneidung des $N$. ophthal-

micus . . . . . . . 308

Durchschneidung des $N$. infraorbitalis.
309 
N. maxillaris inferior $\quad 310$ Durchschneidung des $N$. lingualis . 311 Durchschnciduny des $N$. nuendibuluris

N. abducens. Durchschneidung des $N$, abducens.

N. facialis . Durchschueidung der Chorda tympani.

Durchscheidung des $N$. faciulis

N. acusticus. Durchschneidung des N. acusticus .

N. glossopharyngeus ...... Ausreisung des N. glossophuryngeus.

Dherchschueiduny dessclben s. N. hypoglossus...... 322

N, vagus ........ . 316

Durchscheiding des N. vagus . . 318

N. accessorius . . . . . . 320

Durchscheidung des $N$. accessorius 320

N. hypoglossus . . . . . . 322 Durchschneidung des N. hypoglossus......... 32?

Rickenmarksnerven . . . . . . 323

Plexus cervicalis . . . . . . . . 324

N. cervicalis I. . . . . . . 326

N. cervicalis $11 . . .2 . .326$

N. occipitalis major . . . . 326

N. occipitalis minor . . . . . $3 \geq 6$

N. cervicalis III . . . . . 328

N. auricularis magnus . . . 328

N. cervicalis IV . . . . . 328

N. subcutaneus colli inferior. 328

Nn. supraclaviculares. . . . 328

N. phrenicus . . . . . 32s

Durchschneidung des $N$. phrenicus. 329

Plexus brachialis. . . . . . 330

N. cervicalis V. . . . . . . 330

N. suprascapularis . . . . . 330

$\mathrm{Nn}$. thoracici posteriores . . 330

N. thoracicus longus . . . . 330

Nn. thoracici anteriores. . . . 330

Nn. subscapulares ..... 330

N. thoracicodorsalis. . . . 330

Tabelle der Verteilung des plexus brachialis ......... 331

N. cutaneus brachii minor. : . 332

N. cutaneus brachii major. . . 332

N. perforans brachii . . . . 332

N. axillaris . . . . . 332

N. medianus. . . . . . . 332 Durchschneidung des N. mediunus 333

N. ulnaris : . . . . . . 333

N. radialis . . . . . . 334

N. longissimus pectoris . . . . 335 Durchschneidung des Plexus bruchialis. . . . . . . 335

Nn. dorsales . . . . . . . 336

Plexus lumbalis . . . . . . 336

Nn. lumbales I-III. . . . . . 337
N. lumbalis IV. $\quad 337$

N. iliohypogastricus . . . 337

N. cutaneus femoris anterior . 337

$\mathrm{N}$. lumbalis V . . . . . $33 \mathrm{~s}$

N. genitocruralis. . . . $33 \mathrm{~s}$

N. spermaticus externus . . 338

N. cruralis . . . . . . 339

Durchschneidung des $N$. cruralis . $\quad \$ 339$

N. saphenus major . . . . 340 Durchschneidung des $N$. suphenus major s. Unterbindung der 4. saphena magna. . . . . . 26157

N. Iumbalis VI . . . . . 340

N. obturatorius . . . . . . 340

N. lumbalis VII . . . . . . 340

N. gluteus superior. . . . . 340

N. gluteus inferior . . . . 341

N. cutaneus femoris posterior - 341

$\mathrm{N}$. ischiadicus ...... 341

Durchschneidung des $N$. ischiadicus $\quad 311$

N. cutaneus cruris posterior . 342

N. peronaeus . . . . . 342

Durchschneidung des N. peronucus 342

N. tibialis . . . . . . 343

Durchschneidung des $N$. tibialis . 343

N. saphenus minor . . . 343

Plexus sacralis....... . . 343

N. sacralis I. . . . . . . . 344

N. sacralis II . . . . . . . . . 344

N. pudendus . . . . . 344

N. dorsalis penis s, clitoridis. 344

Genitalnervenkörperchen. . . . 345

N. sacralis III . . . . . 345

Nn. haemorrhoidales medii . 345

N. sacralis IV . . . . . 345

N. haemorrhoidalis inferior . 345

Plexus coccygeus. . . . . . . . 345

N. coccygeus lateralis. . . . 345

\section{Sympathisches Nervensystem.}

Kopfteil ........ . 346

Ganglion ciliare . . . . . 346

Ganglion sphenopalatinum . $\quad 347$

N. petrosus superficialis major 347

N. petrosus profundus major 347

Ganglia otica ..... 347

$\mathrm{N}$. petrosus superficialis minor 347

Durchschneidung der Nn. petrosi superficiales .

Ganglion maxillare. . . . . 348

Halsteil

Ganglion cervicale superius 348

Exstirpation des Qanglion cervicalc superius . . . . . . . 31

N. sympathicus ..... . 348 Durchscheidung des N. syumuthicus an Halso s. N. vagus . . 310

Ganglion cervicale inferius . . 349

Exstirpation des Ganglion cervicale inferius 
Seit

Ganglia dorsalia I-XII . . . . 350

Plexus cardiacus. ..... 350

Ganglion cardiacum . . . 350

Plexus coronarii cordis .... 351

Plexus pulmonales . . . . 351

Plexus aorticus thoracicus. . 351

Exstirpation des Plexus cardiacus. 351

Bauchteil. . . . . . . . . 351

N. synıpathicus ........ . 351

Aufsuchung des N. sympathicus in der Bauchliöhle. . . . . 351

Ganglia lumbalia [-VII. . . . . 351

N. splanchnicus ....... 351

Durchschneidung des $N$. splanchnicus ....... . 35

Ganglia coeliaca . . . . . . 353

Exstirpation der Ganylia coeliaca . 353

Plexus coeliacus . . . . . . . 353

Plexus mesentericus superior . . . 353

Plexus renalis . . . . . . . 353

Exstirpation des Plexus ronalis s. Unterbindung der A. renalis . 261

Plexus spermaticus . . . . . 354
N. spermaticus internus. . . . 354

Plexus aorticus abdominalis . . . 354

Exstirpation des Plexus aorticus abdominalis..... . 351

Ganglion mesentericum (inferius) . 354

Exstirpation des Gunglion mescon-

tericum. 35

Ganglion mesentericum (inferius accessorium . . . . . . . . 3.5

Plexus mesentericus inferior . . . . 3:3:

N. mesentericus inferior . . . 355

Plexus hypogastrici. . . . . . 355

Ganglion hypogastricum . . . 356

N. hypogastricus. ..... 356

Nn. haemorrhoidales superiores . $\quad 3: 36$ Aufsuchung des N. hypogastricus . B⿳亠口冋

Ganglion uterinum . . . . . $3: 36$

Plexus vaginalis . . . . . 350

Plexus cavernosus 357

Plexus haemorrhoidalis . . . . . 357

Ganglia sacralia I-IV . . . . . . 357

Ganglia coccygea I-II . . . . . . 357

Ganglion coccygeum infimum . . . 357

Plexus sacralis medius . . . . . . 337

Literatur-Verzeichmis 


\section{Allgemeine Anatomie.}





\section{E INLEITU N G.}

\section{Naturgeschichte.}

Das Kaninchen - L e pus cun i cul us — gehört zur Ordnung der Nager (Rodentia Linné, Rosores Storr., Rongeurs). Die Nager haben wurzellose Schneidezihne, Eckzihne fehlen, die Backenzihne zeigen quere Schmelzfalten (Dentes complicati). Die Gelenkhöhle für den Unterkiefer gestattet diesem kaum eine Seitenbewegung (I-d. h. Nr. I des Litteraturverzeichnisses).

\section{Familiencharakter der Leporinen.}

Zahnformel $i \frac{2}{1}, m \frac{5}{5}$ oder $\frac{6}{5}$. Zihne wurzellos. Ilirnteil des Schädels gestreckt. Foramina optica in der Medianlinie vereinigt. Processus zygomaticus des Oberkieferbeines mit einer Wurzel. Foramen infraorbitale klein. Vorderfliche des Oberkiefers von einer größeren (Lagomys) oder mehreren kleineren (Lepus) Öffnungen durchbrochen. Knöcherner Gaumen sehr kur', nur eine Bricke zwischen den mittleren Backenzihnen bildend. Foramini incisiva groß, herzförmig. Schlüsselbeine verschieden entwickelt. Fibula rudimentar, nach unten mit der Tibia versehmolzen. Innenflache der Backen eine Strecke lang behaart. Coecum groß, colonartig (1).

Charakteristisch für die Leporinen ist die Anordnung der oberen Schneidezähne. Ilinter zwei oberen großen gefurchten Schneidezihnen stehen noch zwei kleinere Ziihnchen, wahrend in I'nterkiefer nur zwei Schneidezähne vorhanden sind.

\section{Gattungscharakter von Lepus.}

Backenzahne $\frac{6}{5}$. Ohren groß und lang. Schlüsselbeine rudimentir. Schwanz kurz, buschig. HinterfüBe lang, starker als die vorderen. Vorn 5 , hinten 4 Zehen, die Fußsohlen sind behaart.

Was das paläontologische Alter anlangt, so ist die Gatlung Lepus in das europäische Plioeän zurückverfolgt (569).

\section{Artcharakter von Lepus vulgaris,}

Linné, europaeus Pallas, timidus aut., Lièvre. Ohren länger als der Kopf, an der Spitze schwarz. Farbe braungelb, sehwarzlich eingesprengt, im Nacken 
gelbrötlich, ebenso die lateralen Flichen der Extremititen; die medialen Fliichen der letzteren, sowie der Bauch und die ventrale Seite des Schwanzes weik, die dorsale Fliche des letzteren schwarz. Iris gelbbriunlich, Extremitaten und namentlich der Tarsus im Vergleich zum Kaninchen relativ lang.

\section{Lepus variabilis.}

Der $\Lambda$ penhase oder Schneehase, kommt auch in Grönland vor u.s. w., wird im Winter weiß. Zwei Schädel, welche die zweite deutsche Yordpolexpedition 1869/70 mitgebracht hatte und welche sich in der Sammlung des Herrn Antsrat Struckmann in IIannover befinden, sind kürzer,! kleiner, aber relativ breiter als gewiohnliche Ilasenschaidel und lassen die Zusammensetzung des knöchernen Gaumens aus vier durch Niihte getrennten Knochenplatten erkennen. Derselbe ist ebenfalls und zwar in transversaler Richtung beim Schneehasen breiter.

\section{Lepus cuniculus ferus.}

Das wilde Kaninchen. (Lepus Magellanicus. Lapin. Rabbit. Robbeken. Cony. Coniglio. Conejo. Coelho. Karnickel. Kaning. Kanin. Cwningen. Chinesisch t'utu, s. 182.) Farbe obeu graubriunlich, unterwirts, namentlich die Kehle, der Batch und die mediale Fliche der Oberschenkel, weiß. Brust grau. Iris braun. Schwanz obeu schwirzlichgrau, unten weiß. Nacken gelbrötlich, auch der Rücken ins rostfarbige spielend. Ohren ein wenig kürzer als der Kopf. Tarsus relativ kurz. Wiegt bis $1,5 \mathrm{~kg}$.

Bei einem etwa dreivierteljahrigen Kaniuchen von der Insel Borkum Geschenk des Iler'n Hotelbesitzer Bakker daselbst) betrug die Liange von den Lippen bis zur Schwanzwurzel $31 \mathrm{~cm}$, von der Schulter bis zur Schwanzwurzel $22 \mathrm{~cm}$, die ganze Länge in hockender Stellung (Fig. 1, S.8) 24-25 cm, die Linge des Kopfes $85 \mathrm{~mm}$; das Gewicht $750 \mathrm{~g}$.

Das Vaterland des Kaninchens ist Afrika, das südliche Europa, Griechenland und spanien, von wo diese Thiere in das ibrige Europa verpflanzt worden sind. Wild finden sie sich in den wïmsten Gegenden von Asien und Afriki, am persischen Meeplusen, am Kap der guten Iloffnung, in Lybien, in Senegal, in Oherguinea. Viele giebt es in Portugal, Spanien, Italien, Frankreich, Holland, England, Deutschland, besonders in den Diinen der Nordsee, ebenso in den Rheinlanden. Auch in Norwegen kommen sie noch fort und in den Lindern an der Hudsons-Bar, ferner im nördlichen und östlichen Asien, in Kamtschatka. In Schweden kannte Linné sie nur gezihnt; von Europa sind sie nach Amerika gehracht worden, wo sie sich in Siddamerika und auf den französischen Inseln außerordentlich vermehrt haben.

Das wilde Kaninchen leht in sandigem Boden, vermeidet festes und steiniges Terrain. Es gräht sich weitläufige Ilöhlen mit mehreren Ausgängen, welche oft rechtwinklig verlaufen. Am Ende dieser Gänge ist die mit Ileu und den Bauchhaaren des Weibehens ausgestattete Lagerkammer, deren Eingang so eng als möglich ist. Jedes Paar hat seinen eigenen Bau. Das Weibchen verbirgt seine Jungen in einer solchen Abteilung, und verstopft deren Eingang mit Heu und dergl., während es seiner Nahrung nachgeht. 
Spielarten des wilden Kaninchens sind mehrere bekannt. Das Angora-Kaninchen, russisches Kaninchen, Lepus cuniculus angorensis, Seidenhase, mit langem, feinem, seidenartigem Ilaar findet sich um Angora in Kleinasien; es kommt aber auch in Europa fort. Es hat kïrere Ohren, ist grau, weil oder braun: das bis $10-12 \mathrm{~cm}$ lange Ilaar wird durch Auskimmen oder durch Rupfen $(S / 5)$ gewonnen, zu Ituten verarbeitet, wie auch die Ilaut anderer Kaninchenrassen als Pelzwerk benutzt wird. Das langgeschwanzte Kaninchen lebt jenseits des Baikal-Sees; das ungeschwinzte in Brasilien und in Mexiko; eine besonders interessante Varietat ist das Kaninchen von Porto Santo, einer Insel bei Madeira (vergl. 8 ).

\section{Lepus cuniculus domesticus.}

Die Farbe ist grau, graurötlich, schwarz, weiß (Albinos mit roter Iris), gefleckt. Iris.braun. Ohren etwa so lang wie der Kopf.

Zahme Weibchen graben sich, wenn sie irgend können, am Ende der Trächtigkeit eine eigene Lagerkammer, in welcher die Jungen vor den Angriffen der Männchen, die sie auffressen, geschützt sind.

Das Kaninchen ist, wie der Hase, 30-31 Tage trächtig, und bringt 7-8 mal im Jahre 3-9 Junge zur Welt. Jieselben sind neun Tage blind, indem die Augenlidspalte durch Verwachsung der Epithelbekleidungen ihrer Rinder geschlossen ist. Angeblich sind sie anch nackt, die Haarspitzen jedoch mit der Lupe zu erkennen. Nach fünf Monaten sind die Jungen zeugungsfähig; die Paarung erfolgt jedoch gewöhnlich erst, wenn sie ein halbes Jahr alt geworden sind, und ausgew achsen sind die Tiere vicht vor dem Ablauf des ersten Lebensjahres. Die Fruchtbarkeit des Kaninchens ist zum Sprichwort geworden, und nach erlangter Geschlechtsreife ist das Leben der Weibchen kaum etwas anderes, als ein bestindiges Tragen und Gebiren, denn die Geburten folgen meist alle fủnf Wocheu hintereinander. Nimmt man für wirmere Klimate an, daß ein Weibchen jihrlich i mal 8 Junge zur Welt bringt, so steigrt die Nachkommenschaft, vorausgesetzt, daß alle am Leben bleiben, binnen vier Jahren auf 1 274 840 ? Das zahme Kaninchen ist noch fruchtharer; es hat unter gänstigen Umstianden jährlich wohl 10-11 mal und nicht selten I Junge, meist jedoch nur i-8 im Durchschnitt, jiholich 9- $10 \mathrm{mal}$, im Ganzen beispielsweise 7 :3 Junge in einem Jahre (25). Bei sehr jungen Weibchen ist die Anzahl der Embryonen eine geringere: z. B. 1-bّ.

Für entwicklungsgeschichtliche Studien sind Kaninchenembryonen sehr geeignet und vielfach benutzt. Um der Altersbestimmung sicher zu sein, ist die Paarung unmittelbar zu überwachen. Folgende Darstellung liegt darüber vor $(\tilde{\jmath})$.

Es ist beim Kaninchen nicht leicht, den Augenblick der Begattung nit Sicherheit zu beobachten. Zwar setzen sich die Minnchen, sobald man sie zu den Weibchen bringt, sogleich auf dieselben und machen Begattungshewegungen. Allein dabei findet die Begattung noch nicht wirklich statt. Dils Weibchen muß erst einwilligen. Es ist aber auch nicht leicht, sich zu überzeugen, Wann die Weibchen brünstig sind. Sind sie es im hohen Grade, so sind sie sehr unruhig, springen herum, setzen sich auf audere Weibehes. und 
lassen einen grunzenden Ton hören. - Auch erscheinen Vulva und Scheide zu dieser Zeil blutreicher und turgeszierender, als zu anderer Zeit, so daß man daran ein Zeichen hat. Die Begattung erkennt man aber auf folgende Weise. Wenn das Minnchen auf dem Weilochen sitzt, streckt sich dieses plötzlich aus, die Hinterpfoten weit nach hinten. In demselben Augenblick erfolgt die Ejakulation, und das Männchen macht einen heftigen Satz nach rückwärts, von dem Weibchen herunter. Beide setzen sich dann ruhig in eine Ecke, so heftig oft die Jagd vorher war. Meist fängt dann das Weibchen nach 10 Minuten bis einer Viertelstunde wieder an, das Minnchen aufzureizen, beißt es, springt über ihm hin und her, bis die Begattung nochmals erfolgt, und so fort. Untersucht man das Weibchen sogleich nach der Begattung, so findet man in der Vulva und Scheide immer reichliche Samenfiden und kann sich auch noch dadurch von der wirklich stattgefundenen Begattung uiberzeugen. Es ist nur meist sehr langweilig und zeitraubend, diesen Augenblick bei fremd zusammengesetzten Tieren abzuwarten. - Vergl. a. 7.56.) - Die Eier, welche sehr durchsichtig sind, zeigen sich 12 und 16 Stunden nach der Begattung schon ein gutes Stück in der Tube fortgerückt.

Es wird auch angegeben (4), daß ein Weibchen, welches beim Mannchen gewesen ist, von den andern Weilbchen angegriffen und gebissen werde. Es scheint sich jedoch nur um das gewöholiche Verhalten zu handeln, welches zusammen aufbewahrte Tiere gegen fremde einzuschlagen pflegen.

Die Begattung findet mitunter 24 Stunden nach dem Werfen, meist einige Tage nachher, seltener erst nach etwa fünf Wochen statt, wenn die Jungen das Nest verlassen hahen. Hiernach scheint die Brunstperiode letzteren Termin einzuhalten.

Das wilde Kaninchen soll 8-10, das zahme 7-8 Jahre alt werden.

Unterschiede des Geschlechtes sind, abgesehen von den selbstrerstindlichen, nur im Bau des Thorax vorhanden, der bei den Minnchen an seinem oberen Ende etwas enger ist. Das Durchschnittsgewicht eines ausgewachsenen Tieres kann man zu $2 \mathrm{~kg}$ annehmen; die Weibchen werden etwas größer als die Männchen.

Wenn das Kaninchen erschreckt wird, so führt es im Sitzen einen Schlag mit beiden Fußsohlen auf den Boden, der laut genug hörbar ist, um den ubrigen als Warnungszeichen zu dienen. Sind mehrere Mannchen und Weibchen beisammen, so führen die ersteren in der Brunstzeit erbitterte Kämpfe untereinander auf, wobei sie ein eigentumliches Grunzen hören lassen (s. Neurologie, Thalamus opticus!. Sonst schreit das Kaninchen nur bei intensivem Schmerz (S. 7), oder aus Angst. Trotz seiner geringen Intelligenz besitzt dasselbe hinlingliches Gedachtnis. Tiere, die einmal eine schmerzhafte Operation überstanden haben, schreien in angstvoller Erinnerung, sobald sie zum zweiten Male auf das Operalionsbretl gebunden werden. Es ist dabei zu bemerken, daß unter den Operationen nur die Durchschneidung des X. trigeminus in den meisten Fälen und diejenige des $\mathbf{N}$. ischiadicus mitunter Schmerzensiußerungen hervorrufen. Die bei den erwihnten Kimpfen überwundenen Hiinnchen werden nicht selten an den Geschlechtsteilen verletzt und Eiterungen an den letzteren werden, obgleich sie traumatischer Natur sind, zuweilen irrtumlich für Syphilis angesprochen (S. 23). Sie kommen 
nur bei den Mannchen vor. Kaninchen, welche mit Fleisch gefütert worden sind, suchen mitunter sich analoge host zu rerschaffen, indem sie ihren Genossen die langen Ohren wie ein Krautblatt abfressen.

Nach dem Gesagten sind die Kaninchen keineswegs ganz harmlose Tiere, wofür sie gehalten werden. Die Minnchen töten, wie oben erwähnt, regelmäßig die neugebornen Jungen, wenn sie zu denselben gelangeu können; auch manche Mutter beißen sie tot orler fressen sie vollstindig auf. Es soll dies namentlich von Weibchen geschehen, die wunde Zitzen haben.

Jene anscheinende Indolenz, welche sich beim gegenseitigen Abfressen der Ohren wie in dem standhaften Ertragen von Operationen zeigt, ist offenbar als ein Streben, sich tot zu stellen, aufufassen, wie es z. B. bei Käfern vorkommt, und so von Feinden verschont zu werden, gegen die das Kaninchen keine Waffen hat. Im Notfalle flüchtet es sogar in tieferes Wasser und ich babe in solchem einen Kampf mit einem kleinen Ilunde gesehen, welcher erst mit dem Tode des Kaninchens endigte. Zur Wehre setzen sich regelmäßig die Weibchen, welche Junge haben. gegen kleinere Raubtiere; ich habe ein Gefecht von mehreren Weibchen gegen einen großen Kater beobachtet. der in den Stall eingedrungen war, aber vollstandig im Schach gehalten wurde. Die aufgeregten Mütfer umstellten die Katze im Kreise und sprangen zihnefletschend auf sie ein, bis IIilfe herbeikam. Übrigens sollen die Kaninchen sich auch sonst gegen Katzen zur Wehre setzen.

Bei den hier vorliegenden Untersuchungen wurde ausschließlich das zahme Kaninchen, Lepus cuniculus domesticus, benutzt, und zwar beziehen sich alle Angaben, wo nicht ausdricklich etwas anderes bemerkt wurde, auf das in Deutschlaud gewöhnliche Hauskaninchen, welches hier zum Interschiede als deutsches Kaninchen bezeichnet werden soll.

Rassen des zahmen Kaninchens. Seit dem Erscheinen der ersten Auflage sind eine große Anzahl ron spielarten teils neu durch kunstliche Züchtung entstanden, teils in größerer Anzahl nach Deutschland eingeführt worden. Schon früher hatten Ludwig in Leipzig und Ileidenhain (z) in Breslau sog. französische Kaninchen zu experimentellen Zwecken benutzt und eine breitköpfige Art wurde aus Ileidelberg (6) erwihnt. Vach dem Kriege von 1870-71 wurden erstere in großer Anzahl importiert, es bildeten sich überall Vereine für (Geflügel- und) Kaninchenzucht, besondere Zeitschriften ( $z$. B. 4) entstanden, um freilich bald wieder einzugehen. So lange es noch IIasen giebt, wird das Fleisch der letzteren dem weißlichen Kaninchenfleisch rorgezogen werden, auch stellte sich bald heraus, daß die Beschaffung des Futters für eine Anzahl großer französischer Kaninchen in nördlicheren Lindern während des langen Winters zu teuer werde. Ein franzosisches Kaninchen, welches beinahe so schwer ist wie zwei deutsche, frißt aber auch etwa eben so viel wie zwei der lelzteren. Die Fitterungskosten und die Erzeugungskosten eines Kilogramms Schlachtgewicht sind ebenfalls nahezu dieselben $(\tau)$. Dazu vertragen manche Rassen das nordische Klima schlecht. Selbst in den wissenschaftlichen Instituten wurden die Spielarten von größerem Körpergewicht teilweise wieder abgeschafft, obgleich sie beim Operieren manche Bequemlichkeiten darbieten.

In Folge dieser Umstinde vollzogen sich nun aber zahlreiche Kreuzungen zwischen den deutschen domestizierten Kaninchen und jenen fremden Rassen. Wahrend für die erste Auflage ausschließlich das damals in Deutschland 
iiberall verbreitete Kaninchen, jener alte Liebling der Physiologen, benutzt werden konnte, sind jetzt die Mischlinge ron halbem, Viertels- und Achtelblut zufolge aller möglichen unbeaufsichtigten Kreuzungen so überwiegend, dass es, wenigstens in der Gegend ron Gütlingen, schwierig ist, sich des reinen Blutes eines anscheinend deutschen Kininchens von höchstens $2 \mathrm{~kg}$ Körpergewicht) zu vergewissern. Von Wichtigkeit wiren diese Verhaltnisse, wenn es sich um die Mischung mit sog. Leporiden handelt (s. unten).

Als hauptsählichste Spielarten werden aufgezihlt $(8-/ 8)$ das deutsche Kaninchen, französische Kaninchen, Gehegehaninchen, Silberkaninchen, Riesenkaninchen, Widderkaninchen, Angorakaninchen und Hasenkaninchen. Es gieht aber noch eine Menge Unterabteilungen, wie sich sogleich zeigen wird. Auch ist zu lomerken, daß manche der genannten Rassen weder gut charakterisiert, noch überhaupt von Dauer sein düften, unter gleichen Namen kommen im Handel sehr verschiedenartige Spielarten vor.

Als einigermaßen konstante Rassen sind nur das deutsche Kaninchen, das Angora- und Widderkaninchen zu betrachten.

1. Das deutsche hanmchen. Lepus cuniculus domesticus. Stallhase, Kie]-hase. Gewöhnliches Ilauskaninchen (Fig. 1'. Kaum $2 \mathrm{~kg}$ schwer, in mannig-

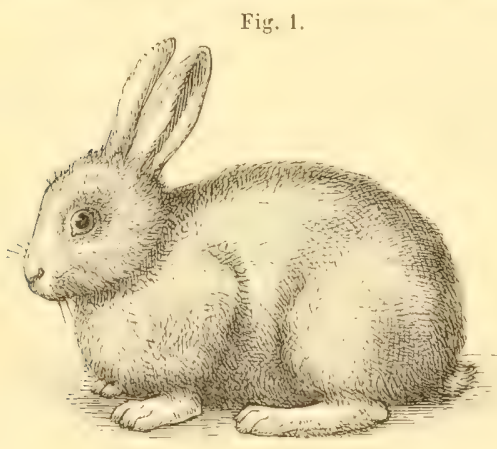

Deutsehes Kaninchen. V. $1 / 6$. faltigen Farben: grau, bläulich, gelbrötlich, schwarz, weiß (Albino), gescheckt.

Das holländische Kanmchen. Nieard. Scheint eine durch Färbung ausgezeichnete, kleinere Spielart des deutschen zu sein. Das Gewicht kann bis $567 \mathrm{~g}$ sinken $(8$, S. 107).

2. Das Gehegetianinchen. Lapin de Garonne. Wiegt $2,5-3 \mathrm{~kg}$, Farbe wie bei dem vorigen, ist ein kürzlich domestiziertes, durch Zuichtung und Futterung schwerer gewordenes, wildes Kaninchen, das in Frankreich im Freien gezogen wird.

3. Das franzisische Kaninchen. Lopin ordinaire, schlichtweg Lapin ge-namnt. Belgisches Kaninchen. Körpergewich wie bei dem vorigen. Farbe meist wrat, atuch schwarz, weiß oder gescheckl. Ist besonders fruchtbar (10 Junge). Ist ein domestiziertes Gehegekaninchen.

4. Das Siberkaninchen. Lepus cuniculus argenteus. Lapin argente. Lapin a fourure. Silvergrey. Silver Rabbit. Pelzkaninchen. Farbe silbergrau. Ahart des vorigen oder des deutschen Kaninchens.

Eine Unterabteilung des Silberkaninchens bildet Lepus cuniculus nigripes (I). Himalayakaninchen. Russisches. Polnisches, Chinesisches Kaninchen. Weiß Alhino) mit schwarzen FüBen, Ohren und Nase. Sie entstehen durch Kreuzung ron silbergrauen mit Chinchillalianinchen 8 . Letztere werden als eine mäusefarbige Unterrasse der Silberkaninchen bezeichnet.

Ileidenhain bezeichnet die franzisischen Kaniuchen in Breslau als bram am Rücken, grau am Bauche, langhaarig, mit sehr großen Ohren; sie bluten leichter aus der Y. jugularis interna beim Ausreißen des X. accessorius aus 
dem Foramen jugulare, weil Vene und Verr bei dieser Spielart fester rerwachsen sind.

5. Das Widderlaninchen. Afrikanisches Kaninchen. Lapin bélier. Lop-ear. Körpergewicht $\breve{b}-7 \mathrm{~kg}$. Farbe grau, hellgell, schwarz oder weiß. Bringen 4 bis 6 mal durchschnittlich 4 Junge. Charakteristisch sind die langen und breiten, herabhangenden Ohren, die eine Lange von einer Ohrspitze zur anderen bis $\$ 5 \mathrm{~cm}$ bei einer Breite ron $1 \mathrm{~cm}$ erreichen $S$. So beschaffene haninchen werden als "full-lops bezeichnet; hingen die Ohren nicht herab. sondern sind sie horizontal gerichtet wie ein aus dem Wasser erhobenes Ruder. so heißen sie »oar-lops«。

Bei alteren Tieren bilden sich transversale schlaffe IIatfalten am Halse, die bis zur Schnauze ausgedehnt werden können.

Der Schidel dieser Rasse ist speziell untersucht worden (\$). Man könnte glauben, das Herabhingen der Ohren sei Folge des Nichtgebrauches der Ohrmuskeln, das Widderkaninchen soll aber einer Kreuzung zwischen dem französischen Kaninchen und dem Kaphasen (Lepus capensis) seine Entstehung verdanken. Dieser Hase hat nimlich lingere Ohren - bis $138 \mathrm{~mm}$ lang 9. S. 97), wåhrend sie beim wilden Kaninchen 78 , beim gewöhnlichen Hasen $104 \mathrm{~mm}$ lang werden. Dabei steht die Schädellänge zwischen Hase und Kaninchen in der Mitte. - In Betreff des Widderkaninchens ist jedoch keineswegs das außere Ohr allein beteiligt, vielmehr zeigt sich der ¿ußere knöcherne Gehörgang nach vorn gerichtet und verschoben. Bei Individuen, die nur ein herabhangendes Ohr besitzen (half-lops, s.

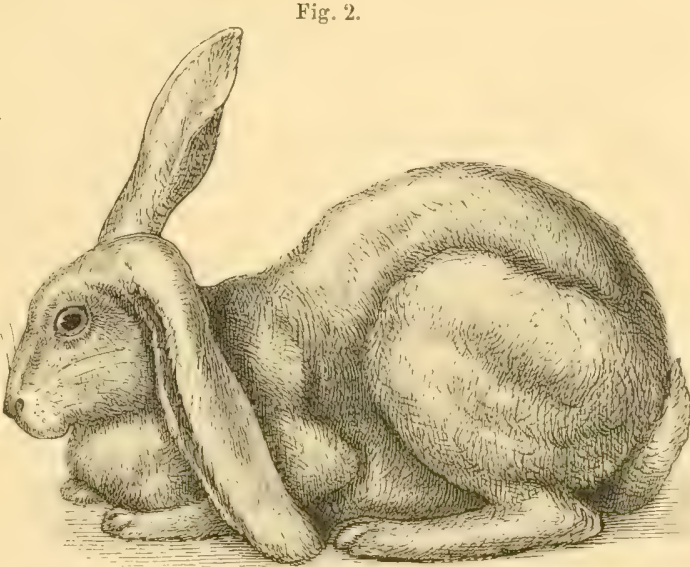

Widherkaninehen mit einem Hängeohr (half-lop). V. etwa ${ }^{1}$ fi. Nach Delamer s. $\delta$, s. $10 \mathrm{~m}$.

Fig. 2), was häufig vorkommt, tritt die Verschiebung des Meatus auditorius externus nur an dieser Seite auf, was jedoch auch bei französischen Kaninchen, die kein hängendes Ohr haben, sich zeigt Fig. 2). Bei den erstgenaunten können fast simmtliche Schädelknochen beteiligt, der Schiidel asymmetrisch, die Knochen auf der affizierten Seite in sagittaler Richtung verlingert sein: nicht selten fehlen ein oder beide außere Ohıen ginzlich. Alle diese Lmstinde deuten offenbar auf pathologische Verinderungen, die in frïher Embryonalzeit aufgetreten sind. Übrigens ist der Schidel zwar viel linger und höher wie beim wilden kaninchen und beim deutschen Kaninchen, keineswegs aher entsprechend breiter, und dies scheint für das französische haniuchen und seine Abkömmlinge ủberhaupt zu gelten (S. 13).

Kleinere Abarten des Widderkaninchens werden als andalusisches hi- 
ninchen, amerikanisches Kaninchen, Bulldoggenkaniuchen, Dachs-Widderkaninchen bezeichnet; eine Kreuzung des Widderkaninchens mit dem französischen oder dem Gehegekaninchen, als Normandiner-, Lyoner- oder Languedoc-Kaninchen, Lapin Rouennais.

6. Das Riesenkaninchen. Lapin géant. Belgisches Riesenkaninchen. Patagonisches Kaninchen. Besonders große Sorte des französischen Kaninchens, $7-8 \mathrm{~kg}$ schwer, aber nicht so fruchtbar wie letzteres. Das in England gezúchtete patagonische Kaninchen oder englische Riesenkaninchen scheint nur in der übrigens variablen Färbung zu differieren.

7. Das Angorakaninchen (s. S. 5).

8. Das Hasentaninchen. Leporide. Lepus Darwini, Züru. Lièvre-Lapin. Es giebt domestizierte Kaninchen, welche in Farbung vollkommen dem Hasen gleichen, an Körpergröße und äußerlich wahrnehmbaren Eigenschaften etwa die Mitte zwischen beiden Arten halten. Namentlich sind die hinteren Extremititen starker entwickelt und die Ohren linger als beim deutschen Kaninchen. Für den Laien fhaben diese Tiere, von denen eine schöne Zucht z. B. im zoologischen Garten in Berlin existiert (1882), eine so frappante Ahnlichkeit mit IIasen, daß die Vermuthung nahe liegt, ein solches IIasenkaninchen könnte, wenn dasselbe zufälig in Freiheit angetroffen würde, für einen wilden Hasen gehalten oder jedenfalls für einen Bastard zwischen Hasen und Kaninchen genommen werden.

Trotzdem handelt es sich für gewöhnlich um nichts weiter, als um firanzösische Kaninchen von Hasenfarbe. Dies sind die unechten Leporiden, wie sie hier in dem Falle genannt werden sollen, daß sie fälschlich für Bastarde ausgegeben wurden. Mit dem Ausdruck Hasenkaninchen sind also hasenfarbige französische Kaninchen ohne Rücksicht auf ihre derartige Abstammung gemeint. Als uleporiden wird übrigens gewöhnlich (I) eine zoologische Unterordnung bezeichnet, relche als einzige Familie die Leporinen enthät.

Es giebt nun eine Anzahl von Mittheilungen $(10)$, wonach es gelungen sein soll. Bastarde zwischen Hasen und Kaninchen zu züchten. Zum Teil sollen diese Bastarde sowohl untereinander, als mit den Stammarten gepart, fruchtbar gewesen sein. Mit einer Ausnahme haben sich jedoch simmtliche bezügliche Angaben als auf mehr oder weniger absichtlicher 'Täuschung beruhend herausgestellt $(I 2,1,5,14)$. Weshall, eine solche unternommen werden konnte, erklirt sich aus dem Umstande, daß Kaninchen in Frankreich gegessen werden, was eine Zeitlang auch in Deutschland der Fall war. Als llandelsartikel schien ein Tier höheren Wert zu haben, wenn dem Kiufer versichert werden konnte, ersteres sei wenigstens ein halber Hase. Man hat sich dabei zu erimnern, daß das Kaninchenfleisch eine weißliche (S. 7) und süBlich schmeckende Beschaffenheit hat und daß die Hasen seit der ersten Revolution in Frankreich seltener geworden sind. Auch werden Ilasenfelle im IIandel relativ höheren Wert haben.

Aus dem Gesag̣ten mağ sich erkliren, weshalb manche Erzahlungen einen zum Teil bedenklichen Eindruck machen: z. B. die Geschichte (ISכ) von einem Ilasenweibchen, welches infolge der Begattung mit einem Kaninchenminnchen sieben Junge zur Welt brachte, wahrend der IIase sonst 1-3 S. 12) produziert. Offenbar kann aber die Anzahl sich periodisch öfnender 
Graaf'scher Follikel durch die fremdartige Begattung nicht verindert werden. Man erkennt das Bestleben eines Laien, eive zwischen Hase und Kaninchen in der Mitte stehende Zucht zu liefern. Ferner der Fall ron einem IHasenweibchen, welchem der Schwanz durch Abbindung entfernt werden mußte, damit das Tier die Begattung nicht hindern konnte. Wenn letzterer Versuch etwas helfen sollte, müßte wohl der Schwanz bis auf seine Wurzel am Os sacrum entfernt werden, welche Operation nicht ausgeführt zu seiu scheint.

Hasen und Kaninchen leben in Feindschaft; zusammen eingespert, greift das Kaninchen, mag das betreffende Par verschiedenen Geschlechtes sein oder nicht, den Hasen an und tötet ihn durch Bisse - meist in die Halsvenen (IJ), wibrend der Hase, ohne sich zu verteidigen, nur zu entfliehen sucht und sich dabei oft tödlich beschäigt, wenn beide Tiere in engem Raume eingeschlossen sind. In der Freiheit verlassen sogar die Ilasen solche Gegenden, in denen wilde Kaninchen in größerer Zahl sich angesiedelt haben. Hierin liegen die Schwierigkeiten der künstlichen Bastardzüchtung, während letztere in der Freiheit offenbar niemals zu Stande kommt. Ilan muß deshalb Hasen und Kaninchen verschiedenen Geschlechtes von frühester Jugend an, solbald sie allein fressen können, zusammen aufziehen und Individuen der eigenen Art von jedem Teile des Paares fermhalten. Sollte trotzdem sich Feindschaft zwischen beiden Gliedern des Pares entwickeln, so könnte man sie durch ein Gitter isolieren, in welchem eine ventilartige Klappe angebracht ist, die dem Hasen Zugang zum Kaninchen verstattet, aber nicht umgekehrt. Indem ersterer in einer auf diese Art kommunizierenden Abteilung des gemeinschaftichen Stalles gesichert ware, ließe sich das Eintreten der Brunstperiode abwarten, wodurch die Kimpfe wenigstens anderen Charakter annehmen wirden. Leider gehen die kleinen Hasen in der Gefangenschaft häufig zu Grunde, ehe sie das Pubertatsalter erreichen.

Die oben als Ausnahme erwahnten einzigen positiven Resultate hat Dr. Conrad, Professor der Staatswissenschaften in Ilalle, auf dem oben angedeuteten Wege erhalten $(10)$. Im Jahre 1866 wurden zu Plochoczin, einem Gule in Westpreußen, mehrere $2-3$ Wochen alte Kaninchen- und Hasenpaare zusammengesetzt. Von diesen blieb ein silbergraues Kaninchenweibchen mit einem Haseumannchen am Leben und ersteres brachte von 1867-68 uber 20 Bastarde zur Welt. Dieselben waren bis in die sechste Generation untereinander fruchtbar, so daß binnen zwei Jahren über 80 Junge erzeugt wurden, im Durchschnitt \& auf jede Geburt. Die hinteren Extremitaten, Ohren und der Kopf waren ein wenig langer als beim Kaninchen; die Farbe hasenartig bramblich, in fler Tiefe grau; das Fleisch war weißlich wie beim Kaninchen. Vier Bastarde der zweiten und dritten Generation sahen wie schwarz und weiß gefleckte deutsche Kaninchen aus. Rückkreuzung mit Kaninchen gelang mehrfach. Entferntere Abkömmlinge (/5) aus der drilten bis sechsten Generation hatten zum Teil an den Spitzen schwarz gefirbte Ohren, lefztere waren langer als der Kopf, die Dorsalseite des Schwanzes meistens schwarz, die Ventralflache weiß. Im Jahre 1880 starb der letzte Abkömmling dieser Zucht zu Ilalle. In jener Gegend Westpreußens gab es 1866 keine französischen Kaninchen; auch war der Hase, als er ausgewachsen war, ein sehr großes Exemplar von Lepus rulgaris s. timidus aut. Briefliche Mitteilung von Conrad). 
Jene fruchthare Bastardzeugung zwischen Iase und Kaninchen galt als cin für die Darwin'sche Deszendenztheorie besonders wichtiger Beweis. Anf solvhem Ilintergrunde erschien es nöthigg, nach Quellen unabsichtlicher Tiuschung zu fragen, denen die fraglichen Züchtungsversuche ausgesetzt sein können.

IIilt man briustige Kaninchenweibchen und -Minnchen getrennt, so führen nicht nur die letzteren, sondern auch die ersteren ofters komplizierte Kletterversuche aus, um zu einander zu gelangen. Lm so eher ist dies der Fall, wenn eines der Thiere sich in Freiheit befundet (17). Es ist klar, daß jede Unrorsichtigkeit eines Wirters z. B. bei Gelegenheit des Fütterns, das nicht immer rom Experimentator selbst überwacht worden ist, zu Irrtumern führen kann, d. h. das Kaninchenweibchen ist scheinbar vom llasen trichtig, mit dem es eingesperrt wurde, in Wahrheit aber von einem mannlichen Kaninchen. Dabei hraucht an eine absichtliche, wenngleich gutgemeinte Tiuschung seitens des Wärters noch gar nicht gedacht zu werden.

Mag man num die experimentelle Seite der Angelegenheit nach den oben erwihnten brieflichen Mitteiluugen als gegen Einwinde gesichert erachten oder nicht - jedenfalls ist noch rersucht worden, auf anatomischem Wege Beweise für die Abstammung der fraglichen Bastarde beizubringen. Ihre Skelette sollen namlich in manchen beziehungen zwischen Ilase und Kaninchen die Mitte halten (3). Hierbei sind zuncichst die Lnterschiede beider Arten zusammenzustellen. Für das wilde Kaninchen liegt eine sorgfaltige Vergleichung des Skelettes mit dem Widderkaninchen $(\$)$, ferner der sog. echten Leporiden, wie sie im Gegensatz zu den angeblich in Frankreich gezuchteten unechten is. 10. genannt zu werden pflegen, mit dem deutschen Kaninchen und dem Hasen (1/4 und /5) vor.

\section{Unterschiede des Hasen und Kaninchens.}

Der Hase leht cinzeln, oberirdisch; das Kaninchen gesellig, wenn irgend thunlich in selbstgegrabenen Bauen. Ersterer führt niemals jenen deu Kaninchen eigentimlichen Schlag mit dem Fuß auf den Boden (S.6), welcher den Kameraden statt eimes Warmugsrufes dient. Das wilde Kaninchen lißt sich sehr leicht zihmen und das zahme verwildert in kurzer Zeit, sobald es die Freiheit erlangt hat. Der Ilase dagegen ist nur zihmbar, wenn er sehr jung in der Cofaugenschaft aufgezogen wird. Die Differenz erklairt sich einfach aus der Thatsache. daß das Kaninchen wie gesağ ein geselligy lebendes Tier ist, der IIase aber nicht. - Die IIasin ist wie das Kaninchen 30-31 Tage trichtig; sie wirft daun 1-3 Junge, die zum Lnterschiede ron den neugeborenen Kaninchen ein entwickeltes Wollkleid und geoffnete Augenlider besitzen.

Srhialel. Das Kaninchen hat ein Os intepparietale, welches beim IIasen fribzeitig mit dem Os occipitis verschmilzt; dieser Lnterschied ist anBerordentlich charakteristisch und faillt atuch am mazerierten schaidel sofort auf (Fig. 3, 4 u. 5).

Der hintere Rand des Foramen manum oceipitale (Fig. $6 \mathrm{Fm} \mathrm{S}$. 14) hat beim Kaninchen einen viereckigen medianen Ausschnitt, weil die Pars squamosa oss. occipitis an dieser Stelle relatir weniger entwickelt und so breit 
ist wie die Anteilnahme derselben an der Begrenzung des Foramen magnum. Dieser Ausschnitt wird beim Hasen von Knochensulsstanz ausgefüllt, oder es

Fig. 3.

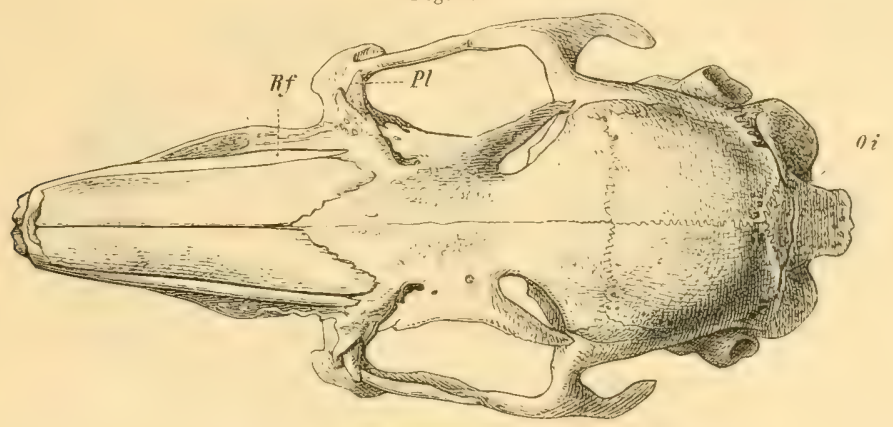

Schädel eines deutschen Kaninchens, von oben. O $i$ Os interparietale. Pl Processus subcutaneus oss. lacrymalis. Rf Ramus frontalis oss, intermaxillaris.

Fig. 4.

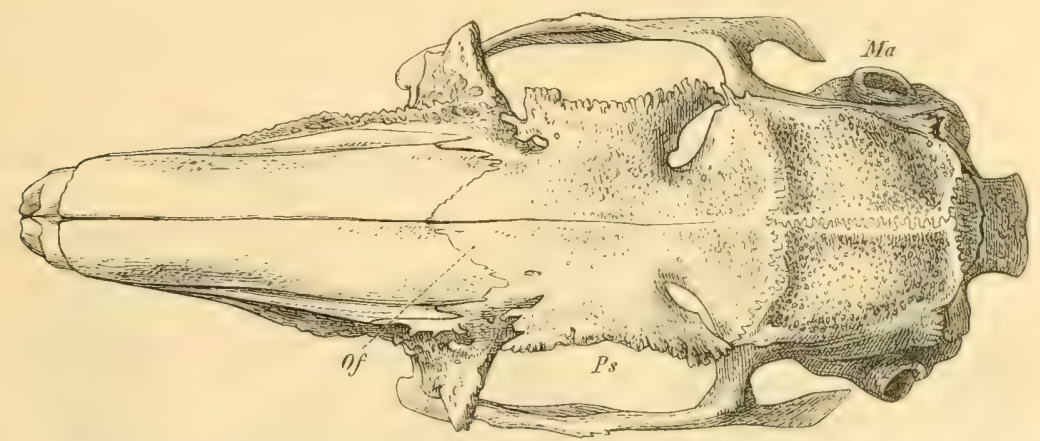

Schädel eines französischen Kaninchens, von oben. Der Schädel ist etwas asymmetrisch, die öffnung ¿des rechten Meatus anditorius externus ( $\boldsymbol{M} a$ ) sieht mehr nach oben, die Ränder der Processus supraorbitales oss. frontis $(P s)$ sind rauh, das rechte $O$ s frontis reicht weiter nach vorn, als das linke $(O f)$.

Fig. 5 .

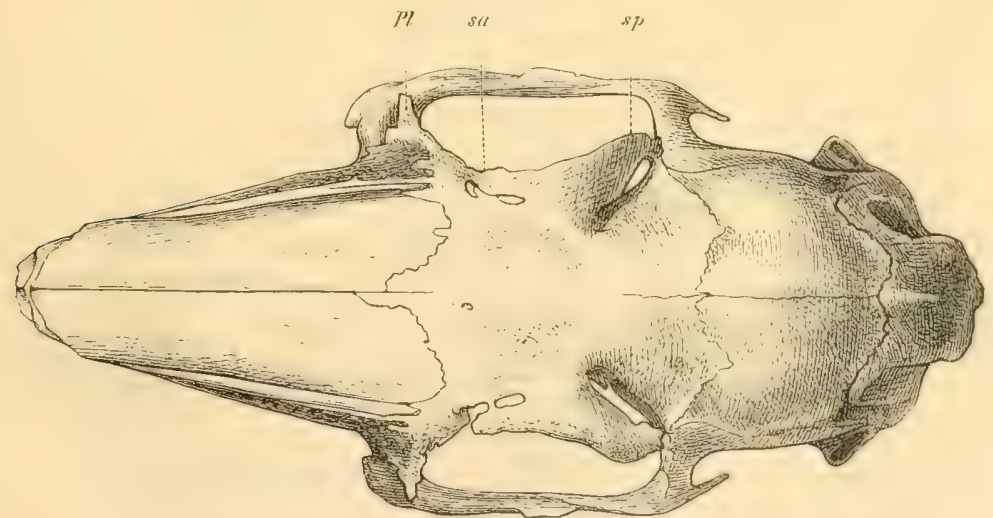

Schädel eines Hasen (Lepus vulgaris), von oben. Im Vergleich zu den beiden Kaninchen sind die Nasenbeine breiter, das 0 s interparietale fehlt, der Processus supraorbitalis posterior $(s p)$ ist stärker entwickelt, der anterior $(s a)$ hilft ein Foramen supraorbitale bilden. Pl Processus subcutaneus oss. lacrymalis. 
ist ein dreieckiger Ausschnitt mit nach hinten gerichteter Spitze vorhanden (vergl. Fig. 6,7 u. 8).

Fig. 6.

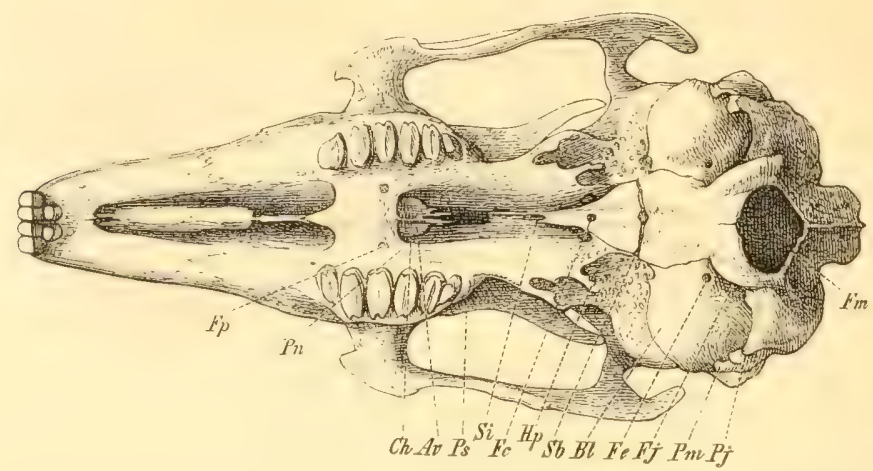

Schädel eines deutschen Kaninchens von unten. F F Foramen palatinum in der Pars palatina oss. palatini. $P n$ Pars nasalis oss, palatini. Ch Choane. A $v$ Ala vomeris. $\mu_{s}$ Processus supraorbitalis ant. oss. frontis. $S i$ Synchondrosis intersphenoidalis, $F_{C}$ Foramen cavernosum. Hp Hamulus pterygoideus oss. sphenoidei posterioris. Sb Synchondrosis sphenobasilaris. Bl Bulla tympani oss. temporum. Fe Foramen caroticum externum. Fj Foramen jugulare. Pm Processus mastoideus oss. temporum. Pj Processus jugularis oss. oceipitis. $F m$ Hinterer Rand des Foramen magnum occipitale.

Fig. 7.

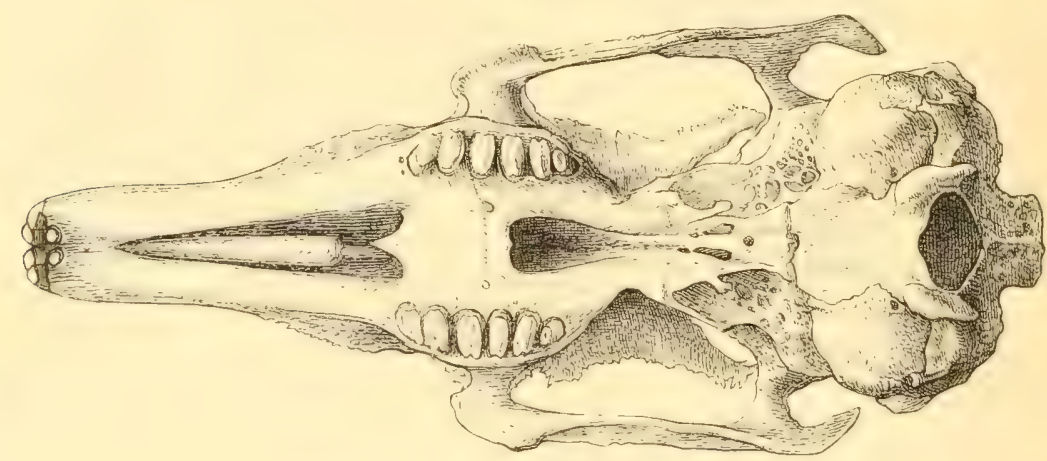

schädel eines franzüsischen haninchens von unten.

Fig. $\$$.

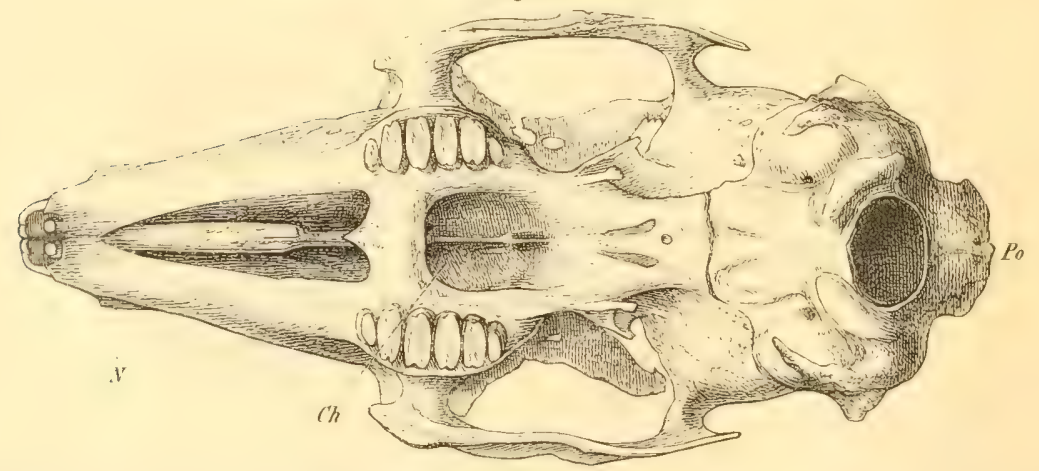

Schādel eines Hasen, von unten. $N$ Vorderes Ende des lateralen Randes des Nasenbeines, welches hier sichtbar ist. $C h$ Choanen, die relativ zum Kaninchen sehr breit sind. Po Protuberantia occipitalis externa. 
Stirnbein. Ferner sind die Arcus supraorbitales beim Hasen absolut und relativ breiter, ihre Processus supraorbitales starker entwickelt, sie berühren fast die Pars frontalis des Stirnbeins, wahrend beim Kaninchen die Incisurae. supraorbitales weiter rom Stirnbein selbst entferut bleiben. Ersteres ergiebt sich aus folgender Übersicht:

Arcus supraorbitales

\begin{tabular}{l|c|c|c}
\hline & Hase & $\begin{array}{c}\text { franzüsisches } \\
\text { Kaninchen }\end{array}$ & $\begin{array}{c}\text { deutsches } \\
\text { Kaninchen }\end{array}$ \\
\hline \hline Länge & $22 \mathrm{~mm}$ & $23 \mathrm{~mm}$ & $18 \mathrm{~mm}$ \\
\hline Breite & $7-$ & $6,5-$ & $3-$ \\
\hline B : L & 0,32 & 0,28 & 0,17
\end{tabular}

Es betragen die Differenzen zu Gunsten des Hasen 47\% beim gewöhnlichen und 12\% beim französischen Kaninchen (14).

Das hintere freie Ende des Jochbeines ist bein Kaninchen relativ und absolut länger als beim Hasen.

Die Nasenbeine sind beim IIasen absolut und relativ breiter; man kann ihren Rand von unten her sehen (Fig. 8), sie messen (1.4) beim Hasen im Vittel $23 \mathrm{~mm}$ oder $28,4 \%$ ihrer Läge, beim französischen Kaninchen $19,5 \mathrm{~mm}$ resp. 22, $2 \%$, beim deutschen Kaninchen $15,5 \mathrm{~mm}$ resp. $24,0 \%$. Wichtiger erscheint der Umstand, daß sie an ihrem vorderen Ende von dem Ramus frontalis oss. intermaxillaris beim Hasen weiter entfernt bleiben und hier eine breitere, nach vorn klaffende Spalte zeigen.

Gesichtsschädel. Was die Gesichtsknochen anlangt, so sind die Choanen beim Ilasen absolut und relativ viel breiter, beide zusammen etwa doppelt so breit wie die Alveolen des dritten Backenzahnes, beim Kaninchen wenig breiter als letzterer (Fig.6, 7 u. 8). Die Differenz resultiert aus der fast senkrechten Stellung des Alveolarfortsatzes des Oberkieferbeines beim Ilasen, wahrend derselbe sowie die Pars sagittalis oss. palatini beim Kaninchen etwas schrajg medianwärts nach oben ansteigt.

Unterkiefer. Beim Kaninchen setzt sich der untere Rand des Ramus vom Corpus aus nach hinten anfangs fast horizontal fort, un dann anfangs sanft, weiter hinten mehr senkrecht aufzusteigen, ebenso beim französischen Kaninchen (Fig. 9 u. 10, S. 16). Dagegen wird beim IIasen die untere Grenze zwischen Ramus und Corpus maxillae inferioris durch eine stumpfwinklig hervorspringende Ecke, Spina maxillaris inferior (Fig. $11 \mathrm{Sm}$, S. 16), markiert, von welcher an der hintere Rand des Ramus sofort nach oben sich wendet und gleichmißiger, einer Kreisperipherie entsprechend aufsteigt. Vergl. über die Schädel 181 .

Wirbelsaule. Der Kopf wird beim Hasen weniger aufgerichtet getragen, daher greift der am oberen Rande gelegene Processus spinosus des Epistropheus hiaten weiter über den Atlas hinauf als beim Kaninchen.

In der Form verschiedener Wirbelfortsitze sollen sich Verschiedenheiten zwischen wilden und Widderkaninchen finden (S), welche jedoch den Cha- 
rakter anatomischer Varietiten haben düften. Der Canalis vertebralis ist breiter im Verhältnis zu seinem Sagittaldurchmesser; die Processus obliqui

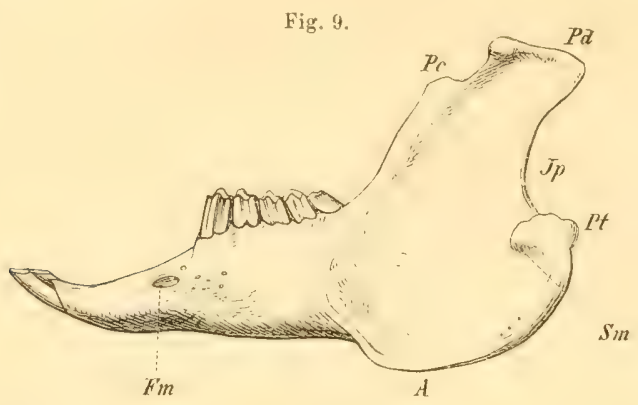

Unterkiefer eines deutschen Kaninchens, im Profil. $P d$ Processus condyloideus. $P c$ Processus coronoideus. $J p$ Incisura semilunaris posterior. Pt Processus pterygoideus. S $n$ spina maxillaris. A Angulus maxillae inferioris. $F m$ Foramen mentale.

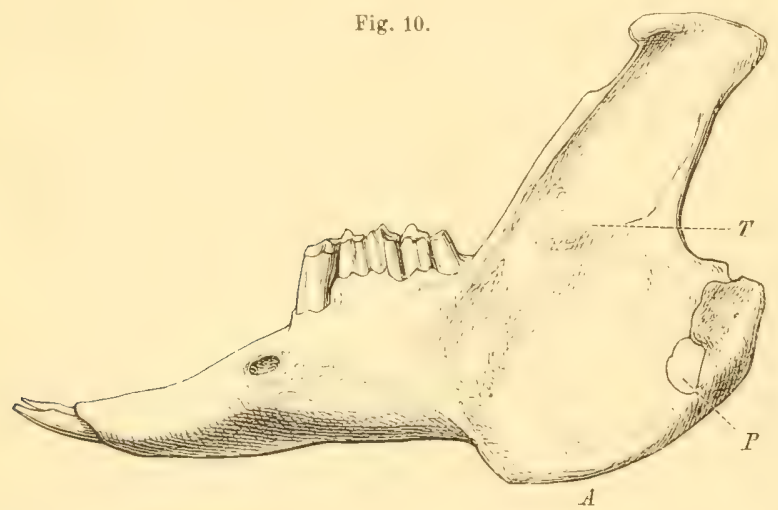

Unterkiefer eines französischen Kaninchens, im Profil. $T$ Tuberculum des Ramus maxillae inferioris, $P$ Perforationsoffnung. A Angulus maxillae inferioris.

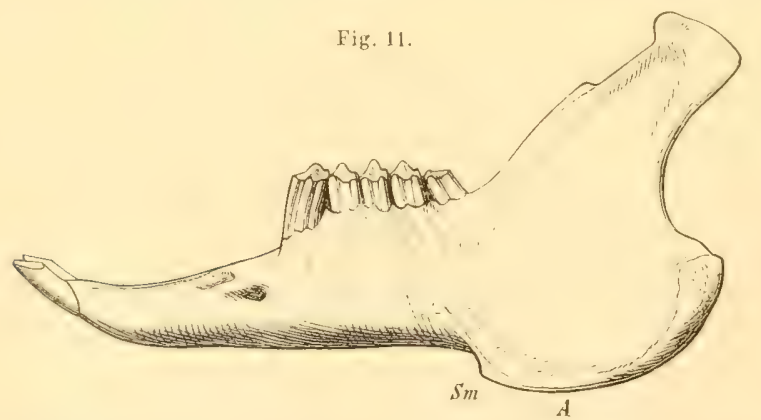

Unterkiefer eines Hasen, im Profil. A Angulus maxillae inferioris, der mehr allmählich ansteigt im Gegensatzzum Kaninchen. $S m$ Spina maxillaris (inferior). superiores des dritten Halswirbels erscheinen von oben gesehen dreigeteilt, die Processus transversi sind an der Spitze gespalten. Beim gewöhnlichen französischen ist alles dies jedoch ebensowenig wie beim wilden Kaninchen und beim Hasen der Fall.

Die anscheinende Ähnlichkeit, welche in der Form der Processus spinosi des siebenten bis zehnten Rückenwirbels zwischen dem Hasen und Widderkaninchen sowie dem französischen Kaninchen - im GegenSatz zum wilden Kaninchen in der That vorhanden ist, resultiertwesentlichaus der Zunahme der absoluten Dimensionen.

Vorderarm. Am wichtigsten, weil mit der Lebensweise der Tiere zusammenhängend, ist die staikere Entwicklung der Ulna in der Breite und Dicke: während sie beim Hasen einen langen schlanken Knochen darstellt und mehr hinter dem Radius gelegen ist, steht sie letzterem beim Kaninchen an Maichtigkeit nur wenig ach und rúckt mehr in eine frontale Ebene mit demselben (Fig. 12 
und 13). Für das Graben in der Erde ist diese Differenz ohne Zweifel von Bedeutung.

An der oberen Extremität betragen die Längendimensionen $(22,1879, \mathrm{~S} .512)$ in $\mathrm{mm}$ :

\begin{tabular}{l|c|c|c|c}
\hline & Humerus & Radius & Ulna & $\begin{array}{r}\text { Carpus und } \\
\text { Hetacarpus }\end{array}$ \\
\hline Hase & 100 & 105 & 122 & 35 \\
Kaninchen & 60 & 55 & 65 & 20
\end{tabular}

Phalangen der Finger. Die tletzten Phalangen sind beim Hasen gespalten (Fig. 15); beim Kaninchen ist diese Spaltung, durch welche die Nägel eine stärkere Befestigung erhalten, nur angedeutet (Fig. 14A). Gewöhnlich (9, S.34, 14, S. 34, 21) findet man freilich die Angabe, daß die Nagelphalangen beim Hasen ungespalten seien. Dies ist jedoch im Gegenteil hier und da beim wilden Kaninchen und am Daumen des deutschen Kaninchens (Fig. $44 \boldsymbol{B})$ der Fall. bei den übrigen Fingern und Zehen kann man auch beim deutschen Kaninchen mit freiem Auge oder mit der Lupe die Spaltung erkennen, während die letztere beim Hasen viel deutlicher, wenngleich kürzer ist.

Femur. Die Oberschenkelbeine des Hasen und Kaninchens sind einander nicht mathematisch ähnlich, sondern in der Profilansicht ist das erstere stiirker nach vorn convex gebogen. Die Differenz betrigt $9 \%$ des größten Abstandes einer Sehne, die zwischen der Spitze des Trochanter major und der Grenze zwischen vorderem und unterem Rande des Condylus lateralis gezogen wird, von dem durch den Vorderrand des Corpus femoris repräsentierten Teil einer Kreisperipherie. Man kann dasselbe auch so ausdrücken, daß man sagt: der Winkelabstand der erstgenannten beiden Punkte beträgt etwa $41^{\circ}$ beim Hasen, $39^{\circ}$ beim Kaninchen.

Fig. 12.

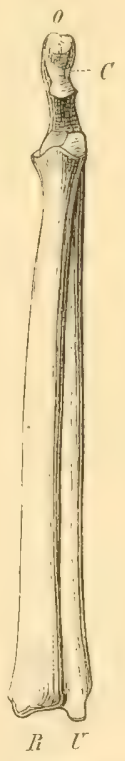

Radius und Ulna eines deutschen Kaninchens, von vorn. $R$ Radius. $U$ Ulna. $O$ Olecranon. $C$ Gelenkthäche der UIna.

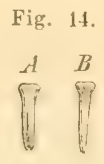

Nagelphalangen eines deutschen Kaninchens, von der Dorsalseite. A. Vom Zeigetinger. B. Vom Danmen.
Fig. 13.

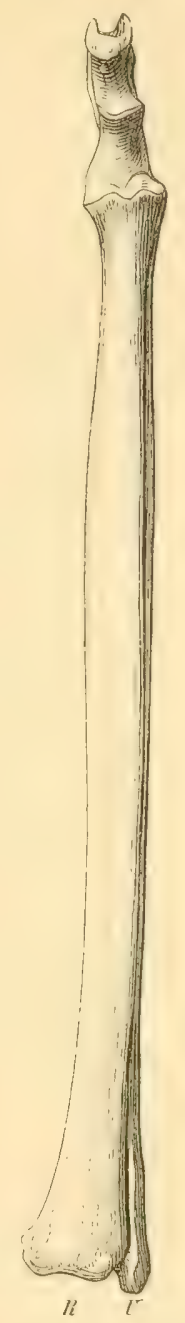

Radius und Ulna vom $\mathrm{Ha}$ sen, von vorn. $R$ Radius. $U$ Ulna.

Fig. 15.

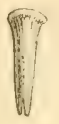

Nagelphalanx des Zeigefingers eines Hasen, von der Dorsalseite. Das nntere Ende ist klaffend. 
Nagelphalangen der Zehen. Sie unterscheiden sich wie diejenigen der Finger.

Eine Anzahl ron weiteren Lnterschieden (vergl. If u. 15) im Skelett haben sich zufolge genauerer Lntersuchung nicht bestiitigt, resp. als inkonstant herausgestellt. Hierzu gehören die von der Abnutzung abhangigen Differenzen unter den Backenzihnen, die starkere Entwicklung des Tuberculum posterius atlantis beim Kaninchen. Die Anzahl der Schwanzwirbel Hase 12-20 oder 12-16, in der Norm 15; Kaninchen 12-16, in der Norm 16: Leporide 14, selten $15 ;$ s. 15$)$ u.s.w. Analoges gilt von den Differenzen zwischen Widderkaninchen und wildem Kaninchen $(S)$ in Bezug auf die Processus transversi und obliqui superiores des dritten Halswirbels, die Processus spinosi einiger Ruickenwirbel (S. 16), den Processus xiphoideus der Brustbeines, den Processus hamatus der Scapula, das Becken u. s. w.

Die Differenzen, welche zwischen den Tarsusknochen des Hasen und Káninchens beschrieben worden sind $(9,5.34)$, werden sich faktisch auf die Vergleichung eines jungen Hasen mit einem ausgewachsenen Kaninchen bezogen haben. Der Processus plantaris oss. navicularis, das (wirkliche) Os larsale I und das (wirkliche) Os metatarsi hallucis stelien namlich angeblich (9) besondere Knochen dar. Der Processus plantaris oss. tarsalis II soll beim Hasen starker entwickelt sein, was ebenfalls beim erwachsenen Ilasen keineswegs der Fall ist. Das Os tarsale II soll einen großen, den scheinbar fehlenden Processus plantaris oss. navicularis teilweise ersetzenden, plantaren Fortsatz haben. Dies ist jedoch nicht der Fall; das Os tarsale II gleicht dem Os tarsale III des Menschen und es scheint eine Verwechslung mit dem Os tarsale IV vorzuliegen, welches allerdings beim Ilasen eine viel stirker entwickelte Tuberositas besitzt. - Vergl. auch 8 , S. 123, und /4, S. 34 .

Cher die Dimensionen der meisten Knochen des Skelettes beim IIasen, deutschen Kaninchen, Leporiden und französischen Kaninchen liegen ausführliche vergleichende Messungen vor (14 und $/ 5)$.

Aus diesen ergeben sich als wichtigste Resultate folgende Differenzen in $\mathrm{mm}$ :

\begin{tabular}{|c|c|c|c|c|}
\hline & Hase & $\begin{array}{l}\text { Deutsches } \\
\text { Kaninchen }\end{array}$ & $\begin{array}{l}\text { Französisches } \\
\text { Kaninchen }\end{array}$ & Leporide \\
\hline Länge d.Schädels & 103 & 81 & 104 & \\
\hline$-\quad-\quad-\quad$ Hase $=1$ & 100 & 86 & & 95 \\
\hline Basilarlänge & 79 & 64,5 & 83 & \\
\hline Breite des Schädels & 32 & & 27 & 27 \\
\hline Länge des Femur & 116 & 85 & & 90 \\
\hline - der Tibia & 129 & 90 & & 102 \\
\hline - des Fußes & 125 & 93 & & 105 \\
\hline
\end{tabular}

Als Schadellange ist die Entfernung rom hinteren Rande der Protuberantia occipitalis externa bis zum Vorderrande der Oss. intermaxillaria, als Basilarliange die Entfernung vom vorderen Rande des Foramen magnum bis zum hinteren Rande der großen Schneidezihne, als Schidelbreite die Distanz zwischen den lateralen AuBenfliichen der Partes squamosae oss. temporum bezeichnet.

Da die milgeteilten Zahlen über die wichtigsten Dimensionen keine 
rechten Aufschlüsse geben, so mögen noch folgende (eigene) Vessungsresultate hier mitgeteilt werden.

Vergleicht man den Scharlel des wilden und eines französischen Kaninchens (Fig. 7, S. 14), so zeigt sich, daß letzterer an Länge mehr als an Höhe, aber fast gar nicht an Breite zugenommen hat. Ausgedríckt in Prozenten der Dimensionen des wilden Kaninchenschidels, stellen sich für die Linge etwa $43 \%$, für die Ilöhe $25 \%$, für die Breite nur $8 \%$ heraus. Erstere wurde von den Schneidezihnen bis zur Protuberantia occipitalis externa: die Ilöhe von der Synchondrosis sphenobasilaris bis zum Scheitel, die Breite an den Partes squamosae oss. temporum gemessen. Legt man aber auch für die Lange die Distanz zwischen dem vorderen Rande des Foramen opticum und dem hinteren Rande des Foramen magnum, welche die Erstreckung der Schiidelhöhle besser reprisentiert, zu Grunde, so erhält man immerhin nur 320\% Laingendifferenz, wihrend die Gesichtslinge vom vorderen Rande des Foramen supraorbitale posterius bis zum vorderen Raude der Nasenbeine um 66\% zugenommen hat.

Cher die Schädelkapazitit bei verschiedenen Rassen des Kaninchens und Hasen vergl. 8 .

Ireichteile. Beim IIasen verwachsen die stark entwickelten Cartilagines Santorinianae des Kehlkopfes unter einander. Lepus vulgaris hat 8-10 Peyer'sche Haufen im Dünndarm, das Kaninchen nur 4-6, was für das wilde, das deutsche und französische Kaninchen gleichmißig gilt; das wilde Kaninchen scheint meist nur 4. Peyer'sche IIaufen zu haben. Cher die Liange des Darmkanales vergl. allg. Splanchnologie. Die Faserknorpelscheibe am Dorsum des ersten Fingergelenkes ist beim IIasen größer, enthalt aber beim deutschen und französischen Kaninchen ebenfalls Knorpelzellen.

Die erwihnte (S. 4) gell,briunliche Beschaffenheit der Iris des IIasen riihrt davon her, daß die Pigmentkörnchen des eigentlichen Irisstroma gelb)lich, anstatt wie beim Kaninchen briunlich aussehen, wihrend diejenigen der Uvea bei beiden Tieren schwarz sind.

Das Gehim des IJasen ist absolut schwerer; sein Gewilht betrigt beispielsweise $14 \mathrm{~g}$ bei einem etwas mehr als $3 \mathrm{~kg}$ schweren Tiere, wahrend ein hall, so schweres Kaninchen ein Gehirn von ungefihr $8 g$ hatte (8). Aber auch Widderkaninchen, die an Körpergewicht dem IIasen gleichkommen, werden an absolutem Gehirngewioht, wie aus der großeren Schädelkapazitait hervorgeht, vom Hasen übertroflen. Wenn die Körpergewichte sich beim wilden und beim Widderkaninchen wie 1:2,17 verhielten, so war das Verhilinis der Körperlangen wie $1: 1,41$, der Schaidelkapazititen wie 1:1,15 (S). Hiermit ist in Cbereinstimmung, daß das Gehirn des Kaninchens relativ zum Kiorpergewicht schwerer ist, als das des llasen, wie es scheint (20) 11 m etwa $12 \%$. Dies ist eine bei Arten ron differenter Körpergröße abberhaupt nicht seltene Erscheinung, da die Leitungsbahnen nicht in demselben Verhiltnis abnehmen können wie letztere Größe. Interesse erweckt aber der Lmstand, daß bei dem durch Domestikation zesteigerten Körpergewicht das Gehirn sich an der Zunahme weniger beteiligt.

Auch über unechte Leporiden (S. 10) liegt bereits eine anatomische Untersuchung vor (19), welche Kaninchen aus der Zucht vou Gayot (vergl. If) 
betraf. Beim Ilasen betrug die Lainge des Vorderfußes $4 . \%$ von derjenigen des Ilinterfußes. Letzterer zeigte $26_{\%}^{\prime \prime}$ der Linge der Wirbelsiule, beim unechten Leporiden $24 \%$ und beim gewöhnlichen deutschen) Kaninchen $23 \%$. Die Finger sind beim Kaninchen freier, die Nigel starker gekrümmt und spitzer; ebenso beim Leporiden. Die Geschlechtsorgane standen der Große nach beim Leporiden in der Mitte zwischen Hase und Kaninchen, die Itoden maßen 40, resp. 36, resp. $30 \mathrm{~mm}$ Linge und 20 resp. $13 \mathrm{~mm}$ Breite oder Dicke. Der Lrsprung des 11 . pubocavernosus soll heim Kaninchen am oberen Rande des Arcus pubis stattinden foffenbar ein Priparationsfehler, W. K.). Die Epididymis enthielt beim Leporiden zahlreiche bewegliche Spermatozoen. Beim Leporidenweibchen waren die Ovarien klein, wie beim kaninchen $18 \mathrm{~mm}$ lang, $7 \mathrm{~mm}$ breit), die [terushorner kurzer. beim Hasen 13, beim Kaninchen 12, heim Leporiden nur $10 \mathrm{~cm}$ lang - diese Diflerenzen weisen darauf hin, daß nicht der jungfriuliche Uterus gemessen wurde. Die Dicke betrug beim Ilasen $7-8$ mm. Die Vagrina ist beim llasen 12, beim Kaninchen 14, beim Leporiden 11 cm lang, das Orificium urethrae beim Ilasen 6 cm vom Orificium uteri entlernt. Im Gimzen gleichen die außeren weiblichen Geschlechtsteile beim Leporiden mehr denjenigen des Kaniuchens, die inneren stehen in der Mitte zwischen denjenigen des Hasen und des Kaninchens. - Diese letzteren Siatze werden jedoch weder durch die anatomische Beschreibung, noch durch die angeführten, ofleubar von Zufilligkeiten beeinflußten Messungen bestitiğ ; zudem ist die an sich höchst verdichtige Zucht bereits für gewöhnliche französische Kaninchen erklärt worden (14).

Was nun die sog. echten Leporiden anlangt, so kann kein Zweifel bestehen, daß die oben angedeutete anatomische Beweisführung (15) fur die $\Lambda$ hstammung derselben mißlungen ist ( / 4$)$. Allerdings ist es richtig, daß die Skelette in manchen Proportionen zwischen Hasen und Kaninchen in der Nitle stehen. Dies gilt aber nur, soweit es sich als Folge ihrer hetrachtlicheren hörperọröbe herausstellt, und ergielot sich in ganz derselhen Weise auch für die gewöhnlichen framzösischen kaniuchen. In allen wesentlichen oben geschilderten Punkten (S.12-17) verhalten sich nicht nur dic gewöhnlichen und die hasenfarligen franziosischen Kaninchen, sonderu auch die sog. echten Leporiden gimz und gar wie wilde und deutsche Kaninchen, ohne irgend eine erhebliche S. 16, Anniherumg nach dem Hasen hin zu zeigen. Auch laßBt die genaue Untersuchung, welche den Leporiden, ron mir' sowie den failschlich in lrankreich fü Bastarde ausqegebenen Tieren bereits (1,3) zu Teil geworden ist, keinen Zweifel, daß Leporide, angeblicher Leporide und französisches Kaninchen im Skeletthau war keine Unterschiede anfweisen. Wollte man nun die Existenz wirklicher Bastarde als gesichert anmehmen und weiter schließen, daß die C̈bereinstimmung zwischen jenen Bastarden und gewöhnlichen französischem Kaniuchen beweise, auch in den lezteren sei II aseublut nach allen möglichen Terhätnissen vorhanden, so wirden doch die Differenzen zwischen deutschem und französischem Kaniuchen aus dieser Hypothese nicht erklithar sein. Jenu cinige Rassen. wie die Riesenkaninchen, gehen sowohl in absolutem Maße, z. B. der Schiolellange (vergl. Fig. 4, \$. 13), als in manchen Proportionen (1/4) noch iiber den Hasen hinaus.

Anatomischerseits kamm also, um es zu wiederholen, für die Existenz von 
Bastarden zwischen Ilasen und Kaninchen hisher kein Beweis geführt werden, viehmehr verhalten sich nicht nur die gewönlichen französischen, sondern auch die vermeintlichen Bastarde oder die eigentlichen Leporiden $(\boldsymbol{I})$ in allen wesentlichen Punkten wie echte Kaninchen.

Für ein hinlänglich anatomisch geschultes Auge sind dabei Messungen gar nicht einmal nötig. Es geniugt zu vergleichen: das Os interparietale, (Fig. 4, S. 13), die Hervorragung der Masenbeine in der Ansicht von unten (Fig. 8, S. 14), die Breite der Choanen (Fig.7 u. 8, S.14) und die Ulna (Fig.9 u. 10, S. 17). Dies ist das Resultat einer sehr ausgedehnten, auf ein Vergleichsmaterial, welches a ll e ehen genamnten Tiere umfißte, gestutzten Lntersuchungsreihe. Die bisherigen Arbeiten charakterisieren sich mit einer Ausnahme /4) insofern als dilettantisch, als sie, auf zu sparsame Zahlenwerte gestützt, teils irgendwelche zufillige Befunde als konstant (z. B. S), teils unwesentliche Rassenabweichungen für wichtig (I5) ansehen.

\section{Krankheiten des Kaninchens.}

Die eingesperrten Tiere sind zahlreichen akuten und chronischen krankheiten unterworfen, die den Erfolg so manchen müherollen Experimentes zu stören im stande sind. Fruher, als das physiologische Experiment allein in Betracht kam, war das weniger störend. Seit dem Erscheinen der ersten Auflage ist aber das pathologische Experiment, also die kunstliche Erzeugung ron Krankheiten beim Tier, speziell beim kaninchen, in den Vordergrund getreten, und vielleicht ist die erste Auflage noch mehr von Pathologen als ron Physiologen benutzt worden.

Wenn auch in dieser Auflage wenig pathologische Experimente verzeichnet stehen, so erklairt sich dies einerseits daraus, daß die Techuik, z. B. Injektion in ein Blutgefißß, dieselbe ist wie beim physiologischen Experiment. Wo dies nicht der Fall ist, erscheinen die technischen Handgriffe so einfach und selbstverstänlich, wie \%. B. Impfungen in die Haut oder Konjunktiva, Einspritzungen in die Bauchhöhle u. s. w.. daß es umnötig erschien, darüber ausführlich zu handeln.

Die pathologisch-anatomischen Verinderungen, welche teilweise für Folgen eines Experimentes gehalten werden könnten, wahrend sie in Wahrheit von anderweitigen Erkrankungen ahhängen, wurden bei den einzelnen Organen verzeichnet (s. Splanchnologie). Am häufigsten werden Rotz, Typhus, Pneumonie und chronische Diarrhöe töllich, merkwirrligerweise tobtet auch die Riude oder Kräize schlieBlich.

Prophylaxis. Das Auftreten solcher Epidemieen ist im stande, den Erfolg von manchem Experiment dubiös zu machen, namentlich wenn die Tiere lingere Zeit nachher am Leben erhalten werden sollen. Es ist deshalb einige Kenntnis der aus zahlpeichen populiren Anleitungen (z. B. IS) bekannten Kaninchenzucht wiinschenswert, obgleich man in den engen, ofter's überfülten Ställen der Laboratorien für gewöhnlich nicht darauf rechnen darf, die junge Nachzucht heranwachsen zu sehen. Die beste allgemeine Prophỵlaxis besteht in Reinlichkeit, woriber das bei der Pneumonie (S. 22) Gesagte zu vergleichen ist, sorgfaltig regulierter Ventilation und Untersuchung der neu eingekauften Tiere auf ihren Gesundheitszustand. Sehr notwendig erscheint 
ein mit dem Kaninchenstall in direkter Verbindung befindlicher Rasenplatz. Was das Futter anlangt, so können die Kaninchen bei ausschließlicher Grasoder IIeunahrung ihr Leben nur kümmerlich fristen: man schafft ihnen den nötigen Stickstoff am billigsten in Kleie, die mit Wasser angerüht wird. Bei saftreicher, frischer Pflanzenuahrung saufen sie niemals, mit Ausnahme der eben entbundenen oder siugenden Mitter, so daB eine besondere Einrichtung fiir Trinkwasser eventuell unnötig wird, wohl aber ist letztere notwendig, wenn trockenes Ifu gefiittert oder jene Kleie durch Getreidekörner ersetzt werden soll. Chrigens ist eine Monotonie der Nahrung auf die Dauer zu vermeiden $(629)$.

Uber die einzelnen Krankheiten ist in prophylaktischer Hinsicht noch Folgendes zu bemerken.

Pnemmonicen treten am hiufigsten im Spatherbst und Winter auf; ohne besondere Erscheinungen dargeboten zu haben, werden die Kaninchen morgens tot gefunden (vergl. Lungen). Man hat in solcher Zeit für eine genügende Sicherung der Thüren und Fenster des stallgebaudes gegen die Kalte Sorge zu tragen, namentlich aber muß ein doppelter hölzerner Fußboden vorhanden sein, aus losen Dielen bestehend, um denselben aufnehmen und deu eigentlichen tiefer gelegenen Boden des Stallgebiudes reinigen zu können.

Chronische Diarrhoe wird bei jungen Tieren leicht tödlich (s. Darmkanal); es ist deshalh auf die Beschaffenheit der Faces zu achten. Die Krankheit entsteht durch Fülterung nassen Grases u. s. w., ausschließliche Fuitterung mit sehr saftreichen Blittern, wie z. B. Kohl, fermer auch durch Gregarinen. In solchen Fällen ist das Futter mikroskopisch zu untersuchen.

Räude oder Krätze wird leicht von einem erkraukten Tier auf andere Stallbewohner ablortragen. Obgleich man das einzelne Individuum heilen kann (s. Iaut), sind doch die einmal eingenisteten Vilhen schwer zu beseitigen. Man muß deshalb jedes neugekafte Kaninchen im Gesicht und am Kopf untersuchen, ob keine Borken zu fühlen sind.

Allgeme in krank he it en. Die hrankheiten der einzelnen Organe sind bei den letzteren erwihnt; die hauptsichlichsten sind: Tuberkulose, Iydrops, Ikterus, Chlorose, Katarhe der Nasen- und Respirationsschleimhiute, Pneumonie, Darmkatarrh, Typhus, Nilzbrand, Tympanitis, Stomatitis mit Salivation, Conjunclivitis, Tariola, Parasiten, namentlich Gregarinen oder Psorospermien, Taenia pectinata, Grsticereus pisiformis (Taenia serrata), Cysticereus elongatus. Monostomum leporis, Echinorhynchus cuniculi, Coenurus cerebralis, Pentastommm denticulatum, Oxyurus ambigua, Distomum hepaticum und Ianceolatum, Sarcoptes minor, Dermatodectes, Symbiotis, Listrophorus, Haematopinus rentriculosus, Dermanyssus avium, Pediculus canis, Dermatokonis, Achorion Schoenleinii und Puccinia graminis.

Von den Allgemeinkrankheiten sind folgende bemerkenswert.

Cholera soll bei Kaninchen zur, Zeit der Epidemie von 1830/31 vorgekommen sein, die Kraukheit soll nur 2-3 Stunden gedauert haben (2.4, S. 437$)$.

Mil:brand. Zur Zeit solcher Epidemieen bei Wiederkituern gehen auch Kaninchen daran zu Grunde (24, S. 436).

Diphtherie oder Diphtheritis. Diese Krankheit soll rom Kaniuchen auf 
Menschen, insbesondere auf Kinder übertraghar sein (25), die mit den Tieren zu spielen pflegten. Wenn diese Behauptung richtig ist, so würde sie in Bezug auf die Prophylaxis gegen die gefahrliche Krankheit ron großer allgemeiner Bedeutung sein.

Erysipelas. Impfungen mit dem Mikrokokhus der Hautrose verbreiten denselben innerhalb der Lymphgefiße und bewirken den Tod $5 \% 2$.

Scarlatina. Auch bei Scharlach gelingt zureilen durch Impfung mit Blut eines Kranken die Infektion des Blutes beim Kaninchen mit Mikrokokken; der Tod erfolgte (einmal) nach 24 Stunden (575).

Syphilis. Uberimpfung soll bereits friber (20i) gelungen sein, ferner hat man (27) durch Injektion von Eiter u. s. w. syphilitischen Ursprunges beim Menschen in die vordere Augenkammer des Kaninchens sekundire syphilitische Affektionen erzeugt. Namentlich Iritis, Syphilome des Corpus ciliare sowie der Lungen wurden nach Monaten auf diese Weise hervorgel)racht und wiederum durch Weiterimpfen auf andere Kaninchen übertragen. - Ob damit die syphilitische Natur der betreflenden pathologischen Verinderungen bei dem Fehlen einer klinisch erweisbaren Allgemeinaffektion erwiesen sei, steht dahin.

Neubildungen von Knötchen und Knoten kommen an den Genitalien und in Unterhautbindegewebe bei llasen, 28) vor"; sekundair können sich Or'hitis und Geschwüre ausbilden. Die Affektion tritt epidemisch auf und ist wahrscheinlich kontagiös; sie wird ron den Jigern als Syphilis oder Venerie hezeichnet, hat jedoch zur Syphilis des Menschen keine Beziehung. Ibrigens liegen bei den meisten Fällen von angeblicher Syphilis (bei Iasen) Geschwüre und Verletzungen an den männlichen Geschlechtsteilen vor, die in den Kimpfen der Mannchen um die Weibchen entstanden sind und bei strenger Kailte ein schlimmeres Aussehen anzunehmen pflegen. (Mündliche Mitteilung von Esser in Göttingen.)

Am Anus des (weiblichen) Kaninchens zeigen sich in seltenen Fillen erbsengroße gestielte papillare Exkreszenzen, die ganz wie Tripperkondylome aussehen und auch denselben mikroskopischen Bau darbieten. Ihre Entstehmg oder Bedeutung ist unbekannt.

Gregarmose oder Psorospermienlirankheil. Die Tiere magern ab, fressen wenig, fiebern, wie die beschleunigten Atemzüge anzeigen, haben zuweilen Husten oder Durchfall. Der Tod erfolgt unter Krimpfen.

In der Leiche zeigt sich die Darmschleimhaut katarhalisch injizier, und stellenweise mit gelbweißlichen linötchen von $2-6$ mm Linge infiltriert. Dieselben bestehen aus Psorospermien. Letztere finden sich auch in den Epithelialzellen der Darmzotten, in letzteren selbst uud deren Lymphgefaßen, in den Lieberkúhn'schen Drüsen und Peyer'schen Hanfen, in den Lymphgefaßen der Bauchhöhle und denjenigen der Leber, ferner sitzen ebensolche Knötchen in der Leber, an der iußeren Wand des Colon (2.9), sowie Psorospermien auf der Konjunktiva beim Schnupfenfieber (s. Nase).

Psorospermien sind ursprüglich amobenähuliche bewegliche Köryerchen, welche als solche wahrscheinlich mit der Vahrung aufgenommen werden. Sie wachsen heran, umgeben sich mit eincr doppeltkonturierten Membran, deren Inhalt peripherisch klar ist. Diese ellipsoidischen Körperchen haben etwa 0,028 mm Durchmesser, 0,034-0,036 mm Länge, 0,013-0,018-0,02 $\mathrm{mm}$ 
Dicke, ihr kugliger, körniger, zentraler Inhalt - die eigentliche Psorospermie - hat $0.011-0,016 \mathrm{~mm}$ Durchmesser $(\tilde{3} /)$. Die eingekapselten Psorospermien sind ron Hake (jo) zuerst gesehen worden. Sie gleichen damn Nematodeneiern und sind für solche gehalten worden, nach einer vorausgehenden Art von Dotterfurchung entstehen im Innern der Membran sichelförmige Gebilde, Gregarina falciformis, mit hellerem Kopfende. Diese verlassen die leere Ilúlle, gelangen mit den Fices ins Freie, wandeln sich wieder in Amöben um, womit der Kreislauf von neuem beginnt.

Da eine wirksame Therapie nicht zu denken ist, die krankheit in eine Kaninchengesellschaft eingeschleppt werden kann, namentlich indem mit solchem Lot beschmutzte Futterreste verzehrt werden, so ergiebt sich die Notwendigkeit der Prophylaxis. Man achtet auf große Reinlichkeit des Kaninchenstalles, liißt Heu und (lergl. aus kleinen hochgelegenen Raufen fressen und zerstört die Eingeweide von Kaninchen, die mit Psorospermien behaftet waren (52).

Die Litteratur der Gregarinose beim Kaninchen ist außer den genannten Schriften bereits eine sehr umfangreiche $(\tilde{5} \tilde{5})$.

\section{Plan der Darstellnng.}

Bei der eigentúmlich kauernden Stellung, die das Kaninchen im Leben gewöhnlich annimmt (Fig. 16), ist es für eine verstandliche anatomische Be-

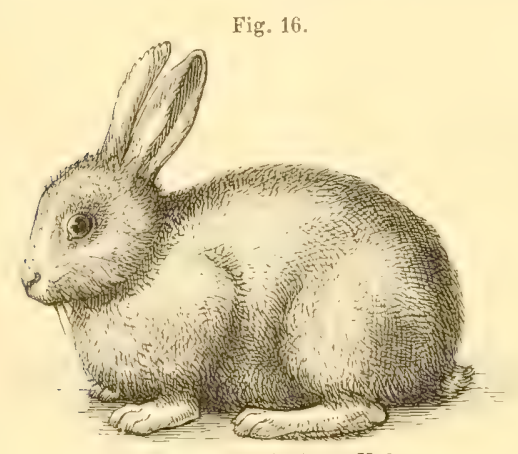

Deutsches Kaninchen. V. ${ }^{1} / 6$. schreibung unerläßlich, von einer ganz bestimmten Haltung des Tieres auszugehen. Da es an sich vollkommen irrelevant war, welche Körperstellung zu Grunde gelegt wurde, so mußten bei der Wahl praktische Gründe und die Unterstütung operativer und experimenteller Zwecke entscheiden. Zur Motivierung der befolgten Darstellungsweise ist es notwendig, hier zunachst den Plan näher zu erörtern, auf welchen das vorliegende Lehrbuch basiert wurde.

Die Darstellung sollte namlich an allen Punkten wesentlich von topographischen Gesichtspunkten ausgehen. Es wire daher ebenso thunlich gewesen, eine topographische Anatomie des Kaninchens zu schreiben: die systematische Anordnung ist jedoch der Ubersichtlichkeit wegen beibehalten worlen. Cherhaupt war es aber keineswegs die Absicht, eine vollstindige Anatomie des Kaninchens in dem Umfange zu liefern, wie sie die Inandbuicher der menschlichen Anatomie enthalten. Die letzteren set\%en war keine anatomischen Kenntnisse voraus; bei der Beschiftigung mit dem Kaninchen dagegen kann wenigstens die Anatomie des Menschen als vollkommen bekaunt angesehen werden. Es genigte also, alles dasjenige mitzuteilen, was sich beim Kaninchen anders verhilt, wie beim Menschen, 
der, mit AusschluB anderer vergleichend-anatomischer Daten. hier als ausschließliches Vergleichsobjekt dienen soll. Manches hingegen, was lediglich eine Wiederholung der menschlichen Anatomie darstellen würde, ist weggeblieben, und wenn rielleicht Jemandem die Darstellung hier und da etwas ungleichmaßig erscheineu sollte (vergl. 122 - wosellost das hier Gesagte nicht berucksichtigt $\mathrm{zu}$ sein scheint), so kann sie doch aus einem beliebigen Handbuch der menschlichen Anatomie mit Leichtigkeit erginzt werden. Ferner war es überflussig, eine Menge von detaillierten Schilderungen, z. B. von Muskelarterien, Ilautnerven etc. aufzunehmen, fleren Studium bei der Kleinheit des Tieres kein praktisches und auch kein theoretisches Interesse darbietet. Aus denselben Grínden konnten Abbildungen, wie sie der systematischen Anatomie entsprechen, entbehrt werden; außerdem ist das Kaninchen so leicht zuginglich, und mit Ililfe des hier vorliegenden Textes die Prajparation so erleichtert, daß es als nutzlos erschien, Abbildungen zu geben, welche jeder durch das Studium der Kaninchenleiche - unter der freilich unerliblichen Beibilfe eines lejcht herzustellenden, mit den Bindern getrockneten Skelettes - ohne Mühe ersetzen kann. Die eingedruckten Ilolzschnitte erstrecken sich daher vorwiegend auf topographische Darstellungen ron Gegenden, die bei hiufiger ausgeführten und schwierigeren Operationen in Betracht kommen.:

Für die Lntersuchung wurden die modernen Ililfsmittel der priparierenden Anatomie in möglichster Ausdehnung angewendet. Beim Knochensysteme kommt sehr viel auf den richtigen Grad der Mazeration an, worin man bald Übung erlangt. CTher die Injektionsmethoden ist die allgemeine Angriologie zu vergleichen: am unentbehrlichsten aber erwies sich in Bezug auf topographische Verhälnisse bei der leichten Verschiebbarkeit der einzelnen Teile im lockeren Bindegewebe des Kaninchens die Benutzung von Durchschnitten gefrorener Priparate. Letztere sind mittels der gewohnlichen Kiiltemischungen wegen der verhailtnismaßig geringen Dimensionen des kleinen Tieres zu jeder Zeit sehr leicht herzustellen. Die Angaben ron Dimensionen einzelner Organe, welche in der speziellen Anatomie sich tinden, haben nur den Zweck, die Beschreibung zu unterstützen. Sie sind daher als ganz beilaufig ermittelt anzusehen. Wenn es sich um die erstmalige Aufsuchung eines Organes ron seiten solcher handelt, die nicht Anatomen von Fach sind, so ist es nützlich, eine ungefihre Vorstellung von der Größe hei schwieriger zu priparierenden Objekten zu haben. Fü die Lrfindung neuer Experimente mag es ebenfalls von Nutzen sein, z. B. in betreff des Mechanismus der Thrinenleitung zu erfahren, daß der oberflichlich verlaufende Ductus nasolacrymalis $2-3 \mathrm{~mm}$ weit ist. Die Gew ichtsangabe $\mathbf{n}$ beziehen sich im allgemeinen auf die Organe eines alten Weibchens von $2093 \mathrm{~g}$ Körperschwere. Der im Dirmtraktus befindliche Kot betrug $160 \mathrm{~g}$ oder ca. $8 \%$. Die Haut nebst den IIaren wog $181 \mathrm{~g}$. Bei einem kleineren Mänchen wog der Körper $1198 \mathrm{~g}$, der Darminhalt $115(6 \%)$, das Skelett nebst den Ligamenten in feuchtem Zustande $160 \%$. die Muskeln $397 \mathrm{~g}$, die Haut nebst den Itaren 182 g, wonach für die ubrigen Organe, inkl. des kaum in Anschlag zu bringenden Fettgewebes 3449 bleiben. Die Ziffern in betreff des Gewichtes des Darminhaltes schwanken schr infolge der verschiedenen Nahrung; die hohen Zahlen (mehr als 20\%), welche zu- 
weilen angegeben worden sind $(54)$, dürften auf reine Ileunahung zu beziehen sein. Ton anderer Seite $\tilde{3} 3$, wurden im Mittel aus zehn Bestimmungen bei Kaninchen von $1262-1739 \mathrm{~g}$ Köpergewicht $170 \mathrm{~g}$ gefunden, sowie $(596)$ an 8 Kaninchen von $1198-1743 \mathrm{~g}$ Körpergewicht durchschnittlich $18,9 \%$, oder 19,2\% 725$)$. Was die einzelnen Organe anlangyt, so beträgt nach Wägungén (56) an zwei Kaninchen in Prozenten des Korpergewichtes das Gewicht:

\begin{tabular}{|c|c|c|c|c|c|c|c|c|c|c|c|}
\hline & Haut & Skelett & IIuskeln & $\underset{\text { geweide }}{\text { Ein- }}$ & $\begin{array}{l}\text { At- } \\
\text { mungs- } \\
\text { organe }\end{array}$ & $\begin{array}{l}\text { Verdau- } \\
\text { ungs- } \\
\text { organe }\end{array}$ & Leber & Milz & $\begin{array}{l}\text { Pan- } \\
\text { kreas }\end{array}$ & $\begin{array}{c}\text { Harn- } \\
\text { und Ge- } \\
\text { schlechts- } \\
\text { organe }\end{array}$ & Herz \\
\hline $\begin{array}{l}\text { Männchen } \\
\text { Weibchen }\end{array}$ & $\begin{array}{l}13,5 \\
13,0\end{array}$ & $\begin{array}{l}12,4 \\
12,5\end{array}$ & $\begin{array}{l}55,7 \\
54,7\end{array}$ & $\begin{array}{l}18,3 \\
19,7\end{array}$ & & & & - & & & \\
\hline Mittel & 13,2 & 12,4 & 55,2 & 19,0 & 1,5 & 10,7 & 6,2 & 0,1 & 0,3 & 1,7 & 0,9 \\
\hline
\end{tabular}

Hervorleuchtend ist hieraus die relativ geringe Entwicklung des Respirationsapparates und der Milz.

Anderweitige Bestimmungen (5.96) an drei Kaninchen, wobei unter Bewegungsapparat die Ilaut, Kuochen, Muskeln und Nerven verstanden sind, ergaben :

\begin{tabular}{|c|c|c|c|c|c|c|c|c|c|c|}
\hline \multirow{2}{*}{$\begin{array}{l}\text { Körper- } \\
\text { gewicht } \\
\text { ohne } \\
\text { Darmin- } \\
\text { halt }\end{array}$} & \multicolumn{2}{|c|}{ Eingeweide } & \multicolumn{2}{|c|}{$\begin{array}{c}\text { Bewegungs- } \\
\text { apparat }\end{array}$} & \multicolumn{3}{|c|}{$\begin{array}{l}\text { Blutmenge in den Einge- } \\
\text { weiden }\end{array}$} & \multicolumn{3}{|c|}{$\begin{array}{c}\text { Blutmenge im Bewegungs- } \\
\text { apparat }\end{array}$} \\
\hline & $g$ & $0 \%_{0}$ & $g$ & $\% \%_{0}$ & g & $\begin{array}{l}\% \text { der Ge- } \\
\text { sammtblut- } \\
\text { menge }\end{array}$ & $\begin{array}{l}\text { \% des } \\
\text { Organ- } \\
\text { gewichts }\end{array}$ & $g$ & $\begin{array}{l}\% \text { der Ge- } \\
\text { sammtblut- } \\
\text { menge }\end{array}$ & $\begin{array}{l}\% \text { des } \\
\text { Organ- } \\
\text { gewichts }\end{array}$ \\
\hline 1023 & 187 & 18,2 & 836 & 81,8 & 28,6 & 62,1 & 15,3 & 10,8 & 37,9 & 1,3 \\
\hline 1244 & 179 & 14,4 & 1065 & 85,6 & 39,2 & 71,3 & 21,9 & 15,8 & 28,7 & 1,5 \\
\hline 1304 & 197 & $1: 3,1$ & 1170 & 84,9 & 44,1 & 60,6 & 22,9 & 28,6 & 39,4 & 2,2 \\
\hline Mittel & & 15,9 & & 84,1 & & 64,7 & 20,0 & & $3 \check{z}, 3$ & 1,7 \\
\hline
\end{tabular}

Hingegen wurde an zehn Kaniochen durchschnittlich gefunden (65;) und zwar auf $1 \mathrm{~kg}$ fettfreies Tier ohne Darminhalt:

\begin{tabular}{l|c|c|c|c|c|c|c|c}
\hline $\begin{array}{c}\text { Bewegungs- } \\
\text { apparat }\end{array}$ & $\begin{array}{c}\text { Assimilisa- } \\
\text { tionsapparat }\end{array}$ & $\begin{array}{c}\text { Körperbe- } \\
\text { deekung }\end{array}$ & $\begin{array}{c}\text { Zirkula- } \\
\text { tionsapparat }\end{array}$ & $\begin{array}{c}\text { Simnes- } \\
\text { apparat }\end{array}$ & $\begin{array}{c}\text { Harn- } \\
\text { appa- } \\
\text { rat }\end{array}$ & $\begin{array}{c}\text { Respira- } \\
\text { tionsappa- } \\
\text { rat }\end{array}$ & $\begin{array}{c}\text { Gesehlechts- } \\
\text { apparat }\end{array}$ & $\begin{array}{c}\text { Blutgefäß- } \\
\text { drüsen }\end{array}$ \\
\hline 669,23 & 135,31 & 121,32 & 41,99 & 14,65 & 8,19 & 5,85 & 2,17 & 0,88
\end{tabular}

Bemerkenswert ist noch, daß der Nabel bei beiden Geschlechtern ungefahr an der Grenze des oberen und mittleren Dritteiles der Linea alba sich befindel: hei einem jungen Männchen fand sich das Verhaltnis des oberhalb des Vabels gelewenen Abschnittes der Linea alba zu dem unteren Abschnitte wie 2: 3. Ther das Verhaltnis der Linge des Darmkanales zur Korperlauge s. die allgemeine Splanchnologie.

Alle diejenigen Verhiltnisse, welche nur durch Hilfe des Mikroskopes mit Sicherheit erkannt werden kömen, mußten in einem Lehrbuch, welches 
topographische und operative Tendenzen verfolgen soll, priuzipiell von der Darstellung ausgeschlossen werden. Da beim Kaninchen alle Teile ein $30-60$ mal kleineres Volumen haben, als beim Menschen, so finclen sich manche dergleichen Beziehungen, die mit dem Messer nicht mehr verfolgt werden können. Sie sind einfach weggeblieben, was bei der Darstellung uberall zu bericksichtigen seiu wird. Namentlich gilt dies vom Faserverlauf in den Zentralorganen des Nervensystems, von manchen Verbindungsfiden zwischen einzelnen Nerven, den Anastomoseu kleinerer Arterien (S.63), den feineren Verhältnissen des Lymphgefaßsystemes, der Sinnesorgane und anderen, welche der Splanchnologie anheimgefallen sein würden. Einige histologische Notizen sind jedoch wegen der Rücksicht aufgenommen, daß sie beim Unterricht im Mikroskopieren praktische Verwertung finden könnten.

Da viele Verhaltnisse des Gefiß- und Nervensystemes durch diejenigen des Knochen- und Muskelsystemes berlingt werden, und sich nach erlangter Kenntuis des letzteren von selbst verstehen, so war es notwendig, in der Osteologie etwas weitläufigere Beschreibungen zu geben, da auf den Bau des Menschen, namentlich im Knochensystem selbst, nur selten verwiesen werden durfte. In der Syndesmologie und Myologie konnten dagegen die Beschreibungen öfters schon mehr vereinfacht werden. Die Jusführung der nicht immer leichten Beschreibung unter meiner Leitung war in betrefl der ersten Auflage in der Osteologie, Syndesmologie und Myologie, mit Ausmahme einiger schwierigen P'artieen des knöchernen hopfes, das Verdienst des Ilerrn Dr. med. A. Böger (jetzt in Osnabrück), dessen Fleiß und Sorgafalt ich rühmend anerkennen muß. Mit Ausnahme der Nomenklatur und einiger Berichtigungen, die Ilerrn Dr. Hilgendorf in Berlin $(S / 8)$ zu verdanken sind, ist dieselbe hier im wesentlichen unverändert geblieben.

Mit Rücksicht auf den eben auseinandergesetzten Plan dieses Lehrbuches wurde nun die stehende Stellung des kaninchens bei der Beschreibung ohne alle Ausnahme zu Grunde gelegt. Auch beim FuBe ist vorausgesetzt, daß das Kaninchen wie der Mensch mit der ganzen Sohle den Bodeu berïhre.

Unter diesen Umstinden bezeichnet $t^{\circ}$ r'n und hinten ganz dieselbe Richtung, wie es in der menschlichen Anatomie der Fall ist. Es ist z. B. die Nase der vorderste Theil des Kopfes, der Nabel liegt an der vorderen Seite des Bauches, das knie an der vorderen Seite der unteren Extremilat u. s. w. Mit oben und unten werden die Richtungen nach dem Scheitel, resp. dem entgegengesetzten Ende des Tieres bezeichnet. Es kann mithin niemals von einer noberen“ Flache des Rumpfes die Rede sein, da die Rückenfliche, weil sie senkrecht gedacht wird, die hintere und niemals die obere genannt wird. "Inten (iegt am Rumpfe z. B. die Afteröffnung, an der unteren Extremitit der Fuß, am Kopfe die Unterkinngegend u. s. w.

Die konsequente Anwendung der Ausdrücke »vorn«, »hinten « u. s. w. in dem angegebenen Sinne dürfte die Benutzung dieses Lehrbuches sehr wesentlich erleichtern. In der vergleichenden Anatomie der Vierfußler wird sonst mit wornu die Richtung nach dem Kopfe bezeichnet. Bei der systematischen Anatomie geht das allenfalls, obgleich z. B. die Umänderung der mit ssuperior" und ninferior" zusammengesetzten Muskelnamen etc. zu allerhand Störungen Veranlassung geben 
wïrle. Sobald es sich aber un genauere topographische Beschreibungen handelt, wie sie hier gegeben werden sollten, ist eine rollstindige Verwirrung des Lesers die unausbleibliche Folge.

Am einfachsten ließe sich der letzteren anscheinend vorbeugen, wenn man für woben" am Rumpfe wie an den Extremitåten den Ausdruck: proximalwärts und für unten: distalwärts einführen oder in analoger Weise : kravialwärts, kaudalwärts etc. sagen wïrde. Erstere Bezeichnungen kann man mit Nutzen hier und da verwenden, z. B. wenn es sich um gebogenen oder spiraligen Verlauf eines Organes wie die $\Lambda$. subclavia handelt. Gegen die ausschließliche Einführung obiger Ausdricke erheben sich aber wiederum Bedenken, die ein Beispiel vielleicht am besten erlaiutern wird.

Die sagittale Lingsachse der Schuppe des Hinterhauptsbeines verliuft beinahe rechtwinklig geknickt. Es ist nun ziemlich gleich, ob man sagt: »die innere Fläche der Schuppe sieht teils nach vorn, teils nach unten“, oder aber: „die ventrale Fläche sieht teils oralwärts, teils kaudalwärtsঞ. Entsprechend von der äußeren Flïche: sie sieht »teils nach hinten, teils nach oben« oder: »die dorsale Flïche sieht teils aboralwairts, teils —? « )Kopfwärts oder »kranialwärts" kann man nicht wohl sagen, denn es handelt sich um Teile am Kopfe selbst und eine häutige Lmschreibung der kranialen Richtung würde schleppend werden. Trotzdem wurde für die neue Auflage die Einführung obiger Terminologie ernstlichst in Erwigung gezogen; was davon abhielt, waren die schon oben betonten Schwierigkeiten in der Muskelbenennung. Man kinn allenfalls „M. serratus dorsalis posticus« sagen statt »M. serratus posticus inferior(; substituiert man aber )M. serratus dorsalis anticus«, statt $)$ I. serratus posticus superior(, oder den $\mathbf{M}$. scaleni anticus und posticus einen M. scalenus ventralis und dorsalis, wie es geschehen müßte, so wird jeder den letzteren Ausdruch auf ein hinter der Wirbelsäule gelegenes Objekt zu beziehen geneigt sein. Es darf nochmals daran erinnert werden, daß die aus der menschlichen Anatomie geliutigen Ausdrücke ron den Praktikern, für die doch dieses Lehrbuch bestimmt ist, ungern mit neuen vertauscht werden, wihlend im Gegensatz dazu den vergleichenden Anatomen die Übersetzung in ihre eigene Terminologie eine Kleinigheit ist. Endlich muß man bedenken, daß die menschliche und auch die Kaninchen-Anatomie, wenn sie für operative Zwecke nutzhar gemacht werden soll, eine sehr viel genauere Darstellung in topographischer Ilinsicht erfordert, als es für phylogenetische Untersuchungen in den meisten Fällen notwendig wird.

bie Ausdricke imnen und außen werden ausschließlich auf die Körperhöhlen und die hohlen oder soliden Organe selbst bezogen. Dagegen bezeichnet medial, medianuärts die Richtung nach der Medianebene des liörpers, lateral, lateraluarts die Richtung, welche senkrecht auf die Medianebene sich von letzterer entfernt. Der Medianebene parallele Ebeuen werden Sagittalebenen genanut. Sagittal heißt eine Linie, die horizontal ron vorn nach hinten verliuft. Frontal wird jede Ehene genaunt, die einer idealen Vorderfliche des Rumples parallel, und zugleich senkrecht auf die Erdoberfliche und auf die Medianebene steht. Transversal heißt die Richtung von links nach rechts, jede transversale Ebene steht zugleich horizontal.

An den Extremititen werden dieselben Bezeichnungsweisen gebraucht. Die obere Extrenitiat wird senkrecht am aufrechtstehenden Korper des Kaninchens herabhingend gedacht, wie der $\Delta \mathrm{m}^{\circ}$ des Menschen. Mithin bezeichnet "unten" an der oberen wie an der unteren Extremitit die Richtung nach den Fingern. respr. nach dem Fuße. An der unteren Extremitit sind die Ausdrücke 
medialu und nlateral selbstverstindlich: an der oberen werden die Bengeseiten des Ober- und Vorderarmes als die medialen angesehen. DVorn liegrt der Radius und die Patella; hinten die CIna und die Wade. Nach allen diesen Definitionen schienen noch Mißrerstinduisse in der Beschreibung des Vorderarmes und der Iland, sowie des Unterschenkels und des Fußes möglich zu sein, da schon die Lagerung der Knochen in einiger Ilinsicht ron der beim Menschen abweichend ist. Wie gesagt, bezeichnet munten die Richtung nach den Fingern resp. dem Fuße. Die anderen beiden Richlungen sind als rolare - dorsale, resp. radiale - ulnare an der oberen Extremitat; als plantare dorsale, resp. als tibiale - fibulare an der unteren bezeichnet worden. Im allgemeinen fillt natürlich mmedial mit "radial" resp. ntibial"; und "ateral" mit wulnar" resp. mibular zusammen. Es schien jedoch gerathen, mit diesen subsidiaren Ausdrúcken so sparsam als möglich umzugehen. Auch heim Fuße ist unter Voraussetzung einer stehenden Stellung des Kaninchens mit nunten" die Richtung nach der Fußsohle, mit proru" die nach den Zehenspitzen bezeichnet. Endlich wird überall unter soberflichlicher" und ntiefer" Lage die geringere oder größere Entfernung von der nähst benachbarten außeren IIaut verstanden.

Was die Terminologie betriflt, so wurde seinerzeit der Versuchung widerstanden, einige hundert neue Namen zu bilden, obgleich dies viel bequemer gewesen wire, als die alten zweckmaßig zu adaptieren, wihrend aber das Verstandnis dadurch wesentlich erschwert worden sein wiole. Da wie gesirgt der Bau des Kaninchens aus praktischen Grunden ausschließlich mit demjenigen des Menschen verglichen werden sollte, so handelte es sich zunichst um die bei letzterem zu Grunde zu legende Nomenklatur. Es wurde diejenigre grewaihlt, welche meinem llandbuche (jzZweck ging dahin, daß jeder Name ohne weitere Erliuterung verstandlich sein sollte, und zwar auch fur solche, welche nur die allgemein-medizinische, keine speziell-anatomische Bildung sich zu eigen gemacht haben.

Die Zurúckführung auf den bekannten Typus des Menschen war an vielen Punkten mit nicht unbetrachtlichen Schwierigkeiten verknüpft. Wer versurhsweise ohne diese Kenntnis z. B. die Muskeln an der vorderen Extremitii zu priparieren unternimmt, wird sofort bemerken, wie sehr durch diese Zuriickführung das Verständnis erleichtert wird.

Der Darstellung wurden ausschließlich eigene Untersuchungen zu Grunde gelegt, und im ganzen Werke ist keine Thatsache von mu einiger Wichtigheit mitgeteilt, die nicht durch sorgfaltige und wiederholfe Priparation konstatiert worden wire. Die sparsamen anatomischen Details. welche in ilteren physiologischen Abhandluugen etc. sich finden - die vergleichenden Anatomen haben fast nur den Hasen gelegentlich untersucht - wurden erst nachtriglich berücksichtigt. Im allgemeinen stellten sich dieselhen als rollkommen unbrauchbar heraus. Die Autoren beschrieben zwar nach besten Kraften geuau: da aber in der Regel das nur durch vollstandige Kenntnis des Kaninchenleibes zu erlangende Verstänhis fehlte, wie die betreffenden, mehr oder weniger abweichend gebauten oder gelagerten Teile zu deuten, resp. mit dem bekannfen Bau des Menschen in Cbereinstimmung zu bringen sind, so blieb den physiologischen Schriftstellern nichts uibrig, als besondere Namen für diesen 
oder jenen abweichend verlaufenden Nerven- oder Arterienzweig zu schaffen, was natürlich wiederum die Übersicht für den Leser keineswegs erleichterte. Die früher zuweilen vorkommenden Fehler (vergl. Erste Auflage S. 9. in betreff der Kaninchenanatomie sind aus der Litteratur jetzt vollstindig verschwunden. Nur bei der Nomenklatur der Schaidelknochen, wie sie auf mikroskopischen Durchschnitten des ganzen Kopfes erscheinen, finden sich hier und da noch Unsicherheiten, die es rechtfertigen, wenn hier Abbildungen der Schädelknochen beigegeben wurden.

Ein topographisch-anatomisches Lehrbuch kann den Praktikanten der phṛsiolog̣ischen und pathologischen Institute manchmal die persönliche Leitung des Lehrers ersetzen. Aber auch Geübtere werden vor schwierigeren Operationen in der Vorlesung sich mit Nutzen ihr anatomisches Gedächtnis durch Lektiure und Abbildungen wiederum auffrischen, was ja die größten Chirurgen bei Operationen am Menschen in analoger Weise zu thun pflegen.

\section{Technik der operationen.}

Die allgemeinen Regeln, welche sich rom Standpunkte des Anatomen für die Ausführung der Operationen geben lassen, sind im Folgenden zusammengestellt. Es handelt sich dabei ansschließlich um Experimente, bei denen das Leben des Tieres wenigstens eine Zeit lang erhalten bleilut. Versuche, die so zu sagen an der Kaninchenleiche oder Teilen derselben angestellt zu werden pflegen, sind ausgeschlossen, weil diese Verfahrungsarten in anatomischer Ilinsicht doch nur auf gewïhnlicher Praparation beruhen. Ferner sind unter den Operationen nur die gewöhnlich rorkommenden berücksichtiğt, welche gerade für den Anfinger in Frage kommen. In Bezug auf die unendliche Mannigfaltigkeit der seltener ausgeführteri, Spezialzwecken gewidmeten, sowie in betrefl der Vorsichtsmaßregeln bei Reizungsversuchen verschiedener Art muß naturlich auf die spezielle physiologische Litteratur (fl u. f2) verwiesen werden. Die einzelnen Operationen sind in einem Verzeichnisse eingangs ihlersichtlich zusammengestellt; die topog̣raphischen Verhiltnisse überhaupt wurden namentlich in der speziellen Neurologie näher erliutert.

Narkotisierung. Anasthesierungen der Kaninchen mittels Aether oder Chloroform führen leicht den Tod herbei und sind ginz zu vermeiden. Ein mit wenigen Tropfen Chloroform imbibierter Schwamm, vor Mund und Nase des Tieres gehalten, bringt nach 6-8 Sekunden die Herz- und Lumgenbewegung zu plötzlichem Stillstande in tiefer Inspirationsstellung. Nach einigen Sekunden beginnen letztere sehr verlangsimnt wieder. Man wihlt daher. wenn eine Narkotisierung notwendig erscheint, die Injektion einiger Tropfen Tinctura opii, oder won 10-20 Tropfen waßriger Opiumtinktur mit etwa $11 g$ Wasser und einigen Tropfen Alkohol (4.'), in die V. jugularis externa, oder die subkutame Injektion von einigen cem eiuer $0,5-10 / 0$ igen Lösung ( $42 ;$ vou Morphiumacetat fí), durch welche Verfahrungsarten eine grobe Veigung zu Reflex- 
bewegungen eintritt. Letzlere werden am leichtesten mittels kleiner Scherenschnitte in die IIaut hervorgerufen. - Fütterung mit Mohn wird merkwürdigerweise ohne Nachteil ertragen (489. s. 24, S. 407).

Chloralhydrat erzeugt einen mehr oder weniger anhaltenden Schlaf, in welchem auf mechanische IIautreizung Reaktion erfolgt, nicht aber auf thermische Reize. Die Respiration wird rerlangsamt; schon eine geringe Dosis des durch den Mund eingeführten oder subkutan injizierten Chlorals indert den Herzschlag und Blutdruck; zur Narkose genügt $1 \mathrm{~g}$ (4l, S. 35); man kann auch $2 \mathrm{~g}$ anwenden $(\tau 0 /$. Bei größeren Dosen erfolgt leicht der Tod. Trotzdem ist das Chloral für viele Zwercke nützlich, namentlich wird dadurch der auf Abneigung gegen die Wissenschaft beruhenden Antivivisektionsagitition ihr bequemster Vorwand genommen. Einspritzungen in die Blutgefißie werden schlecht ertragen $(4 \mathrm{I})$.

Kurare kann man in eine Vene oder durch sulskutane Einspritzung injizieren oder indem man ein minimales Partikelchen trockenes Kurare in eine kleive Schnittwuude der Ilaut bringt, nachdem künstliche Respiration (Trácheotomie) vorbereitet worden ist.

C̈ber die zu benutzenden Spritzen vergl. 46 ; über künstliche Respiration daselbst (S. 520).

Um die Kaninchen apnoisch zu machen, wird etwa die Italfte einer Lösung von $0, \vec{g} \stackrel{g}{\sim}$ Kurare in 25 ecm destilliptem Wasser in eine kleine Halsschnittwunde injiziert $(145)$.

Operationen. Wenn nichts besonderes bemerkt ist, befinden sich die Kaninehen wäbrend der Operationen in der Rückenlage auf ein liinglich-viereckiges Brett festgebunden, welches an seinen vier Ecken Haken für die Befestigung der vier Füße des Tieres trägt. Yarkotisierung ist im allgemeinen nicht erforderlich. Der Kopf des Tieres wird rou einem Gehülfen gehalten, der seine Finger auf den Unterkieferhialften fixiert. Man kann auch eine um die oberen großen Schneidezähne gelegte Schlinge benutzen, welche an einem fünften Ilaken in der Mittellinie des Operationsbrettes am Kopfende des letztereu befestigt wird. Inter den Ilals des Tieres wird ein Kissen geschoben. Man kann auch um die Basis der Ohren zwei weitere Schlingen legen, so daß sieben llaken erforderlich sind, und anstatt letzterer überhaupt geigenwirbelihnliche Holzstiicke benutzen, die durch seitliche Stellschrauben fixiert werden können. Mittels Drehung der Wirbel sind die Schlingen aufzuwickeln oder zu verlängern $(\boldsymbol{i} \vec{j}$. Vor der Operation werden die IIare an der betreffenden Körperstelle mit der Schere abrasiert, die Ilaut angefenchtet. Der Hautschnitt trennt zugleich die efwaigen Hautmuskeln. Die Wundrander werden mit stumpfen Haken auseinander gezogen. Da die Verschiebharkeit der Haut sehr groß ist und man leicht die Orientierung verliert, so macht man alle Itautschnitte, so viel es nur angeht, in der Medianlinie und ohme vorherige Aufhebung der Ilaut in Falten, die übrigens quer auf ihren Verlauf durchschnitten werden muißten. Die IIautschnitte werden am besten mit einem bauchigen Skapell, die Muskelschnitte mit einer Schere, welche vorn abgerundete Branehen besitzt, geführt. Statt derselben kann man an der Bauchhöhle nach lìöflnung des Peritoneum mit Torteil ein vorn geknöpftes gehogenes Bruchmes- 
serbenutzen. Spritzende Arterien werden mit der Pinzette gefaßt und torquiert, oder mit einer kleinen, etwa $2 \mathrm{~cm}$ langen Klemmpinzette geschlossen, deren yehreuzte Branchen ron selbst gegeneinander federnd schließen, und die wihrend der Operation liegen bleibt. Solche Arterien zu unterbinden ist nur ausnahmsweise nötig.

Wenn Blutungen möglichst zu vermeiden sind, wie bei den Operationen an den nervösen Zentralorganen, so füttert man zweckmaßßg die Kaninchen einige Tage ror der Operation ausschließlich mit trockenem Futter, wie Ihafer, Erlosen u. derọl. Die Gerinmung des ausfließenden Blutes wird dadurch beschleunigr (fis: Man kann auch vor der Operation den Truncus anonymus auf cinem Stückchen Zunder unterbinden und nach derselhen auf dem Zunder den Interbindungsfaden mit der Schere leicht durchschneiden, ohne den Truncus zu verletzen.

Im operierte Kaninchen, die zum Erfolge der Operation lingere Zeit am Leben erhalten worden sind, wobei sie am besten von anderen Tieren isoliert werden, zu töten, wihlt mam, je nach den einzelnen Fälen, verschiedene Todesarten. Sind Operationen am Halse vorgenommen, so kann man natürlich die Erdrosselung nicht benutzen u. s. w. Abgesehen von den Tergiftungen, empfiehlt sich, je nach den besonderen Lmstanden, Chloroformieren unter einer Glasglocke, Erölfnung der Rippenwandungen in großer Ausdehnung, oder Einblasen von Luft in die Pleurahohle, an meisten der Nackenstich zwischen Os occipitis und Atlas. Schlige auf den kopf oder besser hinter die Ohren auf den Ilinterkopf, Mbschneiden des IIalses efc., sind rohe Verfahrungsarten; kommt es auf möglichste Blutleere der Gefißße an, so eröfinet man den linken Ventrikel des freigelegten Herzens; den Injektionen mit feinen warmen Massen Jißt man den Chloroformierungstod unmittelbar vorausgehen.

Temperat urmessungen. Die Temperatur betrigt im Mittel $38^{\circ} \mathrm{C}$. 49). Ian kann sie im Rektum bestimmen, sie nimmt aber kontinuierlich ab $(\breve{3} 0)$, wenn das kaninchen in Rickenlage festgebunden ist: die Abnahme kann bei $11^{\circ} \mathrm{C}$. Luftemperatur binnen einer Stunde $2^{0}$ betragen. Am sitzenden Tier fabl man den Schwanz an seiner Wurzel, führt den geölten Quecksilberbehibler sanft rotierend in das Rektum, möglichst hoch, bis 7 cm hinauf. Das "Kaninchen muB dabei auf dem Rande eines Tisches sitzen. Es ist auch eine zweckmaßigere Form des Thermometers für diese Zwecke angegeben worden . $/$ ) : andernteils hat man das Tier in einen durchbrochenen kasten zu setzen empfohlen $(698)$.

Man kann anch einen engen Drahtkifig anwenden (32), der auf ein schriggreneigtes Brelt gestellt wirl, so daß der Kopf des Tieres sich unten befindet. Ohle man wickelt das Kaninchen mit 8-13cm breiten, einige Meter langen Loinwandbinden derart ein, daß Kopf, Ilals und Flauken für das Itmen frei bleiben, wilnend die Hinterbeine an den Bauch gezogen werden (j) . Bei weiblichen kaninchen kamm man statt im Rektum in der Scheide messen. Wenm aber die Messungen sehr hiulig wiederholt werden müssen, so werden auch bei der gribten Vorsicht die mechanischen Insultationen jener Schleimhimte auf die Dater schlecht ertragen und es könmen Entzündungen derselben 
dadurch hervorgerufen werden. Bei solchen Experimenten benutz man am besten die naturliche IIaulfalte zwischen Batch mol Oberschenkel, indem man den zylindrischen Quecksilberhehailter des Thermometer's genau an die Übergangsstelle vom Bauch auf den Oberschenkel legt und den letzteren einigermaßen fest an den Bauch preßt. Wird dies gut ausgeführl, so erhailt man fast dieselben Temperaturen wie in der Vagina und jerlenfalls sind die Messungen unter einander vergleichbar $(54,5.42)$.

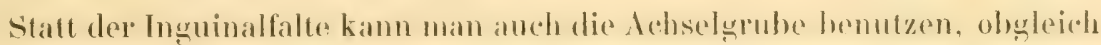
diese weniger zu empfehlen ist, ofler stall des Roklum die Augenlidspalto. Am meisten schwankt die Temperatur der dünnen Ohren.

Unterbind ungeu der Arterien oder Venen. Vorallen Injektionen in das Gefißsystem ist jede Lufthlase in der Spritze sorgfiltig zu entlernen. Lufteintritt in die Venen bei Operationen am IIalse, oder Injektion ron Luft mittels ciner schlechtgefiillten Spritze sind meist sofort tüllich - infolge von limbolie der Aat. coronariae cordis. Vamentlich sind solche Ereignisse bei rer V. jugularis externa zu vermeiden, für die man mitunter eine aus einem Stick bestehende Glasspritze mit Vorteil verwendet. Fü gewiohnlich benutzt man Injektionsspritzen (\%. B. Von Luer in Paris) mil abschraubbaren Platinkanülen. Die Bloßlegung der Gefiaße nach vollendeten Itut- und Muskelschnitten ist ansschließlich mit stumpfen Werkzengen. Pinzenten und Mohlsonde vorzunehmen. Kleine Muskelzweige werden schonend bei Seite gedringr ; man führt erst eine Pinzette, deren Branchen zusammengedrickt werden, ader eine Inohlsonde unter dem Gefaße durch, und damn die Interhindungsnadel, welche mach dem Muster einer chirurgischen angelertigt, aber diinner und schmaler, auch nach kleinerem Radius gehogen und vorn gut alogerundet ist. Die Nadel enthalt eine rotsedfene angefenchtedr Fadenschlinge, so daß jedes Gefiß sogleich doppelt unlephunden werden kamm. Vach Lmstinden ist auch ein dritter Faden erforderlich: einer fiir dir Lnterbindung des Gefißes vor der Injektion, die bei Arterien natürlich weiter oberhalb, bei Venen weiter unterhall, vorgenommen wird. Der zweite Faden dient zum Befestigen der Platinkanuile in dem Gefaßrohr. der dritte zum Unterbinden des Gefißes varch der Injektion.

Die Eroffunng der Gefiak wirl am hesten vorgenommen, indem man die Tunica adrentitia mil einer feinen, genau schließenden Pinzette laßt, das Gefiß etwas aufheht, und die freiliegende Wandung mit einer spitzen, an der Spitze sehr gut schneidenden Schere in schriger Richtung einschneider, ohne das Gefiß ganz zu durehtremmen. Der auf diese Art losgeloste Zipfel der Wandung wird mit der Pinzette anfgehohen, die haniile in das fumen eingefüht, und hei Arterien selbstrerstindlich nach der Peripherie hin, hei Venen nach dem Zentrum hin weitergeschober und festgebunden.

Die Luterbindung der Gefake in der Kontinuirat geschieht nach den when angegebenen Regeln, wobei ein einziger Haden genight. Die speziellen Regeln ergeben sich aus den toposaphischen Verhiltnissen, welche, wie schon bemerkt, meistens in der speziellen Neurologie, resp. bei den Verrendurchschneidungen auseinandergesetzt wurden. 
Die Drüsenausführungsgänge sind im allgemeinen zu fein, um Einfiblung einer kintile zu gestatten; man begniigh sich, sie freizulegen und quer durchzuschneiden.

Nervendurchsehneidungen. Nach Bloklegung der Nerven ist Entlepoung des elwa ausgetretenen Blutes notwendign; man fiiht damn eine llohlsonde unter dem Verven durch, welche zuglesch benatchbarte Arterien oder lemen und verven bei lejeht unvermuted eintretenden kleinen Bewegungen

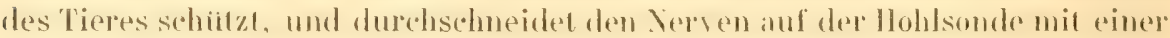
feinen Schere, deren spitze Enden sehr gut schneiden mússen. Will man

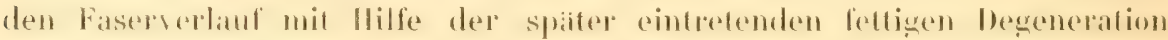
mikroskopisch studieren, so ist die Resehlion aines -3 mm langen Vervenstủckes notwendig: um eine zu rasche Wiedervereinigung zu verhüten.

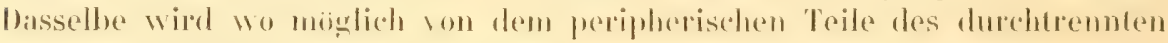
Nerven mittels Pinzette und einer vorn stumplen Schere abgetragen. Die

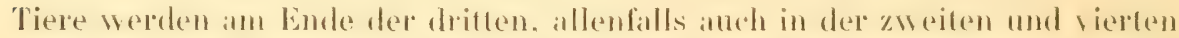

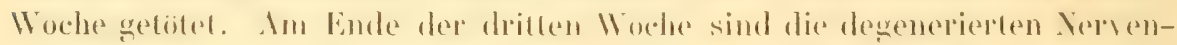
stimmehen moch mit leichligheil anfzulinden, und bon den mormalon mit blokem Auge gul zu unlerseheiden. Awoh mikroskopisch ist die fottige bege-

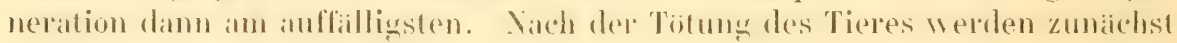

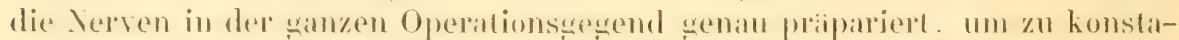

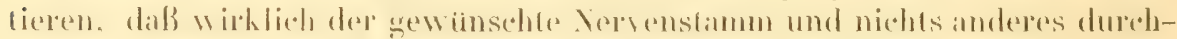
schnitten worden ist. Zu dieser Zeit sind die beiden Enden des in der angergehenen Austehmung resezierten versen gewohmlich schon durch aine dicke, knotige, gelloweibe Inschwellung veloumden, wolehe junges Binde-

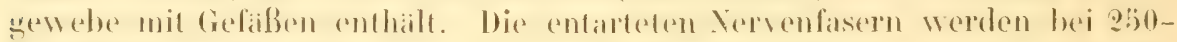
bis 300 fitcher Vergribermon mit efwa äprozentiger Valronlatuge untersucht. Sie zeigen Verlust dex doppelten honturen und reihenweise angeordnete,

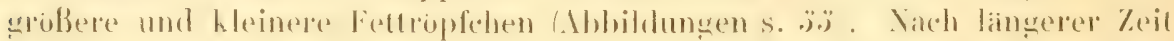

Fig. 17

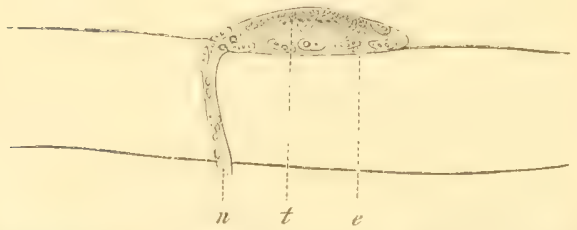

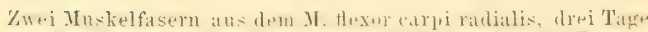

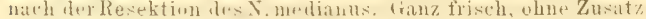
Vergr. 350. Von den Muskelfasern sind nur die Konturen ange geben. is Eettkörnchen innerhalb des Neurilems einer degenerierten doppeltionturierten Nervenfasex. $t$ Reihenweise angeordnete Fettiörnehen, welche aus fettiger Dege-

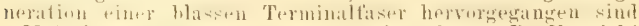
c Motorische Eudplatte mit Kernen in schrigger Profilansicht. Nach W. Krause $(56)$.

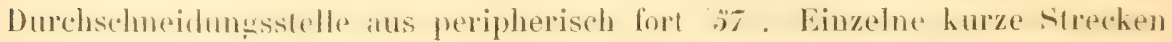
einer peripherischen, entarteten Nervenfaser hionen seheinbar normal sein, werden die Nervenstimmchen völlig atrophisch; sie enthalten auber den Achsenzyliudern und Nemilemscheiden nur noch wenige einzelne Fettröpfchen. Noch später erfolgt vollkommene Wiederherstellung. Einzelne fettig degenerierte Nervenfasern kann man auch in mikroskopischen Nerveuplexus, z. B. der Haut, mittels Natron leicht nachweisen. Die Entartung beginnt bei den motorischen Nervenfasern an deu Terminalfasern in den motorischen Endplatten selbst (Kig. 1\%, 56); bei den sensibeln schreitet sie von der 
wahrend eine weitere Verfolgung der Faser in dem mikroskopischen Priiparar die Degeneration erkennen läßt.

Nach jeder Operation schließt man die Inutwunden durch eine oder mehrere Knopfnähte; anstatt der Fiden benutat man manchmal mit Vorteil feinen geglühten Eisendraht, den die Tiere nicht zernagen können. Es versteht sich. daß die Methoden der modernen Chirurgie, Listerverband, Ätherspray, Kat gutfäden zum Nihen innerer Organe u. s. "I. in thunlichster Genauigkeit zu benutzen sind, wemn es sich um Operationen handelt, nath denen man die Tiere zeitweise am Leben zu erhalten wiinscht. Ilierüber ist anf die Lehren der Chirurgie zu verweisen.

Um operierte Kaninchen, die lingere Zeit am Lehen bleiben sollen, mit Sicherheit unter einer größeren Anzahl ron Versuchstieren herauszudinden, legt man durch die Ohren rine oder mehrere Schlingen von Eisen- oder Hessingdraht, die lamge Zeit als Marken sitzen bleiben. Man kamn atuch mit Auilinfarbstoffen mumerieren. Fä Versuche, nach welchen der Itarn des Tieres aufgefaugen werden soll, sind mit Blech ausgeschlagene Kisten notwendig, deren Boden nach dem Zentrum elwas abfallt, daselbst eine Abzugsröhre hat, die oben von einem feinen Drahtsieh verschlossen ist. Der Deckel des Kastens enthält viele Luftlöcher.

In der allgemeinen A natomie, die als erster Abschnilt der speziclen Anatomie vorausgeht, sind nach dem angedeuteten Plane der Darstellung, welcher den Gebrauch des Mikroskopes im Prinzip ausschloß, keineswegs histologische Details zu erwarten. Es ist vielmehr darin eine abersichtliche Zusammenstellung derjenigen Besonderheiten gegehen, durch welche sich der Bau des Kininchens rom menschlichen unterscheidel, um dem Leser die Muhe zu ersparen, sich dieselben aus den detaillierten Beschreibungen in der speziellen Anatomie selbst herauszusuchen. Will man, un sich der gewöhnlichen Bezeichnungsweise mehr anzuschließen, statl allgemeiner Osteologie z. B. etwa setzen: allgemeine osteologische Bemerkungen, so ist natiurlich dagegen nichts einzuwenden. Hierbei wurden die einzelnen Abschnitte: Osteologie, Myologie etc. sucressive durchgegangen. Wegen der Einzelheiten ist auf die im speziellen Teil niedergelegten Daten zu rerweisen, welche durch ein ausführliches Inhaltsverzeichnis besser zuginglich gemacht wurden. In der speziellen Anatomie enthalten die mit kleiner Schrift gedruckten Notizen außer den Operationsmethoden auch die beobachteten Virietiten. die pathologisch-anatomischen Befunde, Parasiten. und entwichlungsgeschichtliche Bemerkungen. 


\section{Allgemeine Osteologie.}

Das Skeletl des Kannchens besteht aus 21:3 Knochen, wobei die Gehörknöchelchen, die Ziahne und die Ussa sesimoidea nicht gerechnet sind. Hiervon kommen aul den sichialel 10. das (iesicht l:̈, die Wirbelsiale nebst lieuzbein und Schwanz 43, den Thorax 203, die obere Extremitit 66, die untere Exfremitit 3 f Knorhen. Dis skelef des Menschen besteht nach analoger Rechnung aus 205 Knochen.

Als selbstindige Knochen werden dabei diejenigen betrachet, die entweder in erwachsenen Tiere bei der Mazeration sich isolieren oder doch repmöge ihrer Enfwirklungsgeschichte unzwrifolhaft als gesondert betrachtef werden missen, wie \%. B. das Os zygomaticum. Die knochen sind beweglich - durch Gelenke - oder unber eglich miteinander vereinigt. Letzteres geschieht teilweise durch Nihte, suturue, die entweder einfache Nahte, Ilarmoniue, sind; oder die knochenriander greifen mit Zarken ineinander, die jedoch beim Kaninchen sehr wenigg auswebildet sind: Suturae serratue; oder von den knochenrandern itheroreilt der eine den anderen: suburae squamosar, anch wohl falsche Viahte genamnt. - Die Vereingungen durch horpel werlen Synchondrosen genannt, die durch Bindegewebsmassen Symphysen.

Die Zahl der Schidelknochen betrigt פ:), 10 on 15 anf das Gesicht fallen. Hierbei sind die Ossa intermaxillaria nicht gerechnet und die Ossa frontis nur einfich gezihlt. As Teile der Oss. tempormm wurden die Oss. Ympanica, petromastodea, squamosil und intermaxillaria angesehen. Selbstandig sind $\mathrm{im}$ Vurgleich zum Meuschen die Oss. sphenoidalia anterius und posterius, sowie das Os interparietale. Das Os hyoideum wird zu den Gesichtsknochen gezililt.

Der Schädel zeigt viel Ähnlichkeit mit dem eines Vogels. Der Sagitbaldurchmesser ibertrift den Transiersaldurchmesser bedeutend, sowie den Verlikaldurchmesser, wehloh noch geringer ist als letalerer. Die Ähnlichkeit

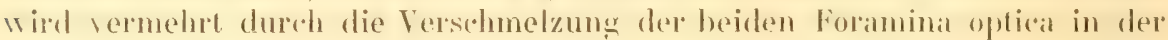

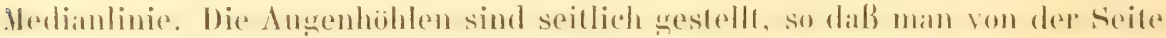
durch beide Augenhöhlen zugleich hindurehsehen kamm. Hore vordere Wambl entspridat der medialen Wand heim Mensihen, die hintere der lateralen. Ferner erinnelt an die Viggel die Bildumg einer senkrechten Lamelle bo dem rinfachen foramen opticum durch den kirper des vorderen keilbeines, somie das Oflensein der Aneenhobhe nach unten, woselbst sie num ron dem Areus zy gomaticus heremat wird. Auch der in der Richtubg ron rorn nach hinten 
sehe kurze Gammen und die Niedrigkeit der Köper beider lipilbeine (ös, sowie die rudimentire Fibula, die Form des Gehirnes sowie die starke Ausbildun: des Flocenlus cerebelli sind in dieser llinsicht zu erwähnen.

Das Studium der Osleologic des Schidels wird dureh den I'mstand spho erleichtert, diß die Vahte zwisehen allen knochen und selhst einzelner Ahleilungen derselben wiblirend des lehens ephalten bleihen. und namentlich hei nicht ausgewachsenen Tieren sehr deullich sind. Eine Ausnahme bildef nur der vordere Rand des Os zygomatidum, welcher mit dem P'rocessus zygomaticus oss. maxillaris superioris frubzeilig knöehern verwachst, sowie die Mae romeris, die mit den Ossa ethmoidea versehmelzen. Cetrennt beiben die Corpora oss. oreipitis und sphenoidei posterioris, die Ossa sphemnidea anterius und posterius, die Partes frontales ossium frontis, das Os interparietale. die Partes sfuamosil, petromastoidea und lympanica oss. temporum, das Os intermaxillare, die Hälften des Unterkiefers u. s. w.

Einige Knochen sind starker, andere weniger entwickelt. In der Entwiekehng bevorzug erscheinen die Ossa oceipitis, sphenoidea, frontis, nasi, maxillare superius und die Masilla inferior. Besonders diunn zeigen sich in der Profilansicht des in der Medianebene halhierten sichidels die Partes orhitales oss. frontis. die Pars squamosil oss. temporum, die Pars nasalis oss. palatini. die dla magna oss. sphenoidei und der untere Teil des Ramus maxillan inferioris. Sehr porös sind die Par's inferior alae magnare, der laterale $\mathrm{Ab}$ schnitt des oberen Schuppenteiles vom Os occipitis und besonders die laterale Flache des Corpus oss. maxillaris superioris proprii unterhalb des lateralen Randes der Ossa nasi. Lm Os occipitis ist die melor tertikale als horizontale Stellung des Foramen magnum orcipitale bemerkenswert: ferner sind zur Orientierung bei gewissen Operationen, z. B. dem Zuckerstich, praktiseh wichtiq die beiden oberhalh der Protuberantia oceipitalis externa an der hinteren iußeren Schidoloberflirhe gelegenen Tubercula occipilale und interparietale. Letzterer Höcker gehört zur Halfte den Scheitelheinen an. Die Alace magnae des hinteren sind nicht grö̈Ber als die Alae parvae des vorderen keilbeines, und es sind diese Bezeidhnungen nur dem sprarhgehratublo zu Liehe angewendet. In Wahrheit sind dieselhen als $\Lambda$ reus rorsales oder Yeurapophysen dieser beiden Schadelwirbed aufunfassen. Die Mla magna erreicht das Os frontis nicht, won dem sie durch die Ala parva und das Os temporum getreunt wird, und ebensowenig das Os parietale. Am vorderen Keilbein nimmt der Körper unter einem Winkel die Richtung nach rorn. Die Fissura orbitalis superior vereinigt in sich anch das Foramen rotundum. Verkwirdig sind die drei Foramina sphenoidalia der Processus prerıgoidei, deren Bedeutung in der Angiologie und Veurologie naher erörterl wird. Das kraffige Stirnbein bildet fast allein die vordere, nur beschrinkte Schaidelgrube: es besitzt recht kleine Sinus frontales. Die Schlafenbeine bestehen aus der Pars squamosa und aus zwei dureh eine Ilarmonie rephundenen Teilen: den Partes petromastoidea und tympanica. Der Processus styloideus fehlt scheinhar und ist heweglich in dem sehnigen [roprunge des M. styloglossus enthalten; dor Processus mastoideus ist wenig entwickelt. Die Ossa nasi haben eino hedeutende lange. und ibre Stellung nihert sich der sagittalen. Die obere und mittlere oder beide hinteren Muschelu sind wen ig entwickelt. Eine Scheide- 
wand zwisthen den heiden Labyrinthen des Siehbeines ist nu teilweise vorhanden: die Lamina perpendicularis erreicht den Vomer nicht. Die Lamina papylarea fehlt und wird dureh den Proressus ethmoidalis des vorderen Keilheines reprasentiert; die laleralen Zellen öfnen sich frei in die Vasenhöhle. Dir untere oder vorlere Muschel hestoht aus relen kleineren knocheuplatt(hell. Im oberhieferbein ist der simus maxillaris wenigg entwickelt; der vordere Teil des Os maxillane superius ist als Os iutermarillare sellastandig vorhanden. Ledzteres besteht aus zwei dureh Ilamonie miteinander verbundenen Abschnitlen, welche mit dem eigrentlichen Oberkieferbein dureh Vaht und IIarmonie sich verhinden. In die zu beiden Seiten des liopfes sich findenden Orhilate gelange man ron hinten ats der Fossa lemporalis. Die Fissura orbilalis inferior wird dureh einen groBen freien Zugang zur Augenhohle reprisentiert. Lateralwarts und unten spannt sich ror der Orhita der schmale, aber hriftige und lange dreus zygomaticus her. Cher den knowehernen Thrinenapparal sei noch erwahnt, daß ein hedeutend entwickelter knöherner Caualis nasolacrymalis vorhanden ist.

Eigentumlich ist am Schidel des Kaninchens die Entwichelung von relativ enorm langen, dibei ganz dimmen und meist spitzen, knöhernen Fortsitzen, die sich an verschiedenen Stellen finden. Cber dem Meatus auditorius externus kleuzen sioh die derarligen Processus squanosi oss. parielalis und der Pars squamosa oss. temporum. Hinter dem Processus mastoideus steigt der den letzteren an Linge iibertreflende Processus jugularis oss. occipitis herab. Derselbe wird hekanntlich $59,5.53$, entweder als Processus transversus des letzten Shabidelwirbels oder als Rippenrudiment an demselben betraldet. Alle iibertrift an Linge der fischgritenartige Ramus frontalis oss. intermaxillaris (Fig. $18 \mathrm{R} /$ ). Welcher mit einem weniger langen Processus maxillaris oss. frontis sich rerbindet. Dem letzteren ihnlich ragt der Processus sphenoorbitalis oss. maxillaris superioris aufwirts zwischen Ala parva oss. sphenoidei und dem Os lacrymale bis zur Pars orbitalis oss. frontis.

Die Oeffnungen des Schädels bieten manches Bemerkenswerte. l)as foramen opticum ist mpar. In Corpus oss. sphenoidei posterioris findet sich ein foramen (־avernosum zum Durchtritt einer großen Vene. Das Foramen rotundum fließt mit der Fissura orbitalis superior, das Foramen ovale mit dem Foramen larerum zusammen. In der Wurzel der Lamina lateralis des Processus pterygoideus finden sich die schon erwihnten drei Foramina sphenoidalia. Das Foramen zygomaticotemporale fehlt; das Analogon des Foramen sphenopalatinum wird nur rom Os palatinum gebildet. Das Foramen incisivum ist ungehener weit, ebenso die Fissura orbitalis inferior. welche mit der Orbita zusammenfließt. S. Betrachtumg des schardels von unten S. 40. Die Betrachlung des Schädels im Ganzen laßt folgende Hauptzüge erkennen.

Betrachtung des Schadels von oben.

Von oben betrachet zeigl der Schadel eine sehr betrichlliche Ausdehmum in der Linge, im Verhälnis zur Breite (Fig. 18, S. 39). Vorn sieht man die Apertura pyriformis, damn folgen die Ossal nasi, an deren lateralen Seiten dic 
nadelformigen Processus frontales der Ossa intermaxillaria nach hinten aufsteigen. Lateralwarts langs der letzteren ragen die kürzeren, diunnen und

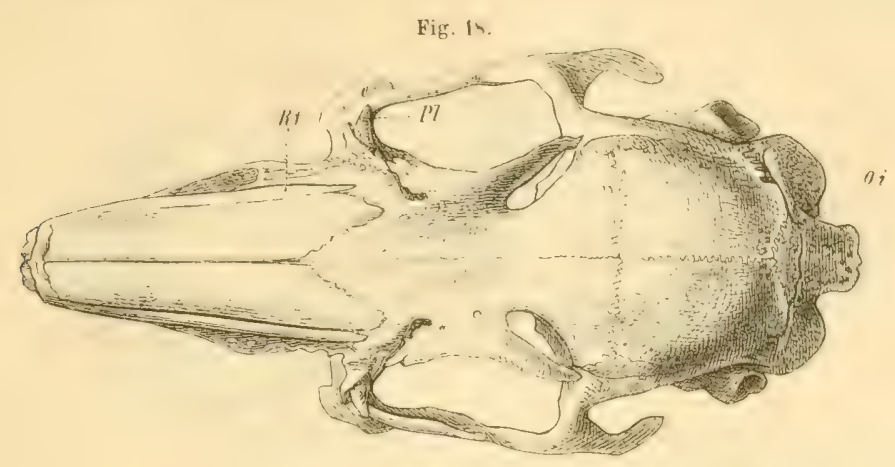

Schädel eines deutschen Kaninehens, von oben. Rf Ramus frontalis oss. intermaxillaris. Pl l'rocessus subcutaneus oss. lacrymalis. Oi Os interpariotale.

spitzen Processus maxillares oss. frontis bach rom. Die Seitenflache des Corpus oss. maxillaris superioris proprii ist porös und durehbrochen; nach unten und hinten erscheint in diesel porösen Knochenmasse das foramen infraorhiLale. Die Pars frontalis oss. frontis lauft nach rorn in eine lange Spina nasalis aus: sie ist schr schmal und durch die Sutura frontalis in zwei llailften geschiealen. Die Areus supraorbitales zeigen lange Fortsäze: Processus supraorluitales anterior und posterior, die nach vorn, resp. nach hinten gerichtet sind. Dic Arcus zygomatici enternen sich lateralwirts ziemtich weit vom Schidel, ebenso die Anguli maxillae inferioris. Die Ossa parietalia bilden den breiresten Teil des Schadels; die Pars squamosa oss. temporum ist sehr schmal in der Richtung von oben nach unten und ebenso die Fossa temporalis, welche mit der Augenhöhle durch den unterhalh des Processus supraorbitalis posterior gelegenen Sulcus temporalis der Pars sfuamosa oss. temporum kommuniziert. Die Pars squamosa liuft nach hinten in den langen, dimnen, sich ibher dem Meatus auditorius riickwirts krimmenden Processus squamosus aus. Cnter dem Meatus auditorius externus lieg̣t das Foramen stylomastoideum. hinter demselben der längliche. spitze Processus mastoideus. und parallel dessen hinterem Rande ragt der Processus jugularis der Pars sfuamosa inferior oss. occipitis abwarts. Zwischen den Ossa parietalia und der Pars squamosa oss. oecipitis liegt das kleine, olliptische, mit der Langsachse transversal gerichtete Os interparietale (Fig. $180 i$. An dessen vorderem Raude fiihlt man in der Medianlinie das Tuberoulum interparietale, an seinem hinteren Rande das grobere Tuberculum oceipitale; danu folgt nach riuckwirts die sehr hedeutende Protuberantia occipitalis externa.

\section{Betrachtung des Schädels von unten.}

Von unten betrachtet zeigt der Schadel vorn dir Nheolen des großen und kleinenschneidezahnes Fig. 19, S.40). Ilinter denselben folgy das ungehemel yroße Foramen incisivum, welches medianwirts durch die in der Medianlinie zusammeustoßenden Partes mediales der Processus palatini oss. intermaxillaris 
und den unteren Rand des Vomer in eine pechle und linhe Hatlle getrennt wird. Dasselloe stelle eine sehr lingliche, vorn spitze, hinten breitere, dreieckige

Fig. 19.

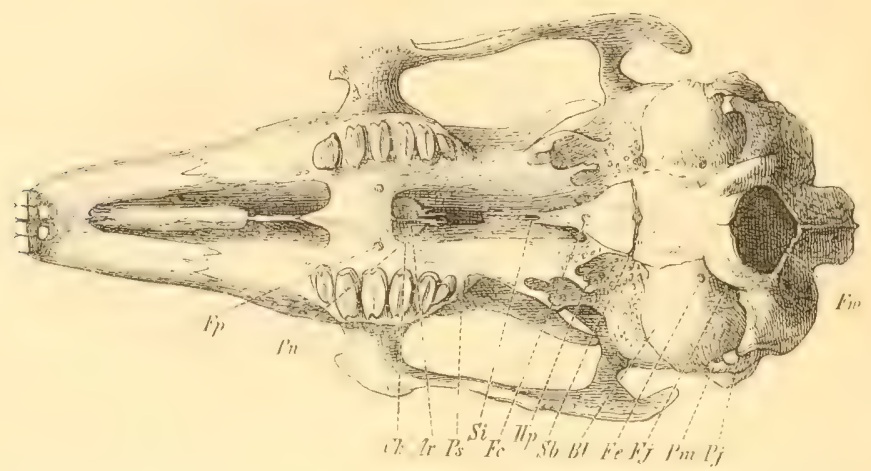

Schädel eines deutschen Kaninchens von unten. Fp Foramen palatinum in der Pars palatina oss. palatini. $P n$ Pars nasalis oss. palatini. Ch Choane. A Ala vomeris. $P$ 's Processus supraorbitalis ant. oss. frontis. Si Synchondrosis intersphenoidalis. Fc Foramen cavernosum. $H p$ Hamulus pterygoideus oss. sphenoidei posterioris. Sb Synchondrosis sphenobasilaris. Bl Bulla tympani oss. tempormm. $F e$ Foramen caroticum externum. $F j$ Foramen jugulare. $P m$ Processus mastoideus oss. temporum. Pj Processus jugularis oss. occipitis. $\quad F$ Hinterer Rand des Foramen magnum occipitale.

Spalte dite: nach hinten werden die rechte und linke Halfte durch die starke Spina nasalis res Proressus palatinus oss. maxillaris superioris getrenut. Am hinteren laleralen Winkel des letateren liegt das Foramen palatinum (Fig. $19 \mathrm{Fp}$ ) . Das lalatum durum ist sehr klein; die Choanen, Choomae, sind in eine fär das Kaninchen im Verogleich zum Ilasen charakteristische ( $\mathrm{S}$. I/4) sehmale Spalte ausgegogen. Iateralwarts zeigen sich die Processus alventares und die Wurzeln der l'rocessus zygomatici ass. maxillaris superioris. Das Os sphenoideum (anterius und posterius) is bedeutend in die Lange gedehnt, die Partes nasales Fig. $19 P n$ ) der Ossa palatina. Welche nach hinten an die Processus pterygoidei sioken, stehen fast horizontal, mit ihrem rorderen Rande mehr nach unten gerichtet; zwischen beiden erscheint in der Medianlinie die unpare Platte, welche den korper des broren lieilheines reprisentier. Nach hinten von der letzleren liegt beiderseits die Fissura ofbitalis (superior), in der Medianlinie zeignt das Corpus oss. sphenoidei posterioris das Foramen ravernosum Fig. $19 \mathrm{Fc}$ ): die Hamuli pterygoidei sind ritckwrts gekrimmt; in der Wurzel der Lamina lateralis processus plerygoidei finden sich drei von hinten nach vorn verlaufende kurze Kanale oder Löcher, die Foramina sphenoidalia. Das foramen lacerum ist weit, und fließt mit der Ineisura ovalis alae magnae zusammen. Die Fissura orhitalis inferior zwisehen Ala magna oss. sphenoidei und Processus alreolaris maxillae superioris ist affallend ueit, so daß die Augenhiblele ron unten hep vollkommen offen ist und nur seillich vom Areus zygomalirus begrenzt wird. In diesem enomen Ilohlraum, dem Carum orbitale. vereinigen sich der untere Teil der Fossa temporalis, die Fossa sphenomaxillaris um pterygopalatina mit der Fissura orbitalis inferior. Das Carum orbitale, "ie es zum Intreschiede von der eigenllichen Orhila genamml wesden kann, fließt nach oben mit letzterer zusammen.

Die (Orbita sellost stellt eine nicht ganz vollstindige halbe Ilohlkugel dar, deren knocherne Wand nach oben und vorn gelegen ist. Das Cavum orbitale 
wird nach rom hegrenz vom Processus maxillaris oss. fromlis. dem Os lacr! male und dem Os maxillare superius; nach oben ron der Pars orhilalis oss. frontis; medianwirts ron dem Os palatinum und Os sphenoideum; nach hinten von den Alae oss. sphenoidei und der Pars squamosa oss. temporum; nach unten von der oberen Flache der Lamina lateralis des Processus pterygoodeus oss. sphenoidei, und dem Os palatinum, sowie rom Ramms maxillae inferioris; lateralwarts nur vom Areus zygomaticus. Das Cavum orbitale kommuniziert mit der Schidelhöhle durch die Foramina shmoidemm, optixum, und dic Fissura orhitalis, mit der Nasenhöhle dureh den Canalis nasolacrymalis und das Foramen sphenopalatimum; mit dem Gesicht dureh dic Cianales infratorhitalis und zygomatienfacialis, mit der Fossa temporalis dureh das Foramen cemporale (s. Os frontis); mil der Fossat pterygoidea dureh das Foramen sphenoidale anterius.

Ausgefuillt wird das Cavum orbitale in dem der eigentlichen Orbita angehörigen Teile von dem Bulbus und seinen Adnexa; im unteren Teile hauptsächlich von den Mm. temporalis, pterygoidei internus und externus, welche am nicht präparierten Kopf den Verschluß nach unten bilden. Mit Blut versorgen die Aa, maxillaris interna und lacrymalis die im Innern des Cavum orbitale gelegenen Teile; in dem Winkel zwischen medialer, unterer und hinterer Wand liegt der N. trigeminus mit seinen Asten. - Die Innenfäche des Periostes der Orbila ist mit Endothelzellen iiberdeckt $(8 \% 0,5.47)$. - Die Ebenen des lateralen Einganges der beiden Orbitae konvergieren nach oben unter einem Winkel von "s0". nach vorn unter einem solchen von $31^{0}(855)$.

An dem Os temporum fillt die glatte, einem Processus mastoideus gleichende Bulla tympani ins Auge; medianwaints ron derselben liegt das Foramen caroticum externum: hinter der Bulla lympani der spitze Proressus mastoideus, und das untere Ende des Processus jugularis oss. oceipitis Fig. 19 Pj, Das Foramen jugulare stellt eine sehr enge, Jangliche Spalte dar, die Foramina condyloidea superius und inferius werden von den processus condyloidei oss. occipitis bedeckt. Die Ebene des Foramen magnmm ist fast frontal gestellt: hinter demselhen erscheint die Crista neciphtalis externa und die stark rorspringende Protuberantia occipitalis externa oss. occipitis.

\section{Betrachtungdes Schädels von innen.}

Die Cavitas cramii enthät die vordere, mittlere und hintere Schiadelyrube.

Die vordere Schadelgrube wird gebildet von den Partes orbitales oss. frontis. Vach vorn wird sie von der sehr steil anfsteigenden Lamina crihrosa oss. ethmoidei und der Crista galli begrenzt, und zeight hier viele kleinere Löher: Foramioa crihrosa, welche in die Jasenhohle führen, und das etwas größere, lateralwarts vom hinteren Ende der Lamina rribrosa gelegene Foramen ethmoideum. welches in die Augenhöhle leitot. In der Medianlinie enthät sie hinter der Lamina cribrosa den Körper des vorderen heilbeines,

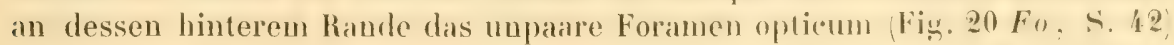
gelegen ist. Der Boden der vorderen Sohidelgrube lient etwa 1,0 an höher,

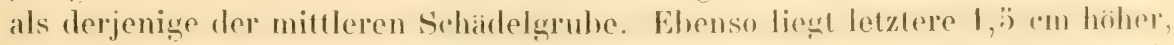
als die hintere Schadelgrube, so daß yleichsam eine terrassenfömige Anordnung im Innern des Schädels vorhanden ist. 
Die mittlere Schidelga uhe wird rom Compusoss. sphenoidei posterioris (Fig. $20 \mathrm{~s} / \mathrm{y}^{\prime}$, den Alae magnae und parvac, den Partes squamosae und den

Fig. 20.

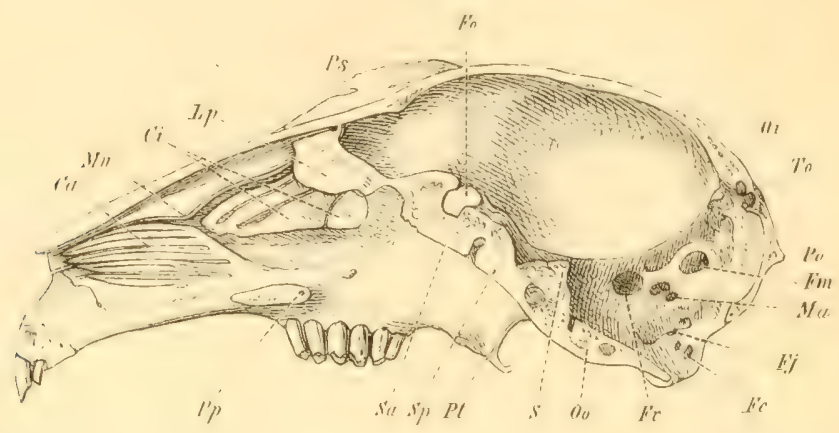

Rechte Schulellälfte ron innen. $C a$ Concha anterior. IIn Iarsupium nasale. $C i$ Concha posterior inferior. $I p$ Lamina perpeulicularis ass. etlumoidei. Ps Processus supraorbitalis anterior oss. frontis. Fo Foramen opticum. $P p$ Qnersehnitt der Par's palatina oss. palatini und des Processus palatinus oss. maxillaris superioris. $S a$ Corpus oss. sphenoidei anterioris. S $S p$ Corpus oss. sphenoidei posterioris. Pt Processus pterygoideus oss. sphenoidei nosterioris. S Sella. Oo Pars basilaris oss. occipitis. Fv Foramen ovale. Fc Foramina condyloidea anteriora. $F j$ Foramen jugulare. If $a$ Meatus auditorius internus, darüber die Apertura interna des Canalis facialis. F $m$ Fossa mastoidea oss, temporum. Po Protuberantia occipitalis externa. To Trberculum occipitale. $0 i$ Vorderes Ende des Os interparietale.

vorleren Flachen der Partes petromastoideae oss. temporum gebildet. Vach rorn geht sie abgerundet mittels der oberen Fiache des Corpus oss. sphenoidei anterioris in die vordere Schadelerube iber; nath hinten wird sie ron tem Ramdr zrvischen oberer und hinterer Flitche des Gorpus oss. sphenoidei posterioris und den oberen Randern der vorderen Flathen der Partes petromastoideate oss. Lemporum begrenzt. Thre Winde sind simmtlich sehr steil. Sie steht durch die Foramina optica. spinosit und die Fissurae orbitales mit der Augenhöhle, dur.h die sulci sphenoidales mit der hinteren schiddelgrube und den Foramina lacera; dureh letztere und das Foramen earernosum mit der unteren Schadeltliche in Verbindung.

Die hintere Schädelgrube stößt nach vorn an die mittlere: nach hinten wirl sie rom oberen Rande der Pars squamosa oss. occipitis begrenzt. Sie wird vom Os occipitis. der medialen Flache der Partes petromastoideate ass. lemporum und der hinteren Flache des Corpus oss. sphenoidei posterioris gebildet. Die hintere Schaidelgrube enthalt die Foramina latcera. die Aperturate internar der Camales faciales, die Meatus auditorii interni, die Fossulae pefosite unter den letzteren, die Fossae mastoideae uber und hinter den ersteren. Die Fossa mastoidea (Fig. $20 \mathrm{Fm}$ ) ist jederseits zwischen den drei Cimales semicirculares oss. temporum eingegraben. S. Splanchnologie. Ohr. Hinter und iber der letzterwahnten Fossa rerliuft der Sulcus transversus in einem Bogen. dessen Konvexitit lateralwarts gerichtet ist. Des untere Schenkel des Boyens verlauft horizontal ïber und hinter der fossa mastoidea am Os temportur. der obere sidhenkel horizontal und medianwitsts sich erhebend an oberen Rande der Pars squamosa oss. occipitis.

Fiar die Zuritckfuhrung einzelner Schädelknochen des kaninchens auf den Wirbeltypus läßt sich folgendes Schema aufstellen : 


\begin{tabular}{c|c|c|c}
\hline Schädelwirbel & Wirbelkörper & Arcus & $\begin{array}{c}\text { Processus trans- } \\
\text { versus }\end{array}$ \\
\hline $\begin{array}{c}\text { Os sphenoideum } \\
\text { anterius }\end{array}$ & Corpus & Alae parvae & Processus transversus \\
$\begin{array}{c}\text { Os sphenoideum } \\
\text { posterius }\end{array}$ & Corpus & Alae magnae & $\begin{array}{c}\text { Lamina lateralis pro- } \\
\text { cessus pterygoidei }\end{array}$ \\
\hline Os occipitis & Pars basilaris & Pars squamosa & Processus jugularis
\end{tabular}

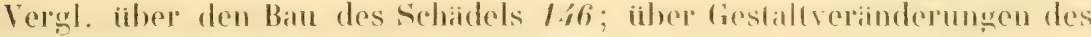
Schadels durch Operationen an jungen Tieren 745.

Am Interkiefer hesteht eine ganz eigentimliche linrichtung in dem Foramen mandibulare, welches dicht hinter dem letzten unteren Backenzahn gelegen ist. Dasselbe enthäl einen venösen kommunikationsast, der zur Regulierung des Blutabfusses aus dem Carum ortbitale wesentlich beizutragen scheint (s, allgemeine Angiologie).

An der Wirbelsiale, die im ganzen aus 46 Wirbehn hestehl. zeigh der Atlas ein Foramen obliqumm zum Durchtritt der $A$. Vertebralis. Auffillig ist die starke Entwickelung der Processus spinosi der Rürken- mol Iendenwirbel, wahrend sie an den oberen Halswirbeln nur wenig ausgeprigl sind. Ehenso sind die Processus transversi der sieben Lendenwirbel stark entwickelt. namentlich sehr lang. während die Processus mamillares dicht neben den Processus spinosi stehen, nach hinten gerichtet sind und " ie Processus spinosi accessorii aussehen. Die Processus transrersi der Wirbelsaule iiberhatupt enthatten in sich die Bestandteile von vies versehieden entwickelten Nbteilungen: Costa, Processus transtersus, Processus mamillaris und Processus transversus accessorius, die an den unteren Rückenwirbeln des Kaninchens sämmtlich vorhanden sind. Die Processus transversi der Lendenwirbelsiule sehen kurzen Rippen sehr ahnlich. Am merkwiurdigsten sind drei Processus spinosi anteriores, welche die oberen drei Lendenwirbel auf der Vorderfliche besitzen. Von deuselben entspringt die Pars rertebralis des Diaphragma. Infolge der starken Entwickelung der Mm. psoas major und quadratus lumborum einerseits, des M. longus colli andererseits, bleibt an der Vorderfliche der Wirbelkörper nur diejenige des sechsten und siebenten Ruckenwirbels von Muskelansiitzen frei. Das Os sacrum besteht aus vier, der Schwanz aus 16 (eigentlich 17) Wirbeln.

Die drei unteren Rippen enden knorplig und frei.

An der oberen Extremitat ist die Clavicula nur rudimentar vorhanden. Das Caput humeri entfernt sich sehr weit davon, Teil einer Kugel zu sein. Am Vorderarm liegt der Radius fast in einer frontalen Ebene mit der Ulna und vor der letzteren; die Dorsalseite ist nach voru, die Volarseite nach hinten gerichtet; Pronations- resp. Supinations-Bewegungen fehlen. Iandwurzelknochen finden sich neun; außer den vom Menschen bekannten noch ein Os rentrale. Der Daumen ist rulimentar vorhanden: die Vagelphalangen bilden mit den zweiten Phalangen einen dorsalwarts offenen, stumpfen Winkel.

An der unteren Exlremität hat das Becken eine fast vertikale Stel- 
lumg und eine hedentende Linge. Die Verbindme mit dem lipeuzbein findel sich elwa in der Mitle seiner länge. Dats Acelahulum der llifte zeichnet sich

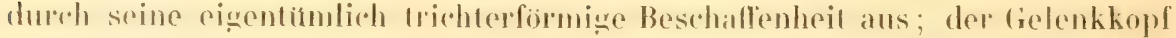

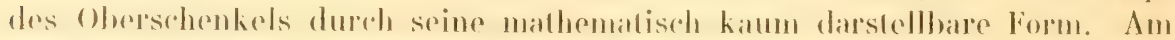

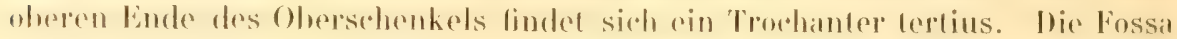

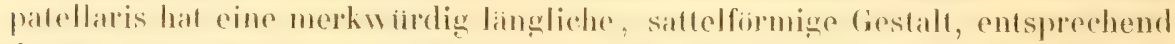
dee Form der Patella. Die Fibula ist wenig ontwiekelt und mit der Tibia in deren llite knibhern vereinigl. Cnter den Tarsusknochen finden sich nur zwei Ossa tarsalia cumeiformia, und es sind nur vier Ossa metatarsi, resp. Zehen vorhanden.

A b bild ungen verschiedener Knochen des Kaninchens s. 22: Kreuzbein Taf. LXV, Fig. 6), Becken (Taf. LXV, Fig. 7), Radius und Ulna (Taf. LXXXY, Fig. 3 u. 4). - Über Lymphgefii ße der Knochen vergl. 6 17. - Der Abstand der Knochenkörperchen voneinander beträgt durchschnittlich 0,044 - $0,016 \mathrm{~mm}(655)$. - Über das $\mathrm{K} n$ ochenmark vergl. 715.

Chemische Zusammensetzung der Knochen. Aus einer sorgfälligen Untersuchung $(60)$, welche sämutliche Altersstufen von der Geburt bis zum vierten Jahre umfaßt, ergab sich zunächst, daß das Knochenwachstum mil dem sechsten Monat abschließt. Untersucht wurden die großen Extremititenknochen inkl. der Clavicula, aber exkl. des Beckens. Die interessantesten Zahlenwerte sind folgende:

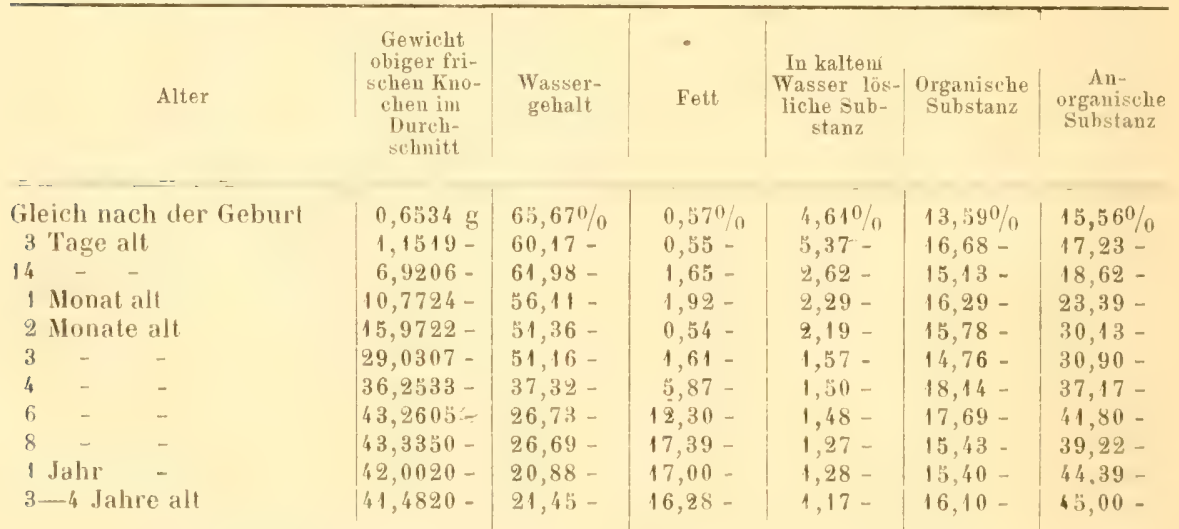

Die Asche jener Knochen ist in $\%$, der Trockensubstanz folgendermaßen zusammengesetzt :

\begin{tabular}{|c|c|c|c|c|c|}
\hline - Alter & $\begin{array}{l}\text { Organische } \\
\text { Substanz }\end{array}$ & $\begin{array}{l}\text { Calcium- } \\
\text { phosphat }\end{array}$ & $\begin{array}{c}\text { Magnesium- } \\
\text { phosphat }\end{array}$ & $\begin{array}{l}\text { Calcium- } \\
\text { earbonat }\end{array}$ & $\begin{array}{l}\text { Calcium- } \\
\text { fluorid }\end{array}$ \\
\hline Gleich nach der Geburt & 46,61 & 45,94 & 1,61 & 4,43 & 1,41 \\
\hline 3 Tage alt & 49,18 & 43,96 & 1,51 & 4,44 & 0,91 \\
\hline $14--$ & 44,82 & 47,76 & 1,52 & 5,90 & 0,89 \\
\hline 1 Monat alt & 41,06 & 50,61 & 1,57 & 3,36 & 1,40 \\
\hline 2 Monate alt & 34,37 & 35,82 & 1,56 & 6,74 & 1,51 \\
\hline- & 32,32 & 57,12 & 1,49 & 7,21 & 1,86 \\
\hline- & 31,28 & 57,90 & 1,53 & 7,68 & 1,61 \\
\hline- & 29,74 & 54,35 & 1,61 & 7,89 & 1,41 \\
\hline $8--$ & 28,23 & 59,50 & 1,46 & 9,03 & 1,78 \\
\hline 1 Jahr alt & 25,76 & 61,21 & 1,48 & 9,64 & 1,91 \\
\hline 3-4 Jahre alt & 26,35 & 60,58 & 1,33 & 9,47 & 2,27 \\
\hline
\end{tabular}


Man sieht, wie der Wassergehalt und die in Wasser löslichen Substanzen mit dem Wachstum abnehmen, während der Fettgehalt im allgemeinen zunimmt. Die genannten Substanzen bestehen aus Eiweißkörpern, Phosphorsïure, Kohlensïure, Schwefelsäure, Chlor, Kali, Natron, Magnesia, Kalk und Eisen in wechselnden Mengen. Bezogen auf die Knochenasche nimmt der Gehalt an Calciumphosphat und Magnesiumphosphat mit zunehmendem Alter ab, dagegen wächst die relative Quantität des Calciumcarbonates. Bezogen auf die T'rockensubstanz wächst die Menge des Calciumphosphates und Magnesiumphosphates mit dem Alter.

K no che nwa chstum. Die Knochen namentlich des jungen Kaninchens sind so zart und porös, daß der berïhmte und so oft wiederholte Versuch von Duhamel $(1742)$ an einzelnen der ersteren auf Schwierigkeiten stößt; wenigstens gilt dies in betrell der Scapula und des Schädels, was schon zu irrtümlichen Erklärungsversuchen Anlaß gegeben hat. Benutzt man hingegen die Diaphyse der Tibia, so zeigt sich, daß die Distanz von zwei Stiften, welche bei einem jungen Tier in die Enden derselben eingeschlagen wurden, sich während des Wachstums durchaus nicht ändert (Fig. 21). Selbst dann nicht, wenn die Genauigkeit der Messungen etwa $0,5 \%$ der zu messenden Größe erreicht $(61)$. Beispielsweise wuchs die Tibia eines französischen Kaninchens binnen ca. Irei Monaten von 105 auf $120 \mathrm{~mm}$ Länge; der Abstand von zivei in die TibiaDiaphyse getriebenen Silberstiften betrug anfangs wie nach Ablauf der genannten Zeil 39,9 $\mathrm{mm}$ mit einem wahrscheinlichen mittleren Fehler von ca. 0,1 mm. Hiernach erscheint die Appositionstheorie des Knochenwachstums gegenüber der Hypothese vom interstitiellen IVachstum bewiesen $(57$, S. 71).

Auch die Resorption des wachsenden Knochens kann an der Tibia junger Kaninchen vortrefllich studiert werden. Die Resorptionsflachen liegen an den oberen und unteren Enden der Diaphyse und es können je zwei Zonen $(61)$ intensiverer und weni-

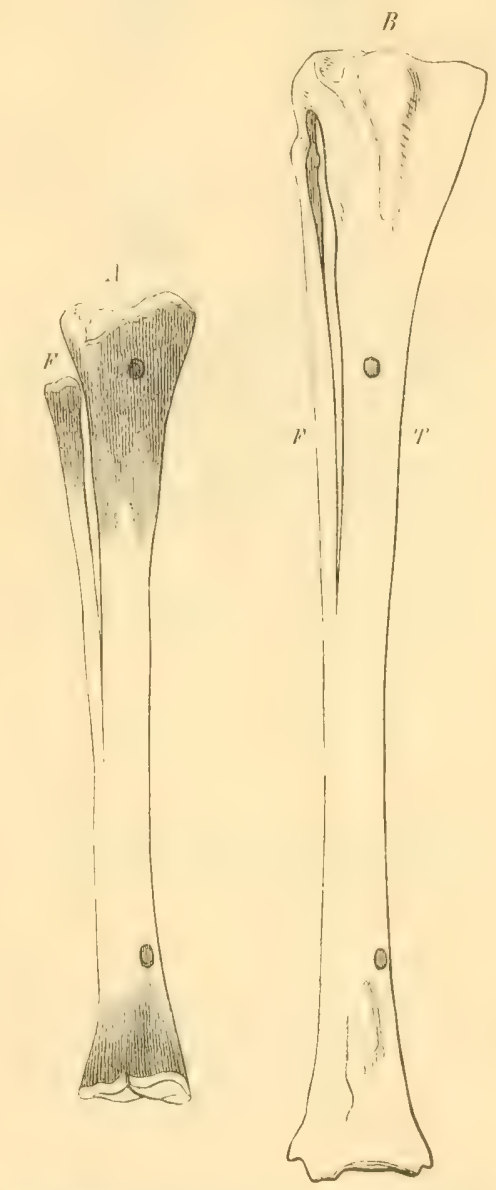
Fig. 21.

Unterschenkelknochen von zwei französischen Kaninchen desselben Wurfes, von vorn. A. Von einem sechswöchentlichen Tiere nach L. Lotze (61), von vorn: die oberen Epiphysen sind entfernt. B. Nach einem ähnlichen Präparat von einem $\left.11\right|_{2=}$ jährigen Tiere; erstere ummittelbar nach dem Einlrücken von zwei Nägeln und Amputation der unteren Extremität; letztere nach einer über ein Jahr betragenden Zwischenzeit, Die Distanz der sichtbaren Nägelköpfe ist in beiden Figuren genau dieselbe. Die Resorptionsfâchen am oberen und unteren Finde ron a sind durch hellere und dunklere Schattierung ansgedrückt. $b^{r}$ Fibula, $T$ Tibia. yer intensiver Resorption unterschieden werden (Fig. 22, S. 46). Die Resorptionsthichen sind mikroskopisch durch das Vorhandensein von Howshipsichen Lakmen und Riesenzellen. die in srößerer Anzahl sich darin tinden, ausgezeichnet. 
Die Röhrenknochen des Kaninchens, namentlich Tibia, Ulna und Radius, sind Fig. 22 .

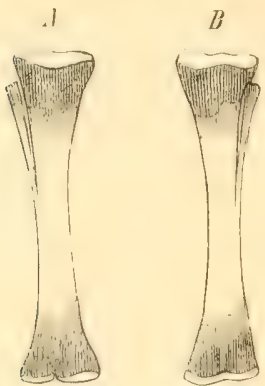
vielfach zu Experimenten über Knochenwachstum (vergl. 650), das obere Ende der ersteren oder die Diaphyse auch zu Injektionen von Jodtinktur oder Milchsiure oder Einschieben von Elfenbeinstiften in die Markhöhle benutzt worden $(651)$.

Pathologische Anatomie des Knochensystemes. In betreff derselben ist zu bemerken, daß Frakturen häufig vorkommen, und schlecht heilen, wenn sie nicht verbunden werden. Am Oherschenkelbein findet in der Regel bedeutende Verkürzung oder Dislokation statt. Uber die

IIttelstücke der Tibia ma Fibula eines neugeborenen französisehen Kaniuchens. Die Resorptionsttächen sind durch hellere und dunklere Schattierung angedentet. Nach einen Präparat rom L. Lotze. A. von rom B. voll hintell Kallusbildung vergl, z. B. 785 .

Transplantierte Perioststreifen, z. B. der Tibia, erzeugen bei jungen Tieren neuen Knochen (62). Man kann auch mit demselben lirfolge Perioststreifen \%. B. Tom Hunde in das Interhathindegewebe eines Kaninchens verpllanzen $(65)$. 


\section{Allgemeine Syndesmologie.}

Die Ligamente des Kaninchens sind fest, weiß und glianzend wie die sehnen. Andere, welche nicht in chatrakteristischer Wrise 1 on dem henachbarten Bindegewebe sich ahsomdern, "wolen nicht speziell beriicksichtign. Die Fibrocartilagines infervertebrales enthalten an ihren oberen und unteren Enden platte, mit heisten vasehene knochenscheiben. Die meisten Ligamente beteiligen sich an der Zusammensetzung der Gelenke. Was letztere hetrillt, so sind ron den möglichen Gelenkverbindungen $(59,5.18)$, abgesehen vom Doppelgelenken mit Zw ischenknorpeln, folgende realisiert, die simmtlich Schleifgelenke sind:

\section{Mechanik der Gelenke.}

\section{Gelenke, deren Flächen Teile von Rotationskörpern reprïsentieren.}

\section{A. Mehrachsige Gelenke.}

1. Kugelgelenk, Arthrodiā. Die Bewegungen der Gelenkflächen, welche kleine Teile von Kugeln darstellen, können um beliebige Achsen ausgrefuhrt werden, die durch den Mittelpunkt des Gelenktiopfes gehen.

\section{B. Zweiachsige Gelenke.}

2. Ellipsoidgelenk oder Walzengelenk. Die Grundfliche entspricht Abschnitten von ellipsoidischen Rotationskirpern. Eine Achse - die Ilauptachse - ist meist betrichtlich linger, als die beiden anderen. Die Bewegung erfolgt in merklichem Grade nur un zwei aufeinander senkrechte Achsen, deren eine die Hauptachse ist.

3. Sattelgelenk. Jede Gelenkfliche ist in einer Richtung konkar, in einer anderen darauf senkrechten konvex. Ist die eine Gelenkflache sehr viel größer, als die andere, so braucht die Konkavitat der letzteren nicht schr deutlich ausgesprochen zu sein. Die Gelenkflichen entsprechen Abschnitten eines Rotationshyperholoides. Die Bewegungen geschehen um zwei aufeinander senkrechte Achsen, die in den verschiedenen Knochen liegen. 
C. Einachsige Gelenke.

4. Kegelgelenk. Sie sind stets durch zwei oder mehrere Gelenke reprisenticrt, deren Flichen ambihernd als schr kleine Teile eines Kegelmantels betrachtet werden können.

๖. Gylindergelenk oder Winkelgelenk, Ginglymus. Die Gelenkflichen stellen 'Teile von soliden resp. Hohlzylindern dar.

6. Schra ubengelenk. Dieselben sind bei weitem am häugsten und vielleicht lassen sich bei genauerer Untersuchung alle Ge-

Fin. $2: 3$

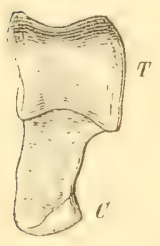

Linker Talus, von oben. I' l'alusrolle. C'Caput tali. lenke des Kaninchens auf diesen Typus zurückführen. Die Schraubenspindeln sind, wie es scheint, an der rechten Körperhailfte sämmtlich dexiotrop $(\delta)$, an der linken liiotrop $(\lambda$, rechtliuufige Schraube der Technik). Die Steigungen der Schrauben sind meist sehr gering; die Bewegungen nihern sich daher den einfachen eines Ginglymus. Anstatt die Knochen aufeinander Ganglinien zeichnen zu lassen, kann man die seitlichen Rollenrinder mit Vorteil als natüliche Ganglinien ansehen.

Die Schraubennatur ist an den Ellenbogen-, Finger-, sprung- und Zehengelenken leicht erkemnbar ausgeprigt. Am Sprunggelenke

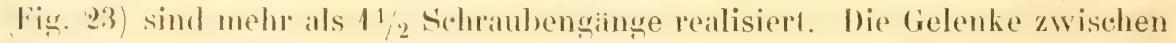
Phalangen und Metakarpusknochen sind Kombinationen von sichrauben- und Sattelgelenken.

D. Gelenke mit unbestimmten Achsen.

7. Straffes Gelenk, Amphiarthrosis. Die Flaichen sind annahernd Ehenen ron stets nur geringem Iurchmesser. Sie künnen wahrscheinlich richtiger als sidhaubengetenke betrahtet werden. Die Bewegungen sind durch zihhlreiche Hemmungen mittels starker ligamente sehr beschrainkt.

Die kleineren Gelenke der Extremitäten kommunizieren häufig mit den Synovialscheiden der sie überkreuzenden Sehnen $(820)$.

Nerven der Gelenke. Sie endigen mit Gelenknervenkörperchen (57, S. 523), die im Kniegelenk $0,06-0,2 \mathrm{~mm}$ Länge und z. B. $0,13 \mathrm{~mm}$ Breite auf $0,17 \mathrm{~mm}$ Länge haben $(57$, S. 523 , vergl. a. 57, S. 541 , ferner $72 /$ und 820$)$. 


\section{Allgemeine Myologie.}

Die Muskeln des Kaninchens sind im allgemeinen von blasser Farbe und weich; ihr Elastizitatsmodulus scheint geringer zu sein, als bei anderen Siugern. Eine Anzahl derselben zeichnet sich durch festere Beschaffenheit, größere und wahrscheinlich auch volkommenere Elastizitä und rötliche Farbe aus. Diese Eigenschaften kommen den fast fortwihrend thitigen Kaumuskeln in hohem Grade zu, ebenfalls den Muskeln des Vorderarmes, ferner manchen langen und rundlichen Muskeln, wie den Mm. semitendinosus und soleus, während die auderen Muskeln derselben Gruppen die gewöhnliche Beschaffenheit zeigen. Eine mit Benutzung dieser Unterschiede durchgeführte vergleichende chemische Untersuchung fehlt zur Zeit; sie würde vermutlich lohnend sein.

Diesen hier wiederholten Sätzen der ersten Auflage (1868) ist noch die Bemerkung über den II. semitendinosus anzureihen (daselbst, S. 119): mauf Querschnitten ist sein rötlicher Muskelbauch in dem weißlichen Fleisch des M. adductor magnus auffallenda.

Später $(1873)$ ist eine anderweitige Lntersuchung (6.4) erschienen, welche zwar keine chemischen. wohl aber mikroskopische und physiologische Differenzen gerade zwischen den Mm. adductor magnus und semitendinosus zum Gegenstand hatte (vergl 65 ).

Rote und weiße Muskeln.

Der M. semitendinosus zeichnet sich mikroskopiseh vor dem M. adductor magnus und anderen weißlichen Muskeln durch folgende Unterschiede aus.

Dickere Schnitte des frischen M. semitendinosus sehen gelblich aus, solche vom M. adductor magnus gleichmäig hell und farblos. An isolierten Muskelfasern ist dieser Unterschied nicht mehr wahrzunehmen, jedoch tritt die Lingsstreifung am M. semitendinosus, die Querstreifung am M. adductor magnus mehr hervor: an ersterem sind die interstitielle Flússigkeit und interstitiellen Körnchen zwischen den Muskelfibrillen vermehrt. - Im II. soleus (vergl. S. b̈l sollen die Muskelficher im Verhaltnis von $6: 5$ höher sein als in den $\mathrm{Mm}$. gastrocnemii s. gemelli surae (186).

Auf dem Querschnill der getrockneten Muskeln ergeben sich die Faseru des M. semitendinosus dicher, im Vittel zu 0,003313 f $\mathrm{mm}$ Fiacheninhalt, wahrend die Fasern des .I. adductor nur 0,00123̈ ( $\mathrm{mm}$ haben. Diejenigen des II. semitendinosus machen im allgemeinen den Eindruck, als ob ein Teil von ihnen die Größe derjenigen des M. adductor magnus häte, waihend ein au- 
derer um mehr als das doppelte großßer erscheint; vermittelnde Zwischenformen finden sich erst bei genauerer Betrachtung. Es ist dabei an den bekaunten Umstand zu erinnern, daß simmtliche quergestreifte liuskelfasern selbst in den lingsten Iluskeln spindelförmig sind und die Läinge von $3 \mathrm{~cm}$ nicht zu überschreiten pflegen: näher nach den Euden hin gelegene Querschnitte erscheinen daher kleiner. Außerdem liegen die Fasern des M. adductor magnus dichter gedringt nebeneinander, wiahrend die des M. semitendinosus durch eine Zone lockeren Gewebes roneinander gerückt sind. Auf dem Liingssehnitt liegen z. B. 10 Fasern des 11. semitendinosus, 16-20 vom M. adductor magnus im Durchmesser des Gesichtsfeldes; beide Ifuskeln zeigen in Essigsäure untersucht stets deutliche Querstreifung.

Nichst der Verschiedenheit der Zahl und Größe der Fasern ist die ungleiche Verteilung der Kerne in beiden IIuskeln auf dem Querschnitt auffallend. Die Kerne der Fasern des M. semitendinosus sind bei weitem zahlreicher, als diejenigen der Fasern des 11. adductor (Fig. 24 u. 2:3', bei jenen kommen 5 herne im Mittel auf jeden Faserquerschnitt, beim II. adductor magnus nur 2. Die kerne des II. semitendinosus sind groß, rundlich, mehr ins Innere vorspringend; auf dem Liangsschnitt breit und kurz, längs des Verlaufes der Fasern in ziemlich regelmäßigen $\Lambda$ bstanden angeordnet, einzeln orler in Gruppen ron drei bis vier zusammen. Die Kerne des II. adductor magnus dagegen sind sehmal, oval auf dem Querschuitt, dem Sarkolem eng anliegend;

Fig. 24 .

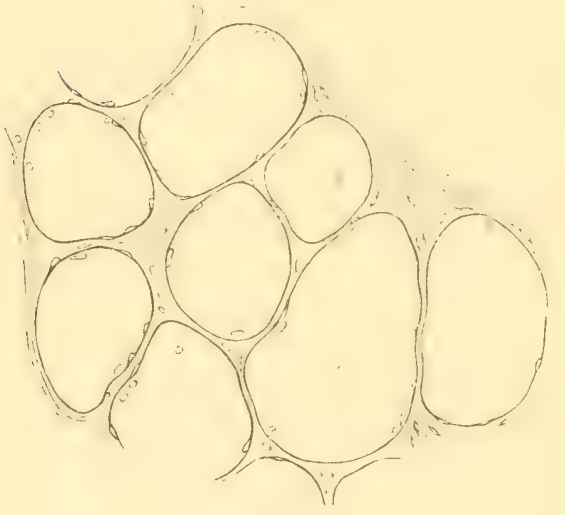

M. semitendinosus nach Alkoholbelıandlung. Querschnitt, Essigsäure, Glycerin. Vergr. 200. Die Muskelfasern sind teilweise von. größerer, Dicke; die Sarkolemkerne zahlreich; einige Kerne liegen im Innern der kontraktilen Substanz.

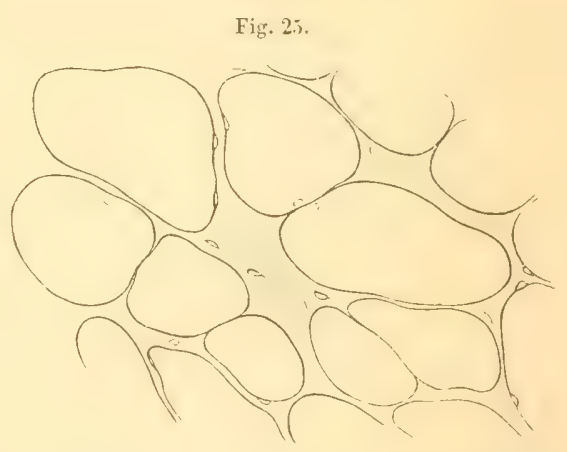

Querschnitt aus dem M. adductor magnus. Methode wie in Fig. 24. Die Sarkolemkerne sind sparsam.

auf dem Längsschnill schmal, stäbehenförmig, lïngsgestellt in gleichen $\Lambda$ bstianden. Der Unterschied der Zahl der Kerne ist auch hier ohne Miihe festzustellen, obgleich derselbe nicht so deutlich hervortritt wie auf dem Querschnitt. Die bemerkenswerteste Differenz zeigt sich aber darin, daß auch im Innern der Muskelfasern Kerne vorhanden sind (Fig. 24).

Auch die Blutgefiße bieten wesentliche Lnterschiede. Injiziert man die A. cruralis mit Berlinerblau, härtet in Alkohol und hellt mit Nelkenöl nebst 
Dammarfirnis auf, so zeigt der M. adductor magnus auf dem Längsschnitt die bekannte Anordnung der Muskelgefiße: größere Gefiße laufen schrig, mehr der Faserrichtung sich nahernd, über die Muskelfasern; die Kapillaren, welche von ihnen ausgehen, liegen geradlinig zwischen den Fasern, doch nicht so zahlreich, daß auf jede Muskelfaser ein neben ihr laufendes Kapillargefiß kime. Hier und da senden sie sich in weiten Abstanden anastomosierende Zweige zu, so daß das Ganze an dicken Schnitten das Aussehen eines weitmaschigen Vetzes bekommt. Der Liugsschnitt des M. semiteudinosus dagegen erscheint viel dunkler; eine Folge des großen Gefaßreichtumes: zahlreiche größere Gefiße verlaufen in einer zu den Muskelfaseru mehr senkrechten Richtung, die Kapillaren zwischen den Fasern sind vielfach geschlaingelt, die Schlingen gehen entweder von dem einen Rande der Faser zum anderen und wieder zurück, so daß das Ganze mitunter korkzieherartig aussieht, ohne daß die Windungen in Wirklichkeit die ganze Muskelfaser umfaßten; oder sie gehen bis zur Mitte der Faser, anastomosieren miteinander und werden rúckliufig, andere bleiben auch erst eine Strecke weit auf der anderen Seite. Eiuige findet man endlich, welche quer über mehrere Muskelfasern rerlaufen und sich mit entfernteren verbinden. Die Richtung der Schlingen ist entweder senkiecht zur $\Lambda$ chse der Muskelfaser oder macht einen spitzen Wiukel mit ihr. Inter sich sind sie teils parallel, teils unregelmißig gegeneinander gerichtet. Zwischen den gewundenen trifft man atch hin und wieder gestreckt rerlaufende Kapillaren. Das aber, wodurch sich der M. semiteudinosus nicht allein vom I. adductor magnus, sondern auch von allen anderen bisher bekannten roten IIuskeln in Bezug auf seine Gefiße auszeichnet, sind kleine Ausbuchtungen der Kapillaren, Kapillar-Anewrysmen, von ovaler form, mit zugespitzten Enden wie eine Zitrone. Ihre Größe beträgt 0,017—0,025 mm, ihre Anzahl in einem Kreise, dessen Radius dem Querdurchmesser von :3 Muskelfasern gleichkommt, etwa $4-5(65)$.

Die Muskelnerven und motorischen Endplatten zeigen in heiden Muskeln keinerlei Interschiede. Dagegen treten solche in physiologischer Hinsicht wiederum auf.

Um dies nachzuweisen, kann man die beiden Muskeln mit Induktionsströmen unter Benutzung eines friiher empfohlenen Hyographion $(65)$ direkt oder indirekt rermittelst ihrer Nerven reizen; die Dauer des Reizes betrug bei den Versuchen 1/4 Minute.

Der Unterschied beider Muskeln ist leicht zu erkennen: die Kurven (Fig. 26) des M. semitendinosus stiegen stetig bis auf eine gewisse Höhe, gaben die ersten Unterbrechungen noch an und gingen dann in eine gerade Linie uber. Erst als die Zahl der Unterbrechungen unter 192 fiel, wurde jede einzelne auch rom $\mathbf{M}$. semitendinosus genau angegeben. Der

Fig. 26.

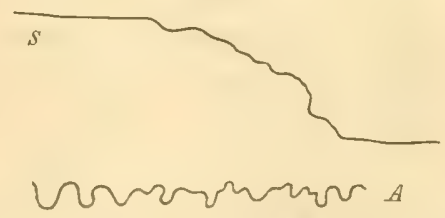

Gurven eines roten und weifen IInskels hei elektrischer Reizung. Nach E. Meyer (65). S M. semitendinosis. A II. adductor magnus. II. adductor magnus dagegen markierte noch bei $35 \%$ Unterbrechungen jede durch eine entsprechende Zuckung. Nach anderweitiger Bestimmung (189) bedarf der rote $\mathbf{H}$. soleus 10 Erregumgen in 
der Sekunde, der weiße M. gastrocnemíus medialis deren $20-30$, um in Tetanus zu verfallen. Dagegen wurde von anderer Seite $(156)$ festgestellt, daß beim nengeborenen Kaninchen die $\mathrm{Hm}$, gastroenemii auf Reizung des $\mathrm{N}$. ischiadicus schon bei 16 Unterbrechungen in der Sekunde in dauernden Tetanus gerathen, wihrend bei dem $21 / 2$ Monate alten Tiere wenigstens 70 Unterbrechungen dazu nötig sind. - Über die sonstigen physiologischen Differenzen und die Technik der Versuche vergl. 64, 65, 185 u. 189; die Zuckungsdauer betrigt beim M. gastrocnemius medialis 0,23 , beim M. soleus 0,2 be (beim Herzmuskel 0,33) Sekunden (801).

Als rote Muskeln zeichnen sich an der unteren Extremitat auBer den schon genannten $\mathbf{M m}$. semitendinosus und soleus aus: die $\mathbf{M m}$. gluteus minimus, vastus lateralis, cruralis, adductor brevis, quadratus femoris; entschieden weiß sind hingegen die $\mathbf{M m}$. rectus femoris, vastus medialis, adductor magnus, biceps femoris und die $\mathbf{M m}$. gastrocnemii s. gemelli surae $(64)$.

Rot sind ferner die Muskeln des Vorderarmes, die hinteren Kopfmuskeln, tiefen Riickenmuskeln, nanentlich die Mm. multifidus, intertransversarii lumbales u. s. w. Ganz konstant scheinen diese Verhältnisse aher nicht bei allen genamnten Muskeln zu sein und keineswegs lißß sich jeder Muskel olnne weiteres in die eine oder andere Kategorie hineinbringen.

Obgleich ihnliche elektrische Differenzen, wie sie oben geschildert wurden, auch bei verschiedenen Muskeln vom Rochen vorkommen sollen (64), so zeigen die übrigen roten Muskeln des Kiminchens oder zunächst der rote M. flexor digitorum pedis longus keine Spur eines solchen Verhaltens, gleichen rielmehr dem weißen M. adduetor magnus. Auch sind die Farbenunterschiede des letzteren und des $\mathbf{I}$. semitendinosus beim IIasen und schon beim wilden Kanincheu sehr verwischt und wenigstens bei dem letzteren (ron der Insel Borkum) fehlen auch die geschilderten mikroskopischen Differenzen rollstindig. Dazu kommt noch, daß auch bei anderen freilebenden Nagern Eichhörn(hen, Ratte, Maus keine, wohl aber bei dem gezahmten Meerschweinchen ganz ahnliche Abweichungen des M. semitendinosus vorhanden sind $(65)$. Man kionnte daraus den Schluß zichen, daß die weißen Musheln durch Nichtgebratuch bei eingesperten Tioren so geworden sind, etwa wie der weiße Brustmuskel des Haushuhnes, Puters u. s. w. Andererseits sprechen aber die mikroskopischen Befunde: die Vermehrung der Sarkolemkerne, der interstitiellen Flïssigkeit und interstitiellen Körnchen. das Auftreten ron Kernen im Innern der kontraktilen Substanz, die Kapiliar-Aneurysmen sehr für eine pathologische Entstehung dieser speziellen Verinderungen, wobei die physiologischen I)ifferenzen aus den anatomischen resultieren mögen. Wie dem sei, so lißł sich aus den ersteren Befunden ummiltelhar eine chronische Myositis nebst venöser Stauung diagnostizieren.

Lis sind hiernach einerseits die Blasse der weißen Muskeln aus Nichtgebratuch der letzteren, andererseits die besonderen Eigentimblichkeiten des II. semitendinosus für krankhaft zu erklaren, wihrend die rote Farbe der iibrigen, auch bei den domestizierten Tieren viel gebrauchten Muskeln selbstrerstindlich normal ist. Elektrophysiologische Versuche an den Unterschenkelmuskeln sind schon vor langer Zeit ausgeführt worden $(828)$. 
Chemische Zusammensetzung der Muskeln. Die Oberschenkelmuskeln bestehen aus $(66)$ :

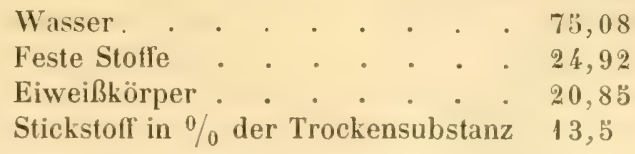

Die Erzeugungskosten eines $\mathrm{kg}$ Kaninchenfleisch (Schlachtgewicht) wurden im Jahre 1873 bei deutschen und französischen Kaninchen zu 50-60 pf berechnet (66, S. 63). Vergl. S. 7.

Der Gehalt blutfreier IIuskeln an Serum-Albumin betrïgt 1,77-1,81 derjenige des Blutes 2, $98-3,4^{0} \%$. - s. 806 ).

Die aus quergestreiften Fasern bestehenden IIuskeln sind mit Ausnahme des Herzmuskels sämmtlich solide, nicht hohl. Die Beschreibung benutzt folgende Terminologie:

A. Längliche Muskeln.

1. Spindelformige Muslieln, mit einem dünneren Kopfe, der als Ursprung bezeichnet wird, einem dickeren, rundlichen, etwas plattgedruckten Bauche und einer dümneren, meist in eine schlanke Sehne auslaufenden Cauda.

2. Zusammengesetzte Mustieln, die ebenfalls ron länglich rundlicher platter Form sind. Dieselben haben :

a. zwei oder mehrere Băuche - Mm. digastrici, polygastrici ;

b. zwei, drei und mehrere Köpfe, die von verschiedenen Stellen entspringen und zu einem Bauche sich vereinigen - Mm. Jjicipites, tricipites etc.;

c. ihre Gauda spaltet sich in mehrere, an verschiedenen Stellen befestigte Sehnen oder Zipfel - Mm. multicaudati;

d. die Muskelfasern laufen von ihrem Ursprunge an schrig auf die Sehne $z u$, welche in betrichtlicher Lange in der Mitte oder am Rande des Muskelbauches frei liegt - gefiederte oder halbgefiederte Muskeln, MIm. pennati oder semipennati.

B. Breite MuskeIn. Dieselben sind zugleich platt und dunn. Ihre Köpfe sind entweder platte, hantahnliche Sehnenstreifen, oder fleischige, kurze Zacken. Fleischig nennt man Muskeln, die kein Sehnengewebe enthalten und eine im Verhälnis zur Linge und Breite nicht unbetrichtliche Dicke besitzen.

G. Kurze Muskeln, von einer ihrer Länge wenig nachstehenden Breite und Dicke. und dünn.

D. Ringfürmig̣e Muskeln - Mm. orbiculares — sind zugleich platt

Die Zahl der Muskeln - abgesehen ron den in der Splanchnologie zu erörternden - betrigut 167 Muskelpaare für die rechte und linke Seite, wozu noch der unpaare M. mylohyoideus und das Diaphragma kommen. Eine ihnliche Rechnung ergiebt für den Menschen ca. 300 Muskelpare. Wahrend also die Zahl der Knochen beim Menschen und Kaninchen sich wie 205:213 ver-hailt, zeigt sich das Verhiiltuis bei den Muskeln umgekehrt, deren Zahl beim 
Kaninchen bedeutend rermindert ist. Von den Muskelparen inkl. der unparen Muskeln kommen auf den

\begin{tabular}{|c|c|c|}
\hline Kopf & & \\
\hline Hals & & \\
\hline Rücken & & \\
\hline Schwan & & \\
\hline Bloust . & & \\
\hline Bauch & & \\
\hline Obere $\mathrm{E}$ & & \\
\hline Untere & & tảt \\
\hline
\end{tabular}

Die Verminderung der Anzahl betrift hauptsächlich die Muskeln des Gesichtes, der Hand und des Fußes.

In Muskelsystem sind stark entwickelt die Kanmuskeln, die Muskeln der Schulter und des Oberirnes, der Ilifte, des Ober- und Lnterschenkels. Die Muskeln des Gesichtes, der Hand und des Fußes dagregen sind wenig entwickelt. An den Extremititen failt sogleich die starke Entwickelung der Flexoren ins Auge, und deren Clhergewicht über die Extensoren, so daß die Extremiliten nie aus der Beugung in völlige Streckung übergehen. Es ist dabei zu erinnern, daß das Kaninchen kein fluchtiges Tier ist wie der IIase, und daß seine Extremititen durch ihren Ban besonders zum Wühlen und Graben geeignet erscheinen, was freilich hei den eingespert im Stall gehaltenen Tieren nicht so hervortritl, weshall) es hier erwihnt werden mag.

Die Kopf- und Gesichlsmuskeln, soweit sie ron Knochen entspringen und nicht den Hautmuskeln angehören, sind sehr einfach; ein M. epicranius findet sich nicht. Die Ohrmuskeln sind entsprechend der Grobe des außeren Ohres betrichtlich entwickelt; sie werden in der Splanchnologie erörtert, sowie auch der große, sich über den ganzen Körper erstrerkende II. cutancus maximus, der an verschiedenen Stellen eineu sehr verschiedenen Grad der Entwickelung zeigrt. Die Brustmuskeln besitzen einen besonderen M. pectoralis superficialis, welcher eine kriffige, besondere Portion des M. pectoralis major darstellt, und die oberflichlichste Schicht bildet. Der M. pectoralis minor hat das Eigentumliche, daß er sich mit einem Teile seiner Fasern an die Clavicula, mit einem auderen größeren Teile an die Spina scapulae und die Fascia supraspinata inseriert. Die Rückenmusheln sind kriftign entwickelt, jedoch weniger manuigfaltig und kompliziert, als bei anderen siugetieren, resp. dem Menschen. Der II. abductor caudae, ein von der Spina ischii entspringender und facherförmig sich ausbreitender Muskel, vertritt zugleich das Ligamentum sacrospinosum. Am Schwanze haben dic Extensoren bedeutend über die Flexoren das Chergewicht, weshall, derselbe sich in steter IIyperextension befindet, wozu iibrigens auch noch die straffen Ligamenta dorsalia wesentlich beitragen. Zahlreiche Besonderheiten der oberen Extremitit, deren Muskelsystem sehr viel vom Menschen Abweichendes darbietet, sind im Folgenden bei den einzelnen Muskeln, welche fehlen oder neu auftreten, erwihnt worden.

An der unteren Extremitit ist der Ursprung des $\mathbf{M}$. sartorius auf die Mitte des Lig. inguinale s. Poupartii gerückt. Der M. semitendinosus ist vom M. adductor magnus vollkommen umwachsen, so daß sein Bauch in das Fleisch des letzteren eingebettet liegt. Der M. biceps femoris hat einen dritten Kopf, der in 
die Unterschenkelfaszie übergeht (vergl. S. :6). Der M. semimembranosus entsendet eine lange, mit dem Teudo Achillis verschmelzende Strecksehne, welche bei fixiertem Kniegelenk die Streckung des Fußes im Sprunge unterstutzt. Der M. plantaris ist so stark wie einer der beiden $\mathbf{H m}$. gastrocnemii, und inseriert sich mit vier Sehnenbundeln an die Zehen. Die Mm. tibialis posticus und flexor hallucis longus fehlen; andererseits sind vier $\mathbf{M m}$. peronaei vorhanden. Eudlich fehlen die $\mathbf{M m}$. extensor und flexor breves digitorum pedis; letzterer wird durch die Sehne des M. plantaris ersetzt.

Was die Muskeln in speziellen anlangt, so ist das Selbstindigwerdon einzelner Köpfe zunichst hervorzuheben. Die Mm. sternomastoideus und cleidomastoideus sind getrennt, ferner der M. pectoralis superficialis rom II. pectoralis major, sowie die $\mathbf{M m}$. abductores brachii rom M. deltoideus; anch sind zwei Mm. stylohyoidei rorhanden. Der M. abductor brachii inferior stellt interessanterweise ein vollkommenes Analogon des M. gluteus maximus dar.

Andere Muskeln treten wanz neu auf. Hierher gehoren die Hautmuskeln s. Splanchuologie), der II. rectus capitis superficialis, die Schwanzmuskeln: Mm. extensores caudae lateralis und posticus, abductor caudae anticus und Ilexor caudae; an der oberen Extremitit die $\mathbf{I m}$. levator scapulae major und basiohumeralis, die Mm. abductores brachii superior und inferior, extensor antibrachii parvus, und extensor digiti (quarti proprius. Die Mur. levator scapulae major und hasiohumeralis entsprechen nach ihrer Funktion und zufolge ihrer Nerven, nicht aher nach ihrem Ursprunge, selhstiandigg gewordenen Bündeln des $\mathbf{M}$. cucullaris; die Mm. abductores brachii erinnern in derselben Weise an abgelöste Portionen des M. deltoideus. Am Oberschenkel verliuft ein M. tensor fasciae cruris; an Lnterschenkel sind vier Mm. peronaei vorhanden.

Wieder andere Huskeln fehlen oder werden durch benachbarte mitvertreten. Von Gesichtsmuskeln sind vur die Mn. zygomaticus major, levatores labii superioris und nasi und der II. buceinator als stirker entwickelte selbststandige Muskeln vorhanden. Ferner fehlt der hintere Bauch des M. Iligastricus s. hiventer) mandibulae und der M. omohyoideus; der M. subclavius scheint durch einen Teil des M. pectoralis minor reprisentiert zu werden. Der M. semispinalis dorsi et colli ist mit dem .I. multifidus verbunden. An der oberen Exlremitat fehlen das Caput breve m. quadrigemini brachii s. bieipitis, die Mm. pronator quadratus, flexor pollicis longus, dessen Sehne von dem M. flexor digitorum profundus abgegreben wird; die Mm. extensores carpi radiales longus und brevis sind so innig verbunden, daß sie wie pin einziger Muskel aussehen. Ferner fehlen die Mm. hrachioradialis, supinator, extensor indicis proprius, dessen Sehne von einer accessorischen Sehne des II. extensor pollicis ersetzt wirl, und die kleinen IIandmuskeln mit Ausnahme der Mn. lumbricales, interossei und eines II. flexor digriti minimi. Der Daumen besitzt nur die Mm. al)ductor pollicis longus) und extensor pollicis (longus, wihrend die $\mathbf{M m}$. extensor digiti minimi und flexor (brevis) digiti minimi vorhanden sind. Am Luterschenkel fehlen die Im. tibialis posticus und flexor hallucis longus (scheinbar): an Fuß sind nur die Mm. lumbricales und interossei vorhanden.

Sehnen. Die Schwanzsehnen des Kaninchens sind zum Studium des Bindegewebes empfohlen worden $(/ j /)$. Man findet darin reihenweise ange- 
ordnete, viereckige, winklig gebogene kernhaltige Plattchen (Fig. 27), welche gewöhnlich Ranvier'sche Zellen (152) genannt werden. Man könnte sie auch Henle'sche Zellen nennen, da bekanntlich $(\tilde{5} 8$, S. 35 u. 15j) Henle $(154)$ dieselben schon im Jahre 1831 beschrieben hatte; die ersten Abbildungen rühren von Billroth $(153)$ her. Daß die fraglichen Befunde unmöglich über den Bau des Bindegewebes im allgemeinen Aufschluß geben können, ist schon öfters betont worden (vergl. 58 ).

Fig, 27.

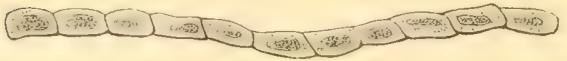

Flitehenausicht einer Ruihe von platten Bindegewehszellen aus piner geslanuten bohwanzselne des haninchens. Kar min. Essigsüure. Yergr. ca. 400 . Nath Adickes $(17 f j)$
Man reißt (152) einzelne Wirbel des Kaninchenschwanzes (oder Rattenschwanzes) ab, befestigt eine der daran hängenden kleinen Sehnen ausgespannt mit Siegellack auf dem Objektglas, behandelt dann entweder mit Karmin und nachher mit Essigsiure (152) oder mit essigsaurer Karminlösung (151, vergl. 147, S. 11).

Zu Experimenten iiber Sehnenentzündung wird die Achillessehne empfohlen $(675)$.

Uber Sehnenendplatten in den Mm. gastroenemii, Augen- und Rückenmuskeln s. 785 und 786 .

Die Faszien bieten sehr wenig Bemerkenswertes. Einige stellen feste, mit elastischen Fasern durchwebte Bindegewebsstrata dar, namentlich die Fasciae cervicalis superficialis, infraspinata, antibrachii, lata, cruris etc. Audere bestehen aus ganz lockerem Bindegewebe, dessen spezielle Beschreibung eine Wiederholung der betreffenden, in der Osteologie, Myologie und Splanchnologie mitgeteilten Thatsachen darstellen würde. Da auch die erstgenannteu Faszien nach Beriicksichtigung der verschiedenen Disposition der unschlossenen Muskeln sich genau wie beim Menschen verhalten, so konnte von einer speziellen Erörterung Abstand genommen werden. Wenn bei deu Operationsmethoden eine Faszie epwihnt wird, so ist stets eine der ersteren Art gemeint, da das Bindegewebe beim Kaninchen so locker und verschiebbar ist, daß eine besondere Nomenklatur für dasselbe keinen Sinn haben würde. Einige in die Faszien eingewebte, für den Verlauf der Sehnen wichtige Ligamente sind feils in der Syndesmologie, teils bei den zugehörigen Muskeln beschrieben worden, z. B. die Lig̣g. carpi dorsale und volaria, das Lig. cruris (beim M. tibialis anticus) etc.

Abbildungen der meisten Muskeln s. in 67.

Parasite $\mathrm{n}$. In den Brustmuskeln wurde einmal ein Coenurus cerebralis beobachtet $(68)$. 


\title{
Allgemeine Splanchnologie.
}

\author{
Sinnesapparate.
}

Ha ut. Dieselbe besitzt stark entwickelte, Ilach ausgebreitete Muskeln. Wunden der Haut heilen leicht durch Verklebung, namentlich wenn Knopfnahte angelegt worden sind. Mechanische Insultationen des Unterhautbindegewebes, sowie des interstitiellen Bindegewebes überhaupt ziehen Bildung von Eiter nach sich, der von Anfang an eine weiche, gelblichweiße, krümlige Masse darstellt und sebr arm an Eiterserum ist. Eiteranhiufungen können daher mit tuberkulösen Ablagerungen verwechselt werden (vergl. 69).

Die Temperatur des Blutes ist wegen des dichten Pelzes der IIaut leicht zu messen: am sichersten in der Inguinalfalte des wie gewöhnlich kauernden Tieres (S. 33).

Ohr. Das äußere Ohr besitzt 20 besondere Muskeln, seine Knorpel haben eine komplizierte Anordnung, namentlich findet sich medianwiits eine dem Schälel aufliegende Knorpelplatte, das Scutulum. Die Tervenverteilung am außeren Ohr ist kompliziert: sensible Nerven sind: R. auricularis des X. ragus, R. auricularis des $\mathrm{N}$. anriculotemporalis aus dem N. maxillaris inferior, N. oceipitalis minor, und der N. auricularis magnus aus dem Plexus cervicalis. Die motorischen Nerven stammen vom N. facialis: Rr. auriculares profundi anterior und posterior, und Rr. auriculares superficiales.

Im mittleren Ohr stellt die Paukenhöhle eine rundliche knöcherne Blase dar: 'die Bulla tympani, welche ganz den Eindruck eines Resonanzapparates macht. Oberhall) derselben liegt eine accessorische Vebenhöhle, die den Cellulae mastoideae des Menschen entsprechen dirfte. Die Mm. mallei und stapedius sind stark entwickelt; ersterer geht durch cine hesondere, von der Tuba Eustachii getrennte Spalte, ron der Ala magna oss. sphenoidei entspringend, zum Processus muscularis mallei. Beide Muskeln des inneren Ohres liegen in besonderen Gruben der Paukenhöhle. Jas Manubrium mallei ist sabbelförmig, die Membrana tympani ist oval, senkrecht und efwas mach rorn gerichtet. Der $\mathbf{N}$. facialis verläuft durch einen Halbkanal.

Im inneren $O / r$ ist die Fenestra vestibuli rundlich. die Fenestra cochleac länglich geformt. Die Canales semicirculares des Labyrinths sind freiliegend, sie begrenzen die Fossa mastoidea oss. temporum, in welcher der Flocculus 
cerebelli sich befindet. Die Cochlea hat $2^{1}{ }_{2}$ Windungen. Der Aquaeductus cochleae ist verhiltnismaßig kurz und weit; der Aquaeductus vestibuli lang und eng.

Die Stellung der Canales semicirculares nach drei Coordinaten des Raumes hiangt offenbar mit der Perzeption der Richtung von durch die Kopfknochen geleiteten Schallschwingungen, und daher mittelbar mit der Form des knöchernen Schadels zusammen. Würde die Richtung des Schalles nur durch llilfe des iußeren Ohres wahrgenommen, so müßte sich eine bedentende Unsicherheit in der Bestimmung der Richtung von Schallwellen herausstellen, die genau in der Medianlinie von oben. hinten oder vorn herkommen, was erfahrungsmäßig nicht der Fall ist $(70)$.

A uge. Die Augen sind nach den Seiten gerichtet, wie bei manchen Vögeln; die mediale Wandung der Orbita wird dadurch zur vorderen; die laterale zur hinteren, was bei der Beschreibung der einzelnen Teile in der Augenhöhle zu herüksichtigen ist. Der Bulbus ist verhallnismäßg groß, wie am Vogelkopfe. Sein Gewicht betrigt mehr als ein Drittel des menschlichen Bulbus, wihrend die Gewichte des ganzen Körpers sich wie 1:30 rerhalten. Die Cornea ist eheufalls relatis sehr grok, ihr burchmesser verhailt sich zu demjenigen des Bulbus etwa wie $\ddot{3}: 6$, wihrend das Verhaltnis beim Menschen kaum wie 1:2 ist. Ihre absoluten Dimensionen sind noch etwas größer, áls die der Cornea des Menschen: $13-15 \mathrm{~mm}$ zu $10-12$ mm. Die Retina führt doppeltkonturierte Nervenfasern; die Innenglieder der Stibchen enthalten einen zentralen Faden ( $7 /$; s. Auge). Die Thrinenwege zeigen nur einen einzigen Canaliculus lacrymalis inferior), dessen Müudung leicht zu sehen und mit einem Knorpelwall umgehen ist. Der Duetus nasolacrymalis ist rerhailtnismaßBig lang; die Ableitumg der Thrimen verdiente experimentell genauer untersucht zu werden, um den Mechanismus derselben besser festzustellen, als es bisher geschehen ist.

Am Geruchsorgan sind zwei Ductus nasopalatini zu bemerken, welche das Foramen incisivum ausfïllen, und die Vasenhöhle mit der Mundhohle in Verbindung setzen. Sie mïnden am Gatumen hinter den kleinen oberen Schneidezihnen. Das Jacobson sche Organ stellt eine enge, von Riechschleimhaut ausgekleidete Knorpelröhre dar.

Respirationsapparat.

Am Kehlkopf ist eine sehr bedentende Diflerenz in der Limge von oben nach unten zwischen dem vorderen Areus und der hinteren Lamina der Cartilağg cricoidea vorhanden; letztre ist bedeutend langer, liegt aber höher und bildet hauptsichlich die hintere Wand des Larynx. Die Epiglottis zeigt an ihrem unteren Rande zwei nach hinten neben der Medianlinie hervorragende spitze Knorpelfortsatze, die Hammli epiglottici. Das Stimmorgan im Ganzen ist wenig entwickelt; die einzigen Tione, welche die Kaninchen von sich gehen, sind in Angst oder heftigem Schmerz ein Geschrei, ihnlich dem eines kleinen Kindes, welches dureh Verengerung der Stimmritze mittels der Kehlkopfmuskeln; ausgenommen den M. (rico-arytaenoideus posticus hervorge- 
bracht wird. Ferner ein eigentümliches Grunzen in der Brunstzeit, dessen Mechanismus unaufgeklät ist s. Yeurologie, Thalamus opticusł.

Die Lungen sind relativ klein, kleiner als bei allen übrigen Saugern, rosenrot; der untere Lappen der rechten zerfillt in zwei kleinere, so daß vier rechte, zwei linke Lungenlappen vorhanden sind. Die Gl. thy reoidea hat einen sehr dünnen Isthmus.

\section{Digestionsapparat.}

Zunge. Auf dem Zungenrücken ist eine nach hinten grelegene, knorpelihnliche Platte bemerkenswert. Die Zungenmuskulatur besteht aus longitudinalen, transversalen und perpendikularen Fasern, die sich mannigfach durchkreuzen. Im allgemeinen werden die longitudinalen Fasern des Zungenrickens von den Mm. hỵoglossi, die der unteren Seite der Rinder von den Mm. styloglossi geliefert. Der M. lingualis nimmt wenig Anteil. Die fransrersalen Fasern des 11. lingualis sind stark entwickelt, sie entspringen am Septum, verlaufen bogenförmig, inserieren sich in der Schleimhaut des Zungenrückens, oder in den Papillen selbsi. Die perpendikularen Fasern stammen von den Mn. genioglossi, zum kleineren Teile gehören sie dem M. lingualis an. Die Mm. stylo- und hyoglossi sind stark entwickelt.

Die speicheldrüsen sind stark entwickelt, es sind jederseits deren sechs vorhanden: Gl. infraorbitalis, buccales superiores und inferior, parolis, submaxillaris, sublingualis. Iie Gl. infraorbitalis ist als eine stark enfwickelte, in das Cavum orbitale hineiuragende Gl. buccalis superior zu betrachten.

Bekanntlich $(141 ; 142 ; 57$, S. 192) unterscheidet man zwei Arten von acinösen Drüsen : Eiweißdrüsen und Schleimdrüsen.

Eiweißdrüsen, seröse Drüsen $(142,144)$, als deren Typus die Gl. parotis überhaupt und besonders die Gl. submaxillaris des Kaninchens (18i) gelten. Sie sezernieren eine Albuminate, Salze und hïufig Fermente enthaltende Flüssigkeit. Die Acini sind trübe vermöge zahlreicher Eiweißköruchen im Innern ihrer Zellen, dem freien Auge sehen sie weißlich aus. Frisch untersucht sind die Grenzen der Zellen schwer zu erkennen, durch Essigsäure werden letztere aufgehellt, durch Chlorwasserstotlsiure getrübt, durch $20^{0}$ "ige Salpetersäure gelblich; in ammoniakalischer Karminlösung färbt sich das Zelleuprotoplasma und der Kern, durch Hämatoxylin nur der letztere. Die Acini besitzen keine Halbmonde. - Zu diesen Drüsen gehören beim Kaninchen die Gl. lacrymalis, infraorbitalis, parotis, sub)maxillaris, die Drïsen der Nasenschleimhaut in der Regio olfactoria und im Jacobson'schen Organ, die Gl. linguales in der Gegend der Papillae vallatae sowie der Fimbriae linguae (erstere überschreiten sie nach hinten nur um $0,5 \mathrm{~mm}$, letztere um 3-4 mm, 145 , endlich die Drüsen des Kehlkopfes und Schlundes zum Teil (184).

Schleimdriisen, welche Schleim sezernieren. Als Typus ist die Gl. sublingualis des Kaninchens zu bezeichnen. Frisch untersucht erscheinen die Zellen der Acini hell, mit deutlichen Zellengrenzen. Sie haben einen Basalfortsatz, welcher den Zellen der Eiweißdrüsen fehlt. - Durch Essigsïure wird das Zellenprotoplasma trübe, es färbt sich nicht mit Karmin, wohl aber der Kern; durch Ḧ̈matoxylin werden sowohl das Protoplasma als der Kern tingiert. An der Peripherie des Acinus sitzt innerhalb der Membrana propria ein Halbmond (Lunula, Rand- 
zellenkomplex), welcher intensivere Karminfirbung annimmt. Nach diesem Typus sind außer der Gl. sublingualis die meisten hleinen acinösen Drüsen (Schleimdriisen) gebaut, namentlich die Drïsen der Nasenschleimhaut mit Ausnahme derjenigen der Regio olfactoria, die Gl. linguales hinter den Papillae vallatae, die Gl. palatinae, oesophageae etc.

In der Bauchhöhle ist die kolossale Vergrößerung des spiralförmig gewundenen Coecum am meisten ins Auge fallend. Dasselbe trigh einen kleinen ovalen Sack und den sehr langen Processus vermiformis, deren Winde dichtgedringte Lymphfollikel enthalten. Nur der Anfang des Colon adscendens ist weit und besitzt muskulöse Liugshänder; der iibrige Teil des ganzen Colon ist dünwandig und eng wie der Dündarm. Die Leber zerfaillt in mehrere Lappen; außer den gewöhnlichen Gallengingen finden sich besondere Ductus hepatocystici. Die Milz ist klein (S. 26) und linglich; das Pankreas flichenhaft ausgedehnt mit fast isolierten Läppchen.

Darmkanal. Das Verhailtnis der Länge des Darmkanales zur Körperlange! ron der Nase bis zum Inus seheint individuell zu schwanken, wie wenigstens aus den wenigen Zahlenaugaben ( / / folgen würde. Cuvier (72) hatte angegeben in $\mathrm{m}$ :

\begin{tabular}{l|c|c|c|c}
\hline & $\begin{array}{c}\text { Wildes } \\
\text { Kaninchen }\end{array}$ & $\begin{array}{c}\text { Zahmes Kanin- } \\
\text { ehen (Duval) }\end{array}$ & $\begin{array}{c}\text { Zahmes Kanin- } \\
\text { chen (Cuvier) }\end{array}$ & Hase \\
\hline Körperlänge & 0,414 & 0,400 & & 0,513 \\
Dïnndarm & 3,192 & 3,150 & 2,697 & 3,794 \\
Coecum & 0,324 & 0,410 & 0,405 & 0,676 \\
Colon und Rectum & 1,082 & 1,080 & 0,974 & 1,623 \\
Darmkanal im Ganzen & 4,598 & 4,65 & 9,033 \\
Körperlänge: Darmkanal $=1:$ & 11,4 & 11,6 & 9,3 & 11,7
\end{tabular}

Die Angaben für das zahme Kaninchen rühren von Duval (1830) her. Cuvier sellost (erste Auflage ron 7.) hatte das Verhaltnis zur Kirperlange beim zahmen Kaninchen wie I : 9,3 gefunden, womit Berthold (53) übereinstimmt:

\begin{tabular}{l|c|c|c}
\hline $\begin{array}{c}\text { Verhältnis zur } \\
\text { Körperlänge }\end{array}$ & $\begin{array}{c}\text { Wildes } \\
\text { Kaninchen }\end{array}$ & $\begin{array}{c}\text { Zahmes } \\
\text { Kaninchen }\end{array}$ & Hase \\
\hline Dünndarm & 7,5 & 6 & 7,5 \\
Coecum & 1,1 & 1 & 1,3 \\
Colon und Rectum & 2,7 & 2,3 & 2,5 \\
Darmkanalim Ganzen & 11,3 & 9,3 & 11,1
\end{tabular}

Aus jener früheren Angabe hat Darwin irrtiunlich yeschlossen, daß diese geringere Limge Folge besserer Nahrung sei, welche dem domestizierten Tiere zu Teil werde. Dagegen fand Crampe $/ 7$ bei vier wilden Kaninchen in $m$ :

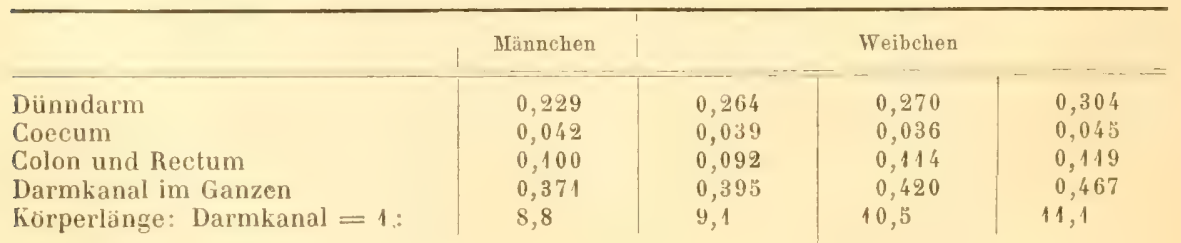


Beim französischen Kaninchen betrigt die Lỉnge des ganzen Darmkanales ungefähr $6 \mathrm{~m}$, wovon $3,1 \mathrm{~m}$ auf den Dünndarm kommen (74).

Vergleicht man bei zwei Kaninchen das Körpergewicht mit der Oberfliche der Schleimhaut des Darmtraktus (rom Magen an), so ergiebt sich ( 75 ):

\begin{tabular}{|c|c|c|c|c|c|c|c|c|}
\hline & $\begin{array}{l}\text { Körper- } \\
\text { gewicht } \\
\text { in g }\end{array}$ & $\begin{array}{c}\text { Darmober- } \\
\text { fläche in } \\
\text { qcm }\end{array}$ & $\begin{array}{l}1 \mathrm{~g} \text { Körper- } \\
\text { gewicht = } \\
\text { qcm Darm- } \\
\text { fläche }\end{array}$ & $\begin{array}{c}1 \mathrm{~g} \text { Körper- } \\
\text { gewicht = } \\
\text { qem Magen- } \\
\text { flüche }\end{array}$ & $\begin{array}{c}1 \text { qcem Darm- } \\
\text { fläche }=g \\
\text { Körperge- } \\
\text { wicht }\end{array}$ & $\begin{array}{c}\text { Magenfläche } \\
\text { (Darm- } \\
\text { traktus }= \\
100)\end{array}$ & $\begin{array}{c}\text { Dünn- } \\
\text { darm- } \\
\text { fläche in } \\
\% /\end{array}$ & $\begin{array}{l}\text { Dickdarm- } \\
\text { fläche } \\
\text { in } 0 \%\end{array}$ \\
\hline $\begin{array}{l}\text { Männchen } \\
\text { Weibchen } \\
\text { Im Mittel }\end{array}$ & $\begin{array}{l}1144 \\
1120\end{array}$ & $\begin{array}{l}2432 \\
2220\end{array}$ & $\begin{array}{l}2,12 \\
1,98 \\
2,05\end{array}$ & 0,104 & $\begin{array}{l}0,47 \\
0,50 \\
0,48\end{array}$ & $\begin{array}{l}5,1 \\
5,2 \\
5,1\end{array}$ & $\begin{array}{l}48,4 \\
47,2 \\
47,8\end{array}$ & $\begin{array}{l}46,6 \\
47,2 \\
46,9\end{array}$ \\
\hline
\end{tabular}

Kot der Kaninchen. Die Menge soll jährlich mehr als $50 \mathrm{~kg}$ betragen ( $\left.76^{j}\right)$, die 127 Pf. Dungwert haben. Seine Zusammensetzung ergiebt, sich (77) wie folgt:

$\begin{array}{lrr} & \text { Frisch } & \text { Trocken } \\ \text { Wasser } & \text { 52,910 } & 6,710 \\ \text { Organische Substanz } & \mathbf{4 1 , 9 2 0} & 83,040 \\ \text { Eisenoxyd } & 0,227 & 0,451 \\ \text { Kalkerde } & 0,485 & 0,962 \\ \text { Magnesia } & 0,242 & 0,481 \\ \text { Kali } & 0,870 & 1,726 \\ \text { Natron } & 0,067 & 0,132 \\ \text { Phosphorsäure } & 0,522 & 1,036 \\ \text { Schwefelsäure } & 0,204 & 0,404 \\ \text { Kieselsäure } & 0,422 & 0,837 \\ \text { Chlor } & 0,124 & 0,246 \\ \text { Sand } & 2,050 & 4,060 \\ & 100,017 & 100,030 \\ \text { Stickstoff } & 0,894 \% & 1,7 \% 0 \%\end{array}$

Die Asche enthält in $\%$ :

$\begin{array}{lr}\text { Eisenoxyd } & 7,275 \\ \text { Calciumoxyd } & 15,545 \\ \text { Magnesia } & 7,756 \\ \text { Kali } & 27,885 \\ \text { Natron } & 2,147 \\ \text { Phosphorsäure } & 16,731 \\ \text { Schwefelsäure } & 6,538 \\ \text { Kieselsäure } & 13,525 \\ \text { Chlor } & 3,974 \\ & 100,480\end{array}$

Bei der Summierung ist eine Korrektion für Chlorgehalt berücksichtigt; die Abweichungen von 100\% stellen die Analysenfehler dar.

Cher den Stoffwechsel beim hungernden Tier, dessen Kotausscheidung berücksichtigt wurde, s. $\$ 46$. Der Stickstoffgehalt des Gesammttieres ohne Haut sinkt bis zum Tode, der $z$. B. am 19. Tag erfolgt, beispielsweise von 3,9 aut $2,1 \%$. 


\section{Harnap parat.}

Die Viere hesitzt nur eine einzige Malpighi'sche P!ramide und Papille; die Vobemioren sind klein, rundlich und feftreich. Die Lageverhailtnisse der rechts- und linksseitigen Organe sind beträchtlich verschieden.

\section{Geschlechtsapparat.}

Mämlicher Geschlechtsapparat. Die Hoden erscheinen groß, z. B. 3 cm lang, 12 mm dick, wihrend die Niere ebenso lang, aber $2 \mathrm{~cm}$ hreit und $1,5 \mathrm{~cm}$ dick ist. Der Annulus inguinalis ist offen, das Scrotum in zwei Scrotaltaschen geteilt. Die Vesicula prostatica ist ganz nach $\mathrm{Art}$ eines Iterus entwickelt. Sie bildet eine große dinnwandige Blase mit einem engeren, der Cervicalportion des weiblichen Iterus homologen Halse: ihre Iloble enthät Samenfaden. Die Prostata ist klein; die Vesiculae seminales dayegen sind ziemlich groß. Der M. bulbocavernosus ist deutlich entwickelt.

Weiblicher Geschlechtsapparat. Der Lterus ist zweihörnig und besitzt zwei Orificia externa. Welche in die Scheide einminden. Der obere Teil der beträchtlich weiten und langen Vagina ist rom Peritomeum äberzogen und muskuloss; derselhe entspricht der Tesicula prostatica des Manuchens. Die Mesometrien enthalten zahlreiche gratte Muskellasem; die Clitoris ist fast so lang als der Penis, dünn und zugespitzt.

Bei neugeborenen Kaninchen ist das Geschlecht ohne anatomische Intersuchung nicht mif sicherheit festzustellen. Wihrend des ersten und zweiten Lebensmonates ermittel man mit Hilfe der Lupe, ob am Geschlechtsğlied ein rundliches Orificium exterwum urethrae wahrzunehmen ist. in welchem Falle ein Penis vorliegt, der aber nicht großer ist, als die Clitoris. Der Introitus vaginae ist eine mediane längliche Spalte.

\section{Drúsen am Beckenausgange.}

In der Beckengegend sind, abgesehen von den Vesiculae seminales des Minnchens, bei beiden Geschlechtern jederseits drei besondere Driisen vorhanden: die CiI. Comperi, inguinalis und analis. Die Gl. Couperi liegt unter der Pars membranarea urethrae beim Mannchen, an der Seitemwand der Vagina beim Weibchen. Die Gl. maeputialis besteht aus Schweiß- und Talgdrusen und sizt in der Ilaut; die Gl. analis befindet sich an der lateralen AuBenwand des Rectum in der llihe des siebenten Shwanzwirbels, bedeutend weiter abwärts, als die Gl. Cowperi. - Das Rectum besitzt einen unpaaren M. rectococeygeus. 


\section{Allgemeine Angiologie.}

Im Vergleich zum Menschen zeichnet sich das Gefaßșstem des Kaninchens durch die Konstanz seiner Verhiltnisse aus. Dies ist am auffilligsten hei den Venen und manchen isolierten, an ganz bestimmten Stellen zu findenden Lymphdrüsen.

Arterien. Die auffallendsten Differenzen im Vergleich zum Menschen sind folgende. Die $A$. carotis sinistra entspringt aus der A. anonyma, die $A$. thyreoidea superior aus der A. carotis communis, welche letztere sehr lang ist. Die A. maxillaris interna geht durch ein Foramen sphenoidale an der Wurzel des Processus pterygoideus oss. sphenoidei. Die Aa. lacrynalis, resp. supranbitalis und frontalis entstehen aus einer A. ophthalmica inferior, einem besonderen Aste der A. maxillaris interna. Die A. communicans anterior fehlt. Die A. brachialis teilt sich erst etwas unterhalb des Ellenbogengelenkes.

Die Aa. phrenicae superiores sind relativ viel starker ausgebildet als die inferiores.

Die A. ileocolica ist sehr entwickelt, stirker als die Fortsetzung der A. mesenterica superior, aus welcher sie entspringt; ebenso ist die $A$. appendicularis stark entwickelt. Aus der A. renalis entspringt die A. intercostalis XII. welche dann die A. suprarenalis und eine $A$. lateralis abdominis entsendet.

Die A. iliolumbalis entsteht aus der A. iliaca communis, die A. vesicalis superior aus der Spaltungsstelle der letzteren. Die $A$. ischiadica giebt die $A$. sacralis lateralis ab, welche letztere die Seitenfliche des Schwanzes versorgl, und die A. pudenda interna, oder sie entspringt gemeinschaftlich mit letzterer.

Die A. cruralis entsendet die $A$. profunda femoris gamz oben am Oberschenkel, sowie eine $\Lambda$. circumflexa abdominis. Am Oberschenkel gielst die A. cruralis ferner eine A. saphena magua ab, welche nahe am FuBgelenk in die Verlaufsbahn der fehlenden A. tibialis posterior eintritt und letztere ersetzt. In der Fußsohle ist ein Arcus plantaris profundus vorhanden; außerdem werden jedoch die Äste für die Zehen von der Fortsetzung der A. saphena magna direkt abgegeben.

Anastomosen benachbarter Arterien unter einander finden zwar haufig genug statt, wie sich aus den Injektionsresultaten leicht ergiebt; sie speziell zu beschreiben ist jedoch unthunlich, insoferu sie nicht mit dem Messer dar- 
gestellt werden können. Da alle Teile beim Kaninchen ein ca. 30 mal kleineres Volumen besitzen, als beim Menschen, so tritt der obige Fall für gewöhnlich ein und an Stelle einer Anastomose, wie z. B. der Ellenhogengelenksarterien, ein Netz feinster arterieller Kapillaren auf. - Direkte Cherginge kleiner Arterien in Venen sind aus dem iußeren Ohr, der Nasenspitze, den letzten Phalangen der Finger und Zehen, der Schwanzspitze und dem Penis beschrieben worden $(610)$.

Venen. In der Beschreibung des Venensystems ist konsequent das Verfahren durchgeführt, die Venen gerade wie die Arterien in ihrem Verlauf vom Herzen zur Peripherie zu verfolgen, wodurch eine viel leichtere Übersicht erreicht wird. Offenbar ist es erlaubt, bei der Beschreibung eines Röhrensystemes von der Richtung zu abstrahieren, in welcher dasselbe vom Strome durchflossen wird. Zufolge der angewendeten Terminologie nehmen die wrößeren Venen in ihrem Verlauf kleinere Äste anf', während die Arterien solche abgelsen. Einige Arterien manastomosieren " mit einander, während nach der hier befolgten Bezeichnungsweise die analogen Venen untereinander "kommunizieren". Ubrigens sind alle diejenigen Verhailtnisse gar nicht erwahnt, welche sich ron selbst verstehen, weil die betreffenden Venen entweder die zugehörigen Arterien begleiten oder mit den entsprechenden Venen heim Menschen in den wesentlichen Beziehungen übereinstimmen. Indessen bietet das venöse System im Vergleich zum Menschen weit mehr Besonderheiten dar, als das arterielle.

Die Venen der oberen Körperhailfte beider Seiten bleiben getrennt, indem sie zu den Vr. cavae superiores dextra und sinistra zusammenfließen. Die erstere hialt den Verlauf der V. cava superior des Henschen ein, die letztere miundet in das Herz vermittelst des Sinus coronarius. Das Offenbleiben der auch beim Menschen als Varietat rorkommenden und im Fötalzustande konstant rorhindenen V. cava superior sinistra wird durch das Fehlen jenes Kommunikationsastes bedingt, der beim Menschen V. anonyma sinistra genannt wird. Da letztere wahrscheinlich aus querverlaufeuden Verhindungen der Vv. thỵreoideae inferiores in früher Fötalzeit sich hervorbildet $\tau \$$ ), so düfte die geringe Entwickelung der Gl. threoidea beim Kaninchen hiermit in Cbereinstimmung stehen. Die V. jugularis interna ist nur rudimentir vorhanden; dafür ist die $Y$. jugularis externa stark entwickelt und kommuniziert durch ein Emmissarium temporale mit dem sinus transversus. Anstatt durch die Y. jugularis iuterua findet das Blut der Schadelhöhle ferner noch seinen $A b$ fluß durch ein Foramen cavernosum im Corpus oss. sphenoidei posterioris unterhallb der Ilypophysis, durch welches der Sinus cavernosus mit einer V. rertebralis mediana kommuniziert. Lefztere verlauft in der Medianlinie vor der Wirbelsiule des IIalses.

Eine sehr merkwïrdige Finrichtung existiert am Lnterkiefer. Unmittelbar hinter dem letzteu unteren Backenzahn hefindet sich ein ovales Foramen mandibulare, durch welches die V. orbitalis inferior mit der $\mathrm{V}$. alveolaris inferior kommuniziert. Wiahrend der Kontraktionen der Kaumuskeln, die so hiiufig wiederhehren, wird die zwischeu den $\mathbf{M}$. masseter und pter! goideus internus verlaufende $\mathrm{V}$. orbitalis inferior komprimiert werden, und in diesen Iomenten wird das Blut aus dem vorderen unteren Teile des Cavum orbitale 
durch das Foramen mandibulare hindurch seinen AbfluB in die $T$. alveolaris inferior nehmen müssen.

Die Armvenen biefen wenig besonderes; nur miindef die stark enlwickelte V. cephalica in die V. circumflexa seapulae, die V. basilica mitunter in eine V. mammaria externa.

Die V. hemiazygos fehlt, dafür ist die V. intereostalis suprema sinistra stark entwickelt. Sie nimmt eine V. phrenica superior sinistra auf, wihrend die dextra in die V. azygos mündet.

Der Brusteil der $V$. cava inferior ist verhaltnismaßịy sehr lang. Die Tr. iliacae communes fehten; in die V. cava inferior minden die Vv. iliacae externae getrennt, die internae mittels eines gemeinschaftlichen kurzen stammes: der V. iliaca interna communis. Inter den Ästen der V. iliaca interna ist die V. ischiadica an meisten ausgebildet. Dieselbe kommmiziert an del Wade mit der V. saphena parva und setzl sich abwarts fort. um als $\mathrm{V}$. tibialis anterior anf dem FuBriacken zu endigen. Sie ist der V. cephalica gamz analog.

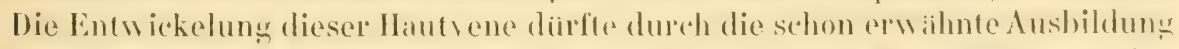
der A. saphena magna bedinger sein. In die V. epigastrica inferior minder pine V. abdominalis, welche die den Mammate entsprechende IIaut des Batrohes und der Brust in ihrer ganzen Ausdehnung durchzieht, und mit den V'. manmitriare externate Verbindungen eingeht. Die V. Saphena magna gelangt als V. libialis posterior zur Fußsohle.

Im L y mph hefaßsystem ist die Konstanz des Vorhandenseins mancher isolierter Lymphorisen in ganz bestimmter Lage auffallend. In der Wurzel des Mesenterium findet sich eine zusammenhangende Masse ron (il. mesentericate, das sog̣. Pancreas Asellii. Die Menge der aus dem Ductus thoracicus austlekenden Flussigkeit betrigt in der Minute 0,0044-0,0055 in 24 Stunden $63-79 \cong$ oder $1 / 17-1 / 15$ des Köpergewidhtes nach 24 stiundigem Fasten 79 . - In den Lymphdrisen sind glatte Mushelfasem zahlreich or- $^{-}$ handen $(57$, S. 357$)$.

Die BI ut menge des Kaninchens ist mit Benntzmeg der farbenprifenden Hethode bestimmt worden. Die mittlere schwankung der zu einem Versuche gehorigen Einzelprifungen ist $z \| 2,5-40 \%$ anzusetzen $(\delta 0$. I)ie speziellen Resultate ergeben sich aus der folgenden Tabelle. Das Körpergewicht wurle unter Abzug des Darminhaltes und der Embryonen ermittelt.

\begin{tabular}{|c|c|c|c|c|c|c|}
\hline \multirow{2}{*}{ Geschlecht } & \multirow{2}{*}{$\begin{array}{l}\text { Körperge- } \\
\text { wieht }\end{array}$} & \multicolumn{2}{|c|}{ Blutmenge in } & \multicolumn{2}{|c|}{$100 \mathrm{~g}$ Tier haben Blut } & \multirow{2}{*}{$\begin{array}{l}\text { Verbältnis } \\
\text { von Blut }= \\
1: \text { Körper }\end{array}$} \\
\hline & & $\mathrm{ccm}$ & $\mathrm{g}$ & eem & $g$ & \\
\hline Jännlich & 669,0 & 32,9 & 34,4 & 4,91 & 3,14 & 19,4 \\
\hline- & 706,0 & 39,7 & 41,5 & 5,62 & 5,87 & 17,0 \\
\hline - & 765,5 & 43,3 & 45,3 & 5,66 & 5,88 & 17,0 \\
\hline - & 786,5 & 44,8 & 46,9 & 5,70 & 6,08 & 16,4 \\
\hline- & 1068 & 48,8 & 51,1 & 4,57 & 4,81 & 20,8 \\
\hline Weiblich, trächtig & 1040 & 66,9 & 70,0 & 6,43 & 6,70 & 14,9 \\
\hline
\end{tabular}

Mit diesen Resultaten stehen andere Angaben in Thereinstimmung, $110-$ nach $1 / 21-1 / 17$, im Mitlel $1 / 18(81), 1 / 14-1 / 16(704)$, oder $1 / 22-1 / 17$ (82) im Mittel aus zehn Bestimmungen gefunden wurden (vergl. a. 690).

Krause, Anatomie des Kaninchens, '2. Auflage. 
Viel yößere Schwankungen werden heobachlet (596), weun man Tiere von ungleichem Ernährungszustande benutzt:

\begin{tabular}{|c|c|c|c|c|}
\hline Grischlecht ete. & 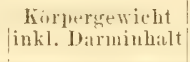 & $\begin{array}{l}\text { Korpurgewieht } \\
\text { obne Datminhalt }\end{array}$ & $\begin{array}{c}\text { Blutgewicht } \\
\text { in } v_{0}^{0}\end{array}$ & 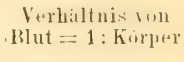 \\
\hline Mager & 1198 & 1023 & 3,7 & 29,0 \\
\hline Fett & 1672 & 1234 & $6, \tilde{5}$ & 15,4 \\
\hline- & 1596 & 1244 & 4,4 & 22,0 \\
\hline Männlich & 1664 & 1422 & 3,4 & 29,0 \\
\hline Weiblich & 1719 & 1460 & 3,7 & 27,0 \\
\hline - & 1743 & 1463 & 3,0 & 33,0 \\
\hline Mittel & & & 5,4 & 18 \\
\hline
\end{tabular}

Dagegen erhailt man dureh direkte quantitalive Bestimmmng des Ilamatins ein Verhailnis von $1 / 16-1 / 17$ (172); oder nach anderer Methode von $1: 12,3$ $-13,3(725)$.

Was die Blutreteilumg in den einzelnen Organsystemen betrift (5.96), so wurden im Mittel erhalten:

\begin{tabular}{|c|c|c|c|}
\hline \multirow{2}{*}{$\begin{array}{c}\text { Gesammtblut- } \\
\text { menge in o| }\left.\right|_{0} \text { des } \\
\text { Körperge- } \\
\text { wichtes }\end{array}$} & $\begin{array}{c}\text { Blutinenge im Bewegungsapparat } \\
\text { (S. 26) }\end{array}$ & \multicolumn{2}{|c|}{$\begin{array}{l}\text { Blutmenge in Drüsen und dem } \\
\text { Gefäßsystem }\end{array}$} \\
\hline & $\begin{array}{c}\text { in ofoder Ge- in } f_{0} \text { des Organ- } \\
\text { sammiblutmenge }\end{array}$ & $\begin{array}{l}\text { in } \% / 0 \text { der Ge- } \\
\text { sammtblutmenge }\end{array}$ & $\begin{array}{l}\text { in } 0 \%_{0} \text { des Organ- } \\
\text { gewichtes }\end{array}$ \\
\hline$\cdots$ & $=\ldots$ & & \\
\hline 5,4 & 30,6 & 63,4 & 18,0 \\
\hline
\end{tabular}

Durch Gefrierenlassen eines frisch getoteten Kinnchens wird die Blut-

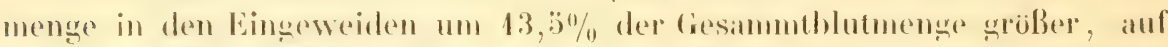
kosten der Blutmenge im Bewegungsapparal s. 206). Besomders blutreich ist die Leber — beispielsweise:

\begin{tabular}{|c|c|c|c|}
\hline \multirow[b]{2}{*}{ Kürpergewicht } & \multirow[b]{2}{*}{$\begin{array}{l}\text { Lebergewicht } \\
\text { in o/o des Kör- } \\
\text { pergewichtes }\end{array}$} & \multicolumn{2}{|c|}{ Leberblutmenge } \\
\hline & & $\begin{array}{c}\text { in o/o ler Ge- } \\
\text { sammtblut- } \\
\text { menge }\end{array}$ & $\begin{array}{c}\text { in } 0 / 0 \text { des Leber- } \\
\text { gewichtes }\end{array}$ \\
\hline 1234 & 4.2 & 16,1 & $2 ;, 0$ \\
\hline
\end{tabular}

Im lebenden kaninchen eroal) sich (996) in betreff der Blutuerteilung durchschnittlich :

\begin{tabular}{c|c|c|c|c}
\hline $\begin{array}{c}\text { Gesammtbiut- } \\
\begin{array}{c}\text { menge in 0/0 des } \\
\text { Korper- } \\
\text { gewichtes }\end{array}\end{array}$ & $\begin{array}{c}\text { Blutmenge im } \\
\text { Bewegungs- } \\
\text { apparat }\end{array}$ & $\begin{array}{c}\text { Blutmenge in } \\
\text { Drüsen und } \\
\text { Gefäßsystem }\end{array}$ & $\begin{array}{c}\text { Blutmenge in } \\
\text { der Leber }\end{array}$ & $\begin{array}{c}\text { Blutmenge in } \\
\text { den Nieren }\end{array}$ \\
$\mathbf{5 , 4}$ & 36,6 & $\mathbf{6 3 , 4}$ & 24,0 & $\mathbf{1 , 9 3}$
\end{tabular}

Für frisch getötete totenstarre Kaninchen wurde in \% der Gesammtblutmenge gefunden:

\begin{tabular}{|c|c|c|c|c|c|c|c|c|}
\hline $\begin{array}{l}\text { Gehirm und } \\
\text { Rueken- } \\
\text { mark }\end{array}$ & Muskeln & $\begin{array}{l}\text { Herz, Lun- } \\
\text { gen, große } \\
\text { Blutgefäße }\end{array}$ & Leber & Milz & Nieren & $\begin{array}{c}\text { Verdauungs- } \\
\text { kanal }\end{array}$ & Knochen & Haut \\
\hline 1,2 & 29,2 & 22,8 & 29,3 & 0,2 & 1,6 & 6,3 & 8,2 & 2,1 \\
\hline
\end{tabular}


Hieraus ergiebt sich das bemerkenswerte Resultat, daß von dem Gesammtstoflivechsel des Kaninchens auf Leber, ruhende Muskeln un! auf die übrigen Organe ungefiihr je ein Dritteil entfillt. Zur Aufkliarung ist jedoch hinzuzufügen, daß das relative Gewicht im Verhailuis zum Körpergew icht ohne Darminhalt beim Kaninchen für die Leber zu 4, $2^{\prime \prime} / 0$, für die Muskeln $z u 37^{\circ} / 0$ (W. Krause), beim Menschen dagegen zu.resp. 2, 7 und $28 \%$ angenommen werden kann.

Injektionen von Wasser in die V. jugularis externa werden tödlich, wenn sie $1 / 50-1 / 30$ des Körpergewichtes betragen, solche in die $\mathrm{V}$. saphena magna erst, wenn $1 / 10$ des Körpergewichtes erreicht ist $(741)$.

Das spezifische Gewicht des Blutes betragt nur 1,0425 (85). Hiermit stimmt uberein, daß zufolge atterer Angaben der Gehalt des Kaninchenblutes an sog. trockenen Blutkörperchen woich 91,5-95,8 p. 11. (84 resp. 8.3) zu setzen ist. Beim neugehorenen Tiere wurden 90,0-91, 2 gefunden (8.i). Der Durchmesser der scheibenfömigen roten Blutkörperchen des Kaninchens betriagt $0,0063 \mathrm{~mm}(\$ 6)-0,0069$.92 u. 6635$) ; 0,0062-0,0080$, im Mittel 0,0069 und die Dicke 0,0017 (\$9); 0,0080 (\$8). Die Anzahl derselben pro cmm 2760000-6030000 im Mittel 3700000 (89, vergl. 7.20). Die Firbekraft eines cmm Blut entspricht der von 3600000 Blutkirperchen des Menschen (89, S. 301), und ist nicht unbetrichtlich geringer als die eines gleichen Volumen von menschlichem Blut. Den Blutumlauf im lebenden Tier kann man im Mesenterium hei 2-14. Tage alten itherisierten Kaninchen stundenlang beobachten, ebenso die Chylusbewegung $(90)$.

Bewegliche Bakterien sind im normalen Blut nicht vorhanden, wohl aber sparsame unbewegliche Körnchen $(666)$.

Gegen Kohlenoxyd ist das Kaninchen empfindlich, ein Gehalt der Einatmungsluft von $0,05 \%$ wird jedoch lange ertragen $(668)$. - Uber den Zuckergehalt verschiedener Gefäßprovinzen vergl. 691.

Die Pulsfrequenz betright im Mittel 220 Schligge in der Minute mitunter 192, v. Bezold bei einem durchschnittichen kiorpergen icht von 1434:nateh anderen $\Lambda$ ugaben $(9 /)$ nur 120 in der Minute, die mittlere kreislatufszeil 7, 22 Sekunden in der Bahn ron einer V. jugularis externa zur auderen, digegen 7,79 im Mittel aller Bahnen. Die Geschwindigkeit des Blutstromes ist relativ grober, die Kreislaufsdauer geringer als beim Mensehen 92). In einer Minute fließen durch das Herz durchschnittich $890 \triangleq$, durch $1 \mathrm{~kg}$ Körpergewicht nur $620 \mathrm{~g}(92)$.

Die Untersuchung des Gefaßsystemes wird am besten nach Injektion der Venen von den Arterien aus mittels Leimmasse, die mit Berlinerblau gefarlst ist, vorgenommen. Die Injektion geschieht am eben durch Chloroform-Einatmung getöteten Tiere, oder man lißßt derselben eine Anfüllung der Arterien mit durch Zinnober gefarbter Wachsmasse folgen. Auch wurten mit letzterer die Arterien gefüllt, ohne gleichzeitig die Venen einzuspritzen. An spatesten gelangt die Hasse in die Aa. ophthalmica superior und digitalis dorsalis fibularis digiti IV. Für die Lageverhailnisse sind Durchschnitte an gefrorenen Körperteilen unentbehrlich. Den Verlauf der Lymphgefäße kann man auch im nicht-iojizierten Zustande mit IIilfe des Sonnenlichtes an frisch getöteten Tieren in ihren Hauptzügen verfolgen. I)ie kleineren subkutanen Stammchen, welche eben anfangen, eine Muscularis zu erhalten. zeigen sternförmige glatte Muskelfasern (647). 


\section{Allgemeine Neurologie.}

Das Gehirn des Kaminchens ist, wie der Schaidel, in manchen Beziehun-

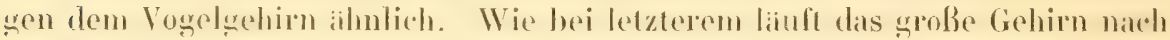
vorn beinahe spitz zu, das Corpus striatum ist selug colof das kleine Gehim hat eimen stark entwickelten, in einer Grube des Os temporum versteckten Ploceulus.

Betrachtet man das Gehirn von oben (s. Neurologie), so fallen an seinem corderen Ende die Lohi olfarerii als kolbige Hervorragumen auf. Das große Gehim ist dreiechig und ohme Windungen, die Eminentia quadrigemina liege in der Gegend, wo die Colliculi anteriores und posteriores zusimmenstoben, nach oben frei. Am Cerebellum ist der Vermis sehr entwickelt, bach oben konvex, die liyri desselhen sind zierlich, und deutlich in Jalppen gesondert. Lateralwarts springe der in der Fossa mastoidea ruhende filocoulus hervor. Die Stringe der Vedulla oblongata sind leicht zu erkennen; am unteren Ende

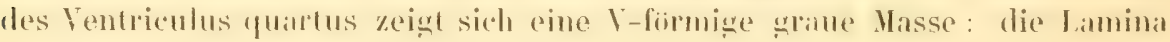
cinerea.

An der Basis - die am besten von unten her, ohne das Gehirn aus dem Sehaidel zu entlemen, mithels limohenzange und schere frei gelegt wird -. sicht man ehenfalls die dobi olfactorii. dahinter das Chiasma optionm, ans welchem die Vu. optici parallel nateh vorn verlanfen. Ilinter denselben folęt das Tuber deincreum, dessen hinterer Rand von dem vorderen Lappen der IIypophysis bedeckt wird. An lateralen Rand des Pons Varolii verlauft der N. trigeminus, dessen llasse die aller übrigen Himnerven zusanmengenommen iibertrift. Die Medulla oblongala ist verhailtnismaibig diek; die Pyramidenstringe sind relativ schmal und deutlich geschieden.

Der Wassergehalt von peripherischen Nerven betrigr $67,13 \% \mathrm{im}$

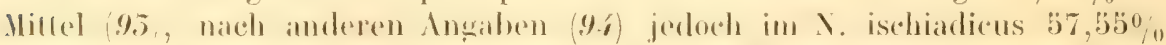

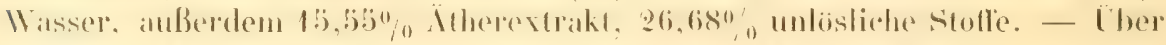

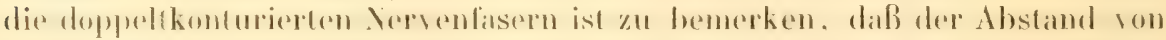

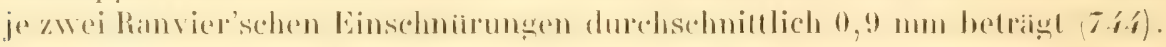

Die Leitungsgeschwindigkeit in peripherischen Nerven wird zu 12,3 m in der Sekunde durchschnittlich angegeben (85I).

Je abweichender das Gehim des Kaninchens gebaut ist, um so auffallender ist die lhereinstimmung des peripherischen Vervensystemes mit denjenigen des Mensehen. Allerdings springl diesellue nicht auf den ersten Blink 
ins Auge. Viele Nerven haben einen abweichenden Verlauf, andere sind stirker oder schwacher entwickelt, indem sie verhälnismäig dick und namentlich in die Linge gestreckt erscheinen, was z. B. in der peripherischen $\Lambda$ usbreitung der Nn. trigeminus und facialis in Gesicht der Fall ist. Auch sonst finden sich viele untergeordnete Verschiedenheiten, aber doch fast gar nichts. was sich nicht gleichsam von selbst verstande, nachdem die Lnterschiede im Bau des Muskel- und auch des Arteriensystemes konstaliert sind. Hierher wehören namentlich die Abweichungen in den Verven der Extremititen. welche durch die geringe Enfwickelung des Dammens und Kleinfingers, sowie durch das Fehlen des Ilallux bedingt werden. Derartige Diflerenzen des Nervensystemes können als sekundire betrachtet werden; theoretisch betrachtet kann man freilich mit analogem Schein von Recht dieselhen für primärer Natur und diejenigen der anderen Sịsteme fuir die alggeleiteten halten. In physiologischer Bezichung ist der Lrsprung und die Endigung der Nerven maßgebend, um ilıre Bedeutung zu verstehen; die Linge der Ieitenden Faseru und die elwaigen Umwege, auf denen sie verlaufen, fallen wenig ins Gewicht. Ind gerade ion diesem Gesichtspunkte aus frappiert, wie schon gesagt, die fast rollstimdige Chereinstimmung unter so rerschiedenen Säugern wic der Iensch und das Kaninchen. Diese Konstanz des peripherischen Vervensistemes ist von großer theoretischer Bedeutung, und die konstatierung derselben kann als ein interessantes Resultat bezeichnet werden, welches aus der vergleichenden Anatomie des Kaninchens sich ergieht. Auch ist die Seltenheit der Varictiten des peripherischen Vervenș stemes hicmit in Uhereinstimmung. Solche sind rom Kaninchen kaum anzuführen, und wenn sie gleich beim Mensehen weil öfter sich finden (9.)', als friber bekannt war, so ist doch ihre Hiufigkeit jedenfalls rerschwindend gegenuber derjenigen der Varietilen im Gefaßsystent. Fü die Aufgaben der Physiologgie wie der modernen Neurologie, welche die Bedeutumer der mamnigfaltig komplizierten Nervenfaserbundel dureh Emillelung ihrer

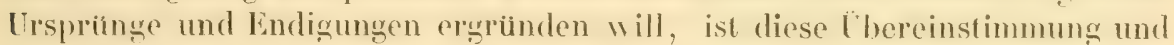
Konstanz der Verhibltnisse ein sehr günstiger. Umstand. Jenn es werden danach die Schlüsse von einem Sauger auf andere, namentlich auf den Menschen, hesser hegrundel erscheinen, und es brancht andererseits wohl nicht hervorgehoben zu werden, daß erst dureh Beschreitung des angedenteten Weges cin Verstindnis sehr vieler Angahen aus der speziellen Veurologie ermogrlicht wird. Tberall, wo von Verbindungen und Faseraustausch verschiedener Nervenstimme untereinander die Rede, hat man bisher mit fast ebensoviel ungelösten Ratseln zu thun. Auf letztere, sowie auf manche scheinbar sehr schwiergere physiologische Streitragen. z. B. die Hemmungswirkungen des Y. Vagus ete, wird vielleicht mehr Licht fitlen, solbald dic Erforsehung der mikroskopischen Nervenendigungen vollendet sein wird.

Unter den Hirnnerven sind die Nn. oculomotorius, facialis, und ganz besonders der X. Irigeminus stark entwickelt; der Y. glossopharyngeus datgegen ist ziemlich fein. Jie Nn. ophthalmicus und maxillatis superior verlassen vereinigl die Srhadelhohle durch die Fissura orhilalis; der N. acustiens verliuft unter dem X. fatcialis (hei aufrecht gehaltenem Kopfe); der N. hypoglossus geht mit zwei Wurzeln durch die Foramina rondyloidea anteriora superius und inferius oss. occipitis. 
Rickenmarksnerven. Die Bildung von Plexus hat die Bedeutung, die einzelnen Faserbinde] auf die Wege zu leiten, auf welchen sie ihre peripherischen Eodigungspunkle prreichen. Seitdem man weiß, daß die doppeltkonturierlen Fasern der Rickenmarksnerven etc. teils mit terminalen Körperchen, reils in motorischen Endplitten, jedenfalls mit besonderen Endapparaten aufhoren, seitdem ist der physiologischen Anatomie von neuem die $\Lambda$ ufgabe gestellt, das Ritsel der Plexushildungen zu lösen, und jedem Ruckemmarksnerven seinen ihm angehörigen Verbreitungsbezirk zuzuweisen. Je feiner die Untersuchungsmethoden wurden, um so beschrinkter hat sich das Vorkommen des früher allgemein angenommenen Ubergreifens der Faserbezirke benachbarter Ritckenmarksnerven in einander herausgestellt. Als wichtigstes Resultat ist der Satz anzusehen: daß die Muskeln ihre Nervenfasern aus derselben Rückenmarksnervenwurzel erhalten, welche die iber ihnen selbst und ihren Sehnen gelegenen llautstellen versorgt. Die in der systematischen Anatomie beschriebenen großeren Nerrenstimme sind nicht mehr als die Jeerstraßen, auf welchen Fasern ganz verschiedenen Ursprungs zu ihren verschiedenen Endigungspunkten gelangen.

Die Emittelung der Verbreitung vou Vervenfasern, die aus einem bestimmten Intervertebralloch austreten, ist bisher nur für den Plexus brachialis durchgefiuht worden. Die hei letzterem in der speziellen Neurologie mitgeteilte Tabelle giebt Resultate wieder, welche teils durch Reizversuche am lebenden Tier, teils durch Nerrenresektionen mit nachfolgender fettiger Entartung der betreflenden peripherischen Fasern. die unter Beihilfe des Mikroskopes nachgewiesen wurde, erhalten worden sind.

Dringend wiuschenswert erscheint jetzt eine vollstindig durchzufihrende Kontrollierung der betreffenden, von einem früheren Beobachter durch das physiologische Experiment erhaltenen Resultate vermöge des zuverlassigeren Weges der anatomischen Untersuchung wach erfolgter fettiger Degeneration, da aus anatomischen wie aus experimentellen Grunden mehrfache Zweifel an der Richtigkeit mancher Details der erwihnten Tabelle zu bestehen scheinen.

Außerdem wire eine Ausdehnung dieser Lntersuchungsmethode auf die Verbreitung der llirnnerven, wobei sich manche vielfach eröterten physiologischen Kontroversen mutmaßlich Jösen wärden, sowie auf die teilweise zugainglichen Vervenstimme für die untere Extremitit in hohem Grade erwünscht. In der That ist dieser Weg bereits mit gutem Erfolge bei den vom N. accessorius herstammenden Rr. pharyngei des $\mathrm{X}$. vagus betreten worden (s. 96 und 1 . accessorius, Durchschneidung!. Clber weitere historische und experimentelle Details s. 96.

Die Verven des Plexus brachialis bieten folgende Besonderheiten. Ein N. subelavius fehlt: der $\mathrm{N}$. perforans brachii s. musculocutaneus perforiert zwar den M. coracobrachialis, endigt aber in diesen Muskel und dem oberen Teile des M. gleno-ulnaris s. biceps brachii. Die motorischen Fasern, welche demselben beim Menschen sonst noch angehören, verlaufen in der Bahn des X. medianus, die sensibeln im X. radialis und dem R. superfecialis desselben. Der X. nudianus verliunt in Begleitumg der $\Lambda$. radialis, welcher der N. radialis lern bleibt; ersterer versorgt zum Teil auch die Volarfliche des vierten Finger's an der Llnarseite mittels eines Verhindungsastes in der Hohlhand. Ebenso 
fallt die Radialseite der Dorsalfliche des vierten Fingers dem N. radialis zu, wahrend der $\mathrm{N}$. ulnaris die Ulnarseite versieht. Diese Modifikationen haluen jedoch auf den Ursprung der betreffenden Nervenfasern aus bestimmten Nin. cervicales keinen Einfluß.

An den Verven der Extremitaten, namentlich in der Vola manus, finden sich Vater'sche Korperchen. Ihre Zahl wird auf $4 \mathbf{5}$ angegeben $(\mathbf{9 7})$.

Von der Ansa cervicalis VIII wird ein N. longissimus pectoris abgegeben, welcher mit der V. abdominalis verliuft und den M. cutaneus maximus zum Teil versorgt. An der Bildung der Ansa cervicalis VIII nimmt auBer dem X. dorsalis I noch ein kleines Büdel des $\mathbf{N}$. dorsalis II Teil, und da aus dem letzteren jedenfalls nur sehr wenig Fasem zur oberen Extremitit gelangen dürften, wie aus den Experimenten aber Nervendurchschneidung am Plexus brachialis hervorgeht (96), so könnte man annehmen, diß einige Fasern des $\mathbf{N}$. longissimus pectoris aus dem $\mathrm{N}$. dorsalis II stammten, obwohl nach anderen Angaben (109) wenigstens ein Teil derselben aus dem X. cervicalis VIII abzuleiten ist. Für jene Annahme ließe sich noch anfuhren, daß der M. cutaneus maximus von anderen Intercostalnerven bis zum $\mathrm{X}$. intereostalis $\mathrm{VI}$ abwäts, mit Ausnahme des ersten, ebenfalls Zweige erhailt. Indererseits kann man auch vermuten, daß dem genannten Muskel Fasern aus dem $\mathrm{N}$. dorsalis I in der Bahn des X. Jongissimus pectoris zugeführt werden. Endlich wäre es möglich, daß die Haut des kleinen Fingers cinzelne Fasern aus dem N. dorsalis II auf diesem Wege erhielte.

Die Plexus hmbalis und sacralis bieten folgende Eigentümlichkeiten dar. Ersterer wird ron den $\mathrm{In}$. lumbales V-VII und einem oberen Ast des N. sacralis I gebildet; die In. Iumbales I- III beteiligen sich an seiner Zusanmensetzung nicht, sondern verhalten sich wie No. intercostales. Der N. lumbalis IV entsendet den $\mathbf{N}$. iliohypogastricus. Der $\mathbf{N}$. cutaneus femoris posterior replauft hinter dem Tuber oss. ischii, die $\mathrm{V}$. ischiadica am Oberschenkel begleitend. Der N. peronaeus entsteht vorzugsweise aus dem I. lumbalis VII; der $\mathrm{X}$. tihialis und die Muskelnerven des $\mathrm{N}$. ischiadicus fur den Obersehenkel aus der Ansa lumbalis III. Ohne Zweifel wird der Unterschenkel und Fuß wesentlich von Fasern versorgt, die in den No. lumbalis VII und sacralis I das Ruckenmark verlassen, und in Analogie mit der oberen Extremitat entspricht der $N$. lumbalis VII dem X. cervicalis VIII, der X. sacralis I dem X. dorsalis I. Utherhaupt lassen sich die Faserzüge der Yerven für die untere Extremitat und das Becken mit besonderer Leichtigkeit bis zu bestimmten Foramina intervertebralia und sacralia verfolgen. Die mediale Seite der IIaut des Interschenkels wird wesentlich rom $\mathrm{X}$. saphenus major, die laterale rom X. saphenus minor versorgt; an der hinteren Seite verbreitet sich der rom $\mathrm{Y}$. ischiadicus anstatt vom $\mathrm{X}$. peronaeus al)gegebene $\mathrm{X}$. cutaneus cruris posterior. Die Nn. peronaei superficialis und profundus sind nicht getrenut; auf den Fuß reicht der $Y$. saphenus major nicht hinab; sowie iberhaupt die Nn. digitales dorsales pedis in gleichmaßiger Ordnung vom X. peronaeus, die rolares vom X. tibialis abgegeben werden.

Der Plexus coccygeus entsteht aus dem X. sacralis IV und den Nn. coceygei $\mathbf{I}-\mathbf{V}$, ist sehr zart und bildel hauptsählich einen $\mathrm{X}$. coccygeus lateralis. 
Im sympathischen Nervensystem sind die größeren Ganglien im allgemeinen graturotlich und scharf umschrichen. Manche Verbindungen des Gangliensystemes, die nicht speziell angegeben werden, sind wie beim Menschon vorhanden. aber nur durch das Mikroskop mit Sicherheit zu ermitteln.

In Kop/teil des sympathischen Vervensystemes ist das Ganglion oticum durch rin kleineres accessorisches Ganglion oticum posterius ausgezeichnet. Das Ganglion interearoticum enthïl Gefißkniuel.

Am Hulsteil wird das Ganglion eervicale medium des Menschen durch das Gallghlion rervicale inferius (G. stellatum 99, s. spezielle Veurologie) repriisentierl, so daß ersteres nur scheinhar fehlt. Das Ganglion cervicale inferius des Menschen ist das thoracicum primum (G. slellatum, fl) beim Kaninchen.

Im Brustteil ist der Plexus cardiacus besonders interessant; seine Fasern stammen jederseits rom R. eardiacus N. ragi, rom N. recurrens, und vom G. cervicale inferius, welches eine mit der A. vertebralis verlaufende Radic hrevis und außerdem eine Radix longat von den obersten Wurzeln des Plexus brathialis enhilu. Der $\mathrm{N}$. splanchnicus minor verlauft in der Bahn des N. splanchnicus major.

Die Gamgliemplexus der Banchhishle, namentlich aber der maimnlichen und weiblichen fieschlechlsorgane, sind bereits sehr genau untersucht (s. spezielle Vemrologie). Jie Vesicula prostalla sowie die Vasa deferentia des Mitunchens erhalten ihre Nerven von einem unparen N. hypogastricus, welcher ein lingliches Ganglion hypogastricum euthät. Die Fasern stammen teils von den Vn. sympathici abdominales, resp. den Ganglia lumbalia V; teils gehen sic aus dem Plexus mesentericus inferior hervor. In letzterem findet sich ein größreses, oberhall, der Wrurzel der $\Lambda$. mesenterica inferior gelegenes fianglion mesentericum (inferius); andere Fasern kommen aus dem an unteren Ende der Aorta descendens gelegenen Plexus aorticus abdominalis.

ber Lterus und die Vagina erhalten Nervenfasern von den Ansae sacrales II und III, sowie rom sympathischen Vervensystem. Die In. uterini stammen hauplsirehlich aus dem X. sacralis III, die Nepven der Vagina vom N. sacralis IV, diejenigen der Vlitoris aus den Ausar sacrales I-III. Die Hauphmasse der sympathisehen Fasern stamml wie heim Mimnchen aus dem Plexus mesenteri"us inferior, ferner aus dem Plexus anticus abdominalis. Dieselben verlaufen im Plexus hy pogatricus dester und sinister zum Plexus vaginalis. Letzterer umgiebt den nicht rom Peritoneum aberzogenen Teil der Vigina, enthitt in seinem oberen Alschnilte jederseits ein konstant vorhandenes Ganglion uterimum. Alle diese sympathischen Plexus fiihren zahlreiche größere und kleinere Ganglien. sowie viele doppeltionturierte neben den blassen Vervenfasern.

Im Bectien sind jederseits vier Ganglia sacralia und zwei Ganglia coc-

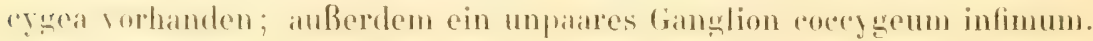


Spezielle Anatomie. 



\section{Osteologie und Syndesmologie.}

\section{K 0 p f.}

Der knöcherne Kopf des kiminchens besteht aus 2̈̈ verschiedenen Kinochen, welche, mit Ausnahme des Unterkiefers, der sich durch ein Gelenk den übrigen zugesellt, und des Zungenbeines durch Yahte miteinander rerbunden sind.

Man teilt den Kopf ein in den Hirnschädel und das knöchernel Ge sicht. Ersterer wird gebildet durch 10 Schadelknochen, letzteres durch 15 Gesichtsknochen, jedoch nehmen an der Zusammensetzung des Gesichtes auch einige Schädelknochen teil. Außer den genannten Knochen des Gesichtes sind von denjenigen, welche die Schädelhöhle zusammensetzen, das Os occipitis, ferner das Os interparietale, die Oss. sphenoidea anterius und posterius, das Os ethmoideum und Os frontis unpar, die Oss. parietalia und temporum aber paarig.

\section{Schädelknochen.}

\section{Os occipitis, Hinterhauptsbein.}

Das llinterhauptshein entsteht aus vier bei jungen Tieren teilweise noch getrennten Stücken, welche in der Ansicht von vorn am deutlichsten sind (Fig. 28). Es sind die Pars basilaris, Partes condyloideae und die Pars squamosa, welche letztere beim halberwachsenen Tiere durch Nähte mit den Partes condyloideae verbunden ist.

Pars basilaris s. Corpus. Der Grundteil zeigt verschiedene Flächen, vordere, obere, untere und zwei seitliche. Die vordere, wie eine der Länge nach durchschnittene Hantel gestaltet, vermittelt die Verbindung mit der hinteren Fliiche des Corpus oss. sphenoidei, welche eine entsprechende Form zeigt. Die Verbindung ist eine Synchondrose: Synchondrosis sphenobasilaris Fig. 28 S b) s. spheno-

Fig. 28.

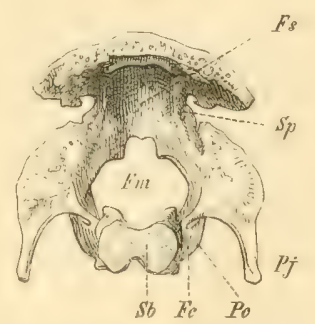

Os occipitis, von vorn. F's Fossa sidgittalis. $S_{p}$. Sulcus longitudinalis pusterior. F'm Foramen magnum. Pj Procesisus jugularis (posterior). Pc Processus condyloideus. $F$ C Furamina condyloideit anteriora. $S b$ Synchondrosis $\rightarrow$ phenobasilaris. 
occipilalis: Iotzore reprisentiert eine fibrocartilago intervertebralis zwischen den beiden letzten Schädelwirbeln (S. 44).

Dic obere Fliche oder der Clicus ist glatt, wrubenformig, welche letzlere Eigensehaft sie durch die sie nach oben uberragenden Seitenflichen erhailt. Ihr vorderes Ende liest ummittelbar an der Wurzel des Dorsum sellae oss. sphenoidei. Vach hinten begrenzt sie mit der unteren Fliche in einem nach born konrexen Rande das foramen magnum. Das hintere Drittel wird durch eine ron den Seitenteilen auf die obere Vliche bogenfömigy sich fortsetzende, nach vorn honvexe C'rista trunstersa von den vorderen geschieden; es ist nicht wrubenfömig und der kirper zeigt dort eine kleime Wölbung nach aufwirts. Die ganze obere Fläche steigt schwach nach vorn und oben an.

Die untere Fläche ist konkay, zeigt eine mittlere Rinne, die an der hinteren Halfte dureh eine sagittale Crista hasilaris in zwei zerfallt. In dem mittleren Teile ist sie schmaler als vorn, und hinten breiter als vorn. Nalch hinten trifft die untere Flathe in dem das foramen masnum ocripitale begrenzenden Rande mit der oberen zusammen.

Die seiblichen firchen springen besonders ibur den vorderen Teil der oberen Flache wor. sind im vorderen Teil hreiter als im hinteren und zeigen im ersteren eine tiefe cirube, Fossa petrolympranious. jugularis, in welehe die

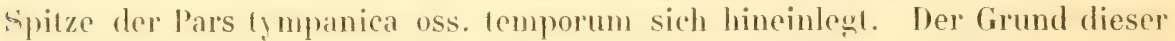
Fossa ist porös.

Der hintere Teil der Seitenfliche ist kaum halb so hoch wie der vordere und geht in die Partes condyloideae úber.

Partes condyloideae s. laterales, Gelenkteile oder Seitenteile. Die Gelenkteile entwirkeln sich aus der hinteren Partie des Körpers oder der Pars hasilaris. Sie hileten die seitliche Begrenzung des Foramen maynum oocipitale und steigen nach hinten und oben an, um in den unteren Teil der Schuppe iiberzugehen; ihre Stellung zur Pars basilaris ist fast senkrecht.

bie lateralen Fiachen zeigen jederseits am hinteren Teile die Processus

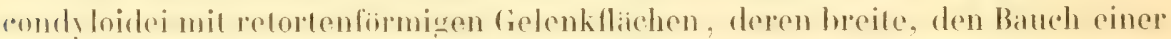
Retorte darstellenden Trobe narh vorn, am Thergange in die Pars basilaris sich befinden. Dis ganze folenklliche ist komex. Im vorderen unteren Teile der lateralen Flache sieht man die Offnumg von zwei Kanblen, die schrigy nach born verlaulen und fïr den N. hypoglossus bestimmt sind: Forumina condyloidea anteriora superius und inferius (Fig. 28 Fc, S. $\%$ ), von denen das obere das kleinere ist. Am oberen Ende der lateralen Fläche sind noch mehrere

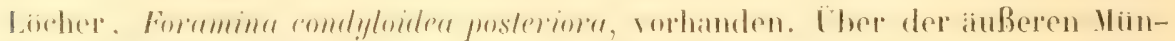
dung dersolben bedindet sich am oberen Ramde jedes seitenteiles ain kleiner seirohter linulnurh, Incisura jugularis: sie wirl nach vorn ron dem niedrigen Pronessus jugularis anterior bespenz (weleher beim Menschen als Varietiat sehe

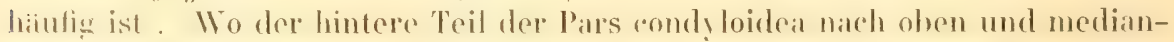
Wirts mmbient, entspringt lateralwirts von dem hinteren oheren bude der

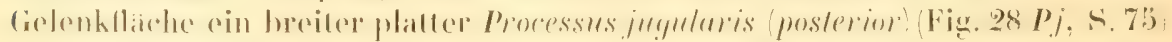
s. lateralis s. paramastoidens, weleher senkereht nateh unlen rerlatuft und sich ziemlich schmell zuspitzt, um dann mil aner knoplfömigen Anschwellumg zu endigen. Dersello reprisentiert den lrocessus transrersus des letzlen sichii- 
delwirbels und leğ sich genau in die Mitte der hinteren Fliche der Bulla tỵmpani oss. temporum, medianwäts neben dem Processus mastoideus.

Der hintere Teil des oberen Randes der Pars condyloidea sowie der obere platte Teil des Processus jugularis (posterior: vereinigt sich durch Schuppennaht (S. 37) mit der Pars petrotympanica oss. temporum.

Die mediale Flache der Gelenkteile zeigt nichts bemerkenswertes, als die medialen Öfnungen der Foramina condyloidea superius und inferius.

Die Foramina condyloidea anteriora sollen nach Größe und Anordnung öfters erheblich variieren $(8 / 8)$.

Pars squamosa, Schuppenteil oder Schuppe. Derselbe ist ein platter, porioser Kuochen; seine Form ist eine vielgestaltige und komplizicrle. Im ganzen hat die Schuppe die Gestalt eines yleichseitigen Dreieckes mit stark abgerundeten Ecken und einer etwas konkaven Grundlinie, welche die

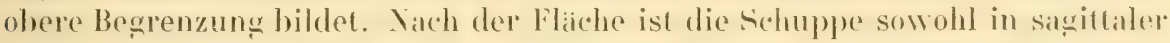
als in transversaler Richtung stark gekrimmt. In ersterer Richtung and die Art, daß nur das mnlere, die Spitze des Dredeckes darstellemde Dritteil mit dem oberen Teil der Partes condyloideae in einer Ebene liegt, wogegen der abrige Teil einen stumplen, beinahe rechten Winkel mit dem unteren l)ritteil biltet und nahezu parallel der Pars basilaris sich erstreckt. - Fur die genauere Beschreibung unterscheidet man an der sibhppe einen unteren und oheren Teil.

Der untere Teil, welcher sich an die Gelenkteile anschließt, vervollstindiegt zunitehst die Begrenzung des foramen magntum nach hinten mol oben. Der dadurch gelieferte zugeschardle Begrenzungstand zeigh in der Mille pinen viereckigen Jusschnitt, dessen laterale Rimeler atwas nach unten

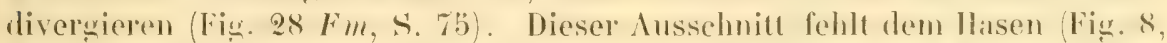

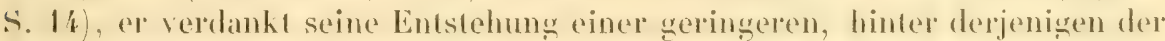
Parles condy loideae zuriekbleibenden Eutwichelung des schuppenteiles nateh monen. Der Ausschnilt ist daher ein wenigr breiter als die Anteihnahme des Sehuppenteiles an der Begrenzung des Foramen magmum is. auch s. 1:

Indem sich die Spitze der Schuppe zwischen die angrenzenden, schrag medianuirls und nach unten ablallenden Rimder dor Processus jugulares

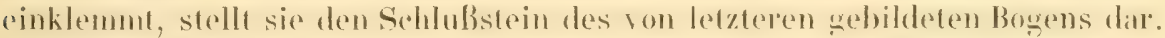

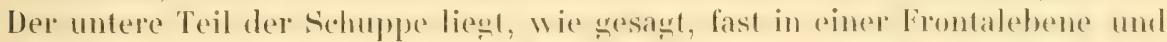

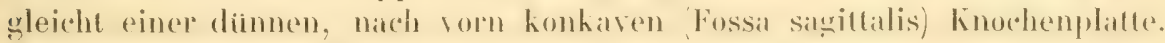

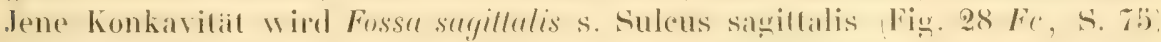

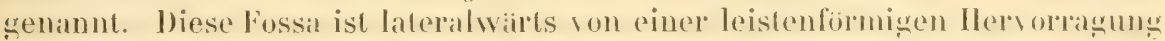

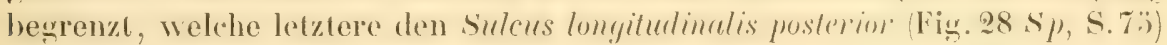
enthalt. Die Firsten erstrecken sich auf den oberen Teil dep schmper und

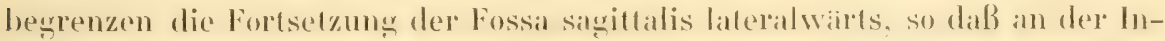
nenfliche keine firenze zwisehen unlerem und oberem sichuppenteile zu hemerken ist.

Die iußere oder hintere Flache des unteren Schuppenteiles zeigt verschiedene Eindricke und Rauhigkeiten. Vom oberen Trile der Schuppe ist sie

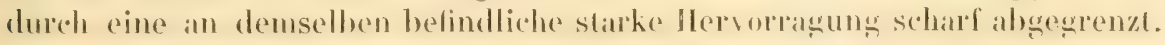
Von der llitle des unteren Randes dieser Hervorasumer lauft eine scharfe Cristre ocripilalis externa s. sagitlalis zum foramen magnmm bis zum unteren 
Ende der Schuppe resp. zur Mitte des hinteren Randes jenes viereckigen Ausschnittes.

Oherhall, der Wurzel des Processus jugularis beleiligh sich auch der rauhe laterale Rand des mnteren Schuppenteiles an der Verbindung mit der Pars petromastoidea des Schlifenbeines. Sie weschieht durch Schuppennaht (S. 37).

Von diesen lateralen Teilen ist der mediale durch zwei starke, leistenformige Hervorragungen geschieden, welche sich his zur Spitze der Schuppe erstrecken.

Oberer Teil der Pars squamosa oss. occipitis. Der obere Schuppenteil zeichnet sich durch seine spongiöse Beschaflenheit aus, die sowohl an der oberen wie an der hinteren Fiache aufaillig zu Tage tritt. Derselbe bildet mit dem unteren Teil einen stumpfen Winkel und liegt fast in einer Ilorizontalehene. Beide Flichen sind sehr deutlich in drei Ahteilungen geschieden, eine mediale und zwei laterale. Auf der oboren oder atuBeren Fliache findet sich in der Vitte der Verbindumesnaht mit dem 0 s interpartetale in der Medianlinie ein kleiner Howher. Tuberulum accipitale, welcher hall, dom letzteren, halb dem $O$ s oceipitis angehort. Hinter demselben erstreckt sich ein vierechiges Plateau (square platform), dessen hirteres Ende in eine starke Hervorragung, die Protuberumtia oceiprtalis externa, ausliaft. Zu beiden Seiten der letzteren sind kleine binkerbungen vorhanden, dann erhebt sich die Limen semicircularis (superior) oss. occipitis jederseits zu cinem Höcker von fast derselben Höhe wie die Protuberantia selbst und setzt sich list sagitlal ferlatend nach vorn bis zum vorderen Rande des oberen schuppenteiles fort. Diese stark hervorragenden fortsetzungen bilden die seitlichen Begrenzungen nicht nur jenes Plateaus, sondern auch diejenige der medianen gegen die beiden lateralen Abteilungen des oberen Schuppenteiles. Letztere sind konvex und sehr porios; sie liegen lateraluirts von der medialen Partie des mnteren schuppenteiles. In die lü̈cke zwischen dem unteren Schuppenteil und den beiden Latcralteilen des oberen Schuppenteiles schieht sich die obere hintere Partie der Pars petromastoidea oss. temporum.

Die innere oder untere Flache zeigt drei Gruben, ron denen die mediale oder die Fossa sagittalis die tiefere ist, welche sich ohme Unterbrechung bis zum Foramen magnum erstreckl. Oberhalb der medialen Grube verliuft in transversaler Richtumg ein tiefer sulcus transersus. der sich lateralwirts in den gleichnamigen sulcus der Pars mastoidea oss. temporum fortsetzt. Nach vorn verbindet sich die Schuppe mit dem Os interparietale und lateralwarts mit den Scheitelbeinen. Bemerkenswert ist in betrefl der Stellung des Hinterhatuptsheines. daß das Foramen maymum occipitale fast frontal gestellt ist.

\section{Os interparietale.}

Zwischenscheitelbein. Sichelhein. Lnparer, linghich elliptischer Knochen (Fig. 29, Oi - Fig. 18, Oi, S. 40), dessen Längsachse transversal gestellt und etwa doppelt so lang ist. als die in sagittaler Richtung verlaufende kleine Achse. Derselbe kann als Abschnitt des oberen Schuppenteiles des Os oceipitis betrachtet werden, da er die obere Spitze des betreffenden Schuppen- 
teiles bildet. Nach vorn verbindet sich die obere Fliche des Os interparietale durch den medialen Abschnitt der Sutura lambrloidea mit den hinteren Rindern der beiden Oss. parietalia; die Kreuzungsstelle dieser Naht mit dem hinteren Ende der Sutura sagittalis ist durch eine kleine Hervorragung, das Tuberculum interparietule, bezeichnet. Auf die lateralen Enden des Os interparietale trifft das mediale Ende des lateralen Abschnittes der Sutura lambdoidea. Der hintere Rand verbindet sich durch Naht mit dem oberen Rande der Pars squamosa oss. occipitis. In der Medianlinie zeigt sich an

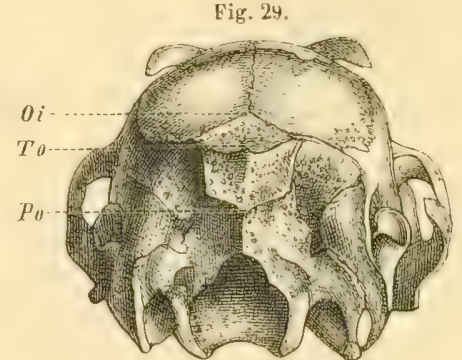

Schädel von hinten. $0 i$ Vorderes knde des 0 s interparietale. To Tuberculum oceipitale. $P_{0}$ Protuberantia occipitalis externa. demselben eine húgelige Hervorragung, das Tuberculum occipitale. Die untere Fliche des Os interparietale enthält den Sinus confluens (s. Angiologie, Venen).

Vor und nach der Geburt besteht das Os interparietale aus zwei Seitenhälften (Fig. 30) die später in der Medianlinie verschmelzen. Man kann den Hasen- vom Kaninchenschïdel, abgesehen von den bedeutenderen Dimensionen des ersteren, daran unterscheiden, daß bei Lepus timidus das os interparietale bald nach der Geburt mit dem Os occipitis verschmilzt. Beim neugeborenen Hasen (Fig. 30) besteht es aus zwei Hälften, welche die hintere mediale Ecke jedes Scheitelbeines einnehmen. Als Varietiit soll obige Verwachsung auch beim Kaninchen sich zeigen (14). Das Os interparietale ist homolog einem an der Spitze der Pars squamosa oss. occipitis beim Menschen als Varielät vorkommenden Os Wormianum (vergl. 40, S. 64). Bei manchen Såugetieren verwächst es mit den Scheitelbeinen, wovon sein Name abgeleitet ist.

\section{Ossa sphenoidea, Keilbeine.}

Das Os sphenoideum (Fig. 31) zerfallt in zwei Teile: einen hinteren Teil oder das hin tere Ke ilbein, Os sphenoideum posterius, und einen vorderen, das vordere Keilbein, Os sphenoideum anterius, die sich durch Niahte und eine Synchondrosis intersphenoidalis miteinander verbinden. Das hintere Keilbein besteht aus dem Körper, Corpus, den großen Flügeln, Alae magnae, und den flügelartigen Fortsätzen, Processus pterygoidei. Das vordere Keilbein besteht

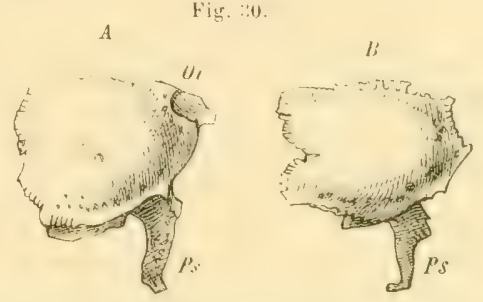

A. Linkes Seheitelbein eines jungen Hasen kurz nachlier Geburt, von der lateralen Seite. $O i$ Hälfte des 0 s interparietale dureh Naht mit dem Scheitelbein vereinigt. B. Linkes Scheitelbein eines jungen Kaninchens, von der lateralen Seite. P's Processus squamosus.

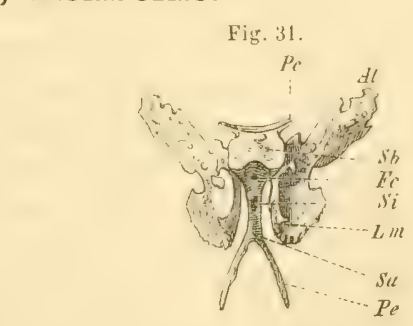

Ossa sphenoidea posterius und anterius, von hinten. P $c$ Processus clinoideas posterior. A $l$ Ala magna. Sb Synehondrosis sphenobasilaris, $b^{\top} c$ Foramen cavernosum. $S i$ Synchondrosis intersphenoidalis, $L m$ Lamina medialis des Processus pterygoideus. $S a$ Corpus oss. sphenoideianterioris. Pe Processus ethnoidalis oss sphenoideianterioris. 
aus dem Körper, Corpus. zwei kleinen Flügeln, Alae parvae, und zwei Siebheinlortsilzen, Processus efhmoidales, welche letztere merkwiordigerweise die Laminate papyaceac des siebheines an ihren vorderen Enden enthalten.

\section{Os sphenoideum posterius, hinteres Keilbein.}

Corpus. Das Corpus liest in der Medianlinie der Schadelbasis und hat rine keilfömige Gestalt. Es ist dummwandig und schließt eine llöhle eiu: simus sphenoidalis. Der Köper besitzt sechs Flichen, von denen die obere und die beiden seitlichen in die schialelhöhle sehen, die vordere sich durch die synchondrosis intersphenoidalis S. 79) mit dem Körper des vorderen Keilheines rerbintet, wihlend die untere frei liegt. Die hintere Flache vereinigt sich mit der Vorderfaiche der Pars basilaris ossis oceipitis und hat eine dieser entsprechendr Gestalt. -- Die obere Flitche, Sella Fig. 20 S, s.43)s. sellaturcica, istausgrohohlt, wird im hinteren Teile von spongioser substanz gehildet. etwa bis zur llitte, wo sie atufhord, und der sinus sphenoidalis natedoben greoflnet ist; letzlerer wird dureh eite Querleiste in zwei Kammern geteilt. Wo die obere fiache in die vordere iberseht, wird der Sinus sphenoidalis in seinem rorderen 'Trile dureh ein kleines knochenplittchen bedeckt. Die obere Fliache ist also in dep Ville durchbrochen. Das Dorsum sellar gehobt seiner Iage nach der oberen Fliiche an. Von der Mitte des oberen Rindes der hinteren Flaiche

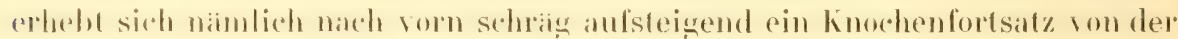
Form eines stmmpfwinkligen Dreieckes, oben und worn mit seideter konkavitit an der hinteren Fliahe. Von der Milte der drom stumpfen Winkel gegenuber-

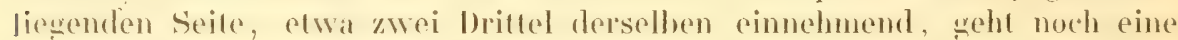
Knochenplatte in horizontales Richtung nateh vorn, den hinteren Teil der Sella

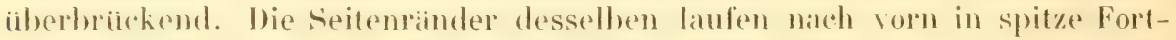

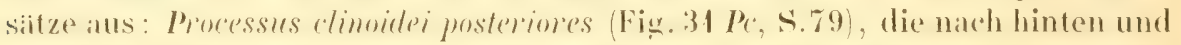

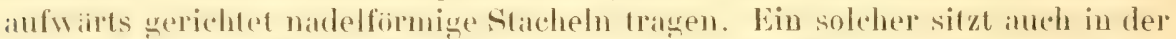
Mite des unteren Endes des Dorsum sellae. An der Basis der Processus elinoidei posteriores zeigt sich an ihrer latrralen Flithe der von hinten nach vorn gerichtete flache Sulcus caroticus. - Die lateralen Seitenflichen werden in ihrem mitteren Teile ron den Wmoehn der Mae magnire und der Processus plengoided aingenommen, im hinteren, mferen und rorderen Teile sind sie frei und zeipen nichts hemerhensw ertes. Sie sind on hinfen unten nach rom und olen gerichtef und rerschmiilern sich in dieser Richlumg keilformig konverererend, wie die obere und untere Flache. Die vordere Flatche, welehe sich dureh die synchontrosis intersphenovidalis s. sphenoidalis (Fig. 31 si) mit drom kioper des vorderen keilheines verhindet, ist eine kleine, flach ausgehihhle dimbe und die kleinste von allen Flichen. Sie sicht zugleich nach oben umf am mazerierten Schidel. Harh Entfernung der synchondrosis intersphe-

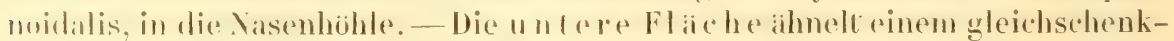
lienen Dreieck, dessen Scheitel von der vorderen Flache abgeschnitten wird. In ihrer Vitte befindet sich eine runde Öfhung, Foramen cuvernosum (Fig. 31, F. Welche in den sinus sphenoidalis lührt und zua in dessen hinter Kammer, unmittelbar hinter der Querleiste.

Die Sella ist bein neugeborenen Kaninchen noch nicht ausgebildet $(8 / 8)$. 
Alae magnae. An den Alae magnae unterscheidet man zwei Teile: die Par's superior und die Pars inferior.

Die Pars superior (Fig.31 $A l, \mathrm{~S} .79)$ s. posterior ist ein platter dünner Knochen, welcher von der Seitenfläche des Körpers in deren ganzer Länge, nicht Breite, entspringt. Mit dem lateralen Rande der oberen Fläche bildet dieser Ursprungsteil einen tiefen Sulcus, den Sulcus sphenoidalis, welcher mit dem der anderen Seite unter spitzem Winkel nach vorn konvergiert, ihn jedoch nicht erreicht, und in der Fissura orbitalis superior mündet. Letztere repriisentiert das fehlende Foramen rotundum oss. sphenoidei mit; der Sulcus sphenoidalis setzt sich mach hinten in das Foramen lacerum fort (S. 86), und endigt am Keilbein mit einem ovalen Ausschnitt im medialen Teil des hinteren Randes der Pars superior alae magnae: der Incisura ovalis, welche mit dem Foramen lacerum zusammenfließt und das fehlende Foramen ovale repriitiert. Die Fissura orbitalis superior wird gebildet durch den vorderen Teil der Seitenfläche des Körpers und den medialen vorderen oberen Rand der Pars superior alae magnae. Sie liegt in einer Frontalebene. Die Pars superior ist breit, nach der Schädelhöhle zu konkav; in ihrem oberen größeren Teile ist der Knochen glatt, im hinteren kleineren Teile durchlöchert, spongios; ihre Richtung ist von hinten und lateralwarts nach vorn und medianwarts. Mit dem vorderen oberen Rande geht sie durch Naht eine Verbindung mit den Alae parvae ein, unterhall, welcher auf der hinteren Fliche ein feiner Sulcus meningeus (für die A. meningea media, siehe Ala parva, S. 83) in transıersaler Richlung vom Foramen spinosum lateralwarts verlauft. Die Pars superior verbindel sich ferner durch ihren lateralen Rand mit der Pars squamosa oss. temporum, durch den hinteren oder unteren Rand mit der Pars mastoidea desselben Knochens. Die vordere Flache ist konvex und bildet die hintere untere Wand der Augenhöhle; an ihrem oberen Teil findet sich eine starke, transversal gerichlete, iu einen nach vorn und unten hakenformig gekrümmten Fortsat $\iota$ auslaufende Crista alae magnae.

Die Pars inferior s. anterior entwickelt sich aus dem unteren medialen Teil der Vorderfliche der Pars superior und erstreckt sich fast in sagittaler Richtung nach vorn, um in die Lamina lateralis des Processus pterygoideus überzugehen. Dort, wo sie unter rechtem Winkel von der Pars superior ahgeht, finden sich in einer schrig von vorn und medianwarts nach hinten und lateralwarts verlaufenden Linie drei Foramina sphenoidalia S. 82 hintereinander. Von dem Foramen sphenoidale posterius steigl ein Sulcus massetericotemporalis an der Vorderflache der Pars superior alae manae aufwarts (in welchem der R. massetericotemporalis des N. maxillaris inferior verliuft, s. Neurologie). Die Pars inferior bildet mit der Lamina externa processus pterygoidei den medialen unteren und hinteren Teil der Augenhöhle.

Varietåt. An der äußeren Fläche der Ala magnạ vor dem Foramen sphenoidale anterius, namentlich aber an der unteren Fläche des spongiösen Teiles der Ala magna finden sich zuweilen $2-6 \mathrm{~mm}$ lange Processus accessorii $(190)$.

Processus pterygoidei. Sie bestehen aus einer Lamina lateralis und medialis, welche nach hinten auseinanderstehen und eine bedeutende Grube 
zwischen sich lassen: Fossa ptrygoidea. - Die Lamina lateralis ist eine Fortsetzumgr der Pars inferior der Ala magna; an ihrer Basis befinden sich drei nach umb pusterius. Das anterius liegt zugleich am meisten medianmirts und ist das grobte es dient zum Durchgang der A. und V. maxillaris interna, s. Angiologie). bie beiden mehr lateralwarts gelegenen Foramina sphenoidalia medium und posterius stellen ion hinten nach vorn gerichtete kurze Kanible dar durch Welche die Rr. pterygoideobucematorius, resp. massetericotemporalis des $\mathbf{N}$. maxillaris inferior rerlaufen). Das foramen posterius sefzt sich in den Sulrus massetericotemporalis der Vorderfliche der Pars superior ala magnae fort.

Die Lamina lateralis reprisentiert den Processus transversus des vorletzten Shatdelwirbels, die Lambina medialis eine Rippe. Cuvier $(100)$ hatte das Foramen sphenoidale anterius für den Canalis Vidianus angesehen.

Die Lamina medialis (Fig. $31 \mathrm{Lm}, \mathrm{S} .79$ ) entspringt vom vorderen unteren Teile der Seitenfliche des keillexinköpers, gemeinsam mit der Irurzel der Pars superior alate magnate. Der hintere und der vorlere schrag nach abwarts und hinten gerichtele Rand der Lamina medialis remeingen sich zu einem

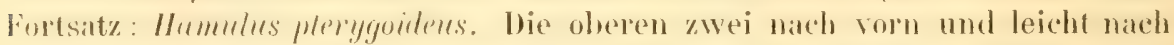
abwirls verlaufenden Rinder vereinigen sich nur in ihrer hinteren Halfte unter spitzen Winkel: in ihrer worderen weichen sie anseinander, wodurch die Incisura plerygonden zu stande kommt. An der Basis der Lamina medialis tindet sich an ihrer medialen Fliche ein schmaler Halbkanal, Sulcus Vidiamus, welcher sich nateh hinfen und lateralwarts auf die Seitenfliche des Corpus oss. sphenoidei fortsetzt.

\section{Os sphenoideum anterius, vorderes Keilbein.}

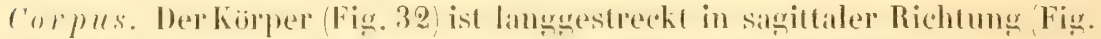

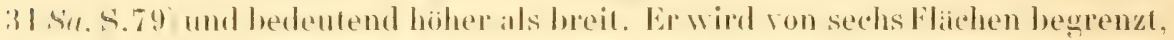

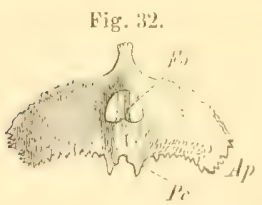

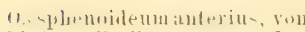
hinten. Fo Corpus oss. sphe-

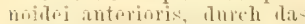
Goramen opticum hindurch

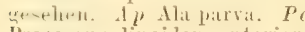
Processus clinoideus anterior. welche nach unten, hinten, oben, vorn und nach beiden Seiten gerichtet sind. Die hintere Flä he sieht mehr nach unten als nach hinten, indem sie in einem sehr stumpfen Winkel sich nach vorn in die untere Fiche fortsetzt. Sie hat eine ovale Gestalt, entsprechend rer etwas unter und hinter ihr gelegenen vorderen Fliche des Os sphenoideum posterius, mit welcher sie wie arwahnt durch die Synchondrosis intersphenoidalis (S. 79) in Verbindung steht; ihr voleres Ende verschmilert sich. - Die un tere Fliiche ist porijs, ihre lateralen Rimder sind gezahnt und verbinden sich dureh Naht mit dem oberen Rande der Parles sigitlales der Gatmenbeine. - Die latera len Flairhen werden zum groblen Teile rom den Wurzeln der Alae parvae und Processus edhmoidales cingenommen. Zwischen den Wurzehn beider bleibt ein mittleres Feld frei, walches gratt ist und den hintersten Treil der medialen Wand der Augenhöhle hilden hilft. - Die vordere Flat che bildet ein vertikales schmales Ohlongum. Welches frei zwischen den beiden Processus ethmoidales die 
Nasenhöhle nach hinten und oben schließt und eine nach vorn schatuende vertikale papierdunne Grista sphenoidalis besitzt. - Die obere Flache ist im hinteren I)ritteil frei und glatt; stellt ein sagittales, mit der Spitze mach vorn gerichtetes Dreieck dar, welches lateralwirts in die obere vordere Kante der Innenfliche der Mlae parvac ohne scharfe Begrenzung úbergeht. Wo mit nach unten konkavem Bogen die vordere Begrenzung der hinteren Wurzeln der Alae parvae von der oberen Flache ausgeht, entsteht dadurch, daß dic Bogen von beiden Seiten her zusammenlaufen, ein kleiuer, in der Vedianlinie durch eine sagittale Rinne geteilter Höker, Tuberculum opticum. Dasselhe bezeichnet das mediale Ende des nicht geschlossenen hinteren Begrenzungsrandes des hierbei als parig betrachteteu linken und rechten Foramen opticum.

Alaeparvae (Fig. $32 A p)$. Es sind zarte, vorwiegend fromtal gestelle Knochenplatten, die mit einander einen nach hinten und oben offenen Winkel bilden. Ihr konkaver unterer Rand, welcher sich ron dem hinteren Rande der oberen Fliche des Corpus lateralwairts fortsetzl, beginnt jederseits mit einem nach hinten und unten gerichteten spitzen Fortsatze: Processus clinoidei anteriores (Fig. $32 \boldsymbol{P c}$ ). Jede Ala parra rereinigt sich daun durch Naht mit dem oberen Rande der Pars superior der Ala magna, durch ihren lateralen Rand mit der Pars sfuamosa oss. temporum. Im medialen Dritteil der Sutur zwischen der Pars superior alae magnae und der Ala parva findet sich das Foramen spinosum (zum Durchtritt der A. meningea media). Von demselben ausgehend verlauft auf der hinteren Flache der Ala parva, welche in die Schidelhühle schaut, ein feiner Sulcus meningeus liur den Ramus anterior der A. meningea media nach oben und lateralwirts. Der obere konvexe Rand der Ala parra verbindet sich mit dem unteren Rande der Pars orbitalis oss. frontis. Der letztgenannte Rand hört an der vorderen Wurzel der Ala parva auf. Jede Ala parva entsteht nimlich mit einer vordereu und hinteren Wurzel. Die vordere entspringt nahe der Medianebene gemeinschaftlich mit derjenigen der andereu Körperhälfte, verläuft nach hinten, biegt sich lateralwarts und abwirts, um sich mit der hinteren Wurzel zu vereinigen. Nach vorn vereinigen sich die Vorderwurzeln beider Kirperhailften zu einer in der Medianebene gelegeneu knöchernen Kommissur der Forderurzeln dej Alat partae. Dieselbe ist an ihrer oberen Flache glatt, mit einem flachen sulcus commissurue versehen (Rest einer in friherer Entwickelungsperiode vorhaudenen Vaht, 8/S!; ihr Torderende reicht bis zum Beginn der Processus ethmoidales. Beide rordere Wurzeln umschließen mit den hinteren und dem Tubereulum opticum das unpare, eigentümlich gestaltete Foramen opticum (Fig. 32 Fo. - Fig. 20 Fo, S. 42). Dasselhe entsteht vermoge des L'mstandes, daß die sehnerven in schriger Richtung von hinten nach rom und lateralwarts die schälelhöhle verlassen. Hinten liegen die Terven dicht aneinander, das Foramen ist hinten unpar, frontal gestellt und gleicht etwa einem Kartenherzen mit nach oben gerichteter, abgerundeter Spitze. Nach rorn füht das formmen in die rechte und linke Augenhöhle; diese beiden Höhlen kommunizieren miteinauder durch den vorderen, sagittal gestellten Teil des Foramen, dessen Grundriß etwa diese Form $x$ haben wirde.

Processus ethmoidales. Sie entspringen jederseits ron dem vorderen Teile der lateralen Flache des Corpus in dessen ganzer Iiohe und außerdem 
von dem vorderen Ende der Kommissur der Vorderwurzeln der Alae parvae, so dalß die ober'n Ränder der derselben Seite angehirenden Teile ineinander iihergehen. Die Grenzlinie markiert sich am mazerierlen Schiidel vermöge des weißlicheren Aussehens der Processus. An ihrer Vereinigungsstelle bildet sich ohen ein kleines rauhes vierseitiges Feld, dessen großkte Ausdehnung in sagittaler Richtung gelegen ist und welches sich nach hinten an den gemeinschaftlichen Teil der Vorderwurzeln der beiden Nae parvae anschließt. Auf der rauhen Stelle ruhen die sich beinahe beribrenden Scheitel des bogenförmigen unferen Randes der Partes orbitales oss. frontis. Die beiden Processus ethmoidales divergieren nach vorn; jeder besteht aus einer festen, senkrechten Knochenlamelle, welche von scharf gezahnten Vahten begrenzt wird. Der obere und untere Ramd rerlaufen horizontal, der vordere schrig nach vorn und unten, so dal der untere beinahe doppelt so lang ist als der obere; letzterer grenzt an den vorderen 'Teil des unteren Raudes der Pars orbitalis oss. frontis. Der vordere Rand rerbindet sich mit dem Processus spheno-orbitalis des Oberkieferbeines, der untere Rand mit dem oberen Rande der Pars sagittalis des Os palatinum. Die beiden Flachen des Processus ethmoidalis sind glatt. Die medialen nehmen den hinteren Teil des Os efhmoideum zwischen sich und decken einge der hinteren siebbeinzellen, die lateraleu bilden den gröBten Teil der medialen Wand der Augenhöhle. Die hintere untere Ecke jedes Proressus ethmoidalis wird ron einem mehr gell)]ich anssehenden kleinen dreicekigen Fortsatze, dem rudimentiren Processus transcersus des vorderen Keilhoinkörpers eingenommen, dessen Abgrenzung durch Naht bei jungen Tieren noch zu erkennen ist und der zur Bildung der Wurzel des Processus sowie der medialen Wand der Augenhöhle beitrigt.

Der Processus ethmoidalis repräsentiert die fehlende Lamina papyracea oss. ethmoidei, welche beim jungen Tier mit dem keilbeinkörper verwächst. Die erwihnten dreiechigen Fortsitze des letzteren sind, wie eine Vergleichung des neusehorenen Kalbes lehrt, die Processus transversi dieses Schädelwirbels, während die Alae parvae Neurapophysen entsprechen.

\section{Ossa temporum, Schläfenbeine.}

bie Sohbifenheine zerfallen in drei Teile: Pars squamosi, Pars petroma-

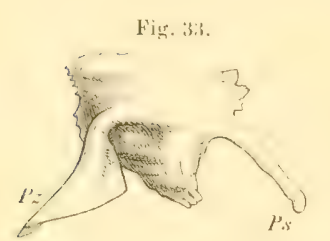

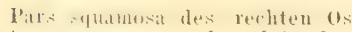
temportum, von der lateralen Seite. P'g Processus zygomaticus, vorn gelegen. Is I'rocessus squamo- II, Harh hinten und unten gerichtet. stoidea und Pars tympanica, von denen letztere beiden sehr innig miteinander verbunden sind, und dem Anscheine nach nur einen Knochen (Os petrotympanieum) bilden; sie sind jedoch durch eine nicht schwer zu lösende Harmonie vereinigt. Der hintere laterale Teil der Schidelhöhle wird fast ausschließlich von ihnen begrenzt; außerdem beteiligen sie sich an der Bildung der Schidelbasis.

Pars squamosa. Die Pars squamosa Fig. 33) hat eine unregelmaßig viereckige Form, sie ist an ihrer lateralen Flache konvex und an der medialen konkan. Das vordere Drittel der Schuppe wendet sich etwas medianwarts, so dalk es mit den beiden hinteren einen stumpfen Winkel bildet, etwa von $150^{\circ}$. 
Aus der Mitte der lat eralen Fläche erhebt sich dort, wo die mediale Biegung beginnt, ein aus dem Zusammenfluß ron zwei nach hinten diveroierenden Wurzeln sich bildender Fortsatz: Processus zygomaticus, welcher sich in einem nach oben konvexen Bogen lateralwarts nach unten und vorn wendet. Der Fortsatz ist anfiuglich mehr rundlich; er rerbreitert sich aber bald und spitzt sich dann in seinem vorderen Teile zu. Der konkave hintere Rand zeigrt in seinem unteren Teile eine kleine Einbiegung; der vorlere ist etwas spiralig gewunden.

Der breite Teil des Processus zygomaticus hat sehr große Ähnlichkeit mit dem Profile eines Ilallostiefels (Fig. 33 Pz). Der untere kourexe Rand desselben verbindet sieh mit dem ihn nach hinten iiherragenden gleichnamigen Fortsatz des Os zygomaticum. Luter $(8 / S)$ und zum Teil zwischen den beiden Wurzeh des Processus zygomaticus liegl die flache, viereckige Fossu mandibularis s. glenoidea fur deu Processus condyloideus des Unterkiefers. Vor der Gelenkgrube auf der unteren Wurzel des Jochfortsatzes findet sich das Tuberculum arliculare, welches die Lange der Wurzol hesitzt, und zugleich mit derselben die Krimmung zuerst nach auf- und damn nach abwirts macht, weshalb es bogenförmig erscheint. Das Tubereulum ist im hinteren und unteren Teile am breitesten, im mittleren am schmalsten.

Das obere Drittel der lateralen Schuppentliche bildet einen flachen Sulcus temporalis und scheidet sich dadurch ron den beiden unteren. Dieser" Sulcus führt wach vorn in die Augenhöhle. Vom hinteren Rande der Pars squamosa geht in der Fortsetzung der unteren Begrenzung des Suldus temporalis cin platter, schmaler Fortsatz unter einem Winkel von etwa $60^{\circ}$ nach hinten und unten, der Processus squamosus (Fig. $33 \mathrm{Ps}$ ). Derselle legrt sich mit seiner medialen Flache genau an die laterale Oberfiche der Pars petromastoidea dicht hinter der Miinduog des Meatus auditorius externus und hilft wesentlich dazu, den erstgenannten knochenteil in seiner Lage zu erhallon; seine laterale Fläche ist frei.

Die mediale Flitche der Schuppe zeigt an der Stelle, welohe der fossi mandibularis entspricht, eine maßige Konvexitat. Der mittlere platte Teil ist von breites, rauhen und zackigen Rindern umgeben, welche die Verhindung mit. den umgebenden Schaidelknochen einleiten und zwar so, daß sie sich auf die angrenzenden Knochen legen. Der vordere Rand rerbindel sich mit dem hinteren Rande der Ala parva oss. sphenoidei, sowie mit dem hinteren oberen Winkel, in welchen sich die Umgrenzmngsiander des Os frontis vereinigen. Der obere legt sich an den lateralen Rand des Os parietale. Der hintere rereinigt sich am oberen Teile mit der Pars squamosa oss. oceijuitis, am mittleren mit der Pars petromastoidea. Zwischen der Par's squamosa mol petromastoidea bleibt am unteren Ende des Processus squamosus oss. parietalis ein Loch oder mehrere offen: das Emissarium temporale (Foramen jugulare spurium von Rathke). Am unteren Teile ihres hinteren Randes rereinigt sich die Pars squamosa mit der Pars tympanira oss. temporum; der untere Rand geht eine Yerbindung mit dem Margo lateralis der Mla magna oss. sphenoidei ein.

Pars petromastoidea und tympanica. Beide Teile des Schlafenbeines (Fig. 34, 35, 36, S. 86) sind, wenngleich eine untrennhare knöcherne Vereinigung nicht vorhanden, doch so innig miteinander verbunden und betei- 
lị̣en sich so gleichmißig an der Bildung des knöchernen Gehörorganes, daß as zuliissił erscheint, ihre beschreibung zusammenzufassen. Sie bilden zusammen einen urregelmaBionen Kuochen, dessen Form unter einen kurzbezeichnenden Ausdruck zu hringen sehwierig sein möchte. Die Länge des Knochens ist hedeutender als seine Breite: er grehört fast iu seinem ganzen Imfange der Schaidelbasis an und ist von hinten und lateralwarts nach rorn und medianwirts werichtet. Sein in der Schädelhoble liegender Teil begrenzt die mittlere schaidelgrube nach hinten. Der kinorhen bietel folgende von einander sich al)grenzende fitichen dar: die mediale, laterale, vordere, hintere und untere.

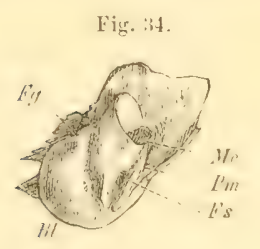

Pars petromastoidea und tympanica des linken Os temporum, vou der lateralen seite. Ie Meatus anditorius externus, $P m$ Processus mastoideus. Fs Foramen stylomastoideum. Bt Bulla tympani. Fg Fissura Glaseri.

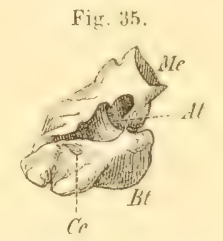

Pars tympanica des rechten $O \mathrm{~s}$ temporum, von dermedialen Seite.

Me Meatus auditorius oxternus. At Annulus tympanicus. Bt Bulla tympani. $C_{C}$ Canalis caroticus.

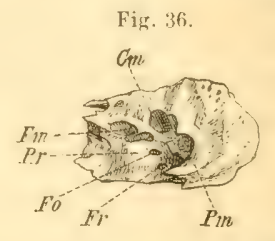

Pars netromastoidea des linken Ostemporum, von unten. Cm Cellulae mastoideae. Fm Fossa muscularis major. $\operatorname{Pr}$ Promontorium. Fo Fenestra ovalis. $F^{\prime} r$ Fenestra rotunda. Pm Processus mastoideus, in optischer Verkürzung.

Die mediale Fläche, welche ganz der Pars petromastoidea angehört und der Schidelhibhte sich zuwendet, ist von oben und hinten nach vorn, unten und medianwirts gerichtet; sie wird von oben nach unten etwas schmaler. An ihrem medialen Ende bleihl zwischen dem letzteren und dem Corpus oss. sphenoidei posterioris ein fon hinten gesehen ovales Loch: das Foramen lucerum, dessen mediale Begrenzung von einem dreiechigen Fortsatz gebildel wird. Nach inrn geht dasselbe in den Suleus sphenoidalis am Corpus oss. sphenoidei pusterioris iiher: nach unten ist es in Kommunikation mil einer weiter ahwarts gelegenen spalte, die durch ein knochenplittohen abgesondert wird. In letzlere Abteilumg míndet der Canalis aroticus und der Caurles tubarins. Ilurch die erstere geht der X. trigeminus.) Die vordere Münduny des Camalis rarotious: das Foramen coroticum intermum liegt medianwarts bon der Nimdung des Canalis tubarius. nach unfen und medianwarts von der griberen oberen Abteilung des Foramen lacerum; es gehört der Pars petromastoidea an, wilhrend der Suleus tubarius, sowie der Canalis caroticus in der Pars Ifmpanicil verafen. Das Foramen lacerum ersetzt das fehlende Foramen urale oss. sphenoidei: das Foramen rotundum fließt mit der Fissura orbitalis superior zusammen. Die Oberfiche der medialen Flache der Pars petromastoidea ist höckerig, am uteren und oberen Ende rauh. in der Mitte glatt. Im mittleren Teile finden sich zwei Foramina, ein größeres und ein kleineres, welche Mandungen von kintilen darstellen. Das größere liegt über dem kleineren und ist die Apertura interna canalis facialis.

Das kleinere gehör dem Meutus auditorius intermus an und fuibrt in das innere (Ohr. Ilinter dem Meatus anditorius internus und der Apertura interna ranalis farialis tindel sich eine tiefe ca. $5 \mathrm{~mm}$, die Pars petromatstoidea gegen den Processus mastoideus hin aushöhlende (Fig. 37 Fmi Grube : Fossa mastoidea 
(fuir den Flocculus cerebelli - s. auch Splanchnologie, Ohr). Am hinteren Rande der medialen Flache und oberhalh des Darohes der Fossa mastoidea verläuft der Sulcus transversus oss. temporum als Fortselzung des Sulcus transversus der Pars squamosa oss. occipitis. Vom lateralen vorderen Ende des Sulcus transversus erstreckt sich im hinteren Teile auf dem Winkel, welchen die mediale und laterale Fläche der Pars petrosa mit einander bilden, der Sulcus petrosus posterior (superior) nach vorn.

Auf den oberen rauhen Teil der medialen Fläche legt sich der obere Teil des lateralen Randes der Pars squamosa oss. occipitis. An denselben stöt unter spitzem Winkel die hintere Flache. Der untere spitzere Teil legt sich in die Fossa petrotympanica der lateralen Flache des Corpus oss. occipi-

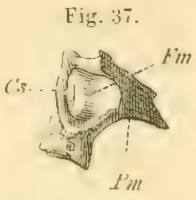

Pars petromastoidea des linken O. tempurum naw Alitragung de: Knochens bis auf die Halbierung:elene tor Fossa mastoildat. Von der lateralen Seite. F'm Fossa mastuilleit. Cs C'analirulus semivircularis superior asseus, lou Eingang in die Fossa mastoidea viherbuckend; dieser Eineraner arscheint in sehräger Profilansicht. Pm Proupsus mantoidell: tis, und bildet mit demselben eine enge Spalte: das Foramen juyulare, welches eine rordere und eine hintere Abteilung hat für die Nn. glossopharyngeus, vagus, accessorius und die V. jugularis interna).

Die vordere Fläche, ebeufalls im Innern der Schidelhöhle befindlich, springt mit einem scharfen Rande betrichtlich ibler die laterale Besrenzung der medialen Fläche hervor. Bei äteren Kinninchen linden sich an diesem Rande Verknöcherungen, welche dem Tentorium cerebelli angehören. Die vordere Flache ist halbmondförmigg gestaltet und leicht konkar. Das untere Ende stößt an den Processus clinoideus posterior des hinteren Keilheines. Das obere grenzt an den Vereinigungswinkel des rorderen und lateralen Randes der Pars squamosa oss. oceipitis. Der laterale Rand verbindet sich mit der Pars trmpanica. Die heschriebene Flache, welche durchaus ylehmaßie beschaffen ist, gehört atusschließlich der Pars petromastoidea an. Medianwirts am Winkel, den die rordere mit der medialen Flache bildel. findel sich oin feines, in den Canalis facialis führendes Loch, der Miatus canalis facialis.

Die laterale Flache (Fig. 34) wird in ihrem oberen Teile von der Pars petromastoidea gebildet und ist von spongioser Beschaffenheit. Dieser Teil liaft in eine nach unten und vorn gerichtete Spitze aus: den Processus mastoideus Fig. 34 Pm; - Fig. $37 \mathrm{Pm}$ ). Derselbe legt sich in eine Rinne zwischen Meatus auditorius externus und der Bulla l!mpani. Vor dem Processus mastoideus, am hinteren unteren Winkel der lateralen Deckplatle des Meatus auditorius externus liegt dis von ersterem mitgebildete Foramen stylomastoideum Fig. 3.4 Fs), der Ausgang des Canalis facialis. Hinter dem lleatus auditorius externus liegen die Oofnungen des Comaliculus mastoideus (fiir den R. auricularis n. vagi). Ein Processus styloidens ist scheinhar nicht vorhandes. In Wahrheit liegt derselbe in dem sehnigen Lrsprunge des 11. styloglossus verborgen, und ist beweglich mit dem Processus jugularis oss. oceipitis verbunden. Dieser Muskel, sowie die heim Menschen vom Proressus styloideus kommenden $\mathbf{M m}$. mandilunae), stylohyoideus und styfopharyngeus entsproingen simmtlich vom Processus jugularis oss. orecipitis. [)or Processus styloideus ist einige Millimeter lang. abgerundet, dreikantig und elwa $0,5 \mathrm{~mm}$ dick. 
Der großßere untere Teil der laieralen Fläche gehört der Pars tympanica an. In der Mitte dieser Flache liegt der knöcherne außere Gehörgang: Meatus auditorius cxtermus osseus, welcher der Bulla tympani aufsitzt. Derselbe ist trichterformig, oben eingekerbt, und führt von hinten oben und lateralwairts nach unten vorn und medianwirts zum mittleren Ohr. Seine laterale Wand ist viel linger als die hintere und vordere und an ihrem unteren Ende von Lijchern umgeben. Am vorderen Rande der Bulla tympani zeigt sich am oberen linde des letzteren und unter dem vorderen medialen Ende des Meatus auditorius extermus osseus cine enge Spalte: Fissura Glaseri (Fig. 34 Fg, S. 86), in welcher sich die Apertura canalis chordae tympani befindet.

Die untere Flache wird ausschließlich von der glatten und konvexen Bulla tympami (Fig. 34 Bt, S. 86) gebildet, deren größte Längendinension in der Sagitalebene gelegen ist. Sie liuft nach vorn in den rauhen Processus tympanicus aus, der sich an die Pars basilaris oss. occipitis anlegt. Hinter demselben und medianwäts ron der Bulla tympani findet sich das Foramen caroticum externum als untere Mündung des Canalis caroticus.

Die hintere Flache ist im unteren Drittel glatt und stellt den hinteren Teil der Bulla frmpani dar. Der obere Teil, der Pars petromastoidea angehörend, dient zur Verbindun mit dem Processus jugularis der Pars squamosi oss. occipitis. Die Verbindung ist eine Harmonie.

In Betreff mehrerer feiner Knochenkanäle etc. im Os temporum s. Splanchnologie (Ohr).

Varietät. Zuweilen finden sich an der unteren glatten Außenfläche der Bulla tympani etwa $2 \mathrm{~mm}$ lange, an der unteren Fläche des Processus tympanicus bis $5 \mathrm{~mm}$ lange Processus accessorii, einmal wurde ein solcher auch an der lateralen Außenwand des Meatus auditorius externus beobachtet (190).

\section{Ossa parietalia, Scheitelbeine.}

Die Ossa parietalia (Fig. 38) sind die einfachsten Schadelknochen. Sie überdachen vorzugsweise die mittlere Schadlelgrube, zum geringen Teil auch die hintere. Sie liegen symmetrisch in der oberen

Fig. 34.

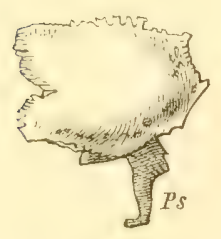

Linkes Scheitelbein eines jungen Faninchens, von der lateralen Sieite. Ps Processus squamosus. Partie des Schädeldaches nebeneinander und stellen schalenförmige Knochen dar, von viereckiger, rhombischer Form. Die obere Fläche jedes Os parietale ist konvex und zeigt im hinteren lateralen Drittel eine längliche, von der Mitte des hinteren Randes lateralwärts verlaufende Erhabenheit: Tuber parielale.

Auf der unteren oder inneren, konkaven Flache finden sịch einige undeutlich ausgesprochene Juga cerebralia. Das mediale Drittel wird von den beiden lateralen durch eine Crista sagittalis abgegrenzt, wodurch ein unpaarer Sulcus sagittalis beider Ossa parietalia von betrichtlicher Breite gebildet wird.

Man unterscheidet, wie schon aus der Form hervorgeht, vier Ränder: Margo coronulis oder den vorderen, welcher die Verbindung mit dem Stirn- 
bein herstellt durch die Sutura coronalis. Margo sagittalis oder medialer Rand, welcher beide Ossa parietalia miteinander in der Sulura sagittalis vereinigt. Margo squamosus s. temporalis oder lateraler Rand, welcher sich mit der Pars squamosa oss. temporum in der Sutura temporalis verbindet. Endlich Margo lambdoideus, welcher sich durch die Sulura lambdoidea an den vorderen Rand des Os interparietale und lateralwarts an die Pars squamosa oss. occipitis anschließt. Von dem Vereinigungswinkel der beiden letzlgenannten Rinder zeht ein dreickiger, von außen sichtharer $(S / S)$, spitz zulaufender Fortsatz, Processus squamosus (Fig. $38 \mathrm{Ps}$ ), lateralwarts und nach hinten, um sich an das mediale hintere Ende der Pars squamosa oss. temporum, zwischen letztere und die Pars petromastoidea zu legen. Derselbe ist ungefahr ebenso lang, wie das Os parietale in transversaler Richtung breit ist; er gehort nur der Tabula interna an; sein unteres Ende ist hakenfömig nach vorn gehogen. Seine Außenfläche ist rauh, die innere Flache glatt; er ist ungefahr so lang, wie das Os parietale breit ist. An der Grenze des oberen Drittels seines hinteren Randes springt ein kniefömiger Höcker vor, welcher sich in die Lücke zwischen dem oberen Teile der Pars squamosa oss. oceipitis und der Pars petrotympanica oss. temporum einschiebt.

Die Mitte der Sutura lambdoidea und das hintere Ende der Sutura sagittalis bilden zusammen eine kreuzförmige, nicht an allen Schadeln ausgesprochene Hervoragung: das Tuberculum interparietale (s. Os interparietale Fig. 29, S. 79).

\section{Os frontis, Stirnbein.}

Das Stirnbein wird eingeteilt in die Pars frontalis und Partes orbitales (Fig. 39). An ersterem kann der vordere Abschnitt noch als Par's nasalis bezeichnet werden. Bei den jüngeren Tieren zerfållt das Stirnbein in zwei durch eine Naht, Sutura frontalis, in der Medianlinie vereinigte Stücke.

Das Stirnbein beteiligt sich an der Bildung der Schädel-, Augen- und Nasenhöhle.

Pars frontalis. Der Stirnteil hat seine größte Längenausdehnung in der Richtung von hinten nach voru: er ist platt und dünn, an seiner oberen Fläche, besonders dem hinteren Teile derselben konvex, an der unteren Fläche entsprechend konkav. Im vorderen Teile der oberen Flache finden sich zwei seichte, nebeneinander liegende Gruben. Die Pars frontalis zerfallt durch die in der Medianlinie verlaufende Sutura frontalis in eine rechte und linke Hälfte (Fig. $39 \mathrm{Sf}$ ).

Der breitere hintere Abschnitt verbindet sich durch die Sutura coronalis mit den beiden Scheitelbeinen, der vordere keilförmig sich zuspitzende mit den hinteren, unter spitzem Winkel nach vorn zusammenstoßenden Rändern der Nasenbeine; er bildet die Spina nasalis. Lateralwarts ragt neben 
derselhen jederscits ein langer spitzer Fortsalz nach vorn (Fig. 39 Pm, S. 89); es ist der Processus maxillaris, welcher der Pars orbitalis angehört.

Dic simus fromlales sind wenig entwickelt, sie reichen in der Medianlinic nach oben his zur Verbindumgslinie zwischen den Mittelpunkten beider Bubi.

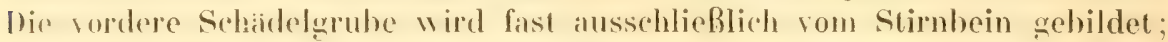
dieselbe ist binglieh und elwa hall, so hreit wie die mittlere und hintere.

Die Partes orbitales steigen von den lateralen Rïndern der Pars frontalis mit medialer Konsexitiit schrig nach unten und medianwarts. Sie sind durchscheinend dünn und zeigen an ihrer medialen Flache mehrere Juga ceremalia. Hhe hinterer Rand vereinigl sich mit dem vorderen Rande der Pars sffuamusa oss. temporum. der untere mit dem eine spirale darstellenden, zarchigen oberen Rande der Ala parva und des Processus ethmoidalis des vorderen keilbeines, und mit der oberen Spitze des Processus spheno-orbitalis oss. maxillaris superioris. Dicht hinter der genannten Spitze zeigt sich am unteren Rande das Fortumen ethmoideum (anterius - für die A. ethmoidalis anterior und den X. elhmoidalis). Der vordere Rand stößt an den hinteren Rand des Os lacrymalr. Die Pars orbitalis bildet die mediale obere Wand der Orhita. Der obere Teil des orderen Randes derselhen liaft nach vorn in einen spitzen langen Forlsatz aus: Processus maxillaris Fig. 39 Pm. S. 89), dessen obere Fliche grubenformig ausgehöhlt ist, um den langen Processus frontalis vom Os infermaxillare in sich aufzunehmen. An der lateralen unteren Seite der Wurzel dieses Fortsatzes findel sich ein kleiner, ebenfalls gespaltener Fortsalz zur Verbindung mit dem Processus spheno-orlbitalis oss. maxillaris superioris.

Von der Mitte der Pars orbitalis entwickeln sich beiderseits mit breiter Wurzel. den oberen medialen Teil der Augenhöhle úberagende Fortsäze: frcus supraorbitales, welche Fortsatze tragen: die Processus suprorbilales unterior (Fig. 39 Pa, S. 89 und posterior (Fig. $39 \mathrm{PP}, \mathrm{S} .89$. Dieselben Laufen parallel mit dog Langsrichtung des knochens und bilden einen mach anfwirts konexen Bogen. Zwischen dem vorderen kleineren und hinteren Eriberen Proressus supraorbitalis rinerseits und dem Rande des Stirnbeines andererseits bleiben dem Göhenserhiltnis beider entsprechende Spalten: Incisurae supraorbitales anterior und posterior.

Das rordere Ende des Processus supraorbitalis anterior wird mit dem oheren Teil des vorderen Ramdes dep Pars orbitalis durch feste Bandmasse rerbunden, welehe die Incisura supratorbitalis anterior aberbrucht, so dar aus derselben cin Foramen supraorbitale anterius entsteht. In analoger Weise wird ein Fortumen supranbitale posterius gebildet dureh Bandmasse zwischen drom hinteren Ende des Processus suplanthilalis posterior oss. frontis und dem voderen oberen Teil der lateralen Flarehe der Pars squamosa oss. Lemporum. AuBerdem spannt sich hrückenförmig sin Ligumentum supraorbitale vom hinferen Ende des Processus supranthilalis posterior oss. froutis zum oberen Ramble der oheren Wurzel des Processus zy gomalicus oss. femporum, wodureh aus deur Sulcus temporalis der Pars squamosa oss. temporum das Foramen trmporale entsteht. Das Ligamentum supraorbitale bilded den hinteren lateralen Rand der Augenhöhle. 


\section{Os ethmoideum, Siebbein.}

Das Os ethmoideum (Fig. 40) liegt zwischen Schidel- und Yasenhöhle, zum Teil in letzterer (Fig. 41). Nur der kleinste Teil des knochens kann als dem Hirnschälel angehörig hetrachtet werden, da er jedoch die Schidelhöhle nach vorn hin abschließt, wird seine Beschreiloung an diejenige der dieselloe

Fig. 40 .

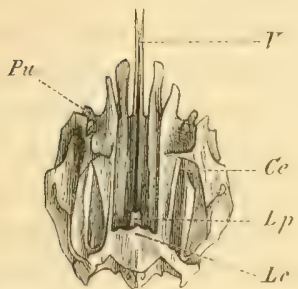

Os ethmoideum und Vomer, vou oben. V Lamina sagittalis vomeris. $C_{\epsilon}$ Cellula ethmoidales der Concha posterior superior. $L p$ Oberex Rand der Lamina perpendicularis oss. ethmoidei. $L C$ Lamina cribrosa. Pu Processus uncinatus.

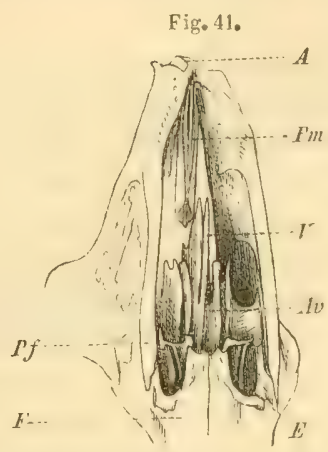

Schädel nach Wegnahme der Ossa nasi, vou oben und etwas vou rechts. A Alveole des linken großen Schneidezahnes. $P m$ Pars medialis des Ramus palatinus oss. intermaxillaris. V Vomer. Av Ala vomeris. $E 0$ s ethmoideum, $F 0$ s frontis. Pf Processus frontalis oss. intermaxillaris.

konstituierenden Knochen hier angereiht. Am Os efhmoideum sind zu unterscheiden: Lamina cribrosa, Lamina perpendicularis und die zelligen Seitenteile oder Labyrinthe.

Die Lamina cribrosa (Fig. $40 \mathrm{Lc}$ ), deren Form ein gleichschenkliges Dreieck darstellt, schiebt sich mit ihrem nach abwirts und hinten gerichteten Scheitel in die Vereinigungsstelle der oberen Rïnder der Processus ethmoidales des vorderen Keilbeines. Die oberen zwei Drittel der beiden gleichen Schenkel verbinden sich mit den vorderen Rindern der Partes orbitales oss. frontis. Die Basis oder der obere Rand wird von der Pars nasalis oss. frontis überdacht, jedoch so, daß zwischen beiden ein geringer Zwischemraum hleibt. Die Lamina cribrosa sellost ist sehr stark durchlöchert, und zeigt teils größßere, teils kleinere, in die Labyrinthe führende Öfnungen: Foramina cribrosa. In ihrer Mitte besitzt sie eine sehr zarte Scheidewand, welche sich jedoch kaum über das Niveau der Platte erheht; dieselbe ist das Homologon der bei anderen Tieren stark entwickelten Crista yalli. Die Stellung der Lamina cribrosa nähert sich der vertikalen.

Lamina perpendicular is (Fig. $42 \mathrm{Lp}$, \$. 92) s. sagillalis ist ein diunner, durchsichtiger, in der Medianehene gelegener, hallmondformiger $(818)$, in seinem vorderen, frei horvorragenden Teile einem Rhombus entsprechender Knochen. Der hintere und obere Rand ist an der Lamina rribrosa befestigt; der untere und vordere Rand sind frei, verbinden sich aber mit dem Septum narium cartilagineum (s. Splanchnologie). Die Lamina perpendicularis liegl zwischen den hinteren Teilen der Labyrinthe. 
Jeder $L a b y r i n t h u s$ besteht aus einer Menge dunnwandiger Knochenplätchen, welche sich mit einander verbinden und zwar so, daß sie kleine Giuge und zellige Riume bilden: Cellulae ellmoillales (Fig. $40 \mathrm{C} e-$ Fig. i $1 \mathrm{E}$, S.91), welche simmtlich mit der Nasenhöhle kommunizieren. Zwischen beiden Labyrinthen bleibt eine breite, spaltförmigge Iucke, welche im unteren I)rillel durch die Lamina perpendicularis halbiert wird, deren hinterer Rand zugleich eine Verbindung der unteren Teile der Labyrinthe herstellt. Am vorderen Rande des Labyrinthes zeigt sich der Processus uncinalus (Fig̣. 40 Pu, S. 91$)$.

Die hinteren Fiachen der Labyrinthe werden durch die Lamina eribrosa mitcinander in Verhindung gesetzt und gegen die Sehidelhöhle ahgeschlossen.

Die Labyrinthe liegen vollstindig in der Vasenhöhle und sind von folgenden knochen umgeben: lateralwirts von den Oss. maxillaria superiora: nach voru stoßen sie an die Conchae anteriores, nach hinten werden sie gegen die Augenhöhle ahgeschlossen durch die Ossa lacrymalia, ihre obere Flache wird überdacht, vorn von den Ossa nasi, hinten von dem vorderen Teil der Pars frontalis des Stirnbeines und dem Processus ethmoidalis des vorderen Keilheines, welcher die fehlende Lamina papyracea ersetzt (S.80). Die Conchae posteriores superior, media lohere Muschel, 157) und inferior hintere Muschel, 187 ) bilden an der medialen Seite des Laby rinthes schnale Ginge, die medianwarts geöflnet sind. Die Concha posterior superior fobere Muschel, 101: vor-

Fig. 12.

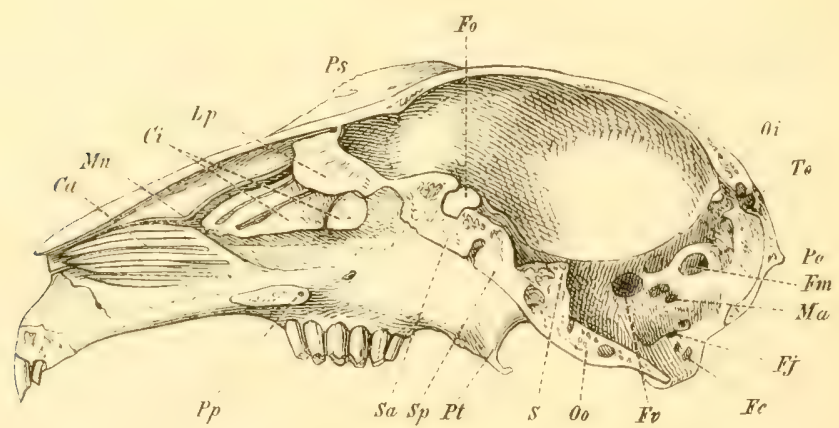

Rechte Schädelhälfte von innen. $C^{\prime} a$ Concha anterior. M Marsupium nasale. Ci Concha posterior inferior. I p Lamina perpendicularis 0ss, ethmoidei. Ps Processus supraorbitalis anterior oss. frontis. Fo Foramen opticum. $P p$ Querschnitt der Pars palatina oss. palatini und des Processus palatinus oss. maxillaris superioris. $S a$ Corpus oss. sphenoidei anterioris. S $p$ Corpus oss. splenoidei posterioris. Pt Processus pterygoideus oss. sphenoidei posterioris. S Sella. Oo Pars basilaris oss, occipitis. F'v Foramen orale. Fc Foramina condyloidea anteriora. Fj Foramen jugulare. If a Meatus auditorius intermus, daräber die Apertura interna des Canalis faeialis. Fm Fossa mastoidea oss. temporum. Po Protuberantia occipitalis externa. To Tuberculum occipitale. $\theta i$ Vorderes Ende des Os interparietale.

dere Muschel, 197) ist die lingste und rerbindet sich mit dem Marsupium nasale; die media ist in ihrer vorderen Hälfe doppelt (Fig. 42), was auch bei der inferior der Fall, doch verlauft die Trenuungsspalte bei letzterer mehr senkrecht (Fig. $42 \mathrm{C} i$ ). 


\section{Gesichtsknochen.}

\section{Ossa maxillaria superiora, Oberkieferbeine.}

Jedes Os maxillare superius zerfält in zwei Teile: Pars anterior s. Os intermaxillare und Pars posterior s. Os maxillare superius proprium.

\section{Os intermaxillare}

oder die Pars anterior, ist bei der bedeutenden Entwickelung der Schneidezihne des Kaninchens ebenfalls ansehnlich entwickelt Fig. 43). Sie besteht aus dem Corpus, dem Ramus frontalis und dem Ramus palatinus.

Das Corpus ist ein von knöchernen Wandungen umgrenzter Hohlraum, welcher den großen vorderen Schneidezahn enthålt. Entsprechend der Form des letzteren ist es von hinten nach vol'n und abwärts gekrümmt. Die knöchernen Wandungen sind als obere, laterale, untere und mediale zu bezeichnen. Erstere drei gehen abgerundet ineinander uber und sind glatt.

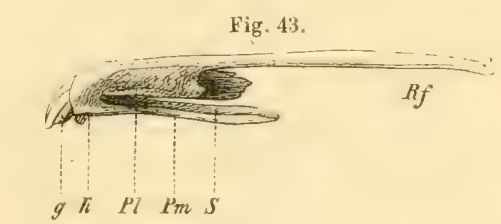

Rechtes os intermaxillare, von der medialen Seite und etwas von oben. g Großer sehneidezahn. $k$ Kleiner Schneidezahn. $P l$ Pars lateralis des Ramus palatinus. $P m$ Pars medialis des Ramus palatinus. Semisulcus palatinus. $R f$ Ramus frontalis. Die obere und die laterale sind die kürzesten, die laterale die breiteste. Am hinteren Teile des Corpus versehwindet die obere Wand, indem die mediale und laterale unter spitzem Winkel zusammentreffen. Hinter der Mündung der Alveole für den großen oberen Schneidezahn liegt eine kleine, trichterförmige Vertiefung für den kleinen oder Reserveschneidezahn. Der vordere Teil der medialen Fliche des Os intermaxillare ist gerieft und verbindel sich durch eine Harmonie mit dem der anderen Seite.

Der Ramusfrontalis (Fig. $43 R f$ ) s. superior entwickelt sich aus dem oberen Teile der lateralen und medialen Fliche und steigt bogenförmig nach oben und hinten. Es ist ein gritenformiger, langer und schmaler Fortsatz, dessen laterale Flache schwach ausgehöhlt ist. Der vordere Teil der letzteren legt sich auf den oberen Rand des Os maxillare superius proprium; der hintere Teil an den Processus maxillaris oss. frontis bis zu dessen Ursprunge.

Der Ramus palatinus ist eine Fortsetzung des unteren Teiles der medialen und lateralen und des hinteren Teiles der unteren Flache. Die von der medialen Fläche stammende Partie: Pars medialis (Fig. $43 \mathrm{Pm}$ - Fig. $41 \mathrm{Pm}$, S. 91) ist fast selbstindig; sie verbindet sich mit der anderen oder der Pars lateralis nur durch ein von ihrem vorderen Ende unter spitzem Winkel nach vorn und lateralwirts verlaufendes Knochenplätchen. Die nach oben gerichtete Flaiche der Par's medialis bildet einen tiefen Semisulcus palatimus (Fig. $43 \mathrm{~S}$ ).

Der gleichnamige Teil der anderen Seite legt sich an den medialen Rand des Semisulcus palatinus an, wodurch der Sulcus palatimus entsteht.

Der laterale Teil, Pars lateralis (Fig. $43 \mathrm{Pl}$ ), des Ramus palatinus ist 
breiter, dicker und kürzer, und an seinem hinteren Ende gezahnt, um sich mit dem unteren vorderen Teil des Os maxillare superius proprium zu verbinden. Zwischen den Partes laterales des linken und rechten Ramus palatinus oss. intermaxillaris bleiht eine mehrere Centimeter lange, vorn spitze, hinten breitere, dreieckige spalte, das Foramen incisium, welches nach hinten dureh die Processus palatini der beiden eigentlichen Oberkieferbeine geschlossen wird.

\section{Os maxillare superius (proprium).}

I) Pars posterior uss. maxillaris superioris (Fig. 44) besteht aus einem Corpus und vier Processus. Letztere sind der Processus zygomaticus, alveolaris, palatinus und spheno-orbitalis.

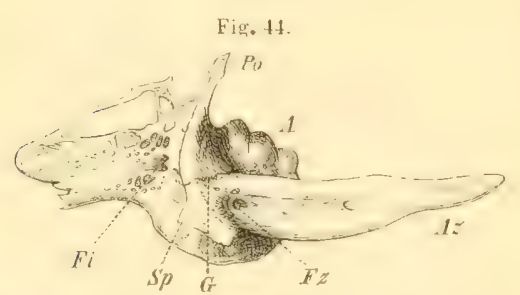

Linkes 0 s maxillare superius und Os zygomaticum, von der lateralen Seite. Po Processus spleno-orbitalis. A Drei Alrwuli. AzArous zyomations. $F$ Furanen zyummaticofaciale. $G$ Gremzlinie des Os zygomaticum gegen

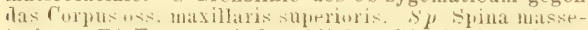
terica. $F i$ Foramen infraorbitale. Die Gesichtsfläche

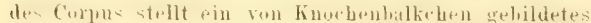
Maschennetz dar.

bindung mit der hinteren des Corpus oss. intermaxillaris

Corpus. Dasselbe hat, wenn man sich die Fortsitze von demselben weggenommen denkt, eine dreieckige keilförmige Gestalt. Es ist von hinten oben nach vorn und unten geneigt, verschmälert sich in dieser Richtung und konvergiert unter spitzem Winkel mit dem der anderen Seite. Genau genommen lassen sich fünf Flachen unterscheiden: die vordere, mediale, laterale, untere und hintere.

Die vordere Fläche ist klein und ungezahnt, sie dient zur Ver-

Die mediale Fläche oder Nasentliche zeigh verschiedene Gruben. Leistrn und knochenplattchen und bildet die laterale Begrenzung des flachen Simus maxillaris, welcher mit den Zellen des Siebleinlabyrinthes ein Continuum darstellt.

Die laterale Flaiche oder Gesichtsfliche stobt oben unter spitzem Winhel mil derjenigen der anderen seite zusammen. Sie ist mit Ausnahme ihres oberen und unteren Randes von spongioser Beschaffenheit, d. h. sie bildet ein zartes Balkenwerk und zeigh viele, zum Teil bedeutende Lüeken, durch welche man in die Yasenhohle gelangt. Durch den unteren Teil dieses Balkenwerkes verliaft parallel mit dem oberen Rande cin anf der medialen und lateralen Filiche durch zarte knöcherne Wandungen begrenzter Kanal, Canalis nasolacrymalis, welcher nach oben und hinten mit dem Semicanalis lacrymalis oss. lacrermalis sich verbindel, nach rorn unter der Concha anterior ausmündet. Die mediale. Wind dieses kimales ist nath unten und lateralwirts mugebogen, ohme daff die untere Wind iberall vollstindig greschlossen wire; die umgebogene knochenlamelle entspricht der C'ristu lacrymalis. Der hintere, an die Augenhihle grenzende Teil ist in der unteren Partie starker und fester; der hintere Teil ist fester und härter, bildel hauptsächlich den nasalen Rand der Orbita. sentet nach oben den Processus spheno-orbitalis ab. Nach unten zeigt 
dieser Teil eine breite Hervorragung, Processus zygomaticus (Fig. 44 Az), mit welcher das Os zygomaticum ( 5.96 ) knöchern verschmolzen ist. Vor diesem Processus sieht man eine tiefe Grube an deren Bildung dis Corpus oss. zygomatici Anteil nimm, die Fossu maxilluris. in derselben mehrere kleine Foritmini, welche in die Alveolen der vorderen Barkenzihne des Olserkieferbeines führen, und medianwirts das gröBere Foramen infraorbitale (Fis. 44 Fi). Dasselbe ist die Mündung des von hinten nach vorn an der medialen, vertikal gestellten Seite der Alveolen des dritten bis fünften Backenzahnes verlaufenden Sulcus infraorbitalis: das Foramen infraorbitale durchbohrt nämlich in fortgesetzter Richtung des genannten Suleus in der Richtung von vorn nach hinten das Corpus oss. maxillaris superioris. Mit dem Augenhöhlenrande der latrralen Fläche verbindet sich knöchern der Processus orbitalis oss. zy gomaltici.

Die schmale untere Flache ist in der vorderen Halfte mit Ausnahme eines kleinen, an die Vorderflache grenzenden gezahnten Teiles glatt; die hintere Hälfte wird rom Processus alveolaris in Anspruch genommen.

Die hintere Fläche oder Augenhohlentliche gehört dem Processus alveolaris an; sie ist breit, nach hinten und etwas lateralwirts steil ahfallend. Am oberen und medialen Teile derselben sieht man drei von oben nach hinten und unten aufeinander folgende, stark hervortretende Jugia des dritten, ierten und fünten oberen Backenzahnes.

Processus alveolaris. Der Processus alveolaris geht aus der unteren Fliche des Ciorpus hervor. oder reprasentiert sie vielmehr. Lir besteht aus einer medialen und lateralen Platte, ion denen letatere bedeutend weiter nach abwirts ragt als erstere. Beide Platten sind durch fiuf Querleisten miteinander verbunden, worlurch sechs Alseoli gebildet werden, von denteu der dritte, vierte und fünfte die geräumigsten und lingsten sind (Fig. 44 A), der sechste der kleinste ist. Die Innenfliche der lateralen Wand der vorderen fün Alveoli zeigt je eine vertikale, jene Innenfliche etwat halbierende Cristu dentalis. Diejenige des ersten Alreolus ist die schwachste, fehlt haufig oder rerdoppelt sich.

Processus palalinus. Ist eine medianwärts gerichtete horizontale, viereckige, starhe knochenplatte von efwa Dritteil der medialen Platte unter rechtem Winkel ahgeht. Der mediale Rand verbindet sich mit dem der anderen Seite durch eine Xiht. Das vordere Ende dieser Verbindung lauft in eine kriftige Spitze aus: Spinu nasalis s. nasalis anterior. Der vordere Rand bildet einen nach hinten konsexen Bogen, an den hinteren legt sich der vordere Rand der Limina horizontalis uss. palatini.

Processus spheno-orbitalis (Fig. 44 Po). Entsteht vom Corpus an der Stelle, wo der mediale Rand des Alveolus des dritten oberen Backenzahnes mit dem hinteren Rande des Processus palatiuns zusammentrifft. Ragt spit\% nach oben, verbindet sich nach rorn mit dem Os lacrymale, nach hinten mit dem vorderen Rande des Processus efhmoidalis des vorderen keilheines. Seine Spitze verhindel sich mit dem I'rsprungsteil des Processus maxillaris oss. frontis. 


\section{Ossa zygomatica, Jochbeine.}

Jedes Os zygomaticum (Fig. 4ä) besteht aus einem Corpus und den beiden Processus orbitalis und zygomaticus.

Das Corpus (Fig. 45 c) bildet ein Continuum

Fig. 45

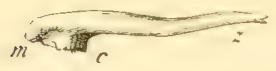

Linkes os zygumatienm eines 12 . tagigen Kaninchens, von unten. Vergr. 2. $z$ Processus zygomaticus. c Corpus. in Spiua masseterica. mit dem Processus zygomaticus des Oberkiefers, es ist rundlich und glatt. Es wird von dem Canalis zygomaticus durchbohrt (durch welchen der $\mathrm{N}$. subcutaneus malae verlauft). Der Kanal beginnt in der Augenhöhle mit dem Foramen sygomatico-orbitale an der lateralen Seite der Alveole des dritten oberen Backenzahnes, biegt sich nach vorn und lateralwiirts, mündet auf der lateralen Fläche des Os zygomaticum mittels des $F_{0}$ ramen zygomaticofaciale Fig. 4. F $F$, S.94) in das Gesicht. Diese beiden Foramina sind am mazerierten Schadel schwer von feinen Ernährungslächern des Knochens zu unterscheiden. Aus dem oberen und vorderen Teile des Corpus oss. zygomatici gehen die beiden Fortsitze hervor, die letzteres fast ganz verdecken; nach vorn läuft dasselbe in eine dreieckige Zacke aus, die Spina facialis.

Der Processus orbitalis wendet sich medianwarts und aufwarts und ist knöchern mit dem lateralen Rande der hinteren Flache des Corpus oss. maxillaris superioris verbunden.

Der Processus temporalis oder Arcus zygomaticus (Fig.44 Az, S. 94) wendet sich unter rechtem Winkel vom Körper nach hinten, um sich mit dem Processus zygomaticus oss. temporum zu verbinden, welcher letatere sich auf den oberen Rand seines hinteren Teiles legt. Der Areus zygomaticus hat zwei Flachen, eine mediale und laterale, die an der vorderen Halfte etwa $5 \mathrm{~mm}$ breit sind. Nach vorn und unten endigt er mit einer schwachen Hervorragung: Spina masseterica (Fig. $45 \mathrm{~m}$ ). Nach hinten zu verschmalert er sich ein wenig und endet frei mit abgerundeter Spitze, den Processus zygomaticus oss. temporum nach hiuten etwas überragend. Die große lateralwarts gerichtete Augenhöhlenöfnung erhiilt durch ihn den unteren Teil ihrer Zirkumfereaz, welche oval erscheint. Zwischen Areus zygomalicus und Processus pterygoideus oss. sphenoidei posterioris bleibt eine große Lücke, durch die man von unten in das Innere der Orbita und die Fossa infratemporalis gelangt.

Das Os zygomaticum verwächst in den ersten Wochen (vergl. 146) mit dem Corpus oss. masillaris superioris. Bei jungen, ein paar Ionate alten Tieren laßß sich die gezachle Grenzlinie gegen den Processus zygomaticus oss. maxillaris superioris an der Außenfliche noch erkennen.

\section{Ossa palatina, Gaumenbeine.}

Das Os palatinum (Fig. 46) besteht aus zwei unter einem rechten Winkel zusammenstoßenden Stücken: Pars nasalis und Pars palatina. 
Pars nasalis (Fig. $46 \mathrm{Pn}$ ) s. sagittalis. Sie hat ihren größten Laingsdurchmesser in der Richtung von vorn nach hinten. Derselhe lialt jedoch nicht genau in eine Sagiltalebene, sondern beschreibt einen kleinen Bogen, dessen Konvexitiat nach oben gerichtet ist; derselbe senkt sich hinten weiter wach unten als vorn. Der Knochen ist sehr dün und fast in seiner ganzen Ausdehnung durchscheinend. Die laterale Fläche legt sich mit ihrem vorderen Drittel an das hintere Ende der medialen Flache des Corpus oss. maxillaris superioris (proprii), sowie des Processus alveolaris.

Die mediale Fliache, welche die untere Inilfte der medialen Wand des Cavum orbitale darstellt, zeigt

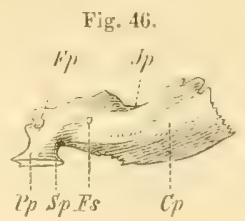

Rechtes $O s$ palatinum, von unten und etwas ron der medialen Seite. $F p$ Foramen palatinum. I $p$ Incisura palatina. $C_{p}$ C'rista palitina. F's lomanen splenopiala tinum. Sp sijuna palatina de Pars nasalis, $P$ p Pars palatina. eine erhabene Firste, Crista palatina (Fig. $46 \mathrm{Cp}$ ), die rom hinteren kande der Pars palatina bis zur Verbindung mil dem Processus pteryodideus oss. sphenoidei posterioris sich hinzielit und su eine Grenzlinio zwischen dem unferen und den beiden oberen Dritteln hildet. Dop vorder Rand der Pars nasalis ist zugleich der hintere der Pars palatina. Der hintere Rand legt sich auf die Verbindung der beiden Lamina des Processus pterygoideus. Der untere Rand liegt in vorderen I)riftel an der medialen Fliche des Processus alveolaris oss. maxillaris superioris. Die beiden hinteren Driltel sind frei. Wo das mittlere Drittel sich an dis vordere anschließt, zeign sich ein halbmondförmiger Ausschnitt: Incisura palulima (Fig. $46 \mathrm{Jp}$ ). I Das hintere Ende des unteren Randes verbindet sich mit dem unteren Ende des hinteren Randes zu einem ziemlich breiten Fortsatz: Proressus myramidalis, welcher die Incisura pterygoidea des l'rocessus ptergogideus oss. splsenoidei ausfuillt. Der obere Rand ist in seinem hinteren Teile frei, in seinem vorderen verbindet er sich mit den unteren Rindern des kïrpers des vorderen keilheines sowie dessen Processus ethmoidalis. Am vorderen Ende der Pars nasalis finded sich ein ovales Loch, Foramen sphenopalatimum (Fig. $46 \mathrm{Fs}$, welches die Augenhöhle mit der Nasenhöhle rerbindet. Nach vorn rvird dasselhe vom Processus spheno-orbitalis oss. maxillaris superioris geschlossen.

Das Foramen sphenopalatinum dient zum Durchgange der A, und $\mathrm{Nn}$. sphenopalatin. (s. Angiologie und Neurologie). In dieser Hinsicht ist es analog dem bei anderen Silugetieren durch den Processus orbitalis und sphenoidalis oss. palatini, sowie das Corpus oss. sphenoidei gebildeten Foramen sphenomaxillare.

Pars palatina (Fig. $46 \mathrm{Pp}$ ) s. horizontalis. Sie geht vom vorderen Ende der Pars nasalis medianwirts und vereing sich mit derjenigen der anderen Seite bei jugendlichen Tieren durch eine Naht, die Jei ailteren Kiminchen einer knöchernen Verbindung Platz macht. Die Verhindung wird hezeidenel durch eine auf der oberen und unteren Flache sichthare Crista, die nach hinten in eine Spitze ausliuft: Sprina palatina (Fig. $46 \mathrm{~S}_{\text {) }}^{\prime}$ 's. nasalis posterior. Die Pars palatina ist dicker als der Nasalteil, aber viel kleiner; viereckig ron Gestalt bildet sie den hinteren Teil des knöhernen Gaumens. Ihr vorderer, spiralig gewundener Rand leg̣t sich an den hinteren des Processus palatinus oss. maxillaris superioris, ihr hinterer Rand ist frei und konkar. An der Vep- 
bindungsstelle des rorderen und lateralen Randes gelangt man auf der unteren Fläche in einen kurzen Kanal, welcher auf der unteren Fliche der Pars palittina mittels des Foramen palatimum (Fig. $46 \mathrm{Fp}, \mathrm{s} .97$ ) mündet, und von da anf die laterale Fliche der Pars nasalis, sowie weiterhiu in die Augenhöhle führt: Canalis palatimus.

Der harte Gaumen ist sehr klein. Er stellt eine Bricke dar zwischen den vier rorderen Alveolen der Backenzihne des Oberkiefers. Woraus seine geringe Lïngendimension sich ergiebt.

\section{Ossa nasi, Nasenbeine.}

Die beiden Ossa nasi (Fig. 47) bilden den knöchernen Yaseurücken. Sie sind lang, unregelmiißig viereckig, nach aufwirts mißig konvex und neigen sich von oben und hinten schwach nach unten und

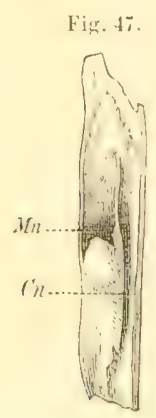

Linkes Os nasi, ron hinten und unten. Hn Harsmuinu nasale. ('i) Cri-ta naritlivorn. Ihre medialen Ränder vereinigen sich unter einem Winkel von etwa $150^{\circ}$. Die lateralen Rander, nach hinten um ein Viertel länger als die medialen, legen sich an den oberen Rand des Ramus frontalis des Os intermaxillare in seiner ganzen Ausdehnung, indem sie nach hinten etwas divergieren. Die vorderen freien Rïnder sind die kleinsten, sie stoBen in der Medianlinie zusammen und haben eine Bogenform mit nach oben und lateralwärts sehender Konvexitä. Thre Vereinigung geschieht unter einem Winkel von ca. $150^{\circ}$. Zwischen den Alveolen der beiden groben oberen sidmeidezihne und den vorderen Rändern bleibt eine herzförmige Lủcke, die ziemlich steil von hinten oben nach vorn unten gestellt ist: Apretura priformis. I) hinteren Rander beider Ossa nasi verlaufen von hinten und lateralwarts nath vorn und medianwarts, und stoßen unter spitzem Winkel zusammen. In die dadurch entstehende geräumige Incisura nasalis schicht sich die Spina nasalis oss. frontis. Die obere Fläche des Os nasi ist glatt; das vordere I) rittel gegen das hintere ein wenig um eine sagittale Achse lateralwarts gedreht. Die untere Flä che wird durch eine über ihre ganze Längenausdehnung sich erstreckende Firste, Cristu nusalis Fig. 46 ('n), in zwei Sulci gretheilt, ron denen der mediale der schmalere ist. In der vitte des lateralen wird durch eine zarte knöcherne Cherdachung ein Ilohlraum von auffallend taschenfirmiger Gestalt, Marsupinm nusale (Fig. $47 \mathrm{Mm}$. - Fig. $20 \mathrm{M} / \mathrm{m}$ S. 42 gebilded, welcher nach hinten offen ist. Derselbe legt sich auf den vorderen Teil des siebbeinlabyrinthes und ist einer Zelle desselben analog.

\section{Ossa lacrymalia, Thränenbeine.}

Das Os lacrymale (Fig. 48) ist ein kleiner, unregelmaßiger, sehr zarter kinochen. Welcher den oberen Teil der vorderen Wind der Augenhöhle bildet, 
die er gegen die Nasenhöhle verschließt; es liegt in einer von oben und hinten nach vorn und unten gerichteten Ehene. Mit seinem medialen Teile schicht sich das Thranenbein in die Inzisur, welche ron dem vorderen Teil der Pars orbitalis oss. frontis und dem Processus spheno-orhitalis oss. maxillaris superioris gebildet wird. Lateralwirts und unten leğ es sich zwischen Processus orbitalis oss. zygomatici und Corpus oss. maxillaris superioris, jedoch schließt es sich nicht innig letzteren beiden Knochen an. Der größere mediale Teil des Thränenbeines ist sehr zart, durchscheinend dünn, der laterale kleinere dick, etwas wulstig und zeigt einen hakenförmigen Fortsaty, den lateralwirts über das Niveau des Augenhöhlenrandes hervorragenden Processus subcutaneus (Fig. 48 Ps.-

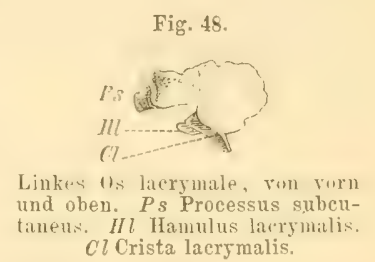
Fig. $3 \mathrm{Pl}$, S. 13) s. Hamulus lacrymalis, der unter der Haut fühlbar ist. In der Mitte des lateralen Teiles des Os lacrymale findet sich eine weite horizontale Incisura lucrymalis, welche in die Nasenhöhle führt. Die hintere Fläche oder Augenhöhlenfliiche gleicht einer sehr schwach geneigten schiefen Ebene, indem der Knochen in der Mitte ein wenig um eine horizontale Achse gebogen erscheint. Diese Vorwoblbung in der Mitte: Crista lacrymalis (Fiw. $48 \mathrm{Cl}$ ), teilt die Lugenhöhlenfläche in eine obere und untere Ibilfte. Die r ordere Flatche oder Kasenhöhlenflache ist grubenförmig rertieft. Lateralwirts verliuft ein nadelspitz endigender fortsatz nach rorn und unten, welcher an der lateralen Soite des Labyrinthes des Os efhmoideum frei in der Yaseuhöhle aufhört. Dieser Fortsatz bildet einen Halbkanal, Semicanalis lacrymalis, welcher lateralwirts offen ist; das hintere Ende des letzteren wird nach unten rom Hamulus lucrymalis Fig. $48 \mathrm{Hl}$ begrenzt. Das erwähte hintere Ende offnet sich dureh die Incisura lacrymalis in die Augenhöhle: nach rom wird seine Fortsetzung rom Canalis nasolaceryalis oss. maxillaris superioris gebildet.

\section{Conchae anteriores s. inferiores, vordere IIuscheln.}

Die Concha anterior Fig̣. 49) liegt hei horizontal gehaltenem Kopfe in einem Vireau mit den Conchae posteriores media und inferior oss. ethmoidei. Sie ist ein kleiner viereckiger Knochen, mit zwei spitzen und zwei stumpfen Winkeln, von merkwürdiger Beschaffenheit. Im vordersten Teile der Nasenhöhle, an der Verbindungsstelle des Os intermaxillare mit dem eigentlichen Os maxillare superius gelegen, geht ihre laterale Flache eine lockere Verbindung ein mit dem rorderen Teil der lateralen Flache des Corpus oss. maxillaris superioris proprii . Dieser laterale Teil ist eine sehr zarte Knochenplatte,

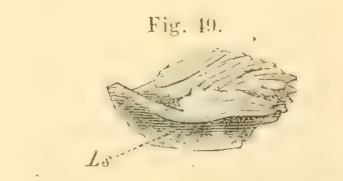

Linke Coucha anterior, von der mellitlen sirite. Ls Liminit sitgittalis, - Verrl. Fig. 20 l'u. $\therefore 4$.

Lamina sagittalis Fig. $49 \mathrm{Ls}$ ), welche nach hinten in einen spitzen Fortsatz ausliuft, der sich in eine Zelle des Siebheines hineinschieht, um die Befestigun 
ten Lamelle sitzt ein Labyrinth von kleinen, parallel verlaufenden, durch feine Knochemplittchen gebildeten Gingen, wolche zum Teil durch wiederholte spaltumg der einzelnen lamellen gebildet werden, und gleichsam ein selhstindignes Os ahmoideum im kleinen datstellen. Zwischen den Labyrinthen beider Seiten, welehe ein wenig ibher den Ramus frontalis des Oberkiefers her orragen, liegt eine lingliche, schmale, durch das Septum narium cartilagineum halbierte Spalte. Von oben werden sie aberdach durch den vorderen Teil der Nasenbeine.

\section{Vomer, Pflugscharbein.}

Eindiunner, inder Medimebene gelegener, mpararernochen Fig. : 0 ), der

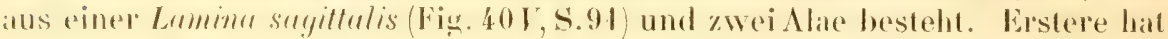

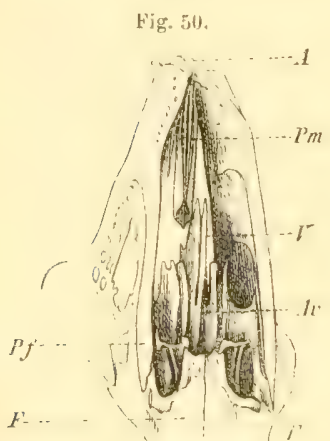

Schädel nach Wegnahme der Ossa nasi, yon oben und etwas von rechts. A Alveole des linken groien Schneidezahnes. Pm Pars medialis des Ramus palatinus oss. intermaxillaris. $v$ Vomer. iv Ala vomeris. $E$ Os ethmoideum. $F O$ s frontis. Pf Processus frontalis oss, intermaxillaris. einen bogenförmigen oberen, einen längeren unteren und einen kürzeren vorderen Rand. Der obere und untere Rand sind viel langer als der vordere. Der obere Rand ist in zwei Blatter gespalten, welche das Septum narium cartilagineum (s. Splanchnologie) zwischen sich fassen. Nach hinten bleibt ein großer Zwischenraum zwischen diesem Rande und der Lamina perpendicularis oss. ethmoidei. Der untere Rand liegt frei zwischen dem hinteren Ende des Processus palatinus oss. intermaxillaris und der Spina nasalis des l'rocessus palatinus oss. maxillaris superioris, ohne sie zu erreichen. Der vordere Rand liuft mit dem vorderen Teile des oberen Randes zusammen in eine gespaltene papierdünne Spitze aus, die oberhalb der Pars medialis des Processus palatinus oss. intermaxillaris nach vorn ragt. Von den Seitenflichen des Vomer entspringen die sehr zarten Alae vomeris, welche an die Labyrinthe des Os ethmoideum sich antegen. Dies ist die einzige Befestigung des Vomer an Knochen. Sein hinterer Teil liegt zwischen den beiden Labyrinthen oss. ethmoidej.

\section{Maxilla inferior, Unterkiefer.}

Der Lnterkiefer des Kaninchens ist im Verhaltnis zum übrigen Scbidel anberordentlich groli. Er besteht aus zwei einander vollkommen entsprechenden Iliblen, die in der ganzen Linge ihres Schneidezahnteiles miteinander verbunden sind, dann aber unter einem Winkel von etwa $30^{\circ}$ divergieren. Die V'erhindung der schneidezahnteile geschieht in den hinteren zwei britteln nur dureh den hleineren unteren Teil der medialen Flachen, so daB zw ischen dem oburen yruberen Teil derselben eine nach oben sich oflnende, tiefe, lingliche und schmale Spalte bleibt, die Fossa incisiva. 
Jede Seitenhalfte des Unterkiefers zerfallt in zwei Teile: Corpus und Ramus.

Corpus maxillae inferioris (Fig. 51). Jedes Corpus besteht wiederum aus zwei Teilen, der Pars incisiva und der Pars buccalis, deren Längendimension fast die weiche ist. Die l'ars incisi a, welche einen sehneidezahn enthailt, ist niedriy und rumblich, jerloch lassen sich an ihr eine mediale. laterale, obere und untere Fiche unterseheiden. Letatere drei gehen abgerundet ineinander iber; die mediale, welche, wie schon erwähnt, die Verbindung mit der gleichnamigen Flache der anderen Seite herstellt, setzt sich schirfer gegen die obere und untere ab. Am hivteren Teile der unteren Fläche finden sich eine Menge kleiner Foramina, welehe in den das ganze In-

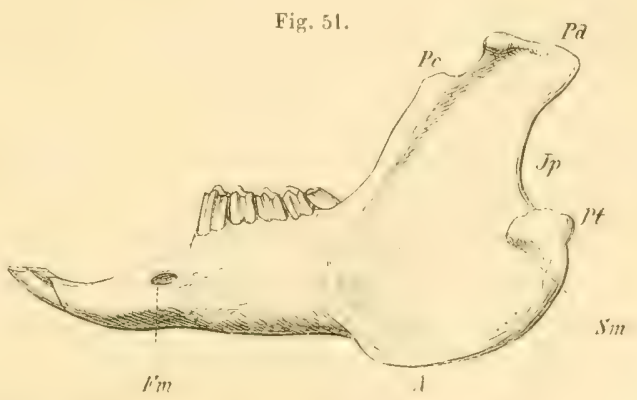

Unterkiefer eines doutschen Kaninchens, im Profil. $P d$ Processus condyloi-

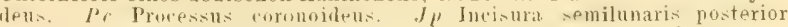
$P t$ Processus pterygoidens. Sm Spina maxillaris. A Angulus maxillae inferioris. $F m$ Foramen mentale. nere der Pars incisiva einuehmenden Alveolus des Schneidezahnes fiihren. Dort, wo die laterale Flache der Pars incisiva in die der Pars buecalis übergeht, findet sich das ovale Foramen mentale (Fig. 51 Fm).

Die Pars bucealis, in welche die Pars incisis anter einem lateralwarts oflenen stumpfen Winkel von etwa $1: 30^{0}$ übergeht. ist loppelt so hoch als diese, jedoch bedeutend schmaler. Auch sie zeigt vier Flachen : obere, untere, laterale und mediale. I)ie obere Fliche enthilt fün tiefe, den knochen von ohen nach unten durchsetzende Alveolen für eben so viele Backenzihne. An der imneren Wand der Alseolen verliuft eine scharfe Firste, die an der lateralen Wand ebenfalls rorhanden und stirker ausgebildet ist. Dieselbe greift in einen Sulcus der anliegenden Flichen der viereckigen Backenziihne ein. Der vorderste Alveolus hat zwei solcher Firsten an seiner lateralen Waud. Die laterale, breite, glatte Fliche geht in die untere, schmale, ebenfalls glatte Fliiche unter abgerundetem $\mathbf{W}$ inkel iber. Im vorderen Teile derselben sind wiederum eine Menge kleiner Foramina. durch welche man in die $\Lambda$ veolen gelangl.

Die mediale Flache wird durch eine bogenförmige Erhabenheit in eine obere und untere Hälfte geschieden. Beide Hälften stellen seichte Gruben dar. Diese Erhabenheit: Eminentia mylohynidea verliuft von der Mitte des hinteren Endes der medialen Fläbe der Pars incisiva aufwarts bis zum letzten Backenzahn und setzt sich in gleich zu beschreibender II eise auf den Ramus maxillae inferioris fort.

Ramus maxillae inferioris. Der Ramus des Lnterkiefers entwickelt sich aus dem hinteren Ende des Corpus. Die obere Flidehe des letzteren steigt unter stumpfem Winkel schrigg aufwirts. Sie bildet eine tiefe Furche, den Sulcus adscendens, welcher von scharfen Rindern begrenzt wird. Der laterale Rand 
besitzl in seincm mitleren Teile eine vorspringende Knochensehuppe, den Pro-

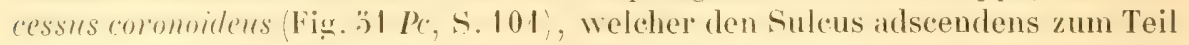
iiberdacht. Der mediale Rand bildet die Fortsetzung der Eminentia mylohyoidea. Am unteren Ende des Suleus adscendens findel sich ein ovales Loch, das Forumen mandilulure, dureh welches man auf die mediale Flaiche des Ramus und in einen Kanal gelangl, weleher das Corpus sehief nach rorn unter den Alreolen durchsetal und in das Foramen mentale ausmindet: Cunalis maxillaris. Durch das Foramen mandibulare geht eine Vene, relche die Vv. alveolaris inferior und orbitalis inferior in Verbindung setzt (S.64).

Die untere liache des Gorpus geht nach hinten allmahlich in den Ramus iiber. Anfangs wendet sie sich ein wenig nach abwarts als stumpfe Spina maxillaris (Fig. j) Sme, erheht sich jedoch bald hogenfömig nach oben, etwa his zur Hibhe, wo die ohere flithe anzusteigen beginnt, und bildet atuf diese

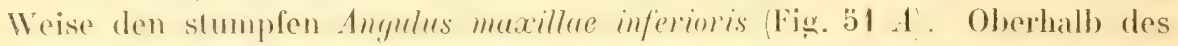
Ingulus ist der knochen sehr diinn und ofters perforient (Fig. 10 P, S. 16).

Der obere hintere Rand des Ramus ist ein halbmondförmiger Ausschnitt, modureh zwei Vorspriange antstehen, ein hinterer unterer und ein vorderer oberer. Ersterer ist klein und spitz: Processus pterygoideus (Fig. 51 Pt, an welchen lasern des 11 . plery goideus internus sich inserieren; letzterer, Processus condyluideus, ist stark entwickelt, viererkig und zeigt an seinem oberen vorderen Teile cine birnfömig̨e uberknorpelte Gelenkfliche, welche sich in die Fossa mandibubaris des Schlifenbeines hincinlegt. Zwischen den Processus condyloideus und coromoideus bleibt eine Incisura maxillae inferioris anterior s. semilunaris anterior, zwischen ersterem und dem Processus pterygoideus die sribere Incismen maxillue inferioris posterior Fig. $31, J p)$ s. semilumaris posterior. Die laterate Flithe des Ramus zeigt in ihrer Mille ein kleines Tuberculum, in übrigen ist sie eben und glatt; die modiale Flache wird durch eine von der Mitte der Incisura maxillae inferioris posterior zur Mitte des Corpus verlatufende langliche Erhabenheit in zwei seichte Gruben geschieden.

\section{Kiefergelenk.}

Das Kieferogenk isl ein kombiniertes Gelenk. und alle Bewegungen erfolgen beim Kaninchew in dem links- und rechtsseitigen Gelenke gleichzeitig und gleichmißi... Der untere Teil jedes Gelenkes besteht aus dem Processus rondyloideus des Lnterkicfers. der vou beiden Seiten her flach zusammenge-

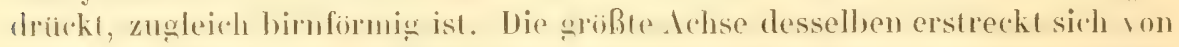
hinten nach vorn, seine cyroßte Breite und scin kolbiges Lude zeigg der Gelenkkupf am rorderen Rande. Zwischen derselhen und der Fossa mandibularis oss. temporum liegt ein bikonkaver Zwischenkuorpel : Fibrocartilago interarticularis. Seine untere Fliche reprisentiert annihernd einen Teil einer Hohlkugel, seine obere hat eine fast ohrförmige Gestalt. Der vordere Rand ist mit größerem Radius beschrieben als der hintere; beide Rinder springen hervor, so daß die obere fibche des Knorpels in der Richtung bon hinten nach rorn konkar gekrimmt erscheint; von links nach rechts dagegen ist sie konvex. Die Fossa mandibularis oss. temporum ist an ihrer lateralen Seite in der Richtung von 
hinten nach vorn schmaler als an ihrer medialen: sie ist ehenfalls in doppelter Richtung gekrimmt, entsprechend dem Zwischenknorpel, wie bei einem Sattelgelenke; doch sind die Krummungen flacher und weniger ausgeprägt. Von vorn mach hinten ist sie konvex, von links nach rechts ist sie konkav. I)as Gelenk wird ron einer straffen Faserkapsel umgehen; besondere Verstirkungsbäinder sind nicht vorhanden.

Da der Gelenkkopf annähernd als einem Cylinder von betrichtlichem Durchmesser und geringer Höhe angehörend betrachtet werden kann, so ergiebt sich für die Öffungs- und Schließungsbewegung ein nicht unbelrachtlicher Lmfang. Die mögliche Offnungsweile des Mundes betrigt bei großen Tieren mehr als 2 cm Distanz der großen Schneidezihne. Diese Bewegung erfolgt um eine horizontal und transrersal gelegene Achse vorzugsweise zwischen Gelenkkopf und Zwischenknorpel. Einseitiges Vorschieben des Lnterkiefers kommt nicht vor; das Vor- und Rückwirtsrutschen geschieht hauptsächlich durch Bewegung des Zwischenknorpels von vorn nach hinten. Annahernd kionnen die Fossae mandibulares als parallele Rinnen betrachtet werden, deren Boden ziemlich ehen ist; in demselben bewegt sich der Unterkiefer nebst Zwischenknorpel, ahnlich wie ein Schlitten, vor- und ruckwarts mit einer Genanigkeit, fiar welche die dachförmige Abnutzung der Backenzahne als das sprechendste Zeugnis angeschen wird. Seitenbewegung findet im wesentlichen nicht statt (S. 3), doch ist auf die Möglichkeit einer Seitenbewegung im Gegensatz zu anderen Jagern besonderes Gewicht gelegt worden (102). - Der Zwischenknorpel enthilt hyalinen Knorpel und feste Bindegewebsmassen.

\section{Os hyoideum, Zungenbein.}

Am Zungenbein unterscheidet man einen Körper und zwei Paar seitliche llörner.

Das Corpus ist keilförmig, mit einer oberen, unteren, hinteren und zwei lateralen fiachen. Die obere Flache zeigt in ihrer Vitte eine ebenfalls keilförmige, nach vorn spitz zulaufende Vertiefung: sic hat die Form eines gleichschenkligen Dreieckes. Die untere Fliche wirde dieselbe Form haben, wenn nicht durch den etwas stumpfen Zusammenfluß der Seitenflichen der Scheitel des Dreieckes abgetragen erschiene; sie geht ohme scharfe Abgrenzung in die hintere leicht nach rorn konkave flache uber. Die beiden rauhen lateralen Flachen vereinigen sich unter spitzem Winkel, jedoch ohne scharfo Kante.

Cornua majora und Cornua minora. Die vier Hörner, von denen die oberen die kleineren sind, artikulieren mittels facher Gelenkflichen mit dem Körper. Die Verhindungen, welche Amphiarthrosen darstellen, werden durch Kapselbinder befestigt. Die Cormu minora treten zum Körper dort, wo sein hinterer und vorderer Rand mit dem lateralen der lateralen Flachen zusammenstoßen. Comittelbar unter dieser Verbindung befindet sich die Artikulation der Cormu majora, die elwas nach abwairts grerichtet sind. Dieselben sind ungefihr doppelt so groß, wie die kleinen llorner, und etwas winklig gebogen. 


\section{Wirbelsïule.}

Die Wirbelsalu besteht aus 13 linochen (S. 36 oder 46 Wirbelu und zerfallt in liunf reschiedene Abteilungen: Halsteil ; Wirbel, Riuckenteil I? Lendenteil (7), Kreuzteil (4), Schwanzteil (16).

\section{Halsteil der Wirbelsäule.}

Vertebrae cervicales. Der Halsteil setzt sich aus den sieben Halswirbeln zusammen, welehe mbereinander dureh fielenhe und Syachondrosen in Verbindung stehen. Her erste Halswirhel artihuliert mit den Processus cond loidei oss. oreipilis: der letzte rephindet sich mit dem ersten Rückenwirbel. Die beiden obersten orler Drehwirhel, Allas und Epistropheus, zeichnen sich vor den iibrigen dureh hesondere Eigentimblichheiten aus. Vorzitglich ist es der

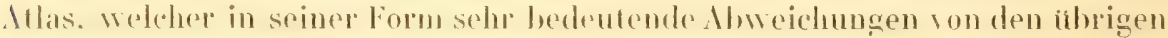
llalswirbeln zeigt.

Allas. Der Allas hat die Form eines Siegelringes und zwar liegt der das siegel darstellende Teil dessellen an der hinteren seite. Der vordere Teil des

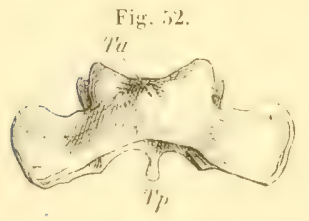

Atlas, vou hinten. Ta Tuberculum anterin,. T' Tulureulum pesterius.

Ringes ist somit weniger hoch und dick als der hintere. In der Mitte desselben ist ein deutliches Tuberculum anterius (Fig. 52 Ta), welches nach unten gerichtet der Vorderflache des Epistropheus aufliegt. An der hinteren Seite ist eine überknorpelte Rinne, in welche sich der Processus odontoideus des Epistropheus hineinlegt. Der untere, sowie der obere hand des vorderen Teiles sind honkav; das Tubereulum anterius teilt den unteren Rand in zwei IIilften.

Zwischen dem vorderen dunnen Teile des Atlas und dem hinteren liegen die rlickeren broitenteile: Massue laterales, welehe lateralwarts in die heeiten, mil ihren Fiachen last verlikal stehenden Proeessus transerersi sich atusziehen. Medianwirts von ihnen und oberhalh liegen die Gelenkflichen: Fossue articulures superiones s. Gavilates glenoideate für das Ilinterhanptsbein. Dieselben

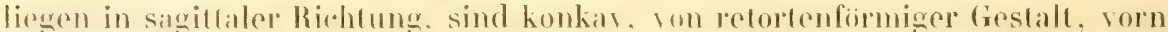
und hinten emporsleigend, das hintere Ende clwas hateralwarts gedreht. Die IVurzel des Processus transversus ist durchbohrt von dem Foramen transversarium. Oberhalb und medianwirts von dem letzteren, zwischen der Fossa articularis fuir den Processus condrodens oss. oceipilis und dem hinteren Teile des Atlas findet sich das Foramen obliquum.

Medianvirts und vorn vom unteren Teil der Processus transversi befinden sich zwei himformige, leicht konkand Golenkflichen, Fossae articulares infermes. zur Irlihulation fü den Epistropheus; ihr spitzeres Ende sieht nach vorn, ihre fiache ist nach unten. elmats nach hinten und medianwaits gekehrt. 
Der hintere Teil des Atlas unterscheidet sich vom vorderen durch bedeutendere Iohe. Ther untere Rand setzt sich ummitchbar in die Querfortsitze fort, der obere liegt ibluer ihnen und zeigh in der Mitte ein kleines Tuberculum posterius (Fig. 52 $T_{P}$ ). Beide Rinder sind konhar, aher sohwarher als der vordere.

Varietait. Das Tuberculum posterius fehlt bäufig beim wilden Kaninchen, ist beim Widderkaninchen stärker entwickelt und mehrfach eingekerbt $(8)$.

Epistropheus. Der Epistropheus hat eine von der des Atlas sehr abweichende form. steht dem letzteren an Breile hedeutend nateh, iubertrifft denselhen dagegen an Lange. Sein ziemlich langer, aher nichl sehr dicker köper trägt in seiner oberen Mitte den Processus odontoideus, Zahnfortsatz, welcher an seiner vorderen Seite iberknorpelt und konvex erscheint. Nach unten und neben dem Zahufortsitz liegen zwei uherknorpelte Gelenkflathen, Fossue arliculares superiores, zur Verbindung mit den unteren des Atlas. Der vordere Rand einer jeden Gelenkfliche setzt sich ununterhrochen in die Vorderflithe des Processus odontoideus fort. Hhre Form ist die eines reehtwinkligen Dreieckes mil alggerumdelen Winkelu, dessen II polenuse einen schwath natch hinten konkaven Bogen beschreibt.

Die untere, zur Verbindung mit dem dritten Halswilbel dienende Fitiche des Körpers ist oval, etwas nach rorn und ohen gerichtet mol rauh. Comittelbar an die beiden Gelenkllichen für den Atlas schließen sich zu beiden Seiten des Körpers die Processus transversi. Thr vorderer Rand ist scharf markiert, verliuft ununterbrochen bis zur Basis des Processus odontoidens und yeht daselbst in abgerundetem Bogen in den der anderen seite iiber, zugleich den vorderen Rand der Gelenkflichen hildend. Dieser Rand liuft nach unten in cinen vom Körper sich ahgrenzenden Fortsat\% aus. Die Processus transversi nehmen die ganze Seitenfliche des Körpers ein, dokumentieren sich aber als Querfortsitze eigentlich nur dadurch, daß sie in rertikaler Richtung durchbohrt sind, indem sie ohne Nbgrenzung in die Seilenteile des Bogens übergehen. an deren hinterem unteren Rande sich zwei vertikal gestelle, etwas lateralwarts gerichtele, ebene Gelenkflichen hefinden. Besonders auffillig am Epistropheus ist der Processus spmosus. "releher sehr entwickelt ist und nach aben und unten über das Niveau der Seitenteile sich erhebt, oben fast bis zur Ilohe des Processus odontoideus. Der Processus spinosus ist ungeteilı.

Dritter bis siebenter Il alswirbel. Ricksichtich der ährigen funf Halswirbel ist Folgendes zu erwihnen. Ihre Hohe nimmt von oben nach unten ab, die der Körper nach unten zu weniger als die der Bogen; ihre Breite nimmt zu. Die Processus transversi springen je weiter nach unten um so starker lateralwarts vor; sie sind simmtlich durchbohrt ron einem Forumen transversarium. Die Gelenkfortsitze, Processus obliqui superiores et inferiores, je zwei an jedem Wirbel, haben eine fast vertikale Stellung: die oberen sehen nach hinten, die unteren nach rorn. Die Processus spinosi sind weniger stark ausgeprägt, es sind von oben nach unten verlaufende Riffe. Yur der des letzten Halswirbels ahnelt denjenigen der Rückenwirbel und hat fast horizontale Richtung. Die Ilalswirbel in ihrer Gesammtheit bilden einen nach voru konvexen Bogen. 


\section{Rückenteil.}

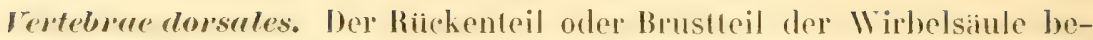
steht ans zwoll in einem nach hinten konvexen Bogen sich aneiuanderreihenden Ritckenwirbehn. Der oberste Rückemwirbel gleicht hinsichtlich seiner Höhe dem letzten IIalswirbel. Nach abwirts nehmen die Räckenwirbel an IIöhe zu, an Breite ab. Ihre Körper sind großer als die der Halswirbel. Auffallend verschioden sind ihre Processus spinosi oder Uornfortsätze von denen der übrigen Wirbel; dieselben nehmen vom ersten bis dritten Wirbel an Linge zu und sind his dahin rundlich und spitz: ron da nimmt ihre Gröke allmählich wieder ah und sie repheritern sich in sagiltaler Richtung. Die ersten drei nur am Anfang und Ende, dio übrigen in hiher ganzen Ausdehumng, um so mehr, je weiter narch unten sie liegen, jedoch so, daß Anfang und Ende immer noch meiter sind, als das Mittelstuck. Die Processus spiuosi sind schwach nach abwarts geneigt und haben meistens eime zwischen der vertikalen und horizontalen ungefahr die Nittr haltende Richtung. Vom sechsten his zehnten wird ihro Zumahme an Starke hesonders merklich, der olfe zeichnet sich durch horizontale stellung aus, won da ah wenden sie sich mmgekehrt wach aufwarts. Von den beschriebenen Richtungen ihrer Achsen abgesehen, biegen sich die spitzen der neun unteren etwas nach oben um, um so mehr, je weiter nach unten man kommt.

Der neutrale Punkt, in welchem abwärtsgeneigte in aufwärtsgeneigte Processus spinosi ïbergehen, liegt zwischen 10. und 11. Rüickenwirbel. Den elften kidchomwirbel hat min deshalb ats antiklinischen 102 oder diaphrigmatischen (10.) bezeichmel. Derselhe sollte die Grenze zwischen Rüchen- und Lendenwirbelsiule bezeichuen, unter Vernachlässigung der Rippen 104); er ist im allgemeinen der kleinste Rückenwirbel, hat auch kleinere Processus transversi.

Jeder Riickenwirhel hat vier Processus obliqui oder Gelenkfortsätze zur Verbindung mit dem olseren und dem folgenden Wirbel. Dieselben haben eine verlikale stellume, son der nur die unteren in elwas abweichen. An den vier mnfren Riickenwirbeln bilden die oberen Gelenkfortsitze den oberen Ursprungsteil der Processus mamillares.

Die Processus transversi der Rückenwirbel sind weniger entwickelt als die der Lenden- und Inalswirbel, sie nehmen von oben wach unten an Starke ab. Gegen ihr freies Ende hin besitzen sie eine Gelenklliche zur Aufnahme des Rippenkijpfehens. Zwischen ihnen und dom Processus oblipui ist oben und unten rin Ausschnit, worlureh die Foramina intervertebratia webildet werden, dieselben sind an den Rürkenwirbeln kleiner und rundlicher als an IIals- und Lendenwirbeln.

Am hinteren lateralen Rande der Processus transversi findet sich jederseits (in hleiner nach hinten gerichteter Iöcker: Processus acessorius. Derselbe ist am crsten Rückenwirled am flachsten und nimmt bei jedem folgaenden ein wonigr an Gioße zu. In fïnften bis siebenten liuft derselbe nach unten in rine llatho Leiste ans. An achlen Ritchenwirbel ist eine homologe, schrig von oben bach unten und lateralwirts verlaufende Leiste vorhanden; an dem oberen Ende rig̣t der Processus transrersus accessorius, am unteren Ende der 
Processus mamillaris nach hinten. An den folgenden Riickenwirbeln nohmen die nach hinten gerichteten Processus mamillares rasch an Lange zu und entfernen sich weiter von den nach unten gelegenen Processus accessorii; am zwïlften Rickenwirbel sind die Processus manillares linger als der Processus spinosus, neben welchem sie nach hinten hervorragen.

Am oberen und unteren Ende der Seitenränder der Körper sind zwei kleine Gelenkflichen rorhanden, die mit der nachst unteren oder oberen des folgeulen Wirbels zur Fossa articularis fiir die Rippenköplehen sich vereinigen. Sie liegt relativ zum Menschen am Wirbelkörper nach vorn geriuckt $(8 / 8)$. Der letzte Ruckenwirbel hat nur am oberen Teil eine solche Galenkfliche.

\section{Lendenteil.}

Tertebrae lumbreles. Der Lendenteil zählt siebeu Lendemwirbel, die den Ritckenwirbehn sich anreihend einen nach vorn etwas konvexen Bogen bilden. Sie zeichnen sich vor den ibrigen besonders durch ihre llöhe und Stirke aus, welche letztere nach unten zu stets wïchst.

Merkwürdig sind ihre Processus transversi Fig. $53 \mathrm{lr}$ ), deren sehr bedentende Linge bis zum sechsten Wirbel zu- und von da wieder abnimmt. Sie entspringen nahe dem oberen Ende des zugehörigen Lendenwirbels, sind lateralwirts nach oben und vorn gerichtet, breit, nit vorderer und hinterer Fliche. Der mittlere Teil ist am schmalsten. Das freie Ende ist senkrecht abgeschnitten, trigt einen gleichseitig dreieckigen dünveren Fortsatz: Proressus triangularis (Fig. 5:3t, dessen spitze nach oben gerichtet ist, wihrend der vordere und hintere leicht konkave Schenkel in das Mittelstück übergeht.?

Der Processus triangularis ist in der Jugend ein selbständiges Knochenstück (105) und wird daher als Rudiment einer Rippe gedeutet.

Der Processus transversus des untersten Lendenwirbels ist grätenförmig und endet in einen Knopf. Die Foramina intervertebralia sind birnförmig und groß, der spitzere Teil liegt nach oben. Die Processus obliqui (Fig. 53 os u. oi) haben eine fast vertikale Richtung; im unteren Teile genauer wie im oberen. Die Processus spinosi (Fig. $33 s p$ ) sind sehr breit, haben zwei seitliche Flächen, sind spitzwinklig zur Wirbelsiule nach aufwarls gerichtet und stellen Dreiecke dar mit abgerundetem Scheitel. Die Scheitel der unteren zeichnen sich

Fig. 5:3. iv

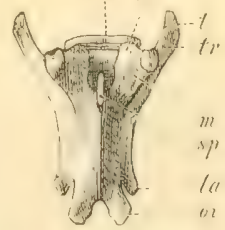

Lendenwirbe], von hinten. $k$ Knochenplatte in der Fibrocartilago intervertebralis. os Processus obliquus superior. $t$ Processus triamenlaris. tr Processus transversus. $m$ Processus mamillaris. sf Prucessur spino.us. ta Prucessus accessorius. o $i$ Processus obliqums inferior. besonders durch ihre größere Rauhigkeit und Breite aus; außerdem nimmt die Linge der Processus spinosi nach unten hin zu. Zu beiden Seiten oberhalh jedes Processus spinosus erheben sich die kriftigen und breiten Processus mamillares (Fig. $53 \mathrm{~m}$ ), deren Richtung sich aber mehr der horizonfalon nihert; ihre Spitze ist besonders rauh und dick. Yom unteren Ende ihrer Basis zicht sich eine rauhe Leiste nach abwarts, welche die seitlichen Bogenhälften in zwei Abschnitte teilt. An den beiden ersten und dem letzten Len- 
denwirhel ist sie jedoch nur angedeutet; an ersten bis fünften liuft sie nach unten in den am unteren Ende des Wirbels abwirts gelegenen Processus arcessorins (Fig. 53 I 1 , S. 107) aus. Diese Leisten reprisentieren letzteren Proressus an den untersten Lendenm irbehn. Die lprocessus mamillares der unteren Riirhen- mol simmblicher lendemwirhel, sow ie die Processus areessorii der Riirken- und oberen fünf Lendemwirbel bilden jederseits zw ei nach oben konvergierende schwach gelogene Linien. In der llitte der Vorderflache der Kibrper der drei ersten Lendenwirbel finden sich drei Processus spinosi anterores. Ilamapophisen, welehe nath oben weribhtet sind. Der l'rocessus spinosus anterior des zweiten lendenw irbels ibererift an diriße den des ersten und letzlerer den des dritten Lendenwidnels. Die Processus spinosi anteriores sitzen am oberen Teile des lörpers. sie setzen sich nach abwirts in eine rauhe Cirista fort, welohe die Vorderflache der Köper in zwei Halften teilt. Diese Crista findet sich auch an allen übrigen Lendenwirbeln.

Varietäl. Sowohl beim wilden Kaninchen (von Porto Santo) als beim Widderkaninchen wurden einmal acht Lendenwirbel beobachtet (8). Der erste Lendenwirbel trïgt anstalt der Processus transversi zwei dreizehnte Rippen von derselben Länge wie die zwölften. - Bei einem alten französischen Kaninchen artikulierte der rechte Processus transversus des siebenten Lendenwirbels durch eine gesonderte Amphiarlhrose mit dem 0 s ilimm. Oberhalb der Gelentlache ragh ein kurzer, spitzer, knöchern vereinigter Processus triangularis nach oben. Auch linkerseits ist der knöchern vereinigte Processus triangularis sehr spitz.

Die Processus spinosi anteriores finden sich unter den Nagern, z. B. noch beim llasen, der sie in derselben Anordnung besitzl wie das Kaninchen; auch beim Aguti kommen sie vor, und vielfach bei niederen Wirbeltieren. Bei Lepus wurden sie von Coiter (1566) entdeckt. Auch das Tuberculum anterius des Atlas reprisentiert eine homologe Himapophyse $(59,5,66)$. Uber die richtige Deulung der Processus transversi bei Lepus borealis vergl. 106.

\section{Kreuzteil.}

Vertebre surutes. Der Kreuzteil, Sahralteil oder das Os sucrum (Fig. 54$)$ Fig. 51

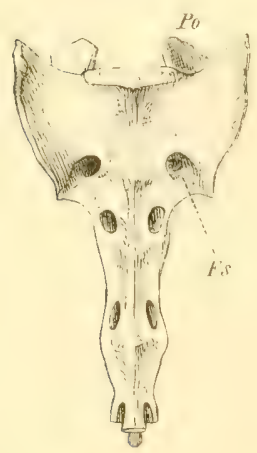

Os sacrum, von vorn; aus vier Sakralwirbeln hestehenil. I'c, P'rocessus ubliguus smperior des ersten Sakmalwirbels. Fs Foramen sacrale primum. besteht aus vier untereinander knöchern verbubdenen Kreuzbein- oder Sakralwirbeln. Es ist nach hinten gewölbt und nach inuen ausgehöhlt.

Mit seinem breitesten obersten Teile oder ersten Wirbel verbindet es sich unter stumpfem Winkel mit dem letzten Lendenwirbel; der Scheitel des Winkels springt in das Becken vol und bildet das Promontorium. Das Kreuzbein ist zwischen die beiden Darmbeinschaufeln wie ein Keil hineingetrieben, und zwar so tief, daß sie fast ganz oberhalb desselben liegen. Die Superficies aturicularis liegt am Tbergange der Schaufel in das Corpus oss. ilium. Man 
kann die Form des Kreuzbeines anch mit einer mit der Basis nach aufwirts gekehrten Pyramide vergleichen.

An der vorderen Fla che des Kreuzbeines zieht sich von der Basis bis zur Spitze eine Leiste hinat, welche die Flitehe in zwei Malften teilt. Seillich von derselhen liegen allemal an unteren Ende des sakralwirbels zwei Löcher,

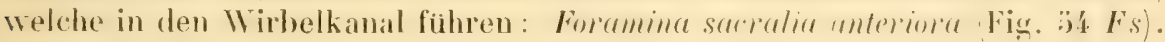

An der konvexen hinteren Flache treten besonders die Processus spinosi hervor, welche gut entwickelt sind. Sie sind kur\%, aber breit und kriftig, ihr freies Ende ist rauh und wulstign: ihre Stellung fast horizontal. An ciroße nehmen sie nach unten hin ab. Zu briden Seiten ziehen sich zwei Reihen von Ilökern herunter, welche sich durch ihre Lage als Reprisentanten der Processus mamillares mol der delenkfortsatze zu erkennen geben: Proressus mamillares spmori und Processus obliqui spmrii Fig. Gelenkfortsitz des ersten kreuzbeinwirbels sind vollkommen auscrebildet, wie es die Verbindung mit den Lendenwirbeln erheischt; ebenso die unter'an des letzten. Auf der hinteren Flidehe finden sich zwischen den Processus spinosi drei Foramina sacratia posteriora media: anBerdem unter dem obersten umbl dicht über den drei unteren Processus obliqui spurii jederseits vier enge Foramina sacralia posteriora lateralia. Der erste kreuzheinwirhel, welcher die Verbindung mit dem lotzten Lendenwirbel und den Hälbeinen herstellt, äbertrith alle anderen bedeutend an Grobe; besonders seine seitenteile sind stark entwickelt. Dieselben tragen die hufeisenformigen Gelenkflichen: superficies anriculares, zur Verbindung mit dem Os ilium (s. Becken, Iliosakralgelenk). Die Seitenteile gehen mit medianwarts konsexen Bogen in die seiten des unter ihnen liegenden teiles iiber, welcher je mehr nach abwirts, um so schmaler und spitzer wird, um sich endlich beweglich durels eine synchondrose mit den Schwanzwirbeln zu verbinden.

\section{Schwanzteil.}

Vertebrre coccygere. Der Schw anzteil hesteht aus sechzehn vollkommen beweg̣lich miteinander verbundenen Schwanzwirbeln. Der Loufang der Schwamzwirbel nimmt bis zum dritten zu, von da aber allmahlich wieder ab. Gegen das Ende hin werden sie immer läger und schmaler, verlieren alle Charaktere eines Wirbels und stellen kleine solide zylindrische Kunochen mil verdickten Enden dar; nur der letzte, küreste, ist nach seinem distalen Ende hin zugespitzt, und hat nahe der Spitze gewöhnlich eine Einkerloung, welche das Vorhandensein eines knopfförmigen, rudimentaren siebzehnten Schwanzwirbels anzeigt. Bis zum siebenten Schwanzwirbel ist die Wirbelnatur noch ziemlich deutlich ausgesprochen: Kioper, Processus transversi. obliqui resp. mamillares, spinosi sind vorhanden. Die Processus transversi sind breit und dium und nehmen den größten Teil des Seitenrandes der Wirbel ein; die Processus spinosi nehmen an Größe von oben nach unten rasch ab.

Der Canalis vertebralis, Wirbelkanal, erstreckt sich bis in das obere Ende des siebenten Schwanzwirbels. Die Gesammlheit der Schwamzwirbe] bildet einen sehr stark nach unten konvexen Bogen. 
Die sehr verschiedenen Angaben (S. 18) über die Anzahl der Schwanzwirbel beruben einerseits auf Übersehen des letzten Schwanzwirbels, andererseits auf dem Hinzurechnen des vierten oder der letzten beiden Kreuzbeinwirhel. Varielaten, z. B. 19 Schwanzwirbel, sind selten, auch das wilde Kaninchen hat 16 (eigentlich 17) Schwanzwirbel, der Hase nur 15.

\section{Ligamente der Wirbelsäule.}

Ligamentum lomgitudinale amterius. Dieses Band nimmt seinen Anfang am Tubereulum anterius atlantis, lauft in der Mittellinie der Wirbelsiule an ded Vorderfliche der Wirbelkirper herunfer und stell einen dimnen schmalen Streifen dar, welcher besonders den Wirbelsynchondrosen fest anhaftet. Am bedeutendsten entwickelt ist es in den Zwischenriumen der Processus spinosi anteriores, welche es ausfült und hier auf diese Art den Ligamenta interspinalia anf der Riuckenseite homolog wird. Nach abwirts wird es dam immer schmaler und verschwindet endlich an den Jetzten Schwanzwirbeln.

Ligamrntum longitudinale posterius. Ilomolog dem vorhergehenden findet sich dieses Band an der hinteren Fliche der Wirbelkorper im Wirbelkanal : es beginnt am Epistropheus und bildet die Fortsetzung der das Liganentum cruciatum bedeckenden fibrosen Membran, welche von der vorderen Peripherie des Foramen magnmm his anf die hintere Fiache des Kiopers des Epistropheus sich erstreckt; es ist strafl gespannt und haftet hesonders den Zwischenscheiben der Wirbel fest an; sein Ende findet es im Innern des Os sarerum.

Fibrocartilagines interertebrales. Die Wirbelkäper werden miteinabder rerbunden durch die Zwischenwirbelscheiben, Fibrocartilagines intervertehrales. Ihre form ist wie die der oberen oder unteren Fliche der Wirbelkirper, d. h. oval. nach rom alsgerundet konver, nach hinten mit einer leichten Konkaritat. Sie bestehen ans Bindegewebe und elastischen Fasern mit eingestrenten knorpelzellen, die aber nur in geringer Menge vorhanden sind, nach dem Zentrum hin sich finden, und einem Gillerthern. Nucleus grehatinosus, welcher dem hinteren Rande niher liegt als dem rorderen. Die Fasern, welche den Kern umgeben, sind teils konzentrisch, teils senkrecht angeordnel, woraus der werhselnde optische Eindruck bei wechsehnder Beleuchtumg resultiert

Die Zwischenscheiben nehmen von oben nach unten an Dicke zu und die der Lendenwirbel zeigen eine bedeutende Ilobhe: die obere und untere Flache, welche mit den nichsten Wirbehn zusammenstobt, besteht aus je einer mit Gruben und Leisten versehenen knochenplatte Fig. "53 k, S. 107), welche letzteren genan in die anliegenden fiachen des Wirbelkäpers passen 107. Sogar zwischen den letzen Schwanzwirbeln sind Rudimente dieser Knochenplattru noch nachzuweisen. Auch das freie Ende des letzlen (siebzehnteu) Schwanzwirbels ist von hyalinem Knorpel uberkleidet.

Ligamentu flaca finden sich am hinteren Teile der Wirbelbogen, dieselben füllen die zw ischen je zwei Bogen bleibenden Zwischenriume aus. Die Bänder entspringen beiderseits vom unteren Teil der Vorderfliche der Wirbelbogen. verlanlen abwirls und medianmials zum oberen Teil der nichstun- 
teren Wirbelbogen und rereinigen sich in der Medianlinic. Sie haben eine gelbe Farbe und bestehen ganz aus elastischen Fasern.

Ligamenta interspinalia und intertranseersaria sind fibrise Bander, welche die Zwischenriume der Processus spinosi und transversi ausfiillen, und deren Entwickelung mit der Entwickelung jener Fortsitze gleichen Schritt hilt.

Ligamentum apicum s. supraspinale besteht aus festen Stringen des dorsalen Randes der Liqamenta interspinalia und setzt sich über die Processus spinosi der Lenden- und Rückenwirbel fort.

Ligamentum machae bildet die Fortsetzung des Ligamentum apicum an den Halswirbeln, stellt eine in der Medianebene zwischen den Nackenmuskeln gelegene Bindegewebs-Scheidewand dar, und heftet sich an die Protuberantia occipitalis externa. An den Processus obliqui superiores und inferiores finden sich zur Befestigung derselben Kapselbinder.

\section{Ligamente zwischen 0s occipitis, Atlas und Epistropheus.}

Ligamenta obturatoria allantis anterius und posterius. Zwischen rorderem und hinterem Ilalbring des Atlas und der vorderen und hinteren Peripherie des Foramen magnum bleiben Lü‘ken, welche durch die genamnten fibrosen Membranen verschlossen werden. Um die Gelenkverbindungen der beiden Knochen finden sich fibröse Kapseln.

Ligamentum cruciatum. Der Atlas und Epistropheus besitzt noch einen besonderen näher zu bericksichtigenden Bandapparat. Das grenannte Ligament verbindet heide Seitenteile des Atlas, inden es den Processus odontoideus des Epistropheus überbrúckt; ron der Mitte dieser Briicke reht ein Fortsatz zum vorderen Umfange des Foramen maguun; ein anderer nach ahwirts zum Körper des Epistropheus.

Am Processus orlontoideus des Epistropheus finden sich damn noch drei nach aufwarts gehende Bander, ein mediales und \%wei laterale. Das mediale oder Ligumentum suspensorium dentis geht von der Spitze des Zahnfortsatzes zum vorderen Rande des Foramen magnum.

Die lateralen Ligamenta alaria erstrecken sich von den Seiten der spitze des Processus odontoideus zur medialen Fliche der Processus rondyloidei oss. occipitis.

Außer den genannteu Ligamenten finden sich an der Wirbelsaule nur noch Kapselbinder, welche die früher beschriebenen Gelenke umgeben.

\section{Ligamente des Schwanzes.}

Ligamentum longitudinale anterius bildet die allmihlich nach unten sich rerlierende Fortsetzung des Ligamentum longitudinale anterius der Wirbelsiult.

Ligamentum apicum caudue bildet die Fortsetzung der Ligamenta interspinalia und des Lig. apicum und ist rerhiltnismaßigy stark entwickelt. Seine je zwei Schwanzwirbel verbindenden fasern sind als Ligamenta dorsalia caudae zu bezeichnen. 
Fibrocartilagines intervertebrales sind flach ausgehreitete Bandmassen, welehe die oberen und unteren Fläben von je zwei benachbarten Schwanzwirbeln miteinander verbinden; vergl. S. 110.

\section{Gelenkverbindungen der Wirbel.}

\section{Kopfgelenke.}

Erstes Kopfgelent. Die Gelenkflichen der Massae laterales des Atlas und der l'rocessus condyloidei oss. oceipitis bilden zusammen einen Ginglymus, in welchem nur Bewegung um eine transversale Achse miglich ist. Der Bewegungsumfang (Neigung des Kopfes nach vorn) betrigt fast $90^{\circ}$.

Zuertes hopfgelent. Der Processus odontoideus des zweiten IIalswirbels dreht sich zwischen dem transversalen Teil des Liganentum crueiatum und dem vorderen Teil des Atlas um eine vertikale Achse. Dieselbe bildet zugleich die Achse cones Kegrels, von dessen Mantel sehr kleine stucke durch die beiden delenke zwischen den Processus obligui des ersten und zweiten Halswirbels realisiert sind.

\section{Wirbelgelenke.}

Die Bew egungsathse der Wirhelsiule rerbindet die (iallertkerne der Fibroartiligines intervertebrales mit einander. Alle Bewegungen adolgen durch Beugungen und Torsion der genamten Linie. Die Bewegungen sind seilliche, nach vorn oder hinfen: stels ist eine geringe Torsion mit den Beugungen verhunden und umgrekehrt. Die Gelenke zwischen den Processus obligui der bemachbarten Wirbel sind Amphiarbrosen und gestatten durch Verschiebung benachbarter Wirbel geveneinander die geschilderten Bewegungen. Bei der fast senkrechten stellung der Gelenkflichen ist übrigens die Torsion, sowie die seitliche Beugung zwischen je zwei Wirbehn beim Kaninchen anBerordentlich unbedeutend, und die Beugung nach hinten, resp. vorn ist in etwas ausgedehnterem Maße an den Hals- mol I.endenwirbeln, nicht aber an den Rủckenwirbeln möglich.

An dem Schwanzteil sind simmtliche Bewegungen in ausgedehntem Maße ansfühthar - namentich die Beugumg dorsalwarts - nicht aher die

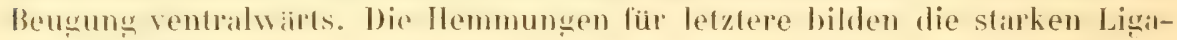
menta dorsalia caudae.

\section{Th 0 l’a x.}

\section{Costae, Rippen.}

las Kaninchen besitzt zwölf Par hippen, welche zum großten Teil die Wirbelsiule mit dem Brustbein in Verbinlung set\%en. Sie sind seitlich komprimiert mit lateraler undmedialer Flache. mit Ausnahme der ersten Rippe, welehe eine obere und untere Fliche besitzt. Ihre Größe nimmt bis zur siebenten 
Rippe (inkl.) zu, von da an wieder ab. Die Breite der Rippen ist bis zur neunten sehr wenig different, die drei unteren werden schmaler und :iußerlich konvexer. Die Neigung der Rippen nach abwirts nimmt von oben nach unten zu; der Winkel, den die Rippenknorpel mit dem knichernen Teile bilden, wird in gleichem Verhailnis kleines. An allen Rippen ist eine flachentorsion um die sagittale Achse bemerhbar. Die lateralen Flachen sind konver, die medialen konkav; der obere Rand scharf, der untere zu einem flachen Sulcus ausgehöhlt, welcher aber nach vorn zu verstreicht. Das Kaninchen besitzt sieben wahre und fünf falsche Rippen. Die knorpel der siebenten, achten und neunten Rippe vereinigen sich zu einem gemeinsamen, dessen Ansatz unten besprochen wird (S. 114). Die kurzen Knorpel der zehnten, elften und zwölften Rippe endigen frei. Die knöchernen Teile der Rippen stellen Bogensegmente von Kreisen dar, welche je weiter nach abwirts im allugemeinen mit um so groberem Radius beschrieben sind; nur fur die zchnte und elfte Rippe wird letzterer wieder kleiner. Ihr hinterer Teil trill mit der Wirbelsitule in Verbindung, und zwar auf doppelte Weise. Das iuberste Ende oder das rundlich überknorpelte Capritulum costae legt sich in die Gelenkflachen, die als Fossae articulares bereits beschriehen wurlen. Das Ciapitulum costae sitzt anf einem rundlichen llalse, Collum costae, welcher vom breiteren Mittelstïck durch den Rippenhöcker, Tuberulum costue, al)gegrenzt wird. Dieses Tuberculum costae setzt sich durch eine kleive ehene Gelentfliche mit dem Processus transversus in Verbindung. Bei den beiden letzten Rippen findet dieses Verhaltnis nicht statt. Die hintepe laterale Partie des Tuberculum costae liuft an der zweiten bis achten Rippe in einen zirmlirh spitzen, nach hinten und aufwäts gerichteten Fortsatz aus.

\section{Sternum, Brustbein.}

Das Brustbein besteht aus drei miteinander in hewegrlichem Zusammenhange stehenden Teilen: Manubrium, Corpus und Processus xiphoideus. Der Körper oder das Mittelstick zerfailt wieder in varsehiedene Glieder. Das Sternum liegt in der Medianlinie der Wirbelsaule gexeniiber und bildet die roldere Wand des Thorax, welcher nach oben sich zuspitzt und bedeutend an Umfang verliert. Die Richtung des Sternum ist daher keine vertikile, sondern es erscheint ein wenig geneigt, so daß seine Lingsachse nach oben verlingert die Wirbelsiule unter spitzem Winkel in der Gegend der ersten Ialswirbel schneiden würde; unten ragt es etwas nach vorn hervor.

Mamubrium sterni. Dasselbe macht etwa ein Drilteil der Linge des Knochens aus und ragt mit seiner oberen Halfte über die erste Rippe hervor. Es hesitzt zwei seitliche und eine hintere Flache. Die vordere Kante, in welcher die seitlichen Flächen zusammenstoßen, ist scharf.

An der Spitze des Manubrium geht sie in einen rundlichen Bogen über, welcher in die seitlichen Kanten auseinanderweicht, wodurch die hintere schmale Fliiche entsteht. Etwas uhber der Mitte des Seitenrandes findet sich eine ovale Gelenkfliche zur beweglichen Verhindung mil dem knorpel der ersten Rippe. Nach unten verbindet sich das Janubrim durch eime Synchon- 
drose mit dem Corpus sterni. Unmittelbar iiber dieser Verbindung setzt sich der Knorpel der zweiten Rippe an.

Jas Corpus oder Mittelstick des Sternum zeigt vier durch Synchondrosen beweglich mit einander verbundene Glieder, welche dreikantig sind, mit zwei seitlichen und einer hinteren Fliche; nach abwirts nehmen sie an Breite zur. an Lange ah. Die scharfe vortere Kante flacht sich nach unten mehr ab und ist am vierten Gliede kaum noch sichthar. Die vordere Flache der Glieder macht den Eindruck ron zwei mit der längeren Kathete an einander gelegten rechtwinhligen Dreiecken. In unteren Gliede sind die Katheten fast gleich.

Oberhall, der Verbiudung von je zwei Gliedern und noch etwas an dieselbe setzt sich allemat ein Rippenkuorpel jederseits bereglich an.

Processus axphoideus. Das untere breite Ende des Korpers rerhindet sich mit dem Processus xiphoideus, einem schmalen, schief nach rechts gewendeten Knochen, welcher durch Anlagerung von Knorpel eine breite rundliche Knorpelplatte darstellt. An seine Yerbindung mit dem Endgliede des Körpers tritt der knoryel der sechsten Rippe und an diesen sehr dicht angrenzend, beinahe damit rerbunden, der gemeinsame Insertionsknorpel der siebenten, achten und neunten Rippe zum Sternum.

Der obere Teil des Processus xiphoideus besteht mikroskopisch aus hyalinem, der mittlere atus elastischem knorpel, der untere aus Knorpel ohne Grundsubstanz $(608$, S. 137$)$.

\section{Ligamente der Rippen.}

Ligamenta costovertebralia sind straffe Kapselbinder, welche rom Collum costae jeder Rippe zu den betreffenden Fossae artienlares der Wirbelköper sich erstrecken.

Ligamentu capiluli costue sind runde Binder, welche vom Capitulum jeder Rippe zur Fibrocartilago intervertebralis verlaten, mit den vorigen zusammenhäggend.

Beim Pferde, Rinde, Schweine, Hunde und der Katze verbinden sich die Lirgr.s. capituli costate beider. Seiten zu einem hinter den Wirbelkörpern verlaufenden Ligamentum conjugale costarum $(108)$.

Ligumenta costotranseresuria sind ebenfalls stratle Kapselbander, welche von den Tuberoula der zehn obersten Rippen zu den Processus Iransversarii der entsprechenden Wirbel verlaufen.

Ligumentu sternocostaliu sind schwache Kapselbinder, welche die Rippenknorpel an das Sternum heften.

\section{Gelenkverbindungen des Thorax.}

Alirulationes costocertelurales. Dio Capritula sämmtlicher Rippen stehen mit den fossate andiculares der IVirhelkirper in Verbindung. Diese Gelenke sind an sich Arthodieen: die Bewregurg wird aber seltr beschrinkt durch die folgenden Gelenke. 
Articulationes costotransiersariae. Die zehn oberen Rippen trageu an ihrem Tuberculum eine kleine Gelenkfliche zur Gelenkverbindung mit dem Processus transversus des zugehorigen Rückenwirbels. Diese Gelenke sind an sich Amphiarthrosen. Zusammen mit den Articulationes costovertebrales aber stellen sie Kegelgelenke dar. Die Achse des Kegels geht vom Cilpitulum aus durch das mediale Ende jeder Rippe in der Richtung von oben und hinten nach unten und vorn und zugleich stark lateralwirts. J weiter nach unten, desto stirker sind die beschrichenen Bewegungsachsen ahwirls geneigt. Vom Kegelmantel sind in den Articulationes costotrausversaria nur sehr kleine Stuicke realisiert.

Articulationes sternocostales. Dic Knorpel der sieben oberen Rippen rerbinden sich mit dem Brustbein durch ebensoviel Amphiarthrosen, indem sich die Knorpel der siebenten, achten und neunten Rippe, wie schon erwihnt, mit einander vereinigt haben. Indessen ist am siebenten Rippenknorpel statt eines Gelenkes haufig nur eine Synchondrose vorhanden (was auch heim wilden Kaninchen vorkommt).

Indem durch das Sternum die neun obersten Rippen beider seiten mit einander verbunden werden, entsteht der knöcherne Brustkorl, Thorax. an dessen Aufbau sich noch die Riickenwirbel und die drei untersten Rippen beteiligen. Bewegungen sind in Brustkorbe nur möglich um die beschriehenen Bewegungsachsen der Rippen. Durch beiderseitige Kompensation der Komponenten, welche die einzelnen Rippen vermöge der Inspirationsmuskeln zugleich lateralwirts nach oben und etwas uach rorn führen würden, bleibt wesentlich nur die Bewegung nach oben ibrig, welche das ganze Sternum mitmacht. Nach vorn und lateralwäls wird eine gleichzeitige geringe Bewegung durch die Torsionselastizitit der Rippenknorpel ermögrlicht.

\section{Knochen der oberen Extremitiit.}

\section{Clavicula, Schlüsselbein.}

Fine knöcherne oder durch Gelenke vermittelte Verbindung der oberen Extremitit mit dem Rumpfe wird nicht durch die Schulterknochen hergestellt. Dieselbe wird nur durch Weichteile eingeleitet, nimlich durch Muskeln und Bänder. Statt der bei anderen Tieren durch die Articulatio sternoclavicularis vermittelten Rumpfrerbindung der oberen Extremilit findet sich nur ein ligatmentoser Strang, welcher rom Sternum zur lateralen Sulte des Ilumeruskopfes sich erstreckt. In diesem fibrösen Strange liegt die Clar icula als ein dünner, gr:itenfömiger, gleichsam nur der Anlage nach vorhandener knochen eingebettet. Ihre Lainge betrigg beilaufig ein Drittel derjenigen der Verbindung zwischen Sternum und Ilumerus. Die ligamentiosen Verbindungen der beiden letzten Knochen mit dem Schlüsselbein werden als Liyamenta sternoclaciculare und cleidohumerale bezeichnet. 


\section{Scapula, Schulterblatt.}

bie Scapula ist ein platter, breiter, elwas linglich nach dem Schultergelenk auslaufender hnochen von der Form eines rechlwinkligen Dreieckes mit abgerundetem rechten Winkel.

Nimmt man die Lingsachse und die Ebene des Knochens in einee Sagittalebene welegen an, so sieht die Ilypotenuse des Dreiecties nach unten und yorn, die kleinere Kathete nach hinten und die größere nach oben.

Der untere vordere Rand bildet mit dem hinteren einen etwas abgerundeten spitzen Winkel: Angulus inferior; ersterer Rand ist breit, so daß man ein Labium extermum und Labium internum an demselben unterscheiden kann. In einem nach anfwaits konvexen Bogen liuft dieser hand mit dem oberen in dis Collum scapulare atus. Der ohere Rand ist schuaro S-fömig gebogen, me-

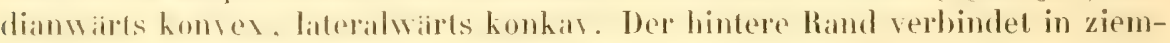
lich stark honvexem Bogen den oberen und unteren Rand. Fin an den ersteren

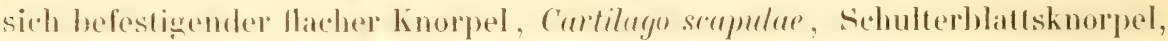
aus hyalinor firundsubstauz und horpelzellen bestehend, gielot den Flachen der Scapula eine noch größere Ausdehnung.

Das Collum scapulae ist dreikantig mit einer oberen, einer unteren, medialen und bateralen Kante; erstere ans der fortsetzmng des oberen Randes, letztere alus Ahflachumg des unteren hervorgehend. An der Spitze des Collum

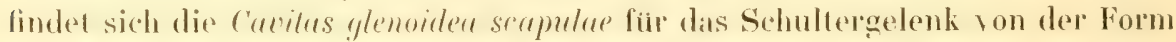
pines Jreirekes mil aldererundeten Winkeln. Kurz vor dem Scheitel des Dreieches sieht man aine Finschnimmgr, so dab derselbe wie ein Fortsatz der dielenkfliche sich ansnimmt. An und neben dem Scheitel zeigyt sich eine kleine Ilervorragung: Tuberculum supraglenoidale.

Medianwirts von diesem sieht man einen zweiten hakenförmigen Vorsprung medianwirts gewendet: Processus coracoideus.

Am unteren Ende des oberen Drittels des hinteren Randes erhebt sich von der lateralen Flitehe des Sulpula eine dreierkige Rauhigheit, die aber batd zu einem scharfen Kamme wird, welcher von hinten unten nach oben und vorn verliuft, und die Sicapula in zwei Absehnitte teilt: Fossa supraspinatu und Fossa infraspinata. Dieser Kamm, Spina scapulae, hebt sich etwas vor dem Crsprunge des Collum scapulae von der Fliche als und lauft mit medianwiipts konvexem Bogen in einen dummen platten Fortsat\% atus, von dessen Spitze unter rechtem Winkel ein zweiter, Processus hamatus, ahgeht. Das Ganze stollt das Acromion dar, welches in der Flucht des Collum scapulae verlauft, his dahin, wo dasselhe in den Gelenhfortsatz übergeht. Tuter dem Acromion her gelangt man aus der Fossa supraspinata in die Fossa infraspinata.

Die inner e oder vordere der Thoraxwölbung anliegende Flache des Schulferblattes ist konkav, die au Bere oder hintere Flache konvex. Nur in den verdicklen Rindern enthilt die Seapula sponguase substanz; im übrigen ist sie durchscheinend dimn. Die Seapula hesitz. nur ein eigenes Band, Ligamenlum transcersum scapmlar, welches den Ausschnill zwischen vorderem Ende der Spina scapulae und dem Acromion ausfüllt. 


\section{Humerus, Oberarmbein.}

Der Ilumerus ist ein röhrenförmiger Knochen mit verdickten Enden. Am oberen Ende sitzt der ibherknorpelle Gelenkkopf für das S'Chultergelenk. Derselbe stellt kein Kugelsegment dar. Durehschmeidet man ihn in der Ehene der sagittalen und transtersalen Achse, so erhiilt man keine Kreissegmente, sondern erkennt in der Peripherie eine Spirale.

Nach vorn geht der Gelenkkopf in zwei durch cine Furche, den Sulcus intertubercularis, getrennte Tubercula äber. von denen das mediale das Tuberculum minus und das Iaterale das Tuberculum majus genannt wird.

Die Diaphyse oder das Mitlelstiick des Humerus erscheint im oberen I)riltel von den Seiten her komprimiert, im mitteren ist sie fast zylindrisch, im unteren wie von vorn nach hinten zusammengedrickt. An dev vorderen Seite des oberen Teils findet sich eine dreieckige Rauhigkeit, spma humeri, welche dureh den ZusammenfluB von zwei vom Tubereulum majus kommenden Cristae gebildet wird. Auch vom Tuberculum mimus setzt sich eine Grista auf das Mittelstück fort.

Am unteren Ende des Humerus sitzt eine rollenartige, iiberknorpelte Gelenkfliche, Trochlea humeri, die einem in der transversalen Ebene liegenden Zylinder gleicht, an welchem eine leistenarligge Hervoragung zu Tage tritt, wodurch die Gelenkrolle in einen lateralen kleineren und medialen griberen Abschnitt geteilt wird. An der hinteren und vorderen Seite sieht man über dem Gelenkfortsatz zwei Gruben, welche durch eine durchscheinende Knochenlamelle geschieden werden: Fossa supratrochlearis anterior und Fossa supratrochlearis posterior. Der Humerus weicht dadurch in zwei Schenkel auseinander, welche bogenfömig in die Trochlea ibergehen. In der medialen Seite des Uberwanges ist ein deutlicher kleiner Forlsatz, Condylus medialis, an der lateralen bloß eine Rauhigkeit, Condylus luteralis, rorhamden.

Die Fossa supratrochlearis posterior ist bedeutend grober als die anterior, weil in sie das Olecranon eingreift.

Die Torsion des Humerus beträgt nur $90^{\circ}(809)$, wenn sie beim Menschen auf $163^{0}-168^{\circ}$ (beim Franzosen, 809 resp. beim Indogermanen, 40, S. 43) anzunehmen ist.

\section{Schultergelenk.}

Das Schultergelenk ist eine Arthrodie. Dic Gelenkverhindung des IIumerus mit der Scapula stellt sich mittels einer fibrösen Kapsel her, welche dureh ein von der Spitze und vorderen Seite des Gelenkpfannenrandes entspringendes Ligamentum capsulare, das sich an den Thergang des Caput humeri in das Tubereulum minus ansetzt, verstirkt wird. An der lateralen Seite des Tuberculum majus wird die Kapsel verstarkt durch das hei der Glavicula erwahnte Ligamentum cleidohumerale (S. 115).

Alle Bewegungen sind im Schultergelenk möglioh. nur eine bedeutende Abduktion ist durch das an das Tubereulum minus sich befestigende Verstiilkungsband ausgeschlossen. 
Faßi man die Stellung des Gelenkkopfes des llumerus zur Stellung der Gelenkpolle (in lillogengedenk) ins Auge und honstruiert man zu dem Ende dic Lehsen der heiden Gelenkenden, sowio des Millelstilckes, um anteh das Verhiblus der ersteren zu letzteren in ihrer Stellung zu erkennen, so ergiebt sich lolgendes. Die Arhse des Oberarmbeinkopfes bildet mit derjenigen der Rolle (in dieselhe Ehene projiziert einen Winkel ron 78", mit der Diaphyse eimen II inkel son 114". Die Arhse der Kubitalrolle steht zur Diaphysenachse senkrecht (109).

\section{Knochen des Vorderarmes.}

Der Vorderarm wird duroh zwei Rijhrenknorhen grebildet, die mit ihren oberen Enden ror, somst aher mehr neheneinander liegen (Fig. 55), so daß der Radius medianwiris, die Ulna lateralıärts zu liegen kommt.

Ein gröBerer Zwischenraum zwischen beiden

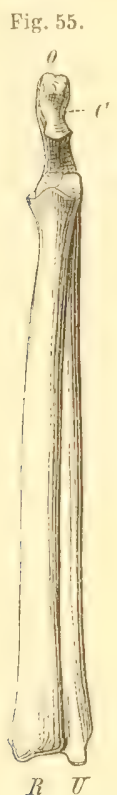

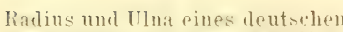
Kininelens, vout vorn. Ri Ratius.

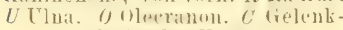
thatehe der Ulnat. Knochen ist nicht vorhanden; doch findet sich in der oberen Irilfte eine an der Dorsalflache ausgeliefte, zwischen beiden Knochen von oben nach unten sich hinziehende Grube, welche an der volaren Seite durch Aneinanderlagerungen beider Knochen geschlossen wird: das Interstitium interosseum antibrachii, in welchem das Ligamentum interosseum antibrachii ausgespannt ist.

\section{Radius, Speiche.}

Der Radius (Fig. 55 l $\mathbf{l}$ ) ist küzer, aber im ganzen starker und dicker als die Ulna, mit Ausnahme von deren oberem Ende. Zugleich ist der Radius stirker konvex nach vorn gebogen, wodurch besonders die erwahnte Grube zwischen beiden Knochen zu stande kommt. Sein oberes etwas verdicktes ubberknorpeltes Ende bildet mit der Gelenkfläche der Ulna die korrespondierende Gelenkfläche für die Trochlea humeri. Das Mittelstibck zeigt eine vordere und hintere Fliche, welche unter abgerundeten Winkeln ineinander übergehen. Das untere Ende ist rerdicht, verschmbilert sich aber wewen die Gelenkfliche, die am weitesten abw irts gelegen ist, wiederum. Die dichste Stelle liegt an der Grenze zwischen Diaphyse und unterer Epiphyse, dadureh wird es bedingt, daß man die Form des unteren Endes mit einem beiderseits abgestumpften boppelkegel verglei(bon kamn. Die don beiden voneinandor ahgewendeten kegeln gemeinschaftliche basis entspridol der (arenzllache zw isehen Diaphyse und Epiphyse. Das unterste Ende zeigh eine honkave Gelenkfliche, um mit dem ersten und zweiten Carpusknochen der ersten Reihe: den Oss. carpi intermedium und ulnare zu artikulieren. 


\section{Ulna, Ellbogenbein.}

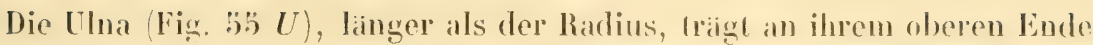
eine ausgehohIte Gelenkfliche (rigr. $\$ 5 \mathrm{C}$ ), welche mit der vor ihr liegenden und an sie sich anschließenden Gelenkfliche des Ratdius hallmondförmig die Trochlea humeri genau umfaßt. Das hintere obere Ende geht in einen ziemlich dicken, nach vorn hin hakenformigg gekrümmten Fortsatz über, das Olecranon (Fig. 550$)$ s. Processus anconaeus. Der vorn überknorpelle Iaken greift bei Streckung des Vorderarmes in die Fossa supratrochlearis posterior ein. Auf der Spitze des Fortsatzes findet sich eine überknorpelte Rinne.

Das Mitlelstück ist ein nach rorn tonvex gekrummter. plallgedriickter Knochen, weleher dem Radius an Breite und Dicke nachsteht und lateralwirts von letzterem, zum Teil hinter demselben liegt. Die ulnare Kante ist abgeflareht und verbreitert sich nach oben und unten.

Das untere Ende der Una, weniger dick als das obere, rundlich zugespitzt, trigut eine konvexe Gelenkfliche zur Arlikulation mit der konkiven des Os carpi ulnare in der ersten Reihe der Carpusknochen.

\section{Ellbogengelenk.}

Das Ellbogengelenk ist ein Schraubengelenk; die Trochlea des Ilumerus ist an der rechten Extremitat dexiotrop. Ungefiihr ein hallop Schraubengang ist für die Una realisiert; die Steigung der Schraube sehr gering. Das fielenk gestattet daher wesentlich nur dic Bewegungen der Fexion und Extension. Die kleinere radiale Gelenkfliche stellt einen geringen Teil ciner flarheren Schraube dar. Der Bandapparat besteht aus einer filrösen Kapsel, welche oberhalb der Trochlea entspringt, die Fossae supratrochleares anterior unt posterior noch mit äberzieht und sich unterhalh der Gelenkfliche hefestigr; ferner aus einem medialen und lateralen Seitenbande, von denen ersteres am medialen Ende der Rolle entspringt und an der medialen (S/S) Seite der Utua sich anheftet, letzteres, an der entgegengeselzten Seite heginnend, unmittelbar unterhalb des Gelenkes an die laterale Seite der Una sich hefestigt. Bei Streckung des Vorderarmes spannen sich beide Bander bedeutend.

An ihrem oberen und unteren Ende sind die Vorderarmknochen besonders durch festes fibröses Gevebe miteinander verbunden. Eine isolierte Bewegung ist denselben nicht möglich.

\section{Knochen der Hand.}

\section{Ossa carpi, Handwurzelknochen.}

Die Inandwurzelknochen, neun an der Zahl, sind in zwoi iblereinanderliegende Reihen geordnet, von denen die obere vier, dif untere fünf knochen enthailt. In der oberen Reihe liegen, von der radialen nach der ulnaren seite 
gerahlı: die Ossa curpi rudiule s. naviculare, intermedium s. lunatum, ulnare s. Irifuetrum und auf der Volarseite des Ietzteren artikuliert mittels einer

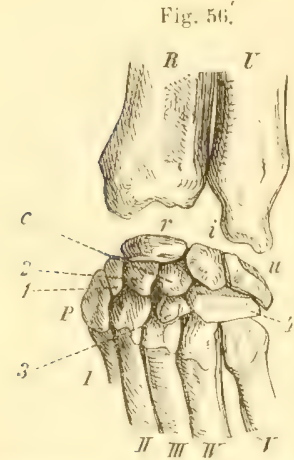

limuhen ler Handworzel, stark

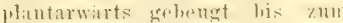
Klaflen der Golenke, run rorm.

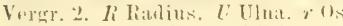
carpi radiale. $i$ os carpi intermedium. $u$ Os carpi ulnare. $c$ os carpi centrale. 1-4 Erstes bis viertes 0 s carpale. $P$ Erste Phalanx des Dammens, $I-\boldsymbol{V}$ Erstes his funftes Os metacarpi. eigenen Gelenkfläche das $O s$ pisiforme. In der zweiten Reihe befinden sich die Ossa carpale $I$ s. multangulum majus, carpale $I I \mathrm{~s}$. multangulum minus, centrale (Fig.56 c) s. multangulum accessorium, carpale III s. capitatum, carpale $I V \mathrm{~s}$. hamatum. Es sind kleine Knöchelchen von mannigfach verschiedener Form, deren spezielle Beschreibung kein praktisches Interesse haben würde. Sie stehen mit dem Vorderarm, den Metacarpusknochen und unter einander durch Gelenke in Verbindung. Die Ossa carpi radiale und intermedium zeigen eine konvexe, das Os carpi ulnare eine konkave Gelenkflache, entsprechend derjenigen der Vorderarmknochen. Die Irtikulation der ersten und zweiten Reihe, sowic der Mittelhandknochen wird durch mehr oder weniger flache Gelenkflichen hergestellt.

Das Os centrale wurde früher $(1 / 1$ u. 594) als der abgesonderte vordere Teil des Os carpi radiale betrachtet, wofür die Vergleichung mit dem Skelett der Katze zu sprechen schien. Vergl. $110,111,595$ u. 40, S. 44.

\section{Ossa metacarpi, Mittelhandkuochen.}

Dir fiunf Mitlelhandknochen sind linglich zylindrisch und von versehiedener frobe. Vom funften bis zum dritten Finger nimmt ihre Linge zu, von da wieder ah. Das Os metacarpi pollicis hat kaum 1/3 der Größe seiner Nachbaren. Allo haben ein oheres und unteres äherknorpeltes, verdickles Eude. Die oberen Enden sind mehr flach: sie artikulieren mit der zweiten Reihe der Ilandwurelknochen, die unteren mit den ersten Phalangen. Die unteren Flivohen sind rollenfirmige Gelenkflichen, jedoch so, daß die über sie hinlaufende firste nicht ganz bis zum dorsalen Ende derselben reicht. Die Mittelhandknochen sind so neheneimander gelagert, daß dic Dorsalfliche der Hand etwas gewölbt erscheint.

\section{Phalanges, Phalangen.}

Der Daumen hat zwei, die übrigen Finger drei Phalangen, welche an

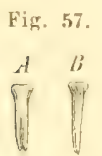

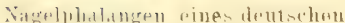
liatiullarla-, fon der Dorsalspite. A. Vom Zeigetinger. B. Vom Daumen.

Länge von oben nach unten abnehmen. Die mittlere Phálanx ist nach oben konkav. Die dritte (Fig.57), welche einen stark nach oben konvexen Nagel träigt, bildet an der Dorsilseite mit der zweiten einen stumpfen Winkel. Die Gelenkflächen der ersten Phalangen sind entsprechend denen der Metacarpusknochen ausgehöhlt; die zwischen zweiter und dritter Phalanx sind Schraubengelenkflächen. Die dritten oder Yagelphalangen sind mit leicht angedeuteten Einkerhungen 
an den Dorsalrindern ihrer Spitze versehen (S. 17, nur die letzte Phalanx des Daumens (Fig. 57 B) ist an der Spitze ungeteilt vergl. 9, S. 34; 1.4, 5.34 u. 21).

\section{Gelenke der Hand.}

Articulatio carpi (prima). Die im Handgelenke ausgefürten Bewegungen. welche hauptsichlich durch das Vorderarmgelenk sich vollzichen, entsprechen deneu einer Arthrodie. Im Vorderarm-IIandgelenk stellen die Gelenkflichen der Oss. carpi radiale und intermedium zusammen einen walzenförmigen Gelenkkopf dar, wahrend die Pfanne am Radius sehr flach erscheint. Das Catpitulum ulnae bildet ebenfalls eine transversal gerichtete Walze, die mit dem Os carpi ulnare und dem Os pisiforme artikuliert. Der Liangsdurchmesser der ersteren liegt in der Richtung von der ITnar- nach der Radialseite, derjenige der letzteren in der Richtung vom Dorsum zur Vola. Die Inuptbewegungsachse des Gelenkes lauft transversal von der Radial- nach der Unarseile: ihr radiales Ende ist etwas abwirts gerichtet. Diese Achse liegt in drei verschiedenen Knochen: Oss. carpi radiale, ulnare und Capilulum ulnae, und die Bewegungsmöglichkeiten zwischen den einzelnen Knochen werden dadurch auBerordentlich kompliziert; ihre Ausdehoung ist aber eine nur geringe. - Die übrigen vorhin angefühten Gelenkflichen entsprechen simmtlich annähernd Ebenen, oder die betreffenden Gelenke sind wenig bewegliche Amphiarthrosen. Die Beschaffenheit der einzelnen Gelenke der IIandwurzelknochen untereinander und mit den Mittelhandknochen, den Lrliculationes carpometacarpeae, auf einen exakten Ausdruck zu bringen, möhte zur Zeit wohl kaum möglich sein.

Der Bandapparat in diesen Gelenken besteht, abgesehen von den Kapselbandern, aus zwei kriftigen Seitenbindern, von welchen das eine vom unteren Ende des Radius entspringt und an die Basis des ersten Metacarpusknochens sich anheftet, das andere rom unteren Jinde der Ulna beginnt und an der Basis des fünften Mittelhandknocheus endigt. Ferner aus einem Bande, welches rom Os pisiforme zur Basis der beiden lateralen Metacarpusknochen verlauft, und endlich aus einem Querband, welches die Basis des dritten und fünten Mittelhandknochens miteinander verbiudet. Fom Os pisiforme geht ein starkes Ligamentum carpi volare proprium zu den medialen Carpusknochen "und zum Os metacarpi des Daumens, unter welchem die Beugesehnen des M. flexor digitorum profundus zur Vola gelangen. Oberflichlicher spannt sich uber die volare Flache des Ligamentum carpi volare proprium das viel schwiichere Ligamentum carpi volare transversum hin. Zwischen beiden Ligamenten verlaufen die Sehnen der Mm. Alexor digitorum sublimis und palmaris. Auf dem Iandrucken findet sich das Ligamentum carpi dorsale, welches durch Scheidewande in sechs Ficher oder Sehnenscheiden geteilt ist (s. Myologie). Dieser Bandapparat, der den freien Bewegungen der IIand nicht allzusehr hinderlich ist, giebt derselbeu eine bedeutende Festigkeit, wozu allerdings das Lagerungsverhaltnis der einzelnen Knochen wesentlich beiträgt.

Articulationes digitorum. Die Gelenke zwischen Mittelhandknochen und 
erster Phalaux bilden eine Kombination von Arthrodie und Schraubengelenk. Auf tem volaren Teil erhebt sich ein scharfer First, welchem radialwirts und ulnarwäts eine kleine spiralig gekrimmte Rolle anliegt. Außer der Exyension und Flexion ist bei iußerster Streckung auch noch Ab- und Adduktion mogych. I)ie Befestiyung besorgt ein Kapselland, ein mediales und laterales Seitenband. Auf der Volarfliche dieser Gelenke sitzen zwei Ossa sesamoidea, Sesambeine, nebeneinander.

Die Cielenke der Phalangen selbst sind ehenfalls Schraubengelenke, sie zeigen dieselben Bänler wie die vorigen. Die Verbindung der zweiten und dritten Phalanx zeigt an der Volarseite ebenfalls ein os sesamoideum, Sesanbein; ist im übrigen lockerer als die der ersten und zweiten.

\section{Knochen der unteren Extremitit.}

Die untere Extremitä zerfält in vier untereinander in einem beweglichen und dureh Geleuhe rermittelten Zusammenhange stehende Ahteilungen: Becken, Oberschenkel, Unterschenkel, Fuß.

\section{Os coxae, Hüftbein.}

Beide Ilübbeine sind rerhunden: vorn dureh die Symphy sis pubis, hinten fassen sio das kreuzhein zwischen sich, welehes wic ein lieil zwischen sie eingeschoben erseheint; die Verbindung dieser drei Theile stellt das Becken dar.

Ia jedes llufthein anch beim Kaninchen der Enfwickelung nach aus drei (eig. vier, s. S. 124 ) verschiedenen knochen besteht, so lißkt sich dasselbe in drei verschiedene $\Lambda$ bschnitte, Os ilium, Os ischii und Os pulbis einteilen, wenngleich kaum noch eine Grenze derselben beim erwathsenen Tiere aufzufinden ist. Alle drei knohen finden einen gemeinsamen Vereingungspunkt in dem Aretabulum oder der Iliffg̣elenkpfanme, und zwar bildet das Os ilium den oberen, das $O s$ ischii den unteren und das Os pubis den mediaten Teil der Pfanne.

\section{Os ilium, Darmbein.}

Das Os ilium ist der qrößte Beckenknorhen und mil seinem größten I) nuchmesser fast gerade aufwarts gerichtet. Das Corpus, welches den oberen Teil der Pfanne bildet, ist verdickt und dreikantig; nach oben verfacht und verbreitert sich der Knochen zu einer fast in der Sagittalebene liegenden Schaufel (Fig. 58 il), wohei derselhe zugleich etwas 10 seine vertikale Arhsegedreht erscheint, so daß der obere schaufelförmige Teil mit dem vorderen Rande ein wenig lateralwirts gerichtet ist. Die Schaufel ist diun und sogar durchscheinend in der Nihe des vorderen Randes; mediale und laterale Flache und Begrenzungsrinder sind an ihr zu unterscheiden. Die laterale Flache ist im unteren Teil konvex und glatt, im oberen Teile rauh; unterhalb des 
oberen Randes, mamentlich am hinteren Drittel, in geringem Maße koukav. Der glatte und der raube Teil sondern sich genau von einander ab, wrodurch eine nach aufwirts konvexe Linie entsteht: Linea arcuata externa. Der untere Teil setzt sich in die verdickte Basis und diese lateralwärs in den Körper des Os ischii, medianwirts in den oberen Ast des Os pubis fort. Die frühere Trennung der Oss. ilium und ischii ist noch durch eine schwache, spiralig von hinten nach vorn verlaufende Linie gekennzeichnet; diejenige zwischen Os ilium und Os pubis jedoch nicht. Die mediale Fläche ist konkav, zeigt ebenfalls zwei Abteilungen: eine obere größere und eine untere kleinere; erstere ist durch ihre Glaitte von der unteren unterschieden. Die untere Flache ist rauh und dick, sie wird fast ganz zur Verbindung mit dem Os sacrum benutzt: Superficies auricularis ossis ilium, mit Ausnahme eines vorderen schmalen Abschnittes. Von der Basis wird sie durch eine ron oben nach uuten und medianwaits schriig verlaufende Linie scharf abgegrenzt; welche

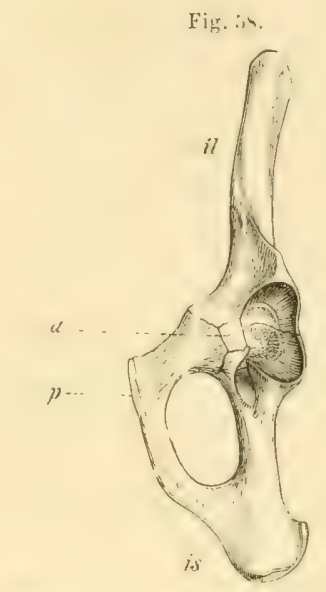

Linkes 11 s ilium, von vorn. its ilium. "Os acetahuli. p Symphy is ose. puhis. is 11 ischii. letztere Linie in das Os ischii und das Os pubis ohne erkennbare Grenze übergeht.

Der obere Rand des Os ilium: die Crista ossis ilium, stell einen nach aufwäts konvexen Bogen dar. Derselbe ist rauh und breit, mit einem Labum extermum s. laterale und intermum s. mediale versehen. In der Mitte des Randes findet sich jedoch eine kleine Einbiegung nebst niner hakenförmigen Hervorragung, so daß ein vorderer und hinterer Abschnilt entsteht, welche an dieser Stelle medianwärts und nach oben konvergierend sich verbinden. Der hintere Abschnitt ist breiter als der vordere. Das linde des oberen Randes setzt sich vom vorderen dureh eine unbedeutende Hervorragung: Spina anterior superior ab.

Der vordere Rand ist scharf, verliuft anfings sehr unbedeutend nach hinten konsex bis zur Superficies auricularis, daselbst eine !lervoragung bildend, Spina anterior inferior, unter welcher sich derselbe abflacht und nach hinten ausbiegt, un, in die Basis des Os ilium übergehend, die Incisura iliacu anterior major zu bilden. Eine Linea terminalis zur Abgrenzung des großen vom kleinen Becken ist nicht vorhanden.

Der hintere Rand bildet unter der Spina posterior (inferior) einen Einschnitt: Incisura ischiadica major, worauf derselbe, wieder me.lianwarts sich wendend, bis zur Spina ischii verläuft.

\section{Os ischii, Sitzbein.}

Das Os ischii (Fig. 58 is) zerfallt in das Corpus und die Rami superior und inferior. Das Corpus bildet den unteren Teil des Acetabulum; crsteres setzt sich nach oben in den Pfannenteil des Os ilium fort, nach vorn und me- 
dianwarts in den Ramus superior ossis pubis. Etwa 1//2 em unterbalb des Acetabuhm zeigt sich eine nach hinten gerichtete Ilervoragung, sprima ischii $($ Fig. $59 \mathrm{ps}$ ), welche die Incisura ischiadica major nach unten begrenzt. Der Körper ist dreikantig mit einer vorderen medialen, einer etwas ausgehohlten vorderen lateralen und einer hinteren Flache.

Ramus superior s. descendens. Unterhalb der Spina ischii beginnt der absteigende Ast als Fortsetzung des Corpus. An demselhen zeigen sich analoge Flachen wie am Corpus; der Ramus superior ist aber unten etwas nach hinten und lateralwirts gebogen. Am unteren Ende sitzt das Tuber ischii (Fig. $59 t)$, eine bedeutende rauhe Verdickung ron unregelmaßiger form. Sine vorspringende obere laterale Ecke kann als Processus lateralis bezeichnet werden $(8 / S)$. Der hintere mediale Rand ist schwach konkar, wodurch die seichte Incisura ischiadica minor entsteht.

Ramus inferior s. adscendens. Vom Tuber ischii entwickelt sich der anfsteigende Ast, welcher nach vorn, medianwarts und oben gerichtet ist und mit dem absteigenden Aste einen spitzen Winkel bildet. Mit dem der anderen Seice medianwirts spitzwinklig konvergierend geht derselbe in den Ramus inferior ossis pubis uber.

Os acetubuli, Pfamenknochen. Beim etwa vierteljärigen Kaninchen ist noch ein vierter knochen im Beckengürtel sichtbar, der obigen Namen crbalten

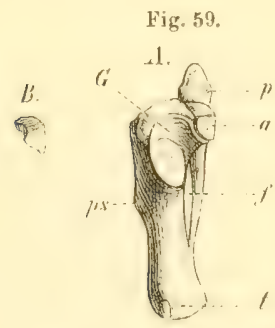

A. Rechte untere Beckenhäfte pines Ireimonatlichen Kinimchens, von oben. $p$ Ramus superior oss. pubis. «Us acetabuli. $f$ Foramen obturatorium. $t$ Tuber isehii. $G$ Hüftgelenkpfanne. $p$ s Spina ischii. - B. Rechtes Os acetabuli, von oben. Flache ist überknorpelt; sie bildet den erwähnten medialen Abschnitt der Hüftgelenkpfanne.

Ist die Nachweisung eines bisher wenig beachteten Elementes im Beckengiirtel schon an und fïr sich von Interesse, so steigert sich dieses noch durch den Unstand, daß sein Vorhommen in der Sïugetierreihe ohne Zweifel ein ganz allgemeines ist. Das (Os acetabuli ist bekannt ion IIylobates leuciscus, Cynocephalus porearius, Galeopithecus variegatus, Iydrochoerus capybara, Lepus timidus, Sciurus vulgaris (W. Krause, $1 / 2$ ). Bei Inuus bezeichnete Gegenbaur (1/5) dasselbe als verkalktes Knorpelstïck, es findet sich auch beim Igel (1/4) und nach Laurillard ( $/ 15)$ bei Raubtieren überhaupt (Os cotylö̈dien). 


\section{Os pubis, Schambein.}

Das Os puhis besteht aus einem Ramus superior und einem Ramus inferior.

Das Ramus superior s. horizontalis stellt mit seinem lateralen Ende den medialen Teil des Acetabulum dar, und verbindet sich in der erwihnten Weise mit den Oss. ilium und ischii (Fig. $60 \mathrm{~s}$ ); mil dem medialen Ende geht derselbe, sich verdickend, in den Ramus inferior oss. pubis über und trifft mit dem der anderen Seite zusanmen, mit welchem er sich zur Symphysis pubis verbindet.

Der Ramus superior ist dreikantig mit einer vorderen, hinteren und unteren Flache. Die obere Kante, Pecten ossis pubis, ist scharf und verläuft bis

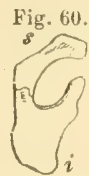

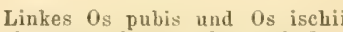
eines neugeborenen franzosischen Kaninellens, vun vorn und der lateralen Seite. $s$ Symphysis pubis. $i$ Tuber ischii. zur Basis des $\mathrm{O}$ s ilium, in welcher sie sich verliert. Im Begiune, nimlich an der Symphyse, ist eine kleine Verdickumg, Tuberculum pubis, und etwa in der Mitte der Limea iliopectimea ein scharf ausgepragter Vorsprung, Tuberculum iliopectineum, vorhanden. Die unteren Rinder sind abgerundet.

Der Ramus inferior s. descendens schließt sich an den Ramus superior an und bildet, wie gesagt, mit dem der anderen Seite die symphysis pubis, welche in vertikaler kichtung eine bedeutende Lange hat, worauf beide, unter spitzem abgerundeten Winkel divergierend, mit dem Ramus inferior ossis ischii jederseits rerschmelzen. Der Knochen zeigt zwei Flachen, eine vordere und eine hintere, sowie einen oberen und einen unteren Rand.

Von den Ästen des Scham- und Sitzheines wirl eine gloße ovale Öfnung umgrenzt, das Foramen obturatorium (Fig. 58 S. 123) s. obturatum, und zwar so, daß die laterale und untere Lmgrenzung dem Os ischii, die mediale und obere dem Os pubis zufillt.

Die Begrenzungslinie des Foramen ohturatorium hildet medianwirts einen stark konvexen Bogen, lateralwirts ist sie mehr gerade.

\section{Das Becken im Ganzen.}

An demselben fillt zunachst seine betrichtliche Linge auf, dabei aber zugleich seine ungemein aufrechte Stellung. Die Langsachse des Beckens nimlich liest fast in der Vertikalebene, eine kleine Abweichung findet sich im oberen Teile von derselben nach hinten, so daß dasselbe ein wenig um die transversale Achse gedreht erscheint, und die Darmbeinschaufeln fast ganz hinter den Processus transversi der Lendenwirbel ihre Lave haben. Es sind daher - anfrechte Stellung des Kaninchens vorausgesetzt - die früheren Bezeichnungen der Rami oss. ischii und pubis als descendens oder adscendens u. horizontalis durchaus zutreffend. Endlich ist nochmals hervorzuheben, dal das große und kleine Becken ohne erkennbare Grenze ineinander abergehen. Vie Conjugata bildet mit der Längsachse der Lendenwirbelsiule einen stumpfen Winkel von ungefähr $140^{\circ}$.

Asymmetrische und abnorime Formen des Beckens kann man experimentell 
erzeugen, wenn man bei jungen Kaninchen eine untere Extremitat amputiert, einzelne Muskeln exzidiert, Muskelnerven reseziert, das Oberschenhelbein in Hüftgelenk luxiert u. s. w. $(1 / 6)$.

\section{Verbindungen der Hüftbeine.}

Die Iliftheine rerbinden sich mit dem Os sacrum und untereinander. Die Verbindung zwischen Ilift- und hrenzbein, Articulatio sacro-iliaca, ist eine Amphiarthose. Es finden sich in beiden Knochen zwei hufeisenfömige Gelenkflichen, die den unteren Rand, sowie die beiden unteren Drittel der Seitenwinde der Superficies auriculares eimmehmen. Der obere Teil ist rauh und führt in eine zwischen dem ïberknorpelten Teil gelegene Grube, welche durch Faserknorpel ausgefült wird. An der hinteren Seite finden sich außer dem tibrösen Periost, welches die Amphiarthrose überzieht, noch sehnige Verstirkungshündel zur Befestigung, von denen eines, das Ligamentum iliosacrale, von der Spina posterior (inferior) zum Processus obliquus spurius des ersten Kreuzheinwirbels verliuft, wihrend ein anderes, das Ligamentum iliolumbale, vom letzten Lendewwirbel entspringt und medianwirts ron den erstgenannten und der Spina posterior neben demselben sich anheftet.

Die beiden Oss. pubis rerbinden sich in der (S. 125) beschriebenen symphysis pubis durch eine dinne, aus hyalinem, theilweise verkalktem Knorpel bestehende $Z$ wischensubstanz. Es wäre claher richtiger, die Symphyse als symohondrosis pubis zu bezeichnen. AuBer dem Periost, welches die Symphyse aberzieht, findet sich am oberen, besonders aber unteren Rande derselhen tibröses Gewebe. Das den scheitel des drcus pubis atusfullende Gewebe, Ligamentum arcuatum inferins, setwt sich, jedoch weniger stark entwickelt, auf die aufsteigenden Äste der Oss. ischii fort.

Eine eigene, das Foramen obturatorium verschliebende Membran ist nicht vorhanden. Die nach demselben benamnten Muskeln entspringen von den Riindern s. Myologrie, Muskeh der unteren Extremitit, Mm. obturator internus und externus), und bilden den Verschluß des Foramen. Ligamenta sacrotuberosum und sacrospinosum (s. Myologie, Muskelo des Schwanzes, M. abductor caudae anticus) fehlen dem Kaninchen ebenfalls.

\section{Femur, Oberschenkelbein.}

Das Femur ist ein langer Röhrenknochen und der stirkste am Skelett des kininchens. Seine beiden Enden sind stark verdickt und besonders das onere von auffallender Form.

An der medialen seite desselben ragt zunidehst der Gelenkkopf: Caput femoris, fïr die Plamme des Hüftheines hervor, welcher medianwirts und nach olen gerichtet ist, mit iiberknorpelter Gelenkfliche von großer Ausdehnung und ellipsoidischer Form. Betrachtete man den Gelenkkopf als Teil einer Kugel, so wirde derselbe wenig mehr als die flalfte einer solchen betragen. Auf seiner spitze ist eine Vertiefung, Focen cupilis femoris, fur die Insertion 
des Ligamentum teres. Der Gelenkkopf sitzt auf einem kurzen, mit der Diaphyse nach oben einen stumpfen Wiukel bildenden Halse, Collum femoris, gegen welchen er sich in dem srößten Teile seiner Zirkumferenz durch einen scharf markierten, unterminierten Rand absetzt, nur an einer kleinen Stelle, dem Trochanter major gegenüber, ist der kand weniger scharf.

Lateralwarts vom Caput femoris faillt ganz besonders eine große rauhe Ilervorragung ins Auge, welche in der Fortsetzung der Diaphysenachse liegt und zu welcher das kurze Collum femoris hinüberfiihrt, es ist der Trochanter major (Fig. $61 \mathrm{ma}$ ).

Zwischen Golenkkopf und Trochanter major bleibt eine Vertiefung, Foss trochanterica, die sich besonders nach hinten und unten ausgiebig erweitert. Sie wird lateralwirts und nach unten abgegrenzt durch eine rauhe Linie, welche von der Spitze des Trochanter major nach unten und medianwirts verläuft, um mit einer höckerigen Leiste, die unter dem Caput femoris beginnt und lateralwarts nach unten und hinten verliuft, unter spitzem Winkel sich zu rerbinden. Letztere Crista ist der Trochanter minor (Fig. $61 \mathrm{mi}$ ); die genannte rauhe Linie die Linea intertrochanterica.

Einige Millimeter unterhalb des unteren Endes des Trochanter major tritt an der lateralen Seite des Femur noch ein zweiter Höcker hervor, der aber minder bedeutend ist als der erstgenannte, dies ist der. Trochanter tertius (Fig. 61 ). Von hinten betrachtet macht die obere Extremitait des Femur den Eindruck eines Rhomboides mit vorspringenden Winkeln.

Die Diaphyse ist mehr oder weniger zylindrisch, ziemlich bedeutend nach vorn gebogen. Die hintere Fläche wird von der vorderen lateralwärts durch eine deutliche Kante geschieden, welche von dem Trochanter tertius ihren Anfang nimmt; an der medialen Seite gehen beide Flaichen abgerundet in

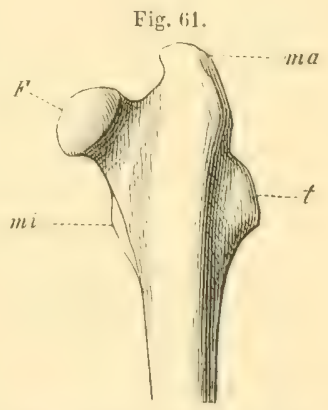

Rechtes Fomur, von vorn. F Fovea capitis femeris. ma Trochanter majur. $t$ Trochanter tertius. mi Trochanter minor. einander uber. Über die Mitte der hinteren Fläche zieht sich von dem Zusammenfluß der beiden obenerwahnten Gristae aus eine nur leicht angedeutete $(S / S)$ Linie hin, welche dieselbe in einen lateralen und medialen Abschnitt scheidet.

Das untere Ende des Femur schwillt zu einer maßigen Verdickung an, auf welcher die überknorpelten Gelenkflichen für die Tibia und Patella sich befinden.

Der Gelenkfortsatz ist eine Rolle mit zwei seitlichen Erhabenheiten, dem Condylus femoris lateralis und medialis, und einer Vertiefung in der Mitte.

Die Überknorpelung des einen Condylus setzt sich auf die des anderen an der vorderen Seite unmittelhar fort, durch eine seichte, sattelfurmige Vertiefung, die sich bis zum Ende der Diaphyse nach aufwarts erstreckt, und in welcher die Patella gleitet, Fossa patellaris. An der hinteren Seite sind die Condylen durch eine bedeutendere, nicht uberknorpelte Vertiefung geschieden, Fossu intercondyloidea. Der mediale Condylus ist gröber als der laterale 
und ragt mehr nach vorn und untes; beide sind, der eine an der medialen, der andere an der lateralen Seite rauh.

\section{Hüftgelenk.}

Die Verbindung des Femur mit dem Ituftbein ist eine beschrinkte Arthrodie, kein Nußgelenk. Der Gelenkknopf legt sich in eine tief ausgehöhlte Pfanne, Acetubulum (Fig. 59 G, S. 124), deren Zirkumferenz unregelmabig ist und zwar so, daß an der medialen unteren und lateralen Seile ein Stuck von Gelenkpfannenrande abgetragen zu sein scheint.

Durch einen faserknorpeligen Ring, Labrum fibrocarlitugineum acetabulis. Limbus cartilagineus, welcher dem freien Rande der Pfanne ringsum aufsitzt, wird deren Tiefe noch vergrößert. Das Innere der Pfanne ist quleichsam in zwei Abteilungen greteilt, eine außere großßere und innere kleinere, so daß es trichterfömig erscheint. Den inneren und auch mehr mediamwirts gelegenen heineren Teil der Pfamne, welcher vom iußeren durch einen weiben, etwas vorspringenden silum geschieden ist, nimmt das Ligamentum teres femoris als Ursprungsstitte in Anspruch, welches sich in der Fovea capitis femoris hefestigt, und eine nicht unbedeutende Stirke und Dicke besitzt. Des iubere Teil der Pfanne ist annihernd Teil einer Hohlkugel.

Das Caput femoris ist wie gesagt ellipsoidisch, und sein größter Durchmesser, sowie derjenige der Pfamme, ist schrigy von oben und vorn nach unten und hinten und zugleich lateralwirts gerichter. Die Befestigung des Femur an das Becken wird nur durch eine fibröse. ziemlich schlaffe Kapsel rermittelt, welche vom Labrum fibrocartilagineum acetabuli entspringt und, das Collum femoris einschliekend, sich an und zwischen den Trochinteren hefestigt. An der oberen, medialen unteren und lateralen unteren Seite ist die Kapsel verdickt durch Sehuenstreifen, welche von dem Corpus ossis ilium, den Oss. pubis und ischii entspringen und die als Ligamenta iliofemorale, ischiofemorale und pubofemorate bezeichnet werden können. Durch die ersteren beiden wird besonders eine bedeutendere Streckung behindert. An der vorderen Seite ist die Kapsel am dünnsten (vergl. 774).

\section{Tibia, Schienbein.}

Die Tibia ist der lingste Knochen am Skelett des Kaninchens. In seiner Vitte findet an der lateralen Seite eine knöcherne Verbindung der Fibula unter spitzem Winkel mit der Tibia statt Fis. 62). Das obere Ende der Tibia ist sehr stark verdickt, dreikintig und Jeicht nach vorn gebogen. Die beiden comdyli tibiae, welche das obere Ende bilden, sind an ihrer oberen Flache uberknorpelt und nach der hinteren Seite etwas sich umbiegend. Wo sie in der Mittellinie anf der Oberliiche zusammenstoßen, finden sich auf der Mittelfliche ein paar kleine Hervorragungen, Eminentiae intercondyloideae tibiae, die eine seichte Girube zwischen sich lassen, welche sich jedoch nach hinten und unten mehr vertieft, sowie das Foramen mutritium tibiue. 
Die überknorpelten Gelenkflachen sind schwach konvex; nur bildef sich am Seitenrande der lateralen durch Erhebung jenes Randes eine leichte Konkavitat. Die Seiten der Condyli sind rauh.

An der unteren Seite des lateralen, am bedentendsten nach hinten vorspringenden Condylus befestigt sich die Fibula knorplig, aber unberveglich durch Synchondrose. Die laterale und mediale Fliche der Tibia vereinigen sich vorn und oben in einer vorspringenden Rauhigkeit, die bald zu einer scharfen Kante wird: Crista tibiae. Von den beiden Kanten der hinteren Fläche ist die laterale ebenfalls scharf, die mediale abgerundet. Die früher vorhandenen drei Flächen vermehren sich nach unten um eine, so daß dann zwei mediale seitliche: eine hintere und vordere, statt der früher einfachen medialen zu unterscheiden sind.

Nach unten zu verflachen sich die Kanten immer mehr und der Knochen nimmt, zugleich dünner werdend, eine mehr abgerundete Form an. Das untere Ende verdickt sich darauf wieder, um dem Fuße die erforderliche Gelenkfliche darzubieten. Dieselbe entspricht der Rolle der Fußwurzelknochen. Der größere oder laterale T'eil artikuliert mit dem Talus, welcher eine Rolle mit sattelförmiger Vertiefung besitzt; der kleinere durch einen tiefen Einschnitt vom ersteren getrennt, mit einer gleichsam aus der Rolle des Talus hervorkommenden, ebenfalls rollenartigen Gelenkfläche des Calcaneus.

In den tiefen Einschnitt greift die laterale, stark sich erhebende Kante des Talus ein. Die gemeinsame Gelenkfliche des Talus und Calcaneus für die Tibia stellt einen Schraubengang dar.

An der lateralen und medialen Seite sind höckerige Rauhigkeiten vorhanden, die an beiden Seiten über das Gelenk hervorspringen, Malleolus lateralis und Malleolus medialis, wodurch Rimnen gebildet werden zum Durchgang von Muskelsehnen.

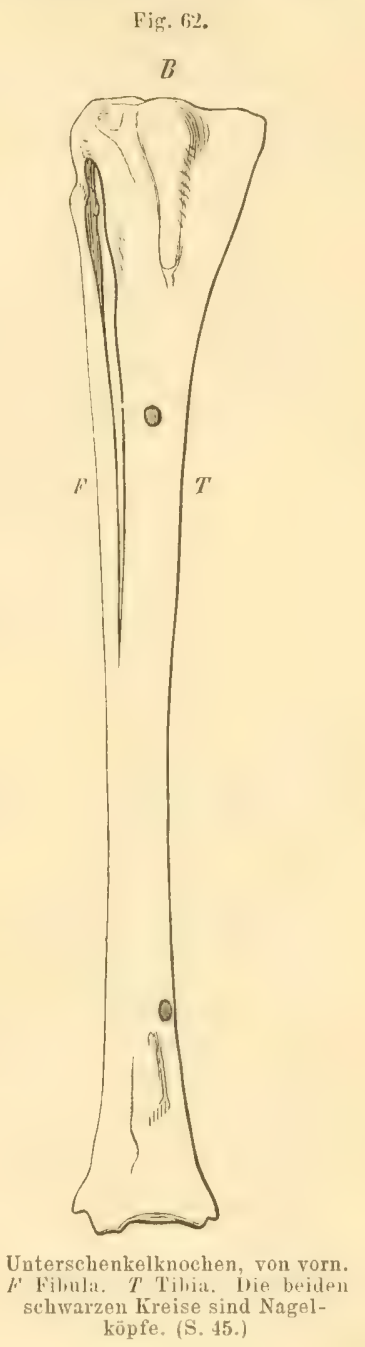

\section{Fibula, Wadenbein.}

Die Fibula ist ein dreikinliger, schlanker und dünner knochen, welcher an der lateralen Seite der Tibia seine Lage hat. Sie ist kaum hall so groß als die Tibia und vereinigt sich etwas oberhalb der Mitte unter spitzem Winkel knöchern mit der letzteren (Fig. $62 F$ ). Ihr oberes Ende, das Capitulum fibulae, ist elwas verdickt und rundlich, stißßt all die nach abwirls gerichtete Cherknorpelung des Condylus lateralis tibiae, ist jedoch unbeweglich. Der 
Knochen bietet drei Flächen dar, eine vordere, laterale und mediale, von

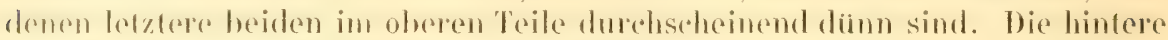
Kante ist die stumpfste, die laterale die flachste.

Der Zwischentaum zwischen Tibia und Fibula. Interstitium interosseum cruris, wirl dureh ein Ligamentum interosseum crmis ausgefiillt.

\section{Patella, Kniescheibe.}

Sie ist als ein Anhang des Unterschenkels zu betrachten, analog einem abgelosten Olecranon, dem sie aber keineswegs homolog ist. lhre form ist

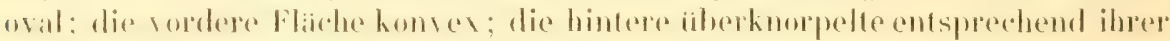
Gelenkgrube am Femur sattelformig.

\section{Kniegelenk.}

Die Articulatio gem, das Kniegelenk, ist ein kompliziertes Schraubenge-

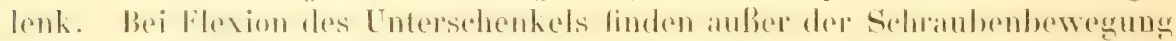
auch noch Rotationen medianwirts statt. Das Gelenk besteht aus fünf Abteilungen. Die latellat artikulert mit dem Femur in cinem Sattelgelenk. Die Flexionshewegumen dinden zwischen den beiden Condyli femoris und zwei

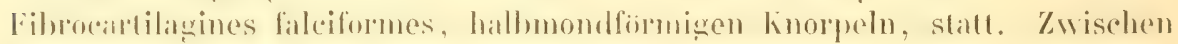

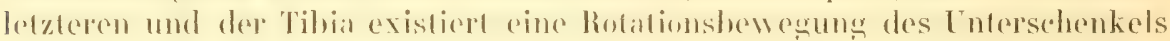

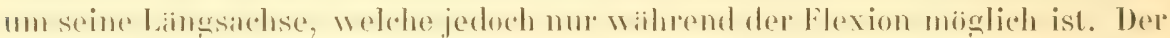

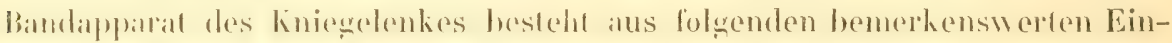
zelheiten. Dire fibrise kapsel sehliebt, wenn man von atuben nateh innen geht, zunachst das diclenk ein. Sie entspringer oberhall, der Condyli femoris und

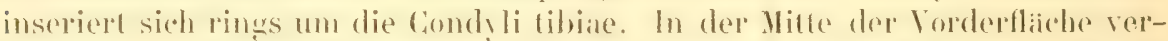
hindel sie sich mit einem starken librisen Bande, in dessen Vilte die Patella liew: dasselle entsteht aus der Insertion der Streckmuskeln des Intersehenhels und hefted sich, won der Patella unterhoehen, an das iblerhnorpelte obere Eande derespinatihiare. Man kaun jene strecksehne als ein Ligumentum patellare superius fon dem eigentlichen Ligamentum putellar (inferius s. proprium) unterscheiden.

An beiden Seiten, jedoch innerhalb der Kapsel, findet man dann die kriftigen Seitenbander, Ligamentu collateralia genu, mediale et laterale. Ersteres entspringt vom Condylus medialis femoris und inseriert sich an die mediale Kante deo Tibia; dasselle ist wrober als das laterale, welehes tiefor vom Condylus lateralis beginnt und höher am Capitulum fibulae endigt.

Bei Streckung des Unterschenkels werden beide Binder sehr stark gespannt, bei Bengumg ersehlallt. Zwischen beiden Bandern findel sich eine mit Fell reichlich gefoulle Ausstialpung der mit der Kapsel innig verbundenen Sinorialmembran, welehe sich won dee Basis der Patella bis zur Insertion des

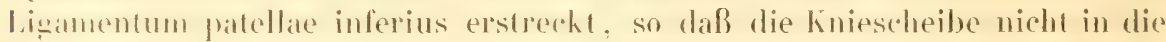

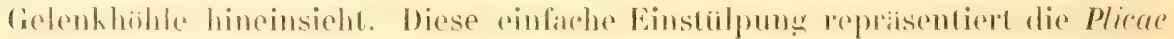
aliformes s. Ligg. alaria des Menschen. An der hinteren Seite des Gelenkes 
verdienen drei Ossa sesamoidea, Sesambeine, Erwihnumg, welche den beiden Condyli femoris und dem lateralen Condylus tibiar knorplig aufsitzen. An medialen Condylus tibiae ist statt dessen nur eine kleine ratuhe IIervorragung vorhanden.

In Innern des cielenkes trifft mam als Hemmungsmiltel der Beugung und Streckung die Ligamenta cruciala an, vou denen das anterius ror, das postrrius hinter den Eminentiae intercondyloblea tibiae entspringt. Jenes heftet sich hinten an die mediale Fliche des Coudylus lateralis lemoris, dieses endigl vorn am Condylus medialis femoris, wodmreh ein Andreaskreuz $X$ entsteht.

Auf den Gelenkflichen der Condyli tihiac liegen zwei hallnmondfürmigne Faserknorpel, Fibrocarlilagines falriformes, welche, nach oben konkar, deusellen diejenige Tiefe verleihen, die von den stark konvexen Condyli femoris beansprucht wird. Der mediale Faserknorpel ist weniger wekrimmt, als der laterale, und großer. Die konveren Rinder heider Knorpel sind mit de fibrösen Gelenkkipsel velwachsen; der laterale laserknorpel ist hoher als der mediale. Der mediale befestigg sioh sodamn an den Condylus latepalis libiate vorn, hinten in der Vertiefung hinfer den Eminentiae interomdyloidear libiae, der laterale vorn am Cond! lus medialis, hinfen an Condylus lateralis so, daf derselbe an seinen Anheftungsstellen hinter dem medialen liegt.

\section{Knochen des Fulses.}

Talus. Der Talus oder das Sprungbein ist ein Knochen von sehr unre-

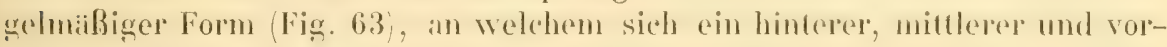
derer Teil unterscheiden läbt. Der hintere Teil, Corpus tali oder Körper, liegt an der tibialen Seite des Calcaneus und lehnt sich fibularwirts an dessen Gelenkflache für die Tibia an, welche in eine an seiner unteren Flache befindliche Grube keilförmig eingreift. Die dorsale Flache ist rollenarlig gestallet, Talusrolle (Fig. $63 \mathrm{~T}$ ), mit einer mittleren bedeutenden Vertiefung und zwei seitlich hervorragenden Rindern, von denen der fibulare an Hobhe den tibialen übertrifft. Die Plantarfläche zeigt den erwähnten keilförmigen Ausschnitt zur Verbindung mit dem Calcaneus. Der miltlere Teil, das Collum tuli, an der Dorsalfiche konkav, an der Plantarfliche konves, ruht auf einem an der tibialen seite des Calcaneus befindlichen Vorsprung; es ist nach vorn, plantarwirts und tibialwirts gerichtet. An dem vorderen, elwas fibularwirts sich umbiegenden Ende des Collum sitzt das Caput tuli Fig. 63 C, welches eine nach rom konvexe Gelenkfliche zeigt, die aus der plantaren des Collum hervorocht, indem dieselbe sich verbreiternd nach rorn und dorsalwarts umbiegt. Wer walzenförmige Kopf des Talus legt sich in die tief ausgehöhlte felenklliche des ror ihm liegenden Os naviculare.

Calcaneus. Das Fersenbein, an Grobe alle übrigen Fußwurzelknochen bedeutend ühertreffend, liegr filubarwirts von dem Talus, und teilweise unter dem letzteren. Der Knochen ist etwa dreimal so lang als breit. An seinem 
hinferen. efwas verdickten Ende hesitzt derselbe eine iberknorpelte Flache, in welcher der Tendo Achillis gleitet. Dic plantare Fliche ist gleichmiBig hombex. Auf der Dorsalliache, die weniger breit ist als die plantare, erhebl sich elwas äher der Mitte die schon erwihnte schraubenfömmige Gelenkfliche zur Artikulalion mil der Tibia S. 1997, welehe an ihrer libialen Seile keilfürmig ist, un in die Vertiefung an der Plantarfliche des Talus hineinzupasseu. An der tibialen Flathe zeigt sich im vorderen Teile ein hreites, unregelmiBigrer, dlach konharer Vorsprung, der Processus mediulis s. Sustentaculum tali, weleher dis Collum tali zu l'agen hat. Dieser ubbeknorpelte fortsalz greht von

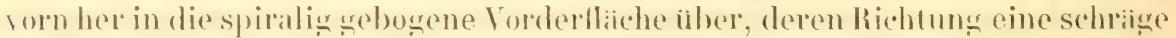
von hinten und libialwirls mach vorn und fibularwirts ist. Dieselbe arlikuliert mit der vor ihr liegenden delenklliche des Os farsale III; tibialwirls liegt sie neben dem Os naviculare. Hinter dem Processus medialis ist noch eine vom Dorsum schrig nach vorn und plantarwarts verlaufende Rinne zu er-

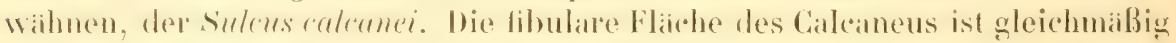
und geht abgerundet in die plantare über, wihrend sie von der dorsalen deutlich sich abgrenzt.

Os naviculare. Das Kahnbein ist ein unregelmaßiger Knochen von nicht hestimmt defonierharer form. Es steht mit simmtlichen Fußwurzelknochen in Verhondung. Vor demselhen liegen die beiden Ossa tarsalia I II. II ; an die tibiale vordere Eohe stebli das Os metatarsi I, an die fibulare das Os tarsale III; an die fihulare Fiatebe legt sich der Calcaneus. Besonders anffillig ist

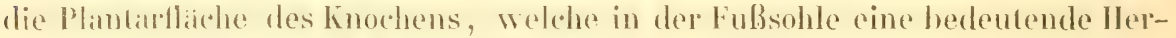
vorrasung hildet, so dalb heim Gehen hauptsichlich mit diesem knochen der

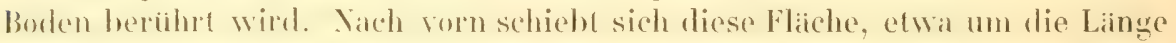
des übrigen Knochens vorspringend, unter die Basis des Os metatarsi I.

Ossa tarsalia s. cuneiformia. Das Kaninchen besitzt nur zwei Oss. "mmeiformiat. Dats os tarsale primmm ist das hloinste, rierechig und legut sich in rinen Iusschnill an der lihularen Seite des ersten Drelatarsusknochens. Das Os tarsale secundum liegt fibularwäts von dem ersten, ist etwa doppelt so

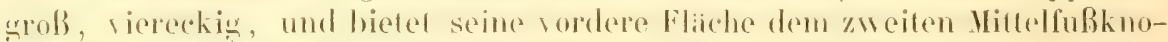

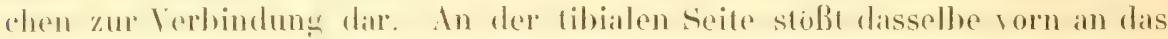
Os melatimsi 1: die fibulare Flatehe geht eine Gelenkrerbindung mit dem $\mathrm{Os}_{\mathrm{s}}$ Larsale III ein.

Entwickelungsgeschichte. Bei älteren Kaninchen (Fig. 64 B) verwïhchst das Os tarsale I mit dem Os metatarsi I. Bei neugeborenen Tieren (Fig. 64 A) ist dagegen die tibiale Hervorragung des hinteren Endes des Os metatarsi I selbstindig und besteht aus einem Os tarsale und einem lainglichen, vorn zugespitzten Knochen, der ein Rudiment. des IIallux darstellt und an dessen vorderes Ende sich von oben her die Sehne des M. tibialis anticus ansetzt. In Wahrheit ist also das Os tarsale I des Kaninchens das II des Menschen, und das Os metatarsi I des Kaninehens reprïsentiert Os tarsale I, Hallux und Os metatarsi II des Menschen.

Os tarsale III s. cuboideum. Das Wüfelbein ist unregelmäig viererokig, liogt or dem Calcaneus, es ist kleiner als das Os naviculare und liegt weiter nach vorn. Vor seine vordere Flache legen sich der dritte und vierte Mittelfußknochen; seine ibrigen Verbindungen sind bereits genamnt. 


\section{Ossa metatarsi, Mittelfufsknochen.}

Die Mitlelfußknochen werden als Ossa melatarsi primum, secundum, ter-

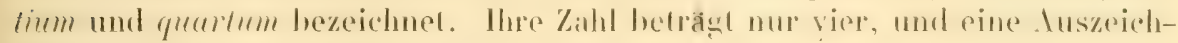
nung des llallux findet nicht statt. Ihre Verbindungen mit den Fußwurzelknochen, welche durch flache Gelenkfliichen eingeleitet werden, wurden bereits besprochen. Miteinander verbinden sich die Bases ossium metalarsi dureh mehr oder weniger ansgedehnte Flächen. Die Basis des Os metatarsi I zeigt den erwähnten viereckigen Ausschnitt; die des IV ist am dicksten und schickt fibularwärts einen rauhen Fortsatz ab, die Tuberositas oss. melatarsi IV. Im abrigen unterseheiden sie sich von den Mittelhandknochen nur noch durch ihre bedeutende Länge und Stärke.

\section{Phalanges, Phalangen.}

Die Phalangen bieten ganz dieselben Verhiilınisse dar, wie die der oleeren Extremitait, abogesehen davon, daß diese an Größe und Stärke jenen betrichtlich nachstehen. Die Enden der letzten Phalangen sind deutlicher gespalten.

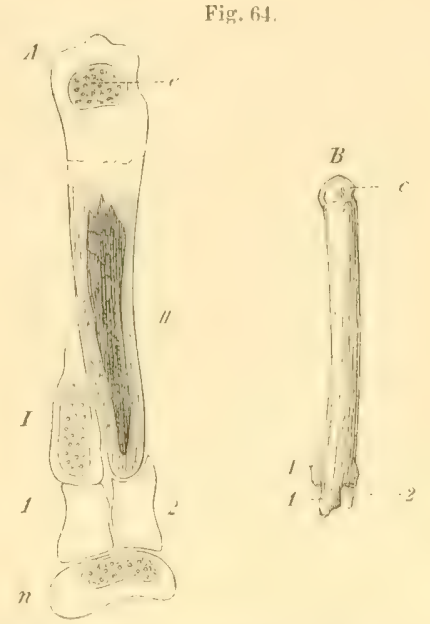

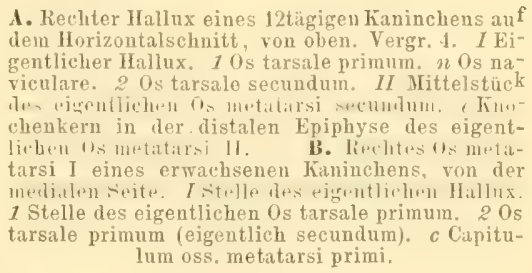

\section{Ligamente des Fulses.}

Die Beweglichkeit des Fußes im Ganzen ist eine sehr geringe; sie beschrankt sich auf die Schraubenbew equngen, welche im Sprungquelenko ausgefuhrt werden. Die Gelenkverhindung zwischen Tibia und Talus, Arliculatio pedis, ist ein deutliches schrabhengelenk: die zwischen jener und dem Calcaneus verhailt sich äbnlich, doch ist ihre Schrambemnatur nicht so ausaesprochen. Der Bandapparat der Fußwurzel hat die Funktion, den Luterschenkel mit den Tarsuskunchen. die einzehen Tirsushnochen miteinauder und den Metatarsusknochen zu verdinden. Der Untersehenkel wird mit

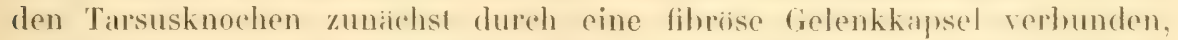
welche sich rings um das Gelenk hefestigt und die Rinnen. Welche durch die Malleolen gebildet werden. zи kanalen erwimzt. Ferner dienen dazu zwei Seitenbander, Ligamenta colluteraliu pedis, das cine an der tibialen. das andere an der fibularen seite gelegen. Das tibiale Seitenband entspringt ron der Vorderfiche des Malleolus medialis libiae, geht nath vorn und tibialwairts und befestigt sich an den Processus medialis calcanei. Das fibulare Band rer- 
libuft vom hinteren hande der kimne hinter dem Malleolus lateralis zur filmu-

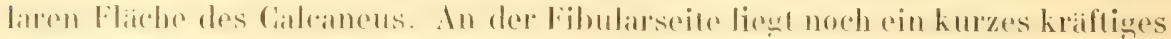
Bamb, Woldes bor dem Malleolus lateralis antspringet und hinten neben dem

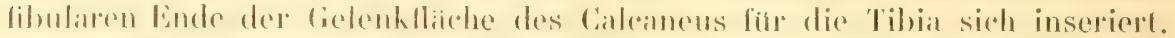

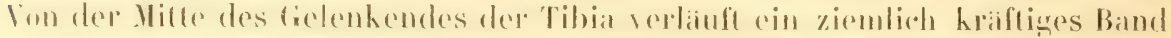

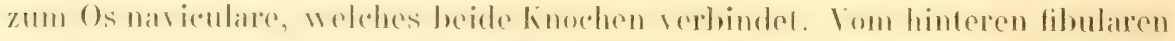

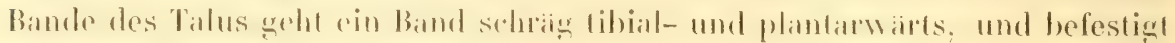
sich am Calcaneus.

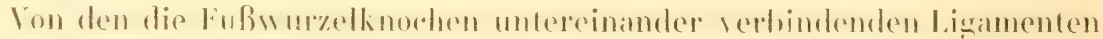
sind noch nennenswert in der Fußsohle: ein kurzes strafles Band, welches den Processus medialis calcamei mit dem Os naviculare verbindet; fermer ein

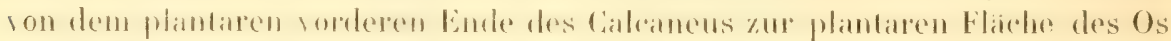

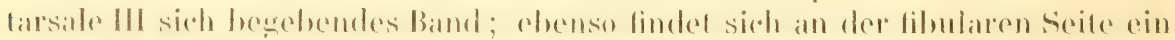

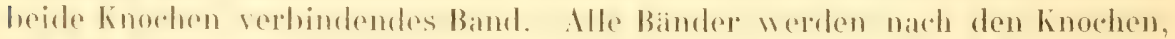

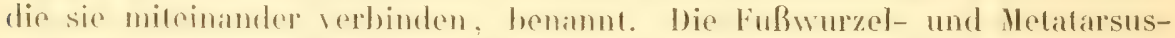

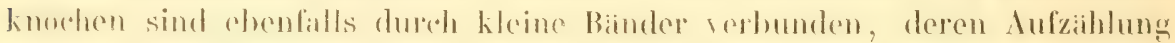
ohne weiteres Interesse sein wiude. Die Bandapparate, welche Mittelfuß-

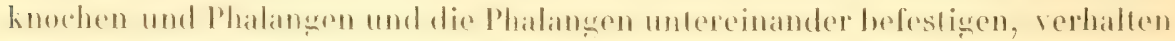
sich wie diejenigen an der lland.

\section{Gelenke des Fulses.}

Die Arliculatio pedis, das Fuß-, Knöchel- oder Sprunggelenk, wurde sethon bei der Tibias s. 199) und den Liganenten des FuBes (s'. 133) mit alogebandelt. Zwischen den Knochen des Fußes untereinander, und zunächst

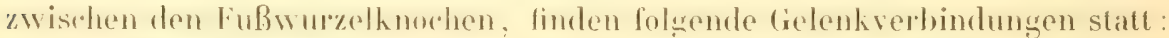

Articulatio talocalcanea besteht aus zwei durch den Sulcus tali geschiedenen konhatren fielenkllichen des Galeanens, denen zwei konvexe Fiachen der Interseite des Tahus entsperehen. Iedzlere stellen Trile eines ellipsoi-

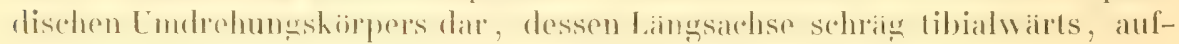
wairls und mit dem tibialen Ende nach rickwirts gerichtet ist.

Articulatio talonavicularis ist eine beschrinkte Arthrodie. Die Bewegungen sind in der Richlung lom Dorsum zur Planta ausgiebiger, als in der Richlumg von der Tibial- zur Fibularseite. Die Rotation um die Liangsachse des Fußes isl sehr beschrinkt. Die Achse der großten mogylichen Bewegung libuft von der Tibial-zur libularseite: iln libiales Ende ist etwas dorsalwäls gerichtel.

Articulatio calcaneocuboidea. Die Verbindung zwischen Calcaneus und ()s larsiale III für sich allein würte einem Schraubengelenk entsprechen, dessen Achse schräg tibial- und dorsalwarts, und mit ihrem fibulareu Ende narh unten grerichtet ist. Sie liegt im Os tarsale Ill. Mit Riucksicht anf dic Anteilnahme des Os naviculare kann man die Articulatio calcaneocuboideonavicularis als ein Kegelgelenk bezeichnen.

Articulatio calcaneocuboideonavicularis. Die Drehungsachse liegt in der liangsathse des fuBes, die Spitze des liegels ist als oherer Fortsatz des Os tarsale III aufwäts und ein wenig tibialwärts gerichtet. 
Articulatio cuneonavicularis prima et secunda. Die erste wiederholt im bleineren MaBstate die Artioulatio Lalonar iendaris; die zweite ist eine Am-

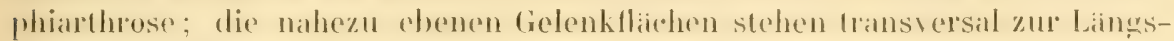
achse des Fußes.

Articulationes tarsometalarseae. Die vier Tarsometatarsal-Gelenke sind

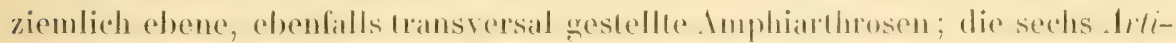

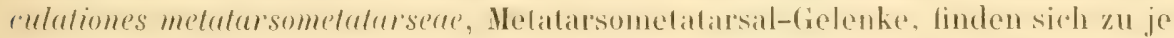
zwei zwischen den Bases von je zwei Metalirsusknochen und stellen je zwei ziemlich obene Amphiarthrosen dar, die durch einen kleinen Suleus seschieden sind. Tur die ohere zw ischen Os melatarsi I und II zeigh einen walzenformsigen Gelenkkopf am ersten Knochen.

Articulationes digitorum (pedis). Die Gelenke zwischen den Oss. metalarsi und den Phalangen, sowie die zwischen den Phatingen selhst bephalten sich wie an den Fingern. 


\section{Myologie.}

\section{Muskeln des Kopfes.}

\section{Muskeln des Gesichtes.}

Ein Teil der mimischen Gesichtsmuskeln des Kaninchens gehoren dem sich iblser den ganzen Kïrper verbreitenden großen Haulmuskel an (s. Splanchnologie, Haut). Als von Knochen entspringend sind zu erwähnen:

11. zygomaticus major ist sehr schwach entwickelt, nur 1-2 mm breit, dimn, antspring vom Processus zygomaticus oss. temporum, liuft schrigg nach vern und unten ibher das vordere Ende des Areus zygomaticus zur IJat der Backe.

M. zygomaticus minor. Ursprung: Vom medialen vorderen Teile des Jochbeinkorpers. Schmaler, dimner Muskel, weleher in sagitlaler Richtung iiber die Wingenflache zur Oberlippe verliuft, in welcher er sich verliert.

11. levator labii superioris. Ursprung: Aus der Fossa maxillaris, welche vom Os zy gomaticum und dem oberen und hiuteren Teil der lateralen Fliche des Os maxillare superius (proprium) gehildet wird. Ls ist ein langlicher, dimner, viereckiger Muskel, welcher nach abwirts verliuft, um in die Oberlippe sich zu inserieren.

11. levetor nasi. Ursprung: Vom Augenhohlenrande des Corpus oss. maxillaris superioris, proprii). Der Muskel verliuft nach vorn und medianwarts, kreuzt sich mit den $11 \mathrm{~m}$. subculaneus faciei (s. Splanchnologie, Ilaut) und levator lahii superioris, welche ihn ron orn und bateralwirts her bedecken, creht in eine dimne, schmale tehme üher, die linger ist, als der Muskel selbst. Insertion: Haut des lateralen Randes des Nasenrúckens.

M. levator anguli oris. Breiter, dünner Huskel von vertikalem Faserverlauf. Ursprung: Laterale Außenfliche des Corpus oss. maxillaris superioris. Insertion: Beharte Innenfliche der Schleimhat (s. Splanchnologie, Mundhöhle) am Mundwinkel (vergl. 101, Taf. II, Fig. 3).

M. dentalis superior (101, Taf. III). Ein dünnes mikroskopisches Bündel des zuletzt genannten Muskels verlïuft in der Frontalebene des zweiten oberen Backenzahnes dicht unterhalb des Canalis nasolacrymalis und an der lateralen Wand des Sinus maxillaris in sagittaler Richtung. 
M. buccinator. Ursprung: Vom unteren Teile der vorderen Flarche des Oberkiefers, sowie von den Alveolarrindern des Ober- und Unterkiefers in ihrer ganzen Ausdehnung. Der Muskel ist fleischig und hriftign, seine Fasern verlaufen von hinten nach vorn und endigen in der Ober- und Unterlippe, so daß die Insertion des Iluskels einen Ialbkreis darstellt. In der Unterlippe gehen von den Muskeln beider Seiten Fasern ineinander über.

II. depressor labii inferioris s. quadratus menti. Linghlicher platter Muskel; entspringt vom unleren Rande des Unterkiefers unterhall, der Gegend des ersten Backenzihnes (S/S), liuft nach vorn, bedeckt vom II. submentalis, inseriert sich in die Haut der Unterlippe.

\section{Kaumuskeln.}

11. masseter. Irsprumg: Mit zwei l'ortionen, einer lateralen und medialen. Die laterale ist die bei weitem kriftigere, entspringt von der lateralen Flache des Areus zygomatieus in ihrer ganzen Ausdehnung und deckt die mediale Portion, welche von der medialen Flache des Areus zygomaticus entspringt. Kurzer, dicker, viereckigner, mit zahlreichen fibrösen Streifen durchzogener Muskel. Insertion: Beide Portionen setzen sich rereinigt an dio laterale Flache des Ramus maxillae inferioris.

M. Temporalis. Ursprung: Von der lateralen Flatehe der Pars squamosa oss. temporum. Geht durch das Foramen temporale (s. Os frontis, S. 90 . Insertion: Processus coronoideus maxillate inferioris und die Incisura anterior maxillae inferioris:

M. plerygoideus intermus. Ursprung: Fossa pterggoidea. Stark ron fibrösen Faszikeln durchsetzter Muskel. Insertion: Unterer Teil der medialen Fläche des Ramus maxillae inferioris.

M. plerygoideus externus. Ursprung: Lamina lateralis processus pterygoidei. Kurzer, dicker, fleischiger Muskel, bedeutend kraftiger, als der vorhergehende. Insertion : die zwei oberen Driltel der medialen Flarohe des Ramus maxillate inferioris, medianwirts bedeckt rom vorigen, bis zur Eminentia mylohyoidea und am medialen Rande des Foramen mandibulare.

\section{Eigentliche oder hintere Kopfmuskeln.}

11. reche capitis posticus superficialis 619$)$. Ist dimn und schwach. Entspringt vom Processus spinosus des Epistropheus, lauft aufwirts, inseriert sich teilweise schrag an die Protuberantia occipitalis externa oss. occipitis dicht neben der Medianlinie.

11. rectus capitis posticus minor. Lrsprung: Vom Tuberculum posterius des Atlas. Schlanker kleiner Muskel, der an die Proluberantia oceipitalis externa neben der Crista sagittalis und medianwirts rom M. rectus capitis posticus major sich inseriert.

M. rectus capitis posticus major. Ursprung: Processus spinosus des Epistropheus, läuft lateralwirts und nach oben, inseriert sich, stirker als der 
vorige, an die l'ars syuamosa oss. oceipitis oberhall, und lateralwiats neben dem oberen Ende des Processus condyloideus.

1I. obliquus cupilis major s. inferior. Dicker, krätiger Muskel. Wird vom 11. rectus captis posticus major teilmeise bederkl, verliuft fast horizontal, entspring rom processus spinosus des Epistropheus und setat sich an den lateralen Rand der hinteren Fliche des Processus transversus des Atlas.

1I. obliquus cupitis minor s. superior. Entspringt vom lateralen oberen Rande des Processus trausversus des Atlas, verlauft nach oben und etwas medianwarts. Inseriert sich an dem lateralen Rande der Protuberantia oceipitalis externa. Bedecht don M. rectus eapilis lateralis und den M. rectus capilis posticus major von hinten her.

M. rectus capilis lateralis. Dicker, kriftiger Muskel. Entspringt gemeinschafllich mil dem M. ohligums caphitis minor bom lerocessus transversus des Alas, rerliuft atufsleigend, inseriert sich an den hinteren Rand des Processus jugularis oss. ocoiphitis loberster M. interlransversarius) und in die Grube zwischen letzterem und dem Processus condyloideus oss. occipitis.

\section{Muskelı des Halses.}

M. stennomastoideus. Ursprung: Gemeinsam mil dem der anderen Seite von der vorderen Fliche des llanubrium sterni. Der Muskel ist ein langer, kriftiger strang mit parallelen Fasern, verlauft schrag nach ohen und lateralwirts zum Processus mastoirleus, wo er sich nach vorn vor dem M. cleidomastoideus hefestigt. Mit dem M. basiohumeralis, welcher kurz vor seiner Insertion unter ihm hervorkommt, bildet er einen spitzen Winkel.

Der M. sternomastoideus ist vom M. cleidomastoideus gänzlich getrennt; ersterer wurde öfters irrtïmlich als M. sternocleidomastoideus bezeichnet. Den M. cleidomastoideus s. bei den Muskeln der oberen Extremitä (S. 145 ).

I. stemohyoidens. Ursprung: Gemeinsam mit dem der anderen Seite und dem II. sternothyreoideus von der hinteren viache des Manubrium und Corpus sterni bis fast zum Ansalze des dritten Rippenknorpels. Etwa in der Höhe des sechsten Halswirbels wird die den Mm. sternohyoidei zukommende Faserpartie sehnig. aber weich daranf wieder fleischig, worauf damn der gemeinsame Ursprung in vier Muskelbauche auseinanderweicht. Die Mur. sternohyoidei liegen an der Vorderfliche der Trathea, lassen einen kleinen Spalt zwischen sich. Insertion: Sie rerlaten gestreckt mit parallelen Fasern zum Zungenbein. an dessen große Ib̈ner bis zum Körper sie sich befestigen.

11. sternothyreosideus. Der L'rsprung dieses Muskels wurde bereits beim II. sternohyoideus angegehen. Er legt sich am die Seiteufliche der Trachea, hinter dem vorigen und lateralwirts von demselhen, weleher ihn an Starke und Breite ubertrift. Insertion: In die Seitenfliche der Cartilag̣o threveodea oberhalb) der Verbindung mil dem Ringknorpel.

H. thyreohyoideus. Entspringl da, wo der vorhergehende sich anselzt; ist hreiter und etwas dicker. Xach kurzem Verlauf findet er seine Insertion an dem Cornu majus oss. hyoidei hinter dem M. sternohyoideus. 
W. stylohyoideus major s. stylohyoideus. Ursprung: Processus jugularis (posterior) oss. oceipitis. Kleiner rumdlicher Muskel, verlituft nach rorn und abwirts zum Cornu majus des Zumgenbeines, an dessen fpitze er sich bofe-

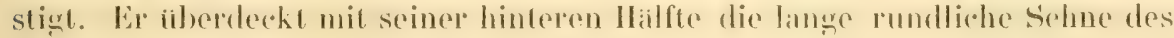
II. mandibulae, welehe an seiner medialen Seite verläuft.

M. mandibulae. Dreieckiger Muskel. Ursprung: Mit einer langen, rundlichen, ghanzenden Sehne ron dem Proeessus jugularisoss. oceipilis: die Sehne geht zwischen den beiden Mm. slylohyoidei hindureh. Insertion: Am unteren Rande des Corpus maxillac inferioris in dessen vorderem Intleil bis zur Iledianlinie.

Der M. mandibulae reprisentiert den vorderen Bauch des M. digastricus beim Menschen. Der hintere Bauch wird beim Kaninchen durch die beschriebene lange Sehne ersetzt. - Die $\mathrm{Mm}$. stylohyoidei major und minor sind dem M. stylohyoideus des Menschen homolog.

11. stylohyoideus minor. Ist diun und rundlich, sehwitcher als der II. stylohyoideus major, lient medianwirls von demselben mol der sehne des M. mandibulate, mithin tiefer. als letatere. Entspringu an der medialen Seite des Ursprumges des .11. sly loglossus und mil der Ursprumgssehne desselben verwachsen rom Processus jugularis posterior) oss. occipitis, inseriert sich an das Cornu minus oss. hyoidei $(8 / 8)$.

1I. mylohyoideus (Fign. 83, I). Ursprung: Von der Linea m lohyodea his dahin, wo der rechte Teil der Maxilla inferor mit dem linken zusammenstißıt. Der Muskel ist hreit und wie ein rèhtwinkliges Dreicek gestaltet; er verbindef sich mil dem der anderen Seite untrennbar, und zwar ist die Verbindungslinie die langere kathete. Er Jiegt über der Gil. submaxillaris. tright dagegen die Gl. sublingualis, welehe an der literalen Seile des M. geniohyoideus liegt. Insertion: Untere Fläche des Körpers des Zungenbeines.

M. geniohyoideus. Lrsprung: Vou der Verbindungsstolle der rechten und linken Lnterkieferhilfte. Er ist einfach, kegelfomig. Die Basis des liegels, welchen er darstellt, inseriert sich an die Vorderfliche des Zungenbeinkörpers.

\section{Muskeln an der Seitengegend des Halses.}

1I. scalemus anticus. Lrsprung: Querfortsatze des vierten his siehenten Ilalswirbels, liegt an der lateralen Seite des M. longus colli und inseriert sich an die erste Rippe, hinter deren Verbindung mit dem Knorpel.

II. scalenus medius. Lrsprung: Einfach gefiedert mit einer spitz zulaufenden, glänzenden, kriftigen Sehne vom Processus transversus des fünften llalswirbels; wach unten breitet er sich ficherförmicr aus und reriatuft lateralwirts vom vorhergehenden zum Thorax, wo er sich an die drilte, vierte und fiufte Rippe inseriert, je weiter nach unten, um so mehr lateralwarts. Die an die fünfte Rippe sich inserierende Zacke entspriugt oberhally der spitz zulatufenden vom Processus transversus des vierten Halswirbels.

1I. scalenus posticus. Ursprung: Lateralwaits vom vorhergehenden von den Processus transversi des vierten, fünften und sechsten llalswirbels. 
Kurzer, fleisehiger Muskel. Weleher sehrigz narh hinten und unten rerlauft und an die erste Rippe oberhall) der Insertion vom .1. iliocostalis dorsi sich inseriert.

11. longus allantis. Ursprung: Vom sechsten bis dritten Halswirbel mit ziemlich langen sehnigen Zarken, welche sich zu anem fleisehigen Muskelbatuch vereinigen, der an die untere llable des Processus transversus des Mtlas sich anheftet.

M. longus colli. Ursprung: Von den Körpern der fiunf bis sechs oberen Ritchenwirbed, ron simmblichen Halsw irbeln, teils sehnig. teils fleischig. In der Medianlinie der Wibhelsiule stoßen die Muskeln beider Seiten zusammen, latcralwaits sind sie inniy mit dem M. rectus eapilis antieus major verwachsen. Insertion: Die von den unleren Wirbeln entspringenden Faserbiundel inserieren sich zum Treil an die Köper der nichst oberen Wirbel, ron denen sioh dann neue Jrspmungsaszikel den übrig bleibenden Fasern heigesellen. Insertion: Am vorderen Ilalbring des Atlas und dem Tubereulum anterius ist die fleischige Endinsertion, welehe mit derjenigen der anderen Seite konvergiert.

M. rectus capitis anticus major s. longus capilis. Ursprung: Medianwirts

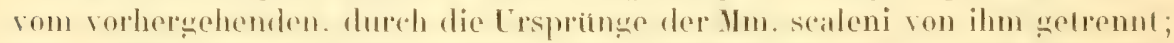
rom seehsten bis exsten Halswirbel inkl.) am Begninne der Querforlsibe. Medianwarts ist er mil dem M. Iongus colli verwathen. Insertion: Sy nehondrosis sphenobasilaris.

II. rectus capitis anticus minor s. anticus. Ursprung: Medialer Teil der Vorderfliche des Processus transversus allantis. Kleiner, straffer, fleischiger Muskel, welcher vom $\mathbf{M}$. rectus capitis antieus major bedeckt wisd. Er verliaft schrig nateh olen und medianwirts. Insertion: Ileftef sich hallgediedert an die Pars basilaris oss. oceipitis lateralwiats vom II. rectus capitis anticus major und hinter demselben.

\section{Muskeln des Riickens.}

\section{Breite Rückenmuskeln.}

Die breiten Muskeln des Rïckens werden zum Teil bei der Betrachtung der oberen Extremitat besprochen. Hier sind zu erwahnen :

M. serratus posticus. Ursprung: Vom Ligamentum nuchae, vom dritten Ilalswirbel, von der Fascia lumbolorsalis bis zur zwolften Rippe. Der Muskel isl dünn und zarkigr, besonders deutlich treten die Zacken im oberen Teile des Muskels hervor, welche schrig von hinten und oben nach vorn und unten verlaufen. In der unteren Fliche des Muskels sind die Zacken wenig scharf geschieden und der laserverlauf ist von der achten Rippe an mehr transversal, otwas nach anfwarts gerichtet. Insertion: $̈$ ubere Flichen der vierten bis zwijften Rippe, efwa in der Milte ihrer linge, je weiter nach unten, um so mehr nach vorn. Die untersten Fasern setzen sich an das vordere Ende der letzten Rippe. I) Mm. serrati postici superior und inferior des Menschen bilden also beim Kaninchen ein Continuúm. 
M. splenius capitis et colli. Ursprung: Vom ganzen Lig. nuchae unter den Mn. cucullaris und rhomboidei, und von den vier oberen Ruckenwirbeln. Der Muskel ist dimn, ziemlich breit, seine Fasern verlaufen schobig nach oben und lateralwirts, je tiefer entspringend, um so steiler ansleigend. Zwischen Hals- und hopfteil tindet sich eine kleme Spalte. so daß man allenfalls zwei Muskeln unterscheirlen kann, wenn man die Spalte künstlich nach oben und unten verlingert. Insertion: Processus transversi der zwei his drei obersten IIalswirbel; die Pars squamosal oss. oecipilis; die Pars pelromastoddea oss. temporum unmillelbar unter der sulura lambdoidea und hinter dem knöchernen Gehörgang nach abwirts, woselbst der obore Teil des Muskels sich mit der Ilals-Insertion verbindet.

\section{Lange Rückenmuskeln.}

M. sacrospinalis. Ursprung: Von der Grista oss. ilium in ihrer ganzen Ausdehnumg his zur Spina anterior superior, von den Processus mamillares der sechs mberen I.endenwirbel und der obersten drei Kreuzbeinwirbel und oberhalb der Crista oss. ilium von der Imnenfläche der den Muskel umschließenden Fascia lumbodorsalis, welehe in ihrem unteren Teile aus vier recht wut von einander trennbaren Blattern besteht. Der M. sacrospinalis ist der krifligste von allen Muskeln, die das Kaninchen hesitzt. Er liegt in der furche zwischen den Anguli costarum und den Processus spinosi der Wirbelsiule, welehe Furche der. Muskel zum größten Teil ausfült.

Zunichst giebt er einen Teil seiner Fasern als Insertion an die Processus transversi der Lendenwirbel, jedoch so, daß sie eine kontinuierliche Fasermasse bilden. Zu den Rippeu gelangt, lassen sich an dem Muskel zwei besondere Abteilungen unterscheiden: M. iliocostalis und V. longissimus dorsi.

M. ilincostalis. Als M. iliocostalis ist diejenige Faserpartie zu bezeichnen, welche sich am meisten lateralwarts an die Rippen inseriert und his $z u m$ letzten Halswirbel reicht. Insertion: Der M. iliocostalis inseriert sich mit zwäl Zacken an die laterale Seite der Anguli costarum. Die unteren fünf Zacken sind besonders dick und fleischig. Oberhalb der Abgabe der fünften Zacke, wo erst eine eigentliche Teilung des Muskelkörpers begimnt, aus welchem die Mn. iliocostalis und longissinus dorsi hervorgehen, werden die Insertionszacken des II. iliocostalis dimner und endigen mit läglichen schmalen Sehnen. Wihrend die Inserlionszacken von der lateralen und hinteren Fliche des Muskels abgehen, erhiilt derselhe an der medialen und vorderen Fliche Verstarkungsbundel von jeder Rippe, die zu einem Muskelbauch sich rereinigend für die Insertionen an die fïnf bis sechs oberen Rippen und den processus transversus des siebenten IIalswirbels das Material liefern. Somil kamn man am M. iliocostalis zwei besondere Abteilungen unterscheiden: M. iliocostalis lumborum und iliocostalis dorsi.

M. longissimus dorsi. Der M. longissimus ist der zweite, medianwairts vom M. iliocostalis gelegene Teil des M. sacrospinalis. Er reicht bis zum Schaidel hinaul und ist bedeutend mehr entwickelt als der M. iliocostalis. Insertion: Der Muskel inseriert sich an der Lendenwirhelsiule Lateralwirts an die Processus transıersi; medianmirts an die friber beschriehenen rauhen Leisten 
der Processus transrersi acecssorii (s. Osteologie, S. 106). Am Thorax gehen die literalen Insertionen von der hinteren Flatehe als und heften sich an die unteren Rander der kippen, medianwirts rom Lrsprunge der acessorischen Bündel für den M. iliocostalis. Die medialen Insertionen entwickeln sieh von der vorderen Flatche und gehen an die nur wenig entwickelten Processus transiersi. Nach oben zu wird der Mushel allmahlich diunner und seine Fasern sind lateralwirts gerichted. Auch der M. longissimus erhailt wie der M. iliocostalis einen hedeutenden Zuschul an Material durch atcessorische Verstirkungsbindel. welehe hesonders von den Processus mamillares der oberen Lenden- mond unferen achl (S/S) Riickenwirbel sich entwicheln, sowie von den Proressus lansversi der oberen Riirken- und Ilalswirhelmit Ausnalmme des ersten.

Die arecessorischen Irsprumgshundel ron den Processus mamillares der unteren Röckemwirbel haben lange, glanzende Ursprungssehnen und lassen sich nur künstleh von dem .I. spinalis dorsi trennen. Gegen die Halswirbel hin rereiniggen sie sich, un in femeinschaft mit den noch iibrigen urspringlichen Fasern des .1. Iongissimus dorsi an die Querfortsitze sich zu inserieren, hinter den Urspriangen des Ilalsteiles rom M. serratus anticus major. Dieser Teil wird als $1 /$. longissimms cervicis bezeichned, der an den Thorax sich inserierende Teil als $M$. longissimus dorsi.

Die ron den fünl his serehs unteren IIalsw irbeln und drej oheren Rückenwibloln hinter den Ansitzen der rorherehenden entspringenden Faserbindel befestigen sich an dem Processus transversus allant is und am unteren Teil der Pars sylumosil oss. oceipitis, mediamwirts rom Meatus auditorius externus, bedechl rom II. splenius caphitis bis hinauf zum Os parietale; sie bilden den M. longissimus capitis.

M. spinalis. Dieser Muskel besteht aus vielen yon den Processus spinosi und mamillares entspringenden Bändeln, welehe leils mit langen Sehmen, teils kurzsehnig oder melu lleischig beginnen, um sich wieder an l'rocessus spinosi zu hefestigen. Der Muskel erstreckl sich bis zum Sohidel und zwar in folemder Weise. Er entspringt von den drei oberen Lenden- und unteren Ritckenwilbeln und inseriert sich an simmoliche folgende Riickenwirbel und die vier bis fünf unteren Halsw irbel mil ebensovielen, hesonders schon an den Ribehenwirbeln trennhareu, fleischigen Zacken. lateralwarts am Thorax hangt dersello durch einige mit besonders langen und glinzenden Sehnen versehene Muskelbiundel mit dem M. longissimus dorsi zusammen. Eignentümlich ist seime Verbindung mit dem Schadel, welche sich dadurch vollzieht, daß in der Hohe der rierten bis fünften Rippe plötzlich ein langes schmates Faserbündel 11. Wrahelomastoideus sich vom Muskel trennt und vor dem M. splenius medianwiots vom .I. longissimus dorsi zum Ilinterhaupt hinansteigu, wo dasselbe sich an den Processus mastoideus oss, temporum befestigt.

Am M. spinalis lassen sich somit drei Abteilungen unterscheiden: Mm. spinales dorsi, cervicis und capitis.

\section{Kurze Rückenmuskeln.}

M. mullifidus besteht aus einer großen Anzahl einzelner Muskelbündel, weldere an die Processus spinosi und tlanstersi simmllicher Ilals-, Rücken-, 
Lenden- und Kirenzbeinwilbel mit Ausnahme des Atlas sich heften. An den Krenz- und Lendenwirbeln ist der II. multitidus am stirksten, an den Riuckenwirbeln an schwithslen entwickelt. Die Biundel laufen von dem helreflenden Processus lransversus sehrig nach oben und medianwirts und setzen sich an darüher gelegene Processus spinosi. Die meho quer laufenden Ableilungen rotieren die Wirbelkiaprer um ihre senkrechte Achse. Die Mm. interspinales und Mm. intertranseresarii verschmelzen mit dem M. multifidus, anch dem 11. spinalis.

Mm. intertransversurii. An den Lendenwirbeln sind sie stark entwickelt. beim zahmen sowie beim wilden kaninchen rot und doppelt vorhanden. Die

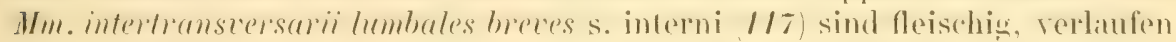
zwischen je zwei benachbarten Processus accessorii. - Die Mm. intertransersurii lumbules longis. externi /17) entspringen sehnigy von jedem Processus aressorius, verlatufen an der lateralen voldeen Seite des M. intertranstersitrius hevis naroh oben und setzen sich, jodesmal dimen lendemw irbel aiberspringend, an den Processus aceessorius des niichstfolgenden Wirhels. Die untersten IIm. interlanstersarii sind die stirksten und reichen bis zm Grista oss. ilimm. die obersten bis zum achten (oder siebenten) Riuckenwirbel.

Die Mm. intertransversarii lumbales longi und breves sind mit den Mm. rotatores dorsi (1/8) zusammengestellt worden (1/7).

In den Rückenmuskeln sowie in den $\mathbf{M m}$. gastrocnemii.kommen Sehnenendplatten $(58,5.45$. 626$)$ vor.

\section{Muskeln des Schwanzes.}

Es finden sich am Schwanze des Kaninchens Streck-, Beugemuskeln, Seitwintszicher und kleine Muskeln zwischen jo zwei Vorsprimgen der einzelnen Wirhel. Die Zahl der Strecher betright vier, je zwei anf jeder Seite, ein medialer und ein lateraler.

M. extensor caudae medialis geht aus dem über den ganzen Körper sich verbreitenden groBen Hatumuskel hervor und befestiut sich efwas unferhalh des oberen Drittels des Schwauzes neben den Dornfortsitzen s. Splanchmologie, Hautmuskeln, S. 170).

11. exiensor caudae lateralis. Ursprung: Von den Processus spinosi der beiden untersten Krenzbein- und simmtlicher Schwanzwirbel, sow ie von den Processus obliqui der letzten Schwanzwirbel. Insertion: An die Processus lransversi simmlicher Schwanzwirbel und nateh Aufhoren derselben an die hintere Fliche der Wirbelkirper, wo der Muskel nur noch sehniy erscheint. wihrend derselbe im oberen Teile fleischig ist.

M. abductor caudae posticus. Ursprung: In der Furche zwischen den Processus obliqui und transversi als Forlsetzum des M. multitidus nach ahwirts. Insertion: Die Crspriinge ron den ()uer- und Gelenkforlsätzen der oberen Wirbel inserieren sich an die der nähstfolgenden Wirbel mit einem 
'Teile der Fasern, ein anderer Teil geht weiter, einige Wirbel überspringend. Der Muskel endigt sehnig an den untersten Schwanzwirbeln.

11. abluntor candae anticus. Ursprung: Spina ischii. Der Muskel hreitet sich nach seinem Ursprunge facherfürmign nach oben und unten aus. Insertion: Mil einem Teil seiner Faseru ansteigend und horizontal verlaufend an die Seitentliche des Kïrpers des Os sacrum; mit einem anderen Teile absteigend an die Vorderfliche der Processus transversi der Schwanzwirhed und ebenfalls an die lateralen fitchen der Körper derselben bis zur Spitze des Schwanzes, von der Mitte desselben an sehnig werdend.

In seinem oberen Teile ist der Muskel ein Homologon des M. coceggeus des Mensehen, wihrend ersterer zugleich das beim Kaninchen fehlende Iig. sacrospinosum rertrit. Es entsteht dureh seine Insertion am Os sacrum das ovale Foramen sacrospinosum. Ein Foramen sacrotuberosum fehlt.

Der M. abductor caudae anticus ist der stirkste unter den Schwanzmuskeln.

H. flexor candae. Irsprung: Tou der Vorderfliche der Wirbelkirper des kreuzheines und der drei bis vier oberen schwanzwirbel neben der Medianlinie. Er verliaft parallel mit dem der anderen Seite, und die nachst oberen Irsprüge inserieren sich an die nichst unteren Wirbel bis elwa zum unteren Irittel des Schwamzes. Der Inskel ist analog dem M. Iongus colli, aber nur sehr schwach und wenig entwickelt.

Als kleine Muskeln sind am Schwanze noch zu erwihnen: Mm. interIranseresarii und inlerspmales. Dioselhen rerschwinden mit dem Aufhören der Processus transversi und spinosi.

\section{Muskeln der Brust.}

Dis die oberlliallichen breiten Muskeln der Brust bei Beschreibung der oberen Extremitit im nachsten Absehnitt ahgehandelt werden sollen, so bleiben hier nur noch die ti e fen Brustmu skeln zur Erörterung übrig.

M. intercostales externi. Das Gebiet dieser Muskeln sind die Zwischenrippenriume, welche sie zum Teil ausfillen. Ihre Fasern verlaufen schrig median- und abwirts, jedesmal vom unteren Rande ciner Rippe zum oberen der nichstfolgenden. Nach hinten reichen sie bis zum Tubereulum costae, nach vorn his an und zum Teil auf die Rippenknorpel. Die oberen Enden liegeu dem Sternum niher als die unteren und in den fünf bis sechs obersten Interstitia intercostalia endigen sie in einger Entfermung von der Spitze der knijchermen Rippen. In den unteren Interkostalriumen reicht ihr unterer Rand am tiefsten und ihr oberer Rand bis an die Spitze der Rippenknochen, so daß ein Teil des Knorpels noch mit zum Ansatz benutzt wird.

Mm. intercostules intermi. Diese Muskeln werden von den rorhergehenden bedeckt: sie sind dünner, aber reiner muskulös, weniger mit Bindegewebe durchwathsen: ihre Fasem rerdaten in entgegengeselzter Richtung, wie die vorhergehenden, d. h. Ion unten nach rorn und aufwirts; sie erstrecken sich 
über die ganzen Interkostalriume bis zum Sternalrande hin. Sie kommen also im Bereich der Rippenknorpel unter den $\mathbf{I m}$. intercostales externi hervor.

Mm. levatores costurum (breves) entspringen von den Processus transiersi der Rückenwirbel und setzen sich an die darmuler gelegene Rippe. Sie hängen mit den Interkostalmuskeln zusammen.

Diaphragma. Man unterscheidet beim Zwerchfell die Lumbalportion und Costalportion: Pars lumbalis und Pars costalis.

Pars lumbalis $\mathrm{s}$. vertebralis. Ursprung: mit drei Zacken von den lateralen Plachen der Processus spinosi anteriores und dem medialen Teil der Vorderlläche der Wirbelkirper der drei oberen Lendenwirbel mit einer platten, länglich sich ausziehenden Sehne. - Der rechte und linke Schenkel des Lumbalteiles werden durch die Aorta descendens von einander geschieden. Am ersten Rückenwirbel vereinigen sie sich, indem die Fasem beider Schenkel nach rorn ineinander übergehen und mit denen des Costalteiles sich verbinden. Nach hinten bleibt eine Offnung, durch welche die Aorta in die Bauchhöhle gelangt: Hiatus aorticus. Derselbe liegt etwas mehr nach links wie nach rechts. Xach rorn strahlen die Fasern des Lumbalteiles in das Centrum tendineum aus. Der rechte Schenkel ist bedeutend michtiger als der linke.

Pars costalis. Die Par's costalis entspringt mil sieben dünen Zackeu von den sieben unteren Rippen an der Verbindung der vorderen Rippenenden mit den Rippenknorpeln, und mit zwei Zarken vom Processus xiphoideus sterni. Sämmtliche Fasern laufen in das lange, sehr dünne, galanzende Centrum tendineum aus, welches seinen bei weitem größten Durchmesser in sagittaler Richtung hat. Oberhalb des Hiatus articus, wo bereits der Lumbalteil völlig sehnig geworden, findet sich eine lange or ale Öfrnung, durch welche der Oesophagus in die Bauchhöhle gelangt: Forromen oesophageum.

Rechts rom Foramen oesophageum zeigt dis Centrum tendineum noch eine zweite Öfnung, welche zum Durchtritt für die Yena cava inferior benutzt wird: Foramen venae cavae.

Der sagittale Durchmesser des Diaphragma übertrifft den horizontalen ziemlich bedeutend, und zwar so, daß das Zwerchfell eine elliptische Form bekommt.

Die drei obersten Interkostalräume verengern sich bei der Inspiration, die vier untersten erweitern sich, die mittleren bleiben im wesentlichen unverändert $(858)$.

V a rietait. Rechterseits oder linkerseits sind vier Zacken für die Pars lumbalis vorhanden; die accessorische kommt vom Körper des vierten Lendenwirbels.

\section{Muskeln der oberen Extremitiit.}

\section{Muskeln, welche die ob. Extr. mit dem Rumpfe verbinden.}

M. cleidomastoideus. Ursprung: Processus mastoideus. Es ist ein länglicher platter Muskel, welcher mit parallelen Fasern von hinten und oben 
schräg nach vorn und unten rerlauft. Insertion: Mitte der Clavicula (s. auch II. sternomastoideus, S. 134).

11. basiohumeralis (transversoscapulaire, 119; Kopfarmmuskel, 109). Ursprung: Pars basilaris oss, occipitis vor dem Foramen magnum. Länglich platter Muskel, welcher von hinten und oben nach rorn und unten verliuft. In der Mitte seines Verlaufes wird er rom M. cleidomastoideus gekrenzt, welcher über ihn hinweggeht. Insertion: Nittels einer unbedeutenden Inseriptio tendinea heftet er sich an das laterale Drittel der Clavicula. Seine Fortsetzung bildet der M. deltoideus.

M. lecator scapulae major. Ursprung: Synchondrosis sphenobasilaris. Linglicher, schlanker Muskel mit parallelen Fasern. Er lieğt nach vorn von dem gleich zu beschreibenden M. cucullaris und nach hinten vom M. basiohumeralis, und zwar so, daß er mit ersterem nach unten, mit letzterem nach oben einen spitzen Winkel bildet. Insertion: Spitze des Acromion und an den Processus hamatus desselben neben der Insertion des Halsteiles des M. cucullaris.

M. cucullaris. Derselbe besteht aus zwei Portionen, einer oberen oder dem Halsteile, und einer unteren oder dem Rückenteile.

Pars superior. Ursprung: Protuberantia oceipitalis externa des Hinterhauptbeines, und Lis. uuchae. Großer, breiter, dünner Muskel, dessen Fasern nach unten und vorn verlaufen und zum Teil konvergieren. Insertion: Acromion und dessen llakenfortsatz neben dem M. levator scapulae major, sowie der Fascia supraspinata.

Pars inferior. Liegt in der Fortsetzung des vorigen. Ursprung: Processus spinosi simmtlicher Riuckenwirbel und, ohme bestimmte Ibgrenzung vom M. Ialissimus dorsi, aus der lasedia lumbodorsalis. Er ist ebenfalls breil und dün mit absteigenden, transversalen und aufsteigenden Fasern. Insertion: Kurzsehnig an den beiden hinteren Dritteln der Spina scapulae.

11. latissimus dorsi. Ursprung: Processus spinosi der neunten und der folgenden Rückenwirbel aus der Fascia lumbodorsalis und mit drei Zacken vom unteren Ende der zehtenten, elften und zwölften Rippe. Großer, breiter, dünner Huskel, der einen großen Teil der hinteren und seitlichen Thoraxwand bederkt. Seine Fasern rerlaufen konvergierend schrag nach oben und vorn, je tiefer unten contspringend, um so steiler. Die oberen Fasern sehlagen sich ibler den unteren Winkel des Schulterblattes herum und bedecken den M. leres major zum größten Teil; an seinem oberen Ursprunge wird der M. latissimus 1 om M. cucullaris bedeckt. Jene Fasern weichen damn auseinander und bilden eine Lüicke, ans welcher die Mm. teres major und infraspinatus hervorsehen. Insertion: Mit der Sehne des M. teres major vereinigt medianwirts von der spina humeri. Die gemeinsame Sehne windet-sich un den Oberarm.

M. rhomboideus cerviculis. Ursprung: Ligamentum nuchae. Der Muskel wird $10 m$ W. cucullaris bedeckt. Je weiter nach oben seine Fasern entspringen, um so steiler abwirts verlaufen sie und um so weiter nach unten inserieren sic sich. lir ist dimn und platt, von unregelmäBiger form. Insertion: Die beiden oberen Drittel des hinteren Randes der Scapula.

M. rhomboideus dorsalis. Ursprung: Processus spinosi der sieben oberen Rückenwirbel. Platler, breiter, ziemlich umfangreicher Muskel, dessen Fasern 
gegen die Insertion hin sich übereinander legen und zum Teil kreuzen. Er liegt ebenfalls unter dem M. cucullaris, oben zum Teil vom vorhergehenden, an seiner Insertion vom M. latissimus dorsi bedeckt. Insertion: Unteres Drittel des hinteren Randes der Scapula.

M. levator anguli scapulae s. levator scapulae minor. Irsprung: Synchondrosis sphenobasilaris. Langer, schlanker, düner, steil absteigender Muskel. Insertion: Unterer Winkel der Scapula.

M. pectoralis superficialis s. tenuis (latissimus pectoris der Tierheilkunde). Ursprung: Manubrium sterni. Er liegt vor dem oberen Teile des M. pecloralis major, an seiner Insertion unter und neben dem M. deltoideus. Seine Fasern verlaufen vom Ursprunge aus divergierend und nach abwirts zum Oberarm, so daß ein platter Muskel entsteht, von der Form eines Dreieckes, dessen abgerundeter Scheitel am Manubrium sterni liegt. (Hinter ihm liegt der M. glenoulnaris). Insertion: Spina humeri rom Caput bis zur Mitte des Ilumerus. Der M. pectoralis superficialis reprisentiert eine selbstindig gewordene Portion des M. pectoralis major.

M. pectoralis major. Ursprung: Von der einen IIilfte des ganzen Brustbeines. Kraftiger, breiter Muskel, welcher die vordere Brusthälfte ganz zudeckt. Seine Fasern sind aufsteigende, transversale und absteigende, die an der Insertion zusammenfließen, und zwar so, daß die oberen sich tiefer anheften als die unteren. In seinem oberen Teile wird er bedeckt rom $\mathrm{H}$. pectoralis superficialis. Insertion: Veben dem vorigen an die Spina humeri.

11. pectoralis minor. Ursprung: Hit zwei Portionen. Vom oberen Ende des Sternum bis zum vierten Rippengelenk, und mit der zweiten unter der ersten gelegenen Portion vom vorderen Ende der ersten Rippe. Er wird bedeckt von den IIm. pectorales superficialis und major. Seine Fasern vor der Klavikularinsertion gleichen einem stumpfwinkligen Dreieck, dessen stumpfer Winkel am Manubrium sterni liegt. Dieselben veraufen schrig nach oben und literalwarts. Insertion: Mit einem groben Teil seiner Fasern an die Clatvicula und das Ligamentum sternoclaviculare, um dann von neuem zu entspringen und, mit den übrigen frei zur Schulter verlaufenden Fasern den M. supraspinatus uberlagernd, sich an die ganze obere Kante der Scapula und die Fascia supraspinata zu inserieren.

M. serratus anticus major. Er besteht ans zwei Abteilungen, dem Halsteil und Brustteil.

Halsteil. Ursprung: Von den Querfortsitzen der fünf unteren Halswirbel und dem hinteren Ende der ersten und zweiten Rippe. Der Muskel wird an seinem Ursprunge rom M. scalenus medius bedeckt. Im weiteren Verlauf liegt er unter dem M. subscapularis. Er ist breit, kraftig, rechteckig, verliuft von oben und vorn, schrig nach hinten und unten. Insertion: Oberer Teil der Inneufliche des Schulterblattknorpels am hinteren Rande der Scapula.

Brustteil. Ursprung: Mit sieben Zacken ron der dritten bis neunten Rippe, wo der Knochen in den Knorpel übergeht. Er ist bedeckt von den Mm. latissimus dorsi und pectoralis major. Seine Fasern assoziieren sich zu einem breiten flachen Muskelküper, welcher die seitliche Wand des Thorax umgreift. Insertion: Die in einen spitzen Winkel konvergierenden Fasern 
heften sich an den unteren Winkel der Scapula, sowie an den hinteren medialen Teil des unteren Randes derselben, einen Teil der Insertion des Halsteiles bedeckend.

\section{Muskeln am Oberarm.}

11. delloideus. Ersprung: Laterale IIalfte der Clavicula, als Fortsetzung des M. hasiohumeralis. Linglicher, natch unten spitz auslaufender, doppeltyefiederfer Muskel, Welcher iiber den Achselhöhlenteil der M. pectorales superticialis und major hinweggeht. Insertion: Vit einer ziemlich langen selone unter der Mitte der vorderen Seite des IIumerus.

H. abductor brachii superior. Ursprung: Spitze des Acromion und Wurzel des Processus hamatus desselben. Liuft nach unten und rorn. Insertion: An der lateralen Kante der Spina humeri.

H. abductor brachii inferior. Ursprung: Fascia infraspinata mit einem bogenformigun Rande sog. Sehmenhogen, das Acromion und dessen Processus hamatus. Insertion: Mit dem vorgen nelon der Ansatzlinie des M. deltoideus im oberen Ibitleil des Ilumerus millels eines rumblichen, sehnigen Ansatzes.

Der Muskel ist als M. abductor longus bezeichnet worden (109). Mit dem M. abductor brachii superior ist derselbe bei der Katze (II. delto-spinale, 1/9); und beim Pferde (der lange Auswärtszieher des Oberarmbeines (120) vereinigt. Die Mn. abductores brachii superior und inferior repräsentieren selbstindig gewordene Bündel des II, dedendens; der inferior isl ein unverkembares Homologon des II. gluteus maximus.

M. supraspinatus. Ursprung: Acromion, Spina scapulae, Fossa supraspinati, oberer schulterblattrand und noch daruber hinatus von der Fascia sulsscapularis, sowie zum Teil von der Fascia supraspinata. Dicker. fleischiger Huskel, welcher die Fossa supraspinala völig̣ ausfiollt. Bedeckt wird derselbe fom VI. aneullaris, dem II. levator scapulate major und dem M. pectoralis minor. Insertion: Mit dem eincen Teil seiner Fasern an die spitze, mit dem anderen an die laterale Seite des Tuberculum majus humeri.

11. infruspinutus. Lrsprumg: Spina scapulae, Acromion, Fossa infraspinata und unterer Rand der Scapula. Er ist weniger fleischig als der vorige, grenzt nath unten an den M. teres major, welcher mit ihm gemeinsam rom unteren hande der sicapula entspringt, wird mit Ausnahme seines mittleren Teiles bedeckt rom Ilals- und Brustleil des II. cucullaris. Er geht schrig nach oben und vorn und schliget sich unter dem Acromion zum Oberarm dicht am Cilput humeri resp. der Schultergelenkkapsel verlaufend. Insertion: Tuherculum majus humeri unterhalb des lateralen Ansatzes des M.supraspinatus.

1I. teres minor. Entspringt sehnig am unteren Rande der Fossa infraspinata. Verlablt zwischen lefzterem und dem M. infraspinatus zum IIumerus, ehenfalls dicht an das Caput humeri angrenzend $(\boldsymbol{S} / S)$. Ist wenig entwickelt. Insertion: Am Humerus dicht unter dem M. infraspinatus.

M. teres major. Ursprung: Vom unteren Rande der Scapula mit Ausnahme des rorderen Drittels. Am hinteren und unteren Winkel der Scapula geht ein Teil seiner Ursprungssehne aus der Insertionssehne des Brustteiles des M. serratus anticus major hervor. Bedeckt wird er con der Pars inferior 
des M. cucullaris, größtenteils aber vom M. Iatissimus dorsi, mit welehem er schrag nach oben und rorn verliuft und an seiner Insertion verschmilzt. Der Muskel ist dick und fleischig. Insertion: Gemeinschaftlich mit dem M. latissimus dorsi unter dem Tuberculum minus humeri, bedecht vom M. coracobrachialis und den Beugemuskeln des Vorderarmes.

M. subscapularis. Lrsprung: Ton der ganzen medialen Fiache der Seapula. Er verstäkt besonders den medialen Teil der Schultergelenkkapsel, während der obere Teil derselben vom M. supraspinatus und der laterale rom M. infraspinatus eine betrichtliche Befestigung erhailt. Insertion: Tuberculum minus humeri.

M. coracobrachialis. Ursprung: Processus coracoideus. Er schligt sich über die mediale Seite des Humeruskopfes herüber, verstirkt oder befestigt, wie der rorige, die Kapsel des Schultergelenkes und geht zu1 Vorderseite des Oberarmes. Insertion: Doppeltgefiedert an die rordere Seite des unteren Endes des oberen Dritteiles des IIumerus dicht unterhalb der gemeinsamen Insertion der Mm. teres major und latissimus dorsi und dieselbe bedeckend.

\section{Streckmuskeln des Vorderarmes.}

11. extensor cutibrachii parvus s. anconaeus quintus (819). Ursprung: Mit langer, platter Sehne von der Faszie der vereinigten Mm. teres major und latissimus dorsi. Länglich-schmaler, eher diinner Muskel, welcher an der medialen Seite des M. anconaeus longus herabliuft. Insertion: Medialer hinterer Rand des Olecranon.

M. triceps brachii liegt an der hinteren und lateralen Seite des Oberarmes und besteht, wie der Name angiebt, aus drei Köpfen :

II. anconaeus longus. Ursprung: Doppeltgefiedert vom vorderen Drittel des unteren Randes der Scapula, welches Drittel der M. teres major frei liaßt. An der medialen Seite des Muskels reicht die Lrsprungssehne bedeutend weiter als an der lateralen Seite, etwa bis zum Ende des oberen Drittels. Es ist ein dicker, fleischiger, spindelförmiger Muskel, welcher über den Mm. teres major und latissimus dorsi und unter dem Processus hamatus der Scapula nach abwirls verliuft, um in der Mitte des Humerus sich mit dem M. anconaeus lateralis sehnig zu verbinden. Diese Verbindung findet aber nur mit dessen hinterem Rande statt, indem der größte Teil der Insertionssehne sellostindig bleibt. Insertion: Einfachgefiedert an Ende der ïberknorpelten Rinue des Olecranon, in welche er sich hineinlegt. Die Insertionssehne geht an der lateralen vorderen Seite des Muskels bis zum oberen Drittel desselben hinauf.

M. anconaens lateralis s. brevis. Ursprung: Laterale Flache des Humerus unter dem Gelenkkopf und dem Tuberculum majus. Weniger kräftig entwickelt als der vorhergehende, mehr plattlanglich. Insertion: Mit dem vorigen am hinteren Rande verwachsen, an die laterale Fliche des Olecranon.

II. anconaeus medialis. Ursprung: Dem M. brachialis internus gegenuher von der ganzen hinteren Fliche des Humerus. Bis zu seiner Insertion bleibt der Muskel ganz unabhängig von den $\mathrm{Mm}$. anconaei longus und lateralis, erst dort verbindet er sich durch einige Sehnenfaszikel mit den- 
solben. Er wird ron heiden bedeckt. Insertion: An den hakenförmigen Fortsatz des Olecramon unterhalb) der iulorknorpelten Rinne und an den oberen Teil der Dorsalfläche der Ulna.

M. anconaeus minimus s. quartus s. sextus (8/9). Ursprung: Condylus medialis humeri, lauft dorsalwarts und quer in Bezug auf die Lingsachse des Humerus. Insertion: Mediale Flache des Olecranon.

Der M. anconaeus quartus des Menschen fehlt beim Kaninchen.

\section{Bengemuskeln des Vorderarmes.}

M. gleno-ulnaris s. biceps brachii s. flexor antibrachii. Ursprung: Vom oberen Ende der Gelenkflache des Schulterblattes. Seine plattrundliche Ursprungssehne, welche sich innerhalb der Gelenkkapsel dem Tuberculum minus genau anschmiegrt, geht durch den ibberknorpelten Sulcus intertubercularis an die Vorderseite des Oberarmes. Nach seinem Austritt aus der Gelenkkapsel geht el in einen dicken, spindelfömigen Muskelbauch über, welcher unten wieder in eine rundliche Sehne ausliuft. Oben wird der Muskel vom Ansitzteile der Mm. pectoralis major und pectoralis superficialis bedeckt. An seiner lateralen Seite liegen die Mm. brachialis internus und deltoideus, an seiner medialen der M. coracobrachialis und weiter unten der II. extensor antibrachii parvus. Insertion: Die rundliche Sehne dringt, nach-

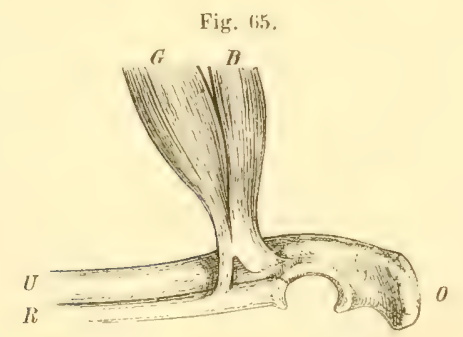

Linker Vorderarm, von der medialeu Seite, um $180^{\circ}$ supiniert. $G$ M. gleno-ulnaris. $B$ M. brachialis intermus. $R$ Ulual, $U$ Radius. o (Hecranon. dem sie vorher einen sehnigen Streifen (sog. Aponeurose des M. biceps brachii), welcher die Ellbogengrube überbrückt, zur ulnaren Seite der Fascia antibrachii abgegeben hat, in die Tiefe und inseriert sich unterhalb des Ellbogengelenkes gemeinschaftlich mit dem M. brachialis internus an die volare Seite der Ulna (Fig. 65), giebt auch eine Sehnenfaserplatte zum membranösen Ansatz des M. brachialis internus an den medialen Winkel des Radius, welche Platte das Rudiment des Tendo m. quadrigemini brachii vom Mensehen reprisentiert (vergl. 59, S. 233 u. 121).

Der Muskel hat zwar nur einen Kopf, indem das Caput breve fehlt; trotzdem besteht er aus zwei Portionen (S. I 1 I).

M. brachialis intermus. Ursprung: In zwei Portionen, die eine von der laleralen Grista der Spina humeri, von der lateralen Flache des Ilumerus bis zum unteren Drittel; die andere von der medialen Crista bis zum unteren Ende der Diaphyse. Beide Portionen, sehr kurzsehnig entspringend, werden an ihrem Lrsprunge durch die Insertionen der Mm. abluctores brachii superior und inferior getrennt, weiter unten dureh die Sehne des V. deltoideus und erst hurz vor dem Ansatze vereinigen sie sich. Das untere Encle ist einfach gefiedert; dasselbe verwachst mit der Sehne des M. gleno-ulnaris s. biceps brachii, setzt sich mit dieser gemeinsam (Fig. 65) sowohl an die volare Seite der Ulna, 
als mil einer membranihulichen Ausbreitung an den medialen Winkel des Ritdius etwas unterhalb des Ellbogengelenkes.

Beim Menschen besteht der M. (quadrigeminus s. biceps) brachii aus vier Portionen: Im. coracoradialis, coraco-ulnaris, glenoradialis und gleno-ulnaris (59, S. 223 , - vergl. 121$)$. Von diesen fehlen dem Kaninchen die $\mathbf{M m}$. coracoradialis und coraco-ulnaris, die Portio glenoradialis ist sehr schwach und verwächst mit der Sehne des M. brachialis internus. Einfacher kann man sagen, daß das Capul breve dem Kaninchen fehlt.

\section{Muskeln des Vorderarmes.}

\section{An der Dorsalseite.}

11. extensor carpi radialis longus. Spindelfarmig, entspringt rom unteren Ende des Ifumerus dicht oberhalb des Condylus lateralis. Verlauft oherflachlich an der radialen Kante des Radius, erhalt bereits in der Mitte desselben eine lange schlanke Sehne, welche, die Sehne des M. ahductor pollicis kreuzend, aber tiefer als diese gelegen, durch das zweite Fach des Liganentum carpi dorsale zum IIandrüchen verlauft. Insertion: Basis oss. metacarpi II.

M. extensor carpi radialis brevis. Etwas schwächer als der vorige, von welchem el bedeckt wird und mit welchem der großte Teil seines Batuches derart verwachsen ist, daß die Trennumg nur künstlich geschehen kann. Entspringt ulnarwarts und mehr dorsalwarts neben dem letzteren rom Condylus lateralis humeri, die Sehme beginnt gleichzeitig mil dej Sehme des V. extensor carpi radialis Jongus, verliuft am dorsalen Rande derselben dicht an sie geschmiegt, im zweiten Fach des Ligamentum carpi dorsale an ihrer ulnaren Seite und heftet sich an die Basis oss. metacarpi III.

1. abductor pollicis. Irsprung: Vom radialen Teil der Dorsalfliche der T'ma und dem ulnaren Teil der Dorsalfliche des Radius, so daß er das ohere und untere Gelenhende der Knochen nichl wanz erreicht. Der Muskel liegt in der Furche zwischen beiden knochen und wird in seinem oberen Teile bedeckt vom vorhergehenden und dem II. extensor digitorum communis. Insertion: Seine Sehne geht oberflichlicher als die des vorigen, mit welcher sie sich kreuzt, durch das erste am weitesten radialwarts gelegene Fach des Ligamentum carpi dorsale zur Radialseite der Basis des Os metacarpi pollicis.

M. extensor pollicis (et indicis). Ursprung: Bedeckt vom M. extensor digitorum communis, mit dem $\mathbf{M}$. adductor pollicis verwachsen aus dem radialen Teile der Grube zwischen Tha und Radius. Seine Schne begleitet diejenige des M. extensor digitorum communis für den zweiten Finger, geht mil derselben durch das dritte Farch des Ligamentum carpi dorsale; wird durch eine Synovialscheide an den Radius befestigt. Insertion: Vit einem Schenke] an das Capitulum des Os metalcarpi des zweiten Fingers; mit einem zweiten, der sich aul dem Ilandríteken oherflichlicher als die Sehnen der Mm. extensores carpi radiales verlaufend mediamwarts wendet, an die Vagelphalanx des Datumens. 
Der 11. extensor pollicis repräsentiert die Mm. extensores pollicis longus, brevis und extensor indicis proprius des Menschen, - derselbe spannt die Kapsel des ersten Fingergelenkes des Zeigefingers (122).

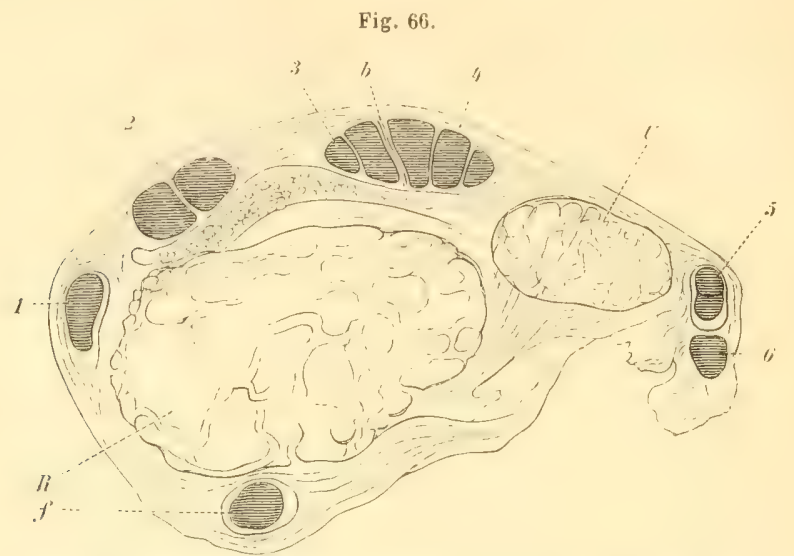

Ligamentum carni dorsale auf dem dorsal-volaren Querschnitt des rechten Vorderarmes, von oben. Nach Behandlung der Handwurzel mit 10/0iger Chromsäure, 50/ iger Chlorwasserstoffsaure, Wasser, Alkohol, Nelkenöl, Dammar. Vergr. 7. $f$ Sehne des in flexor carpi radialis, $R$ Radius, 1-6 Sehnen der Streckmuskeln auf dem Querschnitt in ihren Fächern, 1 MI, abductor pollicis, $2 \mathrm{Mm}$. extensores carpi radiales longus u, brevis. 3 M. extensor pollicis (et indicis). $b$ Bindegewebige Scheidewand $\mathrm{z}$ wischen drittem und viertem Fach des Ligamentum earpi dorsale. $4 \mathrm{M}$. extensor digitorum communis. U Ulna. $5 \mathrm{M}$. extensor digiti quarti proprius. 6 M. extensor carpi ulnaris.

Die trennende Bindegewebswand (Fig. 66 b) zwischen drittem und viertem Fach des Ligamentum carpi dorsale ist in proximal-distaler Richtung wenig ausgedehnt und daraus erkliirt sich, daß Gruber (122) dieselbe übersehen hat. Außerdem hat Letzterer offenbar nicht unbefangen untersucht, und es muß hier leider für die zahlreichen Leser, welche den Petersburger Anatomen nicht kennen, bemerkt werden, daß es in anatomischen Kreisen längst nicht mehr zum guten Ton gehört, auf die unvissenschaftlichen Bemerkungen Gruber's zu antworten. (Vergl. a. 822).

[Beim Menschen fand Gruber eine ähnliche Anordnung, also einen M. extensor pollicis et indicis in $4 \%$ nach Untersuchung von 400 Armen an 200 Leichen und bemerkte (122, S. 474) in betrefl des Menschen: "Wilhelm Krause hat den Extensor pollicis et indicis trotz seiner Bedeutung ignoriert«. Der Muskel steht aber $(40, \mathrm{~S} .105)$ als 11 . extensor pollicis indicisque mit auszeichnender Schrift gedrucht und nicht minder im Register (40, S. 318)]. Auch beim Kaninchen kommen verschiedene Varietäten in ca. $20 \%$ vor, die 1. c. (122, S. 487) nach Untersuchung von 30 oberen Extremitäten verzeichnet sind.

11. extensor digitorum communis. Tresprung: Mit dem M. extensor carpi radialis longus verwachsen vom Condylus lateralis humeri, sowie von der Dorsalfliche der Ulna bis zur Mitte der letzleren. Der Muskel teilt sich in der Mitte des Vorderarmes in vier Schmen fiu den zweiten bis füften Finger; der zweite Finger erhilt eine dünnere Sehne, welche mit dem unteren Schenkel der Sehne des II. extensor pollicis verliuft; die drei anderen Sehnen haben gemeinschaftlich die vierte Scheide des Ligamentum carpi dorsale, durch welche sie zur Hand gelangen. Insertion: Die drei Phalangen des zweiten bis funften Fingers inkl. der Nagelphalanx. 
Auf der Dorsalseite des ersten Fingergelenkes liegt in der Sehne des M. extensor digitorum communis eine dünne runde Faserlinorpelscheibe von $1 \mathrm{~mm}$ Durchmesser und 0,3 $\mathrm{mm}$ Dicke. Sie ist mit dem Skalpell darzustellen und sieht bei älteren oder französischen Kaninchen gelblich oder etwas bräunlich aus. Beim Hasen ist sie größer (S. 19), etwa $2 \mathrm{~mm}$ im Durchmesser und $0,5 \mathrm{~mm}$ dick; Gruber (122, S. 488) hat sie nur bei letzterem Tier gesehen und irrtïnlich darin einen Unterschied zwischen Hasen und Kaninchen zu finden geglaubt. Die Volarfliche besteht aus hyalinem Knorpel mit abgeplatteten Knorpelzellen, die Dorsalflïche und die Ränder werden von Bindegewebe überkleidet.

M. extensor digiti quarti proprius. Ursprung: Vom Condylus lateralis humeri, lateralwarts rom vorigen. Diinner, schlanker Muskel, welcher am Vorderarm oberflachlicher als der M. extensor digiti minimi proprius gelegen ist und in der Mitte des Vorderarmes in eine lange, dünne Sehne ausliuft. Letztere liegt am unteren Ende desselben oberflichlicher als die Sehne des M. extensor digiti minimi proprius, tritt damn durch das funfte Fach des Lig. carpi dorsale auf den Iandrücken, wo sie tiefer liegt als die Kleinfingersehne des M. extensor digitorum communis, mit welcher sie sich kreuzt. Insertion: Verschmilzt auf dem Rucken der Nagelphalanx des vierten Fingers mit der dahin gelangenden Sehne vom M. extensor digitorum communis.

V a rietät. Die Sehne des M. extensor digiti quarti proprius giebt am Handgelenk ein Verstärkungsbündel an die Strecksehne des II. extensor digitorum communis für den vierten Finger ab.

M. extensor digiti minimi proprius. Ursprung: Condylus lateralis humeri mit dem vorigen rerwachsen, von der L'lna bis zur Ilälfte des unteren Drittels. Er wird vom vorigen bedeckt. Die Sehne geht an der unteren Seite der Sehne des M. extensor digiti quarti proprius mit derselben durch die fünfte Scheide des Lig. carpi dorsale, an der radialen Seite der Sehne des M. extensor carpi ulnaris verlaufend und oberfachlicher als die letztere. Insertion: Mit einem Zipfel an das Capitulum des Os metacarpi des fünten Fingers; mit einem zweiten Zipfel setzt sie sich an der uluaren Seite der vom M. extensor digitorum communis für den funften Finger abgegebenen Sehne an das Capitulum der ersten Phalanx desselben.

M. extensor carpi ulnaris. Ursprung: Condylus lateralis humeri und oberer lateraler Teil der Ulua. Nach vorn grenzt er an die beiden vorhergenannten, nach hinten an den M. flexor carpi ulnaris. Insertion: Die am unteren Drittel der Ulna beginnende Sehne liegt ulnarwirts von den Sehnen der Mm. extensores digitorum quarti et minimi und tiefer als die letzteren, geht durch das sechste, am meisten ulnarwarts gelegene Fach des Lig. carpi dorsale und inseriert sich an die Basis oss. metacarpi digiti minimi.

\section{An der Volarseite.}

M. pronator teres. Ursprung: Condylus medialis humeri und Lig. cubiti mediale; geht schief nach unten und vorn an die volare Seite des Radius, in deren Mitte er sich anheftet. Er ist nur nach sciner Homologie benannt, denu eine Pronationsbewegung des Radius um die Ulnat ist durch die Verloindung der Vorderarmknochen untereinander ausgeschlossen. 
11. /léror carpi ratialis. Ursprung: Er hat gleichen L'sprung mit dem vorigen, von welchem er volarwäts liegt. Spindelförmiger, langer, wenig mähliger Muskel. Er zieht sehief zum unteren Ende des Radius, in dessen Mille der Muskel in eine lange Sehne iubergeht, welche an der hinteren Fliache des Ralius an den radialen Rand desselben sehr fest sich anschmiegt. Am Ilandgelenk angelangt, schieht sie sich unter die breite Sehne des M. flevor digitorum profundus. Insertion: An der Volarflache der Basis des zweiten Os metacarpi.

I. flexor digitorum profundus. Ursprung: Mit vier Köpfen; der ob e r$\mathrm{fl}$ ic hliche Kopf ist zugleich der bedeutendste: entspringt hinter dem Il. llexor "arpi radialis am Condylus medialis humeri. Er bedeckt die drei anderen köpfe, den radiales, mittleren und ulnaren. Der radiale Kopf entspringt von der dorsalen Fliche des Radius rom Ellbogengelenk bis zum unteren Drittel des Radius. Der mittle re Kop f neben diesem von der hinteren Flithe der Clna, in gleicher Ausdehnung wie der vorige. Der ulnare Kopf gemeinsam mit dem M. flexor digitorum sublimis, von Condylus medialis humeri. Nachdem drei Köpfe bereils sehnig geworden sind, vereinigen sich alle vier zu einer mähligen, hreiten, platten Sehne, welche rom Lig. carpi volare proprium ibberbritckt wirl und fast das ganze Handgewölbe ausfiill. Insertion: Inter den Lig. carpi volare proprium hervorgetreten, teilt sich die Sehne in funf an die Basis aller Nagelphalangen sich anheftende Zweige. Jie fiur den Daumen ist anfangs rúckliufig; die mittleren drei durchbohren vor ihrer Insertion die Sehnen des M. flexor digitorum sublimis.

\%. palmaris. Ursprung: Lieber dem oberflichlichen hopf des vorhergrehenden, warh hinten $10 m$ Condylus medialis humeri, am Lrsprunge mit ihm remachsen. Kleiner spondelformiger Muskel, weleher noeh vor dem unteren Ende des oberen Jrillels des Vorderarmes in eine lange diunne Sehne ibbergeht. Insertion: Die Sehne verliert sich in die Fascia palmaris und die darunter liegenden Sehnen.

1\%. flexor digitorum sublimis. Ursprung: Mit einem Kopfe gemeinschaftlich mil dem ulnaren lopfe des $\mathbf{I l}$. llexor digyitorum profundus som Condylus medialis humeri und vom oberen Drittel der radialen hinteren Flathe der Una. Der spindelformige Jushellanch, welcher im oberen Teile des Vorderarmes unter dem oberflichlichen Kopfe des 11 . flexor digitorum profundus und dem 11 . palmaris, im unteren Teile neben ersterem Muskel liegt, erzeugt am im unteren Ende des Vorderarmes drei von einander gleich anfangs getrennte sehnen. welche sich bedeckt rom I.ig. carpi volare transversum zur Vola begeben. An der Basis der ersten Phalanx werden sie von den Sehnen des $\mathbf{~ I}$. flexor discitorum profundus durchbohrt und in zwei Srhenkel geteilt, welche aber bereits an dem unteren Ende der ersten Phalanx wieder verbunden sind. Insertion: An die Basis der zweiten Phalangen des zweiten his vierten Fingers.

11. flexor carpi ulnaris. Ursprung: Zwei Köpfe. Mil dem einen Kopfe vom Condylus medialis humeri, mit dem anderen von der medialen Flache des Olereanon, sowie der ulnaren Seite der I'lna his zum untersten Ende. Beide Koppe repeingen sich hald nach ihrem Lrsprunge zu einem mehr platten Muskel, welcher an seinem unteren Ende doppelt wefiedert ist. Insertion: Mit einer ziemlich breiten Sehne an das Os pisiforme. 


\section{Muskeln der Hand.}

11. flexor digili minimi. Ursprung: Os pisiforme und Sehnenscheide des M. Hexor digitorum profundus. Radialwarts ron ihm liegat der M. interosseus fiir den kleinen Finger, welcher in Gemeinschaft mit ihm einen Kleinfingerballen darstellt. Insertion: Beide Seilen del Ossa sesamoidea (s. Mm. intelossei) an der Volarseite des Gelenkes zwischen Os metacarpi und erster Phalanx und weiter abwärts bis zur Nagelphalanx.

II. lumbricales. Ursprung: Drei an Zahl aus der Teilungsstelle der Sehne des M. flexor digitorum profundus. Insertion: Der erste an die Unarseite des zweiten Fingers, der zweite und dritte an die Radialseite der ersten Phalamx des vierten und fünften Fingers.

M. interossei (metacarpi). Je zwei für den zweiten bis fünften Finger. Die Paare lassen sich jedoch nicht genau trennen und gleichen mehr einem einzigen Muskel. Lrsprung: Basis der Mefakarpusknochen der Finges und die angrenzenden Karpusknochen. Die Ilauptuenge der Fasern der kleinen fleischigen Inskeln liegt an der Volarfliche der Ossa metacarpi; nur ein kleiner Teil befindet sich in den einzelnen Interstitia interossea metacarpi. Insertion: Ossa sesamoidea der Gelenke zwischen Os metacarpi und erster Phatanx, welche an der Volarseite sich an jedem genaunten Gelenke befinden; und zwar liegt je eines: das Os sesamoideum radiale an der radialen, das andere, das Os sesamoideum ulnare an der ulnaren Seite.

\section{Physiologie der Muskeln der oberen Extremität.}

Uber die Funktion der Muskeln, welche den Oberarm, den Vorderarm und die Hand bewegen, ist versucht worden $(109$, S. 60), auf anatomischem Wege, durch Messung der Muskellingen bei verschiedener Stellung der Glieder an der Leiche Aufschluß zu erhalten. Die Resultate, deren Bedeutung infolge dieser ungenügenden Untersuchungsmethode nicht zu hoch anzuschlagen ist, sind in der folgenden Tabelle vereinigt, wobei einige Lurichtigkeiten in der anatomischen Beschreibung und darats folgende falsche Aulfassumg und Nomenhlatur einzelner Muskeln stillschweigend korrigiert wurden.

\begin{tabular}{|c|c|c|c|c|c|c|}
\hline \multirow{2}{*}{$\begin{array}{l}\text { Muskeln für die Bewegung des Ober- } \\
\text { armes und Vorderarmes. }\end{array}$} & \multicolumn{6}{|c|}{ Oherarm } \\
\hline & Extension & Flexion & Adduktion & Abduktion & $\begin{array}{l}\text { Rotation } \\
\text { median- } \\
\text { wärts }\end{array}$ & $\begin{array}{c}\text { Rotation } \\
\text { lateral- } \\
\text { wärts }\end{array}$ \\
\hline 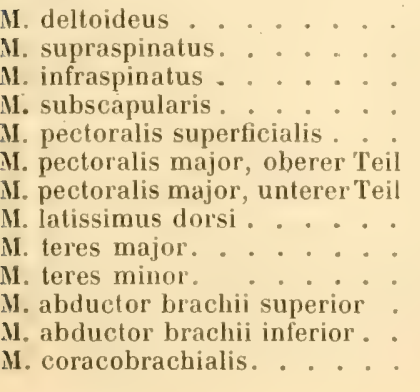 & $\begin{array}{l}+ \\
+ \\
+ \\
+ \\
+ \\
+\end{array}$ & $\begin{array}{l}+ \\
+ \\
+ \\
+ \\
+ \\
+ \\
+\end{array}$ & $\begin{array}{l}+ \\
+ \\
+ \\
+ \\
+\end{array}$ & $\begin{array}{l}+ \\
+\end{array}$ & $\begin{array}{l}+ \\
+ \\
+ \\
+ \\
+ \\
+\end{array}$ & $\begin{array}{l}+ \\
+ \\
+\end{array}$ \\
\hline
\end{tabular}




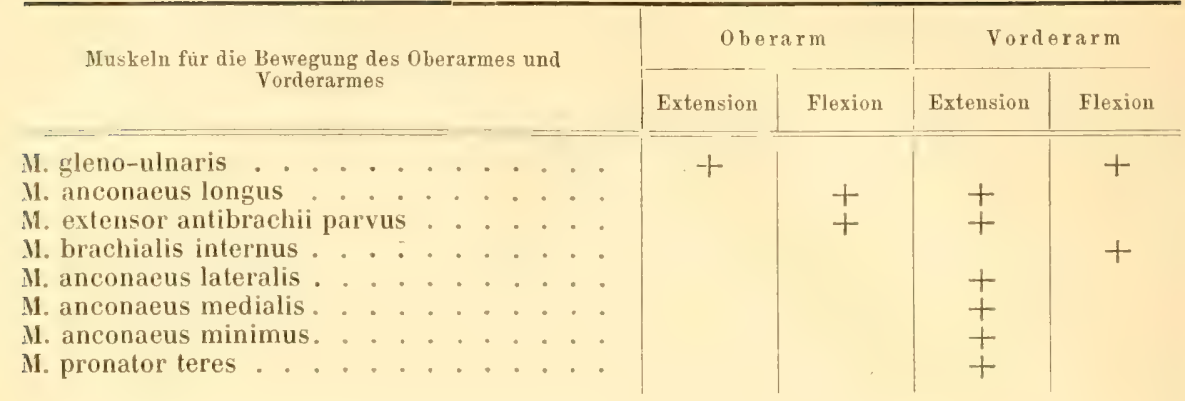

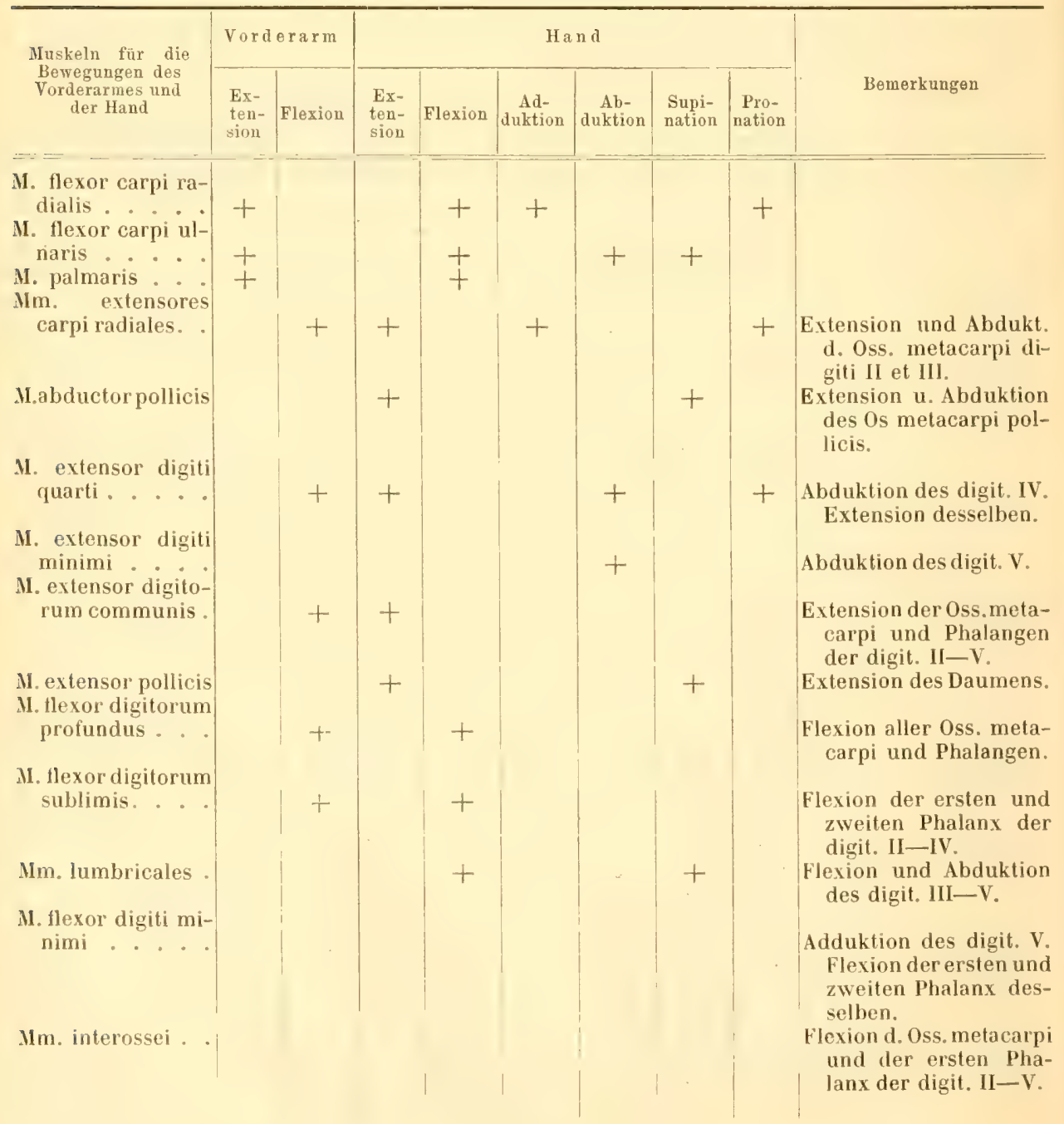




\section{Muskelı des Bauches.}

M. obliquus abdominis extermus s. descendens. Ursprung: Von den zehn (\$IS) unteren Rippen mit ebenso vielen Zacken, welche sich in die Ursprünge der Mm. serratus anticus major und latissimus dorsi hineinschieben, ferner vom Processus xiphoideus sterni und nach hinten und unten vom oberflichlichen Blatt der Fascia Lumbodorsalis. Der Muskel ist dün, aber von- bedeutendem Umfange. Er bildet die zunäblist unter der IIaut liegende Decke der seitlichen Hailfte der vorderen Bauchwand. Insertion: Die vorderen Bündel haben einen kürzeren Faserverlauf als die hinteren; sie verlaufen schrig zur vorderen Bauchwand und bilden vom Processus xiphoideus bis zur Symphysis pubis eine lange schmale Faszie, welche als Scheide für den M. rectus abdominis dient. Die Faszien beider Seiten vereinigen sich in der Medianlinie des Batches, wodurch die Limea alba eutsteht. Die Faszien spitzen sich nach unten zu.

Die hinteren Bündel, welche steiler absteigen, inserieren sich an den vorderen Teil des Labium exteruum der Crista oss. ilium und das Ligamentum inguinale s. Poupartii bis zur Symphysis pubis, wo sie in Gemeinschaft mit der Insertion in der Linea alba die untere Öfnung des Leistenkanales bilden, aus welcher beim maimlichen Geschlecht der Samenstrang zu dem oberhall) der Symphyse gelegenen Iloden hervortritt (s. Splanchnologie, mannliche Geschlechtsorgane). Die Fibrue intercolummares s. intercrurales bilden eine zarte Bedeckung des Annulus inguinalis.

M. obliquns abdominis intermus s. adscendens. Ursprung: Durch den vorhergehenden überlagert vom mittleren Drittel des Lig. inguinale, ron einem zweiten Blatte der Fascia lumbodorsalis bis zu den Rippen, yon denen die unteren fiinf ihm noch zum Lrsprung dienen, und zwar die iußeren Flachen unterhall, der Ursprungszacken des vorhergehenden Muskels. Der Muskel ist dünn; seine Fasern verlaufen schrigg aufwirts, jedoch nicht sehr steil. Die Form des Muskels ist einem langen Trapez vergleichbar, welches schrig von unten und medianwirts nach oben und lateralwarts gerichtet ist. Die küzere der nicht parallelen Seiten liegt unten, die lingere an den Enden der drei unteren Rippen und an der achten und neunten Rippe dort, wo sich deren Knochen und Knorpel verbinden. - Die mediale oder lingere, der lateralen parallele Seite ist nicht gerade, sondern stellt eine Kurve dar; in den zwei oberen Dritteln des Bauches ist sie lateralwarts, im unteren Drittel medianwairts konvex. Diese Kurve bildet den Übergang des Muskels in seine Insertion, welche in den oberen zwei Dritteln faszienartig den medialen Teil des folgenden Muskels überzieht; darauf in ihrer ganzen Linge dem M. rectus ablominis als Scheide dient, auf dessen medialer Hälfte sie sich mit der Insertionsfaszie des M. obliquus externus vereinigt. Der Muskel schickt einen ansehnlichen Teil seiner Fasern als Lmhüllung des Samenstranges durch den Annulus inguinalis zum Hoden, welcher ebenfalls davon ungeben wird. Diese Fasern bilden den $\mathbf{W}$. ('remaster, welcher sich durch seine Stirke auszeichnet. Einen Teil seiner Fatsern liefert jedoch der $\mathbf{M}$. transversus abdominis. 
M. trunstersus abdominis. Ursprung: Vom mittleren Teil des Lig. inguinale, rou einem sehr diunen dritten Blatt der Fascia lumbodorsalis und von der unteren Flache der sieben unteren Rippen, von deren Enden oder Knorpelverbindung bis zum lrocessus xiphoideus. Der Huskel wird vom vorigen bedeckt, ist dicker und umfangreicher als dieser und verbreitert sich nach obeu bedeutend. Seine basern verlaufen nicht transversal, sondern sind etwas nach abwirts gerichtet; sie gehen über die des If. obliquus abrlominis internus medianwiirts weit hinaus und werden noch von einem Teil des M. rectus abdominis iberlagert. Die Grenze, wo die Insertionsaponemrose beginnt, liegt in einer rom Processus xiphoideus schrig nach unten und lateralwirts zum Lig. inguinale verlaufendeu, sehr unbedentend nach lateralwarts konvexen Linie. Die Insertionsaponeurose bildet das hiutere Blatt der Scheide des II. rectus abdominis, ist sehr dün, so daß die Eingeweide durchscheinen. Das hintere Blatt der Scheide wird reder durch ein Teilungshlatt vom M. obliquus internus verstirkt, noch spaltet es sich in der Mitte des Bauches, um die untere IHalfto der iußeren Scheide zu verstirken; erst unter der Hailfte des II. transversus abdominis, magefihr am unteren Drittel desselben, verbindet es sich mit den beiden vorhergehenden zu gemeinsamer Insertion und uberzieht gemeinsam mit dem vorhergehenden den Samenstrang und Hoden mit Fasern.

M. rectus abdominis. Trsprung: Vom Rande des Corpus sterni, ron dem Processus xiphoideus und der vorderen Fliche der knorpel der zweiten bis siebenten Rippe. In seinem Ursprumgsteile, dessen obere Partie ein breites Sehmenblatl bildet, wird er bedeckt rom M. pectoralis major und M. pectoralis superficialis, weiter unten am Thorax durch den Ursprung des M. obliquus externus. Der M. rectus abdominis ist ein sehr langer düner Muskel, welcher in der beschriebenen Scheide an der Vorderfliche des Bauches nach alowirts verlauft, anfangs sich verhreiternd, gegen die Insertion hin wieder schmaler werdend und sich zuspoitzend. Sein medialer hand stobt mit dem der anderen Seite iu der Linea albat zusammen. Der Muskel zeiogt in seinem Bauchteile sechs sehuige Inskriptionen: Instriptiones tendimere, deren Zahl von der Anzahl der Lendenwirbel ahhingrg erscheint. Insertion: Beide Mm. recti abdominis inserieren sich gemeinsam in der Medianlinie der Vorderlliche der Symphyse.

M. quadratus lumborum. Der Muskel zerfillt in qwei Portionen, eine mediale und eine laterale, welche dureh die Reihe der Processus transversi der lendenwirbel gesondert worlen, gesondert entspringen, aber sich zum Teil gremeinschaftleh inserieren. Crsprung der medialen Portion: Von den Kïrpern der fïnl unteren Ritckenwirbel, sowie sammticher Lendemwirbel. Crsprung der fateralen Portion: Ton der medialen Fiache der medialen Extremitat der fiul unteren Rippen, medianwarts vom M. psoas major; von den l'rocessus transversi der liunf unteren Riickenwirbel, sowie simmllicher lendenwirbel. Kroftiger, ungemein langer Muskel, der sich besonders nach oben zuspitzl. Insertion der medialen Portion: Mit sechs Sehmenstreifen fiur diejenigen Bindel, die von den körpern des achten bis zwölften Ruckenwirhels und des ersten Lendenwirbels herkommen, an die Processus triangulares der lrocessus transversi des ersten his sechsten lendenwirbels. Das oberste Biindel inseriert sich an den lrocessus friangularis des ersten Lendenwirbels u. s. II. Diese schmalen Sehnenstreilen verlaufen schrigg von oben 
und median- nach unten und lateralwärts und sind etwa 1 cm von einander entfernt. Insertion der lateralen Portion und des unteren Teiles der medialen Portion: In die Spina anterior inferior oss. ilium, sowie an den vorderen Teil der medialen Fliche der Darmbeinschaufel, oberhalb der Articulatio sacro-iliaca. Die Insertion ist meist fleischig, nur im unteren Teile unterhall) der erwähnten Sehnenstreifen erhailt der Muskel an der Vorderfliche eine schwachsehnige Bekleidung, welche ihn bis zur Insertion begleitet.

\section{Muskeln der unteren Extremitiit.}

\section{Muskeln der Hüfte.}

\section{Äufsere Huiftmuskeln.}

M. gluteus maximus. Ist nur wenig entwickelt. Ursprung: Mit einer flach ausgebreiteten großen Sehne vom oberen oder hinteren Teile des llift- und Kreuzbeines, die dem M. gluteus medius als Faszie dient. Von der Mlitte des Os sicrum bis zum unteren Ende desselben entspringt der Muskel sehr kurzsehnig und erhailt von dort den bedeutendsten Teil seiner Fasern, welche rom oberen Kopf des M. biceps femoris bedeckt werden Der obere Teil des Muskels verläuft abwärts und lateralwairts, bleibt bis zur Gegend des Acetabulum sehnig, wo er in einen platten Muskelbauch äbergeht, welcher sich mit der unteren, teils schwach absteigend teils horizontal verlaufenden Portion verbindet, um doppeltgefiedert in eine Sehne überzugehen. Die ohere Ursprungssehne ist nach unten innig rerwachsen mit der den ersten hopf des M. biceps femoris äberziehenden Faszie, oben und lateralwarts mit dem M. tensor fasciae latae. Inserlion: Mit einer starken, spitz zulaufenden sehne an den Trochanter tertius femoris.

M. gluteus medius. Lrsprung: Vom ganzen oberen lateralen Rande des Os ilium, nach vorn sich unter den Ursprung der $\mathrm{Mm}$. rectus femoris und tensor fisciae latie hineinsehiebend. ferner vom Os saerum bis zum dritten Kreuzbeinwirbel unter dem Ursprunge des II. gluteus maximus. Wird bedeckt vom vorhergehenden, im oberen Teile von dessen breitem, sehnigen Lrsprunge, im unteren vom fleischigen Teile desselben. Er ist bedeutend stäker und kraftiger entwickelt als der M. gluteus maximus und stellt eine umfangreiche Muskelmasse dar, welche die ganze laterale Flache des Os ilium bedeckt, um dessen vorderen Rand der Muskel sich noch auf die mediale Fliche herumschligt. Insertion: Die Fasern des Muskels verlaufen konvergierend zum Trochanter major, dessen ganze laterale Flaiche sie zur Insertion für sich in Anspruch nehmen.

M. gluteus minimus. Ursprung: Von der ganzen lateralen Fläche des Os ilium, unterhall, des M. gluteus medius, von welchem er bedeckt wird. Kräftiger, dicker, balbgefiederter Muskel. Er besteht eigentlich aus zwei Teilen $(8 / 8)$, die vom vorderen Rande des Muskels her zusammengeklappt sind wie zwei Blatter eines Buches. Insertion: An die spitze und mediale Flache des Trochanter major. 
M. pyriformis. Ursprung: Von der Vorderflache des Os sacrum zwischen erstem und drittem Kreuzbeinvirbel. Er kommt aus der Incisura ischiadica major heraus und seine Fasern vereinigen sich zu einer rundlichen Sehne. Er wird bedeckt vom M. gluteus medius. Insertion: Ilintere Ecke des Trochanter major.

11. tensor fasciae latae. Ursprung: Tom vorderen Ende des Labium externum oss. ilium, verwachsen mit den Urspringen des M. rectus femoris, welcher höher entspringt, und mit dem M. gluteus medius, welcher vorn von ihm bedecht und mit welchem er zum Teil verwachsen ist. Im weiteren Verlaufe ist er untrembar mit den Mn, glutens maximus und rectus femoris verbunden. so daß eine Trenuung von denselben durchatus willkurlich ist. Seine Fasern gehen in die Fia scia lata iuber, welche sie spannen. Eine künstliche Trennung ron den Mn. gluteus maximus und rectus femoris kann in der Art rorgenommen werden, daß man den M. fensor fasciate latae in Gestalt eines stumpliwinkligen Dreieckes darstellı, dessen stumpfer Winkel etwas vor, aber im Vireau des Trochanter tertius gelegen ist, und dessen gegeniberliegende Seite die Vitte des Oberschenkels mit dem vorderen Ende der Crista ossis ilium verbindet.

11. obturator intermus. Ursprung: Vom inneren Umfange des Foramen obturatorium, welches dieser Muskel gewen die Beckenhöhle verschließt; er verlauft dann zur Incisura ischiadica minor, wendet sich durch dieselbe um den oberen Ast de's Sitzbeines herum, 110 doppelfgefiedert in eine starke Sehne, deren Fasern gegen die Insertion hin konvergieren, iblorzugehen. Insertion: In der Fossa trochanterica an die mediale hintere seite des Trochanter major.

Mm. gemelli. Es sind zwei kleine Muskeln, von denen der eine oberhalb, der andere unterhalb des M. obturator interuus seine Lage hat.

M. gemellus superior, ein kleiner, birnförmiger Muskel, entspringt on der spina ischii und dem oberen Teil des Ramus superior oss. ischii, geht in eine rundliche, lange sellostandig bleibende Selne ubber, welche oberhalb des M. obturator internus an den Trochanter major sich inseriert.

M. gemellus inferior ist starker als der superior, entspringt vom unteren hinteren Teile des Ramus superior oss. ischii und dem Tuber ischii; seine Sehne verschmilzt mit der des M. obturator internus.

11. quadratus fomoris. Der Mushel ist vierechig, hat die Form eines Trapezes, welches sich an den M. gemellus inferior anschließt. Der obere Teil, welcher rou der unferen Partie des Ramus superior oss. ischii deutlich sehnig entspringt, wird vou den Mm. obturator internus und gemellus inferior bedeckt und inseriert sich tleischig schrig von vorn nach hinten unterhalb des Trochanter major. Der untere T'eil, welcher mehr fleischig von der Vorderfliche des Tuber ischii entspringt, wird sehr bald nach dem Lrsprunge halbgrefiedert, sehnig, und heftet sich mit rundlich-spitz auslaufenden Fasern hinter und unterhall, des oberen Teiles an. Insertion: Die Anheftung des Gesammtmuskels bildet eine schrige Linie vom Ende der Grista des Trochanter minor bis zur Spitze des Trochanter tertius.

11. chturutur extermus. Ursprung: Tom äußeren Umfange des Foramen obturatorium, dessen inßere Verschließung der Muskel bildet. Derselhe verläuft lateralwarts zum Trochanter major, um mit der Sehne des y. obturator inter- 
nus zu verschmelzen. Insertion: Trochanter major, besonders in der Fossi trochanterica.

\section{Innere Hiiftmuskeln.}

M. iliopsoas. Dieser Muskel besteht aus zwei Köpfen, einem oberen und unteren, welche sich gegen die Insertion hin vereinigen.

M. psoas major. Ursprung: Der obere Kopf oder der M. psoas major entspringt mit einer, einen Teil des $\mathbf{I}$. quadratus lumborum bedeckenden sehnigen Ausbreitung von der medialen Fliche der drei untersten Rippen in der Gegend ihrer Anguli, ferner von den Körpern der drei untersten Rücken- und sämmtlicher Lendenwirbel, sowie von der Wurzel der Querfortsätze der letzteren. Es ist ein sehr lauger, nach oben und besonders nach unten sich zuspitzender dicker Muskel, welcher den M. quadratus lumborum ron vorn her bedeckt. Nach unten nimmt derselbe eine laterale Richtung an, um sich mit dem M. iliacus zu vereinigen.

M. iliacus. Ursprung: Der untere Kopf oder der M. iliacus entspringt vom Körper des letzten Lendenwirbels, dem Seitenteile des ersten Kreuzbeinvirbels, von der Articulatio sicro-iliaca und dem darunter gelegenen Teile des Os ilium, schliggt sich darauf uber den medialen Teil des Acetabulum lateralwarts, um sich mit dem oberen Kopf zu einer dicken kurzen Sehne zu vereinigen. Insertion des M. iliopsoas: Trochanter minor.

M. psoas minor. Ursprung: Medianvirts rom M. iliopsoas von den Körpern der vier untersten Lendenwirbel. Der Muskel ist ziemlich stark entwickelt, hat die Form eines stumpfwinkligen Dreieckes, verliuft schrig nach ab- und lateralwaits. In der Gegend des Promontorium geht er in eine glianzende, straffe Sehnenausbreitung uber, welche bis zum Lig. inguinale den II. iliopsoas von vorn her überdeckt. Insertion: Ein Teil dieser breiten Sehne inseriert sich spitz zulaufend an das Tuberculum iliopectineum, ein anderer geht breit in den oberen lateralen Teil des Lig. inguinale iber. Zwischen den beiden Schenkeln, in welche sich die sehnige Ausbreitung spaltet, bleiht eine ovale Lücke (s. Angiologie, A. iliaca externa).

Von der Mitte des Körpers des ersten kreuzbeinwirbels komml ein straffer sehniger Streifen, welcher sich gütelformig über die Sehne des M. psoas minor herủberlegt und an den oberen Teil des Lig. inguinale sich befestigt, beginnend am medialen Rande des Ursprunges des M. sartorius.

\section{Muskeln am Oberschenkel.}

\section{Muskeln an der medialen Seite des Oberschenkels.}

M. gracilis. Ursprung: Symphysis pubis, in ihrer ganzen Ausdehnung, von wo derselbe schriag lateralwirts nach unten verliuft. Langer, breiter, dünner Muskel, welcher einen großen Teil der medialen Fläche des Oberschenkels zudeckt. Insertion: Im unteren Drittel seines Verlaufes geht er in eine große breite sehne über (nachdem vorher der M. sartorius sich mit ihm rer- 
bunden hat), welche an das obere Drittel der Iunenfliche der Tibia sich inseriert, indem sie in die Unterschenkelfaszie ublbergeht.

M. surtorius. Irsprung: Von der Faszie des M. obliquus abdominis externus in der Vitte des Lig. inguinale. Er vereinigr sich unter spitzem Winkel mit dem vorigen elwa in dessen Mitte und bildet den oberen Teil der gemeinsamen Insertionssehne. Insertion: Condylus medialis tibiae.

M. pectineus. Ursprung: Pecten ossis pubis. Der Muskel ist klein und fleischign. Der M. Sartorius und die großen schenkelgefiße bedecken ihn von rorn her zum Teil: ler Muskel rerlauft sehriag lateralwirts zum Obersehenkel, wo derselbe unter den M. vastus medialis sich cinschiebt. Inserlion: Unterhalb des Trochanter minor.

M. adductor brevis. Ursprung: Oberer Teil der Symphysis pubis. Er schließt sichnach unten an den vorhergehenden Muskel an, liegt zum Teil neben, zum Tril unter demselhen. Dagegen liegrt er auf dem $\mathrm{W}$. adductor longus, so daß er gleichsim wie aus einem Fenster zwischen heiden Muskeln heraussieht. An Linge iblortrillt er den II. pectineus, an Dicke steht er letzterem nach, denn er ist mehr platt. Insertion: Doppeltgefiedert unterhall) des 11 pectineus.

I. adductor longus. Crsprung: Von der Symphysis pubis unterhalb des vorhergehenden Muskels, sowie vom Ramus inferior oss. ischii und Ramus inferior oss. pubis. Es ist ein sehr kriftiger fleischiger Muskel von rundlicher Form. Bedeckt wird derselbe vom M. gracilis und oben vom vorhergehenden, mit welchem er gleichen Verlauf hat. Insertion: Lnterhally des vorhergehenden Muskels an der hinteren Peripherie des Oberschenkels vom unteren Ende des Trochanter tertius femoris an bis zum unleren Drittel, hinter dem Ursprung des .I. Vastus medialis, welcher gegen die Insertion hin auf ihm liegt.

I. aductor magnus. Ursprung: Iauptsachlich von der vorderen Fliche des Tuber ischii, mit einem Teil seiner Fasern aher auch ron der hinteren; mit den dort entspringenden Beugemuskeln des Lnterschenkels ist er innig verwahsen. Er ist ein großer, sehr kraftiger Huskel von prismatischer Form, der sich unmittelhar nach unten an den vorhergehenden anschließt und zwar so, daß er mit ihm eiuen eiuzigen Muskelbauch darzustellen scheint; von vorn her wird er ebenfalls wrößtenteils rom M. gracilis bedeckt. Insertion: Kurzsehnig, wie der vorige, an die mediale Seite des unteren Endes des Oberschenkels und die Spitze des Condylus medialis tibiae.

\section{Inskeln an der vorderen Seite des Oberschenkels.}

\section{M. quadriceps femoris s. extensol cruris :}

11. rectus femoris. Ursprung: Der M. rectus femoris besteht aus zwei Bauchen, eimem oberflichlichen oder Gaput longum und einem ron diesem bedeckten Caput breve. - Das Caput longum entspringt vom vorderen Ende des oberen Darmbeinrandes, verwachsen mit dem M. Tensor fasciae latae, damn rom ganzen vorderen hande des Os ilium bis zum Pfannenteile des Os pubis. Der Muskel ist sehr umfangreich und breit, bedeckt die ganze vordere Peripherie des Oberschenkels und einen Teil der medialen und lateralen Fliche, letztere in Gemeinschaft mit dem M. tensor fasciae 
latae. An der lateralen und medialen Seite wird er zuerst sehnig, indem seine Fasern in die Fascia lata ubergehen; die mitteren Fasern reichen bis zur Insertion der anderen Streckmuskeln des Lnterschenkels. - Dis Caput breve, welches eigentlich vollstindig vom Cilput longum getrennt ist, nur eine gemeinsame Insertionssehne mit letzterem hat, entspringt unmittelbar úber dem Acetabulum von der lateralen Flache und dem vorderen Rande des Os ilium; es ist ein spindelförmiger, kriftiger Muskel, der in einer von den Mm. vasti lateralis und medialis gebildeten firube liegr, aus welcher nur der vordere mediale Teil herausschaut. An der Insertion, bis wohin er durehaus mabhingigy ist, verbindet er sich mit den ubrigen Streckmuskeln im Lig. patellae superius.

I. vastus lateralis. Ursprung: Kurzsehnig, einfach gefiedert von der vorderen Flitche des Collum femoris, sowie von der Spitze und vorderen Seite des Trochanter major, und vom Lig. intermusculare laterale, einem an die laterale Seite des Femur angewachsenen und Muskelursprüuge darbietenden fibrösen Streifen. Kriftiger Muskel, doppelt so breit als dick, won länglicher Form. Die Unterfliche des Muskels ist durch eine breite, fleischige Kante der Lange nach in zwei grubenförmige $\Lambda$ bschnitte geteilt. In die mediale Grube legt sich die laterale Flache des Caput breve des M. rectus femoris, in die laterale Vertiefung die laterale Portion des gleich zu beschreibenden M. cruralis. Insertion: Gemeinsame Strecksehme des I'nterschenkels.

1I. vastus medialis. Ursprung: Basis des Collum femoris medianwirts vom .I. cruralis, rom oberen medialen Driltel des Mitlelstiuckes, welcher Teil mit dem M. cruralis verwachsen ist; ferner vom oberen Teil des unleren Drittels und dem medialen Teile der Fascia hata. Wie schon angegeben, liegt der Muskel an der medialen Seite des Caput breve des M. rectus und des II. cruralis, mit welchem letateren er an oberen Teile in Verbindung tritt. Dieser verbindende tiefe Teil liißt sich bis zum unteren Drittel vom oberflichlichen Teil ablösen. Der ganze Muskel hat eine viereckige Form, ist weit weniger stark entwickelt als der If. vastus lateralis. Die diunne, der Breite des Muskels entsprechende Sehne bildet den medialen Teil der gemeinsamen Insertionssehne des M. quadriceps femoris.

M. cruralis. Besteht aus zwei Portionen. - Erste Portion: Ursprung: Von der vorderen und lateralen Fliche des Trochanter major, sowie vom Collum femoris unterhalb des M. vastus lateralis. Ziemlich kräfiger, spindelförmiger Muskel, der anfangs die zweite Portion úberlagert, sich dann aber bald an deren laterale Seite legt und unter dem il. vastus lateralis ganz selbstindig bis zum unteren Ende des Femur verliuft. Insertion: Gemeinsame Sehne des M. quadriceps femoris. - Z weite Portion. Ursprung: Mit der rorhergehenden verwachsen von der Basis des Trochanter major, sodann selbstindig von der ganzen vorderen Flache des Oberschenkels, sowie rom Lig. intermusculare laterale. Insertion: Die Sehne dieses Muskels bildet mit der aller übrigen Streckmuskeln des Lnterschenkels zusammen das kraftige Lig. patellae, welches, nachdem die Pattella in die Mitte sich eingelagert, an die Spina tibiae sich inseriert (S. 130).

$\mathbf{I m}$. subcrurales. Zwei kleine, mehr wie ein einziger Muskel aus- 
sehende Faserparticen, welche unter dem 11 . arualis rom unteren Drittel des femur entspringen und rorn und seitlioh in die kniegelenkkapsel äbergehen.

Über sog. Sehnenreflexe vergl. 752.

\section{Mnskeln an der hinteren Seite des Oberschenkels.}

M. biceps femoris. Ursprung: Mit drei Köpfen. - Der erste Kopf entspringt von den Processus spinosi (spurii) der drei untersten Sakralwirbel und den drei obersten Sihwanzwirbeln, sow ie zum Teil von einer den Muskel sehr strall überzichenden Faszie. Er bedeckt den unteren Teil des M. gluteus maximus bis zu dessen Insertion. Der Muskelbauch ist lang und kraftig, von prismatischer Form und liegt keilförmig zwischen dem M. vastus lateralis und dem zweiten kopf des 11 . biceps femoris unterhall, des Trochanter major. In seinem unteren Drittel rereingt er sich, in eine lange schmale dünne Sehne atuslaufend, mit dem zweiten Kopfe zur gemeinsamen Insertion an den lateralen Seitenramd der Patella, bei welcher ihm die Stelle oberhalb des zweiten Kopfes zufillt. - Der z weite Kopf entspring fleischig rerwachsen mit den Urspriugen des II. semimembranosus von der hinteren Fliche des Tuber ischii. Bald nach seinem Ursprunge verwachst sein unterer Rand mit dem oberen des dritten hopfes. Linglicher starker Muskel, der zwischen dem ersten und dritten hopfe zur Patella verlauft. Inseriert sich an letztere unterhalb des ersten Kopfes, hingt aber auch mit der Insertion des dritten kopfes und durch diese mit der Fascia cruris zusammen. - Der dritte Kop entspringt sehnig hallogefiedert rom Processus hateralis des Tuber ischii mit einer langen diunnen Sehne. bedeckt rom zweiten Kopfe. Nach seiner Vereinigung mit letzterem liegt er unterhalb desselben frei; beide zusammen stellen, je weiter nach unten, einen um so breiteren Muskelküper dar, welcher in dem schrig rom Tuber ischii zur Spitze der Tibia rerlaufenden Teile seine bedeutendste und nicht geringe Dicke besitzt; wie denn der M. biceps femoris in seiner Gesamtheit eine sehr große Flichenausdehmung darbietet. Insertion: Vom unteren Ende der Patella bis zum unteren lateralen Drittel der Tibia, indem er in die Fascia cruris ủbergeht.

1\%. Lensor fasciae cruris, früher accessorischer oder dritter Kopf des M. biceps femoris genannt. Irsprung: Mit einer sehr dünen langen Sehne vom Processus transversus des zweiten Schwanzwirbels, dicht unterhalb des $\mathrm{Tr}_{\mathrm{r}}$ sprunges des M. gluteus maximus.

Dieser Muskel stellt ein lauges, schmales und dünes Muskelband dar von viereckiger Form; er verliuft unter dem unteren hande des dritten Kopfes des II. biceps femoris schrig von hinten nach voru und abwarts zurlateralen Seite der Tibia, wo seine parallelen Fisern in eine der Breite des Muskels entsprechende schme ibbergehen. Insertion: Die Sehne rerwichst mit der des Kopfes kurz vor der Insertion, setzt sich an die Hitte der lateralen Seitenflache der Tibia und geht in die Unterschenkelfaszie úber, welche er anspannen hilft.

Bei der Katze ist der M. tensor fasciae cruris ebenfalls vorhanden (125).

M. semimembranosus. Crsprung: Vom Processus lateralis des Tuber ischii, 
bedeckt rom zweiten Kopfe des M. biceps femoris, nach oben vom ersten Kopfe desselben, ferner mittels eines oberflichlichen fibrosen oder muskulösen Blattes, welches dem I'rsprungsteile des zweiten hopfes des M. bieeps femoris und zum Teil des M. adductor magness aufliegu und mit des den ersten Kopf des M. hiceps femoris derkenden Faszie zusammenhangt. Kriftiger, fleischiger, spindelformiger Muskel, verliuft schrig ahwirts und medianwarts und geht in eine breite, diunne Sehne iber. Die Breite des Mushels hetrigh efwa das Doppelte seiner Dicke. Insertion: Die Sehne hefestigt sich gemeinschaftich mit der des M. gracilis am linde des oberen und Anfang des mittleren Drittels der Tibia. Die hinteren Faserzigge gehen in eine lange, nach unten sich verjüngende Sehne ïher, die in nach rorn konvexem Bogen zur Arhillessehne herabsteigt, mit welcher sie sich verbindet.

M. semitendinosus. Lrsprume: Tuber ischii, durchbohrt den II adductor magnus, der ihn ton allen Seiten umgiebt. Auf Querschnitten ist sein rötlicher Muskelbauch in dem weißlichen Fleisch des II. adluctor magnus auffallend (S. 49). Insertion: Millels einer langen Sehne an den medialen Condylus tibiae, oberhalb des Crsprungs des M. extensor digiti I proprius.

\section{Muskeln am Unterschenkel.}

\section{Muskeh an der medialen und vorderen Seite des Unterschenkels.}

II. extensor digiti primi pedis proprius. Dieser Muskel ist der einzige der medialen Flache der Tibia und homolog dem M. extensor hallucis longus des Mensehen. Ursprung: Condylus medialis tibiae hinter der Insertion des II. adductor magnus neben dem medialen Seitenbande des Kniegreleukes, rom medialen Rande der Spina tibiae, ferner ron der gauzen unteren Ilalfte des oberen und der oberen Hälfte des mittleren Drittels der Tibia. Düner, spitz zulaufender Iluskel, der gleich nach seinem Lrsprunge in eine lange, oben breite, unten mehr rundliche Schne iblorgeht, welche durch die kinne unter dem Malleolus medialis tibiae in der Fußsohle unter der Basis oss. metatarsi I, dann an der tibialen Seite desselben zum Rücken der ersten Phalanx digili I verliuft. Insertion: Die Sehne verschmilzt dasellost mit der ersten Sehue des II. extensor digitorum pedis longus.

M. tibialis anticus. Lrsprung: Condylus lateralis tibiae, laterale Seite der Spina tibiae bis zu deren Eude. Es ist der oberflachlichste aller an der vorderen Seite der Tibia liegenden Muskeln. Unmittelbar unter ihm liegt der $\boldsymbol{M}$. extensor digitorum pedis longus. Der Muskel ist platt, ziemlich breit und ron langlicher Form: unter der Jitte des Oberschenkels geht er sich zuspitzend in eine anfangs platte, nachher mehr rundliche Sehne iber. mit welcher er unter einem straffen Bande, dem Ligamentum cruris, iiber der Sehne des II. extensor digitorum pedis longus auf den Fußriicken tritt. Insertion: Die Sehne verlauft tibialwaits zur Basis des Os metatarsi I, an dessen tibialer Seite sie endigt.

Das straffe Ligamentum cruris ist kurz und dick. geht von oben und medianwarts nach unten und lateralwarts und endigt unten über den lateralen 
Teil des Golenkendes der Tibia. Es hindert das Emporschnellen der Strecksehmen bei der Kontraktion ihrer Muskeln, welches ein sehr bedeutendes sein wiurle, da das Dorsum pedis fibularwirts vor dem Sprunggelenk eine beIrichlliche lortiefung zoigrt, welche die Sehnen des M. extensor digitorum pedis longus passieren.

M. extensor digitorum pedis longus s. communis. Ursprung: Mit plattrundlicher Sehne vom unteren Teile des lateralen Randes der Fossa patellaris. Die Sehne rerliuft durch das Gelenk unmittelbar hinter der Kapsel, welche sie lateralwits vom oberen Ende der Spina tibiae durchbohrt, worauf sie in einen Muskelbauch übergeht, welcher in der Mitte doppelt so breit als dick ist, nach beiden Enden aber allmihlich sich zuspitzt. Noch oberhalb des Lig. (eruris teilt sirh der Muskel in vier Sehnen, welchr unter dem Ligament hindureh zum Fußriucken gelangen. Auf der Dorsalfliche des ersten Zehengelenkes enthailt jecle Sehne cine kleine runde Fuserlinorpelscheibe wie an den Fingern, S. 153). Insertion: An die Phalangen der vier Zehen und zwar an die dritte Phalanx derselben.

\section{Iuskeln an der lateralen Seite des Unterschenkels.}

M. peronaeus longus s. primus. Ursprung: Condylus lateralis tibiae und Capitulum fibulat, wird bedeckt rom II. extensor digitorum pedis longus und rom M. tibialis anticus. Dünner, spitz zulaufender Muskel, weleher schon in der Mitte des Interschenkels in eine lange und schmale Sehne ühergeht, die im Verein mit den folgenden die Rinne unter dem Malleolus lateralis passiert und am fibularen Fußrande sich hinzieht. Insertion: An der plantaren Fache des Os tarsale III.

M. peronaeus brevis s. secundus. Ursprung: Condylus lateralis tibiae, von der lateralen Fliche der Tibia bis zur Mille vom Lig. interosseum eruris und von der medialen Kante der Fibula. Einfach gefiederter, nicht bedeutend entwickelter Muskel, geht ebenfalls in der Mitte des Unterschenkels in eine lange, diunne Sehne iblser, welche durch die Rinne am Malleolus lateralis hindurchgeht. Insertion: Tuberositas der Basis der vierten Zehe.

11. peronueus tertius. Irsprung: Capitulum fibulae und Lig. interosseum cruris, mil dem vorhergehenden verwachsen, lateralwirts von welchem er seine Lage hat. Fs ist rin spindelformiger Muskel, welcher in gleicher Höhe wie die anderen sehnig wird. Seine schmale, diunne Sehne übertrifft an Linge die aller anderen Mm. peronaci: sie geht gleichfalls durch die Rinne am Malleolus lateralis. Insertion: I)ie Sehne verlauft damn zum Capitulum des Os metatarsi der vierten Zehe, wo sie sich zuerst befestigt; ron hier geht sie verschmelyend mit der betreffenden Sehne vom M. extensor digitorum pedis longus zur dritten Phalanx, wo sie endigt.

M. peronaeus quartus. Ursprung: Von der Fibula in ihrer ganzen Ausdehmung und dem Liğ. interosseum eruris. Oben ist der Muskel verwachsen mit dem II. peronacus tertius, tibialwarts mit dem M. peronaeus secundus, welche beiden Muskeln zusammen ihn bedecken. An Stirke ist er ungefähr den anderen gleich. Halhgefiedert geht er, jedoch weiter abwirts als die vorhergehenden Muskeln. in eine lange und schmale Schne iber: welche durch 
die Rinne des Malleolus lateralis auf den fuBrucken tritt und sich oberhalh der Mitte des Os metalarsi IV mit der Strerksehne der kleinen Zehe aus dem II. extensor digilorum pedis longus kreuzt. Insertion: Capitulum des drilten Os metatursi.

\section{Muskeln an der hinteren Seite des Unterschenkels.}

M. triceps surae. Ursprung: Mit drei Portionen, von denen die eine: der $M$. gastrocnemius medialis, vom Condylus medialis, die andere: der $M$. gastrocnemius lateratis, rom Condylus lateralis femoris, sowie rom oberen Ende der Tibia, die dritte: der $\boldsymbol{K}$. soleus, rom Capitulum fibulae unterhall, des Condylus lateralis tibiae entspringt. Die beiden oberflichlichen Kijpfe, von denen der laterale der stirkere ist, konvergieren und vereinigen sich noch am oberen Drittel der Tibia fleischig, bald aber sind sie nur durch einen Sehmenfortsatz verbunden, welcher von dem Tendo Achillis sich zwischen sie hineinschiebt. Der dritte, unter dem M. gastrocnemius lateralis liegende Kopf verschmilzt in der Mitte der Tibia mit demselben; doch reicht seine Muskelsubstanz weiter abwarts als die der Mm. gastrocnemii. Der M. triceps surae in seiner Gesamtheit stellt einen bedeutend entwickelten, kriftigen Muskelbauch dar, welcher die ganze hintere Flache der Tibia bedeckt und medianwiirts in der Mitte den M. plantaris etwas zum Vorschein kommen Jißß. Insertion: Die gemeinsame Insertionssehne ist der starke and dicke, rundliche Tendo Achillis. Sehnenfasern rom Tendo Achillis erstrecken sich mehr oder weniger weit auf die in diese Sehne ib)ergehenden Muskeln. ganz besonders sieht man auf der vorderen Fliche des $\mathbf{M}$. gastrocnemius medialis eine schrige Fortsetzung derselben, welche bis zur Mitte des Muskels hinaufreicht. Die Achillessehne legt sich auf das überknorpelte hintere Ende des Calcaneus und befestigt sich an den hinteren Teil der plantaren Flache desselben.

M. plantaris. Ursprung: Condylus lateralis femoris und von dem darauf befindlichen Os sesamoideum. Kraftiger, schollenförmiger Muskel, der von den IIm. gastrocnemii bedeckt wird. und nicht mit dem ebenfalls von den Mm. gastrocnemii bedeckten II. soleus rerwechselt werden darf. Seine vordere Flache, besonders der mediate Teil derselben, ist ausgezeichnet durch schinmernde, glinzende Schnenfasern, welche rom Ursprung an his zum unteren Drittel den Muskel sehr deutlich bekleiden. Insertion: Die starke platte Sehme verlauft hinter dem Tendo Achillis, gelangt hinter dem hinteren Ende des Calcancus in die Fußsohle und spaltet sich weiter nach vorn in vier Sehnen, welche sich an die zweite Phalanx der vier Zehen unter dem Capitulum befestigen und ron den Sehnen des M. flexor digitorum pedis longus durchbohrt werden. Die Sehnen des M. plantaris verhalten sich somit homolog denjenigen des fehlenden M. flexor digitorum pedis brevis des Menschen. Der M. plantaris ist so stark wie jeder der Mm. gastrocnemii.

M. popliteus. Ursprung: Mit einer plattrundlichen Sehne vom Condylus lateralis femoris, innerhalb der liniegelenkkapsel, unter dem Ursprunge des lateralen Seitenbandes. Der Muskel durchbohrt die Kapsel, worauf er fleischig wird; ist ziemlich dick und breit; verlauft schrig nach unten und median- 
warts, wird ion hinten her durch den M. soleus bedeckt. Insertion: An das obere Drittel der kinte zwisehen medialer umb hinterer Flache der Tibia.

M. llexor digitorum pedis longus s. communis. Ursprung: Vom Condylus Iateralis libiate, Capitulum fibulae, dem Lig. interosseum cruris und dem oben daran grenzenden Teil der Tibia, ron der Fibula, verwachsen mit dem $\mathbf{I}$. peronaeus longus mol in deren Fortsetzung ron der Tibia bis zum unteren Drittel derselhen, woselhst seine plattrundliche Insertionssehme beginnt. Dieselhe schickt an der hinteren Flirche Sehmenfasern fast bis zum Lrsprung des Muskels nach aufwirts. Die Insertionssehne verlauft medianwits zum Malleolus medialis, hinter wolehem hervor sie in die FuBsohle dureh eine Furche unter dem Processus medialis caldanei gelamet. Die Sehme des M. flexor digitorum pedis longus liege in der FuBsohle iber der sehne des M. plantaris und also ron der Haut der luBsohle entfernter, als die genannte Sehne. Insertion: An der Basis der Oss. metatarsi teilt sich die Sehne in vier Strange, welehe durch die Rinne der Oss. sesamoidea an der Articulatio metatarsophalangea zum Gelenke zwischen zweiter und dritter Phalanx der Zehen verlaufen, wo sie sich an letzterer befestigen.

An dem M. fleyor digitorum longus sind zwei Portionen zu unterscheiden (848). Nämlich eine oberflächliche, 11. flexor digitorum pedis tibialis, welche schwächer ist, von der hinteren Fläche der lateralen Kante der Tibia entspringt und in eine platte Sehne übergeht, die mit der Hauptsehne verschmilzt. Diese Portion repräsentiert den M. flexor digitorum longus des Menschen. Die zweite, melır in der Tiefe gelegene Portion, 11. flexor digitorum pedis fibularis, ist bei weitem stärker, sie giebt die rundliche Hauptsehne ab, welche an der lateralen Seite der schwächeren Sehne verläuft und am unteren Ende des Untersohenkels mit derselhen sich rereinist. Die stirhere sehne erscheint homolog dem 11. flexor hallucis longus des Menschen, welcher dem Kaninchen fehlt; als sehr seltene Varietat $(40,5.115)$ giebt der letztgenannte Muskel beim Menschen Sehnen zu allen fünf Fingern.

\section{Muskeln am Fulse.}

\section{Muskelı der F'ufssohle.}

Mm. lumbricales. Ursprung: Die drei Mm. lumbricales der Zehen entspringen von den Teilungsstellen der Sehne des M. flexor digitorum pedis longus; sie sind sehr schwach, ihr Vorhandensein ist kaum mehr als angedeutet. Insertion: $\Lambda$ n der Tibialseite des vorderen Endes der ersten Phalangen der zweiten, dritten und vierten Zehe.

Mm. interossei (metatarsi). Die Zahl der Mm. interossei beträgt vier. Es sind kriftige, lleischige Muskeln, welche mit ihren Seitenrindern aneinander stoßen. Crsprung: Varh unten konvergierend linden sie ihren 'gemeinsamen Crsprung in einem Sehnenblatte. welches den Bases der Oss. metatarsi und den Oss. tarsalia anfliegt, und vom rorderen Ende des Calcaneus und der unteren Flache des Os naviculare entspringl. Inserlion: An das Capitulum der Ossa metatarsi unterhalb) des Gelenkes zwischen letzteren und den ersten Phalangen der Zehen. 


\section{Splanchnologie.}

\section{Sinnes - A pparate.}

\section{Haut.}

Die außere Haut des Kaninchens hat etwa 1364-1375 qen Oberflache; sie stellt ein ziemlich derbes und festes Gewebe von geringer, aber vollkommener Elastizitit dar, welehes an den Öfnungen des Körpers ohne scharfe Grenze in die Schleimhiute übergeht. Sie ist mit Ausnahme weniger und kleiner stellen, namentlich der Fußsohlen und des außeren Ohres, mit den darunter liegenden Teilen nur locker verbunden und gestattet daher eine große Verschiebbarkeit auf den letzleren. Das Lnterhautbindegewebe besteht aus sehr Jockerem Bindegewebe und zahlreichen feinen, elastischen Fasern, wodurch eben die Verschiebbarkeit ermöglicht wird. Ein eigentlicher Panniculus adiposus fehlt selbst bei stark gemisteten Tieren ganz und gar, wihrend man mikroskopisch an den meisten Stellen der Haut Ilaufchen von Fettzellen in das Unterhautbindegewebe eingelagert findet. Nur an einzelnen Partieen: am Vacken, zwischen den Schulterblittern, in der Achselgegend, kommt es unter den angedeuteten Imstainden zu starkeren Fettamhaufungen.

Die Nerven der IIaut sind wegen der Fetllosigkeit der letzteren trotz ihrer großen Feinheit meist leicht zu verfolgen; am besten bei Sonnenlicht. Sie endigen mit Endkolben von linglicher Form und einfacher Terminalfaser (s.auch Vagina u.57, S.541). Uher die Lymphgefaße der Iaut vergl. 681.

Die Haut besitzt quergestreifte Muskelfasern, die zu speziellen II autmuskeln vereinigt sind $\langle\mathrm{S} .170\rangle$ ). Außerdem sind in der Tunicia dartos, sowie an den Iatrbalgen glatte Muskelfasern rorhanden. Die letzteren sind namentlich am Riicken stark entwickelt, durchschnittlich $0,011 \mathrm{~mm}$ breit, an beiden Ansatzpunkten durch clastische Fasern fixiert. Auch an beiden Seiten des Ohrmuschelknorpels fehlen sie nicht (124).

Die II a a balge bieten nichts besonderes; die der großen Spurhare zeigen die von solchen IIaren hekannte Beschaflenheit; ihre Haarpapillen sind sehr lang (722). Die Hare zeichnen sich durch ihre relatir sehr dicke Marksubstanz atus, welche in regelmäßigen Abstanden mit Luft gefüillt ist, so daß die Haare bei durchfallendem Licht schwarze Querstreifen darbieten. Die Haut 
samt den Haaren bildet einen dichten warmen Pelz, das Gesamtgewicht derselben beträgt im Winter beispielsweise $181 \mathrm{~g}$.

Die Ilatre enthalten $3,13 \%$ Schwefel $(125)$; ferner hinterlassen sie $2,88 \%$ Asche, wovon 0,34 Kieselsäure (126).

Die Nervenendigung an den Spürhaaren oder Tasthaaren ist als ein Auslaufen in blasse Terminalfasern mit kolbigen Endanschwellungen beschrieben worden (127; vergl. 57, S. $542, \mathrm{u} .766)$.

Die Talgdrusen sind am stirksten am iußeren Ohr entwickelt, ferner am lateralen Ende der Gl. inguinalis. Sie stellen fur gewöhnlich kleine Anhảnge der Haarbälge dar.

S. hweißdriisen kommen in Form der Gl. inguinalis vor (s. Geschlechtsorgane), und rudimentar an den beharten Lippen (s. letztere). Auch die Schleimbeutel fehlen der IIaut des Kaninchens.

\section{Muskeln der Hant.}

1I. cutaneus mu.rimus. Entspringt hauptsachlich von der Linea alba $(\delta / S)$, ferner ron der spina humeri, von den Insertionsstellen der $\mathbf{M m}$. pectoralis major und deltoidens, weiter abwarts vom Lig. intermusculare laterale. Verliuft medianwirts vor dem M. gleno-ulnaris, dem N. medianus und der $\Lambda$. brachialis, zwischen den Mm. anconaeus longus und pectoralis major, dicht unter der Hant in der Falte, die vom Humerus zum Thorax sich erstreckt, zur IIaut des Ríckens. Sein oberer Rand liegt unterhalb des Angulus inferior scapulae. Insertion: Seine Fasern strahlen nach hinten und unten in die Ilaut der Seitenflächen der Brust und des Rückens aus; die untersten gehen nach hinten in den M. extensor caudae medialis úber.

M. subcutaneus faciei. I'rsprung: Mit einzelnen Bundeln von der knorpligen Nase, der lateralen Flache des Os intermaxillare, dessen Ramus frontalis und dem Processus supraorbitalis anterior oss. frontis. Insertion: Haut des Nasenrïkens und der Stirn.

M. orbicularis oris ist nicht geschlossen, wegen der Spaltung der Oberlippe.

M. depressor alae nasi hängt mit dem M. orbicularis oris zusammen.

M. depressor septi mobilis narium bildet das mediale Ende des nicht geschlossenen II. orbicularis oris, stellt ein dreieckiges, oben spitzes Bundel dar, welches nach oben rerliuft und sich am unteren Raude des Septum mobile narium inseriert.

Die Mm. subcutaneus faciei und levator nasi einerseits, die Mm. orbicularis oris und depressor septi mobilis narium andererseits, bedingen durch ihre abwechselnde Kontraktion das bekannte permanente Spiel der Kaninchennase.

I. submentalis. Ursprung: Ein dummer unparer Muskel, der in der Haut des Unterkiefers entspringt. Insertion: Seine Fasern schlagen sich um den muteren freien Rand des Corpus maxillae inferioris herum und gehen zu denselben Punkten der anderen Seite, indem sie sich wieder in die Haut daselbst inserieren.

M. platysma s. platysma myoides. Ein langer, dünner Muskel. Ursprung: 
Haut der Brust vor dem ersten und zweiten Rippenknorpel. Verlauf schrig aufwarts und lateralwarts zum Lnterkiefer. Insertion: IIant der Wangengegend.

M. extensor caudae medialis. Bildet eine Fortsetzung des M. cutaneus maximus auf den Sehwanz. Insertion: Etwas unterhall, des oberen Drittels des Schwanzes neben den Processus spinosi.

Pathologische An atomie. Injektionen von $25 \%$ iger Chlorkaliumlösung in Wasser unter die Haut des Rückens bewirken nach einigen Monaten Albinismus partialis: weiße Flecken an den betreffenden Stellen, indem die Haare durch freiwerdendes Chlor gebleicht werden (852).

Parasiten der Haut. Sarcoptes cuniculis. minor lebt in der Epidermis der Lippen und Augenlider, macht dicke, weiße Borken und bewirkt Ausfallen der Haare. In den von Milbengïngen unterminierten Borken findet man Minuchen und Weibchen ziemlich gleich an Zahl, Eier mit jungen Milben, abgelegte Hïute, leere Eischalen und braune, ovale Füces. Häulig entstehen kapillare Blutergiisse, später können intensivere Iautentzïndungen, Nasenkatarrhe, ausgedehnte Vereiterungen von Lymphdrüsen und der.Tod eintreten. Die Kritze ist sehr leicht ansteckend; die stark befallenen Tiere mïssen von den gesunden isoliert werden; die wenig affizierten heilt man am einfachsten durch Einreibungen mit Petroleum oder Kaliseife. Man kamn auch Perubalsam mit gleichen Mengen Alcohol rectilicatissimus oder $2,30 \%$ Kreosot mit Ol gemischt aufpinseln $(128)$ oder Styrax liquidus mit einem gleichen Gewichtsteil Olivenöl oder mit drei Teilen Alcohol rectificatissimus gemengt, anwenden (128, S. 42).

Es sind noch andere Bäudemilben beim Kaninchen bekannt (S. 2.2), namentlich Symbiotis, Dermatodectes; ferner kommen vor:

Hämatopinus ventricosus, bräunlich, 2-4 $\mathrm{mm}$ lang.

Listrophorus gibbus, eine einmal gefundene (129) Hautmilbe.

Zufällig gelangen auf das Kaninchen Dermanyssus avium und Pediculus canis, welchem letzteren auch die an die Ilaare geklebten Eier angehören dïrften, die man mitunter tindet. Ferner scheinen zu den verirrten Milben zu gehören: eine Gamasus-Art, bräunlich, ca. $2 \mathrm{~mm}$ lang, die von der Schwalbe herstammen könnte; und eine sehr merkwürdige Milbe, die ich öfters und einmal in sehr großer Anzahl antraf, so daß der Pelz des Kaninchens wie mit Punkten bestiubt aussah. Daher könnte, wie ich denke, his auf weiteres diese Milbe Dermatokonis (i) xóvıs, Staub) genannt werden. Die hier folgende genauere Beschreibung verdanke ich der Güte meines Freundes Ehlers in Göttingen.

"Die Milben, welche zwischen und an den Haaren des Kaninchens lebten, sind mir nicht bekannt, und auch mit der mir zu Gebot stehenden Literatur nicht zu bestimmen. Von allen parasitischen Milben unserer Ilaussäugetiere unterscheiden sie sich durch die Bildung der Klauen und der Freßwerkzeuge. Es ist mir nicht unwahrscheinlich, daß es verirrte Parasiten sind, deren eigentlicher Wolınort die Haut kleiner Siugetiere (Miuse oder Fledermäuse) ist. In Folgendem die Beschreibung der Tiere, die ich vorläufig ohne Benennung lasse.

Körper farblos platt, 0,44 $\mathrm{mm}$ lang, 0,26 mm breit; größte Breite hinter dem zweiten Beinpaare, in der Mitte seicht eingeschnürt; Forderrand gerade abgestutzt, unter ihm ragen die Freßwerkzeuge weit hervor, Hinterrand mit tiefem Ausschnitte, aus dem der kurze kegelförmige After hervortritt. Rückenfläche vorn glatt, auf der hinteren Hälfte mit feinen, parallel von der einen zur anderen seite laufenden Furchen; Bauchflichen mit ebensolchen Furchen, welche um die Einlenkung des ersten und zweiten, sowie des dritten und vierten Beinpatares kon- 
zentrische Halbringe beschreiben und in der Medianlinie zusammenstoßen; ein mittleres field zwischen diesen Furchensystemen. und der mediane Teil der hinteren Körperhälfte mit queren Furchen; die Flankenteile dieses hinteren Körperabschnittes mit Furchen, welche bogenförmig von vorn mach hinten und parallel untereinander verlaufen, Fortsetzungen der Furchen der Rüickenfläche. - Auf der Rïckenflache 12 Borsten: die der ersten Reihe auf der breitesten Stelle des Körpers glatt und ghleich lang, die medialen nahe der Medianlinie, die lateralen gleichweit vom Rande wie von der Medianlinie entfernt. in der zweiten Reihe auf der Höhe des dritten Beimpaares ebenfalls \& gleich lange, die medianen glatt, die lateralen doppelt gefiedert, alle dem kande des Körpers näher, als die entsprechenden der ersten Reihe; weiterhin, nahe am Rande, eine kurze glatte und dahinter eine lange, doppelt gefiederte, deren Spitze bis zum After reicht; am Rande der Riickenseite stehen von den Ecken des Vorderrandes bis zur Itöhe des ersten Beinpares 3 kurze gefiederte Borsten, in der Höhe des zweiten Beinpaares 2 lingere grefiederte übereinander; kurz vor den hinteren licken eine obere sehr kurze glatte und eine untere glatte von etwa zwei Drittel der Körperlänge; auf dem ausgerundelen Ilinterrande stehen f kurze glatte Borsten, 2 nahe den Außenecken, 2 näher der Medianlinie. - Die Borsten der Bauchlläche sind alle kurz und glatt; 3 Paar mediane, von denen die des ersten Paares einander stårker genähert sind, als die der beiden hinteren; sie stehen auf der Höhe des ersten, zweiten und dritten Beinpaares: außerdem neben der Einlenkung jedes Beines eine Borste. Kleine Borsten decken den Afterkegel und stehen längs der spaltförmigen Öfuung. - Freßwerkzeuge weit vorragend: Kieferfühler groß mit zwei dicken Wurzelgliedern, deren jedes auf der Riickenfliche eine große gefiederte Borste trïgt, und einem großen, aus derbem Chitin bestehenden klauenförmigen Endgliede, welches lings der Schneide eine Reihe zahnförmiger Eindrïcke friigt, Palpen dreigliedrig, das Wurzelglied mit einer Reihe ovaler Eindrücke, das Endglied nadelartig spit $\iota$, schwach gekrümmt. Beine gleich lang, das erste und zweite Paar auf der vorderen, das dritte und vierte Paar von diesen getrennt auf der hinleren Hailfte des Körpers eingelenkt, fünfgliedrig; die einzelnen Glieder mit glatten und gefiederten Borsten besetzt, am zahlreichsten die

Fig. 67.

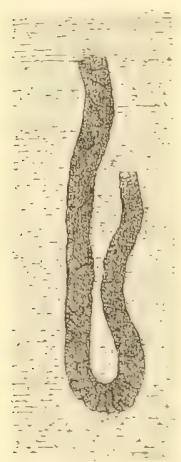

Schleifenförmiges Harnkanälchen der Nierenpyramide eines Kaninchens, mit Eiweißkörnchen und Fettröpchen infiltriert, am dritten Tage nach Überziehen der Haut mit Gummilösung. Mit Wasser. Vergr. 250. Nach Erythropel (140). beiden letzten Glieder, und vor der Endklaue mit einer lingeren glatten Borste; alle Beine und Klauen ohne Stelzen und Haftlappen, die Klaue groß, hakenförmig gekrümmt, an dem konkaven Rande mit einem Bart langer Haare

Favus. Der Favuspilz, Achorion Schoenleinii, wurde auf der Haut gesehen (519).

Überziehen der Haut mit einem luftdicht schließenden Firnis tötet das Kaninchen binnen 24 Stunden, wenn die ganze Haut überzogen ist; nach mehreren Tagen, sobald mindestens $1 / 8-1 / 6$ der Körperoberfläche mit Firnis überzogen sind. Konstante pathologische Veränderungen werden in der Magenschleimhaut, in den Nieren (s. Magen, Nieren) gefunden und der Harn enthält viel Eiweiß. Der Tod erfolgt durch Urämie.

Man hat die Todesursache allerdings meistens in Erkaltung der Tiere zufolge vermehrter Wärme-Ausstrahlung aus den erweiterten subkutanen Blutgefäßen gesucht $(157$ u. 699) und in der That tritt nach $1-3$

Min. langem Eintauchen warm gehaltener Tiere in Eiswasser Albuminurie auf (804). 
Indessen wird der Tod nicht durch Wärmezufuhr verhindert (158), selbst nicht,

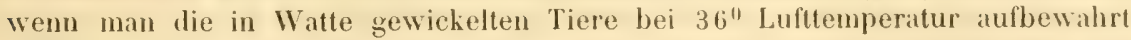
$(159)$. Im Unterhautbindegewebe finden sich schon zwei Stunden nach dem Tode zahlreiche Ammonium-Magnesiumphosphatkrystalle $(150 \mathrm{H.} 159)$, und in den Muskeln ist Harnstoff nachgewiesen (159). Man kann folglich wohl nicht daran zweifeln, daß jene Krystalle bei der Zersetzung von Harnstolf entstehen und daß die Tiere demnach urimisch zu Grunde gehen. Der Grund der Retention des Harnstoffes liegt in der Erkrankung (Fig. 67) der schleifenförmigen Nierenkanälchen, daraus folgt zunächst Verminderung der sezernierten Harnmenge, Albuminurie und dann Urïmie. Aus letzterer erklären sich gleichfalls die konstanten Ekchymosen der Magenschleimhaut. - Zieht man einem lebenden Kaninchen die Haut ab und näht es dann in dieselbe, so tritt nach mehreren Stunden Albuninurie. Nephritis und bald der Tod ein (857).

\section{Ohr.}

\section{Äulseres $0 \mathrm{hr}$.}

Knorpel des infseren Ohres. Die Ohrm schel ist sehr groß und lang; als ihre normale Stellung wird diejenige angesehen, wenn ihre Langsachse senkrecht auf dem Scheitel des Tieres steht. Unter diesen Imstanden ist die konkave, den Eingang zum Meatus auditorius enthaltende Flache lateralwiirts, die konvexe Fliche medianwirts gekehrt. In der oberen Hiilfte oder der Scapha ist die Ohrmuschel blattoormig, wenig konkav, fast ganz eben, der Knorpel papierduinn.

Ein Anthelix ist nicht vorhanden und die Scapha geht daher kontinuierlich in die Conch a iber. Letztere stellt eine flache Grube dar, welche lateralwairts konkav ist und die Mitte zwischen den Partes anterior und posterior helicis einnimmt.

Helix. Nur an der unteren IIalfte ist am vorderen und hinteren Rand der Ilelix vorhanden, dessen Pars anterior und posterior also nirgends zusammenhangen. Beide Teile des Helix sind medianwäts eingerollt, indem die Pars anterior sich zugleich rückwïrts, die posterior nach vorn umgebogen hat.

Die Pars posterior helicis ist halbröhrenförmig eingerollt, nach unten spitz zulaufend in den Meatus auditorius externus cartilagineus úbergehend. Nach unten liuft sie in die schwach spiralig gebogene, nach unten zugespitzte, 8-10 mm lange Spina helicis posterior aus.

Die Pars anterior helicis ist in noch ausgedehnterem Grade umgerollt als die Pars posterior; sie hilft eine blindsackförmige Grube, Fossa conchae, bilden, welche den tiefsten Teil der Concha darstellt und vom Meatus auditorius externus cartilagineus durch eine Ilautfalte von circa ist. Das untere Ende der Pars anterior lauft in die dreieckige Spina helicis anterior aus. Die Spitze des gleichschenkligen Dreiecks, welches die letztere bildet, ragt frei uach unten; die vordere Seite des letzteren hänt mit dem ebenfalls dreieckigen Scutulum zusammen.

Der Trayus hat die Gestalt einer Halbröhre mit vier IÏrnern. Diesellse 
liegt zwischen Pars anterior und posterior helicis, ist senkrecht gestellt, medianwïrts konkav.

Das Cormu superius anterius tragi ist eine lange Spitze, die sich an den hinteren Rand der Pars anterior helicis, demselben parallel, anlegt und das eigentliche Homologon vom Tragus des Menschen darstellt.

Das C'mmu superius posterius tragi legt sich in analoger Weise an den vorderen Rand der Pars posterior helicis und bildet zusammen mit dem oberen Teil der letzteren den Antitragus. Zwischen Tragus und Antitragus bleibt eine schlitzörmige Lücke: Incisura intertragica. Das Cormu inferins anterius tragi ragt zwischen der Spina helicis anterior und der Pars superior des Meatus anditorius externus cartilanineus abwirts und endigt frei. Das Corm inferius posterins ist das kürzeste und rerbindet sich an der Vereinigungsstelle der Pars posterior helicis mil der Pars superior des Meatus auditorius externus cartilagineus mit beiden.

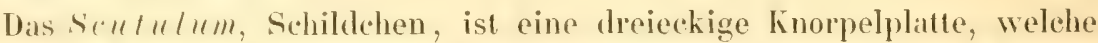
zwischen der oberflichlichen Spina helicis posterior und der Röhre des Meatus auditorius externus cartilagineus gelegen ist, sie stellt eine Verlangerung der Spina helicis anterior nach hinten dar. Die Form ist dreiseitig; die größere Seite liegt in sagittaler Richtung und medianwarts. Die untere Fliche liegt auf der Pars squamosa oss. oceipitis. Der großßte Winkel des etwa gleichschenklig rechtwinkligen Dreiecks, welches das Scutulum bildet, liegt lateralwirts gekehrt und die vordere Kithete hingt in ihrem lateralen Teile mit der Spina helicis anterior zusammen.

Uber das Wachstum des Ohrknorpels s. 765. - Angeborener Mangel eines :iußeren Ohres ist vererbt worden, so daß eine einohrige Kaninchenrasse gezüchtet wurde $(854)$.

Der Meatus auditorius externus cartilagineus bildet die Fortsetzung des Meatus auditorius externus osseus oss. temporum. Ersterer besteht hauptsächlich aus zwei knorpligeo Ringen, die zusammen als Tubus bezeichnet werden. Beide Ringe sind an ihrer hinteren Seite nicht geschlossen. Die Pars superior des Meatus auditorius externus cartilagineus sendet den hakenförmigen Processus uncinatus nach hinten, dessen Anfangsteil an seiner lateralen Seite von der Spina helicis posterior bedeckt wird.

Ligamente des iufseren Ohres. Zwischen den einzelnen Knorpeln des iußeren Ohres finden sich mehrere Ligamente ausgespannt.

Ligamenta anricularia ammularia. Das superius verbindet die Pars superior tubi mit dem Tragus und Helix, das inferius ist zwischen Pars superior und inferior tubi ausgespannt.

Ligumentum anriculare inferius rerbindet das Scutulum mit der Spina helicis anterior.

Ligamentum auriculare posterius zwischen Spina helicis posterior und Gornu inferius posterius tragi.

Ligamentum auriculare anterius verbindet das Cornu superius anterius tragi mit dem unteren Teil der Pars anterior helicis, so daß die trichterformige Gestalt der Auricula in der Gegend des Tragus entsteht. 


\section{Muskeln des äul’seren Ohres.}

Muskeln, die vom Kopfe zu dem Scutulum gehen.

II. intermedius scutulorum. Breiter, dimner, unpantrer Muskel, geht von dem vorderen Teile des medialen Randes des einen Scutulum zum entsprechenden Teile des anderen, ohne eine Zwischensehne zu haben.

M. frontoscutularis s. surcili-aurien. Ursprung: Hinterer Rand des Processus supraorbitalis posterior oss. frontis. Verliaft nach riickwiarts, rerbindet sich zum Teil mit den Fasern des M. scutulo-auricularis superior anticus. Insertion: Die andere Ilailfe seiner Fasern setzt sich an das vordere Ende des Sentulum.

M. cervicoscutularis. Ursprung: In der Medianlinie von dem sehnigen Ligamentum nuchae, mit einem zweiten Kopf ( $8 / 8$ ) von der lateralen vorderen Ecke der Pars squamosa oss. oceipitis. Verlauft schmaler werdend lateralwirts und nach vorn, liegt teilweise unter dem H. intermedius scutulorum, legt sich mit seinem hinteren Rande an den vorderen Rand des M. cervicoauricularis. Insertion: Medialer und hinterer Rand und hinterer Winkel des Scutulum.

Muskeln, die von dem Scutulum an den Ohrknorpel gehen.

M. scutulo-auricularis superior anticus. Ursprung: Vorderer Teil der oberen Flache des Scutulum. Nimmt Fasern des M. frontoscutularis auf. Insertion: Mit einer glanzenden Sehne an den vorderen Teil der lateralen Außenflache der Pars anterior helicis.

M. scutulo-auricularis superior posticus. Ursprung: Ilinterer Teil der oberen Flache des Scutulum. Iusertion: Laterale Außenfliche der Pars anterior helicis hinter dem M. scutulo-auricularis superior anticus.

M. scutulo-auricularis inferior. Ursprung: Mit seinem ersten $\mathbf{K o p}$ fe von der unteren Flache des Scutulum; mit seinem zwe iten Kopfe von der Spina helicis anterior. Insertion: Unterer Teil der lateralen Außenfläche der Pars anterior helicis.

Muskeln, die vom Kopfe zu dem Ohrknorpel gehen.

M. parotideo-auricularis anticus. Ursprung: Hingt mit dem M. platysma zusammen, beginnt in der Gegend des unteren Randes des Corpus und am Angulus maxillae inferioris. Liegt an der lateralen Fliche des M. masseter. Verläuft nach hinten und aufwärts. Insertion: Laterale Außenfliche der Pars anterior helicis.

M. parotideo-an ricularis posticus. Ursprung: Haut des Halses hinter dem hinteren Rande des Ramus maxillae inferioris. Insertion: Ilinter dem M. parotideo-auricularis anticus, auch an die Spina helicis posterior.

M. maxillo-auricularis. Ursprung: Hinterer Rand des Processus temporalis oss. zygomatici und laterale Fläche des Kiefergelenkes. Insertion: Mediale Flache der Par's anterior helicis. 
M. temporo-auricularis. Ursprung: Vertiefung des Os temporum vor dem Meatus auditorius externus osseus. Füll die Furche zwischen Pars anterior helicis und Tragus aus. Insertion: Laterale Außenfliche der Par's anterior helicis iuber der Spina helicis anterior.

11. cervico-auricularis. Ursprung: Ligamentum nuchae. Legt sich mit seinem vorderen Rande an den hinteren Rand des II. cervicoscutularis, sendet auch einige Fasern an den hinteren und lateralen Winkel des Scutulum. Insertion: Mit ausstrahlenden Fasern an die mittlere Partie der medialen Flache der Concha.

M. vertico-auricularis. Ursprung: Oberster Teil des Ligamentum nuchae. Insertion: Unter dem M. cervico-auricularis; sendet atuch einige Fasern an den hinteren Rand des Scutulum.

M. occipito-auricularis. Ersprung: Ligamentum nuchae, nimmt Fasern des M. frontoseutularis auf. Insertion: Bedeckt rom M. vertico-auricularis an die mediale Flache der Concha.

M. helico-occipitalis s. occipitotubularis $(1 / 4)$. Irsprung: Ligamentum nuchae. Insertion: Spina helicis posterior.

Muskeln, die zwischen den Teilen des Ohrknorpels sich befinden.

1I. transiersus auriculae. Erstreckt sich am hinteren Teile der medialen Flache der Scapha und Concha.

M. tragicus major. Ursprung: Spina helicis anterior. Insertion: Vorderer Teil der lateralen Flache des Tragus und der lateralen Außenfliche der Pars posterior helicis.

M. tragicus minor. Irsprung: Lnterer Teil der lateralen Außenflaiche der Pars anterior helicis. Länglicher, schwacher Muskel mit horizontalem Faserverlauf. Insertion: Interste Partie der lateralen AuBenflache des Tragus.

M. tragicus minimus. Liegt in der Furche zwischen Tragus und Pars posterior helicis.

M. helicis superior. Liegt in der Furche zwischen Tragus und Pars anterior helicis. Irsprung: Ilintere AuBenflache der Pars anterior helicis. Insertion: Medialer Raud der medianwirts umgebogenen Pars anterior helicis.

M. helicis inferior. Ursprung: Spina helicis anterior. Insertion: Unterhalb des M. helicis superior.

\section{Wirkungen der Muskeln des äufseren Ohres.}

Simtliche Muskeln werden vom M. facialis versorgt und wirken wohl niemals isolirt. Die Mm. transversus auriculae, tragici major, minor und minimus, sowie die Mm. helicis superior und inferior erweitern das Ohr. Die Mm. scutulo-auriculares superiores anticus, posticus und sentulo-auricularis inferior stellen das Ohr auf dem Scutulum fest beim Aufrichten desselben. Die $\mathbf{1} \mathrm{m}$. intermedius scutulorum, frontoseutulares, maxillo-auriculares und temporo-auriculares richten die in sich festgestellten Ohren auf, wenden deren laterale Flichen nach vorn, sspitzen" die Ohren. Die Mm. cervicoseutularis, cervico-auricularis, vertico-auricularis, oceipito-auricularis und helico-occipitalis ziehen das Ohr ruckwirts : letzlererwendet die rorwarts gerichtete laterale 
Flache wieder lateralwirts. Die Mm. parotideo-auriculares anticus und posticus ziehen das Ohr herab. Wahrscheinlich bedingt gleichzeitige Kontraktion aller Muskeln das Spitzen der Ohren und Erweiterung der Concha; beim Nachlassen der Kontraktion sinken sie in ihre gewöhnliche Ruhelage.

Vergl. über die Ohrmuskeln 67,148 , 151; über Infiltration des Perichondrium mittels Injektion von Natriumindigsulphat 608.

Pathologische Anatomie des iiußeren Ohres. Es kommen aus traumatischer Veranlassung entstandene Othämatome (Fig. 68) vor, wobei der völlig gesunde Knorpel sekundär durch Narbenkontraktion Einschrumpfungen und Verbiegungen erleidet (1.49 u. 151). Durch Impfung von Rotzgift erzeugte brandige Zerstörung des äußeren Ohres ist abgebildet worden (155).

Parasiten des äußeren Ohres. Otitis externa entsteht seltener durch Symbiotis cuniculi s. Dermatophagus, häufiger durch Dermatodectes cuniculi s.

Fig. 68 .

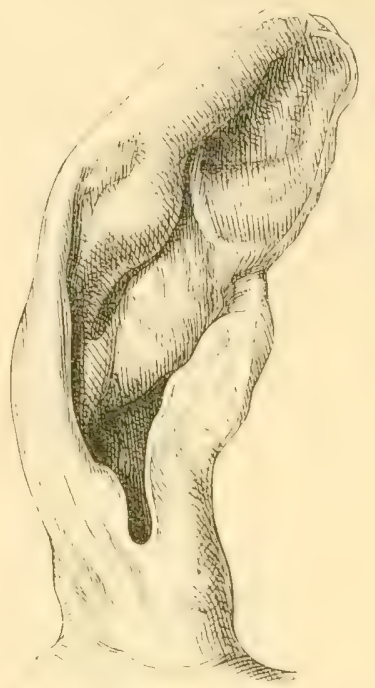

Linkes Ohr mit Othämatom. Nach Haase (149).

Dermatokoptes. Im Meatus auditorius esternus bilden sich dicke Schmalzpfröpfe, welche lebende Milben enthalten. Die Dimensionen sind folgende 132 in $1 \mathrm{~mm}$ :

\begin{tabular}{|c|c|c|c|c|}
\hline \multirow{2}{*}{ Genus } & \multicolumn{2}{|c|}{ Männchen } & \multicolumn{2}{|c|}{ Weibchen } \\
\hline & Länge & Breite & Länge & Breite \\
\hline Symbiolis & $0,31-0,34$ & $0,26-0,2 \mathrm{~s}$ & $0,40-0,43$ & $0,27-0,30$ \\
\hline Dermatodectes & $0,69-0,72$ & $0,44-0,52$ & $0,78-0,81$ & $0,45-0,57$ \\
\hline
\end{tabular}

Einmal wurden Larven von Musca vomitoria im iußeren Gehörgange beobachtet $(152)$.

Blutlauf im äuBeren $\mathrm{Ohr}$. Um die Zirkulationsveränderungen im außeren Ohre, z. B. Mach Durchschneidung des N. sympathicus derselben Seite am Halse bequemer wahrnehmen zu können, ist das Calciumsulphhydrat als zweckmäßiges Enthatrungsmittel empfohlen worden (1;\%. $)$. Man bestreicht mit der wisserigen Mischung das Ohr auf beiden Seiten und entfernt nach 10-15 Minuten die trocken gewordene Mischung samt den Haaren mit einem Messerrücken. - Über Gefrierenlassen der Ohren vergl. 7 70.

Direkter Ubergang von kleinen Arterien in kleine Venen ist beschrieben worden $(15 \tilde{5})$; da die Injektionen jedoch mit undurchsichtigen Massen Zinnober) vorgenommen wurden, so sind Täuschungen nicht ausgeschlossen. Vergl. S. 64.

\section{Mittleres $\mathrm{Ohr}$.}

Tymp $n \|$ $\|$. Die Paukenhöhle ist relativ groß, rund, sich nach hinteu rerschmalernd, und wird hauplsichlich von der basenahnlichen Bulla lym- 
prani (rig.s. 69 Bt, gebildet, welche auf der unteren Flaiche der Pars tympaniea oss. lemporum hervorspringt. Die Bulla tympani wird an ihrer medialen Wand von der Pars petromastoidea zum Carmm lympani geschlossen.

Die olsere Wand des Cavum tympani enthiilt eine kleine Nebenhöhte,

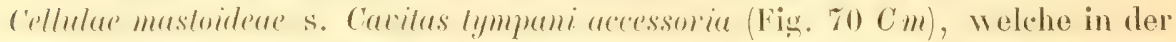
Pars petromastoidea, zwischen der lossa mastoidea oss. temporum und dem Meatus anditorius externus osseus eingebeltef liegl. Die mediale Wand des fetzleren versehliefot die Cartas lympani areessoria an ihrer lateralen Seite; ihre Gestaht ist langlich oral; die Längsachse liegt anmahernd sagittal: die mediale Wand besitzt Leisten und Gruben.

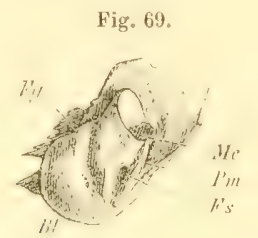

Pars petromastoidea und tympanica des linken 0 s temporum, vou der lateralen Seite. Me Meatus auditorius externus, $p m$ Processus mastoideus. $F^{\prime} s$ Foramen sty lomastoideum. Bt Bulla tympani Fg Fissura Glaseri.

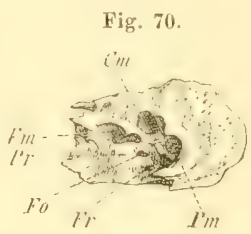

Pars petromastoidea des linken Ostemporum, von unten. Cm Cellulae mastoideae. $F m$ Fossa muscularis major. $P r$ Promontorium. $F o$ Fenestra ovalis. $F^{r}$ Fenestra rotunda. $P_{m}$ Processus mastoideus, in optischer Verkürzang.

Die mediale Wand zeigh das stark vorspringende Promontorium (Fig. Fo

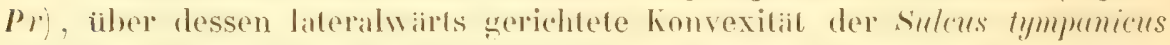
verliuft. Dieser Sulcus begimnt in der Fossula petrosa mit einem feinen Ioche, welches an der hinteren Fliche der l'ars petrosil oss. temporum, dieht neben der Grenze der Pars tympanica und petromastoidea, ziemlich in der Mille derselben und ungefihr in gleicher Entfernumg von der Apertura aquaeductus rochleae (S. 183 und der Wurzel des Processus mastoideus sich zoigt. Diese drei Objekte liegen annihernd in einer Jlorizontalebene. Der Sulcus tympanicus liuft unter der fenestrat rotunda ziemlich horizontal nach vorn, biegt sich vor der Fenestra ovalis nath oben, geht zwischen der letzteren und hinter der Cupula cochleae in die fossa musenlaris major s. unten) und mindet am oberen Ramde derselben auf der $A$ unenseite der Pars petrosa. Das Promontorium zeigt an seinem hinteren Abhange die rundliche Fenestra orulis s. vestibuli Fig. \%0 Fo), unter derselben und mehr nach hinten die kleinere, nach hinten grekehrte, lingliche. Ion Beinhaut verschlossene Fenestio motuda s. cochleae (Fig. $70 \mathrm{Fr}$ ) und iiber beiden den teilweise offenen Canalis facialis s. Falloppiac, der innerlall, des Knochens, weiter nach vorn ein Knie, das Gem canalis facialis bildet. Dasselbe kommunizient durch eine feine Öfnung mit der vorderen Flache der l'ars petrosa oss. temporum und on da steigt der feine Sulcus petrosus anterion über die vordere Fliche der Bulla tympani herab. Unter dem Genu canalis facialis, narh vorn und aufwirts vom Promontorium und von der Fenestra ovalis liegt an der medialen Wand des Carum tympani die tiefe, ovale, mit ihrer I iingsachse sagital und abwarts grerichtete rossa muscularis major lympani (Fig. $70 \mathrm{Fm}$. Diesclbe geht an ihrem vorderen Ende nach unten in einc al)wirts und lateralwirts gerichtele Spalte, Fissura muscularis tympani iiber, 
welche ziemlich gleichmiBig von der Pars tympanica und petromastoidea oss. temporum gehildet wird. Sie ist so ang, daß sie nach der Trennumg beider Teile nur als flacher Sulcus anf der medialen Flache der medialen Wind der Bulla tympani erscheint. Ilinter dem Promontorium, hinter der Fenestra ovalis und oberhalb der fenestra rotumbar zeigt sich die kleine Fussu muscularis minor tympani für den M. stapedius.

Dite vordere Wand geht in den kurzen Camalis fubarius iiber; merlianwairts von demselben mimdet der Gamalis caroticus. Der Camalis Lubarius wird größtenteils, mit Ausnahme seiner medialen Wand, fon der Pars I ympamica gebildet; der Canalis caroticus liegt elenfalls in letzterer ligy. 7 l (c) und mur das Foramen caroticum internum hauplsachlich inder Pars petromastoidra. Von vorn her betrachtet, findet sich an der vorderen Parlie des Os tempormu iiber dem Processus tympanicus am weitesten medianwairts das Foramen carofieum internum; dicht neben demselben lateralwirts und nur durch eine ganz dimne, vertikale Scheidewand gesondert die vordere Mindung des Canalis tubarius; in etwas großerer Entfernung oherhall, des letzteren die Fissura muscularis tympani. Dicht über dem oberen Rande der Fissura muscularis liegt eine punktformige offnumg, durch welehe der suleus tympanicus an der Vorderfliche der Pars petrosia oss. temporum zwischen Pars tympamica und pefromastoidea dicht oberhalb der Fissura muscularis die Paukenhible verißißt.

Die laterale Wand des Cavum tympani enthält das ovale, ziemlich senkrecht stehende, ein wenig nach vorn gerichtete, medianwärts konkave Trommelfell, oder Membrana tympani. Letztere ist in dem regelmaßig oval geformten, oben nicht geschlossenen Annulus tympani (Fig. 7/ At) ausgespannt, welcher den unteren Rand eines halbmondförmigen, nach unten konvexen Wulstes bildet. Am frischen Priparat zeigt der Annulus tympani mit dem beschriebenen, durch die dinne Membrana tympani durchschimmernden Wulst, von der medialen Seite

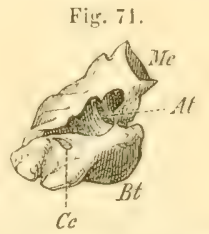

Pars tympanica des rechten 0 s trmporim, von cler merlialensterte. Me Meatus anditorius externus. At Annulus tympani৮us. Bt linlli tympani. her betrachtet, eine frappante Ähnlichkeit mit einem IIufeisen, dessen konvexer Rand nach unten werichtet ist. Die oberen freien Euden des Anuulus tympani springen etwas zugespitzt gegeneinander hervor. Oberhalb) derselben hefindet sich dann wieder eine merkliche Ausschweifung nach vorn und hinten, wodurch an der medialen Wand des Meatus auditorius externus osseus eine zweite ovale Oflnmmg gebilded wird, welche durch die erwahnten vorspringenden Enden des Annulus tympani ron dem Lumen des letzteren abgegrenzt wird. Nach oben sefzt sich die beschriebene Ausschweifung bei jüngeren Tieren in eine spaiter durch Verknöcherung geschlossene, vertikale Fissur des Meatus auditorius externus osseus fort. Diese ovale Öfuung in der Pars tympanica korrespondiert mit der Gavitas Iympani accessoria in der Pars petromastodea; sie wirl von der Schleimhaut der Catvitas tympani accessoria und von dem durch eine Fortsetzung der Beinhaut an letatere Schleimhaut gehefteten inneren Uberzug des Iloatus auditorius externus osseus verschlossen. In der Membrana tympani befindet sich eine Knorpelplatte $(156)$. 


\section{Ossicula anditus.}

Die Gehörknöchelchen stellen die Verbindung zwischen dem Trommelfell und der Fenestra ovalis her.

Der Malleus hat ein dickes, mit einer sattelfümigen Gelenkflache versehenes Capitulum, ein dünnes, rundliches Collum, ein sibelfiurmiges Mamubrium. Die Rauder der lateralen Fläche des letateren sind hedeutend hervorspringend, wähend die schneide der Sabelklinge medianwirts sieht; am oberen Ende des Manubrium sitzt der medianwiirts gerichtete Processus muscularis, an welchem sich der M. mallei inseriert. Der Processus longus liegt im oberen Rande des Trommelfelles; der Processus brevis ist abgerundet.

Der Incus zeigt auf der vorderen Flache des Kiorpers eine saftelförmige Gelenkfliche für den Malleus. Das Crus longum ist zugespitzl und mit einer Rinne versehen, das Crus breve kurz und stumpf. Das Os lenticulare liegt schrig und stellt eine Apophyse des Grus longum dar.

Der stupes ist fast gleichschenklig dreieckig, mit hervorragenden Riudern; das C'apitulum artikuliert mit dem Os lenticulare und sitzt auf einem kurzen Collum; die Cruru sind geradlinigy, das posterius ein wenig dicker als das anterius; die Basis blasenartig aufgetrieben und mehr rundlich, man kamn daher den Stapes auch glockenförmig nennen.

\section{Muskeln des mittleren Ohres.}

Sie sind verhältnismäßig stark; nur zwei existieren.

11. mallei ist ca. $8 \mathrm{~mm}$ lang. Ursprung: Von der unteren Flache der Ala magna oss. sphenoidei an der lateralen seite des N. maxillaris inferior vor dessen Austrittsstelle aus dem Foramen lacerum. Der sehnige Ursprung geht durch eine Spalte, die Fissura muscularis tympani, zwischen Pars tympanica und petromastoidea oss. temporum, in relatis großer Entfernung von der 'Tuba Eustarhii. Der Muskel liegt in der Fossa museularis major tympani, wird von der Schleimhaut bedeckt, so daß die Innenfliche der Bulla tympani glatt. ausgefült erscheint, so lange die Weichteile erhalten sind, und lauft lateralwarts und nach vorn. Insertion: Mit einer kurzen, festen Sehne an den Processus muscularis mallei.

M. stapedius ist $2 \mathrm{~mm}$ lang. Ursprung: Fossa muscularis minor hinter der Fenestra ovalis, oberhalb der Fenestra rotunda. Der Muskel liegt ziemlich horizontal, seine diunne Sehne verlituft nach vorn. Insertion: Collum stapedis.

Tuba Eustachi verliuft anfangs in der Pars tympanica oss. temporum im Canalis tubarius, unterhall, des $\mathrm{I}$. mallei, geht in eine ca. 1 cm lange,

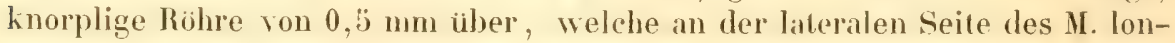
gus colli verlauft und iu den Pharynx mundet. Die Knorpelrohre ist nicht geschlossen; der Knorpel zeigt nämlich auf dem Querschnitt die Figur eines Halbmondes; seine Zellen sind fettreich.

Parasiten des mittleren Ohres. Die Gregarinose oder Psorospermienkrankheit (S. 23) erstreckt sich von der Nasenschleimbat auf die Schleimhant der Tuba Eustachii, der Paukeuhöhle, auch auf den iußeren Gehörgang nach Perfo- 
ration des Trommelfelles. Zuweilen pflanzt sich die Entzündung auf das Labyrinth und die Dura mater des Gehirnes fort $(152)$.

Der Unterschied zwischen Sicherheitsröhre und Ilülfsspalte ist deutlich (vergl. 57, S. 122).

\section{Inneres $0 \mathrm{hr}$.}

Das innere Ohr oder das La by yin th hesteht aus dem Vestibulum nebst den drei Canales semicirculares und aus der Cochlea.

l'estibulum. Dasselbe stellt eine in der Pars petromastoidea oss. temporum eingeschlossene Ilöhle von unregelmaßig wirfolförmiger Geslalt dar. Durch eine von der medialen Wand ausgehende Leiste zerfillt dasselbe in einen Recessus sphaericus und ellipticus. Die laterale Wand kommuniziert dureh die Fenestra ovalis mit dem Gavum tympani.

Die Canales semicirculares werden als superior, posterior und lateralis unterschieden. Diese Bezeichnungen sind von der Richtung hergenommen, welche die jeden Ilalhkreis halhierenden Radien anzeigen, und es sind mithin die konvexen Rinder der Canales semicireulares nach oben, hinten und lateralwarts gerichtet. Ihre Ehenen sind nach den drei lioordinaten des Rammes orientiert und schließen miteinauder höperliche, rechte Winkel ein, was aber beides nur annihernd der Fall ist. Die Ebene des Ilalbkreises steht beim Cianalis semicircularis superior vertikal und frontal, mil dem lateralen Teile elwas nach vorn gerichtet. Die Ehene des Canalis lateralis liegt horizontal, etwas nach unten abweichend; diejenigen des posterior vertikal und sagittal. Der Camalis posterior wird ron der Ehene des Canalis bateralis ammihernd so halbiert, daß der obere $A$ bsehnitl des ersteren um elwas grober wird, als der mntere. Jas obere Ende des Camalis posterior mïndet mit dem medialen des Camalis superior zusammen in das Vestibulum; die iibrigen Mundungen sind getremmt. Die Camales semiciroulares hahen regelmaßige, kreisformige Bietrung und zylindrische Form; ihre Dicke ist im Verhaltnis zur Litnge geringer als heim Mensehen. Die Impullen sind im Verhaltuis zur Dicke des übrigen Teiles der Bogengänge im Vergleich zum Menschen stärker.

Das Verhältnis ist wie $4: 1(157)$. An den häutigen Säcken des Vestibulum finden sich sternförmige Pigmentzellen und im Innern Otolithen.

Eröffnung des Vestibulum $(158)$. Die Fossa mastoidea wird aufgebrochen, der Flocculus cerebelli soll in die Schiidelhöhle geschoben werden (was natürlich nicht ohne Zerstörung desselben abgeht, W. Krause), der Boden der Fossa mastoidea wird lings dessen medialem Rande angehohrt und dabei zugleich das Vestibulum eröffnet. Nun kann man mittels einer feinen Glasröhre die Perilymphe aufsaugen, durch eine Kitutschukröhre, die mit ersterer verbunden ist, abwechselnd Luft einblasen, was $5-10$ mal wiederholt zu werden vermag. Sogleich entstehen Augenbewegungen, nämlich bilateraler Nystagmus, ferner Ilin- und Herpendeln des ganzen Kopfes; beide Erscheinungen sollen auch bei mechanischer Reizung des häutigen Labyrinthes cintreten. Man kann auch die Sacculi und bäutigen Ampullen herausziehen oder durch reine konzentrierte Salpetersäure zerstören.

Verletzung der Canales semicirculares. (Flourens, Bornhardt s. 41, S. 546.) Bei jungen Tieren wird ein Hautschnitt in der Mitte zwischen dem hinteren Rande des Unterkieferastes und dem vorderen Rande des Meatus auditorius externus ge- 
führt, Muskeln und Venen geschont. Die Pars tympanica oss. temporum wird freigelegt und aufgebrochen, der Canalis semicircularis lateralis liegt in gleicher Höhe mit dem Meatus auditorius externus ossens, der Canalis semicircularis posterior wird an der hinteren Wand der llöhlung aufgesucht, der superior ist ohne Gehirnverletzung kaum zu erreichen.

Verletzung oder Zerbrechen der Bogengäinge bewirkt intensiven Nyslagmus, ferner Rotationen um die Lïngsachse nach der verletzten Seite hin; im Anfange natch der Operation auch Störungen im Sitzen und Laufen $(160)$. Esstere Lischeinumgen werden ebenfalls durch Druckisteigerming in der Paukenhöhle hervorgerufen, wenn eingespritzte Fliissigkeiten durch die Fenestra rotunda in das Labyrinth und durch den Aquaeductus vestibuli in den subduralen Raum grelangt sind (1:39). Ferner entstehen jene Lrseheinungen durch Verletzung eines N. acusticus; die Zerstiorung des in der Fossil mastoidea gelegenen Floceulus cerebelli ist dabei irrelevant $(158)$. - Bei der Verletzung des N. acusticus werden auch die Crura cerebelli ad medullam oblongiltam in Mitleidenschaft gezogen und jedenfills durch Auslließen vou Blut und Cerebrospinaltliissigheit (s. jedoch letztere) Nebenwirhungen in Gimg gesetz, die eine sichere Beurteilumg der funhtion der Bogengïnge ausschließen. Indererseits fos hat man die Erscheinungen atuf Gehörschwindel, Vertigo auricularis, zuriekgefïhrt, der auf einem Reflex von den Vestibularenden des N. acusticus auf die Augenmuskelnerven beruhen soll. Die kolossalen Nebenropletzungen, welche das Einblisen von Luft nach der oben angegebenen Methode in der Nachbarschaft der Nedulla oblongata ete. unvermeidlich hervorbringt, machen imch diese Annahme zum mindesten sehr unsicher, und die sleichzeitigen muvermeidlichen Hirnlisionen scheinen vielmehr das Wesentliche zu sein (159). Da für die außer den Kaninchen zu diesen Experimenten benutzten Tauben dieselben anatomischen Vorbedingungen wiederkehren, so kann man hiernach die meistens angenommene funktion der Bogengänge als eines Organes für den Raum-

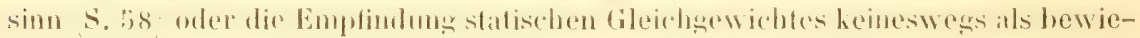
sen ansehen. Sicher ist nur, daß Tiere, die eine Cochlea oder Lagena haben, nach Zerstörung der Bogengäinge noch hören können $(158)$. - Vergl. auch 160 .

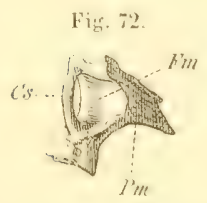

Pars petromastoidea des linken Os temporum nach $\Lambda$ btragung des Knochens bis auf die Halbierungsehene dier Fossa mastoidea. Von der lateralen seile. Fim Fossa mastoidea. CS C'analiculus semicircularis superior osseus, den Eingang in die Fossi mastoidea ïberbrückend; dieser Lingang erseheint in sehriger Prufilansicht. Pm Processus mastoideus.

Ohne weitere Präparation als Eröflnung der Fossa mastoidea oss. temportum von hinten lißı sich der Verlauf der drei Canales semicireulares in der Pars petromastoidea sehr deutlich erkennen. Der Canalis semicireularis superior umgiebt bogenförmig (Fig. 72 Cs) den oberen, medialen und lateralen Rand des Einganges der Fossa mastoidea. Sein mediales Ende miindet oberhalb und etwas nach hinten vom Meatus anditorius internus mit dem vorderen Ende des Canalis semicircularis posterior zusammen. Der obere Teil des Canalis posterior erscheint hervorspringend an der lateralen Oberfliche der medialen Wand der Fossa mastoidea. Eine in der libene des Camalis lateralis golegene horizontale Knochenplatte bildet den Borlen der Fossia mastuideat. Del laterale Teil desselben ist an der medialen Wand dep Civitas Iympani arecessoria, oberhally des II. stapedius und mit seinem vorderen Ende an den Canalis facialis grenzend ohne Praparation sichlbar.

Cochlea. Sie liegt vor dem Vestibulum und vor der Fenestra ovalis, 
innerhalb des Promontorium und ihre Cupula annihernd in gleicher Ilorizontalebene gerade nach vorn von der letzteren.

Die Cochlea hat 21/2 IViudungen; das laterale Ende ihrer Achse ist ein wenig abwirts geneigt; die scalit tympani ist in der ersten balben Windung gerimmiger als die Scala restibuli. Der Canalis spiralis liegt in der IVurzel der Lamina spiralis; sein Querschnitt ist eiformig; der spitzere Teil ist gegen die Peripherie der Cochlea gerichtet. (Vergl. I6I.)

Die außeren Haarzellen im Neuro-Epithel des Ductus cochlearis enthalten nach Hensen (vergl. 57, S. 133) einen Spiralkörper. - Über die Nervenendigung vergl. 777; über den mikroskopischen Bau des Ductus cochlearis und seines Epithels vergl. 855 .

Aquaeductus cochleae und vestibuli. Ersterer ist relativ weit und kur\%, entspringt aus der Scala tympani hinter der Fenestrat rotunda; seine iußere Öflnung, Apertura aquachuctus cochleae, liegt innerhalb des hinteren Teiles der Schiidelhöhle dicht oberhalh des Foramen jugulare. Der Aquaeductus restibuli ist verhialtnismaßBg lamg und eng; er entspringer aus dem Vestibulum, nahe der Stelle, wo die Canales semicireulares superior und posterior zusammen cinminden; er begleitet das mit dem oberen vorderen bude des Canalis semicircularis posterior vereinigte mediale Ende des Canalis semicircularis superior; seine iubere öflnumg, Apertura aquaeductus restibuli, befindet sich medianwirts neben der Mitte des medialen Randes des Einganges der Fossa mastoidea, nach hinten und oben vom Meatus auditorius internus, und stellt eine enge, trichterförmige Spalte dar.

Aus den Aperturae der Aquacductus treten kleine Venen des inneren Ohres aus; die des Aquaeductus vestibuli mündet in den Sinus transversus; diejenige des Aquacductus cochleate in dis untere Ende des genannten sinus s. Angiologiej.

\section{Auge.}

\section{Orbita.}

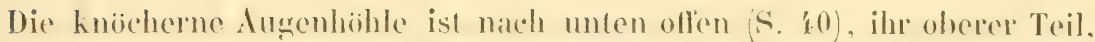
dis aigentlehe Orbita, wirl ron dem unteren Teil dureh cine ziemlich hori-

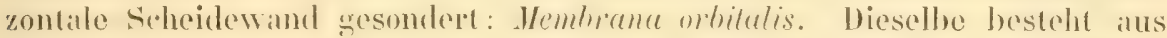
Bindegewehe mit zahlecichen chastischen Fasern und Bändeln on gylatten Mushelfasern. Dureh das Vorhandensein dieser Membran w ird ein Hohlranm gebildet, worin sich der Bulbus bewegt. Ierselhe hat am mihermal die Form einer vierseitigen Hohlpramide. Die Basis dieser Pyramide ist lateralwairts gerichtet und im Nittelpunkt der Basis liegt das Zentrum der Cornear. Die Spitze oder der Grund der Augenhouhte liegt medianwirts; die greschlossenen Seiten der Pyramiden sind nach oben, unten, hinten und vorngerichtel. Tie mediale Wand der Augenhöhle des Menschen ist also die vordere beim Kaninchen, dio laterale des Menschen die hintere. Die vordere Wand ist nicht frontal gestellt, sondern steht rertikal, schrigg lateralwirts umd nach vorng gerichtet. Die obere Wand ist etwas konkav. Die untere Wand wird lateralwarts vom Areus zygomaticus, im ubbrigen von der Membrama orbitalis gebildet; an der 
Begrenzung der hinteren Wand beteiligen sich lateralwarts das Lig. orbitale und der Processus zygomaticus oss, temporum.

Interhalb der Membrama orbitalis liegen vorn der Processus alveolaris oss. maxillaris superioris und die Gl. infrabothalis, hinten die Mm. pterygoideus externus und temporalis, lateralwirts der M. pterygoideus internus; medianwirts verlauft der N. maxillaris superior von hinten nach vorn. Die genannten Teile nebst dem Ramus maxillae inferioris sind es hauptsächlich, welche die untere, nach unten offene Parlie der Augenhöhle: das Cacum orbitale (S. 40) ausfüllen.

\section{Augenlider.}

Die Pulpebrae superior und inferior sind am freien Rande pigmentiert und tratgen eine Reihe von steifen Borsten aler Cilien. Sie enthalten kein Knorpelgewehe, werdon durch sehwache Ligamenta palpebratia nasale und temporale verhunden und zeigen eine einfache Reihe von kurzen Meibom'schen Drïsen. Die Palpelora inferior besitzt in der Mille ihrer Schleimhant eine längliche, horizontal gestellte, flache brhabenheit, welche aus ea. 7-8 dichlgedringten Lymphifollitieln besteht. - Die Palpebra terlia ist homolog der Plica semilunaris conjunctiva des Menschen, der Membrana nictitans der Viagel. Sie wird vou einer scheibenfirmigen, uach vorn konvexen, nach hinten konkaven, am nasaIen Augenwinkel befindlichen knorpelplatle gebildet, welche auf heiden seiten mit Sohleimbant aborzogen ist. Sie seheint nach gleichem Radius wie der

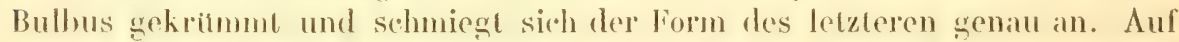
dem vorderen pigmentierten Raude sitzt eine Reihe von Papillen. - Im nasalen Augenwinkel befindet sich die Curuncula lacrymalis. Sie ist 6 mm lang, $2 \mathrm{~mm}$ breit $(167)$, mithin kleiner als beim Menschen.

M. depressor palpebrae inferioris. Schwacher kleiner Muskel; entspringt von der Außenfliche des Processus zygomatici oss. maxillaris superioris, verliult, rom II. orbicularis palpebrarum hedecht, schrigg nath hinten aufsteigend, zur Schleimhant des unferen Augenlides am nasalen Winkel, welehen er herabzieht und den Thrainenahthß befordert. (Von llilgendorf entdeckt, s/s.)

Die Knorpelzellen der Palpebra tertia enthalten viel Fett. - Am oberen Augenlide sind 46, am unteren 40 Meibom'sche Drisen vorhanden (162). - Die Lymphfollitel der Palpebra inferior sind nach Einlegen des Augenlides in Essig leicht mit bloßem Auge zu sehen. Sie sind konstant, bilden eine Gruppe, den Bruchschen Haufen, die einem Peyer'schen Ilaufen des Ioünndarmes analog ist, und hahen durchaus nichts mit der lachomatösen Augenentzündung zu schatlen, was Einige annehmen zu können glaubten (vergl. 165 und 164).

\section{Thränenwege.}

Es ist nur ein einziger Canaliculus lacrymalis (inferior) vorhanden (ebenso

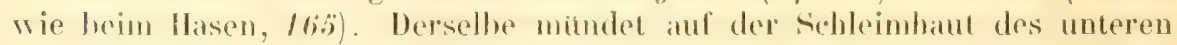
Algenlides, 3-- mom vom freien Rande des fetzteren entfernt, nahe dem nasilen Jugenwinkel, am unteren Ende der Carmoula lareryalis, mil einem Punctum lacrymule. Das letzlere ist leicht sichthar, hat einen wulstigen Rand, 
welcher Knorpelzellen enthilt. Der Canaliculus lacrymalis lauft in horizontaler Richtung nach vorn, stellt eine dreiseitige Iohlpyramide dar. Die obere W and ist schmaler als die nasale und temporale: die Spitze der Pyramide liegt im Punctum lacrymale; die Länge betright $\mathrm{ca} .1 \mathrm{~cm}$, das Lumen $3-3,5 \mathrm{~mm}$ (167), in der Nihe des Punctum lacrymale jedoch nur 0,2 mm. Der Canaliculus lacrymalis geht nach rorn, ohne daß ein bestimmt abgegrenzter Saccus lacrymalis vorhanden wäre, in den Ductus nasolacrymalis über. Letzterer ist 3 - $4 \mathrm{~cm}$ lang, verläuft mehr horizontal nach vorn und abwärts, anfangs dem knöchernen Canalis nasolacrymalis folgend, dann an der lateralen Seite der medialen Wand einer vom Nasenknorpel gebildeten Tasche (S. 193), gelangt vor der vorderen Nasenmuschel naher an die Oberfliche der Schleimhaut und mündet spaltförmig vor der Concha anterior [bei naturlicher Kopfhaltung des Kaninchens (Fig. 1, S. 8) unter (Erste Aufl. S. 127 - vergl. 167) derselben]

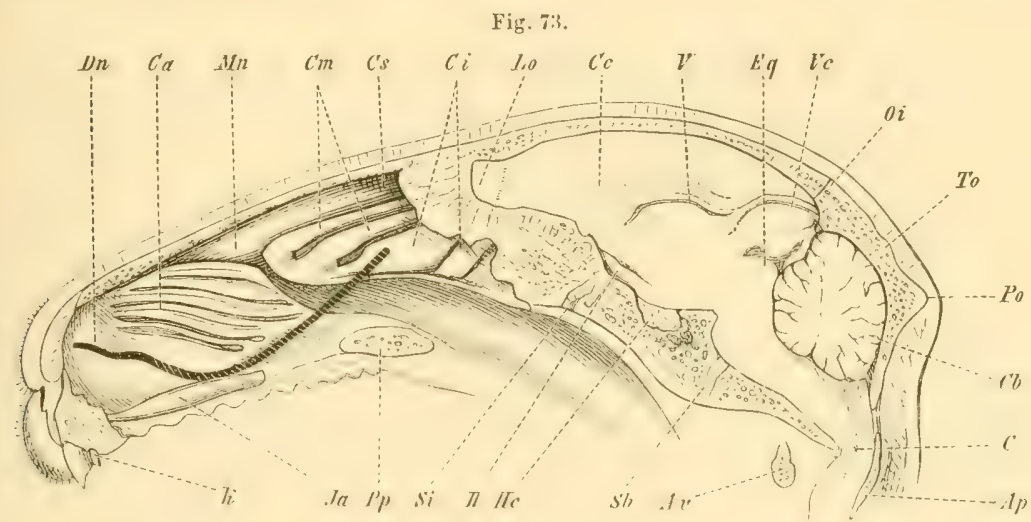

Medianschnitt eines gefrorenen Kopfes. Dn Duetus nasolacrynalis mit Berlinerblau injiziert, sehraftiert soweit derselhe vou Knochen, dunkel soweit derselbe von Schleimhau bedeckt ist (nach 16i). Ca Coneha anterior In Marsupium nasale. Cm Concha (posterior) media. Cs Concha (posterior) superior. Ci Concha (posterior) inferior. Lo Lobus olfactorius. Cc Corpus callosum. V Höhle des dritten Ventrikels. Eq Eininentia quadrigemina. Ve Vena cerebri magna. Oi Vordere Grenzo des Os interparietale. To Tubereulum oceipitale. Po protuberantia occipitalis externa. $C b$ Vermis cerebelli, $C$ Zentralkanal des Ruckenmarkes. Ap Hinterer Teil des Atlas. Av Vorderer Teil des Atlas. Sb Synchondrosis sphenobasilaris. HC Hypophysis cerebri. II N. opticus. Si Synchondrosis intersphenoidalis. Pp Processus palatinus oss. maxillaris superioris. Ja Jacobson'sches Organ, von der Pars medialis des Ramus palatinus oss. intermaxillaris umsehlossen. $k$ Kleiner Schneidezahn.

nahe der torderen Nasenöfrnung. Sein Durchmesser betrigt betriggl $2-3 \mathrm{~mm}$ : in demselben findel sich hiufig $(166)$ an der Miindung des Canaliculus lacry malis eine halbmondformige Klappe (16\%), Vultulu lacrymalis. In hinteren Teile ist der Ductus nasolacrymalis ron knörhernen Wanden, die von dem Semicanalis lacrymalis des Corpus oss. maxillaris superioris gebildet werden, in der Linge ron etwa 2 em umschlossen; der vordere Teil ist memhranos und kann in fransversaler Richtung so komprimiert werden, daß die Schloimhantflachen atufeinander liegen. Derselhe beginnt unterhalb der boderen Muschel und verliuft gebogen nach oben und vorn (Fig. 73).

II. zygomaticolacrymalis. Ein $5 \mathrm{~mm}$ breites, aber dünnes Muskelbïndel entspringt vom vorderen Ende des oberen bateralen Raudes des Os zygomaticum und verläuft zur Wand des Camaliculus lacrymalis, sowie zum Lig. palpebrale nasale $(167)$. 
In den Anfang des Canaliculus lacrymalis setzt sich das $0,017 \mathrm{~mm}$ dicke geschichtete Plattenepithel der Conjunctiva fort, damn folgt geschichtetes Zylinderepithel von $0,037 \mathrm{~mm}$ Dicke.

Mihroskopische Zottenfalten, die das vordere Ende des Canaliculus lacrymalis (den fälschlich sog. Saccus lacrymalis) auskleiden, sind bis $0,06 \mathrm{~mm}$ hoch; sie tragen ebenfalls Zylinderepithel.

Dagegen flimmert das $0,033 \mathrm{~mm}$ dicke Zylinderepithel des Ductus nasolacrymalis teilweise. Die Venen, welche Ietzteren umgeben, haben $0,28 \mathrm{~mm}$ Durchmesser $(167)$.

Anlegung einer Thränenfistel. Einschnilt am unteren Ende des Processus subcutaneus oss. lacrymalis in borizontaler Richtung; die A. und V. angulares bleiben nach unfen; Durchschneidung des M. orbicularis palpebrarum und Spaltung der vorderen Wand des oberen Endes des Ductus nasolacrymalis.

\section{Bulbus oculi.}

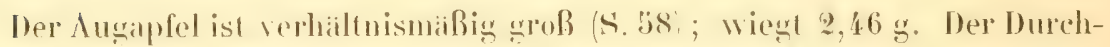
messer hefrigh in rethaler Richtung beispielsweise $18 \mathrm{~mm}$, in sagittaler $17 \mathrm{~mm}$, die optische Achse hat $16 \mathrm{~mm}$ Lainge (17 /).

Die Selera ist riemlich diinn.

Die Cornca ist $13 \mathrm{~mm}$ Jreit, $13,0 \mathrm{~mm}$ hoch (17/). Die Membrama Descemetii hat $0,026 \mathrm{~mm}$ Dicke.

Die Saftkanäle der Cornea sind wie beim Menschen injizierbar (57, S. 148).

Die Menbrana Descemetii wird von den mikroskopischen Irisfortsätzen durchbohrt $(22 S)$, welche sich in der Substanz der Cornea verlieren (vergl.58, S.53).

Die Nerven der Cornea sind außerordentlich schön mit Hilfe des Goldchlorids darzustellen. Sie bilden Plexus mit dreieckigen Anschwellungen an den Knotenpunkten. Aus diesen Plexus treten einzeln verlaufende Nervenlasern aus $(165$, S. 151$)$. Dieselben schienen mit knopfförmigen Anschwellungen zu endisen, welshe die Durchtrittselellen der Nervenfasern in das Cortsea-Epithel gewesen sein dürften. Uber die Endigung der Nerven im Epithel s. 657, 655 und $76 \%$.

Im vorderen Epithel der Cornea bestätigte Löwe $(6 / 5)$ die längst bekannten $(5 \%$, S. 147), grobgranulierten Körperchen, die in Wahrheit in karyokinetischer Teilung begriflene Zellenherne darstellen (7s, s. 27), nannte sie Merhel'sche Tastzellen $(615,5.578$ und 594$)$ und ließ in dem Kem eine Nervenfaser knopfförmig endigen, ähnlich denjenigen in der Frosch-Epidermis (614). Die karyokinetischen Teilungstormen hat Eberth (755) abgebildet.

Durchschneidung der Hornhautnerven am Rande der Cornea. Mit Hilfe eines verdeckten Bistouri $(168)$, welches beispielsweise nur $0,3 \mathrm{~mm}$ tief einzudringen vermag, können die Nervenstïmmchen eines Sektors der Cornea durchschnitten werden, sowohl am Rande, als bis nahe zum Zentrum der Cornea bin. Nach sieben Tagen sind die im $>$ orderen Epithel gelegenen Endfasern zerstört, regenerieren sich aber nachtriglich wieder nach cinfacher Abtragung des Epithels binnen if Tatgen, $\left.745^{\circ}\right)$.

Ätzung der Cornea mittels Höllenstein, Säuren, glühenden Drahtes. Am vierten Tage Wucherung des Epilhels. Kernteilung meist durch spaltung in frontaler Richfung, selten Dreiteilung. Die Zelle mit zwei Kernen teilt sich in derselben Richfung 169). Auch kann man haryokinetische kernteilungen nachweisen $(75.5)$.

Die Chor o idea ist mehr chokoladenbraun als schwarz.

Die polygonalen Pigmentzelien der Choroidea enthalten bei Albinos farblose 
Körnchen. In ihrem äußeren Teile betindet sich ein großer, der Dicke der Zelle manchmal an Durchmesser gleichtommender Fettropfen; bei den weißen Kaninchen besonders deutlich zu erkennen und von gelblicher Farbe. Derselbe erinnert an das Lipochrin $(200)$ beim Frosche. - Die Zellen sind nicht regelmißig sechsseitig, es sitzen kleinere mit einem Kern zwischen größeren mit zwei Kernen $(620)$; es könnte sich dabei um Wachstumsstadien handeln. Die Länge der Melaninkrystalle betrïgt $0,0013-0,0032 \mathrm{~mm}(696)$. - Ein ats glatten Nushelfasern bestehender $1 I$. choroidece, welcher vom M. ciliaris bis zur Eintrittsstelle des N. opticus reicht, ist durch Silber dargestellt worden $(697)$. - Uther den Perichorioidealraum s. $850, \mathrm{~S}, 45, \mathrm{u}, 852$.

Gorpus ciliare ist zart, 1, 2-1,6 mm breit (197) besteht hauptsichlich aus Bindegewebe und enthät Pigment, bei Albinos ist es farblos. Es enthialt den M. ciliaris und den Orbiculus ciliaris.

M. ciliaris, ist I mm lang, seine Büudel latufen getrennt, nahe der sivlera und fast parallel derselben, inserieren sich an das Lig. pectinctum (197).

Orbiculus ciliuris stellt ein dichtes Geflecht von Biindeln doppeltkonturierter Nervenfasern dar, welches nach innen vom Ligg. ciliare liegt. Über die Ganglienzellen an der Basis der Processus ciliares vergl. Iris.

Über die Exstirpation des Corpus ciliare nebst der Iris s. 796.

Ir is. Hhe Farbe ist braun (\$. 19). Jer Durchmesser der Pupille hetrigt am lebenden Tiere im Durchschnitt 4,8 $\mathrm{mm}$ in horizontaler, $5,9 \mathrm{~mm}$ in rertikaler Richtung.

Über den feineren Bau der Iris bei Abbinos und gefïbten Kaninchen siehe 175. Der von Kölliker $(178)$ beschriebene $M$. dilatator iridis verläuft in radiirer Richtung, die Muskelfasern sind zu glatten Bündeln 20\%" geordnel, welcho arkadenförmig in den H. sphincter iridis ïbergehen. Der erstgenannte Mushel ist teits geleugnet $(17 \ddot{3}$ und 175$)$, teils bestitigt 17 i und 206$)$ worden $(180)$. - Die vordere Iristliche ist mit einem Evithelialïberzug versehen, welcher aus unregelmïigg dachziegrelformig iibereinander geligerten Plätchen bestehen soll. - Die Nerven der Iris sind bei Albinos gut zu untersuchen, sie sollen netzö̈mis endisen $180,618,768$ und 797$)$. Ilinter der vorderen Begrenzungshaut liegt eine dïnne, aus zwei sich kreuzenden Lagen, die ein schachbreflihnliches Bild geben, bestehende Schicht faserigen Bindegewebes $(206)$, welches sparsame Lymphkörperchen enthält.

Auch Ganglienzellen sind bei Albinos in der Iris beschrieben worden (179), welche nur in der Basis der Processus ciliares, hier jedoch reichlich verteilt sinul. Sie liegen in den Nn. ciliares $(6 / 8)$.

Iristuberkulose wurde durch Einbringung von Tuberkelmasse in die vordere Augenkammer binnen 20-30 Tagen zuerst von Cohnheim (649) erzeugt. Yon Ihinsell $(8: 1)$ und Deutschmann $(8.2)$ sind in solchen Tristuberkeln sich bewegende Stäbchenbakterien aufgefunden.

Erworbene lugenaffektionen sollen sich, wenn auch in anderer form, vererben können. z. B. Mikrophthalmus. Chorioretinitis disseminata, Aderhatutcolobom nach Iristuberkulose $(662)$, ebenso letztere selbst $(661)$.

Erweiterung der Pupille. Nach elektrischer Erregung des N. sympathicus am IIalse erweitert sich die Pupille auf 10,8 resp. 11,3 mm (19); im Nittel aus fünf Beobachtungen).

Die pupillenerweiternden Fasern entspringen zusammen mit den Gefißnerven des Kopfes aus dem Centrum ciliospiuale des Rückenmarkes (192); nach anderer Angabe (195) kommen beide aus der Medulla oblongata. 
Die Retina enthialt doppeltkonturierte Nervenfasern, welche zu zwei langen, horizontal nach vorn und hinten verlaufenden Bündeln (Fig. 74) vereinigt sind.

Die im Dunkeln ausgeruhte Retina zeigt eine an den Stäbchen-Außengliedern haftende, wenig intensive rötlichviolette Färbung, das Photaesthesin oder den Sehpurpur, welche am Licht rasch vergänglich ist. Die untere Hailfte der Retina ist elwas intensiver gefärbt, als die obere; in horizontaler Richtung verläuft ein stärker gefärbter (in Fig. '74 stärker schattierter) Purpurstreif, die S ehle iste (201), etwa von derselben Breite wie die weißen Bündel markhaltiger Nervenfasern. Letztere kann man als temporales und nasales $B$ ïndel bezeichnen; das erstere ist $6 \mathrm{~mm}$ lang, $3 \mathrm{~mm}$ breit und in maximo 0 , $21 \mathrm{~mm}$ dick, das nasale Bündel nur 4,8 $\mathrm{mm}$ lang, die Ausstrahlung der Faserbündel ist in der Richtung nach oben am unbedeutendsten (6/4).

In der Pars ciliaris betrigt die Dicke der Retina nur $0,025 \mathrm{~mm}(624)$.

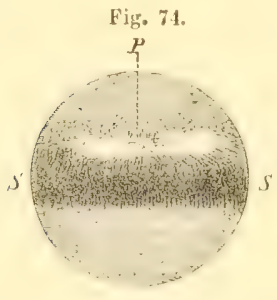

Augenhintergrund ganz frisch, nach Aufbewahrung des Kaninchens während mehrerer stumden in einem dunkeln Raume. Die Schattierung druckt die Intensität der violettroten Färbung der Retina aus, mit Benutzung einer Abbildung von Kiuhne $(20 I)$. $P$ Eintrittsstelle des N. opticus, von welcher nach beiden Seiten weiße Nervenbündel ausstrahlen, ebenso die Äste der $\Lambda$, centralis retinae. SS Sehleiste.

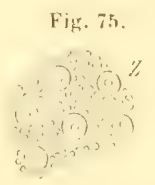

Flïchenansicht des Mosaiks der Stäbchen und Zapfen der Retina aus der Gegend des Aquators des Bulbus, von des choroidealseite her gesehen; frisch mit konzentriertem Ammonimmwolframat. Vergr. 400. Z Innenglied eines Zapfens; der zentrale Punkt darin ist der op tische Querschnitt des Außengliedes. Nach W. Krause (177).

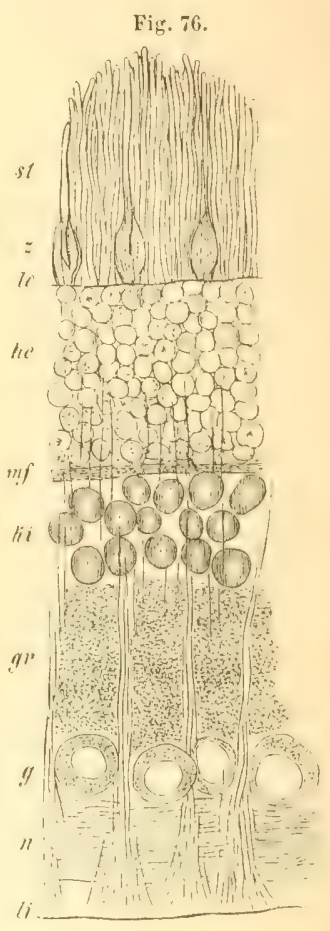

Senkrechter Durchschnitt der Ketina aus dem Hintergrunde des Auges nach mehrwöchentlicher Härtung des Bulbus in iH. Müller scher Flussigkeit, Alkohol, Glyzerin. Vergr. 300. Nach Orth (463). st Stabchenanßenglieder. z Drei Zapfeninnenglieder. le Membrana limitans externa. ke Stabchen- und Zapfenkörner. mif Membrana fenestrata. ki Körnerschicht. or Granulierte Schicht. $g$ Ganglienzellen, $n$ 0ptieusfasern.

ti Membrana limitans interna.

Die Stihchenschicht zeigt regelmäßig verteilte Zapfen sowohl in der Flächenansicht (Fig. 75), als auf dem Durchschnitt (Fig. 76), welche wie die Stäbchen deutlich unterschiedene Innenglieder und Iußenglieder W. Krause darbieten. Nach M. Schultze (198) sollte das Kaninchen unr MAndeutungen von Zapfen besitzen, was mit der Lehensweise des Tieres in dunklen Gängen zusan!menhängen soll. An Priparaten in Kaliumbichromat sind die Zapfen birnförmig, $0,011 \mathrm{~mm}$ lang, wovon auf das Außenglied $0,004 \mathrm{~mm}$ kommen; das Innenglied $0,003-0,004 \mathrm{~mm}$ breit; das Außenglied hat 0,0009 Durchmesser, wihrend das Innenglied der Stibchen $0,002 \mathrm{~mm}$ Dicke auf $0,023 \mathrm{~mm}$ Länge besitzt (202). Auch die Zappenkörner fehlen keineswegs, wie $\mathbf{M}$. Schultze glaubte. In der Achse der Imnenglieder der Stibchen verläuft eine feine Achsenfaser, wie sie früher bein Menschen ebenfalls nachgewiesen wurde (199). 
Die Stäbchenkörner zeigen nach Behandlung mil Iodserum (II. Schultze) oder Goldchlorid (W. Krause) einen einfachen oder doppelten Kern. Frisch untersucht, zeigen sie Einen dunkleren Henle'schen Querstreifen, der auch an Überosmiumsaiurepräparaten sich erhäilt (M. Schultze, 20.5); letzterer hat für den Zusammenhang der Kerne mit dem Querstreifen die Deutung gegeben, daß die Ouerstreifen sekundair durch Zerfallen aus den kernen entstinden. - Vergl. über den Bau der Retina 615 und 615 .

Linse. Die Achse der Linse ist $11 \mathrm{~mm}$ lang; ihre vorderen und hinteren Oberflichen sind nach demsellyen Radius von 14 mm gekrimmt (194). Dagegen wurden bei etwas kleinen Kaninchen gefunden: Durchmesser 10-11, Achse 8,1 , Radius der vorderen Fliche $6-6,3$, Radius der hinteren Flache $5,2-5,3 \mathrm{~mm}$, das spez. Gewicht zu 1,1232 (195).

Über die Regeneration der extrahierten Linse vergl. 752.

Die Linse fluoresziert stark, schwächer die Retina und die Cornea; das Corpus vitreum zeigt Spuren von Fluoreszenz $(196)$.

Die Linsenfasern sind an der Peripherie 0,014, in der Mitte zwischen Zentrum und Peripherie 0,008 , im Kern der Linse nur $0,005 \mathrm{~mm}$ breit $\left(195^{\circ}\right)$.

Schematische Durchschnitte der Linse nebst Augenkammern etc. s. 615.

Glaskorper. Sein Brechungsindex betriggt für die Linie D 1,33471 (623) im Mittel von acht Augen.

\section{Blntgefailse des Bulbus.}

Die A. centralis retinar verteilt sich mit ihren Ästen lings der Bündel von doppeltkonturierten Nervenfaseru, in welche der N. opticus ausstrahlt. Der übrige Teil der Retina ist gefißlos. Nach vorn endigen die Kapillargefaße mit schlingenfömigen Umbiegungen, ohne Anastomosen einzugehen, dagegen finden solche an der Eintrittsstelle des N.opticus mit den $\Lambda$ a. ciliares posteriores breves statt.

Aus dem Vorhandensein dieser Anastomosen erklärt es sich, weshalb die Zirkulation in dem Gefißsystem der Retina nach Durchschneidung des N. opticus an seiner Eintrittsstelle in den Bulbus nicht unterbrochen wird (204).

Die A. u. V. centralis retinae teilt sich noch innerhalb des $\mathrm{N}$. opticus in eine A. (u. V.) retinae nasalis und $\mathbf{A}$. (u.V.) temporalis, jede von 0,034 (resp. 0,045 ) mm Dicke, atußerdem geht eine feine $\Lambda$. (u. V.) retinae superior und inferior von $0,003$ resp. 0,005$)$ mm Dicke nach oben und unten ab $(85 \%)$. Die Länge der Aa. nasalis und temporalis betrigt etwa $4 \mathrm{~mm}$, diejenige der Aa. superior und inferior nur 1,4 mm. In der ganzen Dicke der Opticusfaserschicht, anch am Rande der gefißhaltigen Partie gehen arterielle) Kapillaren von $0,0056 \mathrm{~mm}$ Dicke schlingenförmig direht in venöse Kapillaren über, jedoch werden letztere nicht Begleiterinnen der betreffenden, sondern der zweiten oder dritten nïchstbenachbarten arteriellen Kapillare. Die Maschen des eigentlichen Kapillargefißsystemes haben $0,023-0,05 \mathrm{~mm}$ Weite, dasselbe liegt dicht innerhalb der Membrana limitans, die größten Blutgefiße befinden sich zwischen der letzteren und dem Corpus vitreum (619 und 85.4); die Kapillaren durchsetzen in radiärer Richtung die Opticusfaserschicht, ohne in die granulierte Schicht einzudringen. - Vergl. a. 798.

Die Membrana limitans (interna s. hyaloidea) wird von der Basis der Radialfasern selbst gebildet (vergl. die schöne Abbildung von G. Retzius, 667). 
Beim neugeborenen Kaninchen sind die Stibchen und Zapfen bereits vorhanden, sie gleichen einem Walde feiner Flimmerhatre (684).

Bemerkenswert ist die Indolenz, mit welcher die Kaninchen direkte Insolation ihrer Retina ertragen. Die Augen himmen diher heliopisch genannt werden $\left(6 \varsigma 5^{*}\right)$. Uber die durch konzentrirtes Sonnenlicht entstehenden Verinderungen s. 855 .

Vv. vorticosae. Es sind vier vorhanden. Wenn man den Bubus beim lebenden Tier luxiert, kann man ihre Fortsetzungen, die Vv. ciliares posteriores, sämtlich unterbinden (229).

Uber Eigentünlichkeiten der Gefäßrerloreitung im Bulbus des Kaninchens vergl. 648; über die Untersuchung der Choroidealgefiße und der Retina am lebenden Kaninchen mittels des Augenspiegels s. 598 und 645. Das Auge ist hypermetropisch und nicht selten stark astigmatisch.

\section{Augenmuskeln.}

Es sind neun vorhanden: Mm. orbicularis oculi, levator palpebrae superioris, recti oculi superior, inferior, anticus, posticus, obliqui oculi superior, inferior und retractor bulbi. Der $M$. orthrularis pulpebrarmm ist sehr dün ; der 1 . levator palpebrae suprevioris breit und diun; letzterer kommt vom oberen Umfang des Foramen opticum. Die Mm. retractor bulbi, recti oculi und obliquus superior entspringen von der lateralen Oberflache des Corpus oss. sphenoidei anterioris am vorderen, unteren und hinteren Umfang des Foramen opticum. Die Mm. rectus anticus, retractor bulbi und obliquus superior entstehen vom vorderen Imfange des Foramen opticum; letzterer am weitesten nach vorn. Derselbe geht durch eine fihrose scheide unterhalh des Processus supraorbitalis anterior oss. frontis, welche der Trochlea des Menschen entspricht. Der M. obligmus inferior entspringt ron der vorderen unteren Ecke des Thrinenbeines $(\$ / S)$, dicht hinter dem IIamulus lacrymalis, und ist verhaltnismaißg lang und stark. Verlauft schrig rilckwiarts und lateralwairts, heftet sich an den hinteren unteren Umfang des Bulbus. Am M. retractor bulbi lassen sich vier Portiomen unterscheiden: eine obere, untere, hintere und vordere; dieselben sind platt und sehr dünn.

Der Ansatz des M. rectus superior reicht muskulös bis nahe an den Cornealrand, in seiner Begleitung treten stärkere Gefäße zu letzterem.

Wirkungen der Augenmuskeln.' Die Wirkung des M. rectus posticus kann sich mit der Kontraktion des vom N. oculomotorius versorgten $\mathbf{~ I .}$ retractor bulbi kombinieren, wodurch das Gesichtsfeld nach hinten an Ausdehnung zunimmt. Vorgedräingt wird der Bulbus nach Erschlalfung des $\mathbf{M}$. retractor durch die Elastizitit der Membrana orbitalis unter Mithilfe der Inkompressibilitit der Gl. Harderiana. Krampfhafte Kontraktion der Gglatten Mluskelfasern in der Membrana orbitalis, die unter dem Einfluß des Halssympathicus steht, macht den Bulhus hervortreten. Die Palpebra tertia besitzt heine eigenen Muskeln und nach allgemein akzeptierten Angaben (207) erfolgt bei den IIaussäugetieren die Vorschiebung des dritten Augenlides durch Wirkung des M. reIractor bulbi, welcher den Bulbus gegen die inkompressible Gl. Harderiana andruickt. Da letztere in der Orbita nirgends ausweichen kann, so drängt sie die 
Palpebra tertia vorwärts. Vermöge der Adhäsion der Krïmmungstliche ihrer konkaven Seite an den Bulbus gleitet sie vor dem letzteren nach hinten. Bei gleichmäßiger Zusammenziehung der $\mathrm{Mm}$. rectus posticus und retractor bulbi müßte hiernach die Drehung des Bulbus nach hinten von Verschiebung der Palpebra tertia begleitet sein.

Motorische Endplatten. Die Nervenverteilung im M. retractor bulbi lißßt sich fast eben so gut ïbersehen, wie im M. retractor bulbi der Katze (208). Die Nervenfasern endigen mit motorischen

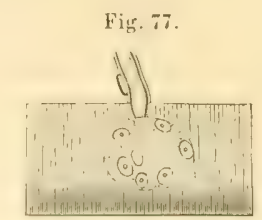

Motorische Endplatte aus dem MI. retractur bulbi. Friseh, uhne Zusatz. Vergr. 250. Endplatten (Fig. 77), deren Kerne unzweifelhaft außerhalb des Sarkolems liegen. Die dafür gelieferten Beweise stiitzen sich wesentlich auf die Thatsiche, diß die motorischen Endplatten sehr dïnn sind, während sie öfters irrtiimlich für Hervorragungen oder Ilïgel gehalten wurden. Über Sehnenendplatten in den Sehnen der Augenmuskeln s. 785.

\section{Drüsen der Augenhöhle.}

Es sind jederseits drei vorhanden: Gl. lacrymalis, Harderiana, infraorbitalis und ein Haufen von Lymphfollikeln in der Schleimhaut der Palpebra inferior (s. letztere S. 184). Die ersteren beiden münden in den Conjunctivalsack; die Gl. infraorbitalis in die Mundhöhle.

Gl. lacrymalis, die Thrinendríse, ist unregelmißig rundlich, $0,05 \mathrm{~g}$ schwer, liegt am temporalen Augenwinkel, vor der temporalen Wand der Orbita, ragt mit einem Lippehen an der lateralen Seite des M. temporalis dureh das Foramen temporale ( $\$$. 90). Die 3-5 Ausführungsgange durchbohren die Schleimhaut des oberen Augenlides am temporalen Winkel (Cuvier, z09, fand nur einen Ausführungsgang). Acinöse Krause'sche Drüsen der oberen Conjunctivalfalte beschrieb Blumberg (2/0).

Erregung der Wurzel des N. trigeninus am frisch abgeschnittenen und halbierten Kopfe bedingt reichlichere Thrïnensekretion, welche mittels Einlegen von rotem Lakmuspapier in den Conjunctivalsack sichtbar gemacht werden kam $(2 / 1$. — s. dagegen 751. Vergl. auch GI. parotis).

Gl. Iarderiana. Die Harder'sche Drüse gehört zu den acinösen Drúsen; sie liegt am nasalen Augenwinkel, medianwarts vom hinteren lateralen Rande des Corpus oss. maxillaris superioris, hinter dem Os lacrymale und erstreckt sich wach hinten an der nasalen Wand der Orbita, oberhalb) der Membrana orbitalis oder des M. obliquus inferior, vor dem Bulbus und etwas medianwirts von demselloen. Die Liangsachse ist ziemlich genau transversal und horizontal gerichtet, die Linge betrigt ca. $2 \mathrm{~cm}$, die Breite $1-1,5 \mathrm{~cm}$, die Dicke 3-7 $\mathrm{mm}$; das Gewicht $0,36 \mathrm{~g}$. Die Form ist unregelmaßig lappig; man unterscheidet mit freiem Auge einen kleineren oberen und hinteren, sowie einen größeren unteren und vorderen Lappen, die sich etwa wie 3: 1 verhalten. Der Ausführungsgang mündet in der konkaven Seite der Palpehra tertia. Der untere Lappen sieht grauroutlich aus, der obere weißlich, wie die Milchdriusen des sïngenden Kininchens; derselbe wird in 1\%/giger Chromsiure 
oder Chromaten hellgelb, wenn der obere Lappen bräunlich aussicht. Überosmiumsäure schwårzt beide Lappen.

Betrachtet man die Drüse in der natïrlichen Kopfhaltung des Kaninchens (Fig. 1, S. 8), so wird der kleinere obere Lappen zum vorderen, der größere untere zum hinteren Lappen. (Erste Auflage S. 1.32.) - Die Verschiedenheiten in der Fäbung beider Lappen sind nicht efwa von versehiedenem Blutgehalt abhängig, der vielmehr in beiden Lappen derselbe ist (den wirklichen Grunds. unten). Die Farbendifferenz war schon mehreren Beobachtern aufgefallen.

Cuvier $(212)$ unterschied beim Ilasen die beiden Lappen als mougeatre und "blanchâtre", Trapp (2/5) namnte den ersteren Pars rubicunda major, den letzleren Pars albescens minor. Wendt (2/4) sagt, daß Trapp beide Lappen zuerst erwähnte, obgleich Trapp selbst Cuvier zitiert.

Mikroskopisch zeigen sich ebenfalls wesentliche Unterschiede der beiden Lappen. Frisch unfersucht erscheinen die Acini des weißlichen Lappens dunkel und körnig bei durchfallendem Licht, wie die Acini der Talgdrüsen. Die Acini des rötlichen Lappens sind heller, ihre fedtröpfchen größer und letztere lassen deshall mehr licht durch; das Aussehen der Acini gleicht auch mikroskopisch demjenigen in der sezernierenden Mamma. Nach etwa zweitigiger Behandlung mit 1\%/giger Uherosmiumsiure sind die Dillerenzen ebenso auffallend (Fig. 78).

Fig. 78 .
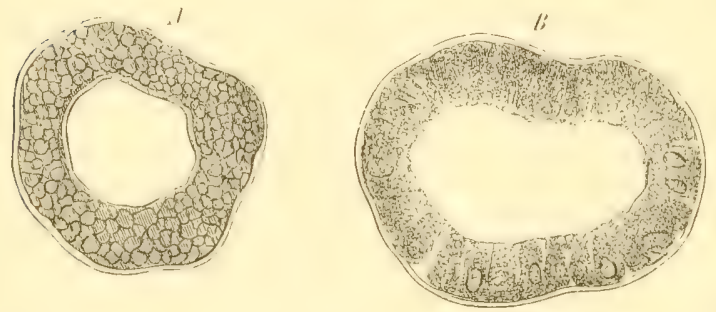

Acini der G'1. Harderiana nach zweitägigem Einlegen frischer Drüsenläppchen in $10 /{ }_{0}$ ige Uberosmiumsäure. Alkohol, Nelkenöl, Dammar. Vergr. 300. A. Aus dem rütlichen Lappen. B. Aus dem weißlichen Lappen.
Die Acini messen 0,3 $0,4 \mathrm{~mm}$, zufolge einer früheren Angabe $(\mathbf{2 1 5})$ nach Quecksilber-Injektion $0,21 \mathrm{~mm}$; im weißlichen Lappen sind sie im allgemeinen größer bis 0,6 $-0,8 \mathrm{~mm}$ im Durchmesser $(2 / 4)$; übrigens liegen die kleineren mehr an der Peripherie der Drüse. Die Acini platten sich öfters aneinander $\mathrm{ab}$, sind stark in die Länge gezogen, so daß sie an tubu-

löse Drüsen erinnern. Sie bestehen aus einer strukturlosen Membran mit auswendig aufgelagerten Kernen. Die Spaltung des Ilauplausfuihrungsganges in zahlreiche Aste geschieht fast plözlich, pinselformig an der konkaven Seite der Drüse. Ersterer ist von niedrig-kubischem Plattenepithel ausgekleidet; die Äste, welche sich wiederum dichotomisch teilen, sowie die feineren Ausführungsinginge führen Zylinderepithel, zwischen den Lippchen verlaufen außer Blutgefißen auch sparsame kleine Nervenstimmchen, aus 2-3 und mehr doppelthonturierten Nervenfasern bestehend, welche wahrscheinlich die Drïse nur passieren und in der Conjunctiva endigen. Das Lumen der Acini ist kuglig oder ellipsoidisch, in beiden Lappen relativ groß, im weißlichen Lappen noch gerüumiger, häutig mit körnigem Inhalt teilweise gefüllt. In beiden Lappen ist das Epithel der Acini einfaches PyramidenEpithel, welches an Zylinderepithel seiner Form nach sich anschließt; die Zellen sind im röllichen Lappen höher. Sie bestehen daselbst ans einem protoplasmalischen Maschenwerk, in welchem srißßere, fettihnliche Tropfen von ziemlich konslanter Größe Fig. 78 A) nebeneinander eingelagert sind und den Zellenkern verdecken; im weißlichen Lappen sind diese Kerne leicht sichtbar, liegen im peripherischen Ende der Zellen dicht an der Membran des Acinus. Die Kerne 
sind etwas ellipsoidisch, beinahe sphärisch, bläschenförmig, mit deutlichen Kernkörperchen. Außerdem enthalten die Drüsen-Epithelzellen im weißlichen Lappen nur sehr feine dichtgedrängte Körnchen und es ist merkwiirdig, daß sich weder diese noch die Tröpfchen des rötlichen Lappens mit Überosmimmsäure schwarz fïben: sie scheinen mehr kolloider Natur zu sein (2/.1). Die chemische Untersuchung (21.4) der Drüse ergiebt im ätherischen Alkoholextraht viel Fett, Lecithin, Cholestearin, außerdem Chlor, Phosphorsäure, Kali und Natron. - Jedenfalls beruht die weißliche Farbe des betreffenden Lappens auf feinster Verteilung dieser stark lichtbrechenden Substanz, welche die Acini bei durchfallendem Licht dunkel, bei auffallendem Licht weißlich erscheinen läßt.

Der Ausführungsgang liefert ein milchiges, feine fettröpfehen führendes alkalisches Sekret in den Conjunctivalsack, die Sekretion ist bei Conjunctivitis vermehrt (216) und die Fettkörnchen scheinen in die Lymphscheiden der Cornealnerven gelangen zu können (57, S. 531). - Vergl. a. 849. - Die Knorpelplatte der Palpebra tertia wird teilweise von der Gl. Harderiana ungeben.

Gl. infraorbitalis s. S. 202.

\section{Nase.}

Cartilago narium stellt eine knorplige Lamelle dar, die nach vorn in eine Spitze ausgezogen ist, welche mit dem Frenulum septi mobilis narium zusammenhänt. Medianwärts verschmilzt sie mit der Cartilago narium der anderen Seite. An dem lateralen Abschnitt kann man eine Pars anterior s. Processus cartilagineus anterior $(167)$, lateral limb $(2 / 7)$, und eine Pars posterior s. Processus cartilagineus posterior, lower and upper limb, unterscheiden. Indem sich namlich die Cartilago narium lateralwarts umbiegt, bildet sie oberhalb des Nasenloches eine nach oben oflene, nach vorn, lateralwarts und medianwärts geschlossene Tasche, deren mediale Wand die Pars posterior darstellt, wihrend die laterale Wand oder den Nasenflügel die Pars anterior einnimmt. Erstere hängt oben und hinten durch eine Schleimhautfalte mit dem vorderen Ende der Concha anterior (sog. Stüzknorpel derselben, upper limb) zusammen. Sie begrenzt lateralwarts den vorderen Abschnitt des Meatus narium inferior (lower nasal furrow). An der lateralen Flache jener medialen Wandung verliuft der vordere Abschnitt (Fig. 73 Dn, S. 185) des Ductus nasolacrymalis. - Die Naseulöcher sind längliche Schlitzöflnungen.

Cavum nasi. Die Nasenhöhle ist groß, von vorn nach hinten sehr lang, enthailt sehr zahlreiche, untereinander kommunizierende, von der Nasenschleimhaut ausgekleidete Abteilungen (Fig. 79, S. 104). Die Vebenhöhlen der Vase oder Sinus sind wenig entwickelt (s. Osteologie).

Die Schleimhaut der lateralen Wand der Nasenhöhle, welche den durchlöcherten, porösen Teil des Corpus oss. maxillaris superioris inwendig auskleidet, enthält zahlreiche, acinöse Drüsen. Zum Teil mil einfachem kurzen Ausführungsgang; zum Teil mit sehr langen, zylindrischen Ausführungsgängen, an deren Enden einzelne Acini sitzen, wie bei den Drüsen im Sinus maxillaris des Menschen. Einer der Ausführungsgänge dieser Drüsen, namentlich einiger größeren am vorderen unteren Ende der medialen Innenwand des Sinus, sowie unterhalb der Concha anterior gelegenen Lïppchen (basale Nasendrüse, 101) mündet merk- 
würdigerweise dicht hinter dem Nasenloche, unter dem vorderen Ende des Marsupium nasale (und ist beim Hasen, obwohl nur 0,2 mm weit, leicht zu sondiereu). Dieser Ausführungsgang (Nasendeckengang, Ductus tecti narium, 101 verläuft von der betreffenden Drüse aus anfangs in der medialen Wand des Sinus maxillaris rückwärts, dann lings der Crista nasi und zwar lateralwärts von derselben in sagittaler Richtung absteigend nach vorn bis zu seiner Nündung, welche nur einige Millimeter oberhalb des vorderen Endes des Ductus nasolacrymalis gelegen ist.

\section{Fig. 74.}

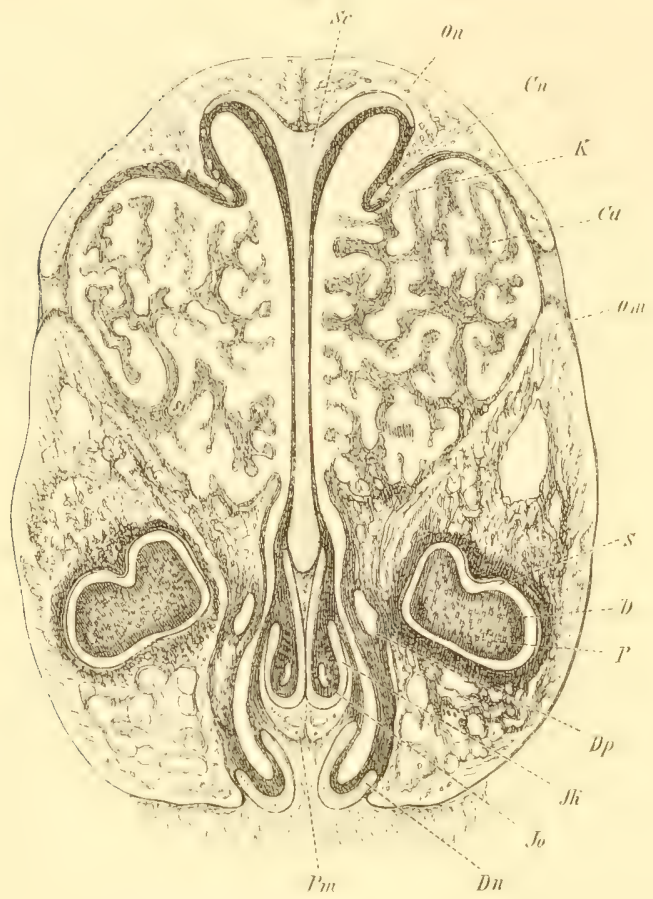

Senkrechter Frontalschnitt der Nase in der Gegend der vorderen Muschel nach Behandlung mit H. Müller'scher Flüssigkeit, 10/0iger Chromsäure, $5 \%$ iger Chlorwasserstotísäure, Wasser, Alkohol, Nelkenöl, Dammar. Vergr. 6 ; bei 30 facher Vergrößerung gezeichnet. Sc Septum narium cartilagineum. On 0 s nasi. Cn Crista nasalis. $K$ Knorpel an der Crista nasalis. Ca Concha anterior. Om Os maxillare superius. $S$ Schmelz des großen Sehmeidezahnes. $D$ Dentin. $P$.Pulpaböhle. $D p$ Ductus nasolacrymalis. Jk Jacobson'scher Kinorpel. Jo Lumen des Jacobson'schen Organes, von Venendurchschnitten umgeben. $D n$ Cartilago nasopalatina des Ductus nasopalatinus. Pm Pars medialis des Ramus palatinus oss. intermaxillaris.

Septum narium cartilagineum. Ist unpaar, liegt in der Medianebene, beginnt am vorderen Rande der Lamina sagittalis oss. ethmoidei, welche im hinteren Teile der Nasenhöhle das Septum narium osseum bildet; wird von den beiden Blättern des oberen Randes des Vomer eingeschlossen, mit welchem zusammen eine vollständige Scheidewand zwischen rechter und linker Hălfte der Nasenhöhle hergestellt wird. Das untere Ende liegt vor der Apertura pyriformis und verschmilzt mit der Cartilago nasi.

Ductus nasopalatinus s. Stenonianus, Stenson'scher Gang (2/9), ist eine knorplighäutige Röhre (Fig.79 Dn) mit einem Lumen von $1 \mathrm{~mm}$ im größten Durchmesser bei einer Länge des Knorpels von etwa $7 \mathrm{~mm}$; letzterer kann Cartilago nasopalatina, Stenson'scher Knorpel genannt werden. Der Ductus nasopalatinus setzt den vorderen Teil der Nasenhöhle mit der Mundhöhle in Verbindung. Derselbe mindet dicht hinter den kleinen Schneidezahnen (S. 197); erstreckt sich von da fist horizontal, in sagittaler Richtung, nach hinten ein wenig aufsteigend. Beide Ductus nasopalatini füllen das Foramen incisivum aus; sie liegen jederseits zwischen der Pars medialis und lateralis des Ramus palatinus oss. intermaxillaris, dem unteren vorderen Ende des Vomer und dem Corpus oss. maxilaris superioris. Der Duelus nasopalatinus ist von dumner Schleimhaut ausgekleidet, welche nach hinten in die Nasenschleimhaut uibel- 
geht; erstere trigt zylindrisches Flimmerepithel, der Knorpel ist hyalin und seine Zellen enthalten jede eimen großen Fettropfen. In der Submucosa finden sich einzelne Lymphfollikel (2/7).

Jacobson'sches Oryan. Der Innenraum der nach oben konkaven Pars medialis des R. palatinus oss. intermaxillaris wird durch eine knorpelröhre, den Jacobson'schen knorpel, ausgefüllt, deren Innenfliche von einer Fortsetzung der Nasenschleimhaut gebildet wird, die ein größtenteils vertikales, nierenförmiges Lumen frei laßß; der Knorpel ist hyalin.

Zwischen der Pars medialis des R. palatinus oss. intermaxillaris und dem unteren Ende des Septum nariun cartilagineum findet sich eine mediane Furche, welche von der V. septi narium mediana und dem submukösen Gewebe der Schleimhatul des Septum narium ausgefüllt wird (vergl. 218).

Mikroskopisch ist das Jacobson'sche Organ bereits zweimal (101 und 217) und zwar sehr detailliert (217) geschildert worden. Die Lïnge desselben betrigt $15-20 \mathrm{~mm}$, die Dicke inkl. des Knorpels in transversaler Richtung 1,3, in vertikaler Richtung 3,1 mm. Das Lumen mißt $0,14 \mathrm{~mm}$ in querer, $0,45 \mathrm{~mm}$ in senkrechter Richtung. Vorn und hinten ist dasselbe rund, im Mittelteile der Lïnge des Organes aber eine senkrechte nierenförmige Spalte.

Der Knorpel ist im ganzen rinnenförmig, auf einer Strecke seines Verlaufes im vorderen Teile jedoch ringfömig geschlossen. Die Knorpelzellen enthalten vielfach große Fettropfen. Was die Schleimhat anlangt, so wird sie von geschichtetem, 0, 2-0,3 $\mathrm{mm}$ dickem Cylinderepithel ausgekleidet, an der medialen Wand ist jedoch das Epithel $0,39 \mathrm{~mm}$ dick und stell ein aus drei Zellenlagen geschichtetes flimmerndes Neuro-Epithel dar; sie wird von Ästen des N. olfactorius versorgt, die submuköse Plexus bilden und von Nerven-Epithel bedeckt werden, wïhrend der übrige Teil der Schleimhaut geschichtetes Zylinder-Epithel zeigt. An dieser Stelle konmen Lymphfollikel von ca, 0, 2 mm Durchmesser in der Subnucosa vor, während an der Peripherie bis zu dem umgebenden Knorpel hin ein venöses Maschenwerk (sog. kavernöses Gewebe, 101) sich ausdehnt. Acinöse Drüsen münden auch in die obere und untere Kante des Lumens ein, dieselben haben den Charakter von Eiweißdrüsen (S. 59). An der lateralen Wand ragt in der hinteren Hailfte des Organes eine longitudinale Anhäufung acinöser Drüsen (mlandfold, 2/7) in das Lumen hinein, welche inkl. des Epithels 0,17 mm Dicke hat. - Etwas $(1 \mathrm{~mm}, 680)$ vor der oberen Ötrnung des Ductus nasopalatinus liegt die punktförmige vordere Mündung (2/7) des Jacobson'schen Organes; das hintere Eude ist geschlossen.

Die Naseuschleimhaut ist in ihrem obersten Teile am Septum, dem Marsupium nasale und den hinteren Muscheln von briunlicher Farbe, nicht flimmernd. Da hier der N. olfactorius endigt, so wird dieser Teil als eigentliche Geruchsschleimhaut, Regio olfactoria, bezeichnet.

Das flimmernde Epithel hat 0,09 $\mathrm{mm}$, das nicht flimmerude 0,16 $\mathrm{mm}$ Dicke (220). Sowohl die Zylinder- als die Stäbchenzellen (221) des letzteren tragen Haare, die jedoch unbeweglich sind (57, S. 178; 58 und 101). Das bräunliche Pigment liegt in den unteren verdickten Enden der Epithelialzellen. — Die Nerven sind zahlreich, doppeltkonturiert; ihre Endigung ist nicht bekannt. Über die L y m phgef $\mathrm{a} ß$ e der Nasenschleimhaut s. 850 u. $85 \%$.

II intere II uscheln. Eigentumlich sind der Schleimhat derselben, vielteicht auch des Septum cartilagineum, kleine, linglich-ovale, isolierte, ein- 
gesprengte Knorpelinseln. Dieselben bestehen aus dichtgedrängten kleinen Knorpelzellen in einer fast verschwindenden hyalinen Grundsubstanz und sind von einem besonderen Perichondrium úberzogen. Sie haben etwa 0,16$0,33 \mathrm{~mm}$ Linge auf $0,11 \mathrm{~mm}$ Breite. Wahrscheinlich sind es Reste aus dem Verknöcherungsprozesse der Muscheln.

Pathologische Anatomie. Der Rotz zeigt sich in einer eitrigen Absonderung der Nasenschleimhaut; das Sekret kann lirystalle von Kalkoxalat enthalten (222). Diese ansteckende Krankheit vermag alle Tiere eines Stalles in kurzer Frist zu lïten, wenn man nicht durch sorgfilltige Isolierung die kranken Tiere aussondert. Da Durchfaille im Verlauf der Affektion auftreten, so kann dieselbe mit Typhus etc. verwechselt werden. Spontane Ansteckung seitens rotzkranker Tiere sowie gelungene Einimpfung เon Kolzgift vom Pferd oder Menschen auf Kaninchen sind mehrfach bekannt geworden(225).

Nasenkatarh oder Schnupfentieber. Die Tiere fressen wenig, sitzen traurig da, athmen mühsam. Aus der Nase erfolgt spïter stïrkerer Ausfluß, so daß die Haare naß werden; öfters ist auch Conjunctivitis vorhanden. Der Verlauf ist bald akut, bald chronisch. In der Leiche zeigt sich Katarrh der Nasen- und Conjunctivalschleimhaut, das Sekret enthält wie die Schleimhäute selbst zahlreiche Psorospernien (22.4). Man kann $0,5-1 \%$ ige wäßrige Karbolsäurelösung einmal täglich eintröpfeln resp. einspritzen, auch hat man Kupfersulphat $(0,016-$ $0,032 \mathrm{~g}$ zweimal täglich) innerlich versucht $(225)$. - Übrigens stellt sich das sog. Schmupfenfieber nicht immer als eine Gregarinose, sondern mitunter als tötliche lobäre Pneumonie oder Laryngitis, Tracheitis und Bronchopneumonie (226) heraus; auch fragt sich, wo die Grenze gegen den Rotz zu ziehen ist. Von anderer Seite (227) wird die Affektion ohne Zweifel irrtïmlich fïr eine Pilzkrankheit oder Mykose der Schleimhaut gehalten.

Die vordere Huschel ist sehr kompliziert gebaut (S. 99); vor derselben mindet der Duclus nasolacrymalis (Fig. $73 \mathrm{l}) \mathrm{n}$. S. 104). Die Schleimhatut enthall ansgebildete Veneuplexus und einzelne acinöse Eiweißarusen.

\section{Mundhöhle.}

Die Lippen sind jede mit a. 40 langen, steifen Spürharen besetzt, deren Bitge auBerordenflich mervenreich sind (S. 170). Die menten und hinfen befindlichen Hatre sind linger und dicker als die iibrigen. Die Funktion derselben hei der Lebensweise des Kaninchens in selbstgegrabenen Gingen ist unverkennbar.

Die Oberlippe ist in der Medianlinie durch die bekannte "llasenscharte" urespalten, so daß die großen Schmeidezihne frei liegen. Die beiden IIalften verbinden sich in der Medianebene durch ein zartes Fremulum septi narium cartilaginei mit dem letzteren (s. auch Hautmuskeln, S. 170).

Die Mundhaut trigut auf jeder Seite einen breiten, von der Mundöfnung bis zu den Backenzihnen reichenden Streifen von langen, steifen, dichtstehenden Haren, zwischen welchen unter dem Mikroskop große Papillen hervorragen.

Zwischen den kleinen Haarbälgen am Lippenrande liegen rudimentäre Schweißdrïsen. Es sind 1 on Zylinder-Epithel ansgekleidete Schläuche, welche in 
den Haarbalg münden; ihre Länge beträgt z. B. 0,28, die Dicke 0,05 mm, das blinde Ende ist häufig umgebogen (vergl. 101). - Die Länge der Mundböhle beträgt $67 \mathrm{~mm}(827)$.

\section{Zähne.}

Die Schneidez ihne oder Nagezihne, Dentes incisivi s. scalprarii s. Incisores tragen eine merkliche Lage von Schmelz nur auf ihrer Vorderfliche. Daher schleift sich die hintere Partie des Zahnes schneller ab, als die Vorderfläche, und derselbe hat stets eine meißelförmige Schneide. Allerdings ist anch auf der hinteren Flache eine freilich sehr diinne Lage von Schmelz vorhanden, was sie von denen aller anderen Yager unterscheidet (2.52). Die scharfe Kante ist vorn gelegen, in der Projektion von unten zeigt sich aber an jenen Zïhnen des Oberkiefers deren Riıckwärtskrimmung (Fig. 6 und 7, s. 14). Die Anzahl der Schneidezähne betright vier im Oberkiefer, zwei im Unterkiefer, indem sich dicht hinter den beiden großen Schneidezihnen des ersteren zwei viel kleinere Dentes incisivi posteriores finden. Diese Anordnung kommt, mit Ausnahme der Hasen, bei keinem anderen Tiere vor (Gaumenzahne finden sich bei Reptilien u. s. w.).

Die oberen großen Schneidezihne sitzen in den Alveolen des Os intermaxillare. Sie besitzen auf ihrer Vorderfliche eine Längsfurche, welche deu unteren Schneidezähnen fehlt.

Der obere große Schneidezahn umfaßt etwa $130^{\circ}$ eines hreises von $1 \mathrm{~cm}$ Radius, ist aber in Wahrheit ein Stück einer Spirale (s. unten Pathol. Anat.). Die Kurve des unteren Schneidezahnes ist mit etwas größerem Radius beschrieben. $(236)$.

Die Schmelzfasern an den Schneidezähnen haben etwa 0,0037 mm Dicke

Varietät. Die beiden hinteren kleinen Schneidezähne fehlen zuweilen, sowohl bei deutschen (245) als bei Hasenkaninchen (242).

Pathologische Anatomie. Wird ein Schneidezahn nicht fortwïhrend durch den Gebrauch bis auf seine normale Länge abgeschlillen, so wïchst derselbe unaufhaltsam weiter und bildet eine Spirale (Fig. 80), die anfangs an den Stoßzahn eines Elephanten erinnert. Wenn der entgegenstehende Schneidezahn verloren gegangen ist, oder wegen einer Fraktur des Unterkiefers, die unvollständig geheilt ist, die entgegenstehenden Schneidezähne sich nicht treffen kömmen, so schleifen sich die freien Enden zu Spitzen ab,

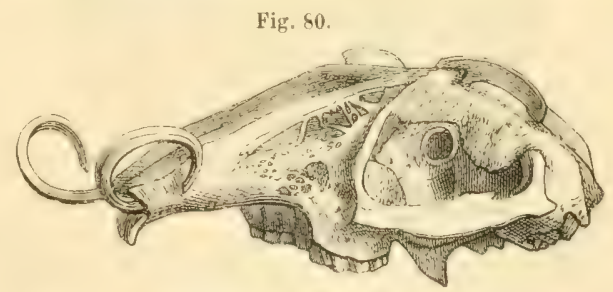

Schâdel mit zwei aufwät se gekrummten Schneidezahnen. etwas verkleinert.

welche gegen den Schidel rückwirts wachsen. Dasselhe ist auch bei den hinteren Schneidezïhnen des Oberkiefers der Fall. Falls die Schneidezähne hei diesem ungehinderten Wachstum aul den entgegenstehenden liefer treffen, so durchhohren sie die Haut und den Knochen und können von hinten her in letzteren oder in den Nund eindringen (250 - vergl. a. 24, S. 38). Will man dies abnorme 
Wachstum kïnstlich erzeugen, so darf man nur einen Zahn ausziehen, weil das Tier sonst durch Verhungern zu Grunde gehen kann.

Die Schneidezähne reproduzieren sich nach ihrer Entfernung ganz vollkommen, wenn der Zahnkeim unverletzt geblieben ist (257).

Backenzihne, Dentes molares, zeigen sich sechs im Oberkiefer, fün im Unterkiefer. Sie haben quere Linien von Schmelz auf ihren flachen Oberflachen und cinfache Wurzeln. Ihre medialen und lateralen Flachen tragen Lingsriffe, deren Anzahl wechselt. Die des Oberkiefers zeigen nur Eine Furche, ihre Dicke ist von vorn nach hinten viel geringer, als in transversaler Richtung, während die Backenzähne des Unterkiefers einen mehr quadratischen Querschnitt besitzen. Letztere haben tiefere Furchen an der lateralen Seite und meistens zwei deutlichere Lingsriffe. Der erste untere Backenzahn ist der starkste, besitzt zwei Laingsfurchen auf der lateralen, eine auf der vorderen Fliche; der fünte oder hinterste ist kleiner, sein hinteres Ende schrig nach hinten und unten gerichtet; die laterale Fliche zeigt eine flache Lingsfurche. Am kleinsten ist der hinterste oder sechste obere Backenzahn. Die aus der Schleimhaut frei hervorragenden Teile der Backenzahne sind zum Teil pigmentiert.

Was den feineren Bau anlangt, so sind die Backenzähne lamelliert, Dentes lamellati, Blitterzihne. Sie bestehen nämlich aus Dentinsubstanz, die von Schmelzplatten iberzogen wird, und letztere werden ihrerseits durch Zement verbunden (Fig. 81). Folge dieser Anordnung (die noch bei Cavia, Elephas u. s. w. vorkommt) ist ungleichmäßige Abnutzung dieser verschieden harten, aber stets gleich-

Fig. 81.

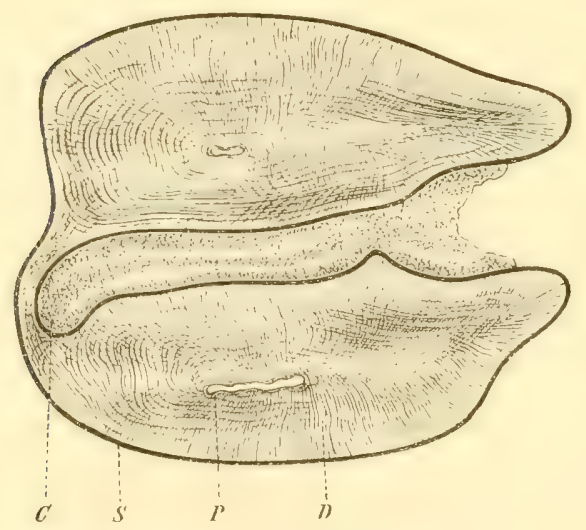

Querdurchschnitt eines rechten Backenzahnes, von oben. Nach Behandlung mit 5\% oiger Chlorwasserstoffsäure, Wasser, Gummilösung, Alkohol, Nelkenōl, Dammar. Vergr. 22. $C$ Zement. S Schmelz. P Pulpahöhle, $D$ Dentiu. mäßig nachwachsenden Substanzen: daher springen an der Kaufläche die Schmelzfalten als scharfe Riffe hervor, während das Zement sich rascher abnutzt als das Dentin. Jeder Abteilung kommt eine abgeplattete Pulpahöhle zu (Fig. 81); in das Dentin reichen Blutgefaße beinahe bis zu dessen Oberfläche, von der letzteren aus hinein.

Varietät. Es ist einmal bei einem Widderkaninchen ein überzähliger Prämolarzahn an einer Seite beobachtet (254).

Zahnwechsel. Die definitive Zahnformel lautet:

$i \frac{2}{1} \cdot c \frac{0}{0} \cdot p m \frac{3}{2} \cdot m \frac{3}{3}=28$ oder abgekürzt :

$$
i \frac{2}{1} \cdot m \frac{6}{5}=28 \text {. }
$$

Das Milchgebiß besteht einige Tage nach der Geburt aus den Schneidezaihnen nebst drei oberen und zwei unteren Prämolaren, so daß die provisorische Zahnformel lautet:

$$
i \frac{2}{1} \cdot p m \frac{3}{2}=16 .
$$


Eckzähne sind niemals vorhanden. Die vier großen Schneidez:ihne sind von vornherein bleibende; der zweite oder bintere Milchschneidezahn wird aber durch den definitiven kleinen Schneidezahn erset»t. Einige Zeit bestehen beide gleichzeitig, so daß, da die großen Schneidezïhne, wie gesagt, einem Wechsel nicht unterliegen, einige Tage nach der Geburt (255) jederseits drei Schneidezihne im Oberkiefer vorhanden sind, von denen der mittlere der Milchzahn ist 25.4 . Hierauf bezieht sich wohl eine Angabe F. Cuvier's $(255)$, wonach bei sehr jungen Hasen ein dritter Zahn in jedem Os intermaxillare hinter dem kleinen Schneidezahn existiert, derselbe soll sehr bald verloren gehen und seine Alveole obliterieren. Cuvier hat sieben Arten der IIasen untersucht, Carus (251) verallgemeinert die Angabe für die Leporidenordnung (S. 10 ) überhaupt.

Der Zahnwechsel findet beim Kaninchen (wie beim Hasen) etwa 18 Tage nach der Geburt statt (25j). Die drei vorderen Backenzilune des Oberkiefers und die zwei vorderen des Unterkiefers folgen auf vorausgegangene Milchzähne und erscheinen gleichzeitig mit dem letzten Backenzahn. Was das Genauere anlangt, so brechen im Oberkiefer die beiden vorderen Molaren elwas früher durch als die drei definitiven Primolaren, daun folgt der hinterste Molarzahn. Ehenso werden im Lnterkiefer dic beiden Prämolaren ersetzt, damn brechen fast gleichzeitig die beiden vorderen und etwas späler der hinterste Molarzahn durch. Den Milchbackenzähnen sind von mehreren Seiten (258, 252 u. 254) Wurzeln zugeschrieben worden, von anderer Seite (259) werden dieselben mit Recht geleugnet. Der Anschein eines drei- oder vierwurzeligen Zahnes ist am I'rischen Präparat sehr täuschend; schon mit der. Lupe sieht man aber, diß die vermeintlich kegelförmigen Wurzeln Reste der Schmelz- und Dentinlamellen sind, welche durch die dem Ausfallen des

Fig. 52.

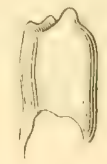

Rechter vorlerer Milibivkenzabn aus lem Unterkiefer eino: 12tägigen Kaniuchens mit zwej scheinbaren Wurzeln. Vergr. 5. Milchzahnes vorhergehende Resorption zugeschärft worden sind (Fig. 82).

Über die Zähne des Kaninchens und Hasen siehe auch 240 u. 241; über den feineren Bau derselben s. 256.

\section{Gaumen.}

Nur ein kleiner miltlerer Teil des faumens wird von den Processus palat tini oss. maxilaris superioris und den Partes palatinae oss. palatini gebildet. Vor demselben liegt das Foramen incisivum, welches durch eine feste, mit Querrunzeln, die in der Medianlinie geteilt sind, versehene mul rom sichleimhaut uberkleidete Membran verschlossen wird. Die vorderen von den 16 Ouerrunzeln verlaufen etwas gebogen, jede stioßt mit der korespomdierenden der anderen Seite unter einem stumpfen Wiukel zusammen, dessen Spitze nach hinten grerichtet ist. Die hintersten Querunzeln liegen unter dem Palatum durum; die vier letzten verlaufen mehr gerade; die hinlerste liegt dem vierten oheren Backenzahne gegeniiher. Dicht hinter den kleinens.hneidezilmen findet sich eine rundliche Platte, die nach hinten beiderseits in die vorderste Querfalte des Gaumens ausliuft und am lateralen Rande dieser Schleimhautplatte jederseits eine enge, lingliche Spalte, die Mündung des Ductus nasopalatinus (S. 194). Über die Nerven des harten Gaumens vergl. 5\%, S. 542. 
Das Velum palalinum oder der weiche Gaumen ist sehr lang, circa $3 \mathrm{~cm}$; enthält eine große Anzahl von aciuösen Drüsen. Seine Dicke betrigt ca. $2 \mathrm{~mm}$. Die Urula fehlt; der Arcus glossopalatinus ist sehr flach, zwischen letherem und dem Areus pharyngopalatinus liegt die Tonsille. Beide Areus enthalten Muskeln: Mm. glossopalatimus und pharyngopalatimus.

Die doppeltkonturierten Nervenfasern sollen sich (an Präiparaten aus Kalimmbichromat) an der Spitze der Gaumenpapillen in piuselförmig ausstrahlende varikiose Nerventibrillen aufasern und letztere in terminalen Ganglienzellen (Tastzellen) endigen. Die betreffende Abbildung (10I, Taf. VI, Fig. 27) zeigt jedoch, daß es sich um die gewöhnlichen Zylinderzellen der tiefisten Zellensehicht handelt. - Die Länge des weichen Gaumens beträgt $10 \mathrm{~mm}$, seine Breite $7 \mathrm{~mm}$ $(827$, S. 32$)$.

Die Tonsillen sind sehr weniw entwickelt, liegen nabe oberhall, der Épiglottis; jede ist "5 mm ron oben nach unten lang, 2 mm hreit. Das Organ erscheint hier in seiner einfachsten Form: es ist eine Grube vorhanden, deren Wandung von zahlreichen Lymphfollikeln und zwischengelagerten LymphgefaßBen gebildet wird. Eine Art Kapsel von Bindegewebe grenzt die Follikellage, die einem eingestülpten l'eyer'schen Ilaufen entspricht, nach außen ab; in die Grube münden zahlreiche acinöse Driisen, deren Ausführungsginge zwischen den Lymphfollikeln rerlaufen. Das Organ im Ganzen reprasentiert gleichsam eine vergrößerte Zungenhalgdrüse des Menschen (657).

\section{Muskeln des Velum palatinum.}

M. levator veli palatini. Ursprung: Untere Fliche der Pars petrosa oss. tempormm und Tuba Eustachii, verlauft abwarts und nach vorn. Insertion: Velum palatinum.

M. Lensor veli palatini. Lirsprung: Laterale FJache der Lamina medialis des Processus pterygoideus oss. sphenoidei. Insertion: Der Muskel geht in eine glinzende platte Selne uber, welche sich um den IIamulus pterygoideus herumschlagt und in transrersaler Richtung in das Velum palatinum ausstrablt.

\section{Zunge.}

Die Zunge ist relativ groß, linglich, ihre untere Fliche in bedeutender Ausdehnung bis zum Frenulum linguce frei. Die obere Fliche ist in ihrer nur ein wenig großeren vorderen Halfte weich, feucht und mit kaum durch das bloße Auge wahrnehmbaren Papillue fungiformes besetzl. Hinten findet sich im medialen Teile cin glatter, trockener, hornahnlicher, 2 cm langer, vorn zugespitz endicrender Vorsprung, der eine knorpelharte Platte darstellt. Hinter demselhen zeigt sich lateralwirts jederseits eine deutliche Papilla circumvallata.

Fimbriae linguae. Vor dem unteren Ende des Areus glossopalatinus findet sich an heiden Seitenrindern der Zunge ein hesonderes Geschmacksorgan. Es sind elwa 20 schrigg abwarts veranfende Schleimhatfalten, in deren Basis Geschmacksknospen liegen. Inter denselben verbreiten sich Äste des $N$. glossopharyngeus.

v. Wyss $(244)$ hat diese von C. Nayer $\left(245^{\circ}\right)$ beim Kaninchen entdeckten Fimbrien als Papilla foliata bezeichnet. 
Die Länge der Fimbriae linguae beträgt $5-6 \mathrm{~mm}$, die Breite $2,5-3,5 \mathrm{~mm}$, die Anzahl der Querfurchen nur 10-14 (6903). Die Anzahl der Geschmacksknospen, von denen jedesmal 4 übereinander zu sitzen pflegen, in Summa 7440 jederseits $(620)$. Die Länge der Geschmacksknospen betrïgt $0,0575 \mathrm{~mm}(6.57)$.

Nerven der Zunge. An den Ästen der Nn. glossopharyngeus, lingualis und hypoglossus imnerhalb der Zunge kommen mikroskopische Ganglien vor $(246)$, welche den Ganglienplexus des Darmkanales zu parallelisieren sind. In den Zungenpapillen sind früher einmal ovale Körperchen als Enden der Geschmacksnerven beschrieben worden $(247)$. In Wahrheil kommen, in den Papillae fungiformes wenigstens, zylindrische Endkolben vor (W. Krause). An dem Seitenrande der Papillae circumvallatae zeigl das Epithel Geschmachsinospen /Schmeckbecher, 248). Nach Durchschneidung des N. glossopharyngeus entartet das Epithel der Papillae circumvallatae und Fimbriae linguae fettig 621 ); man kann jedoch daraus die nervöse Natur der Epithelialzellen der Geschmacksknospen nicht ohne weiteres ableiten, weil Resektionen sensibler Nerven von Ernährungsstörungen wie beim N. Irigeminus begleitet zu sein pllegen. - In der Unterzungenschleimhaut haben die zylindrischen Endkolben ca. 0, 11 mm Länge, 0,03-0,04 Breite $(860)$.

\section{Mnskeln der Zunge.}

M. hyoglossus. Besteht aus drei Abteilungen. Der M. ceratoglossus (Fig. 82, ?) entspringt vom Cornu majus oss. hyoidei, der M. basioglossus vom Corpus oss. hyoidei, der $\boldsymbol{M}$. chondroglossus vom Cornu minus oss. hyoidei. Verlaufen in longitudinaler Richtung am lateralen Zungenrande, bedeckt vom M. styloglossus; nur die hinteren Bündel des $\mathbf{M}$. ceratoglossus laufen auf dem Zungenrúcken, unmittelbar unter der knorpelartigen Platte desselben gegen die $\mathrm{Me}-$ dianlinie konvergierend, nach vorn. Insertion: Zum größten Teile in der Nähe der Zungenspitze; mit einzelnen Ansätzen auch an der Oberfläche der freien Zungenhälfe.

M. genioglossus. Ursprung: Verbindungsstelle des hinteren Randes beider Halften des Corpus maxillae inferioris. Insertion: Strahlt nach rúckwärts und aufwärts gegen die Zungenoberfläche aus, liefert die perpendikulären Fasern der Zunge mit Ausnahme der lateralen Rander und der Zungenspitze, wo die letzteren dem M. lingualis angehören. Beide $\mathbf{M m}$. genioglossi werden durch das Septum linguae getrennt.

M. styloglossus. Ursprung: Processus jugularis (posterior) oss. occipitis,

Seitenansicht des Pharynx und Kehlkopfes (nach Sehneider, 250). 1 M. Inylohyoideus. 2 M. hyoglossus, vor demselben der hintere Rand des M. geniohyoideus, 3 II. sternohyoideus, abgeschnitten. $4 \mathrm{MI}$ thyreohyoideus, oberes Ende, abgeschnitten. 5 Membrana thyreohy oidea. 6 Cartilago thyreoidea. 7 M. thyreohyoideus, unteres Ende. $\delta$ M. sternohyoideus, abgeschnitten. $9 \mathbf{M}$. cricothyreoideus. 10 Trachea, 11 M. styloglossus, 12 MI. stylopharyngeus. $X I I \mathrm{~N}$. hypoglossus. IX N. glossopharyngeus. $13 \mathrm{~A}$. lingualis. 14 Cornu majus oss. hyoidei. 15 II. constrictor pharyngis medius. 16 Ramus internus des $\mathrm{N}$. laryngeus superior. 17 Ramus externus des $\mathrm{N}$. laryngeus superior. $18 \mathrm{M}$. constrictor pharyngis inferior. $19 \mathrm{R}$. cardiacus $\mathrm{n}$. vagi. 20 N. recurren. 210 esophagus. 
laterahwirts rom M. stylohyoideus minor. In seinem sehnigen Lrsprunge liegt der mit der Spitze des Processus jugularis posterior) oss. occipitis beweglich verbundene, ahgerundet dreikintige, einige mm lange und etwa $0,5 \mathrm{~mm}$ dicke Processus styloideus (S.87). Verlauft abwirts vor dem M. stylohyoideus minor, tritt in den hinteren Teil der Zunge, erstreckt sich im unteren Teile des Zungenrandes (Fig. 83, $11, \mathrm{~S} .201$ ) lateralwirts neben den Mm. hyoglossus und genioglossus mit longitudinalen Biudeln nach rorn, verschmilzt teilweise mit dem Muskel der entgegengesetzten Seite am vorderen Rande der Mm. hyoglossi. Insertion: Schleimhat des vorderen Teiles der Zunge, nahe der Spitze.

11. lingualis. Der eigene Muskel der Zunge besteht aus transversalen, perpendikuliren und longitudinalen Fasern, welche die übrigen Zungenmuskeln mannigfach durchkreuzen und von einander trennen. Die transversalen Bindel entspringen am Septum, verlaufen bogenförmig lateralwarts und aufwirts, sondern die Fasern der Mm. genioglossi und die perpendikuliren Fasern des M. lingualis in viele einzelne'Bliatter. Insertion: Schleimhaut des Zungenrickens und der unteren liache der Zungenrinder; am ersteren treten mikroskopische Sehnenfasern in die Papillae fungiformes ein. - Die perpendikularen lasem begimnen und endigen in der Spitze und in den Seitenrindern der Zunge selbst. - Die longitudinalen Fasern sind vereinzelt und schwach; sie liegen in der Schleimhaut. - Vergl. 249.

\section{Speicheldrüsen.}

Jederseits sind sechs vorhanden : Gl. infraorbitalis, buccalis, mandibularis superficialis, parotis, submaxillaris, sublingualis.

Fig. 84.

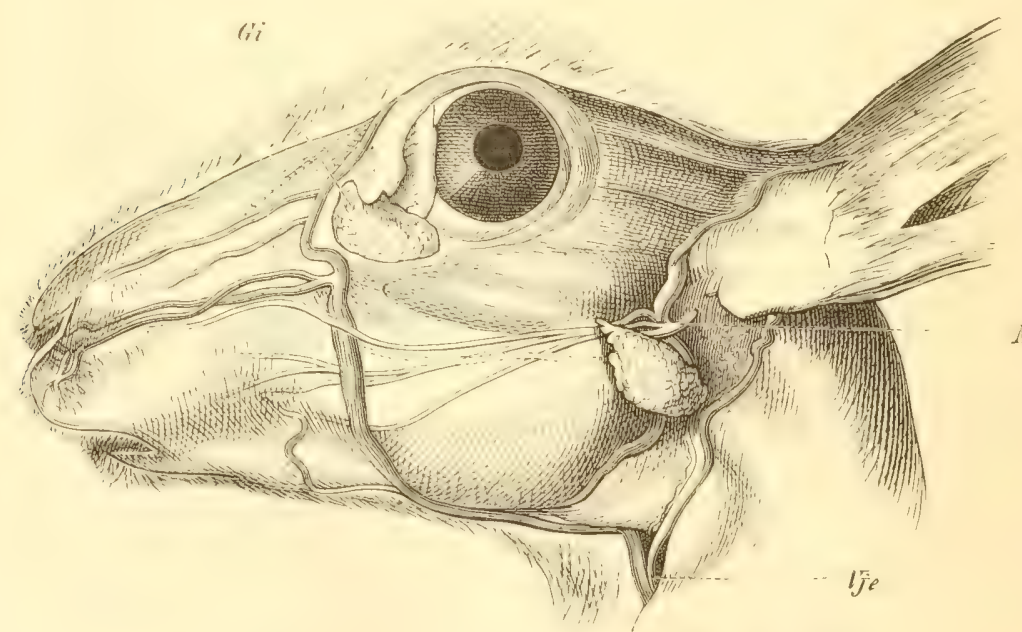

$\lambda F$

$N f \mathrm{~N}$. facialis. $\nabla j \in \mathrm{V}$.jugularis externa. $G i$ Gl. infraorbitalis.

Gl. infraorbitalis. Hre Linge in sagittaler Richtung betrigt etwa $8 \mathrm{~mm}$; ihre Breite und Dicke Lall) so viel; ihr Gewicht $0,15 \mathrm{~g}$. Sie liegt (Fig. 84) 
im unteren vorderen Winkel des Carum orbitale, hinter der Wurzel des Processus orbitalis oss. zygomatici und dem vorderen Ende der Palpebra inferior, lateralwarts von den Alveolen des dritten bis funften Backenzahnes, vor und medianwiirts von dem M. pterygoideus internus, unter dem II. obliquus oculi inferior und der Gl. Harderiana, von letzterer durch die Membrana orbitalis getrennt. Nach unten wird sie noch vom oberen Rande des hinteren Teiles des M. buccinator begrenzt; nach hinten reicht sie an die Insertion des M. temporalis am Processus coronoideus maxillate inferioris. Ihr feiner Ausfiihrungsgang verliuft an ihrem unteren Ende abwairts, mundet in die obere Umschlagsfalte der Backenschleimhatu, in der Gegend des dritten oberen Backenzahnes. Sie ist als eine stark entwickelte Gl. Juccalis superior zu betrachten.

Die Acini sind stark in die Länge gezogen; z. B. 0, $14 \mathrm{~mm}$ lang, 0,05 $\mathrm{mm}$ breit und dick. Man hann die Drüse zu den tubulösen Eiweißdrüsen (S. 59 ) rechnen; das Zellenprotoplasma wird durch Alkohol getrïbt und durch Karmin, nicht aber durch Hämatoxylin gefärbt. Die Drüsenepithelzellen sind von niedriger Zylinderform, Halbmonde fehlen.

Blutgefäße erhält die Drüse von den A. und V. infraorbitales. - Ihre Nerven verlaufen beim Ilunde in der Bahn des N. buccinatorius, dessen Erregung Sekretion veranlaßt $(231)$. — Uber das Bindegewebe in ihrer Umgebung vergl. 5j2, S. 37.

Glandulue buccales. Sie stellen bedeutend entwickelte Drüsenpakete dar, liegen zwischen den Bündeln des M. buccinator und der Backenschleimhaut. Die superiores bestehen aus einzelnen Lappchen, welehe mit kurzen Ausführungsgängen neben der GI. infraorbitalis einmünden.

Die Gl. buccalis inferior stellt einen mehr abgeschlossenen, beinahe zylindrischen Drüsenkörper dar, von ca. $12 \mathrm{~mm}$ Linge, $4-5 \mathrm{~mm}$ Breite und Dicke und $0,11 \mathrm{~g}$ Schwere. Die Gl. buccalis inferior liegt mit ihrer Lingsachse parallel dem oberen Rande der Pars bucalis des Corpus maxillae inferioris, lateralwirts von den unteren Backenzihnen, vor dem vorderen Rande des M. masseter. Thre $4-5$ kurzen Ausfihhrungsginge liegen in einer horizontalen und sagiltalen Reihe vor- und lateralwaits rom ersten und zweiten unteren Backenzahne. - Vergl. 101 und 252.

Gl. mandibularis superficialis (101). Eine kleinere, längliche Druse erstreckt sich am unteren lateralen Rand der Pars incisiva des Corpus maxillae inferioris entlang der Alveole des Schneidezahnes.

Gl. parotis ist viel großer als die Gl. submaxillaris, wiegt $1,1 \mathrm{~g}$ oder fast doppelt so viel als letztere. Sie besteht aus drei zusammenhingenden Teilen. Der obere Teil stellt eine platte, unregelmaßige Scheibe von $1 \mathrm{~cm}$ Durchmesser und 2-3 Dicke, mit zugeschirften Rindern dar; derselbe liegt vor dem iußeren Ohre, hinter dem oberen hinteren Rande und dem Lrsprunge des M. masseter, unterhalh des hinteren Endes des processus temporalis oss. zygomatici und füllt diesen. Raum aus. Der Verbindungsteil ist schmal, $2-3 \mathrm{~cm}$ lang, $3 \mathrm{~mm}$ hreit, 1-2 nm dick, erstreckt sich abwirts hinter dem Angulus maxillae inferioris. Der untere Teil (Fig. 103, 39) ist dreiseilig prismatisch, $1,5 \mathrm{~cm}$ lang, $4-5 \mathrm{~mm}$ dick, liegt am hinteren Abschnitt der Insertion des M. pterygoideus internus an die Maxilla inferior. Nach oben grenzt derselbe an die Sehne des M. mandibulae, lateralwarts an den M. pterygoi- 
deus internus, nach vorn an die Gl. subnaxillaris; nach hinten wird derselbe von der Faszie, dem M. parotideo-auricularis posticus und der llaut bedeckt.

Die Acini haben 0, 04 , ihre Zellen 0,01-0,012 mm Durchmesser (252, S. 34). Die Zellenkerne in den Acini der auf Sympathicus-Reizung thätig gewesenen Drüse sind kuglig, mit deutlicher Kernmembran und Kernkörperchen versehen. In der ruhenden Drüse sind sie dagegen eckig, zackig, ohne scharfe Konturen und Kernkörperchen (11.;, S. 59). - Veranlaßt man ein Kaninchen durch mehrstündiges Humgern zu reichlicher Nahrungsaufnahme und tötet es elwa eine Stunde nach dem Kauen, so sind diese Unterschiede leicht zu bestätigen (W. Krause). Von anderer Seite $\left(185^{\circ}\right)$ ist versucht worlen, jene form der Kerue auf deren Schrumpfung in Alkohol zurïckzufïhren. - Man kïnnte aus obiger Beschreibung schließen wollen, daß es sich um Kernfiguren, speziell Küuelformen, um massenhafte Zellenerneuerung durch Karyokinese handle; indessen liiß। Safranin- Ind Hamatoxylinfärbung nicht mehr als das Angegebene erkennen.

Man kamn bei narkotisierten jungen Tieren die peripherischen Acini auch im Leben mikroskopisch untersuchen $(773)$. - Über Einimpfung von Hundswuth und Impfungen mit Speichel vom gesunden Menschen s. 857, S. 204.

Nerven erhält die Gl. parotis vom N. sympathicus und vom N. facialis, die in der Bahn des N. petrosus superficialis minor (252) vom Ganglion geniculum zu den Ganglia otica und ron dort durch den Verbindungsfaden des Ganglion oticum posterius mit dem N. auriculotemporalis des N. masillaris inferior zur Drüse gelangen (205). Der N. trigeminus enthält in seinen Wurzeln keine Sekretionsfasern für die Gl. parotis, was man (254) frïher angegeben hatte (s. auch Neurologie, Kopfteil des sympathischen Nervensystemes).

Duclus parotideus s. Stenonianus. Der Ausfialurungsgang der Gl. parotis hat ca. 0,2 mm Durchnesser; beginnt am oberen Teil der Drüse, verlauft innerhalb der Faszic, an der lateralen Seite des M. masseter, ungefihr in der Mitte seiner Ausdehnumg von oben nach unten, zwischen den Ästen des $\mathrm{N}$. facialis und parallel mit der $A$. transrersa faciei, biegt sich um den vorderen Raud des M. masseler, um sich in die Backenschleimhaut gegenúber dem letzten oberen Backenzahn einzusenken.

Aufsuchung des Ductus parotideus. Da derselbe zu fein ist, um mit Leichtigkeit die Einführung einer Kanüle zu gestatten, so durchschneidet man ihn quer und fangt den ausfließenden Speichel z. B. in rothem Lakmuspapier auf. Hautschnilt in vertikaler Richtung, in dessen Verlingerung das Hornhautzentrum fallt. Die Nerven und Gefiße (Fig. 85) bis auf den M. masseter werden gleich mitdurcbschnitten; die Blutung steht von selbst. Bei Kaubewegungen fließen Speicheltropfen aus (254). Um Speichelversuche unter Erregung der Wurzel des N. facialis schnell auszuführen, kann man den Kopl des mit einem wie eine Hacke geformten Instrument dekapitierten Tieres mittels desselben, nachdem vorgesägt worden ist, halbieren $(\mathbf{8 6 1})$, auch die Gehirnhälfte leicht aus dem Schidel entfernen. - Bei anderen Pllanzenfressern (Schaf etc.) verläuft der Ductus parolideus bekanntlich hinter dem Angulus maxillae inferioris abwärts.

Nach Einführung einer feinen Glasröhre kann man binnen 30 Hinuten ca. $0,5 \mathrm{ccm}$ Speichel durch Reizung des N. sympathicus am IIalse gewinnen (255). Der Ductus parotideus ist von einem Ganglien-fïhrenden Plexus umgeben $(2060)$.

$G l$. submaxillaris ist von ellipsoidischer Gestalt, die Lingsachse von ra. I,5 am erstreckt sich in sagittaler Rirhtung: die Dríse wiegt 0.6 g. Sie liegt mediam arts vom rorderen Teil des Insatzes des 11 . pterygoideus inter- 
nus, nach unten von der Faszie und dem M. submentalis bedeckt, nach hinten grenzt sie an den unteren Teil der GI. parotis. In der Medianlinie stößt sie mit der Drüse der anderen Seite zusammen; über ihr liegt der M. mylohyoideus.

Fig. 85.

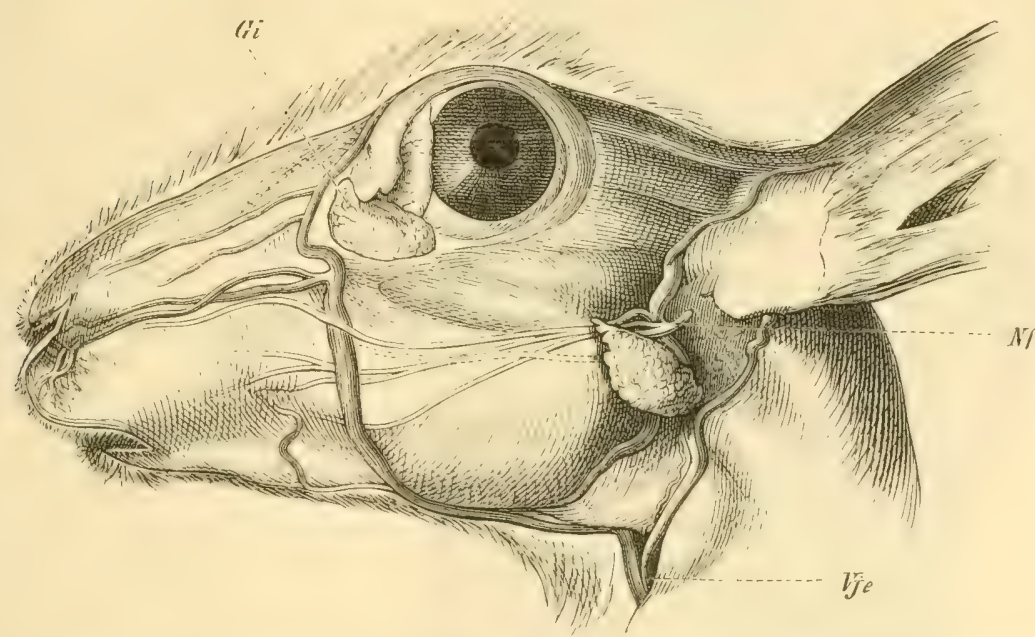

$N f \mathrm{~N}$. facialis. $\quad V_{j}$ V.jugularis externa. $G i$ Gl, infraorbitalis. - Der obere Teil der Gl, parotis ist nach unten und vorn zurückgeschlagen, um den Austritt des N, facialis aus dem Foramen stylomastoideum zu zeigen. Der Ductus parotideus ist punktiert. Die Venen sind injiziert.

Tubulöser Teil der Gl. submaxillaris. Ein Läppchen von 3-4 mm Länge $(258)$, aber wie es scheint nur 0,3-0,4 mm Dicke zeichnet sich durch seine besondere mikroskopische Struktur aus. Dasselbe liegt allseitig von acinöser Drüsensubstanz umgeben (Fig. 86) in meistens nur geringer Entfernung von den in den Hilus der Gl. submaxillaris eintretenden stärkeren Blutgefäßen und Ausführungsgängen; bei neugeborenen Kaninchen aber befindet es sich an der Peripherie der Drüse $(258)$.

Die eigentliche Gl. submaxillaris ist beim Kaninchen nach dem Typus derEiweißdrüsen (S.59) gebaut. Die Acini messen 0,03 , die Zellen derselben $0,01-$ $0,015 \mathrm{~mm}(232)$. Die Epithelialzellen der Acini fïrben sich relativ weniger in Karmin, intensiver diejenigen der Ausführungsgïnge, auch der feinsten, selbstverständlich werden unter diesen Umständen die Kerne tingiert. Die Drüsenepithelzellen sind pyramidenförmig, die Kerne, wo sie ellipsoidisch sind, mit der Längsachse senkrecht zur Achse des Ganges Fig. 86. gestellt.

Der tubulöse Teil (Fig. 87, S.206) derGl. submaxillaris färbt sich intensiver. Bei schwächerer Vergrößerung erinnert sein Aussehen an einen feinen Durchschnitt durch einen Schweißdrüsenknïuel. Jener Teil besteht aus gewundenen, dichotomisch verüstelten, blind endigenden (Fig. $87 \mathrm{~b}$ ) Kanälen, die ein durch Bindegewebe vom übrigen Teil der Drüse abgegrenztes Konglomerat bilden. Sie werden von einer einfachen Lage Plattenepithelialzellen von $0,00\{\mathrm{~mm}$ Höhe auf $0,01 \mathrm{~mm}$ Breite 
(258) ausgekleidet; die Kerne derselben sind kuglig und, wenn sie ellipsoidisch sind, mit ihrer Laingsachse tangential zum Lumen des Ganges gestell ( 258$)$. Aus-

Fig. 87.

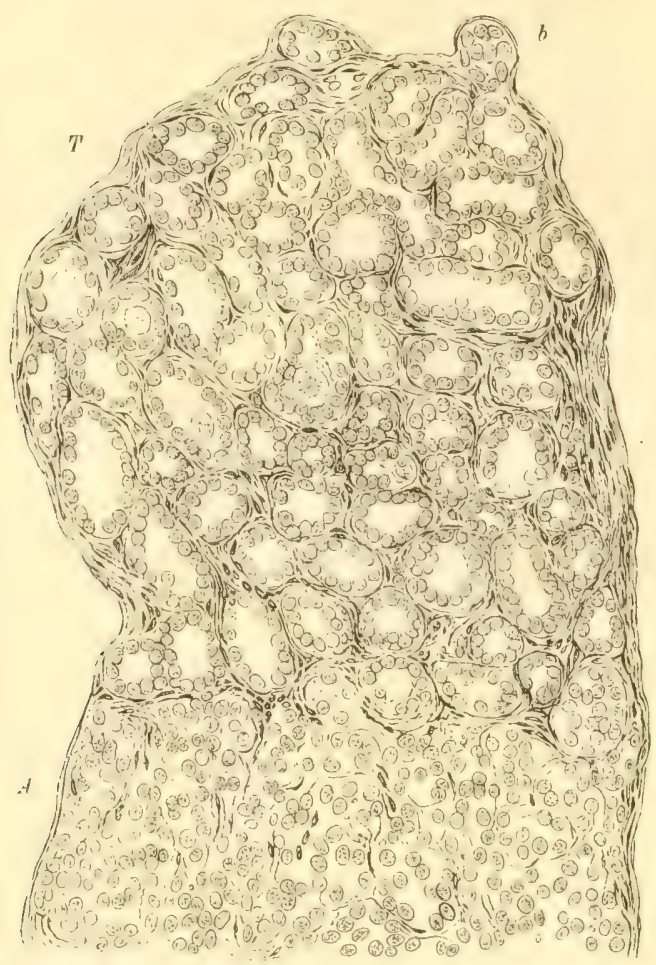

Präparat von Fig. 86. Vergr, 250. T tubulöser Teil der Gl. submaxillaris. A Algrenzung durch Bindegewelie gegen den acinösen Teil der Druse. $b$ Blinde Endigung eines Drüsenkanales. wendig wird die Membrana propria der Acini von einem kernhaltigen Gewebe umgeben: Diese Kerne (Fig. 87) gehören offenbar glatten Muskelfasern an. Das Lumen der Gänge ist zylindrisch, 0,017 $-0,02 \mathrm{~mm}$ weit (Fig. 87 ) und hiufig von einem Schleimpfropf ausgefüllt. Vom Ductus submaxillaris aus können dieselben injiziert werden (258).

Nach allen diesen Thatsachen liegt unzweifelhaft ein morphologisch und funktionell differierender Drüsenabschnitt vor. Da bei Kaninchen-Embryonen von $56 \mathrm{~mm}$ Körperlänge eine Anlage des Ductus sublingualis existiert, die spåter zu Grunde geht (259), so könnte mau dieselbe in Beziehung zu diesem im Innern der

Gl. submaxillaris eingeschlossenen Gebilde bringen wollen. Danach wäre deren tubuloser Teil die eigentliche, auf rudimentirer Stufe stehengebliebene Gl. sublingualis und die Verbindung mit dem Ductus submaxillaris, wie sie aus den Injektionsresultaten erhellt, als sekundiir aufzufassen. Die oberhalb des M. mylohyoideus gelegene (S. 208) Gl. sublingualis des Kaninchens wire aber der durch den Ductus sublingualis s. Bartholinianus charakterisierten eigentlichen Gl. sublingualis anderer siugetiere keineswegs homolog. Andererseits verdient eine Vermuthung von Ileidenhain (briefliche Milteilung an W. Krause vom Jahre 1879) jedenfalls Beachtung, wonach es sich um einen rudimentiir gebliebenen Abschnitt der GI. submaxillaris selbst handeln wïrde; diese Annahme vermag jedoch das Vorhandensein glatter Muskelfasern nicht zu erklären.

Nach der Entdeckung (258) des fubulösen Drüsenabschnittes war es begreiflich, daß ein solcher auch bei anderen Säugern vermutet wurde. Das unter obigem Namen bei Itunden und Katzen beschriebene 238) Gebilde hat sich jedoch als die Gl. sublingualis herauscestell $(260)$. Beim Kaninchen war eine solche Verwechselung deshalb unmöglich, weil der M. mylohyoideus die Gl. submaxillaris und sublingualis von einander trennt (S. 208). In der Gl, submaxillaris des Menschen kommt ein ähnliches tubulöses Rudiment vor (258). 
Nerven erhält die Gl. submaxillaris vom Ganglion linguale; sie begleiten den Ductus submaxillaris, führen Ganglien, die auch im Innern der Druse zahlreich vorhanden sind (W. Krause, 26/). Die A. submaxillaris wird von sympathischen Gefaßnerven begleitet; die sekretorischen Fasern stammen wahrscheinlich vom N. trigeminus und $\mathrm{N}$. facialis $(257, \mathrm{~S} .292)$ und verlaufen, wie es scheint, zum Teil in der Chorda tympani; die Endigung der doppeltkonturierten Fibrillen ist nicht bekannt. Von den blassen oder marklosen i)rüsennervenfasern dagegen ist anzunehmen, daß sie sich in der Gl. parotis des Schweines an die Wandung einzelner Acini anlegen und, wie es schien, mil sekretorischen Endplatten aufhören. Auch ließen sich multipolare Zellen aus dem Bindegewebe zwischen den Acini isolieren $(262)$. Für die Erforschung der relativ sparsamen doppeltkonturierten Fasern ist die Methode des Einlegens der GI. submaxillaris des Kaninchens mit ihrem schleimigen, fadenziehenden Inhalt in sehr verdünnte Chromsäurelösung nicht geeignet.

Ductus submaxillaris s. Whartonianus. Der Ausfïhrungsgang der Gl. submaxillaris hat $0,3 \mathrm{~mm}$ Durchmesser, $3 \mathrm{~cm}$ Lánge und ist sehr dinnwandig. Derselbe liegt anfangs über dem vorderen Teil der Gl. submaxillaris, verläuft an der lateralen Seite der Ursprungssehne des M. mandibulae, sich mit derselben in schräger Richtung kreuzend, nach oben und vorn; kreuzt sich auch mit der A. maxillaris externa, unter welcher er liegt, fast rechtwinklig; gelangt am hinteren Rande des M. mylohyoideus über denselben und den M. geniohyoideus; verläuft dann oberhalb der GI. sublingualis an der lateralen Fläche der Mm. hyoglossus und genioglossus nach vorn und medianwirts und öfnet sich neben dem Frenulum

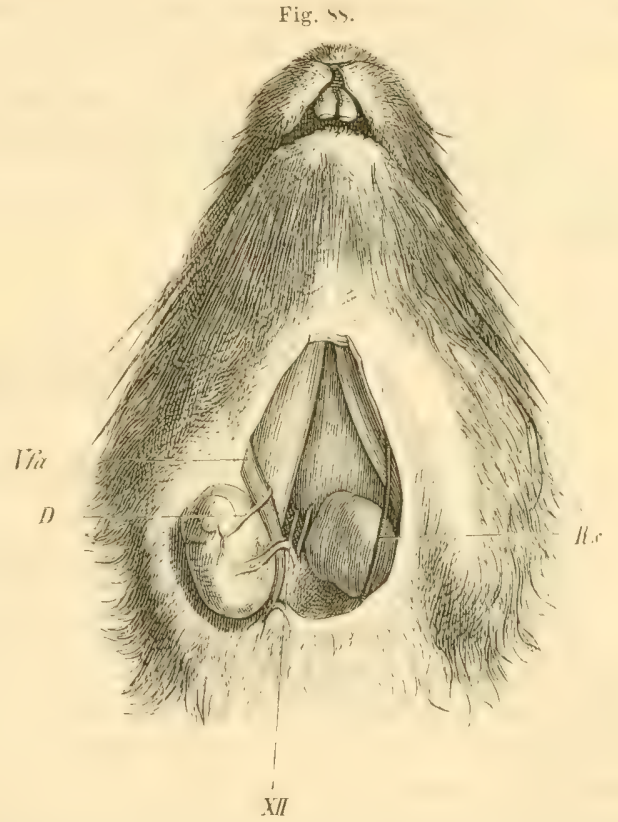

Anfsuchung des Ductus submaxillaris, Rechterseits ist die GI. submaxillaris aus ihrer Nische lateralwärts geschlagen. D Ductus submaxillaris. Weiter rückwärts treten die A., dahinter die V. submaxillaris in die Druse. Vfa V. facialis anterior. Nach der Medianlinie him erscheint das Cornu majus oss. hyoidei, und parallel demselben $X I I$ der N. hypoglossus. $R$ s Ramus submentalis sinister aus der A. maxillaris externa sinistra. linguae, ohne daß eine papillenähnliche Mündung vorhanden ware.

Nach Hilgendorf $(8 / 8)$ ist jederseits eine Papille neben der Medianebene etwa an der Grenze des vorderen und miltleren Dritteiles der Entfernung zwischen Schneidezahn und erstem Backenzahn des Unterkiefers vorhanden.

Aufsuchung des Ductus submaxillaris. Der Kopf des Tieres wird, nachdem dasselbe in der Rückenlage befestigt ist, hinten übergebengt, so daß die Scheitelgegend das Brett berübrt, und in dieser Lage entweder durch einen Gehilfen mit 
der Hand oder mittels einer un die großen Schneidezähne des Oberkiefers gelegten Schnur fixiert. Hautschnitt in der Medianlinie von dem hinteren Rande der Vereinigungsstelle beider Unterkieferhälften bis zur Cartilago thyreoidea. In der Medianlinie stoßen beide Gl. submaxillares zusammen; man hebt eine davon mit zwei Pinzetten an ihrem medialen Rande auf und schligt das vordere Ende der Drüse in derselben Weise lateralwïrts (Fig. 88, S. 207). Der Ductus submaxillaris erscheint als feiner weißlicher Strang am medialen Rande des M. mandibulae, zwischen letzterem und der V. sublingualis, mit welcher derselbe sich kreuzt. Hinter dem Ductus submaxillaris, durch einen kleinen Zwischenraum getrennt, liegt die A. und unmittelbar hinter der letzteren die V. submaxillaris.

Bei der Eröllnung des Ganges werden fast unvermeidlich die denselben umgebenden Nervenplexus verletzt (265).

Gl. sublingualis ist linglich, ca. $14 \mathrm{~mm}$ lang, $3 \mathrm{~mm}$ breit, $2 \mathrm{~mm}$ dick, wiegt $0,1 \mathrm{~g}$. Sie liegt auf dem Boden der Mundhölle, woselbst ihre Ausführungsginge münden, oberhalb des M. mylohyoideus, der sie von der Gl. submaxillaris trennt, an der lateralen Seite des M. geniohyoideus.

Die Acini messen 0,03-0,04 mm, die Zellen derselben 0,015 mm (264).

Ne rven. Die Nervenstämmchen bilden im Innern der Drüse Plexus, welche Ganglienzellen führen $(185)$.

Pathologische Anatomie. Salivation. Profuser Speichelfluß ist nur Symptom einer Stomatitis.

\section{Respirations-Apparat.}

\section{Kehlkopf.}

\section{Knorpel des Kehlkopfes.}

Der Larynx ist relativ groß, von oben nach unten ca. $8 \mathrm{~mm}$ lang, besteht aus sieben Knorpeln.

Cartilago thyreoidea (Fig. 89, 90, 91) ist viel breiter als hoch, besteht aus den unter einem spitzen Winkel vorn in der Medianlinie zusammenstobenden Laminae laterales dextra und simistra. Jede derselben stellt eine viereckige Platte dar; der hintere obere Winkel liuft in das Cormu superius (Fig. $89 s$ ) aus, welches das Os hyoideum nicht erreicht, küzer und viel schmaler ist, als das Cornu imperius (Fig. 91 i) am hinteren unteren Winkel; das Cornu superius ragt his zur Ilibe des oberen Randes der Epiglottis. Am obereu Rande zeigt sich in der Medianlinie, wo vorn die Laminate laterales zusammenstoßen, ein kleiner Ausschnitt, die Incisura thyreoidea (superior); der untere Rand ist konkav.

Va rie tät. Häufig ist ein Foramen thyreoideum (Fig. $90 \mathrm{Ft}$ ) in der Lamina lateralis cartilaginis thyreoideae für den lburchtritt des N. laryngeus superior vorhanden. Nahe dem hinteren Rande derselben steigt (in der Norm, 250) eine rauhe Linea obliqua s. eminens (Fig. $90 \mathrm{La}$ ) ziemlich senkrecht herab, sie horrespondiert den Ansitzen der Mm. sternothyreoideus, thyreohyoideus und thyreopharyngeus. 
Carlilago cricoidea ist ringförmig, der vordere Teil in der Richtung von oben nach unten sehr kurz und wird fros fig. 89 c) genannt, der hintere Teil stellt eine viereckige Platte: Laminu cartilaginis cricoideae frig. 90/, Fig. 91/j dar, welche riemlich senkrecht und frontal gestellt ist. Der Arous ist nach vorn konver, sein unterer hambl liegt bedeutend tiefer, als derjenige der Lamina; letztere bildet hauptsichlich die hintere Wand des Larynx.

Fig. 89 .

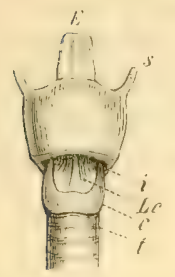

Kehlkopfknorpel von vorn. Nach Schneider (250). E Epiglottis. s Cornu superius eartilaginis thyreoideae. $i$ Cornu inferius derselben. $L c$ Lig. cricothyreoideum medium, $c$ Arcus cartilaginis ericoideae. $t$ Trachea.
Fig. 90.

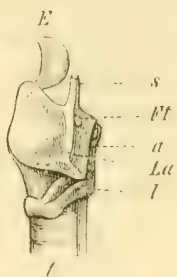

Kehlkopfknorpel von der Seite. Nach Schneider $(250)$. E Epiglottis. $s$ Cornu superius eartilaginis thyreoideae. Ft Foramen thyreoideum, a Cartilago arytaenoidea. La Linea obliqua. l Lamina cartilaginis ericoideate. $t$ Trachea.
Fig. 91

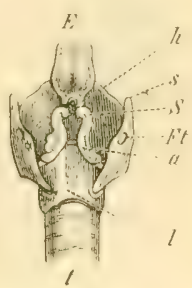

Kehlkopfknorpel von hinten. Nach Sehneider (250). E Epiglottis. $h$ Hamuli epiglottici. s Cornu superius cartilaginis thyreoideae. $S$ Cartilago Santoriniana. F't Foramen thyreoideum. a Cartilago arytaenoidea. $l$ Lamina cartilaginis cricoideae, t'l'rachea.

Nach Wollf $\left(265^{\circ}\right)$ ist die letztgenannte Lage dem Kaninchen vor allen anderen Sïugern eigentümlich. Meckel $(266)$, der diese Angabe bestreitet, hat Woltt's Meinumg falsch verstanden.

Cartilagines arytaenoideae dextra und sinistra (Fig. 91a). Sie siml verhalmismaßig groß; jede stellt ammihernd eine dreiechige Platte dar, deren unterer, hinterer Winkel ein rechter ist. Die gröBere Kathete liegt horizontal und ist die untere; die kleinere vertikal und ist die obere; die Hypotenuse liuft schrigg vou hinten und oben nach vorn und unten und ain wenig medianwirts. Die obere Spitze der Garlilago artalienoidea triagt eine getrennte lingliche knorpelplatte: Cartilago santorinianu (Fig. 9I S). An der laterilen Seite des hinteren unteren Winkels befindet sich ein kleiner Höcker: Processus muscularis.

Cartilagines Wrisbergianae sind klein und gekrümmt.

Epiglottis (Fig. 89, 90, $91 \mathrm{E}$ ) ist groß, rundlich, hat am oberen Rande in der Medianlinie einen Einschnitt. Ihre hintere Flache trigt zwei rom unteren Eude derselben noben der Medianlinie nach hinten hervorragende spilze Knorpelfortsátze, die Hamuli epiglottici (Fig. $91 h$ ).

Cuvier (267) betrachtete irrtiimlich die Itamuli epiglottici als Ilomologa der Cartilagines Wrisbergianae. - Die hintere Fliache der Epiglottis besitzt Geschmacksknospen (57, S. 198), ebenso die Schleimhaut der Cartilanines arylatenoideae $(762)$. Uber die laryngoshopische Untersuchung am lebenden Tier s. 805 .

\section{Ligamente des Kehlkopfes.}

Membrana thyreohyoidea ist sehr dünn, ebenso das Lig. Ihyreohyoidemm medium (Fig. $92 \mathrm{tm}, \mathrm{S} .211$ ). 
Ligamenta thyreohyoidea lateralia dextrum und simistrum verlaufen von den Spitzen der Cornua majora oss. hyoidei zu den Spitzen der Cornua superiora cartilaginis thyreoideae.

Ligumenta cricothyreoidea (Fig. 89 Lc, S. 209) und crico-arytaenoidea sind schwach.

Ligamenta thyreo-arytaenoidea superiora und inferiora. Das Lig. thyreoaryluenoideum inferius oder das Stimmbaud ist ea. $\ddot{~ m m ~ l a n g, ~ e n t s p r i n g t ~ v o n ~ d e r ~}$ Ilinterflache des Winkels, den die Lamina laterales cartilaginis thyreoideae mit eintmder bilden; beide stimmbinder erstrecken sich nach hinten, die enge Gilottis zwischen sich lassend, lings der lateralen Fliche der IIamuli epistottici zum vorderen Rande der Cartilacrines arytanonodeae. Sie enthalten die Mm. thyreo-arytaenoidei. Das Lig. thyreo-arytuenoidenm superius liegt nahe oberhath und parallel dem inferius, ist diinn, zart und etwas flach, liult auf den IIamulus epighothicus zu, lateralwarts von demselben endigend. Die Ventriculi laryngis s. Morgagnii sind klein.

Die Ligg. thyreo-arytaenoidea superiora et inferiora sind noch mit Plattenepithel überzogen $(268)$.

Ligamenta hyo-epiglotticum und thyreo-epiglotlicum sind umpare, ersteres ist ein langes, festes, libroises Band; das Ligamentum ylosso-epiglofticum ist ziemlich breit.

Varietät. Das Lig. hyo-epiglotticum ist häufig muskulös: M. hyo-epiglotlicus, was für die Norm gehalten wird $(8 / 8)$.

Ligamenta epiglotlica. Jeder Hamulus steht mit der hinteren Fliche der Epigylottis durch eine siggittal gestellte Sohleimhatfalte in Verbindung.

Über die Wirkung dieser Falte ist eine komplizierte Theorie entwickelt worden $(269)$, welche auf falschen anatomischen Voraussetzungen beruht.

\section{Muskeln des Kehlkopfes.}

M. cricothyreoideus (Fig. 94 ct. - Fig. 83, 9, S. 201. - Fig.95 ct, S. 212). Crsprung: Unterer Rand der Cartilago thyreodea. Liegt neben der Medianlinie vor der Membrama cricothyreoidea und bedecht dieselbe von vorm her vollstandig. Insertion: Oberer Rand des Areus cartilaginis ericoideae. Ubber seine Wirkung vergl. 855 .

M. crico-arytaenoideus posticus (Fig. 92 cp. - Fig. 93 cp). Ursprung : Ilintere Flache der Lamina cartilaginis cricoideae. Breiter, viereckiger Muskel, der die Stimmritze erweitert. Insertion: Processus muscularis cartilaginis arytaenoideae.

1. crico-arytaenoidens lateralis (Fig. 92 cl). Lrsprung: Oberer Rand des hintorsten Teiles des Arcus rartilaginis cricoideae. Ist schwach entwickelt. Insertion: Untere vordere Flache des Processus muscularis cartilaginis arytaenoideae.

M. thyreo-arytaenoideus (inferior) (Fig. 92 $t a$ ). Liegt im Lig. thyreo-arytaenoideum inferius. (Fehlt öfters - 769, S. 83.)

11. thyreo-epiglotticus. Irsprung: Cartilago thyreoidea dicht oberhalb des M. thy roo-iry tarnoideus. Liuft aufwairs. Insertion: Hinterer Rand der Epiglottis. 
M. arytaenoideus transversus (Fig. 92 at. Fig. $93 a t$ ). Unpar, ist sehr schwach, verläuft von einer Cartilago arytaenoidea zur anderen.

M. glosso-epiglotticus (Fig. 92 $g l$ ) ist als abgelöstes Bündel des M. hyothyreoideus zu betrachten $(270$ - vergl. jedoch 769 , S. 25$)$.

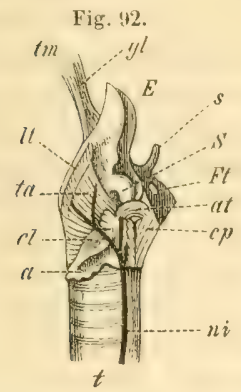

Muskeln des Kiehlkopfes und der $\mathrm{N}$. laryngeus inferior, von der Seite. Nach Schueider (250). Die Lamina lateralis der Cartilago thyreoidea ist weggenommen. $t m$ Lig. thyreohyoideum medium. gl M. glosso-epiglotticus. E' Epiglottis. s Cornu superius dextrum cartilaginis thyreoideae. $S$ Cartilago Santoriniana. F't Foramen thyreoideum. a $t$ M. arytaenoideus transversus, $c p$ II cricoarytaenoideus posticus. $n i \mathrm{~N}$. laryngeus inferior. $t$ Trachea. $a$ Areus cartilaginis cricoideae. cl M. cricontrytaenoideus lateralis. $t$ a M. thyreo-arytaenoideus. it Sehnittrand der Lamina lateralis sinistra cartilaginis thyreoideae.

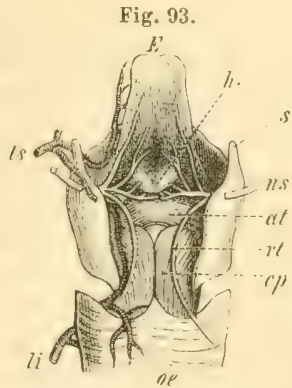

Muskeln, Arterien und Nerven im Innern des Kehlkopfes, von hinten. Vergr, 2. Nach Schneider (250). $E$ Ejpiglottis, $h$ Hamulus epiglotticus. $s$ Cornu superius eartilaginis thyreoideae. ns $\mathrm{N}$. laryngeus superior internus. at M. arytaenoideus transversus. $c$ p M. crico-arytaenoideus posticus. $o e$ Oesophagus. li A. laryngea inferior, welche mit der A. laryngea superior anastomosiert. is $\Lambda$. laryngea (superior).
Fig. 44.

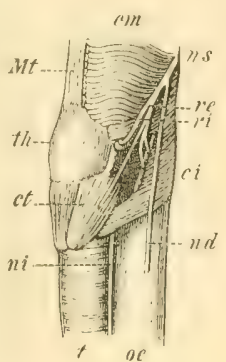

Muskeln und Nerven an der Außenseite des Kehlkopfes. Nach Schueider (250). cm M. constrictor pharyngis medius. $n s$ $\mathrm{N}$. laryngeus superior. $\quad c i$ M. constrictor pharyngis inferior. oe Desophagus, $t$ Trachea, $n i$ $\mathrm{N}$, laryngeus inferior ct $\mathrm{MI}$ cricothyreoideus, th Cartilago thyreoidea. It Membrana thyreohyoidea.

Die $\mathbf{M m}$. crico-arytaenoideus lateralis, thyreo-arytaenoideus und arytaenoideus transversus bilden ihrer Wirkung nach einen gemeinschaftlichen H. compressor laryngis und verengern die Stimmritze, wihrend sie der M. rrico-arytaenoideus posticus erweitert: wie es bei den Sïugern überbaupt der Fall ist (270).

\section{Schilddrüse.}

Die Gl. thyreoidea (Fig. 95, S. 219) ist bramribtich, besteht aus einem Lobus dexter und sinister und dem Isthmus; sie wiegt 0, I g. Jeder Lobus ist linglich, platt, nach oben in ein mehr oder weniger spityes Cornu glandulae thyreoideat ausgezogen; liegt zwischen der hinteren oberen Ecke der Cartilago thyreoidea, der Cartilago cricoidea, den obersten (a. 9 Trachealringen, dicht an die lateralen Flichen dieser Teile geheftet, und der A. carotis communis; wird von vorn her durch den M. sternothyreoideus bedeckt. Nach unten ist jeder Lohus ehenfalls zugespitzt und hat nach vorn einen ziemlich scharfen Rand. Der letztere geht in der Gegend von dem J-9ten Trachealring in den sehr dünnen Isthmus glandulue thyreoidecues. Par's intermedia (Fig. 9\$i, S. 212) iber, welche an die vordere Wand der Trachea geheftet ist und beide Lobi untereinander verbindet. Am lebenden Tiere sieht der Isthmus wie ein 
flaches, dünnes Blutextravasat aus. Jeder Lobus ist ca. $17 \mathrm{~mm}$ lang, $7 \mathrm{~mm}$ breit; der Isthmus mißt von oben nach unten ca. $6 \mathrm{~mm}$.

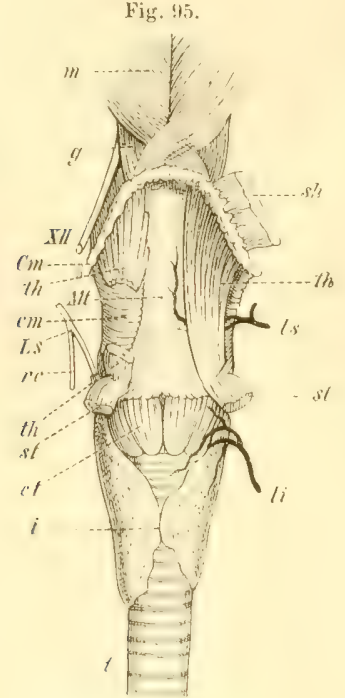

Muskeln und Arterien des Kellkopfes, von vorn. Nach Sehnei-

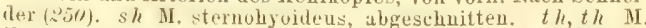
thyreobyoideus, is A. laryngea (superior). st st $\mathbf{I}$. stermothyreoideus, abgeschnitten. $l i$ A. laryngea inferior, welche Aste zum H. cricosthyreoildess und zur Gil. thyreoidea abgielit. $t$ Trateheas. i lsthmus gl. thyresiluate. et M. cricothyrevidens. Ls N. laryngeus superior. $r e$ Ramus cardiacus $n$. vagi. cm M. constrictor pharyngis medius. Mt Membrana thyreohyoidea. $C m$ Cornu majus oss. hyoidei. XII N. hypoglossus. g II. geniohyoideus, $m$ M. mylohyoideus.
Abbildung s. a. in 816 . Die Acini sind sehr klein, länglich, beispielsweise $0,08 \mathrm{~mm}$ lang, $0,036 \mathrm{~mm}$ breit; der Isthmus stellt ein durchsichtiges mikroskopisches Untersuchungsobjekt dar.

Gl. parathyreoidea. Diese kleine Blutgefäßdrüse reprïsentiert eine Gl. thyreoidea accessoria, welche auf embryonaler Entwickelungsstufe stehen geblieben ist. Sie liegt (271) am seitlichen Teil der Schilddrüse, bisweilen am hinteren Rande derselben und durch lockeres Bindegewebe mit ihr verbunden, ist oval oder spindelförmig, 2-5 mm lang. Manchmal liegt eine ähnliche Drüse an der Luftröhre in Fett unter dem. Isthmus gl. thyreoideae. - Der mikroskopische Bau ist wie beim Menschen $(58,5.71)$ auch in betreff des Vorkommens von Kolloidmasse; die Zellen jedoch enthalten konstant jede einen etwas größeren Feltropfen.

Pathologische Anato-

mie. Struma der Gl. thyreoidea ist zuweilen beobachtet (272).

\section{Luftröhre.}

Die Trachea ist lang und eng, besteht aus $48-50$ unvollstindigen Kuorpelringen, deren hintere Enden verhaitnismißig weit ron einander abstehen: sie sind ziemlich hart und fest. Die oberen sind breiter als die ubrigen; der oberste Ring wird von vorn her dureh die Cartiligo arooidea bedeckt, das Lumen der Trachea nimmt von oben nach unten ab.

Tracheotomie Hautschnitt in der Medianlinie, unterhalb des durchzufühlenden oberen Randes der Cartiligo thyreoidea begimend. Durchschneidung eines M. sternothyreoideus in senkrechter Richtung. Eröllnumg mehrerer Luftröhrenringe in der Medianlinie mittels einer spitzen Schere oder eines spitzen Messers, wihrend die: Trachea mit diner Hakempinzette fixiert wird. Verletzungen des Isthmus gl. thyreoideae sind gleichgültig.

Die Zahl der Atemzüge kann man durch eine in die Trachea eingebundene, leicht ansprechende Pferfe einem großen Auditorium hörbar machen (275). 


\section{Lungen.}

Die Lungen sind verhiltnismaßig klein, rosenrot, sehr weich. Die rechte Lunge hat einen oberen, einen mittleren und einen in wei Abschuite zerfallenden un tere $\mathrm{n}$ Lappen. Der Lolus inferior mediulis ist kleiner als der lateralis, ragt von der Wur\%el des letzteren nach hinten und unten herah; zwischen heiden geht der Brustleil der V. eava inferior hindurch. Die linke Lunge besteht aus einem oberen und einem unteren Lilppen. Die rechte Lunge wiegt 6,4 , die linke nur $4,0 \mathrm{~g}$.

Wie bei den meisten Singetierarten ist an der rechten Lunge ein Bronchialast (eparlerieller Seitenbronchus, 274) vorhanden, welcher oberhalb der A. pulmonalis dextra verlauft. Seine Entfermung ron der Teilungsstelle der Trachea hefriggt 4,9 mm, vom zweiten Bronchialast (erster hyparterieller Bronchus 9,8, des letzteren vom dritten dagegen 16,1 mm 27. Ein medianwirts und nach hinten his gegen den lungentand hin verlaufender $A$ st wird als Stummbronchus aufgefaßt, on dem die ibrigen Bronchialaste, Seitenbronchi, abgehen. Der Quersehnitt des ersteren, in Prozenten der Stammweite der Tratchea ausgedrückl, sowie der relative Querschnitt der Seitenbronchi ergiebt sich (274) aus folgender Tabelle:

Relativer Querschnitt der Bronchien.

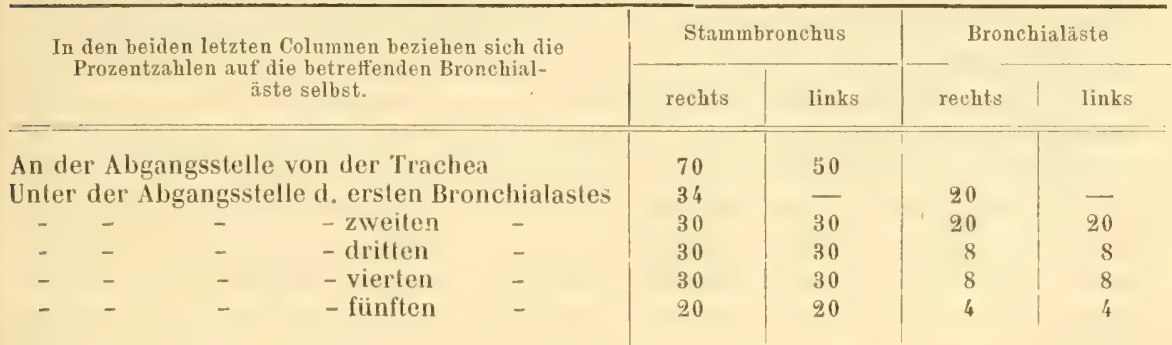

Die Infundibula sind, wie korrosionspriparate zeigen, nicht weiter oder stellenweise sogar enger, als die feinsten zugehörigen Bronohialiste $\left.956^{\circ}\right)$.

Über das Lungenepithel s.790. - Einsprengungen lymphadenoiden Gewebes finden sich an Zweigen der $A$. pulmonalis und an den feineren Bronchien (609). Uber die Lymphgefißße der Lunge vergl. 747.

Nerven. Vergl. über dieselben 68z. An der hinteren Wand der Bronchien finden sich mikroskopische Ganglien (275).

Pathologische Anatomie. Die Verinderungen nach Durchschneidung der Nn. vagi bestehen in einer lobulären Bronchopneumonie; man kann grünes Futter in den Alveolen finden. (Vergl, eine speziellere Schilderung in 276.)

Tuberkulose der Lungen scheint selten vorzukommen (vergl. 277), obgleich Laënnec sie für häutig hielt, wenigstens fehlen die beim Nenschen und Allen gewöhnlichen Erscheinungen der Phthise: kisige Pneumonie, Peribronchitis, Kavernenbildung u. s. w. Eine frïhere Angabe (278) beruhte aul einem Misverständnis. - Ủber experimentelle Erzeugung von Tuberkeln durch Impfung tuberkulöser Sputa vom Henschen u. s. w. S. 277; von anderer Seite $(829)$ 
ist jedoch die Tuberkelnatur der experimentell erzeugten miliaren Knötchen bestritten worden. - Über Fütterungstuberkulose vergl. 655.

Lobäre Pneumonie ist im Winter namentlich bei jungen Kaninchen häufig und verursacht sroße Sterhlichkeit. Der Tod erfolgt in Stadium der roten IIepatisation. Die Kohlensäureausscheidungr ist bei Pneumonie und Pleuritis, die durch Injektion ron rothem Wein in die Pleurahöhle hervorgebracht worden war, bedeutend vermindert, wie aus folgender Tabelle hervorgeht (279).

$1 \mathrm{~kg}$ Kaninchen exzerniert in 1 Morgenstunde:

in trockener Luft bei $+12,5^{0}=0,606$ Kohlensäure,

$\begin{array}{llll}- & - & - & +37,50=0,451 \\ \text { in feuchter } & - & -\end{array}$

Dagegen exzernierte z. B. ein $2037 \mathrm{~g}$ schweres männliches Kaninchen bei mittlerer Temperatur:

$\begin{array}{lllll}\text { vor der Operation } & \text { in } 3 & \text { Morgenstunden } & =3,820 \text { Kohlensäure, } \\ \text { unmittelbar nachher in } 3 & - & =3,877 & - \\ \text { den 1. Tag } & \text { in } 3 & - & =2,951 & - \\ -2 .- & \text { in } 3 & - & =3,217 & - \\ -3 .- & \text { in } 3 & - & =2,308 & - \\ -4 .- & \text { in } 3 & - & =1,838 & - \\ -4 .- & \text { in } 3 \text { Nachmiltagsstunden } & =1,731 & -\end{array}$

Lungenödem kommt vor, auch neben Tuberkeln (24, S. 398). - Über letztere S. S. 213.

Pa rasiten. In den Lungen findet sich eingekapselt Pentastomum denticulatum Rudolphi (identisch mit Linguatula serrata Frölich, Pentastomum serratum Rudolphi in den Lungen von Iasen). Das Weibchen hat $4,5-5,5 \mathrm{~mm}$ Länge, vorn 1,1 $\mathrm{mm}$, hinten $0,7 \mathrm{~mm}$ Breite. Von Schiff $(280)$ wurde dasselbe in den Lungen bei anscheinenden Typhusepidemieen mit Ulzerationen der Peyer'schen Drïsen des Dünndarmes und der Lymphfollikel des Blinddarmes im Jahre 1846 beobachtet (s. Pathologische Anatomie des Darmkanales S. 219).

Ferner kommt in den Lungen Strongylus commutatus s. retortaeformis vor (281) und zwar ziemlich häufig (829). Die erwachsenen Tiere liegen in den Bronchien zu oft schwer entwirrbaren Knäueln zusammengeballt, Eier und Embryonen finden sich in den Alveolen. Diese Parasiten erzengen starken Bronchialkatarrh, ferner diskrete tuberkelartige Knötchen, auch größere Infiltrationen und Preumonie (829).

Pleura. Ligamentu pulmonalia dextrum und sinistrum gehen rom Diaphragma zum hinteren unteren Rande der unteren Lungenlappen.

Pathologische Anatomie. Hydrops pleurae, Wassererguß, ist in der Pleurahöhle zuveilen in geringer Quantitä vorhanden (24, S. 401).

Eröffnung der Pleurahöhle. Die rechte Seite ist vorzuziehen. Hautschnitt in der Mediantinie des ganzen Sternum bis abwärts zum oberen Rande des Processus xiphoideus. Ablösumg des H. peetoralis major von seinem Ursprunge am Sternum oder Durchschneidung desselben parallel der Faserrichtung. Die Mammae werden eventuell mit der IIaut bei Seite gezogen. Durchbohrung des vierten oder fünften Interkostalraumes mit der Ilohlsonde, Einführung eines trichterlörmigen Ohrspiegels, durch welchen bei jedem Atemzuge ein Luftstrom austritt, der ein Licht aushlasen kiann. Der Luftzutrilt allein bedingt selten Pleuritis; Einführung von Schrotkörnern oder Injektion von Kochsalzlösung veranlaßt sie.

Exstirpationen von Teilen einzelner Lungenlappen werden leicht ertragen; man benuzt am besten die Vorderlliche des dritten oder vierten Interkostalrames 
ohne Rippenresektion (285). Auch eine ganze Lunge kanu man nach solcher Resektion exstirpieren $(826)$.

Nach künstlich erzeugtem Pneumothoras erhïlt man durch Injehtion von der Trachea aus zierliche Korrosionspräparate (2S2). Man kann Rose'sehes leichtflüssiges Metallgemisch auch zu Bronchialausgüssen der normalen Lunge benulzen (274, S. 2).

Die Lungenbewegung kann man ohne Erölfnung des Thorax nach Bloßlegung des Herzens (s. Angiologie, Herz) beobachten. Jie Exhursion des vorderen Teiles des unteren Randes der linken Lunge betrïgt bei tiefen Inspirationen last zwei Interkostalräume.

Über die Atembervegungen siehe 284 u. 285. Die Inspiration verhält sich zur Expiration der Zeit nach wie 100:126 286 , Die Auzahl der Inspirationen beträgt 80-100 - nach anderen Angaben (287) nur 36 in der Minute.

\section{Thymus.}

Die Thymus ist eine große Lymphrlrise. Bei jungeren Tieren ist sie stark entwickelt. Sie wiegt, von lett thunlichst befreit, 1, 1 g ; ihre Linge betrigt (a) 2, liegt senkreckt, der obere Rand ist konvex, der untere konkav. Sie besteht aus zwei Lappen, die in ihrem oberen Teile rereinigh sind. Sie wird von dichtem Feltgewebe eingrehillt, das im Winter an die Struktur einer Winterschlaldrúse erinnert. Dasselhe besteht namlich aus einem dichten Kapillarogefißnetz, in dessen Maschen ein feines Bindegewebsnetz und das Felt cingelagert sind (vgl. 57, S. 359). - Die Thymus liegt im oberen Teil des Thoras, hinter dem Sternum, hinter den Knorpeln der ersten his dritten Rippe, in den obersten beiden Interkostalramen, vor dem Mreus artae, den Vr. cavae superiores, den Nn. vagi, sowie dem oberen Teil der beiden llerzatrien.

Uber die Entwickelungsgeschichte der Thymus s. 810, S. 876.

\section{Digestions-Apparat.}

\section{Pharynx.}

Der 'harynx stell cin muskulöses Rohr dar, in welchem einzelne Bündel sebwer zu unterscheiden sind; nach vorn hängt dasselbe mit dem Zuugenbein oder Kehlkopf, nach oben mit den Mm. levator und tensor veli palatini zusammen. Seine Linge hetrigt $32 \mathrm{~mm}(\$ 2 \%)$. Yur der M. constrictor pharyngis medius (11. syndesmopharyngeus. - Fig. 83, 15, s. 201) ist relativ stark entwickelt $(769)$.

M. stylopharyngeus. Ursprung: Processus styloideus (s. Zunge, M. styloglossus, S. 202). Insertion: Verlauft abwirts zur lateralen Flache der Seitenwand des Pharynx. 


\section{Oesophagus.}

Der Oesophagus (Fig.83,21, S. 201) besteht aus der Pars cervicalis, thorareica und abdominalis; verliaft am IIalse hinter der Trachea, linkerseits iiber deren lateralen Rand herroragend. Goht dureh das foramen oesophageum des Diaphragma; sein in der Battehhöhle gelegener Teil bis zur Kardia hat ca. 2 cm Länge.

Die Schleimhaut enthält acinöse Drüsen (288; vergl. dagegen 789). Die Mushelschicht des Oesophagus besteht in seiner sanzen Länge atus quergestreiften Fasern. - Die Bew egungen baben den Charakter animalischer liontratiomen 299).

Nerven. Die motorischen Nerven verlaufen in der Bahn der Nn. vagi und accessorii; die für den oberen Teil ausschließlich im N. recurrens des N. vagus $(500)$. Dir quergesfreiften Mushelfasern haben zahlreiche motorische Endplatten (arborisations terminales, 581 ).

Über Ganglien im Oesophagus s. $50 \%$. Sie finden sich zuweilen an den Ästen des N. recurrens des N. vagus zum oberen Teil des Oesophagus (502, einmal).

Unterbindung des Oesophagus, Oesophagotomie. Operation wie bei der Unterbindung der $\Lambda$. carotis communis (s. Angiologie). Man benutzt die linke Seite, an welcher der Oesophagus leichter zuginglich ist; die großen Gefaßstämme und Nerven werden lateralwirts gezogen. Zwischen den hinteren Enden der Knorpelringe der Trachea fïhrt man mittels der Pinzette oder Unterbiudungsnadel den Faden hindurch.

\section{Magen.}

Der Magen ist in transversaler Richtung bedentend ansgedehnt, der Un-

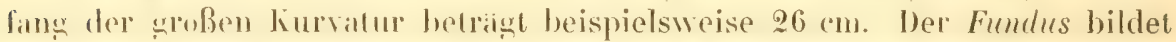
links von der Kardia einen tiefen Sark; die Kardia stellt eine Wölhung von ellipsoidischer Gestalt dar, in deren Mitte sich der efwas erweiterte Oesophagus rinsenkt. Links rom P’ylorus findet sich ein einigermaßen ahgeschnirter Sack, Antrum pylori. wolcher viel dickere Jushelhaut besitzt: letztere ist am Pylorus elwas grmulstet. An den ibligen Partieen des Magens ist die Muskularis dünn.

Uber rhythmische Kontraktionen des Magens s. 505; ïber den Magen von Lepus borealis 504. - Sehr selten wird der Magen leer angetroflen, dann enthält der Schleim polygonale Zellen $(57$, S. 210$)$.

Als Pförtnerwulst der Muskelschicht wird ein sehr in die Länge gezogenes Oroid beshrieben 582, desen schmalerer Treil gegen den Hagen, der dichere gegen dis Inodenum gerichtet ist. Die rom Magen herkommende Längsmuskelfaserschicht verdickt sich auf das 6-8fache, die Quermuskelschicht ist ebenso dick, bildet zwei gebogene Linsen, welche die Hailfte der erstgenannten Schicht umgreifen und nach außen von der letzteren liegen. Die ovalen Linsen sind in der Mitte durch einen schmalen Strang querverlaufender Muskeln verbunden.

Der Pylorusteil enthïlt schlauchförmige Drüsen mit zylindrischem Epithel, welche an den Enden gewunden und oft gabelig geteilt sind 637 , vergl.604, 632 und $6 \% .5$, . Die Drüsen in den ïbrigen Gegenden enthalten große, hörnige, polygonale Zellen (Belegzellen), die sich mit Uberosmiumsäure schwärzen $(686)$, und hathen hein deulliches Lumen; die Teilungssteflen liegen of der Mindung ziemlich 
nahe (505). Zur Demonstration frischer Magendrüsen ist das Kaninchen wegen leichter Isolierbarkeit der Drïsenschlïuche und der Ditlerenz zwischen polygonalen Zellen (Belegzellen) einerseits, den kegelfömigen Zellen (Iauptzellen) indererseits am meisten zu empfehlen $\{584)$. Erstere kommen auch in den Drüsen des Pylorusteiles vor $(6,32)$, während die Pars pylorica vielleicht mil Ausnahme einer schmalen, intermediären Zone nach anderer Angabe (65.5) nur Schlemdrïsen enthält. - In der Schleimhaut finden sich solitïre Lymphfollikel (288, S. 21). $(506)$.

Nerven des Magens. Die Ganglien in der Magenwand beschrieb Remak

Pathologische Anatomie. Nach Überziehen der Haut mit einem luftdicht schließenden Firnis (S. 172) bilden sich konstant in der Magenschleimhant, nahe der großen Kurvatur, mehr oder weniger zahloiche dunkle, stecknadelkopfbis erbsengroße Ekchymosen yon meist kreisrunder, zum Teil mehr ovaler Form, mit honvexer, die über ihnen liegende Schleimhatschicht in die Ilöhe drängender Oberfliiche $(150$, S. 72). - Gastritis (5/5) und Magenerweichung $(5 / 6)$ sind sehr selten.

Pa rasiten. Taenia pectinata Goeze ist selten (siehe Parasiten im Dünndarm, S. 219).

Anlegung einer Magenfistel. Hautschnitt in der Medianlinie am Processus viphoideus beginnend, Zusimmennähung der Wundrinder des Magens und der Bauchwand.

Injektionen in den Magen. A. Mittels der Schlundsonde. Man sperrt mit einem passenden Kork die Schneidezähne des kauernden Tieres auseinander, führt hinter demselben einen nassen elastischen Katheter vorsichtig und langsam in den Pharynx, Oesophagus und Magen. An der größeren Beweglichkeit des Katheters fühlt man, wenn man im Magen angekommen ist. Man injiziert mittels eines Trichters oder einer Spritze durch den Katheter. - B. Mittels Einstichs in die Bauchdecken. Man perkutiert den Magen, der einen matten Ton giebt und sich dadurch nach links und unten von dem tympanitischen Ton des Dïnndarmes abgrenzt. Einstoßen einer Spritzenkanüle mit scharler Spitze oder eines feinen Troikars und Injektion. Die Wunden verkleben leicht (507).

Aufällig ist die Immunität des Kaninchens gegen Atropin (755).

\section{Darmkanal.}

Der Darmkanal besteht aus dem Duodenum, Dinndarm, Coecum mit dem Processus vermiformis, Colon, Dickdarm und Rektum. Über die Dimensionen vergl. S. 60.

Das Duodenum ist anfangs etwas weiter, ohne Falten; es bildet eine bedeutende bogenförmige Krümmung (s. Fig. 9\%, S. 225).

Der Dünndarm zeigt Limgsfalten der Schleimhatu; er enthiilt in seinen unteren Falten nur 4 bis 6 Peyer'sche Itaufen (vergl. S. 19). Abbildung eines Durchschnittes durch die Darmwandung s. in 814.

Das Coecum ist enorm entwickelt, ibertriff den Magen wenigstens zehnmal an Inhalt. In dem größereu, der Valvula coli benachbarten Teile, dem eigentlichen Coecum, ist dasselbe dunnhiutig, die Schleimhaut glatt, aber mit solitaren Lymphfollikeln besiet. Yon außeu sieht man an diesem Teile Falten, welche dureh eine inwendig verlaufende spiralfalte von etwa 5 mm Breite be- 
dingt werden. Die Windungen, ca. 25 an Zahl, stehen etwa $2 \mathrm{~cm}$ ron einander entfernt. Gegen den blind geschlossenen Teil des Coecum hin werden sie niedriger, rücken niher zusammen und verschwinden schließlich. Der letztgenannte, kolbig endigende Teil, der Processus vermiformis, ist von wechselnder Lainge, $7-10 \mathrm{~cm}$ lang, er macht $1 / 6-1 / 4$ des ganzen Coecum aus. Seine Wandung ist stark verdickt durch dichtgedrängte Lymphfollikel: der ganze Processus vermiformis stellt eine einzige, sehr große, flichenhaft ausgebreitete Lymphdruse dar. In den Anfang des Coecum öfnet sich mit weiter Mündung ein weißlicher, ovaler, \& 'm langer drüsiger Anhang: der Sacculus rotundus, dicht neben dem Übergange des Dunndarmes in den Dickdarm. Die Windung desselben enthält ebenfills dichtgedraingte Lymphfollikel und hat ea. $2 \mathrm{~mm}$ Dicke. Die Valvulit coli und ihre Nachbarsehaft ist ebenfalls mit Lymphfollikeln besetzt.

Das Colon zeigt nur in seinem Anfangsteil, der fast ebenso weit als das Coecum ist, drei Lingsstreifen, Taeniae coli, zwischen welchen ebenso viele Reihen vou kleinen sackarligen Erweiterungen gelegen sind; beide Anordnungen hören weiter nach dem Rektum hin auf, indem sich die Taenien am Colon adscendens aufwirts eine nach der anderen verlieren. Die Schleimhatut des Colon enthalt solitire Follikel. Der Durehmesser des Colon nimmt bald bedentend al,; dasselbe wird diinnwandig wie der Dünndarm; der untere Teil des Dickdarmes, welcher olne scharfe Grenze in das $\mathbf{k}$ e k t 1 m iibergeht, sowie letzleres selbst, enthalten in ziemlich regelmaßBigen Abstinden feste rundliche Kotmassen. Das Rektum hat Lingsfalten der Schleimhaut wie der Dünndarm.

Gl, an alis s. Geschlechts-Apparat.

Muskeln des Rektum s. Muskeln am Beckenausgang.

Über die Beschaffenheit des Darminhaltes im Normalzustande s. 50\%, S. 73. In den Dünudarmzotten, die im oberen Teile des Dünndarmes $0.75 \mathrm{~mm}$ Höhe, 0 , 25 $0,75 \mathrm{~mm}$ Breite haben (760), beginnt das venïse Kapillargefia in der Zottenspitze $(716)$. Die $S c h$ le im ha ut des untersten Teiles des Colon hat $0,37-0,45$, die Muskularis 0,28-0,32, die Serosa 0,12 mm Durchmesser (288) Im Duodenum und noch darüber hinaus (604) finden sich Brunner'sche Drisen, im übrigen Darmkanal schlauchförmige Lieberkiihn'sche Drüsen., sowie solitïre Lymphfollikel; die Lymphfollihel des Sacculus rotundus haben 2-3 $3 \mathrm{~mm}$ Durchmesser. Im Aufing des Coecum trägt die Schleimbaut Zotten, welche 0 , 20-0, $22 \mathrm{~mm}$ lang und an der Basis $0,25-0,37 \mathrm{~mm}$ breit sind; im weiteren Verlauf des Colon werden sie breiter und flacher, so daß gegen das Colon descendens hin ihre Lïnge 0,1 , ihre Breite $0,16-0,18 \mathrm{~mm}$ betriigt; dann verschwinden sie ganz. Sie enthalten schlauchförmige Drüsen von $0,19-0,22 \mathrm{~mm}$ Länge und circa $0,05 \mathrm{~mm}$ Durchmesser.

Uner die Blutgefiße s. 288 u. 508 ; ïber die Lymphgefäße 508 u. 760 ; iiher die Brunner'schen Drüsen 604.

Die Epithelialzellen des Dëundarmes zeigen die sogenannten Porenkanäle der Basalmembran besonders deutlich. Ganz frisch untersucht finden sich zwischen denselhen in regehmïßizen Abstinden glinzende Becherzellen, die anch im Dickdarm vorkommen (509; vergl. 787).

Lymphfollikel. Im Processus vermiformis werden dieselben von $0,1-$ $0,7 \mathrm{~mm}$ weiten Lymphsinus ungeben, die Lndothelzellen der letzteren messen 
$0,03-0,058 \mathrm{~mm}(636$, S. 419, Fig. 296).

Ihre Oberfläche trägt eine niedrige Zotte, die Muskularis der Mukosa durchbrechen sie nicht (57, S. 215$)$.

Nerven des Darmkanales. Die Ganglien des Kaninchendarmes wurden von Manz zuerst gesehen (510. - Vergl. $5 / 1$ u. 512.) - Die Anzahl der Ganglien wurde zu ca. 100 auf 733 c $\mathrm{mm}$ im submukösen und zu 2000 auf derselben Flïche $\left(1 \square^{\prime \prime}\right)$ im intermuskulïren Geflecht geschïtzt $(5 / 5)$. Vergl. a. 7.46. Im Rektum fand Billroth (5/4) Ganglienzellen.

Pathologische Anatomie des Darmkanales. Invagination des Darmkanales ist zweimal beobachtet $(515, \mathrm{~S} .102 \mathrm{u} .105)$. Typhus tritt epidemisch auf, ohne bestimmtere Symptome als Apathie, Versehmihen der Nahrung, Durst, Durchfialle, welche letztere die Haare der Aftersegend und der Hinterbeine schmutzig-gelb firben. In den Leichen zeigen sich Hyjerämieen des Dünndarmes und Blinddarmes, Intiltration sämmtlicher Lymphfollikel des Darmkanales und der Mesenterialdrïsen mit Detritus, welcher aus zerfallenen Lymphkörperchen herstammt $(5 / 5)$. Bemerkenswert ist, daß Schitf bei einer solchen Epidemie Pentitstomum denticulatum in den Lungen antraf (s. Parasiten der Lunge, S. 214 ).

Chronische Diarrhöen sind eine sehr häulige Todesursache junger Kaninchen; in der Leiche findet man den Anus beschmutzt, den Inhalt des Dünndarmes dünnflüssig, größtenteils aus Gas bestehend, den Kot im Kolon sehr weich, die Schleimhaut gerötet. Häulig sind die Gl. mesentericae geschwellt, gelblich weiß, fester, selbst käsig, ganz wie bei sog. Skrophulose des Menschen. Psorospermien (S. 222) finden sich in großer Menge bei diesen Zustinden, doch scheinen sie nicht die einzige Veranlassung zu bilden.

Akuter Darmkatarrh. Symptome: Durchfall, Appetitlosigkeit, Durst, rasche Abuahme der Kräfte. Der Tod erfolgh meist binnen 24 Stunden. Die Sektion ergiebt Injektion und Schwellung der Darmschleimhaul; zu den Ursachen werdeu bereiftes oder gefrorenes Grünfutter etc. gerechnet (24, S. 29).

Enteritis mit Fibrin- Auflagerungen auf der Schleimhaut kamn als akute epidemische Krankheit auftreten.

Tympanitis wurde zuweilen beobachtet $(5 / 8)$.

Parasiten im Dünndarm: Taenia pectinata Goeze, $3-50 \mathrm{~cm} \mathrm{lang,}$ Kopf mit vier Saugnipfen, ohne llakenkranz. Echinorhynchus cuniculi Bellingham, nur in Irland beobachtel. Distomum lanceolatum Mehlis, kann aus dem Ductus choledochus ïberwandern s. Parasiten der Leber, S. 222). - Uber Psorospermien und Gregarinose vergl. S. 23.

Rhabdonema strongyloides Leuckart s. Strongylus papillosus Perroncito s. Anguillula intestinalis wurde in der Lombardei zientich häufig beim Kaninchen angetroffen $(8.58)$. - Das Genus Rhabdonema Lenckart zeichnet sich dadurch aus, daß dasselbe, wie es zuerst von Rhabdonema nigrovenosums. Ascaris nigrovenosa bekannt geworden ist, heterogon ist, $d$. h. eine Wechselfolge freier und parasitischer geschlechllich entwickelter Generationen aufweist Leuckart, 859). Die freie Generation ist als Anguillula stercoralis beschrieben.

Oxyuris ambigua Rudolphi, kommt in Coecum und Colon vor, namentlich während des Herbstes und Winters. Länge des Männchens 4,5-7 mm, des Weibchens $9-14 \mathrm{~mm}$, Dicke $0,8 \mathrm{~mm}$. Das Schwanzende trigt einen spitzen Stachel. - In der Darmwandung wurden bisweilen gelbliche Flecken beobachtet, die aus Tausenden von Oxyuris-Eiern bestehen (24, S. 45).

Pilzfäden auf den Darmzotten sind einmal konstatiert (5/7).

Im Inhalt des Darmkanales kommen die Sporen der Puccinia graminis (sog. Puccinia favi) mitunter in sehr großer Menge vor (W. Krause). 
Prolapsus ani ist bei chronischem Darmkatarrh beobachtet (24, S. 45).

Uber Neoplasmen am Anus S. S. 23 (Syphilis).

Punktionen von Dünndarmschlingen mit feinen Nadeln werden gut ertragen $(86 \tilde{)})$

\section{Lage des Darmkanales.}

Der vordere Teil der Bauchhohle wird aroßktenteils und namentich rechterseits von dem enorm entwickelten Coecum ausegefullt. Dasselbe bildet eine doppelte rechtliufige (Jiotrope) Spirale, deren Achse ziemlich horizontal in der Ilibhe des Nabels gelegen und rom hinten nath vorn gerichtot ist. Die Lage bieted bein toten Kaninchen vielfache Verschiedenheiten. Gewöhnlich liegt der Anfang jener spirale neloen der Medianlinie nach rechts und unten vom Xabel, wosellost das untere Ende des Dünndarmes und das obere des Dickdarmes sich millels des Goecum vereinigen. Die erste volle Umdrehung der spirale liegt der Bauchwand unmiltelhar an; der Anfangsteil derselben liegt in der llitte zwischen dem absteigenden und andsteigenden Sehenkel; die Lingsalde des Aufangsteiles ist rom $\mathrm{Anfang}$ des Coecum schrig nach oben, rechts und hinten gerichtet. Zw ischen $\Lambda$ nfangstoil und anfsteigendem Sehenkel der ersten Windung liegt der $\Lambda$ nangsteil des Colon, ebenfalls unmittelbar an der vorderen Batchwand. Der aufsteigende Schenkel des zweiten IIalfte der ersten Windung rağt nach links úber die Medianlinie hinäber. Die zweite Windung wird hauplsibhlich dureh den nach rechts und unten abvirts steigenden Processus vermiformis gehildet. Derselbe hiegt sich damn wieler aufwirts und endig̨t, von Dimndarmschlingen ungeben, zwischen großer Kurvalur des Magens und der vorderen Wand der linken Niere, links von der Medianlinie, fast in der Gegend, wo Magen und linke Niere sich am nichsten sind. Der Processus vermiformis ist auf beilen lateralen Seiten von dem Colon adscendens umgeben, welches am $A$ fang des Processus verniformis sich ahwirts bient und eine Schlinge um sein blindes Ende bilded, deren auf- und absteigender Schenkel untereinander parallel und etwas schrig nach unten gerichtet sind. Ilinter dem Anfangsteil des Colon adscendens, ebenfalls hinter dem Anfange der zweiten halben Windung des Coecum und dem Processus vermiformis verlauft der unterste Teil des Dimndarmes; vom Coecum an gerechnet erst aufsteigend, damn nach rechts umbiegend und absteigend. Das obere Ende des aufsteigenden Schenkels der den Processus vermiformis umgebenden Dickdarmschlinge biegt sich nach links und verlauft als Colon transversum hinter der großen kurvatur des Vagens, um sich in das Colon deseendens fortzusetzen.

Der vom Coecum entferntere obere Teil der ersten ganzen Windung desselben wirl mach oben von der großen Kurvatur des Magens durch einige Dünndarmschlingen ahgegrenzt. Nach Eröflnung der Batuchhöhle in der Medianlinie bekommt man einen großen Teil des Diundarmes zuniachst gar nicht zu sehen, da derselbe von der ersten aranzen Windung des Goerum fast vollstimdige verdeckl wirel und nur nach links und oben melur frei liegl, an die vordere Batuchwand grenzend. Der untere Rand des ahsteigenden Teiles der ersten halhon Windung des Coecum grenzt nach unten an die Harnhlase.

Die erwibnte Dimndamsehlinge bildet das unlere Ende des Dimndarmes, begleited den Processus vermiformis anf seinem ginzen Wege, sowie das 
Coecum, indem sie an der knnkaven seite der von dem letzteren gebildeten Schlinge verläuft, und mündet nach unten in das Goecum.

Das Colon adscendens macht einen nach unten kouvexen Bogen, welcher schlingenformig von der Gegend des zweiten Lendeuwirhels sich abwiirts erstreckt. Nur von dem unteren Ende dieses Bogens an zeigt das Colon descendens die Taeniae coli, welche, wie erwahnt, dem iubrigen Colon des Kaninchens fehlen. Itinter diesem Bogeu, entlang der $\Lambda$. mesenterica superior, liegen die großen Lymphdrüsen des Mesenterium. Kleinere finden sich einzeln auch in unmittelbarer Nachbarschaft des Dümdarmes. Der aufwarts steigende Teil der Schlinge gelangt lateralwarts an die konkave Seite der l'ars verticalis des Duodenum, folgt derselben aufsteigend bis zur großen Kurvatur des Magens, hinter welcher die Fortselzung des Colon als Colon Iransversum in transversaler Richtung nach links verliuft. Oberhalb der linken Niere biegt sich das linke Ende des Golon transversum schlingenfömig uach unten foder erst nach rechts, so daß eine nach links konkave Schlinge oberhall, der linken Niere liegt), verliuft als Colon descendens linkerseits nahe der Medianebene links von der Aorta descendens abdominalis und der V. cava inferior nach unten, und gelangt unter unbedeutenden Biegungen zum Eingang des kleinen Beckens, woselhst das Colon descendens in das Reclum übergeht.

Von der Lage des Darmkanales beim Hasen gab schon Caspar Bartholinus eine Abbildung (s. 520). Thom. Bartholini, Acta Hafniensia). - Situs imersus der Eingeweide scheint nur einmal beobachtet zu sein $\left(865^{\circ}\right)$.

\section{Leber.}

Braunrot, sehr weich, unelastisch, wiegt z. B. 82,4 $g$, zerfallt in vier Ilauptlappen und mehrere kleinere. Der obere hintere Rand ist fast ebenso zugescharft, wie der untere vordere Rand. Die Fossa transversa bildet mit der Fossa longitudinalis dextra die Form eines $\Gamma$. Letatere enthailt in ihren vorderen Teile die Gallenblase, welche rom vorderen, freien Rande der Leber betrichtlich entfernt bleibt. - Die Form der Leber und ihrer einzelnen Lappen bieten sehr mannigfaltige Varietaten dar, die hier nicht bericksichtigt zu werden brauchen.

Der Lobus sinister wird durch die Incisura interlobularis von dem übrigen Teil der Leber abgegrenzt; am vorderen oberen Rande der genanuten Incisur endigt das Ligamentum suspensorium (S. 296). Der linke Lappen zerfillt in einen Lobulus sinister anterior und posterior, ron denen der erstere der kleinere und mehr nach rechts gelegene ist.

Der Lobus dexter zerfiall ebenfalls in einen großen vorderen und einen kleineren hinteren Lappen, den Lobulus dexter anterior und posterior, die noch einige kleinere Linschnitte zeigen. Der Lobulus dexter posterior ist an der hinteren Flache konkav; er ahmt die Form des oberen Teiles der vorderen Fläche der rechten Niere nach, vor welcher er liegt.

Der Lobus quadratus liegt unterhalb der Fossil transversa, ist sehr unregelmäig geformt, erstreckt sich mit seinem Lingsdurchmesser in sagittaler Richtung abwirts bis zum vorderen unteren Rande der Leber oder bis in die Niilıe des letzloren. Derselbe hïngl durch einen brickenförmigen Fortsalz mit 
dem Lobulus sinister anterior zusammen. Nahe vor demselben setzt sich das Ligamentum teres an einen Ast der V. portarum.

Varietät. Das Ligamentum teres bleibt durchgängig. - Der Lobus quadratus fehlt.

Der Lobus caudatus ist unregelmaßig, verwachst an seinem oberen Teile mit dem Lobulus dexter posterior oder auch mit dem Lobulus dexter anterior; zwischen beiden geht an dieser Stelle die V. cava inferior hindurch; nahe der Verwachsungsstelle heftet sich das Ligamentum coronarium dextrum an. Der untere Teil des Lobus caudatus lauft in eine zungenförmige Spitze aus: Tuberculum papillare.

Die Maschen der Blutkapillaren sind eng (57, S. 226), die Gallenkapillaren leicht injizierbar, z. B. mit Berlinerblau oder Argentum nitricum (753), aber auch ohme Injektion in der durch Alkohol gehirteten Leber zu erkennen $(656)$; ihr Durchmesser betrigt $0,0048-0,0025(6.57,5.54: 5)$. Jede Leberzelle ist mit drei bis vier Gallenkapillaren in Berührung, die mithin zahlreicher sind als z. B. beim Menschen (659). - Über die Körnchen in den Leberzellen vergl. 717. - Über die Lymphefaße der Leber s. 759 und 763. - Sternfömige Bindegewebszellen, sog. Sternzellen, liesen in interstitiellen Bindegewebe der Liippchen $(676)$.

Das Blut der V. portarum enthält im cmm $3210000-5540000$, das der Vv. hepaticae nur $2430000-3480000$ Blutkörperchen $(866)$. - Die Leber enthilt 431,35 Teile organische Substanz, 8, 1 m unorganische Stolle, 560,52 Wasser $(52,5)$.

Parasiten der Leber. In der Substanz sind gelbe käsige Knötchen von unregelmäßiger Form sehr häufig. Dieselben bestehen seltener aus abgestorbenen verlefteten und verkalkien Exemplaren des Pentastomum denticulatum (s. Parasiten der Lunge S. 214), hïutiger aus solchen des Cysticercus pisiformis (s. Parasiten des Peritoneum S. 297), am gewöhnlichsten aber aus Psorospermien (S. 23). Letztere infiltrieren mifunter die Lymphgelißße der Leber (W. Kranse); sie kommen in Leberzellen eingeschlossen vor (521); sie hönnen auch verhalken (.522). Außerdem kommen in der Leber, den Gallenwegen und der Gallenblase Distomum hepaticum und lanceolatum Mehlis vor. Ersteres ist platt, bräunlich, wird 18 $32 \mathrm{~mm}$ lang, $8-1 / 4 \mathrm{~mm}$ breit; letzteres ist schlanker, lanzettförmig, \&, $5-9 \mathrm{~mm}$ lang, 1-2 $\mathrm{mm}$ breit. Es vermag in den Dünndarm überzuwandern.

Exstirpation von Stuicken der Leber. Hautschnitt in der Medianlinie, am Processus xiphoideus beginnend, ca. $6 \mathrm{~cm}$ nach abwärts, Abtrennumg kleiner Stijche mil der galvanohauslischen Schneideschlinge (Meißner, mündliche Mitteilung).

Ductus choledochus. Mündet in die obere Wand des Anfangsteiles des Tuodenum, etwa 1 cm nach rechts von der Kardia. Ist so weit, daß er die Einführung einer Kintile gestattet. Derselbe teilt sich in die Duchus cysticus und hepulicus. Letzlerer führt die Galle aus dem Lobus hepaticus sinister ab; in den Ductus eysticus minden successive kleinere Duchus hepatocystici, gewohnlich drei an Zahl, welche für die übrigen Lappen der Jeber bestimmt sind.

Gallenliase. Ihr fimdus enthiilt Ganglienzellen (57, S. 228); iber die Nerven vergl. 715.

Auch beim Rinde sind Ductus hepatocystici vorhanden.

Pathologische $\mathrm{A}$ natomie. Der Ductus choledochus ist stellenweise erweitert und verengert; die Erweiterungen stellen cystenartige Säcke dar. - In der Gallenblase sind Psorospermien gefunden und es wurde vermutet, daß sie durch den Ductus choledochus dahin, sowie in die Gallengänge der Leber gelangen $(862)$.

Aufsuchung des Ductus choledochus. Hautschnitt in der Medianlinie, am Pro- 
cessus xiphoideus beginnend bis zur Nabelgegend. Der Pylorus wird stark nach abwärts, vorn und lateralwärts, die Leber in die Höhe gezogen. Der Ductus cysticus und choledochus verläuft von der Gallenblase (s. Fig. 97, S. 225) zum Anfang des Duodenum, dicht neben und nach rechts von dem Pylorus. Etwas nach links von letzterem kommt die A. hepatica hinter den Magen her, sie liuft aufwärts zur Leber, in schräger Richtung von links nach rechts und oben vor den Ductus choledochus (Fig. 96) tretend. Der Ductus cysticus wird zum Teil von vorn her durch den Ramus dexter der $\mathrm{A}$. hepatica bedeckt. Bedeutend lateralwärts, resp. hinter dem Ductus choledochus und der A. hepatica liegt die Vena portarum. - Unterbindung des Ductus choledochus führt nach etwa einer Woche den Tod herbei und bewirkt Anfüllung der Gallengänge in der Leber (718).

Anlegung einer temporären Gallenfistel $(596)$. Hautschnitt wie oben, eine Kanüle wird in die entleerte Gallenblase eingebunden, der

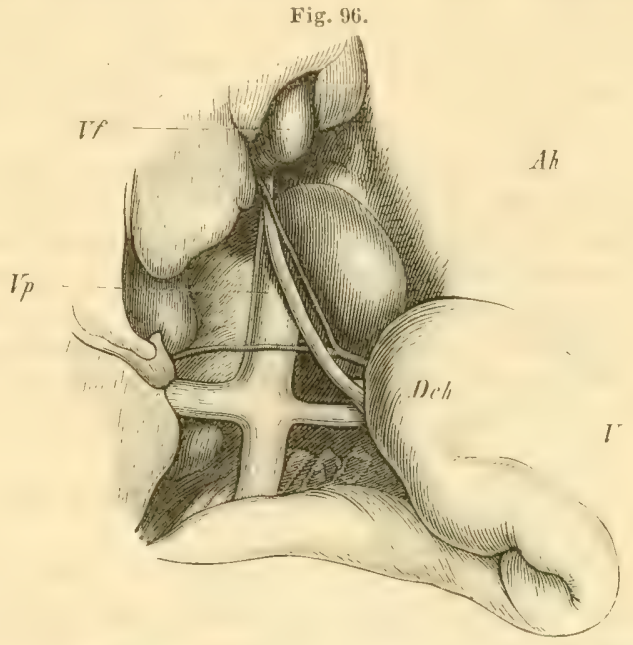

$D$ ch Ductus choledochus in das Duodenum mündend. T Marren. Vf Giallenblase, in die Lebersubstanz teilweist eingebettet. $A h \mathbf{A}$. hepatica, sich in den R. dexter, weleher nehen dem Ductus choledochus verläuft, und den R.sinister teilend. Vp V.portarum, hinter den letzteren verlaufeud, mit ihren Ästen. Die Leber mit der Gallenblase ist nach oben geschlagen.

Ductus choledochus dop-

pelt unterbunden, die austropfende Galle gewogen. Die Leber produzierte im Ruhestande bei (sechs) Kaninchen vou 694-1107 g Körpergewicht ohne den zu $20 \%$ angesetzten Darminhalt) im Mittel $115,7 \mathrm{~g}$ Galle, ein Kilogramm Kaninchen $133 \mathrm{~g}$ oder fast $10 \%$ des Körpergewichtes. Der Bhutgehalt der Leber betrïgt ca. $1 \% / 0$ des Körpergewichtes (S. 66), die Leber wiegl 4. 2" " des letateren (vergl. jedoch S. 26). Jene hohe Zilfer der Gallenausscheidung im Vergleich zum Menschen $(1,4 \%$ des Körpergewichtes) oder zu Fleischfressern Katze, 1, $45 \%$ ) entspricht der permanenten Verdaumgsthitigkeit des Pflanzenfressers.

\section{M ilz.}

Klein, langlich, blaßrötlich, ihre Lymphfollikel sind dem bloBen Auge sichtbar. Sie wiegt 0,65 g. Zum Gewicht des ganzen Körpers verhailt sich ihr Gewicht 12 Stunden nach der Mahlzeit wie $3600: 1$; 8 Stunden nach der Mahlzeit wie 2552:1; bei jungen Tieren ist die Milz relativ schwer $(52 \%)$. Nach Daubenton (52.4) wiegt sie beim wilden kaninchen $0,18-0,4: 3 \mathrm{~g}$ und es verhitt sich ihr Gewicht zu denjenigen der Leber wie 1 : 270 , wahrend das Verhailtnis beim zahmen Kaninchen 1 : 190 betrigt, womit Meckel (525) nach ciner Mittelzahl aus sechs Wägungen übereinstimmt. Aus den in Text angeführten Zahlen folgt das Verhailtnis wie 1:12\%. - Der Überzug der Milz enthiilt glatte Muskelfasern (526); nach Vagusreizung kontrahieren sich die Trabeculae ( 700$)$. 
Die Milz enthält 316,09 Teile organische Substanz, 5, 16 unorganische Stofle, 678,75 Wasser $(525)$.

Septi cäm ie. Die Milz ist bei dieser Krankheit vergrößert, weich, blaurot und hyperämisch oder graurot. Die Affektion hat bei Linimpfung eine Inkubationsdauer von $10-12$ Stunden, die Temperatur steigt bis zu $42^{0}$, die Respirationsfrequenz sinkt. Später verhäit sich beides umgekehrt, der Tod tritt gewöhnlich unter klonischen Krämpfen 16-20 Stunden nach der Impfung ein. Im Blut und in den feweben finden sich Bahterien, die doppelt so lang als breit sind, die Endstiiche lassen sich durch Methylenblau firben, nicht aber die Mittelstücke ( 856 vergl, a. 671 und 857, S. 210 u. 343).

Exstirpation der Milz. Schnitt durch Haut und Muskeln, $6 \mathrm{~cm}$ lang; entweder in der Medianlinie am Processus xiphoideus beginnend, oder vom vorderen Linde der durchzufühlenden elften linken Rippe gerade nach abwärts. Bei der ersteren Methode tritt heine Bhutung ein, der Magen nuß aber herrorgezogen werden; hinter dem oberen Teile der großen lurvatur verbirst sich die lingliche, im Leben bläulichrote Milz. Nach der Exstirpation fand Maggiorani Abnahme des Faserstotles, des Albumins und der roten Blutkörperchen im Blute.

\section{Pankreas.}

Das lankreas (Fig. 97) oder die Banchspeicheldrise ist ron sehr linglicher Form, erstreckt sich vom oberen Ende des Duodenum vor der A. hepatica, V. portarum und V. cava inferior schrig abwirts und nach links; reicht an der linken Seite am oberen Rande des Colon transversum bis hinter das untere Ende der Milz. Es hat ca. 18 cm Linge, 2 cm Breite, wiegt 0,61 $\mathrm{g}$, ist sehr flach atusgelneitet in der Mesenterialfalte, welche die Partes horizontales superior und inferior des Juodenum mit der Pars verticalis verbindet. Der Kopf ist rom Kärper nicht gesondert; die läppehen liegen bei mageren Tieren wie pripariert dar.

Der Ausführungsgang, Ductus pancreaticus s. Wisungianus, liegt etwa in der Ausdehnung von $3 \mathrm{~mm}$ frei, ist sehr diunnwandig, hat ea. $1 \mathrm{~mm}$ Durchmesser, münlet ca. 40 cm vom P'ylorus und folglich fast eben so weit vom Duclus choledochus entfernt in die Pars horizontalis inferior des Inodenum.

Acin i des Pankreas. ZweiZonen - eine peripherische radiär gestreifte, aber blasse und eine dem Lumen des Acinus benachbarte, mit dunkeln, in Alkalien erblassenden Körnchen, die also kein Fett sind, angefüllte Zone - lassen sich in den Zellen der Acini wihrend der Verdauung unterscheiden; beide Zonen werden durch den Zellenkern getrennt (J2), dessen Lage jedoch nicht konstant ist (1, ., S. 176). In das Innere der iußersten Acini setzt sich eine dem Epithel der feinsten Ausfïhrungsgänge angehörende, spindelförnige Zelle (sog. zentro-acinäre Zelle, .58 fort; zwischen den Zellen sollen injizierbare Drisenkapillaren verlunfen (.j 28 und 5.29) oder diese Ritume mit Lymphe gefiill sein $(677)$. - In Hungerzustinde nchmen die erwähnten Kïmchen indessen den größten Teil der Zelle ein (1.4. S. 201 ).

Blulgefäße. Die äuBerste Peripherie der Drüsenlïpehen soll von Blutkapillaren nicht erreicht werden $(675)$, was beim Henschen sich jedoch anders verhiilt $(57$, S. 229, Fig. 136). Über eine Methode den Blutlauf am lebenden Tiere zu beobachten, vergl. 677 .

L y mphgefaße. Schon mit freiem Auge sind meistens trübe aussehende bis 1-2 $13 m$ messende L.ymphfollikel sog. intertubuläre Zellenhaufen) sichtbar, deren 
Blutgefaße eigentiimliche, den Nierenglomeruli ähnelnde Konvolute von weiten Kapillaren darstellen. - Die ausführenden Lymphgefißstimmchen verlaufen entlang dem Mesenterium zum Anfang des Ductus thoracicus (Cisterna chyli, 5.50).

Die Nerven des Parkreas sind wahrscheinlich Ganglien-führend wie die des Menschen (551); sie verlaufen mit den Arterien.

Aufsuchung des Duc-

tus pancreaticus. Schnitt in der Medianlinie, mindestens $6 \mathrm{~cm}$ lang, Verfolgung des Duodenum vom Magen an in einer Strecke von etwa $40 \mathrm{~cm}$, Abtrennung des Processus vermiformis von der Pars horizontalis inferior des Duodenum. Der Ductus pancreaticus (Fig. $97 \mathrm{DW}$ ) mündet in die obere Wand des letzteren.

\section{Nach Unterbindung}

des Ductus pancreaticus treten keine merklichen Ernährungsstörungen beim Kaninchen auf; die Absonderung, die anfangs unter einem Druck stattfindet, welchem eine Quecksilbersiule von 16,817,3 mm Höhe entsprechen würde $(770)$, dauert wenigstens dreißig Tage nach Anlegung einer Pankreasfistel unverändert fort (555), ohne daß das Körpergewicht abnimmt. Uber die mikroskopischen Veränderungen an so behandelten Drüsen s. 144. - Die Sekretion kann $0,6-0,7 \mathrm{ccm}$ in der Stunde betragen $(770)$.

Varielat. Bernard hat einen accessorischen, in den Ductus choledochus mündenden Ausführungsgang des Pankreas beschrichen, dessen Existenz zur Beweisführung für eine übrigens längst als unrichtig erkannte Theorie Bernard's

in betrefl der Funhtion des panhreatischen Saftes, die Fette zu emulsionieren, unentbehrlich erschien. An der von Bernard (5.5.4) angegebenen Stelle verliiuft ein Ast der A. gastro-epiploica dextra (S. 260), welcher vom Pankreas und Duode-num her zum unteren Ende des Ductus choledochus in schriger Richtung, fast parallel demselben sich begiebt und an letzterem sich veristelt. An nicht injizierten Priparaten ist eine Verwechslung dieser Arterie von nur 0, $2 \mathrm{~mm}$ Dicke mit einem Drïsenausfïhrungsgange immerhin möglich. Hiervon abgesehen, so könnte der fragliche zweite Ausfülrungsgand den Bernard sellost keineswers immer fand, wenigstens als seltene Variefit vorkommen, was ich jedoch ebenso wenig gesehen Krause, Anatomie des Kaninehens. 2. Auflage. 
habe, als es von seiten Schiffs $(5,55)$ der Fall gewesen zu sein scheint. Aber von vornherein ist einleuchtend, daß die Existenz eines \usführungsizanges, der in den Ausfiihnugsang einer anderen Irüse einmïndet, ein anatomisch ziemlich exzeptionelles Faktum darstellen wïrde (vergl. jedoch S. 206). Durch die hier gegebene Nachweisung ist wohl die Quelle des Irrtumes genügend aufgedeckt.

\section{Peritoneum.}

Das Peritoneum ist eine sehr dünnwandige, glatte Membran, welche die Batucheingervede durch falten, Ligamenta peritonei, mit der Batuchwand und untereinander verbindet. Die vorzüglichsten sind folgende:

Ligamenta coronaria hepatis. Das sinistrum geht rom Diaphragma zum oberen Rande des Lobulus sinister posterior hepatis; das dextrum an den hinteren Rand des Lobulus dexter anterior.

ligumentum suspensorium hepatis. Verliuft in sagitlaler Ebene, nahe der Medianelene rom Diaphragma zur Leber, den Lobus dexter rom sinister scheidend.

(Imentum mimns geht von der Fossa transrersa hepatis aus, heftet sich an die Curvatura ninor des Mag̣ens; geht narh rechts in das schmale Liggmentum hepaloduchlenule iber, welches von der Fossa transversa zur oberen Wand des Anfanges des Duodenum sich erstreckt.

line Falte, die Ligumentum antri pylori wenamnt werden kimn. setzt sich zum linken Rande der Vorderfliche des Antrum pylori fort.

Ligamentum phrenicogastricum geht linkerseits vom hinteren Rande des Zwerohfelles zur Kardia in transversaler Richtumg und hangt mit dem Ligamentum gastrolienale zusammen.

Ligamentum gastrolienale befestig̣t die konkase filache der Milz an den Fundus des Magens; ist sehr breit und lang.

Ligamentum gastrocolicum geht von der großen Kurvatur und hinteren Flache des Magens zum Colon transversum.

Mesocolon adscendens erstreckt sich von der hinteren Wand des Perito-

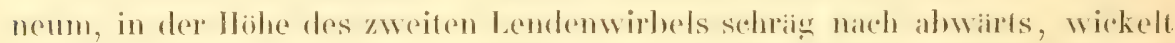
anBer dem Colon atserendens die Windungen der Pars horizontalis inferior und rerticalis des Inodenum, mobst dem Goecum und dem Processus remiformis ein. Die verbindenden Bbitler heißen Ligamenta dhodenocolicum und coecocolicum.

Mesorolon trunstersum. Erstrecht sich vom rechtsseitigen Ende der hleinen Kurvatur des Magens, von der hinteren Fliche desselben und vor dem Pankleas nach rorn. Nach rechts geht die Wurzel desselben in das Ligamentum hepalocolicum iiber, welches sich zum oberen Rande des Lobulus dexter posterior erstreckt. AuBerdem lassen sich Faserzige des Saceus peritonei an der hinteren Bauchwand verfolgen, wolche von der Wurzel des Mesocolon fransiersum vor der Vorderfliche dor rechten Niere sich ausdehnen und Ligamentum drodenorenale genaunt werden können.

Mesocolon descendens ist mehrere Centimeter breit, oben schmaler als unten: erstrekt sich senkrecht nahe der Hedianlinie der Wirbelsiule ron der- 
selben nach vorn, indem es vom zweiten Lendenwirbel bis zum Os sacrum abwarts reicht. In demselben verlaufen die $A$. und V. mesentericae inferiores.

Mesenterium geht in der Höhe des zweiten Lendenwirbels von der Rückenwand des Bauches aus, haingt mit dem Mesocolon adscendens zusammen.

Mesorechum bildet die Fortsetzung des Mesocolon deseendens nach uuten.

O mentum majus. Dasselbe zeichnet sich durch seine durchlöcherte StrukIur aus; die Löcher sind bedeutend kleiner als die bindegewebigen Balken zwischen denselben $(660)$. Dasselbe enthält Lymphfollikel (5.52-vergh.57, 5. 297).

Die L y mph gefä Be des Diaphragma kommunizieren durch offene Mündungen mit der Bauchhöhle (556; vergl. 57, S. 341 und S. 344); ebenso mit den Pleurahöhlen (557).

Im Mesocolon fand Hassall (.;5) zwei Vater'sche Köperchen. Herbst beslitigte das Vorkommen (559).

Pathologische Anatomie. In der Bauchhöhle kommen zuweilen freie Körper vor: Eisäcke, welche reife Embryonen enthalten können (540). Beim

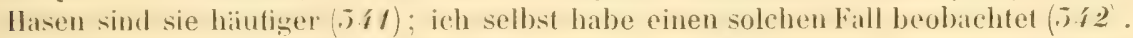

Ohne Zweilel ist das Ei sehundir, etwa durch Abschnïrung eines Stieles frei geworden.

IIydrops ascites ist nicht selten bei herabgekommenen Kaninchen (24, S.49).

Parasiten des Peritoneum. Am Omentum majus, Mesenterium, dem serösen Überzuge der Leber, besonders aber im Becken ist Cysticercus pisiformis Zeder häufig. Die Blasen haben 9-14 $\mathrm{mm}$ Länge, $5-7 \mathrm{~mm}$ Dicke. Sie sind von einer Bindegewebshiille ungeben; in der Blase selbst findet sich Kopf und Hals eines Bandwurmes, der Taenia serrata Goeze, welcher im Dünndarm des Hundes lebt, vier Saugnäpfe trïgt und mit einem schönen Ifakenkranz bewalfnet ist. Der weißliche Hals enthiit zahlreiche Kalkhörperchen. Vielleicht gehört zum Cysticercus pisiformis das Monostomum leporis kuhn. Auch Cysticercus elongatus Leuchart ist am Peritoneum beobachtet, ebenso eimmal coenurus cerebralis frei in der Bauchhöhle (545).

Eimmal habe ich eine seltene Mißbildung: einen Cysticercus cellulosae mit sechs Saugnäpfen, beim Menschen gefunden - Erste Auf1. S. 165].

Injektionen in die Bauchhöhle geschehen am besten in der Linea alba mittels einer Einstichkanüle. Man hann auch Gase, z. B. Kohlensïure $(823)$, auf diese Art injizieren. Bei mäßigen Quantititen folgt danach Sichschütteln des Tieres, Absinken der Körpertemperatur, auch der Puls- und Respirationsfrequenz, nach Injektion von mehr als $400 \mathrm{ccm}$ tritt Dyspnoe und der Tod ein $(825)$.

\section{Haru-Apparat.}

\section{Nieren.}

Jede Niere wiegt $7,3-7,5 \mathrm{~g}$; die linke scheint etwas schwerer zu sein. In Nierenbecken ist nur Eine Papille, resp. Malpighi'sche Pyramide vorhanden. Die rechte Niere roicht vom unteren Rande der rechten elften Rippe bis zum oberen Rande des zweiten Lendenwirbels, die link N $^{2}$ e re von der Mitte des zweiten bis zur Mitte des vierten Lendenwirbels; die linke Niere liegt mithin bedentend weiter abwarts als die rechte (Fig. 98, s. 228). 
In betreff des mikroskopischen Baues vergl.545. Die Glomeruli tragen kein Epithel (679); über deren verschiedene Größe s. 761 und vergl. 58, S. 75.

Füllt man das Nierenbecken vom Ureter aus mit Injektionsmasse und isoliert die letztere durch Korrosion, so erhält man die Form des Nierenbeckens im AbguB; dissolbe zeigt sich mit blattartigen Ausstülpungen versehen, von denen bei Lepus vulgaris vier an der Dorsalfliiche, drei an der Ventralfläche, je einer am oberen und unteren Ende des Nierenbeckens liegen (546).

Die Niere enthält 404,03 Teile organische Substanz, 5,85 unorganische Stoffe, 590,11 Wasser (525).

Pathologische Anatomie. Nach Exstirpation einer Niere nimmt die andere binnen 24 Stunden im Verhältnisse von 1:1,06-1,28 an Gewicht zu; die Durchmesser der gewundenen Harnkäülchen steigen von $0,04-0,045 \mathrm{~mm}$ auf $0,047-0,05 \mathrm{~mm}(544)$.

In Folge einer Unterbindung der $\mathrm{A}$. und $\mathrm{V}$. renales kann die betreffende Niere, wenn das Leben des Tieres erhalten bleibt, zu Grunde gehen. Auf diese Art verindert und sekundïr verkalkt, bildete eine linke Niere eineu steinharten Knoten von $1 \mathrm{~cm}$ Länge, $8 \mathrm{~mm}$ Breite, $5 \mathrm{~mm}$ Dicke.

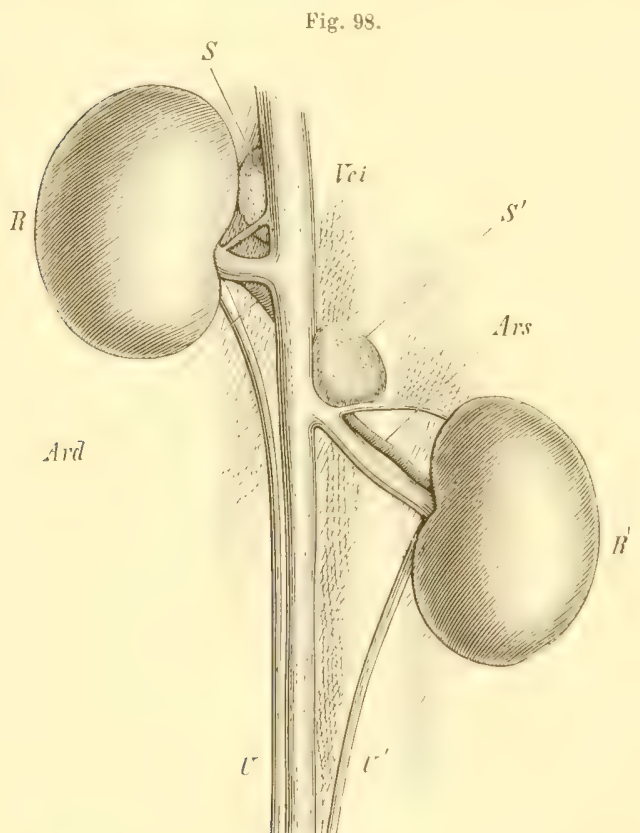

$r$ Rechte Niere. $R^{\prime}$ Linke Niere. $S S^{\prime}$ Rechte und linke Nobenniere. Ici V. "ava inferior. Ard, A $v^{*} \mathrm{~A} \mathrm{Aa}$. renales dextra und sinisira. $I I^{\prime}$ Rechter und linker Ureter; der rechte verläuft ganz nahe neben der $V$. cava inferior, der linke etwas mehr sehräg, abwärts.

Nach Unterbindung der V. renalis füllen sich die schleifenförmigen Kanälchen der Nierenpyramide, welche übrigens im frischen Zustande auf Längsschnitten leicht ohne Zusatz (547) nachzuweisen sind, mit einer feinkörnigen, zum Teil aus Fett bestehenden Masse. Im Urin finden sich, neben Eiweiß, sparsame, öfters mit Epithelialzellen besetzte Fibrinzylinder, die aus den offenen Kanäilchen herstammen dürften (548). Dieselben Veränderungen zeigen sich in Nieren von Kaninchen, die durch Überziehen mit Gummilösung (s. Haut, S. 172) getödet worden sind $(549)$. Nach Injektion von Quecksilberchlorid $\quad(0,004-$ $0,006 \mathrm{~g}$ ) in das Unterhautbindegewebe infiltrieren sich nach einigen 'Tagen die Ferrein'schen Pyramiden der Rindensubstanz mit Calciumphosphat $(550)$.

Nach Einwirkung von Chloroform (s. Großhirnrinde) Iritt Kolboidmetamorphose der Epithelien der gewundenen Harnkaniilchen auf $(\ddot{0} / 0)$.

Werden die A. und V. renales (sinistrae) nebst dem Ureter einerseits vor dem Toule unterbunden, so wird das spezitische Gewicht des Organes geringer gefunden (Rindensubstanz 1.049), als bei der nicht unterbundenen Niere (Rindensubstanz 1,051-1,060), und auch geringer, als wenn der Tod durch Verblutung herbeigeführt wird, sowohl in der unterbundenen Niere Rindensubstanz 1,0:4- 
1,059, Marksubstanz 1,048), als in der nicht unterbundenen Niere (Rindensubstanz 1,059-1,061, Marksubstanz 1,052). Diese Thatsache erklät sich aus dem geringen spezifischen Gewicht $(1,0425)$ des Kaninchenblutes. Das ersterwähnte spezitische Gewicht $(1,049)$ ist als das der Rindensubstanz wihrend des Lebens zukommende zu betrachten, während dieser Substanz selbst, vom Blut srößtenteils befreit, die Zahl von mindestens 1,064 beizulegen sein dürfte (551).

Exstirpation der Nieren. Operation wie bei Unterbindung der Aa. renales (s. Angiologie).

Exstirpiert man die linke Niere beim neugeborenen Kaninchen und untersucht das Tier, nachdem es ausgewachsen ist, so findet man die rechte Niere auf das Volumen und Gewicht beider normalen Nieren heranzewachsen, die Zahl der Glomeruli aber nicht vermehrt $(605$. - vergl. a. 674). Über die Folgen zeitweiliger Unterbindung der $\Lambda$. renalis, Verkalkung der IIarnkanälchen, Herstellung eines Kollateralkreislaufes vergl. 672; über sekundire Hypertrophic des linken Herzventrikels und das normale Verhältnis des Gewichtes beider Nieren zum Herzgewicht (wie $3,5: 1$ bei älteren; 2,6: I bei jüngeren Tieren) vergl. 675 ; über die Zerstörung des Plexus renalis S. A. renalis (S. 261).

\section{Ureteren.}

Der rech te Ureter verliuft medianwirts von der Spitze des Processus transversus des zweiten Lendenwirbels, ror dem M. psoas major dexter an die rechte Seite der V. cava inferior geschmiegt (rig. 98) senkrecht abwirts, kreuzt sich in der Ilöhe der Teilungsstelle der Aorta abdominalis mit den 1. und $\mathrm{V}$. spermaticae internae dertrate, die vor dem Lreter liegen. Letaterer gelangt dann vor den A. und $V$. iliolumbales dextrae und vor der $\Lambda$. iliatrat communis dextra herabsteigend in das kleine Becken.

Der linke Ureter verlauft vom Ililus der linken Niere, welcher dicht lateralwirts neben der Spitze des Processus transversus des dritten Lemdenwirbels liegt, schrig abwirts und medianwirts, nach vorn und medianwirts von den Processus transversi des vierten bis sechsten I.endenwirbels und vor dem M. psoas major sinister.

Über die Nerven und Ganglien des Ureters und Nierenbeckens vergl. 57 , S. 248 und 697 .

Unterbindung der Ureteren s. A. renalis (S.261).

\section{Harnblase.}

Ist sehr dünwandiy; wenn sie gefüllt ist, dränct sie die untere Mundung des Coecum in die Höhe. Sie ist alsdamn birnfömig, das stumpfe Ende oder der Scheitel jedoch gegen den Urachus hin zugespit». Die Aa. und V. vesicales dextrae und sinistrae laufen an den Außenflichen ihrer lateralen Wände in die Iöhe und anastomosieren am Scheitel. Von ihrem oheren Eude reicht der Urachus in der Plica vesicalis media bis zum Vabel. Die Plicar vesicales laterales für die ligamentösen Reste der Aa. umbilicales sind sehr flach, die Plicae rectovesicales des Mäunchens dagegen stark rorspringend. 
Die gefüllte Harnblase soll bis zu den Rippen reichen können (552). Dieser Angabe diirfte jedoch ein Mißverstiudnis oder eine Verwechslung zu Grunde gelegen haben.

Über den Verschluß der Harnblase vergl. 719. - Das Epithel wird im Zustande starker Ausdehnung der Harnblase ganz niedrig und platt (687).

Nerven der Harnblase. Im submukösen Bindegewebe finden sich Ganglien-fïhrende Nervenplexus und Bündel glatter Muskelfisern, welche letztere gegen

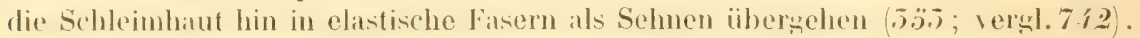

Der Il a rn ist trübe, gelblich, von unangenehmem Geruch, alkalisch. Die Truibung kommt her von Erdphosphaten und -carbonaten, aluch von AmmoniumMagnesiumphosphat; das Cialciumearbonat erscheint meistens in form der sog. Dumb-bells: zwei oder mehrere ans Nadeln bestehende kugeln werden durch ein Mittelstück verbunden, welches letztere aber fehlen kann, so daß die Kugeln oder Halbhuzeh direkl mit rinander verschmolzen sind. Außerdem finden sich Okläider von Galciumosalat. Der Ifarn enthiilt Harnstoll, viel Hippursäure, sehr wenig Phosphorsäure, auch Milchsäure. Es soll darin normalerweise ein Eiweißkörper vorkommen (354). Durch Fleischfütterung wird der Harn sauer; ebenso bei Inanition (555). Der Brechungsindex beträgt 1,3445 (772).

Pathologische Anatomie. Blasensteine sind beobachtet worden (24, S. 64 )

\section{Nebennieren.}

Jede wiegt ca. 0,22 2, ist rundlich, weiBgelblich, in der Rindeusubstanz sehr fettreich $(57$, S. 251).

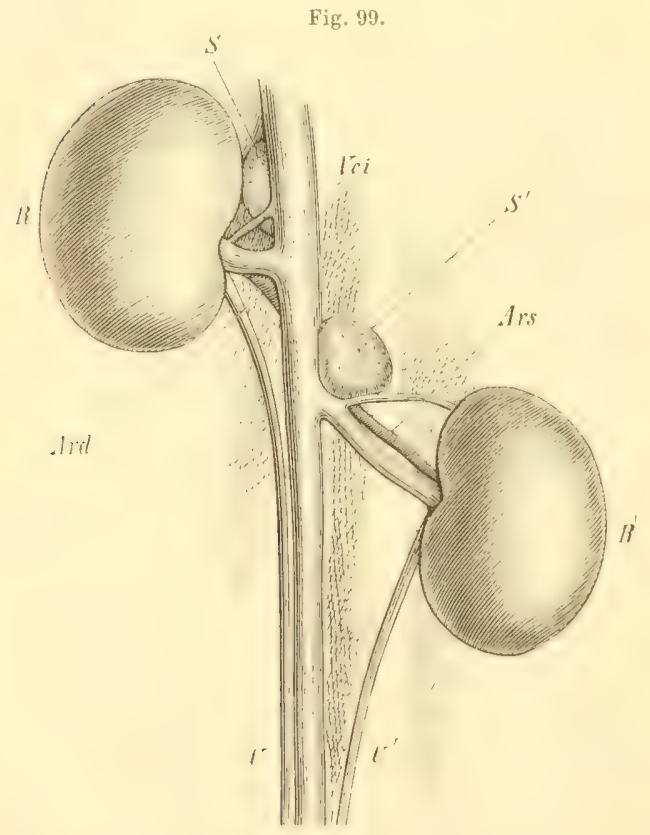

$R$ Rechte Niere. $R$ Linke Niere. $S S$ Rechte und linke Nebenniere. Vci V. cavi inferior. Ard, Ars Aa. renales dextra und sinistra. $U U^{\prime}$ Rechter und liuker Ureter.

Die rechte Nebenn iere liegt links neben dem oberen Teile der rechten Niere, an deren linken Rand geheftet (Fig. 99). Nach rechts grenzt sie an die $\mathrm{V}$. cava inferior und die A. coeliaca, nach unten an die $\mathrm{V}$. renalis dextra, nach hinten an die Pars lumbalis des Diaphragma. Sie liegt in der Ilöhe des zwölften Riickenwirbels.

Die linke Nebenniere liegt viel tiefer als die rechte, in der llöhe des oberen Randes des zweiten Lendenwirbels, links von der Aorta abdominalis, uber den A. und V. renales sinistrae, vor der A. lateralis abdominis sinistra.

Bei einem Männchen in der Brunst wurde das Gewicht beider Nebennieren zusammenzu 1, 0 Iggefunden. 
Nerven. Die Nervenstämmchen in der Marksubstanz bestehen aus blassen Fasern und enthalten zahlreiche Ganglienzellen (Holm, 557. - W. Krause).

Varietat. Einmal wurle eine accessorische Nebenniere von der Größe einer kleinen Erbse vor der V. cava inferior beobachtet, wahrend die eigentliche rechte Nebenniere hinter der genannten Vene lag (24 und 556 ).

Exstirpation der Nebennieren. S. Fig. 99. Hautschnitt in der Medianlinie, am Processus xiphoideus beginnend, mindestens $6 \mathrm{~cm}$ lang. Die Operation ist binnen 24 Stunden tötlich.

\section{Geschlechts-Apparat.}

\section{Männliche Geschlechtsorgane.}

\section{Hoden.}

Jeder Hoden wiegt etwa $1,45 \mathrm{~g}$, ist $z$. B. $3 \mathrm{~cm}$ lang, $12 \mathrm{~mm}$ dick, birnformig, nach unten diuner werdend; das Volumen und Gewicht nimmt in der Brunst zu. Derselhe ist von zylindrischer form, geht mit einer $\Lambda$ rt von $\Lambda_{\text {h- }}$

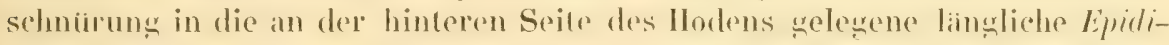
dymis ibher, welche aus Caput und Camdat besteht und wesentlich dureh WVindungen des Vas deferens gebildet wird.

Vergl. über den Bau der männlichen und weiblichen Geschlechtsorgane überhaupt 578. - Die Membrana propria der Samenkanälchen ist $0,001 \mathrm{~mm}$ dick (622).

Epididymis. Das vordere $5 \mathrm{~mm}$ lange Ende des Caput epididymidis ist zungenförmig, es kann als Processus capitis epididymidis bezeichnet werden $(5 s$, S. 92). Die Epididymis enthält glatte Muskelfasern $(558)$. - Über die Zwischensubstanz (resp. die Zwischenzellen) der Samenkanälchen vergl.579 u. 611 .

Ovarium unasculinum. Stellt ein solides rötliches orler bei Blutleere blasses und dann schwer aufzutindendes Pünktchen von 1 mm Lïnge auf 0,70 mm Breite unterhalb des Processus cappitis epididymidis dar, der Stiel ist $0,3 \mathrm{~mm}$ breit, das Flimmer-Epithel der Oberfläche $0,028 \mathrm{~mm}$ dick (58, S. 92). - Auf Grundlage seiner Entwickelungsgeschichte wird das Organ von anderer Seite für einen Rest des oberen Endes des Müller'schen Ganges gehalten $(811)$.

Samenfäden. Sie bestehen aus einem Kopf, welcher eine ovale, vorn abgerundete Scheibe darstellt, nebst schwanzförmigem Anhang. Ersterer ist länger als beim Menschen, vorn breiter und stumpfer abgerundet (Fig. 100); auch der Schwanz ist bedentend länger. Die Dimensionen des Kopfes betragen: Länge

Fig. 100.

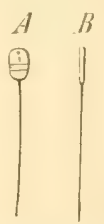

Samenfitlen des Kaninchens. A. der Kopf von der Fläcbe gesehen, mit einem dunklen Querhande. IB. anf der Kante $0,005 \mathrm{~mm}$, Breite $0,0036 \mathrm{~mm}$, Dicke $0,001 \mathrm{~mm}$; die Lïnge inkl. des Schwanzes betrïgt $0,045 \mathrm{~mm}$. Nanche haben ein dunkleres mittleres Querband Valentin 359, W. Krause). An eingetrockneten Samenfiaden sah Valentin 3,39) mitunter 
zwei bis vier dunklere Querbänder, die an die Reifen eines Fasses erinnerten. Leeuwenhock 1.560$)$, der die Samenfäden des Kaninchens zuerst abbildete, slaubte auch im Kopfe eine Anzahl kleiner Körnchen und ein größeres in der Nähe des Schwanzes zu erkennen. - Über die Entwickelung der Samenfäden s. 792.

Die chemische Beschaffenheit des Samens ist bei einem brünstisen, alten Männchen untersucht worden (j6f). Die Reaktion im Iloden war neutral, in der Epididymis leicht athalisch. Im Filtrat fand sich etwas Albumin; der Riickstand war lisklich in Alkillien, wurde durch lissigsiure grefillt; nur ein kleiner Teil war in Uberschuß lislich. Ferrokalimmeyanür bewirkte eine geringe Trübung.

Kastration. Hautschnitt nach der Länge der Skrotaltasche. Der Hoden wird hervorgezogen und mit dem Shalpell hurz abgeschnitten. I'ulerhindung von Blutgefaßen ist wenigstens bei jungen Kannehen gewöhnlich nicht nötiæ. Man hat auch den samenstrang unterhunden, ohme ihn abzuschneiden, und den Rest der Natur überlassen. Es hesteht die Gefihr einer tïtlichen Peritonitis, weil die Höhle der Tunica vaginalis propria mit der Bauchhöhle kommuniziert. - Vergl. a. 554.

\section{Lage der Hoden.}

Canalis inguinalis. Der Annulus inguinalis stellt eine langliche, medianwirts ron der 1. epigatrica inferior, sehr nahe der Medianlinie gelegene Spalte dar, dureh welehe das Vas deferens und die Vasa spermatica interua beim Weibchen das Ligamentum nteri rotundum, gehen. Der kurze Leistenkamal wird bedderseits vom oberen Tril der lloden mit ausgefullt; dieselben liegen nebst der Epididymis und dem unteren Teile des Vas deferens im Processus rayinalis peritonei. Iotzlerer steht mit der Bauchhohle in offenem Zusimmenhange, so daß die Hoden in dieselbe zuritcktreten hionen; seine untere Wind ist in einer, der Ilatfe eines Skrotum entsprechenden Falte der Batchhaut: der shrotulusche, jederseits neben dersymphys oss. pubis dureh das aus querostreifien Mushelfaseun bestehende Gubernaculum testis s. IIunteri festweheftet. Die Skrotaltasche enthiilt mnter der Haut die Tunica dartos, welele aus diinnem Bündeln ron glatten Muskelfasern besteht, und den $M$. "remuster, der gut 'ntwichelt ist (s. M. obliquus abdominis internus S. 157).

\section{Vasa deferentia.}

Das Vas deferens ist ziemlich weit, weich, die Muscularis wenig entwickelt, deren gratle Langsmuskelfasern Bberwiegre Verläuft in Begleitung der Vasa spermatiea interna an deren medialer seite und an der hinteren medialen Soite des Hodens aufwirts und nach hinten, gelangat durch den Ammulus inguinalis in die Bauchhoble, und sich mubiegend und an der latelablen Wand der Harnbase abwartssteigend in das kleine Becken. Das Vas deferens verlauft dann nahe vor dem Creter, an der lateralen und Vorderfliche der Vesienula prostatica, mit dem der anderen Seite konvergierend, zeigt nahe seinem Ende eine lingliche Erweiterung und mündet in die Vesicula prostatica.

Aufsuchung des Vas deferens. A. Ohne Eröffnung der Bauchhöhle. Hautschnitt in semhrechter Richtung durrh die Skrotaltasche, am Leistenringe beginnend, ea. $3 \mathrm{~cm}$ lang, Hervorziehen der Hoden. 
B. Mit Eröffnung der Bauchhöhle. Hautschnitt in der Medianlinie, am oberen Rande der symphysis oss. pubis begimend, mindestens $6 \mathrm{~cm}$ lang. Hervorziehen der Hoden aus dem Skrotum nach aufwärts, Durchschneidung des Gubernaculum testis $(558$, S. 11$)$.

Über die Folgen der Unterbindung des Vas deferens s. 688.

\section{Vesicula prostatica.}

Die Vesicula prostatica s. Itriculus masculinus stellt eine unpare langliche, von vorn nach hinten abgeplattete. nach oben mit zwei kurzen, don Uterushörnern des Weibchens analogen Ausstülpungen: Cormua resiculae prostalicae, versehene, ziemlich dimnwandig̣e Blase von fast 3,5 c'm Lainge, 1,5 em Breite dar. Dieselbe liegt in der Medianlinie hinter dem unteren Teile der llarnblase (Fig. 101). Sie beginnt in der Mitte des Colliculus seminalis urethrae mit einem einfachen Os utriculinum vesiculae prostaticae, welches als eine transversale, dem Orificium uteri externum entsprechende, 2-3 mm breite Spalte in einem Bogen um den Colliculus seminalis herumlauft, so daß letzterer nach vorn konvex, nach hinten konkav erscheint. Von da an erweitert sich die Vesicula prostatica allmählich bis 11 -13 mm úber ihrer Mündung, woselbst sich" auf der Vorderflache eine Einschnürung teigt. Dieser untere Teil hat eine an der Hinterwand dickere Schleimhaut, die von der Mundung an mit $5-7$ in der Mitte 0,3 mm dicken Lingsfalten, die durch Seitenäste zu einem zarten Netze verbunden werden: frbor vesiculae prostaticae, versehen ist.

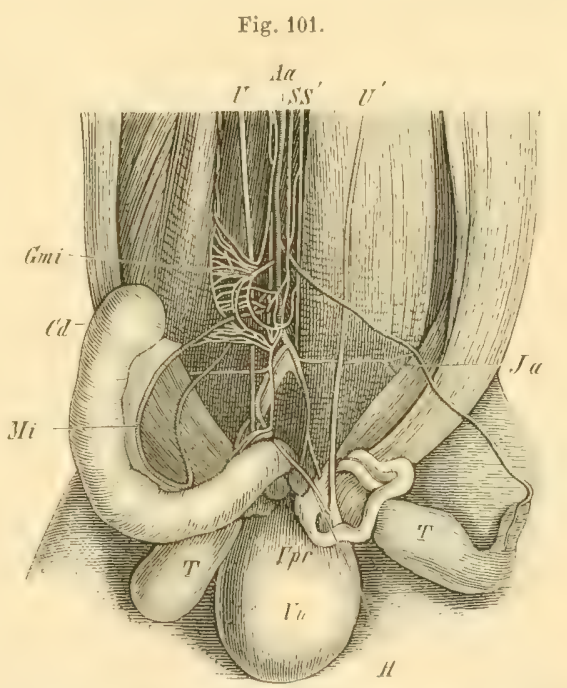

Iu Harmblase. Vpr Cornua resiculae prostaticae, als kleine runde Höcker wherhalb der Harnblase erseheinend

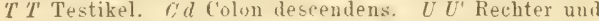
linker Ureter. A a Aorta abdominalis. Nach Loeb uni Eckhard $(t 1 \delta)$. S $\$$. Neurologie, Bauchteil des sympathisehen Nervensystems. Der obere Teil der Vesicula prostatica oberhalh der Binschnürung ist weit, seine Innenwand glatt: ihre Ilohle einfach. ihre Wandung koutraktil und enthilt glatte Muskelfasern, die geflechtartig verbunden sind. Au ihrem oberen Ende besitzt sie zwei laterale Zipfel Fig. $104 \mathrm{~T} / \mathrm{pr}$. Die Vasa deferentia minden ca. 2 mm von einander entfernt und 3-7 mm oberhalb des Os utriculinum nebeneinander mit ziemlich großen Öfnungen, jeder auf einer ca. 1,35 mm breiten Papille in die Vorderwand der Vesicula prostatica.

In der Schleimhaut finden sich rundliche Drüsen eingebettet (562).

Die Vesicula prostatica entspricht rermöge ihrer Muskulatur, ihrer Mündung, die einer Uterusmündung aualog ist, ihrem Arbor etc. vollkommen dem Uterus, 
oder genauer dem vom Peritoneum überzogenen oberen Teil der Scheide beim weiblichen Kaninchen; gewöhnlich wird sie jedoch für eine unpaare Vesicula seminalis gehalten (565), wofür sich anführen läßt, daß sie nach Kölliker (8io, vergl. 8/1) aus einer Erweiterung und Verschmelzung der Wolfr'schen Gänge des Embryo hervorgehen soll. Sie enthilt in ihrem weißlichen Inhalt konstant Samenfiden (564), und ist also ihrer Funktion nach immerhin als Samenreservoir zu betrachten. Lutwichelungsgeschichtleh entspricht sie so sehr dem Uterus, daß es nach E. II. Weber noch beim neugehorenen Kannchen bemahe unmöglich failt, beide Organe mit bloßem Auge zu unterscheiden (565).

\section{Prostata.}

Die Prostata ist wenig entwickelt, länglich-oval, dünn, gelblich; ihre Rinder sind alugerumble Sie hesteht ans oinem Lolus mediulis und zwei Lobi laterales: sie lient hinter dem unferen Teile der hinteren Wand der Vesienla postatiea. Der untere Teil der lateralen hander kam sich unterhall, der Vesiculae seminales an der lateralen Wand der Vesioula prostatica fortsetzen. Ihre Arini liegen zwischen Zijgen vou ghatten Muskelfasern; ihre Ausfuhrungsginge öfnen sich am Colliculus seminalis.

Uber den mikroskopischen Bau der Prostatas. 794.

Nerver. Die Nervenstämmchen inmerhalb der Prostata führen mikroskopische Ganglien (Leydig, 566. - W. Krause), welche teils kleiner (4-6 Ganglienzellen), teils größer $(15-20$ Zellen) sind $(665)$.

Pathologische Anatomie. Die Acini der Prostata sind häufig erweitert und erhalten konzentrisch geschichtete Konkretionen. Sie besitzen Zylinder-Epithel $(566$, Taf. I. Fig. $1-3$, und 562 , S. 499, Fig. $242-$ s. a. 665).

\section{Samenbläschen.}

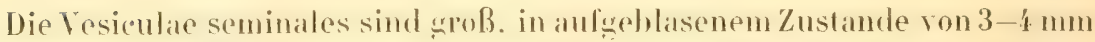
Durchmesser, " zwischen dersellen und der Prostata nach oben und hinten, müden nach vorn jede mit einer hesonderen Offumg neben den Vündungen der Vasa deferentia in die Harnoöhre

Sie bestehen atus rehiltnismaBiy weiten, dimmwandigen. gewundenen Schläuchen.

Die Vesiculae seminales können im leeren Zustande leicht iibersehen werden; sie enthalten schleimige Flïssgheit, die Samenfiden führen kamn. Man hat sie als ein zweites Prostatapaar betrachtet $(566)$.

\section{Harnröhre.}

Die Urethra ist eng; die Pars prostatica kurz, enthält den Colliculus seminulis, iu dessen Mitte die Vesicula prostatica mündel; hinter demselben liegen die Einmüudungsstellen der Vasa deferentia und über letzteren diejenigen der 
Vesiculac seminales. Die Pars membranacen ist lang; an ilsrem vorderen Ende liegen die Glandulae Comperi. Die Pars aternosa stellt einen gleichmißin weiten Hohlzylinder dar.

Die Muskeln der Harnröhre bieten nichts bemerkenswertes $(56 \%)$.

\section{Penis.}

Ist $2,5 \mathrm{~cm}$ lang, fast gerade nach abwäts gerichtet; seine Glans lang und spitz.

\section{GI. Cowperi.}

Jede ist ca. $1 \mathrm{~cm}$ lang; 2 $\mathrm{mm}$ breit; liegt jederseits vor der Prostata,

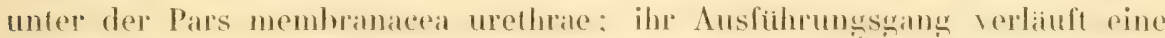
strecke weit nach vorn, müulet in sehriger Richtung in den Anfang des Pins cavernosa urethrae.

Das Epithel der stark gelappten (799) Drüse ist in den Acini pyramidenförmig, in den Ausliihrungsgingen zylindrisch, in der Umgebung der letzteren tinden sich quergestreifte Muskelfasern $(800)$.

\section{GI. praeputiales.}

Jede fil. praputialis s. inguinalis wiegt $0,12 \mathrm{~g}$, ist langlich-oval, $13 \mathrm{~mm}$

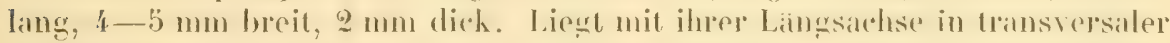
Richtumg an der lateralen Seite der Wurzel des Penis, Iaßt sich mil der Ilaut aufheben, die an der lateralen seite des Praphutium in einer hallomondfiomigen Stelle hardos ist. Der grössere mediale Te il hat brimnliche Farbe, der laterale Toil zeigl weiBliche hnotchen, liegt unterhath des unteren Endes der skrotaltasche. Das eigentimbliche Sekret ergeßs sich atuf die erwihnte haarlose Hautstelle.

Der bräunliche mediale Teil besteht aus gewundenen, mit Ausführungsg̈̈̈gen versehenen Kanbilen, die denjenigen der schweißdrüsen homolog sind. Letztere fehlen im ïbrigen der Haut des Kaninchens (S. 170). Die Kanälchen der Gl. praeputialis enthatten brïunliche Fettröpfchen, ahnlich wie sich in der Schwanzdrüse des Hirsches finden $(568)$. Der weißliche böckrige la terale T eil der Gl. praeputialis besteht aus großen Talgdrisen, welche in Harbilge einmünden ( 566 , S. 32. Taf. III. Fig. 25-28). - Beim Biber liefern diese Drüsen das Castoreum; das Sekret des brïunlichen Teiles ist beim Kaninchen sehr stark riechend.

\section{G1. anales.}

Die Gl, analis ist $(\cdot a .1,5 \mathrm{~cm}$ lang, 3-4 nm breit, abgeplattet; liegt jederseits an der lateralen Außenwand des Rektum, in der Hohe des siebenten Schwanzwirbels, etwa $8 \mathrm{~mm}$ oberhalb des Anus.

Ihre Acini enthalten sehr viel Fett; ihr Sekret hilft olleubar die Oberfliche der harten rundlichen Kotmassen für den Durchtritt durch den Anus geschmeidig zu machen. 


\section{Weibliche Geschlechtsorgane.}

\section{Eierstöcke.}

Jedes Ovarium wiegt ra. $0.2 \% g$, ist oval, etwas abgeplattet, ungefahr doppelt so langals hreit, weißlich. Die Oberflache ist mit einer Anzahl ron kleinen wasserhellen Blaischen: den Graf"sthen Follikeln besetzt, von denen die wroßeren etwas hervoragen und der Oberflache ein hökriges Ansehen verleihen. Die Orarien liegen jederseits in der Hobhe des vierten Lendenwirbels vor dem M. psoas major; das linke unterhall, des unteren Randes der linhen Niere. Die Lingsachse ist vertikal gestellt; die vordere Flache ist vom Mesometrium und den Fimbrien der 'Tuba Falloppiae bedeckt.

Die kleinsten Follikel, in denen man ein Ovulum unterscheiden kann, haben $0,11-0,27 \mathrm{~mm}$ Durchmesser; in seltenen Fällen finden sich zwei Ovula in demselben Follikel, 569 , zweinal). Das reife 01 ulum hat $0,17 \mathrm{~mm}$ Durchmesser, das Keimblischen 0,0 , 5 mm; ersteres wurde von De Graaf (.570) entdecht. Das Keimbischen enthït ein Kornfadenwerk, dessen Fiden nach Chromsäure-Behandlung eine kïrnige Struhtur zeigen (807). - Die Follikel werden erst eine Zeit lang nach der Geburt sichtbar.

Die Corpora lutea sind bald nach ihrem Entstehen deutlich hervorragend, sternfoirmig, zu dieser Zeit nicht gelb gefirbt, stark injiziert (8/8), der Bluterguß soll aber pathologisch oder trammalisch sein $\{817\}$. Wenn keine Befruchtung stattgefunden hat, so erreichen sie am fünften Tage (571) den höchsten Grad ihrer Entwickelung.

Über die Nerven des Ovarium vergl. 754.

Exstirpation des Ovarium, Ovariotomie, s. 776.

\section{Gebärmutter.}

Der Uterus ist zweihornig, der untere Teil eines jeden Cormu uteri ist in der Länge von etwa $7 \mathrm{~mm}$ mit dem der anderen Seite zusammengeheftet, mündet aber getrennt mittels des doppeIten Orificium uteri extermum in die Scheide. Jedes Cormu uteri ist bei erwachsenen, nicht trichtigen Tieren etwa 7 cm lang, 3-1 mm weit und bogenförmig lateralwärts gekrümmt.

Die Schleimhaut trïgt im Cervikalkanal Flimmer-Epithel, übrigens kleine, mehrfach geschichtete Platten-Epithelien und einzeln stehende Zotten (572). Sie enthait gedringt stehende schlatuchfömige Drüsen (575), deren Zylinder-Epithel flimmert 707$)$. Zur Zeit der Brunst ist die Innentliache des Tterus mit rötlichem, Blutkörperchen führendem Schleime bedeckt.

Über die Lymphgefaßße vergl.57, S. 288; über die Nerven 808 . Das Platzen cines Graaf'schen Follikels erfolgt etwa 9-10 Stunden nach der Begattung. Gleich nach der Geburt findet letztere zwar auch statt, aber keineswegs jedesmal; gewöhnlich erfolgt sie im ersteren Falle 6-8 Stunden nach der Geburt. Bringt man dasegen im Winter isoliert gehaltene. Weibrhen wihrend der Sommermonate zum Minnchen, so kanu man mit Sicherheit auf Befruchtung rechnen (581). Das 
Eindringen der Spermatozoen, deren Anzahl, gegen 50 hetragen kann, durch die Zona pellucida des Eies erfolgt in der Regel 13 stunden nach der Begattung (.) 81 , vergl. 756), der Eintritt des Eichens in den Uterus etwa um die 70 ste Stunde. Daß Spermatozoen in den Dotter selbst eindringen, ist mehrfach konstatiert (582, 756); es werden auch der Zona pellucida Porenkanäle, die als Mihropylen fungieren können, zugeschrieben $(597)$. - Über die weiteren Vorgänge im Kaninchen-Ei s. 749.

Während der Schwangerschaft vergrößert sich auch ein zufälig nicht schwangeres Horn des Uterus so sehr, daß es am Ende derselben einem Uterushorn gleicht, welches balbreife Frïchte enthäit 572, S. 30). Abbildungen von Kaninchen-Embryonen verschiedenen Alters s, in 577.

Bei der Geburt kann Inversio uteri eintreten; durch Lufteintritt in die Venen des Uterus soll unter diesen Umständen der Tod erfolgt sein (57.1). Yorfall des Uterus und der Harnblase ist einmal beobachtet $(578)$.

Die Plazenta jedes Eies hat eine runde, kuchenartige Form; sie zeigt sich meistens in zwvei, auch in drei Abteilungen oder Kotyledonen gesondert (569, S. 137 ). Über ihren feineren Bau siehe z. B. 575, 748 und 840.

Reizun!y des literus durch den Induktionstrom erzeugt (.58.5) bei trächtigem Uterus intensive Kontraktionen, wenn die hintere Wand der Vagina - bei nicht trächtigem Uterus, wenn die Hörner besonders in den Abschnitten, wo sie parallel verlaufen, mit den Elektroden berührt werden. Warmes Wasser von $45-55^{0}$ gehört zu den kriftigsten Erregungsmitteln bei trächtigem, wie bei leerem Lterus.

Zuklemmen der Aorta descendens abdominalis (s. letztere S. 259) nach Isolierung der vor ihr rerlaufenden sympathischen Nervenstimmchen, ebenso Verblutung, sowie durch Atmungssuspension (Kurare, S. 31 bewirkte dyspnoische Blutbeschaffenheit verstärken die rhythmischen Kontraktionen des Lterus in der Regrel nur bei trächtigen Tieren, bei diesen aber konstant $(.585)$. Diese Kontraktionen treten auch dann noch auf, weun vor dem Zuklemmen der Aorta descendens abdominalis die vor der Aorta verlaufenden Nerven des Plexus aorticus abdominalis und die den Uterus mitversorgenden Nn. sacrales III und II durchschnitten, sowie das Ganglion mesentericum exstirpiert worden waren $(585)$.

Vermindérung der Blutzufuhr mittels Unterbindung der Aa. uterinae (s. letztere S. 264) hebt die rhythmischen Kontraktionen des trächtigen L'terus nicht anf (585, S. 391$)$.

Ebenso erfolgen bei nichtträchtigen Kaninchen auch nach Durchschueidung des Plexus aorticus noch Kontraktionen, wenn man den Lumbalteil des Rückenmarkes zwischen den Wirbeln hindurch mittels eingestochener Elektroden reizt (585, S. 387). Vergl. a.712u. 871 .

Elektrische Reizung des peripherischen Teiles des durchschnittenen Plexus aorticus abdominalis, wobei man die Nerven an den Unterbindungsfiden hervorhebt (584, S. 424), äudert die Ursprungsstelle der rhythmischen Kontraktionen der Uterushörner. Sie beginnen nicht an dem oberen Ende der Vagina. sondern von den Tuben, seltener von dem Mesometrium aus, wie es ïberhaupt bei nichttrïchtigem Uterus die Regel ist. In letzterem werden durch elehtrische Reizung des Sympathicus Kontraktionen ausgelöst, die vielleicht nur durch Gefaßßstaung bewirkte, vielleicht wahre, den peristaltischen Bewegungen ähnliche Zusammenziehungen sind (585, S. 384$)$.

Auf die Exstirpation des Ganglion mesentericum (s. letzteres, Fig. 101 fim i, s. 233 , kitnm man die Entfernung ron zwei Nervenstimmchen folgen lassen $(.585)$, welche rom Ganglion nach oben zum Plexus coeliacus verlaufen. Die nach abwärts ziehenden Nerven werden bis zur. Spaltungsstelle der Aorta abdominalis strechenweise abgetrennt. Die Plexus hypogastrici werden an der lateralen Seite des Rektum ab- 
wïrts bis zu den Ganglia uterina verfolgt. Ferner werden die Äste der Nin. sacrales III und IV, nachdem letztere aus den betreffenden Foramina saralia hervorgetreten sind, durch Ablïsung desjenigen lockeren Bindegewebes mittels stumpfer Werkzeuge zerrissen, welches das Rectum mit der Vagina und der hinteren Beckenwand verbindet. Auch die im Mesenterium bogenförmig sich verzweigenden Nervenstimmchen und die No. spermatici werden, nach doppelter Unterbindung der Blutgefiiße, mit welchen sie verlaufen, in mehreren Partieen durchschnitten. In gleicher Weise werden die in beiden Platten des Mesometrium mit den Gefäßen verlaufenden Nervenzweige abgeklemmt, unterbunden und durchschnitten.

Unmittelbar nach Durchschmeidung aller dieser Nerven findel man die inneren Geschlechtsorgane intensiv gerötet, die Blutgefiße erweitert und stäher hervortretend. Die Erregbarkeit des lterus und der Vagina anf direkte Reizungen ist wesent-lich gesteigert. Sekundär entsteht Peritonitis; ferner beim trächtigen Tiere in der Anfangsperiode der Trächtigkeit Abortus während der Operation oder gewöhnlich in den ersten 36 Stunden nach derselben. Ist dagegen die Träichligheil schon weiter fortgeschritten, so sterben die Embryonen ab und werden in der Regel am 7 - loten Tage nach der Operation ausgestoßen, vielleicht in Folge von Ernälırungsstörungen, da die operierten Kaninchen sehr wenig fressen ( 585$)$.

Über Reflexbewegungen des Uterus nach Reizung peripherischer Nerven, auch der Mammae, vergl. 859 .

Superfötation. Da das Kaninchen einen zweihörnigen Uterus besitzt, so wäre es theoretisch möglich, daß während der Trüichtigkeit des einen Cornu eine Befruchtung im anderen stattfinde. Von nicht-wissenschafticher Seite liegen eine Anzahl von Angaben vor (579), wonach z. B. 8 Tage nach der Geburt von anscheinend reifen Jungen eine zweite Serie ebenfalls ausgetragener Embryonen gefolgt sein soll. Die Fille sind indessen nicht hinreichend grenau untersucht, um die Fehlerquellen auszuschließen. Trächticke Weibchen scheinen das Männchen nic-mals anzunehmen; jene Beobachtungen können eben so wohl teils als partielle spätgeburten, teils als frühgeburten gedeutet werden, und selbst an gröbere Irrtiimer ist zu denken, indem cin fremdes Weibchen im gemeinschaftlichen Stalle ein Nest mit Jungen besetzl haben und nachher von der Eigentümerin, deren Jungen gestorben waren, vertrieben worden sein kann, welche letztere die fremden Kinder zu säugen überuahm.

Kïnstliche Befruchtung von Eiern aus den größten Follikeln auf Unterlage der Uterusschleimhaut ist rersucht worken (580). Man wiblt trïhtige Tiere, die dem Werfen nahe sind, um reife Eierstocksfollikel zu erhalten.

Verschließung eines Cornu uteri. Entleerung der Harnblase durch Druck; Hautschnitt in der Medianlinie, dicht oberhalb der Symphysis pubis, 3 bis 6 cm lang, Vorzichen der Uterushörner, Querschnitt in der Nïhe des unteren Endes; das Mesometrium wird ca. I 'm weit cingeschnitten, um eine zufillige Wiedervereinigung zu hindern $(576)$.

Exstirpation eines Cormu uteri kann nach vorgängiger doppelter Unterbindung desselben nebst dem Mesometrium ohne Blutung vorgenommen werden $(569, \mathrm{~S} .85)$.

\section{Muttertrompeten.}

Hie Tuben, Tubar Fullopprae, setzen sich ron den Iateralen Enden der Cornua uteri his zu den Ovarien fort; sie sind viel dummer, ron dunklerer Farbe, ziemlich stark geschlingelt, im Ganzen 8-10 cni lang. Sie rerlaufen in senk- 
rechter Richtung lateralwärts von den Processus triangulares der drei untersten Lendenwirbel, vor den $\mathbf{I m}$. psoas major und quadratus lumborum.

Sie bestehen aus einem engeren medialen und einem weiteren lateralen Teil (Isthmus und Ampulle, 6.39 ; ; ersterer beginnt am Uterus und ist ca. 3,5 ('m, letzterer 6,: ('m lang. Der engere Teil ist relatil zur Grobe des Tieres doch ziemlich weit, verliuft rom Uterus al, eine strecke weil gerade, zeigt einige Windungen, ehe der weitere Teil anfingt. Letzterer verliuft in mehr flachen Windungen und am freien Ende ganz gestreckt, wo derselhe in die vom Peritoneum gebildete, von Flimmer-Epithel ausgekleidete Tasche, in welcher das Ovarium liegt, mündet. Die Falten im weiteren Teile bieten nichts besonderes; am oberen freien Ende des letzteren finden sich die Fimbrien.

Wenn das uterine Ende einer Tube verschlossen ist, so können sich in ersterer bis 100 unbefruchtete Eier nach und nach anhäufen $(585)$.

Über die Technik zur Aufsuchung der Eier in der Tube vergl. $58 \%$

Lnterbindung und Durchtrennumg einer Tube nebst Exstirpation des Ovarium schließt Schwangerschaft im Cterushorn derselben seite nicht aus $\left.(79)^{-}\right)$: es trill olfenbar Überwanderung des ()vulum aus dem sesumben Eierstock durch die Bauchhöhle hindurch ein.

\section{Scheide.}

Die Vagina ist bei Weibchen, die geboren haben, etwa so lang wie ein Cornu uteri, ca. 8 cm, und weit genug̣, um den kleinen Finger einzuführen. Sie liegt zum Teil unler der Symphysis pubis, etwas schrig nath rorn verlaufend. Dieser Teil ist fast $20 \mathrm{~cm}$ lang. Die Vagina erstreckt sich durch das kleine Becken in das groBe und verbindet sich nach oben mit dem Lterus. Ihr oberer, hinfer der Iarnblase gelegener Teil wird rom Vesometrium mit eingewickelt, welehes bis zur Hohe des oberen Randes der Symphysis pubis hinabreicht und auch hinter der Srheide zwischen derselben und dem Rektum die Excautio recto-uterina s. Douglasii auskleiden hilft. Von da an nach unten wirl die Vagina mit dem Rektum durch eine Bindegewelshulle vereinigt, so daß beide Organe zusammen scheinbar einen einfachen Schlauch darstellen.

Der rom Peritoneum überkleidele Teil der Scheide enthïl glatte Muskelfasern in seiner dicken Wandung; derselbe repriasentiert eigentlich das Corpus uteri und ist der Vesicula prostatica des Männchens analog $(585)$.

Das Epithel der Vagina hesteht aus Platten-Epithel, doch zeigen die Orificia uteri externa Flimmer-Epithel (572, S. 7). Auch Drüsen finden sich in der Vagina (\$\$6. Nach der Begattung enthäl die Scheide Urin und Samenfiden. Uher

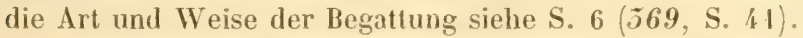

Verschließung einer Stelle der Vagina. Operation wie bei Obliteration eines Cormu uteri (S. 238). Querschnitt durch den oberen Teil der Scheide; der obere Scheidenteil wird an die Banchwunde angenäht; letztere durch Naht geschlossen. Die Operation ist gefiahrlich; man wiblt halberwachsene Weibchen, die noch nicht geboren haben. Tiere, welche sie ïberstanden haben, lassen fortwährend die Minnchen zu $(576)$.

Exstirpation eines Stückes der Vagina. Hautschnitt in der Medianlinie des Bauches über der Symphyse beginnend. Die auszuschneidende (585, S. 390), 
nach abwïrts sich verschmälernde Partie von $2,5 \mathrm{~cm}$ Länge auf $1,5-2 \mathrm{~cm}$ Breite wird markiert und mit zwei Pinzetten in eine Falte gefaßt. An den vorgezeichneten Konturen werden unter den Pinzetten feine Katgutfiden durchgeführt und nach Exzision der sanzen Wanddicke zusammengehnüpft. Das ausgeschnittene Stück kontrahiert sich lebhaft. Die Folge der Operation ist Stillstand der FötusEntwickelung bei trïchtigen Tieren, Aufhören aller mylhmischen Kontraktionen des Uterus, die Geburt tritt nicht ein und die Embryonen sterben ab $(\tilde{5} 8 \tilde{5})$.

\section{Mesometria.}

Jas Ovarium liegl in einer dem Ligamentum uleri latum entsprechenden Falle des Peritoneum, dem Mesometrinm. Beiderseits entspringt das letztere in der Hohe des vierten Lendenwirbels, linkerseits nahe unterhalb des unteren Randes der linken Niere. Vor dem II. psoas major, in einer fast senkrechten Linie, die bis zum oberen Rande des siebenten Lendenwirbels hinabreicht. Das Mesometrium geht nach vorn zum Orarium, welches efwa in der Hohe des vierten Lendenwirbels vor dem M. psoas major liegt.

Das Mesometrium setat sich an die Cornua uteri niher deren Vorderflache und seine vordere Platle gelangt direkt zur Vorderflable der Scheide, wahrend sich die hintere an den vorderen Rand der lateralen AuBenfliche der Vagina ansetat, indem sie erst die genannte Fliche und daranf die hintere Fiache der Scheide ïberzieht. In der Medianlinie rerschmelzen an der Soheide und den vereinimten unteren Teilen der Lterushormer das rechte und linke Mesometrium miteinander.

An der vorderen Platte jedes Mesomelrium haftef rine Schicht ron glatten Muskelfasern, welche von einem in der Medianlinie anf der Vorderfliche der Scheide gelegenen Faserzug nach beiden Seiten laleralwials ausstrahlen und sich untereinander vielfarh geflechtartig verbinden. An der hinteren Patte finden sich zwei solche senkrechte Faserziıge, ron denen Muskelfaserbindel nach oben zu den Iterushirmern gehen; der mediale liegt benachbart und parallel der lateralen AuBenfliche der Scheide, der laterale ungefiihr iu der Mitte des Mesometrium. Letzterer sendet auch Faserbindel in lateraler Richtung aus. Zwischen den beiden Muskelschichten verlanfen die Gefiße und Nerven des Lterus. Auch in dem Trile des Mesometrium, welcher zu den Tuben weht, finden sich etwa $\$ 0$ Bündel von glatten Mushelfasem $(587$ - s. a. 585$)$.

Einmal wurde eine "Wimperblase an dem freien Rande des Mesometrium, in der Nähe des Ovarium gefunden (589). Die Wimperblasen stellen mit Flimmer-lipithel ausgekleidete, mutmißlich durch Einstülpung und Abschnärung der Schleimhaut entstandene Säcke dar.

Spritzt man feingeriebene suspendierte Tusche $u$. dergl. in das Abdomen, so sind die Kürnchen später mikroskopiseh in Cterus und selbst in der lingina nachzuweisen $(650)$.

Lignmentum uteri rotumbum. Entspringt von dem oberen Ende des Cornu uteri, valiuft in Ammus inguinalis und Canalis inguinalis, entsprechend dem Gubernaculum testis beim Minnchen. 


\section{Äufsere weibliche Geschlechtsorgane.}

\section{Introitus vaginae.}

Der Scheideneingang ist ron einem Paar Falten: den Labia, eingefaßı, welche große Talgdrüsen enthalten; kleine Schamlippen fehlen. Am oberen Teil des Introitus stehen jederseits $5-6$ stirkere IIaare, weiter lateralwirts findet sich eine zweite Reihe $(818)$.

Die Clitor is ist ca. $2 \mathrm{~cm}$ lang, an der Basis $5 \mathrm{~mm}$ breit, also fast so lang als der Penis, aber dünner; die Glans ist sehr spitz zulaufend. Das Lig. suspensorium clitoridis ist schwach, es rerliuft in einer Furche zwischen den Corpora cavernosa clitoridis. Ein 11 . retractor maeputii clitoridis entspringt jederseits von der lateralen Fliche des Corpus clitoridis, ist schmal und sebr dünn, verlituft nach oben und vorn zum Praeputium elitoridis $(8 / 8)$, welches er zurückzieht. - Die Ilaut des Introitus kann man so zurückziehen, daß die Glans clitoridis $5-8 \mathrm{~mm}$ weit frei hervorsieht $(818)$.

Urethra. Hinter der Clitoris, $4 \mathrm{~cm}(-5 \mathrm{~cm}, 818)$ oberhalb des Scheideneinganges, mündet die kurze, $4 \mathrm{~mm}$ weite Urethra.

Nach Experimenten, die von mir im Fribjahr $188: 3$ in Göttingen angestellt wurden, scheinen die Kämpfe zwischen Kaninchen und Hasen (S. 11) auf geschlechtliche Beziehungen, die unten (S. 243) nochmals erwähnt werden, zurückfiilırbar zu sein. Indem das Mïnnchen (Kaninchen) den (weiblichen Hasen mit den Schneidezähnen faßt und festzuhalten sucht, während letzterer sich gewaltsam losreißt, werden ihm große Hautlappen, nebst Hautvenen und Huskelfetzen abgerissen, wobei schließlich infolge der Eiterungen das Tier zu Grunde zu gehen pflegt. Daß Hasen mit Kaninchen desselben Geschlechtes sich nicht vertragen werden, liegt auf der Iand. Somit erklärt sich die erwähnte (S. II) Feindschaft zwischen beiden Arten in der einfachsten Weise und es bleibt nur lie Frage übrig, wie sich wohl der Regel nach ein Kaninchenweibchen zum Hasenmïnnchen verhält; gerade dies ist die Modifikation, wobei Conrad Bastarde erzielte.

\section{GI. Cowperi.}

Die Gl. Cowperi ist lauglich, etwas großßer als die des Minnchens, ra. 1,5 cm lang, $3 \mathrm{~mm}$ breit, $2 \mathrm{~mm}$ dick. Sie liegt parallel der lateralen AuBenflache der Scheide, an die $\mathbb{W}$ and der letzteren und den lateralen Raud der Clitoris geheftet, dicht unter dem Ramus inferior oss. pubis, Jateralwarts rom unteren Rande der Symphysis pubis. Sie wird bedeckt rom lateralen Rande der Gl. praeputialis (\$/8 - (s. mannliche Geschlechtsorgane, S. 23:5).

\section{GI. praeputiales.}

Die GI. praeputialis s. inguinalis liegt jederseits lateralwirts vom Scheideneingang, ist ca $1,5 \mathrm{~cm}$ lang, $3 \mathrm{~mm}$ breit, $2 \mathrm{~mm}$ dick, wiegt $0,1 \mathrm{~g}$; rerhailt sich ubrigens wie beim Mannchen (S. 235). Der laterale Teil der Drüse ist gelblich, etwa $4 \mathrm{~mm}$ lang, $3 \mathrm{~mm}$ breit $(8 / 8)$. 


\section{G1. anales.}

Die Gl. analis liegt jederseits weiter abwarts als die Gl. Cowperi, an die laterale Außenlliche des Rektum geheftet (s. minnliche Geschlechtsorgane, S.235).

V a rietiit. Die Gl. analis ist in mehrere kleinere Drüsen zerfallen.

\section{Mammae.}

Die Milchliusen liegen am Bauche nehen der Medianlinie und bilden beim Weibchen eine scheinbar zusammenhingende weißliche Drüsemmasse, die jedoch in eine Anzahl von einzelnen Drüsen ahgeteilt ist, deren Ausfiihrungsmündungen auf den Zitzen sich iffnen. Wihrend der Laktation haben die Mammae jeder Seite z. B. $27 \mathrm{~g}$ Gewicht, $40 \mathrm{~cm}$ Linge, 2-4 cm Breite, 3-5 mm Dicke. Bei saugrenden Weibchen siud die Zitzen $(6-10)$ stark entwickelt; beim Mannchen ganz rudimentar. In jeder Zitze finden sich 5 weite Milchgange $(590)$. Die Zitzen liegen in einer Linie, die vom lnorpel der 7ten, 8ten oder 9ten Rippe heginnt und zur Symphysis pubis verlinft, mithin von beiden Seiten her natch unten kouvergiert. Die oberste Zitze findet sich entweder an der bezeichneten stelle des Thorax oder oberhalb derselben ror dem M. pectoralis superficialis in der Höhe des oberen Raudes des Sternum oder z. B. in der Höhe des Ansatzes des finften Rippenknorpels an das Stermum. Die übrigen Zitzen liegen in regelmäigen Abstinden von einander und dem oberen Rande der Symphysis pubis. Die einzelnen Mammae stellen ganz flach ausgebreitete rundliche sicheiben dar, deren Zentrum in der Zitze liegt; nach Entfernung der Haut zeigen sich die einzelnen Läppchen wie präpariert.

In den Acini sind nach Injektion von Zinnober etc. in eine Vene keine Farbstofliörnchen aufzufinden $(\mathbf{7 3})$. — Zwischen den Drüsenläppchen kommen glatte Mushelfasern vor (7.5), sowie Zwischenzellen $\left.7.55^{\circ}\right)$, erstere finden sich auch in der Zitze $(812)$. - U Uber die Entwickelung der Mamma s. 812.

Varietït. Bei hasenfarbigen französischen (belgischen) Kaninchen fand Darwin $(8, \mathrm{~S}, 106)$ in der Regel nur 6 Zitzen — was jedoch auch bei anderen Rassen vorkommt. Die Differenz wird mit einer geringeren Fruchtbarkeit in Beziehung gebracht. Bei deutscheu Kaninchen sollen öfters nur 8 Zitzen vorhanden sein (14) - hierbei ist das oberste Paar übersehen worden.

Die Milch ist so dicht wie die beste Sahne, sparsam; man erhält durch Melken in der Stunde kaum einige Tropfen $(864)$. Sie scheint nur einmal analysiert worden $(\$ 64)$ zu sein; der Fettgehalt beträgt ca. $22 \%$. Dieses Fett ist durchsichtig, farblos, llüssig selbst bei Wintertemperatur. Eine Vergleichung (86.4) ergab in Prozenten:

\begin{tabular}{l|c|c}
\multicolumn{1}{c|}{ Fettgehalt } & Ölsäure & $\begin{array}{c}\text { Feste Fett- } \\
\text { säuren }\end{array}$ \\
Milch, erste Analyse & & $-10,3$ \\
$-\quad$ zweite & 72,5 & 13,4 \\
Subkutanes Fettgewebe & 59,2 & 34,5 \\
Eingeweide und Nieren & 59,2 & 39,0 \\
Fett des Hafers & 57,1 & 11,0
\end{tabular}

Der Gehalt an flïchtigen Säuren muß im Vergleich zur Kuhmilch bedeutender sein $(\$ 6.4)$. 


\section{Muskeln am Beckenausgang.}

Das Perinaeum ist in beiden Geschlechteru wenig ausgedehnt; dasselbe wird rom Rekfum mit den Gl. anales, den Mm. flexores caudae, ischiocavernosi und der Urethra, resp. der Vagina begrenzt.

1\%. pubocavernosus. Ursprung: Cnterer Rand der Symphysis pubis. Ist stark entwickelt, bauchig. Insertion: Dorsum penis.

M. ischiocaternosus entspringt unter dem Corpus cavernosum penis resp. clitoridis von dem Ramus inferior oss. ischii. Insertion: Laterale Flache des Penis resp. der Glitoris. Der Muskel hebt den Penis nach vorn.

II. bulbocavernosus ist sehr dün, hängt nach hinten mit dem M. sphincter ani zusammen, entspringt in der Medianlinie von einem sehnigen Streifen des Corpus cavernosum urethrae, strahlt unterhalb des letzleren nach vorn aus.

H. constrictor pulendi s. cunni hängt mit dem M. sphincter-ani zusammen, liegt in den Labien, ist homolog dem M. bulbocareruosus des Mannchens.

II. lecator ani. Crsprung: Ramus inferior oss. pubis und Ramus inferior oss. ischii. Ist sehr diunn, verlauft abwarts. Insertion: Peripherie des Rektum.

M. rectococcygeus ist umpaar. Trsprung: Vorderflache des unteren Randes des zweiten Schwanzwirbels. Langer, schmaler Muskel, z. B. 4 cm lang, $2 \mathrm{~mm}$ breit, durchseheinend. Liaft hinter dem Rektum aufwarts, teilt sich in einen rechten und linken Schenkel. An der Teilungsstelle tritt ein weißer, vom Plexus mesentericus inferior abstammender Nervenzweig in den Muskel, der aus glatten Muskelfasern besteht. Insertion: Ilintere Wand des Reklum.

Dieser Muskel ist bei anderen Säugetieren viel stärker entwickelt und stiilpt z. B. beim Pferde die Rektumschleimhaut am Schluß der Kotentleerung nach außen um. Die Arterien kommen von der A. mesenterica inferior; die Venen gehen zu der gleichnamigen Vene; die Nerven stammen von zwei Hauptïsten des erwähnten Nervenstammes, in welche sich Ietzterer vor seinem Eintritt teilt. Sie bilden einen reichhaltigen Plexus, der viele doppeltkonturierte neben blassen Nervenfasern und Ganglien enthält. Erstere zeigen hïutig wiederholte Teilungen. Dit dieser Muskel, obwohl aus glatten Iuskelfasern bestehend, großenteils von doppeltionturierten Nervenfasern versorgt wird, deren Endigungspunkte in Verhältnis zur Anzahl der glatten Muskelfasern sehr sparsam sind, - es kommen Hunderte von Muskelfasern auf jede Nervenstammfaser (591) — so eignete sich derselbe vielleicht zur Feststellung der Nervenendigung an den glatten Muskelfasern, über welche die neueren Arbeiten zu sehr widersprechenden Resultaten geführt haben. Anscheinend sind motorische Endplatten vorhanden (.591). Durch Goldchlorid färben sich die Nervenfasern im IIuskel schwarz und ebenso ein dichtes Netzwerk in dem umgebenden Bindegewebe, welches dem Lymphgefißsystem angehören dürfte.

M. sphincter ani ist wenig entwickelt.

Durchreißungen des II. sphincter ani können bei geschlechtlichen Kämpfen vorkommen: indem das Männchen das nicht brünstige Weibchen mit den Schneidezähnen zu fassen und festzuhalten sucht, kam die Afteröfinug verletzt werden. Die prolabierte Rektumschleimhaut wächst polypeniholich aus, bedeckt sich mit geschichtetem Platten-Epithel und bildet auf diese Art die erwähnten (S. 23) papillären Excrescenzen. 


\section{Angiologie.}

\section{Herz.}

Das Pericardiu $m$ ist ein sehr dünnhiutiger geschlossener Sack.

Das $I / l^{\prime}:$ selbst wiegt im leeren Zustande und inkl. des Anfangsteiles der großen Gefaße ca. 4, b.

Die Muskelfasern des Herzens zeigen im Normalzustande dentliche Fibrillen; bei Tieren, die mit subkutanen Injektionen von Nitrophenylpropiolsäure vergiftet wurden $(1,25-1,5 \mathrm{~g}$ führen in wenigen Minuten den Tod herbei), zeigen sich nach Anwendung saurer Tinktionsmittel die Querlinien in auffilliger Weise gefirbt und körnig $(656)$. S. 52$)$.

Die Zuckungsdauer des Herzmuskels beträgt 0,33 Sekunden (801, vergl.

Die doppelthonturierten Nervenfasern des Herzmuskels endigen mit motorischen Endplatlen, wie sie den quergestreiften Muskelfasern z. B. von Fischen zukommen. Die eigentümlichen Wirkungen der Herznerven lassen sich also keinenfalls aus ihrer Endigungerliären. - Obigre Angabe (Erste Auflage S. 178) ist fiir einen schreibfehler gehalten, jedoch indirekt bestitigt worden (.592 vergl. 58, S. 99).

Das Atrium dextrum tragt an seiner vorderen Wand die Auriculu dextru, welche sich nach links und aufwirts biegt, vor dem Anfangsteil der Aorta descendens. In das Atrium dextrum miinden die Vv. (aivae superiores und inferior; das Ostium der V. cara superior dextra hat eine starke, sichelforrmig̣e, lleischige Leiste als Andeutung einer Klappe; das Ostium der sinistra besitzt eine große, halbmondförmige, häutige Valvula Thebesii.

Der Ventriculus dexter zeigt an seinen Offnungen die Valrula tricuspidalis und Irei Valvulae semilunares pulmonales, welche am vorderen rechten, am vorderen linken und am hinteren I'mfang des Ostium arteriosum angeheftet sind.

Das Atrium sinistrum trägt an seiner vorderen Wand die aufwärts gekrümmte, nelsen der Wurzel der A. pulmonalis liegende Auricula sinistra. In dasselbe münden die Vv. pulmonales.

Der Ventrirulus simister hat glattere Innenwand und starkere Muskulatur als der Ventriculus dexter; an seinen Öfnungen befinden sich die Valvula 
bicuspidalis und die drei Valvulae semilunares aorticate. Letztere sitzen am vorderen, am rechten hinteren und am linken hinteren Umfange des Ostium arteriosum.

Die Lage des Herzens betreffend, so befindet sich dasselbe im Thorax hinter dem Sternum und den Knorpeln der ersten und zweiten Rippe bejderseits, und zwar reicht es vom unteren Rande des ersten bis zum unteren Rande des zweiten Rippenknorpels. Die Spitze ragt his in den dritten linken Interkostalraum links vom Sternum.

Im Leben reicht das Herz etwas weiter nach unten. Sticht man fünf Nadeln durch die fïnf oberen linken Interkostalräume in das Herz und läßt das Tier verbluten, so richten sich die Köple der Nadeln abwärts (595). Nach Durchschneidung der beiden Nn. vagi rückt das Herz noch etwas weiter abwärts (594).

Der (negative) Druck innerhalb des Herzbeutels wurde am lebenden Tiere zu einigen Millimetern ermittelt $(586)$.

Höchst wahrscheinlich verläuft die Kontraktion der Herzkammern von der Spitze nach der Basis $(588)$.

Die L y mph gef äß des Herzens bieten nichts besonderes (595).

Pathologische Anatomie. Chronische Endocarditis hinterläßt mitunter Verïnderungen, die nicht mit den durch akute Endocarditis erzeugten verwechselt werden dürfen $(396)$.

Einführung einer Nadel in das Herz. An der Stelle des Herzstoßes im 3ten Interkostalraum, ca. $1 \mathrm{~cm}$ links vorn Sternum, wird eine ca. $8 \mathrm{~cm}$ lange, dünne, an der Spitze mit einem Widerhaken versehene Middeldorpf'sche, richtiger Jung'sche Nadel nach aufwirts in die Muskelsubstanz des linken Ventrikels eingestochen. Die Schwingungen der Nadel zeigen die Bewegungen des pulsierenden Herzens im verkehrten Sinne. Wenn die Nadel an ihrem anderen Ende einen Knope trïgt, so kann durch Anschlagen desselben an ein Trinkglas die Zahl der Herzschäge vielen Beobachtern hörbar gemacht werden. Oder man kann einen mit roter Seide umsponnenen Draht als leicht sichtharen Zeiger benutzen (.59). Sicherer geschieht die Zählung mit dem Stethoskop (399). Man kann auch mit der schwingenden Narlel einen leichten Hebel verbinden. dessen einer Arm in ein Quecksilbernäpfehen taucht, einen galvanischen Strom öfnet und schließt und dadurch ein Zählerwerk von Siemens und Halske auslöst (400).

Bloßlegung des Herzens.

A. Mit Eröflnung des Thorax. Kurare-Vergiftung, Tracheotomie und Einleitung der kïnstlichen Respiration. Hautschnitt in der Medianlinie längs des Sternum, Durchschneidung der Rippenknorpel mit der Schere beiderseits, Ablösung vou den Bauchmuskeln, die knorpel der ersten Rippen bleiben unserlet $t$, um die Aa. und Vv. mammariae internae zu schonen, das Sternum wird nach oben zurïckgeklappt und mit Ilaken festgehalten. Die Blutung aus den Aa. und Wr. intercostales anteriores steht von selbst.

B. Ohne Durchschneidung der Rippenknorpel und ohne Eröffnung der Pleurahöhlen. Injehtion von Opiumtinktur in die I. jugularis citerna, Hautschnitt in der Mediantinie längs des Sternum, Ablösung des M. pectoralis major sinister vom Sternum und des sehnigen Lrsprunges des M. rectus abdominis, Entfernumg der Mm. intercostales im 2ten-5ten linken Interkostalraum mit Schonung der Pleura und der A. mammaria interna sinistra, die nötigenfalls im zweiten Interkostalraum unterbunden wird. Die Einatmung weniger Tropfen Chloroform macht die llerzbewegung zeitweise so langsam, daß man hei der Systole die Anschwellung des an seiner Vorderfliche sichtbaren linken Ventrikels, die Lokomotion des Herzens nach abwïts, die Rotation nach rechts deutlich beobachten hann 
C. Von der Seite. Beide Aa. mammariae internae werden mit dem Sternum in eine Ligatur gefaßt, letzteres bleibt in seiner Lage $(758)$. - Oder einfach durch Resektion einiger Rippen (779).

Das Foramen ovale schließt sich am 12. Tage nach der Geburt, der Ductus arteriosus ist erst am 26. Tage obliteriert (597).

\section{Arterien des grofsen Kreislanfes.}

\section{Aorta.}

Aortu adscendens. Sie steigt fast geradlinig in der Medianlinie aufwirts, reicht vom oberen Rande des zweiten Rippenknorpels bis zum oberen Rande des ersten. Verliuft anfangs innerhalb des Herzbeutels, links vom Anfang der A. pulmonalis, nach rechts und vorn an den oberen Teil der Auricula dextra, nach links und vorn an deu oberen Teil des rechten Ventrikels grenzend. Dann geht sie hinter der Thỵmus aufwirts, nach rechts manchmal durch Fett von dem N. vagus dexter und der V. cava superior dextra geschieden und setzt sich in den Arcus aortae fort. Äste:

A coronariae cordis dextra und sinistra s. magna (592). Die dextra entspringt aus dem vorderen Sinus Valsalvae, die sinistra aus dem hinteren linken. Die drei Sinus Valsalvae stellen leichte Erweiterungen der Wurzel der Aorta adscendens dar. Die Miundungen der A. coronariae kömnen mit den Valvulae semilunares der betreffeuden Sinus bedeckt werden. Die A. coronaria cordis sinistra rerliaft anfangs etwas unter der oberfichlichsten Muskelschicht; sie viebt den $R$. anterior ab, welcher auf der Vorderflache des Herzens herabläuft.

Der R. anterior kann mit der Klemmpinzette komprimiert werden. Durchschnitten spritzt sein oberer Teil systolisch (402). - Schiebt man die A. pulmonalis nach recbts, so kann man, zwischen letzterer und Auricula sinistra Fig. $102)$ eindringend, die A. coronaria sinistra an der konkaven Seite der Aorta adscendens aufsuchen und mit der Klemmpinzelle schließen. Man kann auch die einzelnen Äste durch die oberflächliche Herzmuskulatur oder die A. coronaria dextra fasien. Die Vr.coronariae cordis entleeren sich fast vollstandig (592). Oder man umsticht die A. coronaria cordis sinistra $(670)$.

Vergl. über die Unterbindung der Aa. coronariae cordis 540 ; über artifizielle Erzeugung von Klappenfehlern des Herzens resp. Zerstörung der Aortenklappen mittels einer Sonde s. 850. - Die Aa. coronariae sind Endarterien in dem Sinne, daß stärkere Anastomosen fehlen (664).

Varietät. Es ist eine A. coronaria cordis dextra accessoria vorhanden, die ebenfalls aus dem vorderen Sinus Valsalvae entspringt.

Die Anzahl elastischer Lamellen beträgt in der Media der Aorta überhaupt $16-25(658)$.

\section{Arcus aortae.}

Arcus aortae verliuft von rechts nach links in transversaler Richtung und zugleich ein wenig nach hinten in der oberen $\Lambda$ pertur des Thorax vor dem 
Körper des zweiten Ritckenwirbels. Seine obere Wand ist konvex, die untere konkav; er liegt hinter dem Manubrium sterni, vor der Trachea, links ron der V. cava superior dextra. Sein linker Teil biegt sich über den Bronchus sinister und endigt an der linken Seite des dritten Rükenwirbelkörpers hinter der V. cava superior sinistra. Sehr mahe der Medianlinie entspringen aus seiner konvexen oberen Fliche rechterseits der Truneus anonymus, linkerseits die $A$. subclavia sinistra.

Varie tät. Der Arcus aortae verläuft über den Bronchus dexter (405).

Aus dem Arcus entspringen zuweilen kleine Nackengefißße direkt (404).

Truncus anonymus s. eleidocaroticus. Verläuft hinter dem obersten Teile des Sternum und der Thymus, hinter dem Knorpel der ersten Rippe und der V. eava superior dextra, an der rechten Seite der Trachea, nahe der Medianlinie senkrecht und etwas nach rechts aufsteigend, giebt unmittelhar nach seinem Ursprunge die A. carotis communis sinistra ab. Der Truncus anouymus ist nur kurz und spaltet sich in die Aa. carotis communis dextra und subclavia dextra.

Varietät. Die Länge des Truncus anonymus wechselt beträchtlich und reduziert sich zuweilen beinahe auf Null. Bei zwei Kaninchen unter mehr als 80 kamen aus dem Truncus anonymus nur die beiden Aa. carotides communes, während die A. subclavia dextra links neben der A. subclavia sinistra entstand und sich hinter dem Oesophagus zum rechten Arm wendete $(404$, S. 15). Diese Varietat beruht auf dem Otfenbleiben eines Teiles der fötalen Aorta descendens dextra $\left(405^{\circ}\right)$.

Unterbindung des Truncus anonymus. Hautschnitt in der Medianlinie $4 \mathrm{~cm}$ lang, dessen Mitte auf den oberen Rand des S ernum fällt. Abtrennung des Ansatzes der Mm. sternomastoidei, des II. pectoralis major im ersten Intercostalraum vom Sternum. Isolierung des oberen Endes des Sternum oberhalb der ersten Rippen, Abtrennung desselben mit der Schere. Ablösung des Ursprunges der $\mathbf{M m}$. sternohyoidei und sternothyreoidei mittels Pinzette und Messer, Durchschneidung des Bindegewebes, welches als Fortsetzung der Fascia cervicalis die Äste des Arcus aortae von vorn her bedeckt. Entfernung des Fettgewebes mit zwei Pinzetten. Lateralwärts liegen beiderseits die $\mathrm{V}$. cavae dextra und sinistra mit ihren Ästen und die Nn. ragi. Weiter rückwärts können die Nu. sympathici, der Ductus thoracicus, die Pleurasäcke, nach unten das Pericardium verletzt werden. Der Truncus ano-

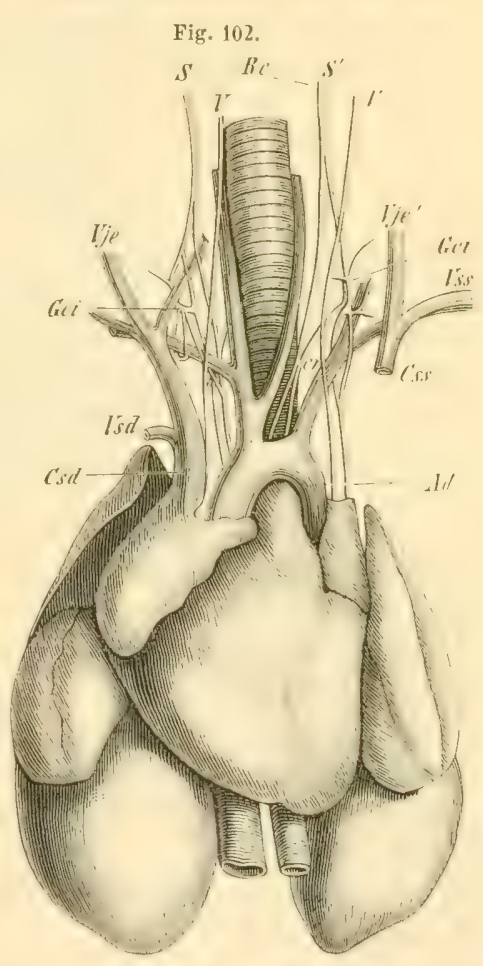

Herz mit dem Truncus anonymus, aus welchem die Aa. carntides dextra und sinistra und die A. - ubclavia dextra hervorgehen. Nach Ludwig (99). Die A. subclavia sinistra kommt aus dem Ireus aurtace. Ad Aorta descendens. $t$ 's $d \mathrm{~V}$. cava superior dextra. C'ss V. cava superior sinistru, abgeschnitten. Is $d$ V. subelitio dextra. Vss V. subclavia sinistra. Vje V. jugularis externa dextrit. Vjé V. jugularis externa sinistra. Siehe auch Neurologie, Brustteil des sympathischen Nerrensy stemes. 
A. carotis communis.

nymus (Fig. $102,5.247$ ) wird nach rechts und vorn gezogen, an seiner linken Seite fïlırt man die Unterbindungsnadel ein. Die A. subclavia sinistra liegt an der linken Seite der A. carotis sinistra, an der rechten Seite des N. vagus sinister sehr tief; sie liuft schräg nach links und oben. Sie wird etwas nach vorn mittels der Pinzette gezogen und mit einer kleinen Unterbindungsnadel dicht an ihrem Ursprunge umschlungen, wobei der N. sympathicus sinister zu vermeiden ist. Der Truncus anonymus und die A. subclavia sinistra können auch mit der Klemmpinzette geschlossen werden. Die Operation dauert 10-30 Minuten, nach Unterbindung beider Stämme treten binnen 3-45 Sekunden, selten später, allgemeine Muskelkrämpfe auf.

Als Ḱlemmpinzetten benutzt man Serres fines von Neusilber, $6 \mathrm{~cm}$ lang, die Arme laufen hinter der kreuzung noch $3,5-4 \mathrm{~cm}$ fast parallel fort und endigen mit stumpfrandigen glatten Plattchen von $5 \mathrm{~mm}$ Liange und $3 \mathrm{~mm}$ Breite (406).

Der Arcus aortae kann bei derselben Operation mit einer größeren Klemmpinzette von $8,5 \mathrm{~cm}$ Linge, deren Branchen an ihrem freien Ende in der Länge von $3,5 \mathrm{~cm}$ genau aufeinander passen, glatt an den Rändern abgerundet und $3,5 \mathrm{~mm}$ breit sind, genau verschlossen und dadurch das Rüchenmark zeitweise der Blutzufuhr beraubt werden. Beim Weibchen ist der Arcus aortae wegen der Bildung des Thorax leichter zugänglich, als beim Mänchen; halberwachsene Tiere sind bei weitem vorzuziehen $(407$ und 404, S. 14 แ. 60 ).

\section{A. carotis communis.}

A. carotis communis (Fig. 103,20) ver]äuft hinter dem M. sternohyoideus, in ihrem oberen Teile auch hinter dem M. sternothyreoideus, an der lateralen Seite der Trachea, die sinistra auch ror dem Oesophagus aufwarts, dann lateralwarts vom Kehlkopl bis zur llöhe des Angulus maxillae inferioris, lateralwarts vom oberen Ende des II. sternohyoideus und hinter dem unteren Teile der Gl. parotis. Iasellost teilt sie sich in die Aa. carotis interna und externa. Äste:

1. thyreoidea superior (Fim. 103, :1) entspringt in der Ilohe des ersten bis vierten Trachealringes, verlauft bogenformig medianwirts und abwarts, versorgt die Gl. thyreoidea und giebt Rr. tracheales, oesophagei, sowie einen $R$. descendens ab, der an der medialen Seite der V. jugularis interna, ueben der Trachea herabsteigt.

Varietät. Die A. laryngea entspringt aus der medialen Wand der A. carotis communis, anstatt aus der A. carotis externa. - Nach Schneider (250) kommt in der Norm eine A. laryngea inferior (Fig. $95 \mathrm{li}, \mathrm{S} .212$ ) aus der A. carotis communis.

A. pharyngea adscendens entsteht nahe dem oberen Eude aus der A. carotis communis.

Unterbindung der A. carotis communis, s. Neurologie, Durchschneidung des N. vagus.

\section{A. carotis externa.}

A. carotis externa ist stark entwickelt im Verhältuis zur A. carotis interna, macht einen kleineu, medianwarts konvexen Bogen, giebt von ihrer 
medialen vorderen Wand die A. laryngea, dann die Aa. lingualis und maxillaris externa, deren Ursprung ofters gemeinschaftlich ist, ah, von ihrer hinteren

Fig. 103.

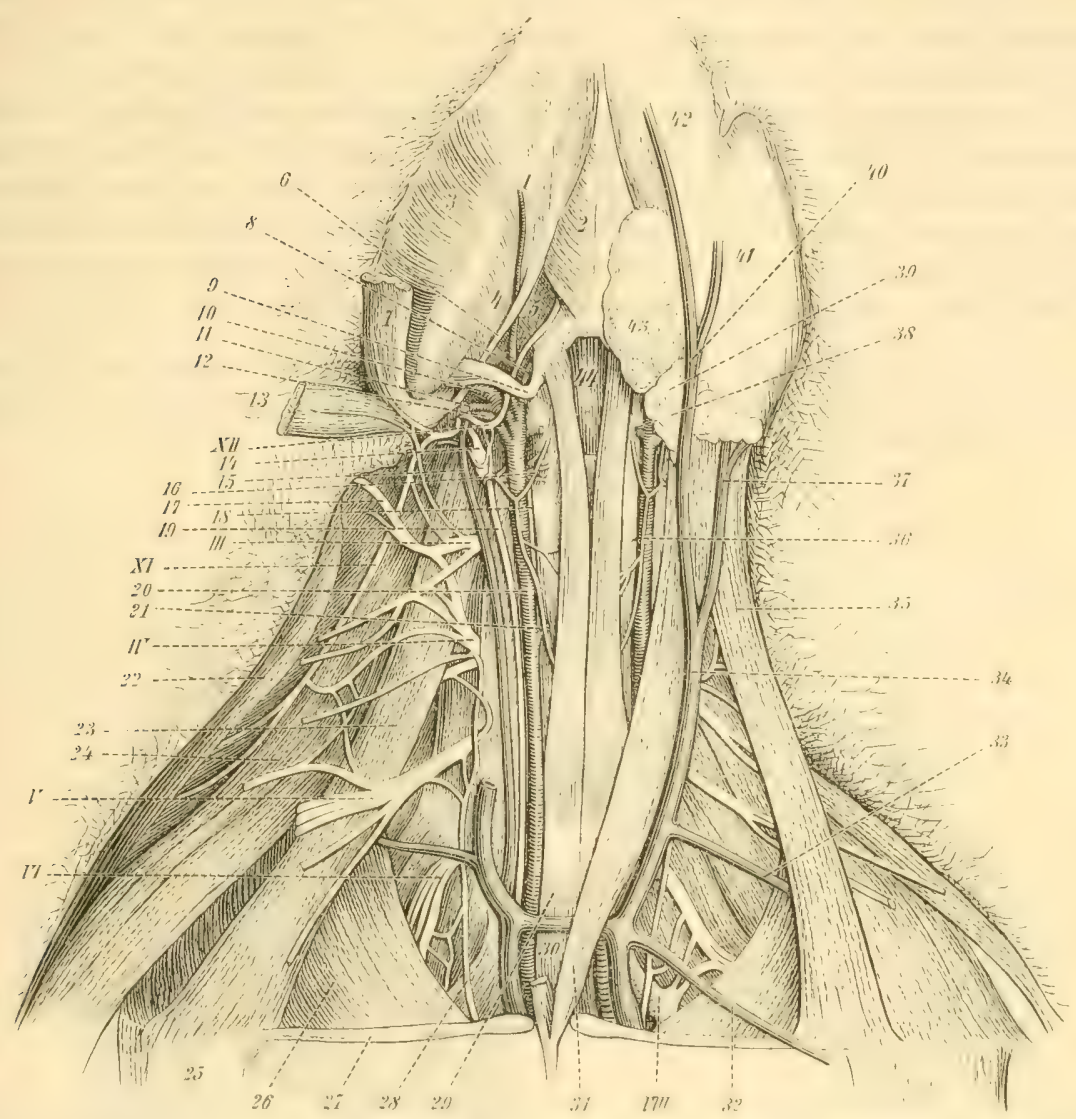

Ansicht des Halses von rorn, mit injizierten Arterien und Venen. Nach Schneider (250). Rechterhand oberflächliche Sehicht, linkerhand tiefe Sehicht. 1 A. maxillaris externa, 2 M. mylohyoidens. 3 II. masseter. 4 II. pterygoideus internus, 5 M, styloglossus. 6 Sehne des MI mandibulae, 7 Oberes Ende des MI sternomastoideus, abgeschnitten. 8 A.lingualis. 9 Cornu majus oss. hyoidei, an welches sich der M. stylohyoideus major inseriert. $10 \mathrm{~A}$. carotis externa, nach $\mathrm{Abgabe}$ der $\mathrm{Aa}$. oceipitalis ete. $11 \mathrm{~A}$. occipitalis. $12 \mathrm{~A}$, carotis interna. 13 Oberes Ende des M. cleidomastoideus, abgeschnitten. XII N. hypoglossus. 14 Plexus ganglioformis des $\mathrm{N}$. vagus. $15 \mathrm{~V}$. jugularis interna. $16 \mathrm{~N}$, laryngeus superior, $17 \mathrm{~N}$, auricularis magnus, $18 \mathrm{~N}$, sympathicus. $19 \mathrm{~N}$. vagus. $I I I \mathrm{~N}$. cervicalis tertius. $X I \mathrm{~N}$. accessorius. $20 \mathrm{~A}$. carotis communis, $21 \mathrm{~A}$. thyreoidea superior. IV N. cervicalis quartus. 22 M. cueullaris, 23 M. basiohumeralis dexter. 24 M. levator scapulae major. $V \mathrm{~N}$. cervicalis quintus. $V I \mathrm{~N}$, cervicalis sextus. $25 \mathrm{M}$. deltoideus, $26 \mathrm{M}$. pectoralis minor. $27 \mathrm{Cla}-$ vicula. $28 \mathrm{~N}$.phrenicus. 29 M. sternohyoideus. $30 \mathrm{~V}$. jugularis transversa. 31 M. sternomastoidens (linkerhand abgeschnitten). VIII N. cervicalis octavus. 32 Subkutane Vene der oberen Extremität (Varietät). $33 \mathrm{~V}$. transversa seapulae, abgeschuitten. 34 V. jugularis externa. 35 M. basiohumeralis sinister. $36 \quad \mathbf{R}$. descendens n. hypoglossi. $37 \mathrm{~V}$. facialis posterior. $38 \mathrm{~A}$. laryngea (superior). 39 Unterer Teil der Gl. parotis. $40 \mathrm{~V}$. facialis anterior. $41 \mathrm{~V}$. maxillaris externa, abgeschnitten. $42 \mathrm{~V}$, submentalis, in die linke $\mathrm{V}$. $\mathrm{fa}=$ cialis anterior müdend. $43 \mathrm{Gl}$. submaxillaris. 44 Iembrana hyothyreoidea.

Wand die A. occipitalis, verlauft dann an der lateralen Seite des M. stylohyoideus major (Fig. 103,o), an der medialen des M. pterygoideus internus aufwarts und spaltet sich in die Aa, temporalis superficialis und maxillaris interna (Fig. 104, S. 250).

Varietät. Die A. maxillaris externa entspringt aus der Teilungsstelle der 
A. carotis externa. - Die A. auricularis posterior wird direkt von der A. carotis externa abgegeben. Uberhaupt ist die Verästelung der letzteren Arterie mannigfachen Verschiedenheiten unterworfen.

A. laryngea s. laryngea superior (Fig. 95ls, s. 212. - Fig. 103, 38, S. 249) Jiuft nach vorn und medianwairts, rersorgt den M. hyothyreoideus, das obere Ende der Mm. sternothyreoideus und sternohyoideus und den Kehlkopf.

A. occipitalis (Fig. 103, 11) entspringt von der hinteren Wand der A. carotis externa, verliuft riickwäts, aufwirts und lateralwarls am oberen Rande des Processus transversus des Atlas, bedeckt rom M. cucullaris, giebt $\Lambda$ ste zur Ilinterhauptsgegend, die bis zur Scheitelgegend aufwarts reichen und einen starken $R$. inferior, der sich bogenformig zu den hinteren IIalsmuskeln wendet und mit einem Aste der A. transversa colli anastomosiert.

Varietä. Sie giebt die A. auricularis posterior ab. Angeblich in der Norm 408) konstant den Ast der A. auricularis posterior für den vorderen medialen Ohrrand.

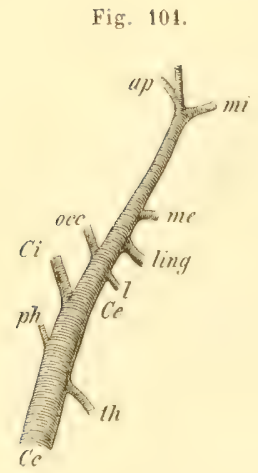

Äste der Aa. carotis communis und externa, schematisch. $C c$ A. carotis communis, $t h$ A, thyreoidea superior. $p h \mathrm{~A}$. pharyngea adscendens. $C_{i} \mathrm{~A}$. carotis interna. $C e \mathrm{~A}$. carotis externa. $l$ A. laryngea (superior). ling A. lingualis, occ A. occipitalis, $m e$ A. maxillaris externa. mi A. maxillaris interna. $t s$ A. temporalis superficialis, $a p$ A, auricularis posterior.
Fig. 105.

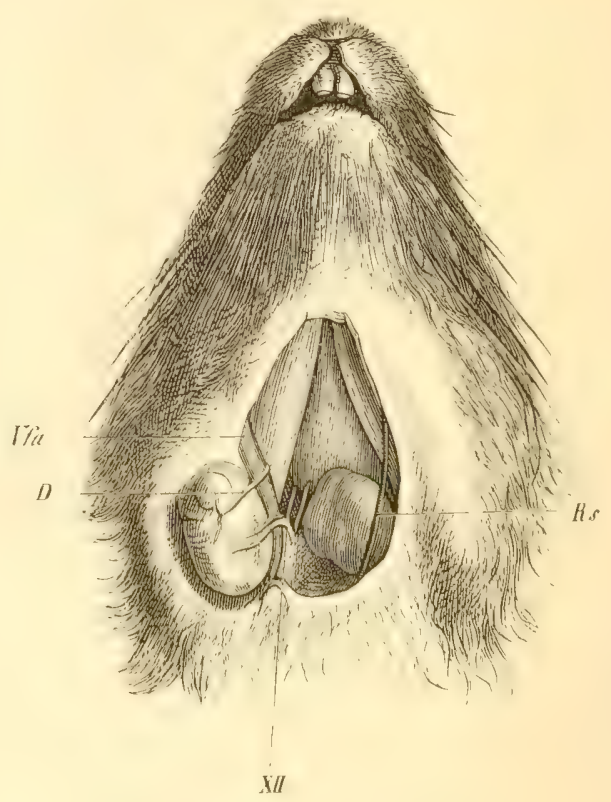

A. und V. submaxillares. Rechterseits ist die GI. submaxillaris aus ibrer Nische lateralwärts geschlagen. $D$ Ductus submaxillaris. Weiter rückwärts treten die A. dahinter die V. submaxillares in die Drüse. Vfa V. facialis anterior. Nach der Medianlinie hin erscheint das Cornu majus oss. hyoidei und parallel demselben der N. hypoglossus. $\quad X I I$ N. hypoglossus, Rs Ramus submentalis sinister aus der A. maxillaris externa sinistra.

1. lingualis Fig. 103, s) verlauft am oberen Rande des Cornu majus oss. hyoidei, an der medialen Seite des sehnigen Ursprunges des M. mandibulae, gieltt $R r$. sublinguales zu den Zungenmuskeln, erstreckt sich im M. genioglossus nach vorn und verästelt sich in der Zunge.

A. maxillaris externa (Fig. 103,1) verlauft nach vorn und lateralwärts an 
der medialen Flache des M. mandibulae, oberhalb der Gl. submaxillaris. Auf dieser Strecke giebt sie einen R. submentalis, einen oder zwei Rr. submaxillares (Fig. 105) fúr die genannte Druse, Rr. masseterici, pterygoidei und parotidei. Alsdann biegt sie sich am vorderen Rande des M. masseter um den Körper der Maxilla inferior, steigt an dem vorderen Rande des $M$. masseter aufwärts,

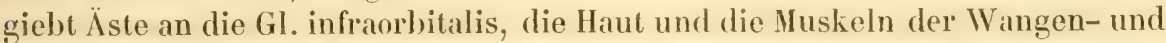
Nasengegend, ferner die Aa. coronariae labii superioris und inferioris ab, welche Zweige zu den Gesichtsmuskeln und der Haut der oberen, sowie der unteren Lippe entsenden, und endigt als A. angularis am vorderen Teile des unteren Augenlides.

A. temporalis superficialis verliuft hinter dem Angulus maxillae inferioris, oberhalb der Sehue des M. mandibulae, vor der Bulla tympani, giebt die Aa. auriculares anterior und posterior, sowie Rr. masseterici und pterygoidei interni ab. Alsdann steigt sie vor dem Ohr oberhalb des M. temporalis senkrecht zur Scheitelgegend aufwirts und entsendet vor dem Ohre noch die A. transversa faciei. Äste:

A. auricularis posterior ist stark entwickelt, steigt hinter dem iußeren Ohre aufwärts zur medialen Fliche desselben, teilt sich in die drei Äste: $R r$. anriculares anterior, medius und posterior, die gegen die Spitze des Ohres hin bogenförmig anastomosieren und an der medialen Flache desselben verlaufen.

Die Äste der A. auricularis posterior zeigen rhythmische Erweiterungen und Verengerungen ihres Lumens, 2-8 mal, meistens $3-5 \mathrm{mal}$ in der Minute. Die Kontraktionsdauer ist größer als die Expansionsdauer. Bei schwarzohrigen Kaninchen sind diese Bewegungen, die von dem unteren Teile des Centrum ciliospinale des Rückenmarkes (s. letzteres) abhängeu, am hesten zu selien (409). Vergl. a. 695. - Samuel (408, S. 220) unterband die Arterie an der Ohrwurzel; er zog Albinos vor.

Eine Abbildung der Arterien des Kaninchenohres s, in 155.

1. auricularis anterior verliuft aufwäts und versorgt die Muskeln an der Vorderfläche des außeren Ohres.

A. transversu fuciei verlauft nach vorn, unterhalb des Arcus zygomaticus, an der lateralen Seite des M. masseter, verteilt sich in demselben und der Haut des Gesichtes; versorgt auch den hinteren Teil des unteren Augenlides.

1. maxillaris interna ist stark entwickelt. Verliuft aufwarts an der medialen Seite des M. pterygoideus internus, hinter dem N. maxillaris inferior, giebt die A. tympanica ab, welche durch die Fissura Glaseri in die Paukenhohle gelangt, dann die starke $\Lambda$. alveolaris inferior, von ihrer hinteren $W$ and die A. meningea media; außerdem Äste für die Kaumuskeln. Dann geht sie durch das Foramen pterygoideum anterius in der Wurzel des Processus pterygoideus oss. sphenoidei, giebt dicht vor demselben die Aa. ophthalmica inferior und alveolaris superior ab, wendet sich nach vorn, verliuft an der medialen Seite der Alveolen der hinteren Backenzihne des Oberkiefers nach vorn und spaltet sich in die Aa. infraorbitalis und pterygopalatina.

A. alveolaris inferior verlauft nach vorn, gelangt in den Canalis maxillaris, giebt Rr. dentales ab, tritt aus dem Foramen mentale hervor.

A. meningea media dringt durch das Foramen spinosum zwischen bei- 
den Flügeln des Keilbeines in die Schäidelhöhle, liuft im Suleus meningeus der Ala magna aufwarts und lateralwåts zur Dura mater.

A. alveolaris superior versorgt die Zăhne des Oberkiefers.

A. ophthalmica inferior verliuft an der vorderen Fliche der Pars superior alae magnae oss. sphenoidei, biegt sich ïber den N. opticus nach vorn, und gelangt so an dessen rordere Seite; anastomosiert daselbst mit der A. ophthalmica superior (s. unten A. carotis interna). Äste:

A. lacrymalis, welche sich als $A$. supraorbitalis durch das Foramen supraorbitale posterius in das Gesicht fortsetzt.

A. frontalis, welche in derselben Weise durch das Foramen supraorbitale anterius geht; gleich nach ihrem Irsprunge giebt sie meistens die stark entwickelte 1 . ethmoidalis anlerior ab, welche durch das Foramen ethmoideum in die Nasenhöhle gelangt.

Rr. musculares an die Augenmuskeln.

Aa.ciliares longae nasalis $\mathrm{u}$. temporalis $(648)$, die erstere unter Beteiligung der $\Lambda$. ophthalmica superior (Fig. $106 \mathrm{cn}$ ); sie geben Äste zur nasalen und temporalen Seite der Chorioidea.

1. infraorbitulis verliuft oberhalb des $\mathrm{X}$. infraorbitalis, geht durch den Canalis infraorloitalis in das Gesicht. Sie versorgt den Zwischenkiefer, die Glandulae infraorbitalis und Harderiana und die Palpebra tertia.

A. plerygopalatina verliuft unter dem $\mathrm{N}$. infraorbitalis nach vorn, teilt sich oberhalb des hinteren Randes der Pars palatina oss. palatini in die Aa. palatima anterior und sphenopalalima. Erstere geht durch das foramen palatinum zum Gammen, verliaft nach vorn, indem sie der Schleimhaut des harten Gaumens Äste gicht: letztere gelangt durch das Foramen sphenopalatinum in die Vasenhöhle, reszweiggt sich an der Nasenscheidewand, und im hinteren Teile des Labyrinthes der Nase.

\section{A. carotis interna.}

A. carotis interna ist schwach entwickelt, wird von der A. carotis externa durch die Mon. styloglossus und stylopharyngeus getrennt, verliuft an der medialen Seite der Bulla tympani oss. temporum aufwirts, tritt in den Canalis caroticus oss. temporum und durch denselhen in die schidelhohle, verlauft an der medialen Seite des 1 . trigemiuns. an der lateralen Seite des Corpus oss. sphenoidei posterioris im sulcus caroticus nach vorn: wendet sich aufwarts an der medialen Seite der Eintrittsstelle des Noculonotorius in die Fissura orbitalis, lethteren Nerven rechtwinklig kreuzend. Auf diese Weise macht sie also drei Biegungen, nachlem sie in das mntere Ende des Cimalis anoticus getreten ist. Sie grebt dann die Aa. commmicams posterior und ophthalmica superior ab und spaltet sich in die Aa, cerebri anterior und media.

V arietät. Sie giebt die A. occipitalis ab, welche so stark ist wie die Fortsetzung der A. carotis interna selbst.

A. communicans posterior greht bateralwaits vom Infundibulum narb hinten, giebt die A. choroidea ab und múudet in die A. cerebri posterior.

1. ophthutmica superior Fig. $1060 s$ ist sehwach entwickelt; verlauft nach vorn zum Foramen opticum, tritt durch letzteres an der lateralen unteren Seite 
des N. opticus in die Augenhöhle, wendet sich unterhalh des N. opticus an dessen vordere Seite, anastomosiert daselbst mit der $\Lambda$. ophthalmica inferior. Sie giebt die Aa. centralis retinae (S. 189) und ciliares posteriores breves (Fig. 106) al, beteiligt sich auch an der Bildung der A. ciliaris longa nasalis (Fig. $106 \mathrm{cn}$ ).

A. cerebri anterior ist stark entwickelt, geht oberhalb des N. opticus nach vorn, verläuft, sich umbiegend, beinahe in der Medianebene, zwischen den Spitzen der Stirnlappen der Großhirnhemisphären aufsteigend, giebt die A. ethmoidalis posterior ab, krümmt sich dann bogenförmig nach hinten, wendet sich lateralwärts und teilt sich in einen $\mathbf{R}$. superior und inferior.

Die A. ethmoidalis posterior verläuft auf der oberen Fläche des Lobus olfactorius cerebri nach vorn, gelangt mittels feiner Zweige in die Nasenhöhle zu den Conchae posteriores.

Der $R$. superior der A. cerebri anterior verastelt sich auf der oberen Fläche des Stirnlappens; der $R$. inferior verlauft an der lateralen Flache des Stimlappens und reicht bis zum Hinterhauptlappen. Eine A. communicans anterior ist nicht vorhanden.

A. cerebri media ist schwach entwickelt, versorgt die untere und laterale Fläche des mittleren

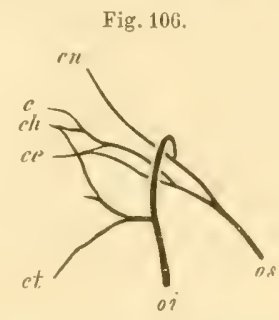

Schema des Ursprunges der Ciliararterien des rechten Auges. Vergr. 2. Nach H. Virchow $(G \neq S)$. $c n \AA$. ciliaris longa nasalis. $c$ Eine A. ciliaris posterior brevis aus der $\Lambda$. ophthalmica superior. $c h$ Eine A. ciliaris posterior brevis, welche aus einer Anastomose \%visehen denAa.ophthalmicae superior und inferior hervorgeht. $c e A$. centralis retinae. ct $\Lambda$. ciliaris longa temporalis. o $i$ A. ophthalmica inferior. os A. ophthalmica superior. Teiles der Großhirnhemisphare, anastomosiert mit den Aa. cerebri anterior und posterior.

\section{A. subclavia.}

\section{A. subclavia.}

A. subclavia verlauft vor dem M. scalenus anticus, hinter und über der V. subclavia, oberhalb der Nin. cervicalis VII und dorsalis I, hinter dem Lrsprunge des M. stemomastoideus und dem M. pectoralis superficialis.

Unterbindung der A. subclavia. A. Oberhalb der Clavicula. Operation wie bei Unterbindung des Truncus anonymus (S. 247).

B. Unterhalb der Clavicula. Hautschnitt in der Medianlinie, $3 \mathrm{~cm}$ lang; die Mitte des Schnittes failt auf den oberen Rand des Sternum. Ahtremung des M. pectoralis superlicialis vom unteren Rande der Claviculat. Der Muskel wird mit der vor demselben liegenden, aus dem M. pectoralis major kommenden Vene nach unten gezogen; die V. jugularis externa bleibt nach oben und medianwärts, die V. subclavia nach unten. Vor dem M. scalenus anticus, über den Nn. cervicalis VIII und dorsalis VIII, unter den Nn. cervicales VII und VI liegt die A. subclavia. (Fig. $107 A s$, S. 254). Man umschlingt sie mit einer sehr stark gekrümmten Unterbindungsnadel, besser mittels zwei Pinzetten.

\section{Äste der A. subclavia.}

Truncus cervicovertebralis entspringt von der oberen Wand der A. subclavia, giebt die Aa. rertebralis und cervicalis superficialis ab. Die Aa. 
mammaria, intercostalis suprema, cervicalis profunda und transversa colli entstehen mittels eines gemeinschaftlichen kurzen Stammes aus der A. subclavia. Diese Arterien können auch einzeln entspringen oder ihre Ursprünge sich in anderer Weise kombinieren.

A. vertebralis tritt in das foramen transversarium des sechsten Ilalswirbels, giebt Rr. musculares und spinales ab, welche sich wie die der Aa. inter-

Fig. 107.

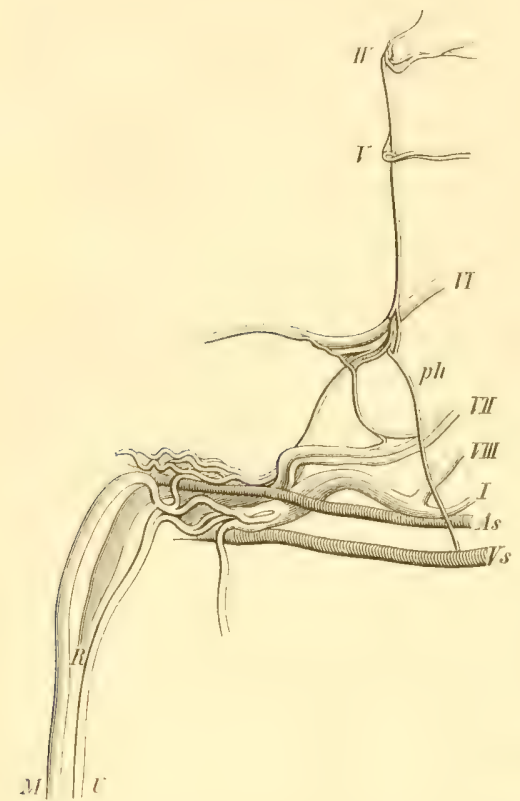

As A. subclavia dextra. $V$ s V. subclavia dextra. $I V-V I I I \mathrm{Nn}$. cervicales quartus-octavus. $p h \mathrm{~N}$. phrenicus. $I \mathrm{~N}$. dorsalis primus. $R \mathrm{~N}$. radialis, $U \mathrm{~N}$. ulnaris. $M \mathrm{~N}$. medianus. costales verhalten, gelangt in das Foramen transversarium des Atlas, biegt sich medianwärts, dann nach vorn und etwas aufwärts, geht durch das Foramen obliquum des Atlas und giebt die Aa. spinales anterior und posterior ab. Alsdann verläuft sie, die Dura mater durchbohrend, zur vorderen Flache der Medulla oblongata und fließt am unteren Rande der Pars basilaris oss. occipitis mit der Arterie der anderen Seite zur A. basilaris zusammen. - A. basilaris verliuft auf der oberen Fläche der Pars basilaris oss. occipitis unterhalb der Medulla oblongata und dem Pons Varolii, giebt in der Mitte der Lange desselben die A. cerebelli inferior, etwas weiter nach vorn $\operatorname{die} A$, auditiva $\mathrm{ab}$ und spaltet sich in die Aa. profundae cerebri dextra und sinistra.

A. profunda cerebri s. cerebri posterior lauft lateralwärts und nach vor'n an der lateralen hinteren Seite des Tuber cinereum. Giebt die A. cerebelli superior und etwas weiter nach vorn die A. cerebelli posterior für den in der Fossa mastoidea oss. temporum gelegenen Flocculus cerebelli ab und versorgt nach Aufnahme der A. communicans posterior mit mehreren Zweigen die untere und hintere Flache des Ilinterhauptlappens der Großhirnhernisphäre.

A. cerviculis superficiulis verliuft an der lateralen Seite der V. jugularis externa, hinter den Mm. levator anguli scapulae und cleidomastoideus, denselben Äste gebend.

A. mammaria interna. Entspringt aus der A. subclavia in der oberen Thorax-Apertur, hinter der V. cava superior sinistra, verliuft nach rorn an der medialen flache der ersten Rippe, biegt sich dicht lateralwarts von dem lateralen Ende des knorpels derselben nach unten und verliuft hinter den Knorpeln der zweiten bis siebenten Rippe und den medialen Euden der Mm. inter'ostales interni, etwa $3 \mathrm{~mm}$ vom lateralen Rande des Stermum eutfernt, abwarts durch die vorderen medialen Enden der entsprechenden Interstitia intercostalia. An vorderen Ende des linorpels der siobenten Rippe setzt sie 
sich als $A$. eprigastrica superior hinter demselben in den M. rectus abdominis fort, verlauft gerade abwarts steigend bis zur Nabelgegend, woselbst sie mit der A. epigastrica inferior anastomosiert. Sie giebt suceessive $R r$. intercostales anteriores an die betreffenden Interstitia intercostalia und die Mm. intercostales interni, welche mit den Aa. intercostales anastomosieren, auch die IIant der vorderen medianen Brustpartie mittels durchbohrender Äste versorgen.

Ferner entsendet sie die A. pericardiacophrenica, welche mit dem N. phrenicus verliuft, die A. musculophrenica und endigt, wie gesagt, als A. epigastrica superior.

Unterbindung der A. (und V.). mammaria interna. Schnitt in der Medianlinie aut den Processus xiphoideus, Durchschneidung des M. rectus abdominis in senkrechter Richtung in dem Raume zwischen den Knorpel der sechsten Rippe und dem Processus xiphoideus. Die 1 . mammaria interna liegt an der lateralen Seite der Arterie.

A. intercostalis suprema verlauft an der hinteren Wand des Thorax, vor den Köpfen der ersten bis dritten Rippe abwäts; die dextra auch hinter der V. cava superior dextra. Giebt Rr. tracheales, starke Rr. bronchiales, Rr. oesophagei und die Aa. intercostales I-III ab.

A. cervicalis profunda entsteht von der hinteren Wand des Truncus cervicovertebralis, verliuft hinter der $\Lambda$. vertebralis und anfangs an der medialen Seite des N. cervicalis VIII, verästelt sich in den tiefen Halsmuskeln.

A. transversa colli verlauft hinter den Nn. cervicales VII und VI lateralwarts, in einiger Entfernung parallel dem oberen Rande der Scapula, vor und bedeckt vom M. cucullaris, hinter dem M. rhomboideus dorsalis, giebt diesen Muskeln, sowie dem M. supraspinatus Äste.

\section{A. axillaris.}

A. axillaris verliuft in der Achselgrube zwischen den Nervenstimmen des Plexus brachialis, entsendet vou ihrer vorderen Wand die Aa. thoracicoacromialis und thoracica longa, von ihrer unteren die Aa. subscapularis und circumflexae humeri, von ihrer oberen Wand die $A$. profunda brachii.

Varietat. Die Aa. thoracico-acromialis und thoracica longa entspringen gemeinschaftlich; ebenso können die Aa. subseapularis und circumflexae humeri mittels eines kurzen gemeinschaftlichen Stammes entstehen; oder letztere werden von der A. profunda brachii abgegeben.

\section{Äste der A. axillaris.}

A. thoracico-acromialis verlaiuft nach oben, giebt einen R. deltoideus ab, sowie einen Ast zum M. pectoralis superficialis.

A. thoracica longa verliuft abwirts, entsendet einen Ast, der an hiuteren Ende des Knorpels der ersten Rippe sich abwarts und lateralwarts wendet; versorgt die $\mathbf{M m}$. pectorales major, minor und superficialis, sowie den M. serratus anticus major.

1. subscapuluris ist stark entwickelt, verliuft rükwäts am unteren Rande der Scapula, giebt Äste an den M. anconaeus longus, ferner Rr. musculares in die Fossa infraspinata zum M. infraspinatus und reicht mit langen 
Zweigen im M. cutaneus maximus, sowie im M. latissimus dorsi (R. thoracicodorsalis) bis zur Höhe des ersten Lendenwirbels abwirts.

Aa. circumflexae humeri anterior und posterior umgeben das Oberarmbein unterhalb des Caput humeri.

A. mofunda brachii verlauft anfangs hinter dem Nervenbiandel der Nn. radialis, medianus, ulnaris (s. Fig. 107. S. 254) nach abwirts, dann oberhalb) der Mur. latissimus dorsi und teres major nach hinten; entsendet die $A$. collateralis radialis. welche hinter dem Humerus an der medialen Seite des M. anconaeus medialis verliaft, damn mit dem N. radialis an dessen vorderer und lateraler Seite bis zum Ellenbogengelenk sich erstreckt.

\section{A. brachialis.}

A. brachialis verliuft in der Furche zwischen den Mm. gleno-ulnaris und anconaeus medialis, dicht unterhalb der Fascia brachialis zur Ellenbogengrube; sie liegt an Oberarm anfangs hinter und lateralwarts vom N. medianus, yelamet am unteren Dritteil des Oberarmes an die vordere Seite des $\mathbf{N}$. medianus, und kreuzl sich in der Ellenbogengrube nochmals mit dem N. medianus, der an ihre radiale Seite tritt. Etwa I cm unlerhalb der Ellenbogengrube spaltet sic sich in die Aa. ratialis und ulnaris. Die Y. brachialis begleitet die Arterie an ihrer hinteren Seite, der N. ulnaris liegt anfangs lateralwärts, spater hinter der A. brachialis. Äste:

A. collateralis ulnaris superior zum M. anconaeus longus; zwei bis drei Rir. musculares zuin M. gleno-ulnaris.

A. collateralis ulnaris media zum M. anconaeus medialis.

A. collateralis ulnaris inferior zum Ellenbogengelenk.

\section{A. radialis.}

A. radialis giebt die starke $A$. recurrens radialis ab und verlauft an der uluaren Seitedes X. medianus, gelangt, an dessen Dorsalseite sich erstreckend, an seine radiale Seite, gied) Muskeliste an das obere Ende des M. flexor digiforum sublimis. Sie liegt am unferen Dritteil des Vorderarmes, nur von der Faszie bedeckt, zwischen der Sehue des II. Hexor arpi ralialis und dem Radius und wird ulnarwirts begremzt ron den Sehnen der Im. flexores digitorum sublimis und profundus. Oberhall, des Handerelenkes giebt sie die A. princeps pollicis ot indicis ah, gelaugh an der Volarseite der Sehne des M. flexor digitorum sublimis, vom ligamentum carpi volare transversum bedeckt zur Ilohlhand. An der Ilandwmzel gieht sie den R. profundus ah und teilt sich oherhalb des Dammens in die Aa. digitales communes volares II - IV. Äste:

Die A. princeps pollicis et indicis ist die A. digitalis communis volaris $\mathrm{I}$. Sie liuft an der radialen seite der A. radialis, tritt mit derselben in die llohlhand und seudet die Aat. digitales rolares pollicis und indicis radialis ab.

R. profundus der $A$. radialis wendet sich an der Radialseite der Basis oss. metacarpi II in die Tiefe, giebt die A. interossea metacarpi I für die Radial- und L Inarseite des ersten und die Radialseite des zweiten Fingers 
ab. Das Ende des R. profundus fließt mit der A. ulnaris zur Bildung des Areus volaris zusammen.

Aa. digitales volares communes $I I-I V$ versorgen die Ulnarseite des zweiten, den dritten, vierten und die Radialseite des liinften Fingers mit je zwei Aa. digitales.

Varietät. Die A. radialis giebt die A. recurrens ulnaris ab.

\section{A. ulnaris.}

A. ulnaris verlauft schrig ulnarwäts, anfangs an der Dorsalseite des M. flexor carpi radialis, volarwitets von der Utha, gielot unmiltelbar narch ihrem Ursprunge die $\Lambda$. interossea antibrachii ab, sowie die A. recurrens ulnaris, geht dann zwischen den Mm. flexor carpi uhnaris und flevor digitorum profundus abwarts, verliuft vom unteren Ende des oberen Initteiles des Vorderarmes an ganz oberflichlich, von der Fascia antibrachii bedecht, an der Dorsalseite des X. uluaris, zwischen der Sehne des M. extensor carpi ulnaris und dem II. flexor digitorum sublimis, damn an der Radialseite der Sehme des II extensor carpi ulnaris, giebt noch am Vorderarm die $\Lambda$. volaris digriti l ulnaris ab. Die A. uharis sellost geht an der Ulnarseife des Os pisiforme auf die Volarseite und den uluaren Rand des M. flexor digili V ïber, gieht die $\Lambda$. dorsalis digiti $V$ ulnaris ah, schliggt sich um den letatgenannten Muskel dicht an dor Volarseite der Basis der Oss. metacarpi V-II verlaufend und bildet mit dem R. profundus der A. radialis den Areus volaris. Äste:

1. interossea antibrachii verliuft in Interstitium interosseum an der Volarseite des Vorderarmes bis zur IIandwurzel hinab.

A. recurrens ulnaris ist stark entwickelt, anastomosiert mit der A. collateralis ulnaris inferior, entsendet Muskelaste zur ulnaren seite des Vorderarmes.

A. dorsalis digiti V ulnaris wendet sich am ulnaren Rande der Basis oss. metacarpi V dorsalwäts, giebt auch dem M. flexor digiti V Äste.

\section{Arcus volaris.}

Der Arcus volaris liegt an der Volarseite der Basis der Oss. metacarpi II-IV, giebt die Aa. interossene metactrpi II-IV ab, welche in den Interstitia interossea II-IV verlaufen und die Aa. dorsales dig̣iti II ulnaris, dig̣ili III und IV radiales und ulnares, digiti $\mathrm{V}$ radialis entsenden.

\section{Aorta descendens thoracica.}

Verlauf. Vom Körper des zweiten Rückenwirbels an steigt sie an der linken Seite der Ruckenwirbelkorper his zum Iliatus aorlicus des Diaphragma herab. Sie liegt im Cim um mediastini posterioris, hinter dem Pericardium und dem Oesophagus; rechlerseits grenzt sie an den Ductus thoratcicos und die V. azygos, linkerseits an das linke Blatt des hinteren Mittelfelles. Iste: Außer kleineren Zweigen zu der Luftröhre, dem Oesophagus und dem hinteren Mitfe]- 
raume entsendet sie jederseits acht Aa. intercostales und die Aa. phrenicae superiores.

Aa. intercostales IV-XI. Dieselben entspringen an der rechten und linken Seite der Aorta thoracica; die dextrae gelangen hinter dem Ductus thoracicus und der V. azygos vor der vorderen Fliche der Rückenwirbelkörper auf die rechte Seite. Unter dem Collum costae entsendet jede A. intercostalis einen $R$. dorsulis, der am oberen Rande des IIalses der darumter liegenden Rippe nach hinten verlauft, den Wirbelkanal, die Muskulatur und IJaut des Rückens in der Gegend seines zugehörigen Rückenwirbels versorgend. Nach Abgabe dieses Astes verlauft jede A. intercostalis unter der zugehörigen Rippe zwischen den $\mathrm{Mm}$. intercostales interni und externi nach vorn; unmittelbar am unteren Rande der Rippe liegt die $\mathrm{V}$. intercostalis, dann folgt die Arterie, dann der $\mathrm{N}$. intercostalis. Sie entsendet nahe dem lateralen Ende der Rippe einen $R$. sumacostalis, welcher an der Inmenfliche der letzteren an ihre obere Kante gelangt und sich langs derselben veristelt. Die Aa. intercostales versorgen die Muskeln der Thoraxwand.

Aa. phrenicue superiores dextraund sinistra. In der IIöhe des elften Rückenwirbels entspringen aus der vorderen Wand der Aorta thoracica miltels eines ganz kurzen stammes die Aa. phrenicae superiores, welche nach vorn zum Diaphragma verlaufen und in der Pars lumbalis des letzteren sich verzweigen.

Varietåt. Die Aa, phrenicae dextra und sinistra entspringen aus der A. intercostalis dextra XI.

Unterbindung der Aorta thoracica. Die Unterbindungsnadel wird zwischen 7. und 8. Rippe wie beim Stenson'schen Versuch (S. 259) eingeführt (729).

\section{Aorta descendens abdominalis.}

Verla uf. Im Hiatus aorticus des Diaphragma beginnend, steigt die Aorta abdominalis in der Furche zwischen den medialen Rindern des rechten und linken M. psoas major herab. Sie liegt vor den körpern der Lendenwirbel und dem medialeu Rande des linken M. psoas major, hinter der Kardia, dem Magen, der Auheftungstelle des Mesenterium und dem Saccus peritonei.

Im oberen Teile der Banchhöhle, nämlich in der Höhe des zweiten Lendenwirhels, liegt die V. cava inferior vor der Aorta abdominalis, weiter abwarts an ihrer rechten Seite. Letztere teilt sich vor der Mitte des siebenten Lendenwirbels in die Aa. iliacae communes.

Unterbindung der Aorta descendens abdominalis. A. Mit Eröffnung des Bauches und des Peritoneum. s. Unterbindung der A. iliaca communis (S. 263). Einspritzung mehrerer Grammen Chloroform in die Aorta veranlaßt eigentümliche Bewegungen der unteren Extremitäten (409).

B. Mit Erötlnung des Bauches, ohne Eröffnung des Peritoneum.

Befestigung in der Rückenlage, der linke Schenkel wird von einem Gehilfen gehalten und medianwärts rotiert. Hautschnitt am vorderen Ende der linken zwölften Rippe beginnend, ca. $6 \mathrm{~cm}$ lang in senkrechter Richtung abwärts. I) urchschneidung des M. quadratus lumborum; die Muskeln werden mit Haken krïftig auseinander gezogen, das Peritoneum wird geschont $(410)$. 
Man kann die Aorta auch zeitweise mit einer Klemmpinzelte schließen, um sie später wieder zu öffnen (385, S. 387), ebenso nach Eröffnung des Peritonealsackes. - Uber Zuckergehalt des Harnes nach Unterbindung der Aorta unterhalb der Nierenarterien vergl. 691.

C. Ohne Eröffnung des Bauches, mit Verletzung des Peritoneum. Stenson'scher Versuch.

Das Tier wird in sitzender Stellung gehalten, der Kopf zur linken Hand des Operateurs. Kleiner Hautschnitt in der Höhe des Processus spinosus des vierten Lendenwirbels an der rechten Seite der Wirbelsäule lateralwirts neben den Processus transversi. Einführung einer gebogenen Nadel, die einen Halbkreis von $3 \mathrm{~cm}$ Rarlius darstellt, für mittelgroße Tiere bestimmt ist und in einer Scheide von $2,5 \mathrm{~mm}$ Durchmesser lauft. Die Nadel ist breit, platt, vorn zugeschliffen; in dem Ohr der Nadel befindet sich eine geölte Plattschnur. Die Nadel wird langsam eingeführt; sobald der Widerstand aufhört, die Scheide vorgeschoben, mit dem stumpfen vorderen Ende der letzteren die Wurzel des Mesenterium durchbohrt, was bei größeren Tieren am Widerstand gefühlt werden kann. Das Ende der Scheide wird gegen den linken M. quadratus lumborum angedringt, so daß man sie mit der linken Hand durch die Haut fühlt; damn die Nadelspitze durch die Muskeln und die Haut gestoßen, die Schnur doppelt langsam um die Aorta geführt. Dieselbe faßt die V. cava inferior und die Ureteren mit. Über den Processus spinosi zusammengebunden, wird der Blutlauf in den unteren Extremitäten sistirt, Lähmung derselben tritt meist nach $5-15$ Minuten ein. Löst man die Schnur, so kehrt die Leistungsfahigkeit zurück; dies kann mehrere Male wiederholt werden; Peritonitis pflegt nicht einzutreten (k/l). Der Tersuch gelingt leicht, auch mit einer gewöhnlichen gekrümmten Nadel (4/2).

Man kann das Kaninchen in der Mitte bis auf die Aorta descendens abdominalis und die $Y$. cava inferior durchschneiden $(4.5)$, welehes Verfahren sich nicht mehr empfiehlt.

\section{Äste der Aorta descendens abdominalis.}

Von ihrer vorderen Wand von oben nach unten successive die Aa. coeliaca, mesenterica superior, mesenterica inferior, spermatica sinistra, spermatica dextra. Aus der hinteren Wand die Aa. lumbales I-VI. Rr. musenlares für die Mm. psoas majores; seitlich die Aa. renales.

A. coeliaca. Ein kurzer Stamm, der nach vorn verlaufend sich in die Aa. lienalis, coronaria ventriculi sinistra und hepatica teilt. Fon seiner oberen Wand entpringen gemeinschaftlich die sehr schwachen Aa. phrenicae inferiores.

Unterbindung der A. coeliaca. Man kann von hinten her auf dieselbe eindringen; Hautschnitt wie bei Unterbindung der A. renalis (414) S. S. 261.

A. coronaria rentriculi sinistra liuft nach oben und links, giebt einen Ast ab, der sich halbkreisformig links neben der Kardia um dieselbe nach rorn biegt, kleine Rr. cardiaci und viele starke Rr. gastrici entsendel, ron welchen ca. sechs his acht an der hinteren Fliche der linken Seite des Mageus sich verzweigen. Die A. coronaria ventriculi sinistra gelaugt zur Vhitte der kleinen Kurvatur des llagens und anastomosiert mit der A. coronaria ventriculi dextra.

A. lienalis. Verlauft geschlingelt nach vorn zum oberen Ende der Milz, entsendet vorher die A. gastro-epiploica sinistra, welche sich am linken Ende der großen Kurvatur des Magens verastelt; lauft damn, einen nach links kon- 
vexen Bogen bildend, langs des medialeu Randes der Milz abwirts und sendet zahlreiche Äste in dieselbe: ferner Zweige zum Omentum majus, Rr. pancreartiei zur Cauda des Pankreas, sowie vier bis sechs starkere Rr. gastrici zur großen Kurvatur des Magens. Dieselben amastomosieren untereiuander und mit der A. gastro-epiploica sinistra.

A. hepatica. Verlauft in der rechten Seite der Kardia nach oben, hinter dem Pankreas und vor der V. porlarum, giebt die A. coronaria ventriculi dextra ab, welche die rechte Seite der Kardia und der kleinen kurvatur des Magens versorgl, wobei sie mit der A. coronaria rentriculi sinistra bogenfümig anastomosiert. Weiter nach vorn entsendet sie die A. gastroduodenalis. Dieselbe liuft hinter dem Pylorus abwirts, seudet $\ddot{A}$ ste an die obere Fliche des Anfaugsteiles des Duodenum, giebt ferner die A. gastro-epiploica dertra ab, welche an der großen Kurvatur des Magens nach links rerliuft und mit der A. Eastro-epiploica sinistra anastomosiert. Endlich versorgt die A. gastroduodenalis, bogenfömig an der medialen konkaven Seite des Duodenum verlaufend, letztere und die rechte Partie des Omentum majus mit zahlreichen Ästen; sie anastomosiert mit der $\Lambda$. pancreaticoduodenalis inferior (A. pancreaticoduodenalis superior).

In der Leberpforte verliuft die schwach gewordene A. hepatica an der rechten Seite und ror der V. portarum, sowic an der linken Seite und vor dem buctus choledochus. Sie teilt sich spitzwinklig in die Rr. hepatici dexter u. simister, welche kleinere Zweige zu den verschiedenen Leberlappen senden. Der erstere giebt auch die an der linken Seite des Ductus eysticus verlatufende A. cystica zur Gallenblase ab.

Unterbindung der A. hepatica s. Aufsuchung des Ductus choledochus (S. 322). Man kann auch einen Ast isoliert unterbinden (750).

A. mesenterica superior. Entspringt vor dem oberen Rande des zweiten Lendemwirbels, liuft schrig abwirts und nach vorn. Nahe ihrem Lrsprunge entsteht aus ihrer linken Seite die $A$. colica media, welche das Colon transversum versorgt und mit der .1. colica sinistra anastomosiert. An ihrer linken Seite giebt die $\Lambda$. mesenterica superior successive 10-12 Aa. intestimales ab. welche in Mesenterium reraufen, nahe dem Iarm untereinander bogenfirmig anastomosieren und den ganzen Dündarm versorgen. Das Ende der $A$. mesenteria superior verhailt sich ebenfalls wie eine $A$. intestinalis und anastomosiert bogenförmig mit einem Aste der A. ileocolica.

An der rechten Seite der $\Lambda$.mesenterica superior entstehen aus derselben die slarke A.pancreaticodurdenalis inferior, welche an der konkaren Seite des Duodenum verliuft, letzleres versorent und mit dem mnteren Ende der A. gastroduodenalis anastomosiert. Ferner die A. colica dextra, die Aste zum Colon adscendens abgiebt, mit der A. colica media nach oben und der A. ileocolica nach unten anastomosierend. Gesenuber der dritten A. intestinalis entsteht die A. ileocolica, welche starker ist, als die Fortsetzung der A. mesenterica superior selhst. Sie griebt zwei $\mathrm{Aste}$ an das Colon adscendens ab, rerteilt sich

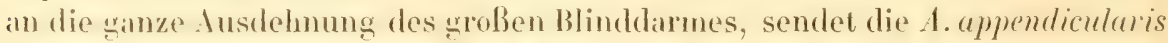
an den Processus vermiformis und endigg am $\Lambda$ nfange des Colon adscendens. Einer ihrer Endiste anastomosiert mit dem Ende der A. mesenterica superior. 
Unterbindung der A. mesenterica superior. Sie kann von hinten her fast ohne Verletzung des Peritoneum unterbunden werden; Hautschnilt wie bei Unterbindung der A. renalis (414, S. 49).

A a. renales dextra u. sinistra. Die dextra entspringt dicht unterhalb der A. mesenterica superior von der Mitte des zweiten Lemdenwirbels, lauft lateralwirts und efwas aufwirts zur rechten Viere. Die sinistra entspringt ca. I cm weiter abwarts, ist bedeutend langer als die dextra, verlauft schrigg lateralwarts absteigend zur linken Niere. Aus der A. renalis entspringt nahe ihrem Anfange jederseits die $A$. intercostalis $X I I$. Dieselbe läuft aufvärts, giebt die A. suprarenalis ab; eine A. suprarenalis sinistra accessoria kann aus der A. renalis sinistra direkt. entstehen. Etwas weiter aufwärts entsendet die A. intercostalis XII eine A. lateralis $a b-$ dominis, welche starker ist als die Fortsetzung der A. intercostalis XII selbst. Die A. intercostalis XII verläuft unterhalb des $\mathrm{N}$. intereostalis XII, oberhalb der V. intercostalis XII, von beiden begleitet. Ebenso verhält sich die schräg abwärts steigende A. lateralis abdominis zum N. Lumbalis I. Ietztere verzweigt sich im oberen Teile der Bauchmuskeln, namentlich des M. transversus abdominis.

Unterbindung der A. renalis. Hautschnitt in der Medianlinie, ca. $6 \mathrm{~cm}$ lang, dessen Mitte auf den Nabel fällt, oder von der Spitze des Knorpels der elften

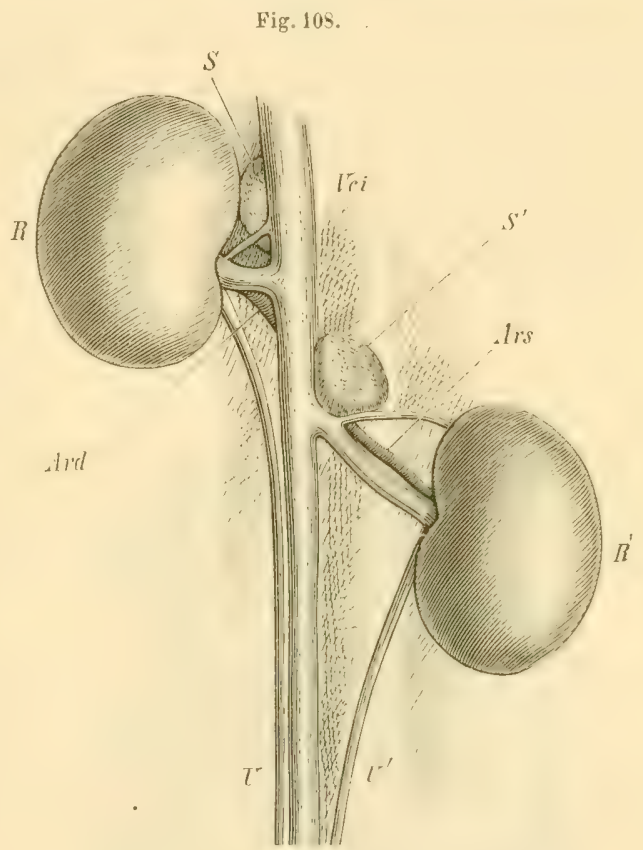

$R$ Rechte Niere. $R^{\prime}$ Linke Niere. $S S^{\prime}$ Rechte und linke Nebenniere, $V c i \mathrm{~V}$, cava inferior. Ard, Ars Aa renales dextra und sinistra. Unter der linken Nebenniere mündet die V. Iumbalis $I$ sinistra in die $V$. renalis sinistra; die $V$. renalis dextra steht an ihrer Eintrittsstelle in die Niere abnormer Weise aurch oine $V$. aberrans mit der $V$. cava inferior in Verbindung. linken Rippe, die man durchfiihlen kann, senkrecht abwirts. Im letzteren Falle Schnitt durch die Mın. abdominis, Ablösung der Fascia transversa abdominis mit der Hohlsonde vom M. quadratus lumborum, wenn man die Erölnung des Peritoneum zu vermeiden wünscht.

Die Darmschlingen werden von einem geübten Assistenten zurückgehalten, der dabei die Bauchwand in eine Art Tasche aufheben kann Meißner). Man fühlt mit dem Finger nach der Niere neben der Wirbelsäule, durch Druck ist die linke Niere leicht aus der Bauchwunde heraus zu befördern, was man jedoch besser vermeidet. Die rechte Niere (Fig. 108) liegt höher, von einer Aushöhlung des rechten Leberlappens nach oben bedeckt, die Unterbindung ist an dieser Seite viel schwieriger und kann noch durch eine V. aberrans (s. V. renalis) erschwert werden. Zwischen A. und V. renalis, welche letztere unter der Arterie verläuft, liegen die Stämmchen der Nn. renales proprii (Sekretionsnerven der Niere, 410 ), 
die man exstirpieren kann. Die Gefißnerven umspinnen die A. renalis (416, vergl. a. 695). Darf man die Bauchböhle eröffnen, so ist der Schnitt in der Linea alba vorzuziehen, weil Blutungen vermieden werden; will man die Eröffnumg vermeiden, so durchschneidet man die Bauchmusheln nach dem seitlich geführten Hautschnitt und trennt mit der Hohlsonde die lascia transversa zwischen dem Mm. quadratus lumborum, der Niere und dem Peritoneum durch.

Bei letzterer Operationsmethode ist es vorteilhaft, den Schenkel der zu operierenden Seite von einen Gehülfen halten und im Hüfgelenk medianwiirts rotieren zu lassen, wobei das Tier etwas mehr in eine Seitenlage kommt.

Die Nierenkapsel enthält Zweige aus den Aa. suprarenalis und spermatica interna, welche mit Ästen der A. renalis anastomosieren (417).

Ober die Schwierigkeiten des Eindringens vom Rücken des Tieres her auf die Niere s. 605. - Über die Folgen der Unterbindung s. S. 228; über die Unterbindung eines Astes der A. renalis s. 791.

Rr. musculares der Mm. psoas majores. Nahe unterhall der Abgaugsstelle der $A$. renalis sinistra entspringt ein kurzer Stamm aus der Aorta abdominalis, welcher sich in zwei Rr. musculares für den rechten und linken M. psoas major teilt.

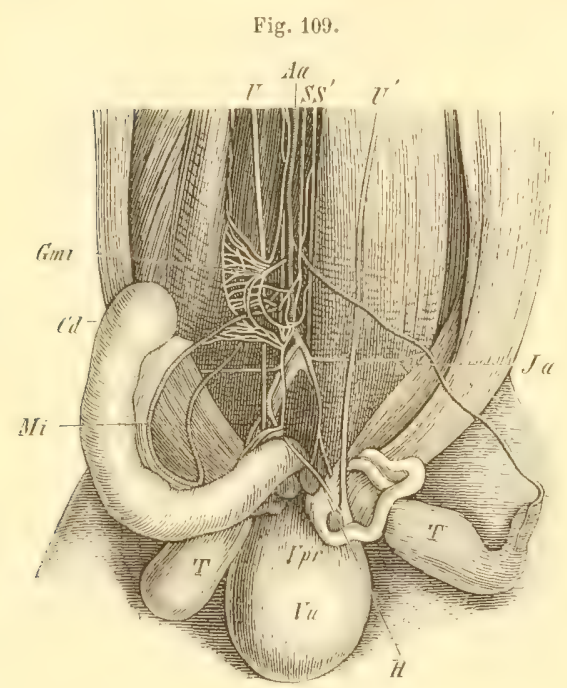

$V u$ Harnblase. $V p r$ Cornua vesieulae prostaticae. $T T$ Testikel. $C d$ Colon descendens. $U U^{\dagger}$ Rechter und linker Ureter. If Aorta abdominalis, aus welcher die Aa. spermaticae internae entspringen. Nach Loeb und Eckliard (418). Die A. spermatiea interna sinistra verläuft bogenformig zum Testikel: das untere Ende der stwas tiefer entepringenden destra wird dureh das folon descendens verifeckt. Ja $A$. iliolumbalis. Yi A. mesmotrica inferior. $\therefore$ anch Neurologie, bituchteil des sympathischen
Nerrensystems.

Aa. lumbales commune's $I-V I$. Sie entspringen in der Mitte des zugehörigen Lendenwirbels, laufen gerade nach hinten und teilen sich vor den Körpern der betreffenden Lendenwirbel jede in eine $A$. lumbalis dextra und sinistra, die sich in den Mm. psoas major, minor und quadratus lumborum verästeln, auch Zweige in den Canalis vertebralis, sowie zur Muskulatur und Haut des Rückens in der Lendengegend absenden.

Aa spermaticae dextra u. sinistra entspringen nebeneinander vor dem sechsten Lendenwirbel, ein wenig oberhalb oder unterhalb der A. lumbalis VI, die dextra auch wohl etwas weiter abwärts als die sinistra.

Dieselben verlaufen beim Miannehen (Fig. 109) abwirts und lateralwairts, die sinistra vor der Aorta abdominalis und dem M. psoas minor sinister, die dextra vor der V. "aiva inferior und dem M. psoas minor dexter, krenzen sich mit der A. iliolumbalis an jeder seite und gelangen an der unteren Begrenzung des großen Beckens zum Hoden.

Beim Weibehen entspringt regelmiißig die $\Lambda$. spermatica dextra höher als die sinistra fl:9). Die Aa. spermatieae verlaufen dann innerhall, des Me- 
sometrium lateralwirts und nur wenig absteigend; sie versorgen das Ovarium und den lateralen Teil der Tuba und anastomosieren an letzterer mit der A. uterina.

A. mesenterica inferior (Fig. $109 \mathrm{M} i$ ). Gegenüber der A. lumbalis VI entspringend, teilt sie sich in die $A$. colica sinistra, welche aufwarts steigt und mit der A. colica media anastomosiert und in die A. haemorrhoidalis interna, welche den untersten Teil des Colon descendens, sowie die oberste Partie des Rektum versorgt.

A. sacralis media entspringt etwas oberhalb der Teilungsstelle der Aorta abdominalis in die Aa. iliacae communes, entsendel die Aa. lumbales VII dextra und sinistra, oder beide mittels eines gemeinschaftichen kurzen Stammes: der $A$. lumbalis communis VII, verliuft dann in der Medianlinie an der ventralen Fläche der Schwanzwirbelsäule bis zur Spitze.

Die $\Lambda$. sacralis media giebt Ästchen für Gefißkniucl ab, welche die Gl. coccygea repräsentieren (420, vergl. 610, S. 620, sowie 57, S. 325 ). Dieselben finden sich vom achten Schwanzwirbel an bis zur Spitze des Schwanzes (121).

\section{A. iliaca communis.}

\section{A. iliaca communis.}

A. iliaca communis verläuft schriag lateralwärts, vorwärts und abwairts vor dem M. psoas minor; ist nur kurz und teilt sich in die Aa. iliacae interna und externa.

Unterbindung der A. iliaca communis. A. Mit Eröffnung des Peritoneum. IIautschnitt in der Medianlinie, ron der Symphysis pubis beginnend nach aufwirts, $6 \mathrm{~cm}$ lang. Durchschneidung der Linea alba; die Darmschlingen, namentlich dits Coecum und Colon werden nach oben gehalten. Aufsuchung des unteren Endes der Aorta descendens abdominalis in der Medianlinie; nach lsinten und rechts liegt die V. cava inferior. Die Aa. iliacae communes sind verhältnismïßig kurz. Einspritzung von Chloroform durch eine eingebundene Kanüle erzeugt sogleich Totenstarre der zugehörigen Extremitit; meistens schreit das Tier.

B. Ohne Eröflnung des Peritoneum. Haut- und Muskelschnitt $6 \mathrm{~cm}$ lang, parallel dem vorderen Rande des Os ilium, dessen Spina anterior superior man durchfühlı. Die Darmschlingen werden nach der entgegengesetzten Seite geschoben.

\section{Äste der A. iliaca communis :}

A. iliolumbalis ist stark entwickelt, entspringu (Fig. 109 J a) dicht unterhalb) des Ursprunges der A. iliaca communis; wendet sich in transversaler Richtung vor dem M. psoas major lateralwarls, leilt sich unterhall) der Spina anterior inferior oss. ilium in einen oberen und unteren Ast. Ersterer verliuft aufsteigend zu den Bauchmuskeln und verzweigt sich mehrfach in der IIöhe der Spina anterior superior oss. ilium; letzterer gelangt vor dem M. iliacus und hinter dem oberen Teil des Lig. inguinale zur Hat des Bauches.

A. vesicalis superior entsteht aus der Spaltungsstelle der A. iliaca com- 
munis, verlauft anfangs vor dem oberen Ende der V. iliaca interna, beim Minnchen auch unterhalb des Vas deferens zur Blase, an der lateralen Seite des unteren Endes des Ureter, sendet eine starke A. ureterica nach oben liings des Ireler und aine A. deferentialis nach unten langs des Vas deferens zur Epididymis.

1. uterina entspringt beim Weibchen ans der Spallungsstelle der $A$. iliaca communis, verliaft unterhalh des Treter \%wischen den Platten des Mesometrium aufwiarts, giebt die A. vesicalis superior, dann eine A. vaginalis superior al), verliuft gegen die Vitte der Linge des Cormu uteri hin und spaltet sieh in zrrei Ilauptiste. die mil Bogen, welehe gegen die Cormua uteri konvex gekrimmut sind, medianwirts und lateralwarts sich erstrecken und der konhaven Seite des Cormu uteri zahlreiche Zweige zusenden. Die medialen Zweige beider Aa. nterinae anastomosieren miteinander in der Medianlinie.

Varietät. Die A. vesicalis superior entsteht beim Weibchen aus dem Anfange der A. iliaca externa.

Unterbindung der A. uterina. Schnitt in der Medianlinie des Bauches. Aufsuchen der Aa. uterinae in den Teilungsstellen der Aa. iliacae communes in die Aa. iliaca externa und hypogastrica, Isolierung der ersteren und doppelte Unterhindung derselhen. Man hann horhtriehtige Kaninchen atherisieren is.j); s. auch Uterus (S. 237). Fiir die Blutzufuhr zu den inneren Geschlechtsorganen bleiben die Aa. spermaticae und vaginalis media (letztere aus der A. haemorrhoidalis media) in Funktion. Der Tod erfolgt nach einigen Tagen an Peritonitis.

\section{A. iliaca interna.}

A. iliaca interna verliuft schrigg lateralwints absteigend an der hinferen Wand des heinen Brokens. giebt die $\mathrm{A}$. purlemda internat oder auch die A. haemorrhoidalis media ab und spaltet sich in die Aa. obturatoria und ischiadica) oder letztere entspringt gemeinschaftlich mit der $\Lambda$. pudenda interna.

\section{Äste der A. iliaca interma:}

1. haemorrhoidalis mediu entspringt ror dem Austritt der A. iliaca internat aus dem kleinen Becken, oder von der A. pudenda interna, verliuft zur lateralen AuBenwand des Rektum; beim Manochen als A. prostatica zur Vesicula prostatica und zur Prostata; beim Weibchen als A. vaginalis media zur Srheide, welche Arterie mit derjenig̣en der anderen seite anastomosiert.

1. obturatoria gelangt, anfangs an der medialen Seite des M. obturator intermus abwirts steigend, zwischen die Mn. obturatores internus und externus, lault am lateralen Rande des foramen obturatorium abwirts und reristelt sich hauptsächlich in den genamnten Muskeln.

1. ischiadica gelangt unterhalb des M. pyriformis nach hinten aus dem kleinen Becken heraus, giebt einen $R$. cutaneus, der sich außerhalb der Faste anfwitrts arstreckt und in weitem Bogen mit der $\Lambda$. iliolumbalis anatstomosiert. AuBcrdem Äste an den II. biceps femoris; alsdann verlituft die A. ischiadion alowirls, hinter dem .y. obfurator exteruns, und spallet sich in die Aa. sacralis lateralis und pudenda interna. 
1. suchatis laterulis rerliaft jederseits an der lateralwarts gerichteten dorsalen Kante des Schwanzes.

A. pudenda interna geht vor der A. ischiadica aus dem Becken durch die Incisura ischiadica major hinaus, tritt an der medialen Seite des M. obturator internus in das kleine Becken wieder ein, verliuft an der lateralen Seite des Rekfum wach vorn, giebt die $\Lambda$. hacmorrhoidalis externa ab und gelangt unter der Symphysis pubis zum Penis, resp. zur Cilitoris. Sie entsendet die Aa. profunda und dorsalis penis, resp. elitoridis. - Die A. haemorrhoidalis externa entsendet eine starke A. perinea, welche an der lateralen Seite des Rektum abwarts lauf, die (il. analis versorgend, und bis zur Afteröflnung hinabreicht.

\section{A. iliaca externa.}

A. iliaca externa läuft lateralwärts und abwärts, vor dem M. psoas minor, an der medialen Seite des II. iliopsoas, geht unter dem Lig. inguinale durch die ovale Liucke, welche die beiden Blatter der Sehne des Ir. psoas minor zwischen sich lassen, und heißt von hier ab A. cruralis.

\section{Äste der A. iliaca exterua:}

1. epigastricu inferior entspringt ummiltelbar oberhall, des Lign. inguinale, latuft vor dem Peritoneum hinter dem II. rectus abdominis anfwirts, den Bauchmuskeln Äste geliend. Ferner entsendet sie bald nach ihrem Ursprunge die A. spermalice exterm. Isetztere wendet sich hinter dem Lig. inguinale medianwarts, giebt nach kurzem Verlauf einen Ast ab, welcher unter dem Lig. inguinale zum M. adductor brevis gelangt. Alsclann verlatult die A. epigastrica inferior oberhall, des Lig. inguinale beim Minnchen zur Tunica vaginalis communis, zur Epididymis und zur Skrotallasche, beim Weibchen zu den Labia des Introitus vaginae.

Unterbindung der A. iliaca externa s. Unterbindung der A. iliaca communis B. (S. 263).

\section{A. cruralis.}

A. cruralis verläuft in der Furche zwischen den Mm: adductores und II. Vastus medialis abwirts, durchbohrt den M. adductor magnus nahe seinem untersten Insertionspunkte und gelangt in die kniekehle, woselhst sie A. poplitea genamnt wird. Dicht unterhalh des Lig. inguinale giebt sie die A. profunda femoris aus ihrer hinteren Wand, weiter abwirls aus der lateralen Wand die A. circumflexa femoris lateralis, und bald darauf aus der vorderen Wand die A. corcumflexa abdominis, endlich nahe oberhalh ihres Durchtrittes dureh den $\mathrm{H}$. adductor magnus aus ihrer vorderen Wand die Aa. articularis genu superficialis und saphena magna.

Varietät. Die A. articularis genu superficialis wird von der A. saphena magna abgegeben. Letztere entspringt schon am mittleren Dritteil des Oberschenkels.

Unterbindung der A. cruralis. Hautschnitt von $3 \mathrm{~cm}$ Länge, senkrecht auf 
die Richtung des Lig. inguinale; an der Stelle beginnend, wo man dicht unterhalb des Ligamentes die A. cruralis pulsieren fühlt. Durchschneidung der Fascia lata und des M. sartorius nach dessen Längsrichtung. Die $\Lambda$. cruralis liegt in der Mitte (Fig. 1/0), die V. cruralis medianwårts, der N. cruralis lateralwärts. Die A. profunda femoris entspringt dicht unterhalb des Lig. inguinale und geht sogleich nach hinten; man bindet unterhalb ihrer $\Lambda \mathrm{b}$ gangsistelle die Kanüle ein, wenn man z. B. durch Injektion von einigen Grammen Chloroform die Wadennuskeln in Totenstarre versetzen will. Die V. profunda femoris begleitet die gleichnamige Arterie, beide hindern nicht. Die Aa, circumtlexae abdominis und femoris werden zur Seite gezogen oder nötigenfalls unterbunden und durchschnitten.

\section{Äste der A. cruralis:}

A. profinda femoris verliuft abwarts am lateralen oberen Rande des M. pectineus und hinter dem M. adductor brevis, auf der vorderen Fliche des

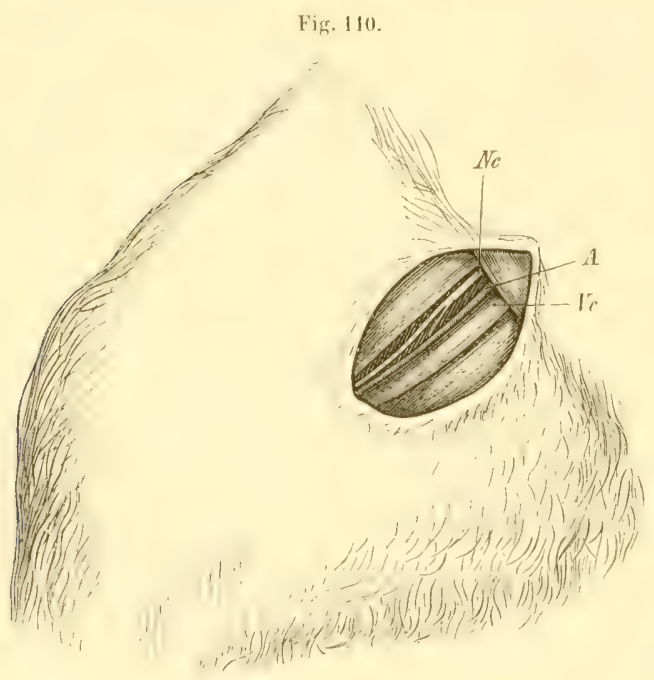

A A. cruralis, unterhalb des Lig. inguinale hervortretend. $\forall \in \mathrm{V}$. cruralis. $N C \mathrm{~N}$, eruralis.
M. obturator internus und vor dem M. quadratus femoris, verzweigt sich in den $\mathrm{Mm}$. adductor longus und magnus, welche sie nicht durchbohrt. Bald nach ihrem Ursprunge entsendet sie die A. circumflexa femoris medialis, die dicht oberhalb des Trochanter minor hinter das $\mathrm{Fe}$ mur gelangt.

A. circumflexa femoris lateralis entsendet einen Ast zum II. vastus medialis, einen anderen zum M. rectus femoris, wendet sich dann aufwärts und rủckwirts an der lateralen Seite der Siehne des M. iliopsoas und giebt auch Äste zum M. gluteus minimus.

A. circumflexa abdominis verläuft, die Fascia lata durchbohrend, nach vorn und aufwarts, dann lateralwirts aufsteigend veristelt sie sich in der Ilaut der Weichengegend und des Bauches bis zur Spina anterior superior oss. ilium.

1. articularis genu superficialis ist sehr lang, verlituft zum Condylus femoris medialis, gelangt an der medialen vorderen Seite der Patella zum Rete articulare genu.

A. saphena magna verläuft am mittleren und unteren Dritteil des Oberschenkels abwäts an der medialen Seite der Mm. adductor magnus und sartorius, hinter letzlerem und der sehnigen Ausbreitung des M. gracilis, tritt am unteren Rande des .M. gracilis unter die Fascia lata, verlauft damn in zwei Blatter der liaszic cingeschlossen an der medialen Seite des unteren Endes des M. adiluctor magnus, Äste zum Kniegelenk abgebend, ferner an der medialen Flache des II. gastrocnemius medialis vor der langen Sehme des $\mathbf{I}$. semimembranosus. Dann giebt sie oberhalb des Fußgelenkes die A. malleolaris 
ab, welche sich an der hinteren Seite des Unterschenkels zum Malleolus lateralis begiebt, tritt an die mediale und hintere Seite der Sehne des M. flexol digitorum pedis longus, heißt von hier ab A.tibialis posterior, welche hinter dem Malleolus medialis und der Sehne des M. extensor digiti I proprius, an letztere geschmiegt, in die Fußsohle gelangt. Sie entsendet den R. plantaris profundus, gelangt unter der für die erste Zehe bestimmten Sehne des II. flexor digitorum pedis longus in das Interstitium interosseum metatarsi I, giel)t die Aa. digitales plantares tibialis digiti $I$ und communis I fü die Fibularseite der ersten und die Tibialseite der zweiten Zehe ab und spaltet sich, indem sie sich lateralwirts wendet, in die Aa. digitales plantares communes $I I$ und $I I I$.

V a rie tät. Sie endigt im Rete articulare genu (422, zweimal).

Unterbindung der A. saphena magna. Hautschnitt längs der medialen Seite des Oberschenkels. Die Arterie verliuft in der Faszie eingeschlossen, sie ist sehr fein, aber an den begleitenden Vv. saphence magnae leicht kemnbar; die grïßere V. Saphena magna verlïult an ihrer vorderen Seite, die kleinere an ihrer hinteren. Auch der N. Saphenus begleitet die Arterie und giebt derselben Gefißnerven. Durchschneidet man denselben, so erweitert sich plötzlich die Arterie; reizt man den peripherisehen Stumpf des Nerven, so verengert sie sich. Sie kann nach Bedürfnis bis zum Fuß verfolgt werden (422). - Vergl. a. 710.

R. pluntaris profundus der $\Lambda$. tibialis posterior verläuft oherhalb der Sehne des M. flexor digitorum pedis longus und hildet unterhalb der Fußwurzel mit dem Ende der A. peronaea den Areus plantaris.

\section{Arcus plantaris.}

Aus demselben gehen die Aa. interossecie plantares 1-III hervor, welche an den vorderen Enden der Interstitia interossea mit den Aa. digitales plantares communes anastomosieren. Ein Ast der A. interossea III tritt durch das Interstitium interosseum vahe an dessen hinterem Ende und anastomosiert mit der A. peronaea.

\section{A. poplitea.}

A. poplitea verlauft zwischen den Mm. adductor magnus und biceps femoris, dann zwischen den Köpfen der Mn. gastrocnemii. Im oberen Teile der Kniekehle giebt sie von ihrer hinteren Wand die A. Saphena parra ab;

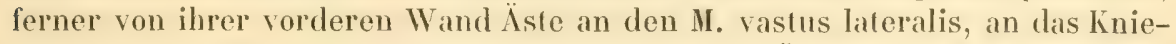
gelenk, namentlich die A. articularis genumediu und $\ddot{\Lambda}$ ste an die Mm. gastrocnemii, soleus und flexor digitorum pedis longus. Letzterer Ast reprasentiert die A. tibialis posterior des Menschen. Alsdanu durchbohrt die A. poplitea unterhalb der Condylen der Tibia das Ligamentum interosseum eruris und spaltet sich in die Aa. tibialis anterior und peronaea.

A. saphena parva verlauft rückwirts hinter dem Kopfe des M. gastrocnemius lateralis an die laterale Seite desselben, dann zwischen zwei Blattern der Fascia cruris eingeschlossen abwarts zur Haut der hinteren Seite des Unterschenkels.

A. tibialis anterior verläuft oberflachlich zwischen deu Mm. extensor digi- 
torum pedis longus und peronaeus longus, giebt Aste an die Muskeln der Vorderseite des Interschenkels, gelangt hinter den M. extensor digitorum pedis longus. Hinter dem Kopf desselben gieht sie die 1. libialis anterior recurrens al, verlauft hinter dem genamnten Muskel und dessen Sehme abwarts zum Fußrucken und heißt von hier an A. dorsalis pedis.

1. dorsalis pedis. Dieselbe greht dicht unterhalb des fußgelenkes an dessen Dorsalseite $\mathrm{A}$ ste an das Gelenk und die A. digitalis dorsulis tibulis digiti I ab und teilt sirh in die Lu. interossene melatursi dorsales I-III, welche die ubrigen Aa. digitales dorsales pedis tibiales und fibulares entsenden.

1. peronaen verdiuft im Interstitim interossemm cruris zwischen Tibia und libula, giebt die A. motritia tibrae ah, geht unterhall, des Lig. eruris dureh,

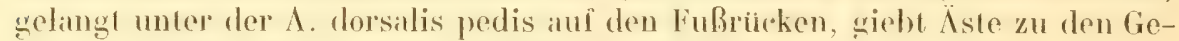
lenken, biegl sich dicht hinfer der Insertion der Sehme des M. peronaeus brevis und or $^{\circ}$ dem Ansilz der Sehne des M. peronaeus longus um den lateralen FuBrand in die FuBsohle und gieht die 1. digitulis plantaris fibularis di-

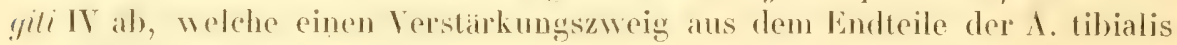
posterior erhiilt.

Unterbindung der A. nutritia tibiae. Die A, nutritia tibiae dringt in die Tibia nahe der Stelle, wo Tibia und Fibula verschmelzen, ungefihr in der Mitte der Linge des Unterschenhels. Man legt den Knochen mittels eines Längschnittes von $2 \mathrm{~cm}$ an dieser Stelle frei, bohrt eine feine Nadel in das Lumen der A, nutritia tibiae, welche abgekniffen wird. Nach 1-12 Wochen zeigen sich Knochenneubildungen in Folge der Nekrose (425).

\section{Venen des grofsen Kreislaufes.}

\section{Vena cava superior.}

\section{V. cava superior dextra.}

V. cava superior dextra mündet in die obere Wand des Atrium dextrum an deren rechter oberen Seite, steigt an der rechten Seite der Aorta adseendens und des Truncus anon!mus anfwarts, nimml die V. azggos auf, gedangt hinter der ersten Rippe und vor dem Lrsprung der A. mammaria interoa dextra in die obere Apertur des Thorax, wosellost sie die Vr. mammaria interna, interoostalis suprema. phrenica superior, thyreoidea inferior, jugularis externa und subclavia dextrae anfnimmt. Ihr oberes linde teilt sich in die beiden zuletzt genannten Venenstämme. Äste:

V. azygos mindet in die V. cara superior dextra, nahe deren oberem Eude, in der Hoihe des hinteren Endes der dritlen Rippe ror der $A$. intercostalis suprema dextra, hiegt sich ibher den fechten Bronchus in derselben Hobe nach hinten und steigt an der rechten Seite der Aorla descendens thorateica abwirts. Sie nimml die Vr. intereostales dexbrae V-XII, die sinistrae VII-XII auf, durchbohrt die Pars lumbalis des Diaphragma und setzt sich in der Bauchhöhle in die obere oder die beiden obersten Vv. lumbales fort. 
$V$. intercostalis suprema dextra mündet in die V.cava superior dextra etwas oberhalb der V. azygos. Sienimmt die Vv. interostales dextrae I-IV auf.

Varietä. Sie mündet in die V. azygos.

V. phrenica superior dextra verliaft vor der rechten Lungenwurzel, hinter dem rechten Ventrikel zur rechten Seite des Centrum tendineum des Diaphragma, nimmt Rr. pericardiaci und mediastinici anteriores auf, kommuniziert mit der $V$. phrenica inferior dextra.

$R r$. vertebrales dextri sind Venen, welche durch die Foramina intervertebralia dextra zwischen ersten, zweitem und drittem Ruckenwirbel in den Wirbelkanal eindringen.

\section{V. cava superior sinistra.}

V. cava superior sinistra mündet in die hintere Wand des rechten Atrium an deren linker Seite, links neben der Mündungsstelle der V. cava inferior. Verliuft an der hinteren Flache des rechten Atrium, dann in der Transversalfurche an der hinteren Fliche des Iterzeus zwischen linkem Ventrikel und linkem Atrium schriig nach links und aufwirts, wendet sich hinter dem linken Vorhof vor der V.pulmonalis sinistra mehr gerade nach oben, steigt hinter dem linken Vorhof und dem oberen Lappen der linken Lunge vor dem linken Ende des Arcus artae aufwirts. Sie nimmt successive die Vv. coronariate cordis, die Vv. phrenica superior, intercostalis suprema, thyreoidea inferior sinistrae auf. Dann gelangl sie hinter die erste Rippe linkerseits und nimmt an deren oberem Rande vor der A. subelavia sinistrat die Vv. mammaria interna, jugularis externa und subclasia sinistrae anf, indem ihr oberes Ende sich in die zuletzt genannten beiden starken Venenstämme teilt.

Entwickelungsgeschichte. Der horizontale Anfangsteil der V. cava sinistra bis zur Einmündung der V. coronaria magna entspricht den Sinus coronarius des Menschen (424).

\section{Äste der V. cava superior sinistra:}

I. coronaria cordis dextra s. parva mündet in den transversalen, im Sulcus atrioventricularis veraufenden Abschnitt der V. cava superior sinistra dicht neben deren Múndung in das Atrium dextrum.

$V$. coronaria cordis media neben der V. coronaria dextra.

V. posterior ventriculi cordis sinistri. Eine oder zwei schwache Venen.

$V$. coronaria cordis magna sive sinistra.

Vergl. über die Herzvenen 425 .

I. phenica superior sinistru verlauft vor der linken Lungentrurzel hinter dem linken Ventrikel zur linken Seite des Centrum teudineum des Diaphragma, nimmt Rr. pericardiaci und mediastinici anteriores auf, kommuniziert mit der V. phrenica inferior sinistra.

$R r$ vertebrales sinistri sind Venen, welche durch die Foramina intervertebralia sinistra zwischen erstem, zweitem und dritlem Riickenwirhel in den Wirbelkamal eintreten. 
$V$. intercostalis suprema sinistra mündet in das obere Ende der V. cava superior sinistra. Sie nimmt die Vr. intercostales sinistrae I-VI auf.

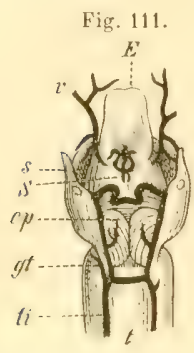

Kehlkopf von hinten. mit injizierten Venen. Nach Schneider (250). E Epiglottis. v vordere Venen des Kehlkopfes, die sich in die $V_{v}$. lingualis und facialis anterior ergießen, s Cornu superius der Cartilago thyreoidea. S Cartilago Santoriniana. $c p$ M. prico-arytaenoideus posticus. gt Venen, aus der Gl. thyreoidea kommend. $t i \mathrm{~V}$. thyreoidea inferior. $t$ Trachea.

Entwickelungsgeschichte. Sie repräsentiert den oberen Teil der V. cardinalis sinistra (426).

Die Vv. intercostales dextrae und sinistrae I - XII verlaufen unter dem entsprechenden unteren Rippenrande oberhalb ihrer zugehörigen Aa. intercostales.

\section{Kleinere Äste der Vr, cavae superiores:}

V. mammaria interna mündet in die V. cava superior, verlauft an der lateralen Seite der A. mammaria interna.

Unterbindung der V. mammaria interna s. Unterbindung der A. mammaria interna (S. 255).

I. thymeoiden imferior s. thyreoidea (Fig. 111 li) senkt sich in die $V$. cava superior, verlauft an der lateralen Seite der Trachea, die sinistra auch vor dem Oesophagus.

\section{V. jugularis interna.}

V. jugularis interna (Fig. 103 15, S. 249. - Fig. 14633, S. 329) ist schwach entwichelt, mündet in die Zusammenflußstelle der Vr. jugularis externa und subchavia, verliuft an der lateralen Seite und hinter der A. carotis communis, sowie lateralwirts vom N. vagus, nimmt Vr. thyrevideae superiores, ferner die $V$. lingualis und $\overparen{A}$ ste aus den tiefen IIalsmuskeln auf. Sie kommuniziert mittels der letzteren mit der V. rertebralis ihrer Seite, sowie auch mit der V. rertebralis mediana. An ihrem oberen Ende gelangt sie in den hinteren Teil des Foramen jugulare hinter den Nn. vagus und accessorius und nimmt den Sinus transversus auf.

Unterbindung der $\mathrm{V}$. jugularis interna s. Neurologie, Durchschneidung des N. lagus. Ausgeführt wurde diese Operation zuerst von Kußmaul und Tenner (427).

simus transiersus (Fig. $112 \mathrm{~S} t \boldsymbol{\text { ) }}$ ) beginnt im Foramen jugulare, lauft aufwirts im Sulcus transversus der Pars mastoidea oss. temporum, hinter der Hemisphare des kleinen Gehirnes und oberhalb der Fossa mastoidea oss. temporum, dann sich umbiegend, fast horizontal medianwirts ror der genannten Henisphiare und endigt im Confluens sinum unter der Spitze des Os interparietale. Das obere Ende des aufsteigenden Teiles nimmt den simus petrosus auf, welcher im Sulcus pelrosus posterior (superior) oss. temporum nach vorn verlauft, und kommuniziert durch ein Emissarium temporale mil der V. temporalis superficialis (s. letztere S. 274).

Sinus longitudinalis anterior (Fig. 112 Sla) ist unpaar, mundet in den Confluens sinum, verliuft in der Medianlinie unterhalb) der Sutura sagiltalis nach vorn, teilt sich an seinem vorderen Ende in zwei Iste. welche jederseits 
die hinteren Enden der Lobi olfactorii cerebri an ihrer Abschnürungsstelle von den Stirnlappen des großen Gehirnes umfassen.

Sinus longitudinalis posterior (Fig. $112 \mathrm{Sl} / \mathrm{p}$ ) ist parig, mündet hinten in das hintere Ende des horizontalen Teiles des Sinus transversus, läuft vorwärts auf der oberen Fläche des Vermis superior cerebelli, mündet nach vorn in den Confluens sinuum.

Confluens sinum s. Sinus confluens (Fig. 112Sc). Der venöse Hohlraum, in welchem die beiden Sinus transversi, der Sinus longitudinalis anterior, die Sinus longitudinales posteriores und die V. cerebri magna zusammentreffen, heißt Confluens sinuum und liegt unter dem vorderen Ende des Os interparietale.

I. cerebri magna (Fig. $73 \mathrm{Vc}, \mathrm{S} .185$ ) mündet in den Confluens sinumm, verliuft am unteren Rande der Falx cerebri und in der Furche zwischen den Colliculi anteriores der Eminentia quadrigemina nach vorn, gelangt in den dritten Ventrikel.

$V$. collateralis cerebri. Eine starke, ganz konstante Vene, welche an der Spitze der Unterflache des Stirnlappens entspringt, an der letzteren und der Unterfliche des Schlafelappens nach hinten verlauft, beide ungefahr der Lainge nach halbierend. Ungefahr ihr mittlerer Teil passiert in sagittaler Richtung die Fossa Sylvii. Hinten biegt sie sich uber die hintere Flache des Schlafelappens nach oben und seukt sich in eine an der lateralen Seite des Schlafelappens verlaufende $\mathrm{V}$. cerebralis inferior oder in den Confluens sinumm.

Simus cavemosus steht mit den Sinus transversi in Verbindung, umgiebt, ringförmig die Sella oss. sphenoidei posterioris, erstreckt sich unterhall der Hypophysis cerebri, kommuniziert durch das Foramen cavernosum mit der V. vertebralis mediana. Nimmt an seinem vorderen Ende die V. ophthalmica superior auf.

Y. ophthalmica superior bildet einen kurzen, dicken Stamm an der oberen Wand des hinteren Winkels der Augenhöhle.

\section{V. jugularis externa.}

V. jugularis externa (Fig. 103, 34, S. 249) ist stark entwickelt, verläuft am Halse ganz oberflichlich, ron der Haut und dem M. platysma bedeckt und von zwei Blattern der Fascia cervicalis eingeschlossen, vor dem M. sternomastoideus und am medialen Rande desselben. Sie teilt sich in der Höhe der Cartilago cricoidea in die Vv. faciales anterior und posterior. An ihrem unteren Ende nimmt sie die Vv. thymica und transversa scapulae auf; eine von beiden $V_{r}$. jugulares externae auch die $V$. vertebralis mediana. Beide Vv. jugulares externae stehen untereinander durch eiven querlaufenden Kommunikationsast: $\mathbf{V}$. jugularis transversa (Fig. 103, 30, S. 249, an ihrem unte- 
ren Endteile in Verbindung. Die letatere verliuft etwas oberhalb des oberen Randes des Sternum vor den $\mathbf{M m}$. sternohyoidei.

Die V. jugularis externa zeigt einen mit der Diastole der Herzventrikel synchronischen, sog. negativen Puls. Die Welle ist anadikrot und katamonohrot. Der erstere aufsteigende Teil entspricht der Ventrikeldiastole und Vorhofsystole, der absteigende oder katakrote Schenkel der Ventrikelsystole (847).

Varietät. Ls ist eine V.colli mediana vorhanden, welche am unteren Drittteil des Halses in die $\mathrm{V}$. jugularis externa sinistra mündet, nahe der Medianlinie subkutan aufwirts steigt und an linken Rande der Trachea bis zur Haul vor dem Kehlkopf gelangt.

Die Vv. faciales anterior und posterior vereinigen sich auf einer oder auf beiden Seiten erst in der Mitte der Länge des Ilalses.

Unterbindung der $\mathrm{Y}$. jugularis externa. Der Kopf des Tieres wird von einem Gehilfen stark nach oben gewendeb oder durch rine un die großen schneidezalnne des (bherkiefers gelegte Sohlinge fiviert, so daß die Scheifelgegend das Brett berïhrt, auf welchem das Tier befestigt ist. Hautschnitt in der Medianlinie des Halses (Fig. 113), unterhalb der Cartilago thyreoidea beginnend, $2-3 \mathrm{~cm}$ lang. Die Haut wird nach rechts, resp. nach links verschoben und etwas aufgehoben, bis lateralwïrts die bliuuliche, dicke $V$. jugularis externa dextra resp. sinistra zum Vorschein kommt. Sie läßt sich leicht isolieren.

\section{Ïste der V. jugularis externa:}

T. facialis anterior verliuft, vom M. platysma bedeckt, unterhalb der Gl. submaxillaris und am unferen Rande der fil. parotis schridg anfwirts und nach rom, teilt sich am vorderen Rande des M. masseter, am unteren Insertionspunkte desselben um den Rand der Maxilla inferior sich hiegend, in die Ir. maxillares externa und interna.

Fig. 113.

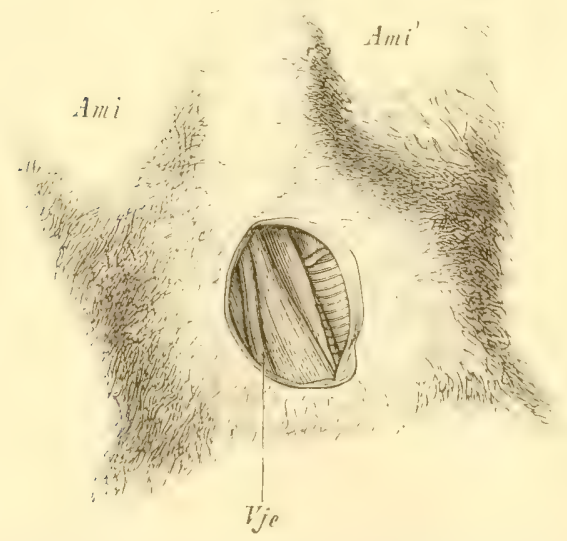

Rechte Seite des Halses, die durchschnittene Fascia cervicalis ist am medialen Rande des Hautschnittes sichtbar. Neben der Medianlinie erscheint die Trachea und Cartilago cricoidea. $v j e V$. jugularis externa. A $m i, A m i^{\prime}$ Anguli maxillae inferioris.

V. maxillaris externa. (Fig. 103 41, S. 249) begleitet die A. maxillaris an deren hinterer Seite in der Furche vor dem vorderen Rande des M. masseter (Fig. 114, S. 273), nimmt die $V$. orbitalis inferior, weiter nach vorn die $V_{V}$. coronariae labii inferioris und superioris auf; geht lateralwairts vom M. levator labii superioris und dem $\mathrm{N}$. facialis aufwarts und endigt als $V$. angularis am vorderen Augenwinkel.

V. angularis (Fig. 114) verliuft an vorderen Augenhöhlenrande aufsteigend lateralwirts, am vorderen Ende des Processus zygomaticus oss. frontis, geht durch das Fo- 
ramen supraorbitale anterius in die Augenhiohle, nimmt Venen aus dem oberen Teile derselben auf.

$V$. coronaria labii inferioris verläuft am unteren Rande des M. buccinator zur Unterlippe.

$V$. coronaria labii superioris verläuft am oberen Rande des M. buccinator, oberhall, des X. farcialis, unterhall, des X. infrarbitalis zur Oberlippe.

$V$. orbitalis inferior mündet in die V. maxillaris externa am unteren Teile des II. masseter, liuft am vorderen Rande dessellen, zwischen letzterem und dem M. pterygoideus internus aufwarts, kommuniziert durch das Foramen mandibulare maxilae inferioris mit der $\mathrm{V}$. alveolaris inferior (S. 64), gelangt in das Gavum orbitale, zwischen die Glandulae infraorbitalis und Harderiana, aus dem rorderen und unteren Teile des Carum orbitale das Blut zuriickleitend.

$V$. maxillaris interna mundet in die $V$. facialis anterior, steigt zwischen M. mandibulae und der Maxilla inferior, damn zwischen dem M. pteryogoideus internus und dem kamus maxillate inferioris aufwirts, nimmt die $I$. sublingualis, sowie die r. alceolaris inferior aus dem Canalis maxillaris auf,

Fig. 114

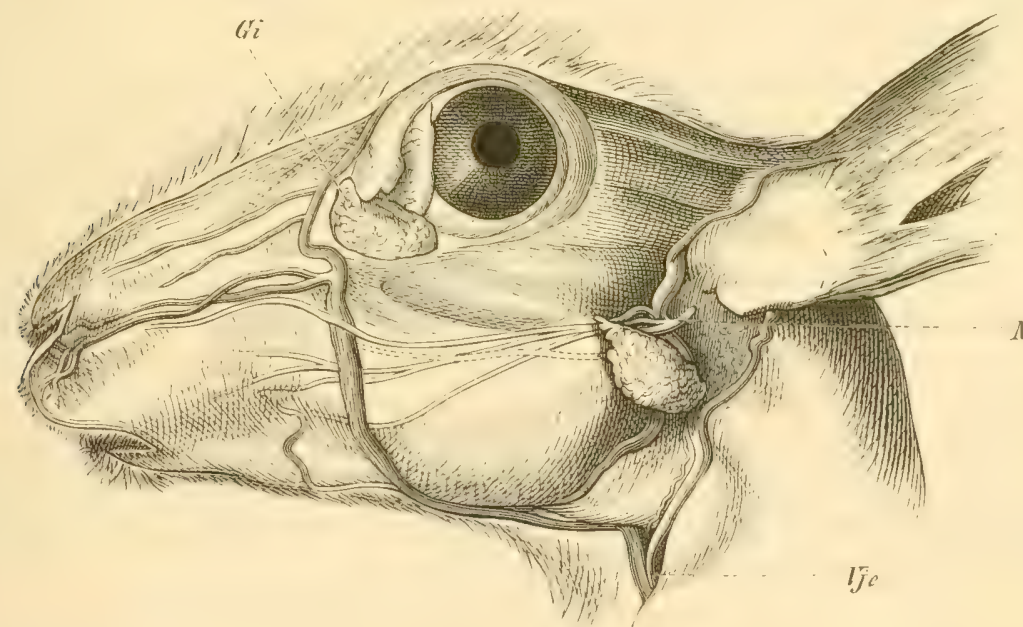

Nf N. facialis, $G i$ Gl. infraorbitalis. V je V. jugularis externa, injiziert. Sie teilt sich an ihrem oberen Ende in die Vy, faciales anterior und posterior. Erstere setzt sich in die $\mathrm{V}$. masillaris externa fort, welche die $\mathrm{Vr}$ coronariae labii inferioris und superioris a ufnimmt und als $V$. angularis endigt. Die $V$. facialis posterior nimmt coralb des zurückgeschlagenen oberen Teiles der Gl. parotis die V. auricularis posterior auf und dicht oberhalb des N. facialis die schwache V. transversa faciei. (s. Fig. 55, S. 205.)

geht durch das Foramen pterygoideum anterius in der Wroel des Processus pterygoideus oss. sphenoidei posterioris nit der A.maxillaris interua und geht in die V.ophthalmica inferior über. Die Venenplexus der unteren Muschel sind stark entwickelt; unter dem Septum cartilagineum narium verlauft eine unpaare $V$. septi narium mediana.

V. submentalis mediana (Fig. 103, 42, S. 249) ist unpaar, mündet in die 
rechte oder linke $\mathrm{V}$. facialis anterior, verliuft in der Medianlinie unter dem Rande des M. mandibulae, nur von der Haut bedeckt.

$V$. facialis posterior (Fig. 103, 37, S. 249) geht durch die GI. parotis, von ihren Lappehen lateralwirts bedeckt, hinter den Angulus maxillae inferioris, verliuft hinter dem Ramms maxillae inferioris, nimmt Fig. 114. S. 273) die Vr.auricularis posterior und transrersil faciei auf. welche letatere nur schwath entwickelt ist, und teilt sich, lateralwirts bedeckt rom M. parotideo-iluricularis posticus, in die Vv. temporalis superficialis und ophthalmica externa.

Varietat. Die V. facialis posterior teilt sich in die Vv. temporalis superficialis und auricularis anterior, nimmt weiter abwärts die V. auricularis posterior auf. Die V. ophthalmica externa senkt sich in die V. temporalis superficialis.

V. auricularis posterior mündet in die V. facialis posterior, steigt hinter dem Ohrknorpel aulwarts, gelangt an dessen mediale Fliche und teilt sich in einen R. anterior und posterior. Der R. anterior ist die stärkste Ohrvene, verliuft in der Mitte der medialen Fitche des Ohrknorpels, begleitet die A. auricularis an ihrer hinteren Seite, kommuniziert nahe dem oberen Ende des Ohrknorpels bogenförmig mit dem R. posterior und der V. auricularis anterior. Der $R$. posterior ist eine starke, nahe dem hinteren Rande des Ohrhnorpels verlanfende Vene, welche die entsprechende Arterie ebenfalls an deren hinterer Seite begleitet.

V. temporalis superficialis verlatuft zwischen Meatus auditorius externus osseus und dem hinteren Ende des Processus temporalis oss. zygomatici, dicht an Knochen, wendet sich oberhally des Meatus auditorius exteruus osseus umbiegrend nach hinteu, nimmt re. temporales profundate ans der Substanz des M. temporalis und die V. amicularis anterior auf, von welcher sie durch den M. maxillo-aturicularis getrennt wird, und kommuniziert mit dem Sinus transversus durch ein das Os temporum in schriger Richtung durchlohrendes, vor dem Meatus auditorius externus osseus gelegenes Emissarium temporale (S. 85).

Entwickelungsgeschichte. Das Emissarium temporale oder Foramen jugulare spurium Rathhe bildet in früherer fötalzeit den llauptabzugskanal für das Blut aus dem Innern des Schädels. Nls Varietiit beim Menschen svurde dasselbe von Otto (428) beschrieben.

$V$. auricularis anterior verlauft an der medialen, hinteren Seite der A. auricularis anterior, kommuniziert am oberen Rande der Ohrmuschel bogenförmig mit der $\mathrm{V}$. auricularis posterior.

Abbildung der Ohrvenen s. /53. Man kann sie, wie die Arterien, auch am lebenden Ohr studieren.

V. ophthalmica externa verlauft vorwäts und aufwärts am oberen Rande des hinferen Endes des Processus temporalis oss. zyonomatici und am hinferen Rande des breiten Teiles des l'rocessus zygomaticus oss. temporum, hinfer und unterhalh der Gl. lacrymalis. Sie gelangl damn, medianwirts von dem ligw. supraorbitale duroh das Foramen zygomatico-orbitale nnterhall, des M. auricularis profundus anticus in die Augenhohle. erstreckt sich 
medianwirts an deren hinferer $\mathbb{W}$ and und nimml Blut aus dem M. rectus oculi posticus etc. auf.

V. vertebralis mediana ist unpaar, mündet in das untere Ende der V. jugularis externa dextra oder sinistra, liuft in der Medianlinie des Italses zwischen den Mn. Longi rolli, dann zwischen deren schrögen Anstilzen an das Tuberoulum anterius des Atlas und vor demselhen anfw irts. Kommunizicrt mit den Vr. vertebrates dextra und sinistra, sowie dem oberen Ende der V. jugularis interna unterhall, des Foramen lacerum, gelangl damm an die Vorderfliche der Pars basilaris oss. oceipilis, sowie des Corpus oss. splunoidei posterioris hinter der Rathenstheimhaut nateh rorn, sendet einen $\Lambda$ st durch das foramen cavernosum oss. sphenoidei posterioris zum Sinus cal (r)osus und feilt sich iu die Vv. septi narium dextra und sinistra.

$V$. septi narium verläuft an der lateralen Seite des Vomer, ist stark entwickelt.

V. transversa scapulae (Fig. 103, 33, S. 249) mündet in das untere Ende der V. jugularis externat, geht durch den Plexus bradhalis riokwirls in die Fossa supraspinata.

\section{V. subclavia.}

V. subclaria mündet mit der V.jugularis externa zusammen in den Anfang rler V. cava superior hinter der Insertion des .r. sternomastoideus. Verliuft lateralwarts zum Arm hiuter dem Irsprunge des M. pereloralis superficialis, der Clavioula und dem Il. pectoralis minor, for dem gemeinschaftlichen Bindel der No. cervicalis VIII und dorsalis I Fig. 107, S. 2:34) und geht vor der ersten Rippe in die $\mathrm{V}$. axillaris über.

\section{Äste der V. subclavia:}

Vv. mammariae externae. Eine oder zwei Venen, die beim Weibchen zu der obersten Mamma gehen. indem sie hinter dem M. pectoralis major ans der A.hselhöhle hervortreten. Dieselhen amastomosieren mil der V. ahdominalis (s. V. iliaca externa, S. 279).

Varietä. In eine V. mammaria externa mündet die V. basilica, welche außerhalb der Fascia brachialis und antibrachii zur Haut der unaren Seite des Ober- und Vorderarmes gelangt und sich bis zur IIand erstreckt.

V. axillar is verläuft im unteren Teile der Achselhöhle nach unten, be-

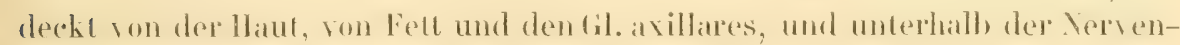
stamme des Plexus brachialis.

\section{ïste der V. axillaris:}

$V$. cephalica mundet in die V. circumflexa scapulae, einen Ast der $V$. subscapularis, gelangt zwischen den Mm. infraspinatus und teres major, damn am lateralen hamde der Insertion des M. defoideus zwischen letzterem und dem M. anconaeus longus, sowie dem M. teres major unter die Faseia brathialis, verlauft an der Vorderseite des Oberarmes, bon zwei Blaittern der Faszie cingeschlossen, abwits, ehenso an der radialen hante der Streckseite des Torderarmes vor den Mm. extensores radiales, dann zwischen den unteren Enden des Radius und der L'lna zur Dor'saltliache der Hand, nimmt die Vr. interosseae metacarpi dorsales I-IV auf. 
Die V. cephalica wird am oberen Teile des Oberarmes vom N. perforans brachii, am unteren Dritteil des Oherarmes und am Vorderarm von den drei Ästen des $\mathrm{R}$. superficialis des $\mathrm{N}$. radialis begleitet.

1. Wrachiulis ist einfach vorhanden, verlauft an der hinteren medialen Seite der A. brachialis.

$V$. basilica ist schwach entwickelt, mündet in die $\mathbf{V}$. brachialis an der medialen Seite des M. gleno-ulnaris, medianwarts rom Ansatz der Sehne des II. pectoralis major an den Ilumerus die Fascia brachialis durchbohrend: verliuft an der medialen Seite des Oberarmes unter der Haut, zwischen zwei Blitter der Fascia brachialis eingeschlossen abwäts, nimmt am Oberarm, sowie unterhall, der Ellenbogengrube von der ulnaren Seite des Vorderarmes kleine Hautvenen auf.

\section{Vena cava inferior.}

V. c ava inferior mündef von unten her in die hintere Wand des Atrium dextrum an deren unterem Rande, ungefihl in der Höhe des vierten Rückenwirbels, rerliuft in der Brusthöle abwirts zwischen den beiden unteren Lappen dex rechten Lunge und an der rechten seite des Oesophagus. Dieser Brustteil der $\mathbf{T}$. cava inferior hat ungefihr $3 \mathrm{~cm}$ Lange. In der Höhe des achten Ruckenwirbels tritl sie durch das Foramen venae cavae des Diaphragma, nimmt die Vr. hepaticae auf, liegt anfangs zwischen den Lobi caudatus und dexter hepatis an deren Verwachsumgsstelle und in die Lebersubstanz eingewraben, dimn an der rechten Seite der Aorta descendens abdominalis in der Höhe des zweiten Leudenwirbels, ror den Lirsprüngen der Aa. renales, vor der rechten Vehemmiere. Alsdann verlauft sie an der rechten Seite der Aorta descendens abdominalis, gelangt hinter deren unterem Ende zwischen die Aa. iliage communes und uimmt etwas oberhalb des Promontorium die Vr. iliacae externate und die V. iliaca interna commmnis auf. Die Vr. iliacae communes fehlen.

\section{Äste der V. cara inferior:}

Vv. hepaticae s. S. 281 .

Tv. phrenicae inferiores bilden einen Kranz an jeder Seite um das Centrum tendineum des Diaphragma, welcher radiar verlaufende Äste aussendet; sie senken sich in die $\mathrm{T}$. cava inferior unmittelbar unter ihrer burchtrittsstelle durch das Foramen venae cavae.

Iv. renales. Die dextra ist kürzer als die sinistra; erstere verläuft horizontal lateralwirts, letztere schriis absteigend; beide oberhalb der entsprechenden A. renalis (Fig. 108, S. 261).

V a rietiat. In die dextra mündet an ihrer Eintrittsstelle in die rechte Niere eine aus der V. cava inferior etwas weiter aufwärts herkommende V. aberrans, welche die A. renalis von vorn her bedeckt (s. Unterbindung der A. renalis, S. 261). Diese Varietät scheint nicht ganz selten zu sein, da Meißner nach mündlicher Mitteilung dieselbe ebenfalls beobachtet hat.

In die dextra ergießt sich die $\boldsymbol{V}$. ureterica superior dextra, welche an der medialen Seite des rechten Ureters verlïuft und mit der $Y$. spermatica interna dextra kommuniziert. In die sinistra mündet die sich analog der dextra verhaltende $\mathrm{F}$. ureterica superior sinistra am lateralen Ende derselben. 
In die sinistra mindet die V. lumbalis I sinistra. Zugleich ist (bei einem Weibchen) eine starke V. lumbalis adscendens sinistra vorhanden; sie mündet in den unteren Vereinigungswinkel der Vv. cava inferior und renalis sinistra, verlïuft an der vorderen linken Wand der Aorta descendens abdominalis vor dem M. psoas minor, wendet sich in der Höhe des siebenten Lendenwirbels vor den Mm. psoas minor und major lateralwirts und abwirts zum M. iliacus, atus dessen Substanz sie Äste aufnimmt. Ebenso erhält sie Zweige aus den Mm. psoas major und minor.

Unterbindung der $\boldsymbol{V}$. renalis $\mathrm{s}$. Unterbindung der A. renalis (S. 261). Man benutzt die sinistra, um eine Anschwellung der Niere auf ihr doppeltes Volumen binnen 24 Stunden und Albuminurie hervorzurufen.

$V v$. suprarenales. Die dextra müdet in die V. cava inferior; mitunter zusammen mit der V. lumbalis I dextra. Die sinistra in die linke Wand der V. cava inferior, oberhalb der V. renalis sinistra oder in letztere selbst.

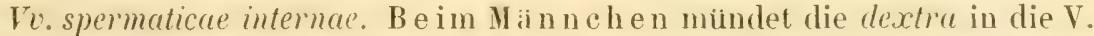
cava inferior in der Höhe des sechsten Lendenvirbels, verliuft in Begleitung der A. spermatica (interna) am medialen Rande des M. psoas minor und vor der V. cava inferior ahwäts. Ihr oberes Ende liegt vor dem rechten Ureter, welchen sie in schriger Richtung kreuzt. Sie verlaiuft am medialeu Raude des II. psoas minor dexter und vor der $\mathrm{V}$. cava inferior abwarts, ein wenig lateralwäls und vorwarts, und ror dem M. psoas major zum rechten Iloden.

Die sinistra verläuft von ihrer Eimmindungsstelle in den Wiukel, den die Mündung der V. renalis sinistra in die V. cava inferior bildet, schrig lateralwäts und abwärts, vor der forta abdominalis und den linken hand derselben von vorn her bedeckend, gelangt dann an die mediale Seite der $A$. spermatica sinistra; kreuzt, mit derselben verlaufend, etwas unterhalb der Teilungsstelle der Aorta abdominalis den linken Ereter und geht vor demselben vorbei zum linken Hoden.

Beim Weibche n munden die Vv. spermaticae internae in die V. cava inferior, elwas unterhall, der Ursprungsstellen der Aa. spermaticae aus der Aorta abdominalis, die dextra in derselben Hohe wie beim Mannchen; verlatlfen lateralwirts mit den Aa. spermaticae vor den $\mathbf{M m}$. psoas major und minor zum Ovarium und den Tubae Falloppiae.

Vv. lumbales $I-V I$ verlaufen am oberen Rande der entsprechenden Aa. lumbales.

Sinusartige anastomosierende Kanäle, die zwischen Knochen und fibröser Auskleidung des Wirbelkanales verlaufen, sammeln das venöse Blut an der Basis der Wirbelbogen und gehen (an der Lendenwirbelsiule) zwischen je zwei Wirbeln in weite dünnwandige Blutsiicke über, die an den Vervenwurzeln von der Seite her das Mark überlagern (429).

\section{V. iliaca interna communis.}

V. iliaca interna communis. Ein kurzer, in der Medianlinie verlaufender Stamm, welcher in das Ende der V. cava inferior mindet, vor dem Promontorium abwarts steigt und die Vv. iliacae internae dextra und sinistra aufnimmt.

Varietät. Sie nimmt an ihrem unteren Ende die V. sacralis media auf. 


\section{V. iliaca interna.}

V. iliaca interna verläuft an der medialen Seite der A. iliaca interna, nimmt die Vr. uterina, obturatoria, ischiadica, sarralis media und haemorhoidalis externa auf.

\section{Åste der V. iliaen interua:}

Y. sacralis media ist unpaar, mindet in die rechte oder in die linke $\mathrm{V}$. iliaca interna, verläuft hinter der A. sacralis media.

Varietät. Es sind zwei Vv. sacrales mediae vorhanden, welche die A. sitcralis mediat an deren linker und rechter Seite begleiten. Eine derselben mündet in die $\mathrm{V}$. iliaca interna communis (S. 277).

$V$. hacmorhoidalis externa verlauft beim IVeibchen an der lateralen AuBenfliche des Reklum. Sie nimml Venen aus dem Plexus raginalis renosus auf, welcher hinter dem Arcus pubis gelegen ist.

V. obturatoria ist sehr klein, verlauft an der medialen Seite der A. obturatoria.

$V$. ischiadica verläuft an der medialen Seite der A. ischiadica, gelangt beim Austrilt aus dem Borken unterhalb des 11 . priformis an die mediale Seite des I. ischiadiens und hinter die $\Lambda$. isthiadica. Sie nimmt die Vy. sacralis bateralis und pulendit interna anf, fermere eine Ilautvene, welche mit dem korrespondierenden R. cutaueus der $A$. ischiadical S. 264) aufwiirts verläuft und in weitem Bogen mit der $V$. iliolumbalis anastomosiert.

In die $V$. pudenda interna müdet die $V$. dorsalis penis resp. clitoridis, kommuniziert jedoch dureh einen starken, in der Leistengegend subkutan verlanfenden $A$ st mit der V. epigastrica inferior. Sie rerliult an der lateralen Seite der Arterie, ist parig vorhanden und wesentlich Hautvene.

Die Inaplfortsetzung der V. ischiarlical kommt der V. cruralis an Starke gleich, erstreckt sich hinter dem Tuber ischii und den kiopfen des M. biceps femoris unter die Fascia lata, alsdamn am hinteren Raude des M. biceps lemoris dicht unter der laszie zum Interschenhel. Emas unterhall der huiekehle anastomosiert sie mil der $\mathrm{V}$. Saphena parva, gelangt an die laterale Seite des Lutersehenkels or die Mm. peronatei und reroinft als $\mathbf{r}$. tibialis anterior hinter dem N. peronaeus und fibularwarts von der Sehne des M. extensor digritorum pedis lomens. Sir gedamel am oberen binde der Sehne des lebteren an deren libulare seite, geht fibularwirls neben dem Ligamentum cruris zur IIant des fuBritckens und der Dorsalseite der \%ehen. Die V. ischiadica ist mithin der $\mathrm{V}$. cephalica homolog.

Varietät. Die V. tibialis anterior verläuft an der Sehne des M. extensor digitorum pedis longus und mit derselben hinter dem Ligamentum cruris. - Die $V$. ischiadica nimmt an der Wade eine $V$. saphena parva accessoria auf, welche ziemlich parallel, weiter medianwïts und fibularwärts als die eigentliche V. saphena parva verliuft. - Es ist eine V. aberrans vorhanden, welche oberhalb der Knichehle in die V. ischiadica mündet, schräg abwirts mol medianwärts läuft, ziemlich die Mittellinie der Wade einhaltend, und sich am unteren Dritteil des Unterschenkels in die $\mathrm{V}$. saphena magna einsenkt. 


\section{Äste der V. ischiadiea :}

I. sacralis lateralis rerlauft an dem lateralen Rande der Dorsalflache des Schwanzes.

\section{V. iliaca externa.}

$V$. iliaca externa verläuft beiderseits an der medialen und hinteren Seite der Aa. iliacae externae.

\section{Äste der V. iliaca externa:}

$V$. iliolumbulis verliuft an der oberen Seite der A. iliolumbalis; ebenso die Vene, die den unteren Ast derselben begleitet; diejenige. welche mit dem oberen Ast sich fortsetzt, liegt an dessen medialer Seite.

$V$. vesicalis superior mủndet in die V. iliaca externa, verläuft an der medialen Seite der $A$. resicalis superior, nimmt die $V$. ureterica inferior auf. Beim Minnchen erhalt sie außerden die I'. deferentialis; beim Weibehen ist ein gemeinschaftlicher starker Stamm für die $V$. vesicalis superior umd $r$. uterina vorhanden, der in die V. iliaca externa mundet; die Verzweigumg der V. uterina verhält sich ganz wie diejenige der Arterie.

I. epigastrica inferior rerliuft an der medialen Seite der A. epigastrica inferior, nimml die I. spermatica externa auf. Außerdem eine starke V. abdominalis, welche aus dem Leistenringe hervortritt, einen Kommunikationsast zur V. dorsalis penis resp. clitoridis anfummt, damn in der Fascia abdominis aufwäts steigt, beim Weibehen simlliche Mammae durchsetzend und İste aus denselben aufnehmend. Ihr oberes Ende greht mehrfache Verbindungen mit den Vv. mammariae externae (s. V. subclavia, S. 275) ein.

Entwickelungsgeschichte. Der untere Teil der V. abdominalis ist wahrscheinlich ein Rest der fötalen Bauchvene (s. 450).

V. cruralis verläuft rom Annulus cruralis ab an der medialen Seite der A. cruralis, gelangt in der llitle des Obersehenkels hinter der $\Lambda$. articularis genu superficialis ror die A. cruralis. und tritt ror derselben dureh den M. adductor magnus.

Unterbindung der V.cruralis. Siehe Unterbindung der A. cruralis, S. 265. Wenn man Flüssigkeiten in wrößerer Entfernung rom Herzen in eine Vene injizieren will, so benutzt man die V. cruralis, statt der V. jugularis externa.

Abtrennung der unteren Extremität bis auf die $\Lambda$. und V. crurales läßt die Ernährungsvorgänge anfangs ungeändert (451).

\section{Äste der V. cruralis:}

I. profundu femoris rerlauft an der medialen hinteren Seite der A. profunda femoris.

V. rircumflexa abdominis rerliuft in der Weichengegend subkutan lateralwärts und aufwärts zur Spina anterior superior oss. ilium.

Varietait. Sie nimmt bald nach ihrem Ursprunge eine $V$. epigastrica superficialis auf, "rekhe senkrecht aufwïts steigt, lateralwiirts in ciniger Entfernung von der Medianlinie sich verästelt und mit der V. abdominalis kommuniziert.

$V$. articularis genu superficialis. 
V. suphena magna mindet an der Grenze des mittleren und unteren Drittteiles des Oberschenkels in die V. cruralis, verliuft abwarts vor der A. saphena magna au der medialen Seite des M. gastrocnemius medialis, parallel mit einer

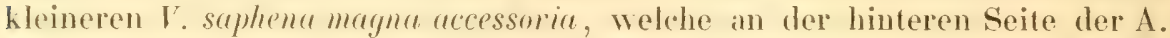
saphena magna sich erstreckt. Dann gelangt die V. saphena magna als V. tibialis posterior an der hinteren Seite dep A. tibialis posterior hinter der Sehne des M. extensor digili I proprius und vor der Sehne des M. flexor digitorum pedis lougus zur IIaut der Fußsohle. In der Wadengegend kommuniziert sie durch einen schräg verlaufenden Ast mit der V. saphena parva.

r. poplitea verdauft in der Kniekehle, an der vorderen Seite der A, poplilea, nimmt die I. saphena parta auf, welche zwischen dem M. tensor fasciae rruris und dem 11 . gastrocnemius lateralis hinter letzterem Muskel abwärts zur Haut der Wade sich erstreckt.

Letatere Vene verlauft an del lateralen Seite des 11 . gastrocnemius lateralis, auBerhalb der Fascia cruralis, dann weiter tibialwarts als die V. ischiadica und fibularwirts ueben dem Tendo Achillis nach abwirts bis zur Gegend des Malleolus Iateralis. In der Mitte des Unterschenkels kreuzt sie sich mit der $\mathrm{V}$. ischiadica und kommuniziert mit derselben.

\section{Vena portarum.}

V. portarum verläuft im Lig. hepatoduodenale, hinter der A. hepatica und dem Ductus choledochus, entsteht aus dem Zusammenfluß der Vr. mesen-

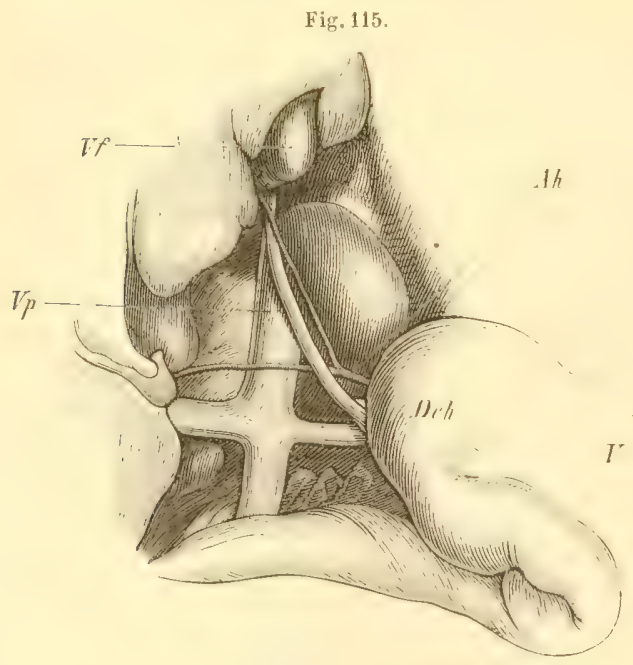

$V p$ V. portarum. Dch Ductus choledochus. V Magen. Vf Gallenblase, in die Lebersubstanz teilweise eingebettet. $A h \Lambda$. hepitica, sish in ton R. dexter, weleher nelen dem Inutus choledochus verläuft, und den $R$. sinister teilend. Die $V$. portarum hinter den letzteren verlaufend mit ihren Ästen. Die Leber ist nach oben geschlagen.

einen Ast der Pfortader isoliert unterbinden (730 u. 755). terica superior und coronaria ventriculi superior, nimmt an ihrem oberen Ende eine $V$. pylorica auf, teilt sich in einen kiurzeren $R$. dexter und einen längeren $R$. sinister, welche in der Leber sich verasteln.

Die V. portarum besitzt inwendig eine Spiralklappe $(821)$.

Unterbindung der $V$. portarum. Hautschnitt in der Medianlinie, am Processus xiphoideus beginnend bis zun Nabelgegend. Der Pylorus wird stark nach abwärts, vorn und lateralwärts, die Leber in die Höhe gezogen (Fig. 115). Vor der V. portarum verlaufen die A. bepatica und der Ductus choledochus. - Man kanı auch 
I. coronaria ventriculi superior nimmt hinter des kleinen Kurvatur des Magens die $r$. lienalis auf, welche, entsprechend der geringen Größe der Milz, nur schwach entwickelt ist.

1. mesenterica superior verliaft, die $\Lambda$. mesenterica superior begleitend, anfangs senkrecht in fortgesetzter Richtung der V. portarum abwäts, dann nach links, dann wieder nach unten. Sie nimmt die Venen des Dünndarmes und Dickdarmes, sowie die V. mesenterica inferior auf.

$V$. mesenterica inferior mündet in die V. mesenterica superior in der Iöhe der Ursprungsstelle der A. colica media, indem sie sich oberhalb der letzteren nach links wendet, verliuft dann in der Wurzel des Iesocolon descendens absteigend; hegleitet in ihrem unteren Teile die A. mesenterica inferior. - Vergl. $45 \%$.

\section{Vv. hepaticae.}

Meistens sind fünf rorhanden: zwei slirkere aus dem Lobus hepatis sinister und dem Lobulus dexter anterior, welche in die vordere Wand der $V$. cava inferior im Foramen venae cavae des Diaphragma einmünden; drei kleinere aus den ibbrigen Leberlappen seuken sich in die rechte Seite der $\mathrm{V}$. cava inferior weiter abwärts, innerhalb der Leber.

V a rietät. Die Vv, phrenicae inferiores münden in die oberen-Vv. hepaticae.

\section{Arterien und Venen des Lungenkreislaufes.}

\section{A. pulmonalis.}

Entspringt aus dem oberen Ende des rechten Ventrikels, biegt sich aufwirts, dann rickwirts und etwas nach links, zwischen Atrium sinistrum und der Aorta adseendens, hinter dem $\Lambda$ satz des zweiten Rippenknorpels an das Sternum und der Thymus. Sie grenzt nach unten an das Atrium dextrum, nach links an den Areus atortae und die V. cava superior sinistra, nach oben an den Areus aortae, nach rechis an die Aorta adscendens und das obere Ende der Trachea. Vor letzterem teilt sie sich in die A pulmonales dextra und sinistra. Aus der Teilungsstelle eutspringt das dumne Ligamentum arteriosum, welches hinter der V. cava superior sinistra, in der Ilöhe des medialen Endes der dritten linken Rippe sich in den Anfang der Aorta descendens thoracica inseriert.

Die Äste der Aa. pulmonales verlaufen unmittelbar oberhalb der zugehörigen größeren Bronchien. - Über ihre Anastomosen s. 755.

\section{Vv. pulmonales.}

Die Venen der Lungenlappen münden auf jeder Seite an der Grenze zwischen oberer und hinterer Wand des Atrium sinistrum, entweder zu einer 
1. pulmonalis communis drotra und sinistra rereinigt oder als zwei getrennte, ummittelbar nebeneinander mändende Stimme auf jeder Seite: Vu. pulmonales superior und inferior. Die V. pulmonalis dextra liegt rechts von der V. cava inferior, links von der Vena cara superior dextra, die sinistra links von der V. "ata inferior, rechts und nach hinteu vou der V. (ava superior sinistra. Die V. pulmonalis sinistra ist etwas hiuzer als die devtra. Die Iste beider Venen verlaufen unterhalb der zugehörigen größeren Bronchien.

\section{Lymplıgefii Is-System.}

\section{LymphgefäIse.}

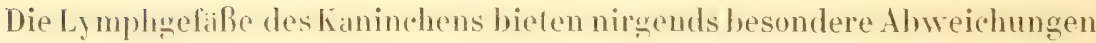
ron denen des Menschen dir.

Ductus thoracicus. Derselbe mündet in den Vereinigungswinkel der Vr. jugularis externa und subclaria sinistrat: hat im gefülten Zustande ungefahr die Weite der V. azygos.

Über den Chylus s. $86 \%$. Vergl. auch S. 65.

Der Truncus lymphaticus communis dexter verhălt sich analog; die Trumei lymphatiri jugulares dexter und simister sind verhaltnismaßig weit; jeder derselhen roicht von der Gl. cervicalis profunda vor dem M. sealenus anticus neben der V. jugularis interna bis zum Ductus thoracieus resp. Truncus lymphaticus communis dexter abwairs.

\section{Lymphdrüsen.}

Die Lymphdriisen sind graurötlich und weich) folgende sind konstant:

Gl. fuciulis liegt Jings des 1 . infratortalis am oberen Rande des M. buccinator.

Gl. revicales superficiules. Mehrere Drusen liegen ueben der V. jugularis externa unter dem M. platysma in der Ilöhe der ersten Trachealringe.

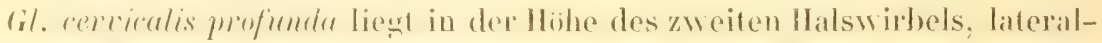
wirts rom N. vagus, den Aa. carotis externa und interna. mit ihrem bateralen Rande unter dem vorderen des M. sternomastoideus.

lil. massetrica liegt am vorderen hande der Insertion des M. masseter an der lateralen Seite des Unterkiefers.

Gl. axillares, $2-3$ an Zahl, in der Achselhöhle unter der V. axillaris.

ril. scapularis liest in dem Winkel zwischen mterem Rande der Scapula und dem Ursprungsteil des $\mathbf{M}$. anconaeus longus.

Gl. bronchiales liegen an der Teilungsstelle der Trachea.

Gl. mesentericte superiores s. Pancreas Asellii, stellen eine an der IVurzel 
des Mesenterium gelegene, aus Lymphdrusen bestehende, zusammenhägende Masse von ea. $3 \mathrm{~cm}$ Länge auf $1 \mathrm{~cm}$ Breite dar.

Gl. mesentericae inferiores, 2-3 liegen neben den A. und V. mesentericae inferiores, ctwa in der Mitte der liange der letzleren im Mesorolon descendens.

Gl. hypogastricae, mehrere an Zahl, umgeben die V. iliaca externa.

Gl. ingumalis smperior liegl an der Durchtrittsstelle der $\Lambda$. iliolumbalis durch die Bauchwand.

Gl. inguinalis inferior liegt am Ende der A. circumflexa abdominis, vor dem Kople des M. rectus lemoris.

Gl. ischiadica liegt medianwïts von der V. ischiadica, hinter dem R. superior oss, ischii.

Gl. poplited liegt am lateralen ropderen Rande des unteren Teiles des $\mathbf{V}$. semimembranosus, hinter dem hopfe des II. gastrocuemius medialis. 


\section{Neurologie.}

\section{Zentrales Nervensystem.}

\section{Rückenmark.}

Die Medulla spinalis reicht abwairts bis in den Anfang des zweiten Kreuzbeinwirbels. Der Zentralkanal (Fig. 120 C, S. 290) ist mit Cerebrospinalflüssigkeit gefüllt. Das Gewicht betrigt $3,6 \mathrm{~g}$. Die Cervikal- und Lumbalanschwellung ist wenig ausgeprigt. Das im Canalis sacralis gelegene unterste Ende des Rückenmarkes zeigt dasellsst ein fadenförmiges Aussehen, wobei aber die mikroskopische Struklur der Medulla sich bis zum Anfang des Filum erhilt. Der Zentralkanal stellt eine sagittale Spalte dar, in der Gegend des Processus spinosus spurius II nimmt derselbe eine auf dem Querschnitt T-förmige Gestalt an, entsprechend einem rentriculus terminalis (57, S. 382). Die Tiefe des Ventrikels in sagittaler Richtung betrigh 0,37, die größte Breite hinten 0,11 mm. - Dis Filum terminale heginnt in der Höhe des Processus spinosus des zweiten Kreuzbeinwirbels, reicht über das Ende des Canalis sacralis im siebenten Schwanzwirbel distalwirts noch ein wenig hinaus und endigt am achten Schwanzwirbel. - Vergl. auch S. 301.

Bei neugeborenen und mittelmäßig großen Kaninchen soll das Filum terminale bis an das Ende der Schwanzwirbelsüule reichen (45j). - In etwa viermonatlichen Kaninchen erstreckt sich dasselbe jedoch nur noch entlang dem neunten Schwanzwirbel, wobei ein spaltförmiges Lumen erhalten bleibt. Der obigen Angabe liegt vielleicht eine Verwechselung mit der A. sacralis media zu Grunde, welche allerdings bis zur Spitze des Schwanzes reicht (Erste Auflage S. 196).

Operationen am Riickenmark. Durch Kompression oder Unterbindung des Arcus aortae links neben dem Ursprung der A. subclavia sinistra kann man den größten Teil des Rückenmarkes anämisch machen (434-s. L'nterbindung des Truncus anonymus. S. 247).

Durchschneidung des Rückenmarkes.

A. Des oberen Endes. Hautschnitt in der Bauchlage des Tieres, in der Medianlinie, an der Protuberantia occipitalis externa beginnend ïber einige Processus spinosi abwïrts. Ablösung der Mluskeln, bis die Wirbelsïule frei liegt; Unterbindung der verletzten Gefäße. 
B. Einer Stelle im Verlauf des Rückenmarkes. Bauchlage des Tieres. Haulschnitt über einige Processus spinosi, Ablösung der Rückenmuskulatur, Trennung der Wirbelbogen mit einer feinen Knochenzange, Eröffnung der Dura mater, Stillung der Blutung durch Schwamm und Zunder. Die Durchschneidung der vorderen und hinteren Wurzel gelingt leicht mittels einer nach der Schneide gebogenen Scheere; die isolierte Durchschneidung einzelner Stränge hat sehr große Schwierigkeiten wegen der Weichheit, Kleinheit und tiefen Lage des Rückenmarkes (455).

Nach einer anderen Methode (456) macht man zwei Schnitte parallel der Medianlinie bis auf die Ursprungsstelle der Processus transversi am tief itherisierten und in der Bauchlage auf das Brett gebundenen Tiere. Zwei Wirbelbogen werden beiderseits freigelegt, mit einer Knochenzange die Arcus von :5-6-8 Wirbeln erst auf der einen, dann auf der anderen Seite durchtrennt, die Dura mater bloßgelegt. Jetzt wird zum ersten Male das Blut vorsichtig und oberflaichlich abgewischt, das Brett in eine schiefe Lage gebracht, damit das Blut abfließt. Dura mater und ebenso Arachnoidea werden mit einer spitzen Pinzette aufgehoben, mit der Schere der Länge nach aufgeschnitten und mit Hilfe von Querschnitten lateralwärts umgeklappt. Die Pia nater wird für Operationen an den Hintersträngen mit einem nadelförmigen sehr feinen, tlach untergeschobenen Messerchen (amerikanisches Augenmesserchen von Luërj über den Seitenstrüngen der Lïnge nach getrennt, stäkere Gefaße verschoben oder torquirt, wobei jede Bewegung des Tieres zu vermeiden ist.

An den Halswirbeln kann man nach Beugung derselben nach vorn zwischen zwei Wirbeln ohne Eröffnung eines Areus (z. B. mit einer Staarnadel) eindringen und die hintere Partie durchschneiden.

Die Vorbereitung des Rückenmarkes zur späteren Sektion geschieht am besten durch Einlegen in so verdünnte Chromsïurelösungen, daß graue und weiße Substanz deutlich geschieden erscheinen.

Partielle Durchschneidung des Rïchenmarkes. Einstoßen eines 8 mm langen, 2-3 mm breiten, hinten geknöpften Messerchens durch das Mark in den Wirbelkürper: so daß es festsitzt und unter seinem Schutze die Zerstörung z. B. eines Seitenstranges vorgenommen werden kann. Mit Hilfe von zwei Messerchen kann man beide Seitenstränge erhalten und die graue Substanz ganz zerstören. Härtung des Rückenmarkes in Alkohol zur mikroskopischen Konstatierung der Ausdehnung der Verletzung. Es wurde der Lendenteil benutzt, die interspinale Muskulatur abgeschabt, und zwischen zwei Processus spinosi ein Stück Wirbelhogen mit einer Knochenzange entfernt (457. Vergl. 631 u. 751 ).

Zerstörung des Lumbalteiles. Befestigung des Kaninchens in der Bauchlage. In der Gegend des letzten Rückenwirbels ein Längsschnitt in der Medianlinie. Die Rückenmuskeln werden in der Longitudinalfurche zwischen den Processus spinosi und transversi abgeschabt, die Wirbelbogen nahe am Körper mit einer feinen Knochenzange durchgebrochen, das Rückenmark freigelegt, guer durchgeschnitten und abwärts his in das Os sacrum mit einer gebogenen Ilohlsonde oder gliihendem Kupferdraht zerstört (585, S. 392).

Nach Reizung des oberhalb oder unterhalb des Atlas durchschnittenen Cervikalteiles des Rückenmarkes verengern sich die Körperarterien, namentlich dic Aa. mammariae internae, epigastricae superiores, thoracicae longae, subscapulares, radiales, phrenicae superiores, die Arterien des Magens, die Aa. hepatica, lienalis, mesentericae superior und inferior, renales, uterinae, vaginales superiores, iliolumbales, epigastricae inferiores, crurales, saphenae magnae (458). 
Reizungen des Lumbalteiles lassen sich bei uneröffnetem Wirbelkanal durch Einsenken ron Elektroden zwischen benachbarten Wirbehn ausfiihren (5.5. . . . 387).

Zwischen dem sechsten Halswirbel und dem vierten Brustwirbel befindet sich im Rückenmark das Centrum ciliospinale (459) für die Bewegung der Iris und der Kopfarterien; im vierten Lendenwirbel eine mehrere Millimeter lange Stelle, das Centrum genitospinale (440) für die Bewegung der Vasa deferentia, der Harnblase und des Rektum.

Nach anderen Angaben (vergl. 578) liegt das Centrum vesicospinale zwischen dem fïnften und sechsten Lendenwirbel.

Übrigens entspringen nach anderer Angabe (441) die Gefäßnerven des Ohres und die Pupillen-erweiternden Fasern aus der Medulla oblongata und verlassen gemeinsam durch die vorderen Wurzeln der Nn. cervicales V'II und VIII, sowie der $\mathrm{Nn}$. dorsales I und II das Rückenmark, um sich von hier zum Halsteil des $\mathrm{N}$. sympathicus zu begeben. Der Plexus caroticus internus verbindet sich mit dem N. trigeminus in der Gegend des Ganglion Gasseri.

Nach anderer Angabe ( 585 ) wäre das Kaninchenrückenmark für die Untersuchung der spinalen Zentren nicht zu empfehlen.

\section{Gehirn.}

\section{Unterhirn, Subencephalon.}

\section{Medulla oblongata.}

Ventriculus quartus. Das Corpus restiforme bildet an der Stelle, wo sich dasselle umbient. $11 m$ sich als Crus cerebelli at medullam oblongatam

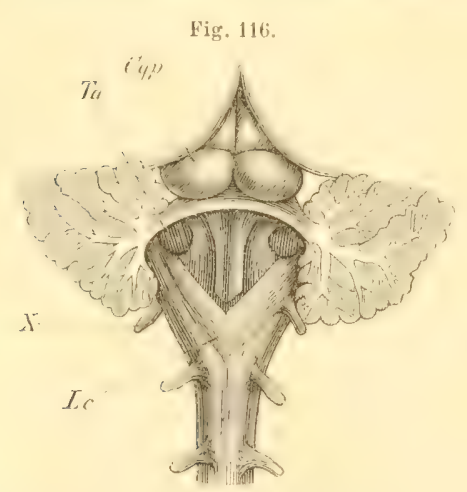

Ventriculus quartus von hinten gesehen. Das Cerebellum ist durchschnitten und abgetraefin: aach Formaril. Ta Tuberoulum acu-tirum. C'y colliculi pusteriures tminentiat quadrigeminae. $\mathrm{X}$ N. vagus. Lc Lamina cinerea. fortzusetzen, ein Knie: Genu s. Cervix corporis restiformis (sog. Arm des Corpus trapezoides, 455). Neben demselben liegt am oberen Ende der lateralen Begrenzung des Bodens des vierten Ventrikels oder der Fossa romboidea, Rautengrube, das sog. Tuberculum acusticum.

Dies ist eine hügelförmige Hervorragung (Fig. 116 Ta), die zerstreute Ganglienzellen enthält (S. 301), deren Zusammenhang mit dem $\mathrm{N}$. acusticus jedoch zweifelhaft ist (S. 287). Medianwarts vom Tuberculum acusticuñi verliuft aufsteigend unmittelbar neben dem Sulcus medianus die Emimentia teres durch den oberen Teil der liatengrube. Schrigg lateralwarts aufsteigend liegt im unteren Teile des Ven-

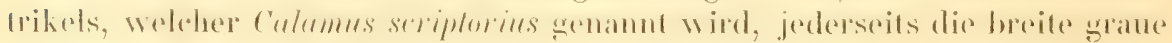
Lamina cinerea (1ig. $116 \mathrm{Lc}$ ). Ihr medialer oberer Teil reprasentiert den etwas gebogenen S laguskerar. der laterale untere den Gilossopharyngensheru (as.j). Die Basis der Laminate cinereate ist nach oben, die spitze nath unten gerichtet, sie erreichen das untere Ende des Calamus scriptorius, werden 
lateralwirts von den wenig entwickelten Funieuli glaciles und cumeati mediales), weiter nach oben ron den atseinamderweichenden Funiculi cuneati laterales begrenzt. Striae medullares als Irsprimge des N. arusticus sind nicht sichtbar.

Das Tuberculum acusticum (Tubercuhm laterale medullae oblongatae, Stieda) könnte der Vermuthung nach zur unteren sensibeln Trigeminuswurzel in Beziehung stehen (vergl. jedoch 574, 589 u.591). Von den Franzosen (s. z. B. 442) wird dasselbe als Tubercule de II $\mathrm{enz}$ el bezeichnet. Letztere Autoren I. und K. Wenzel, 445) nennen es Taeniola. Vor der Geburt ist dasselbe noch nicht zu bemerken (444).

Der untere Teil der Lamina cinereat ist als Calamusganglion (15.j) bezeichnet worden.

Uber den oberen Trigeminuskern und den IIypoglossuskern des Kaninchens s. 445 .

Zuckerstich. Um künstlichen Diabetes hervorzurufen, muß die Medulla oblongata innerhalb einer Stelle verletzt werden, welche vom oberen Ende der Lamina cinerea bis fast zum oberen Ende der Corpora restiformia reicht und circa

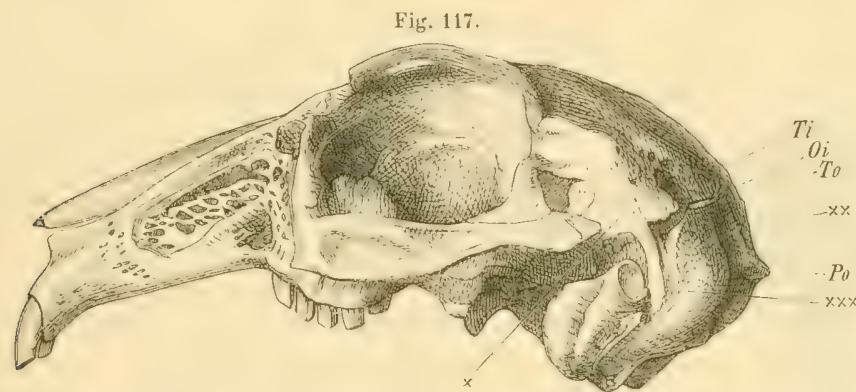

Schädel von der Seite. Ti Tuberculum interparietale. $\quad 0 i$ s interparietale. To Tuberculum occipitale. $\times \times$ Einstichstelle für den Diabetesstich. Po Protuberantia occipitalis externa.

5 mm Durchmesser hat. Man macht dem festgehaltenen, aufrecht sitzenden Kaninchen, dessen Kopf man mit der linken Hand fixirt, in der Medianlinie einen Schnitt von 2 $\mathrm{cm}$ Länge, der nach hinten auf der Protuberantia occipitalis externa endigt. Man fühlt letztere als größeren Knochenvorsprung (Fig. 117) und vor demselben einen zweiten kleineren: das Tuberculum occipitale, welches das vordere Ende der Pars squamosa oss. occipitis, wo dasselbe an das $O$ s interparietale in der Medianlinie sich anlegt, bezeichnet. Vor dem letzteren liegt noch ein kleiner Vorsprung: das Tuberculum interparietale, an der Verbindungsstelle zwischen Os interparietale und den beiden Oss. parietalia (Fig. 118). Da.unter dem Os interparietale der Confluens sinuum

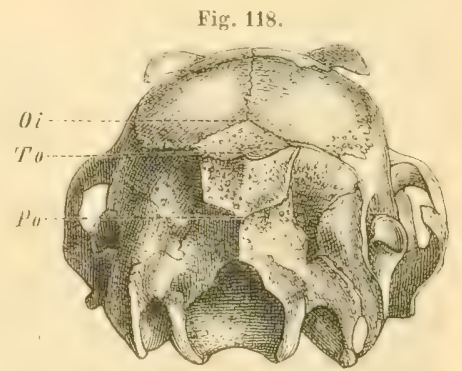

Schädel von hinten. $O i$ Vorderes Ende des

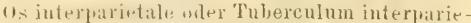
tale. To I'uberculum vecipitale. Po Prutuberantia occipitalis externa. liegt (S. 272), so hailt man sich hinter dem Tuberculum occipitale und durchbohrt in der Mitfe zwischen lefzterem und der Protuberantia occipitalis externa das Hinterhauptsbein mittels eines geraden 
stählernen Meißels von $7 \mathrm{~cm}$ Länge und 1,5 mm Breite, der mit einem hölzernen Griff versehen ist; oder mittels des Neurotomes von Longet (s. Durchschneidung des Crus cerebelli ad pontem, S. 291). Man kann auch eine Staarnadel oder ein spitzes Blatt einer feinen Schere benutzen (1, 6 ). Die Schneide des Meißels wird in transversaler Richtung senkrecht durch den Knochen geführt, wobei leichte seitliche Bewegungen mit dem Griff das Eindringen erleichtern. Man durchbohrt das Cerebellum und die Medulla oblongata bis auf die Pars basilaris oss. occipitis. Der Harn wird nach etwa einer Stunde zuckerhaltig; der Diabetes dauert nicht länger als 2. Stunden. Gewöhnlich folgen Rollbewegungen um die Längsachse des Körpers und später Lähmungserscheinungen. Nach erfolgreicher Operation

Fig. 119.

Lo

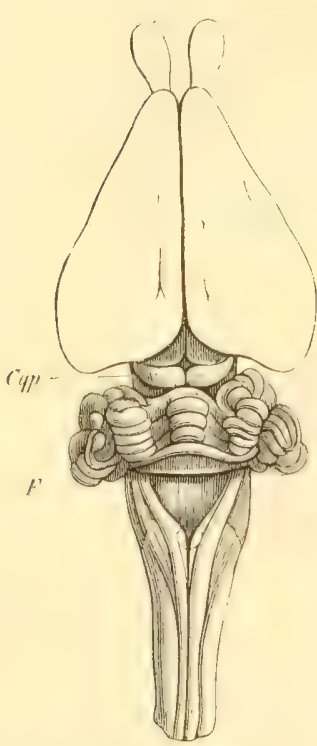

Gelirn und Medulla oblongata von oben. Nach Flourens $(450)$. $L$ o Lobi olfactorii des großen Gehirns. $C q p$ Colliculi posteriores eminentiae quadrigeminae. $F$ Flocculus cerebelli, der in der Fossa mastoidea oss. temporum sich befindet. Noeud vital. tragen die Tiere den Kopf ein wenig zurückgeworfen, was jedoch nur Folge der Blutung zu sein scheint.

Die Gegend, deren Verletzung Diabetes erzeugt, entspricht dem Hypoglossuskern (446); indessen kann man mit einem breiteren Instrument auch vom hinteren Teil des Pons Varolii Diabetes erzeugen (447), sowie ebenfalls unterhalb der unteren Spitze des Ventriculus quartus (446, S. 116).

Auch entsteht Diabetes, wenn man Flüssigkeit in den letzteren einspritzt (448), und mitunter bei Blutungen innerhalb des Schädels.

Vergl. noch 449, sowie Cerebellum (S. 291).

Noeud vital. In der Substanz der Medulla oblongata vor der Lamina cinerea des Ventriculus quartus liegt der Noeud vital (Fig. 119) von Flourens, dessen Verletzung den Respirationsbewegungen, sowje dem Leben sogleich ein Ende macht. Man kann mit einem kleinen Hohlmeißel von $3 \mathrm{~mm}$ Durchmesser oder mit einem doppelschneidigen Scalpell von $5 \mathrm{~mm}$ Breite den Noeud vital treffen, nachdem man von hinten her das Ligamentum obturatorium posterius zwischen Atlas und Os occipitis durch einen Haut- und Muskelschnilt frei gelegt und dann gespalten hat $(450)$. - Man kann bei hinreichender Übung das Instrument direkt durch die Haut einstoßen wenige Millimeter unterhalb des hinteren Randes des Foramen magnum (41). Vergl. a. S. 304 (Respirationsbündel).

Durchschneidung der Pyramidenstränge. Die Pyramiden können isoliert von vorn oder von hinten her durchschnitten werden. Um sie in der Höhe des un-

teren Endes des Ventriculus quartus zu trennen, legt man das Ligamentum obturatorium posterius von hinten her frei etc. $(456, \mathrm{~S} .305)$.

Corpus trapezoides s. Trapezium. Die Gegend am unteren Rande der Bricke, nehen der Austrittsstelle des N. abducens, zwischen dem lateralen Raude des Pyramidenstranges und den Nn. facialis und acusticus (Fig. 128, z u. s, S. 298) jederseits wird als Corpus trapezoides bezeichnet. Infolge der Kürze der Brücke treten hier librae arciformes als eine düme Lage transversaler Verrenfasern zu Taqe, die jedoch beim Kanincheu wenig entwickelt siod. Das genannte Corpus entspricht eigentlich dem unteren Teile der Brücke des Menschen. Vermigne geringerer Ausdehnung der oberflichlichen queren 
Brückenfasern nach unten liegen die Pyramidenstränge (Fig. 122 Py, S. 293;, die sich an Präparaten aus Müller'scher Flüssigkeit durch ihre weiße Farbe hervorheben, frei. Das Corpus trapezoides reicht bis zu den obersten Wurzelfasern des N. hypoglossus.

\section{Pous Varolii.}

Pons Varolii s. Pons (Fig. 129 P, S. 293). Die Britcke ist entsprechend den Crura cerebelli ad pontem wenig entwickelt: die Länge betrigt $7 \mathrm{~mm}$, die Breite am vorderen Rande des N. trigeminus $14 \mathrm{~mm}$. - Von der Schleife, Lemniscus, ist das obere Schleifenblatt nur in Form eines kleinen Anhanges des viel stärkeren unteren Blattes vorhanden (480).

Das Foramen coecum posterius ist kaum angedeuted, das unterius (59, S. 776) besser zu erkennen. Der Sulcus basilaris ist flach.

Pathologische Anatomie. Im vorderen Teil des Pons und im hintersten Teil des Pedunculus cerebri fand sich eine Bindegewebseschwulst bei einem Kaninchen, das 14 Tage lang spontane Rotationen um seine Längsachse gemacht hatte $(456$, S. 351$)$.

Durchschneidung des Pons Varolii. Quetscht man mit dem für die Durchschneidung des N. trigeminus (S.309) bestimmten Neurotom in transversaler Richtung die Fasern des Pons, welche an der Vorderfliche zunächst der Schädelbasis verlaufen, so entstehen klonische Krämpfe sämmtlicher Streckmuskeln des Körpers, wodurch außer Opisthotonus mit Zurückwerfung des Kopfes ein sehr eigentïmliches Aussehen der Extremitäten bedingt wird (W. Krause).

\section{Emineutia quadrigemina.}

Colliculi anteriores s. Corpora quadrigemina anteriorat. Sie sind viel gröber als die posteriores, ihre freie Flache ist fast gerade nach oben und etwas nach vorn gerichtet, ihr hinterer Rand wird von den Großhimbemispharen nicht bedeckt (Fig. 119. - Fig. 120 Eq, S. 290).

Colliculi posteriores s. Corpora quadrigemina posteriora. Ihre freie Flache ist nach hinten gerichtet.

Aquaeductus Sylvii ist weit.

Die Länge und Breite der Eminentia quadrigemina betrïgt ca. $11 \mathrm{~mm}$; nach anderer Angabe (454) in der Medianebene nur 7, $25 \mathrm{~mm}$, wobei jedoch auf die steil abfallende Ilinterflitche des Colliculus posterior Rücksicht zu nehmen ist.

\section{Kleinhirn, Cerebellum.}

Das kleine Gehirn ist durch einen Zwischenraum, in welehem die Eminentia quadrigemina von oben her sichtbar wird, vom Großhirn getrennt. Es ist im Verhaltnis zum Großhirn stark entwickelt; sein Gewicht betrigt 2,2 g und rerhialt sich zu demjenigen des Großhirnes genauer wic 1: 2,8-3,1. Seine Lange von vorn nach hinten betraigt 9-14 mm; seine Breite 16-25 mm $(45 /)$. Das Cerebellum hat deutliche Gyri und besteht aus dem Vermis und zwei Hemisphären.

Beim Hasen ist das Verhältnis zwischen Groß- und Kleinhirn wie 6:1 (452). 
II misph ïren. An jeder Ilemisphäe sind vier Hauptlappen zu unterscheiden: Lobus superior anterior; Lobus superior posterior und inferior posterior, die zu einem Lobus posterior s. superior posterior sich vereinigen,

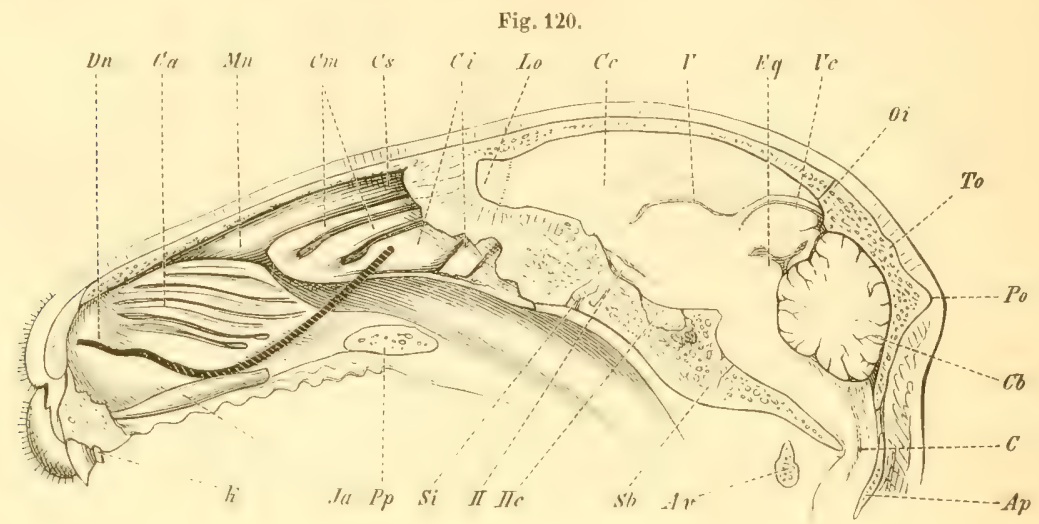

Medianschnitt eines gefrorenen Kopfes. Dn Ductus nasolacrymalis mit Berlinerblan injiziert, schraffiert soweit derselbe yon Knochen, dunkel soweit derselbe von Schleimhaut bedeckt ist (nach 167). Ca Concha anterior. $M m$ Marsupium nasale. Cm Concha (postexior) media. Cs Concha (posterior) superior. $C_{i}$ Concha (posterior) inferior. Lo Lobus olfactorius. Cc Corpus callosum. V Höhle des dritten Ventrikels. Eq Eminentia quadriremina. $\quad l c$ Vena cerebri magna. $\quad O_{i}$ Vordere Grenze des Os interparietale. To Tuberculum occipitale. Po Protuberantia occipitalis externa. $C b$ Vermis cerebelli, $C$ Zentralkanal des Ruckenmarkes. $A p$ Hinterer Teil des Atlas. Av Vorderer Teil des Atlas. Sb Synchondrosis sphenobasilaris. HC Hypophysis cerebri. II N. opticus. Si Synchondrosis intersphenoidalis. Pp Processus palatinus oss. maxillaris superioris. Ja Jacobson'sehes Organ, von der Pars medialis des Ramus palatinus oss. intermaxillaris umsehlossen. $k$ Kleiner Schneidezahn.

weil der Sulcus horizontalis nur flach ist (Fig. 116, S. 286); Lobus inferior anterior, der unter dem Lobus superior anterior liegt.

Floc(ulus s. Lobus posterior. Am aufailligsten ist die starke Entwickelung und Lage der Flocke (Fig. 119 F, S. 288, - Fig. 129 F, S. 293), welche die Fossa mastoidea oss. temporum ausfült. Sie erinnert in beiden Beziehungen an das Vogelhirn.

Sämmtliche kleineren Abteilungen der Hemisphären und des Wurmes kann man nach Loewe (455) wie beim Menschen deutlich unterscheiden.

Die Lage des Plocculus erinnert an das Vogelhirn (457). Nach anderer Angabe ( 158 ) ist jedoch außer dem hier sogenannten noch ein eigentlicher Flocculus an seiner sewöhnlichen Stelle, nämlich an der lateralen Außenfläche der Medulla oblongata vorhanden, jedoch von sehr zarter Beschaffenheit.

Zerstörung der Flocke des Cerebellum. Will man dieselbe isoliert ausführen, so kann man einfach eine Nadel $2-3 \mathrm{~mm}$ hinter dem Meatus auditorius externus osseus in horizontaler Richtung oder schrïg vorwäirts einstoßen. Die Tiefe der Fossa mastoidea betrigt etwa $5 \mathrm{~mm}$. Da im oberen Rande des Einganges der Fossa mastoidea oss. temporum der Canalis semicircularis superior verlauft (S. 182), so wird bei einer operativen Zerstörung des letzteren fast unvermeidlich die Flocke des Cerebellum verletzt. Mit dieser fehlerquelle sind die bei Kaninchen und Viggoln ausgefibrten Durchschneidungen dieses Bogenganges behaftet. Auf die hicaus resultierende fehlerquelle ist (bei der Taube) bereits friher aufmerkSam gemacht worden $(868)$. Vergl. S. 182.

Iermis. Der Wurm ist groß im Verhiltnis zu den Ilemispharen, liegt 
mit seiner oberen Fliche in demselben Niveau mit derjenigen der letzteren; eine Falx cerebelli fehlt dem Tentorium cerebelli.

Crura cerebelli. Die Crura cerebelli ad eminentiam quadrigeminam bieten nichts besonderes; die Crura cerebelli ad pontem sind verhibltnismäßig schwach; über die Grura cerebelli ad medullam oblongatam s. S. 286.

Exstirpation des Cerebellum. Durch einen Längsschnitt wird die Haut am Hinterkopf in der Medianlinie gespalten, die Muskulatur der Quere nach teilweise getrennt, mittels der Knochenzange der Schädel erötfnet. Man hält sich der Blutung wegen unterhalb des Sinus transversus (f/, S. 508). Man kann das ganze Kleinhirn oder eine Ilemisphäre oder den Vermis oder Teile derselben mit Messer und Schere abtragen. Blutungen werden durch Feuersehwamm gestillt. $90^{\circ} \%$ der Tiere starben bald (669). - Vergl. a. 41, S. 508 u. 540, 606, sowie 728.

Größere Verletzungen des Vermis posterior kïnen Diabetes erzeugen 708 , S. 41, S. 551 ).

Durchschneidung des Crus cerebelli ad pontem. Ohne Eröffnung der Schïdelhöhle; von vorn her. Man benutzt ein stählernes Messerchen (Fig. 121), welches vorn zugeschärft ist. Dasselbe befindet sich an einer stählernen Schraube von $5 \mathrm{~cm}$ Lïnge, $1,5 \mathrm{~mm}$ Dicke, die eine durchbohrte kreisförmige stählerne Platte trigt, in deren zentraler Fig. 121.

Bohröflnung sich die zugehörige Schraubemmutter befindet. Mittels der Platte kann die Tiefe bestimmt werden, bis zu welcher das Instrument in den Schidel eindringen soll, wonach die Schraubenmutter eingestellt wird. Die Schraube selbst sitzt an einem vierkantigen hölzernen Grifl, dessen eine Fläche mit einer weißen Marke versehen ist, um die Lage der Hesserschneide innerhalb des Schädels erkennen zu können. Einstich wie bei der Durchschneidung des N. ophthalmicus (s. N. trigeminus, S. 309 ); das Messer wird ein wenig weiter rückwärts gerichtet $(459)$.

Bei dieser Operation von vorn her wird der Pedunculus cerebelli ad pontem sehr häufig verfehlt und man trifft nur die Hemisphiren des Kleinhirnes $(\{60)$. Infolge der Durchschneidung treten Rotationsbewegungen um die Längsaclise des Körpers ein.

Die Vela medullaria anterius und posterius sind verhältnismäßig dick.

Die mikroskopische Beschaffenheit des Cerebellum bietet nichts vom Menschen abweichendes (461).

\section{Groishirn, Cerebrum.}

Das Gesamtgehirn wiegt ca. $9 \mathrm{~g}$; sein Gewicht verhält sich zu dem des Körpers wie 1:150-142; bei viertigigen Kaninchen ist das Verhaltnis wie 1:52-32-31 (beim erwachsenen Menschen. wie 1:35\} - s. 4.45 u. 462. - Der feste Rückstand beträigt 21,4\% (771).

Das Gewicht des Großhirnes betrigt $6,8 \mathrm{~g}$; seine Linge 32 mm, seine größte Breite $27 \mathrm{~mm}$. - Der Äherextrakt betrignt $21 \%$, wahrend das Rückenmark nur 9\% liefert (456). 


\section{Basis des grofsen Gehirnes.}

Pedunculi cerebri. Dieselben sind stark entwickelt; eine Substantia nigra ist nicht zu erkennen. - In Betrefl des Tractus peduncularis transversus $\mathrm{s}$. Substantia perforata media.

Der feinere Bau der Haubenregion ist gelegentlich untersucht worden (480), woraus hier einige Unterschiede gegenüber dem Menschen hervorzuheben sind.

Die obere Trigeminuswurzel ist stark entwickelt, die Ganglienzellen des Locus coeruleus und der Substantia nigra sind ungefirbt. Das Haubenbündel des Ganglion habenulae, sog. Meynert'sches Bündel S. 295, ist stark entwickelt, entspringt aus der Laninat perforata posterior s. Ganglion interpedunculare, verläuft schräg dorsalwärts und nach oben zum Ganglion pedunculi conarii s. habenulae; diese beiden Ganglien sind ebenlalls stark entwickelt. An Stelle eines Nucleus pedunculi cerebri s. Corpus Luysii existiert nur eine diime, undeutlich begrenzte Ganglienzellen-Anhäufung.

Über die allgemeinen Vorsichtsmaßregeln bei Operationen am Gehirn s. 41.

Durchschneidung des Pedunculus cerebri. Man sucht am skelettierten Kopf den entsprechenden Punkt auf, durchbohrt den Schädel und eine Hemisphäre des Großhirns mit einem nadelartigen Instrument und schiebt letzteres so weit nach der Medianlinie vor, daß das Instrument beim Niederdrücken während des Herauszichens die beabsichtigte Verletzung oder die des Thalamus opticus ausführt, worauf Manègebewegungen eintreten $(456,5.342)$. Man kann auch von oben und vorn her einstechen (17.5). Am besten fält die Einstichstelle in den Schädel, wenn durch Reizung Kontraktionen der Ilarnblase eintreten sollen, ungefihr $2 \mathrm{~mm}$ neben der Medianlinie, $5 \mathrm{~mm}$ vor der Protuberantia occipitalis externa in die Verbindungrimie der hinteren Känder beider Meatus auditorii externi. Das kleine Gehirn wird dabei hinter den Colliculi posteriores der Eminentia quadrigemina durchbohrt. Die Tiere bleiben nicht lange am Leben (474). - Man kann auch das 0 s temporum anbohren, um das Neurotom einzufuihren (T06). - Uber Folgezustände im Magen und Darmkanal vergl. 692.

Wird der Schädel dagegen an zwei Stellen, 4 mm lateralwärts von der Medianlinie, $9 \mathrm{~mm}$ vor der Protuberantia occipitalis und $11 \mathrm{~mm}$ weiter nach vorn durchbohrt, und führt man damn durch jedes Loch einen Kupferdraht bis auf die Schiidelbasis, so entsteht bei Induktionsschlägen Verengerung aller Körperarterien $(475)$.

Manigebeveyung-Operation. Schnitt in der Medianlinie durch die Kopfhaut, Bloßlegung der Schädelnähte. Durchbohrung eines Scheitelbeines an seinem rorderen oberen Winkel an einem Punhte, der von der Sutura sagittalis und coronaria ziemlich gleich weit, etwa $2-4 \mathrm{~mm}$ entfernt ist, mittels einer kurzen, scharfen Stahlspitze. Einführung einer sehr feinen Staarnadel, deren schneidende Ränder nach rechts und links gerichtet sind, in senkrechter und etwas mehr nach vorn gencigter, oder in etwas nach hinten und medianwïrts geneigter Richtung bis auf die Schädelbasis; eventuell Bewegung der Nadelspitze nach rechts und links. Verletzung des vorderen Endes des Thalamus opticus im ersten Falle; des 'Tuber cinereum und der benachbarten medialen Partie des Pedunculus cerebri im zweiten Falle. Im ersten Falle (Verletzung des vorderen Teiles des Thalamus) tindet Manigebewegung nach der verletzten (Magendic), im zweiten (Verletzung des hinteren Dritteiles des Thalamus odej der Pedunculi cerebri nach Longet) nach der unverletzten Seite statt (476).

Epilepsie. Künstliche Erzeugung von Epilepsie ist beim Kaninchen noch nicht 
gelungen. - Die Erscheinungen bei Vergiftung mit Blausäure haben viel Ähnlichkeit mit einem epileptischen Anfalle, der allerdings mit dem Tode endigt ( $\{303)$.

Substantia perforata media s. Lamina perforata posterior s. Ganglion interpedunculare (Gudden - vergl. 645). Aus derselben treten betrichtlich uach rorn von dem Vorderrande der Briake die No. oculomotorii hervor (Fig. 122 III); sie liegt zwischen den Bull)i fornicis und dem Pons.

Tractus peduncularis transversus (464) s. Fascio pedoncolare traverso (6.3). Von der Substantia perforata media entspringt jederseits ein schmaler, oberflachlicher weißer Markstreifen(Fig. I24. Tr, S. 295), welcherden Pedunculus cerebri an dessen lateraler Seite umwindet; atsteigend gelangt derselbe zwischen das Corpus geniculatum mediale und den vorderen Rand des Colliculus anterior eminentiae quadrigeminae und endigt im Tuberculum posterius thalami optici $(455)$.

Der Tractus peduncularis transversus soll Opticusfasern zur Medulla oblongata führen (464).

Nach anderer Angabe könnte derselbe mit einer hinteren sensibeln Wurzel des $\mathrm{N}$. oculomotorius zusammenhängen (vergl. 59, S. 736), was jedoch bestritten wird (641).

Tuber cinereum (Fig. 129Tc) hängt durch ein dickes Infundibulum mit der $\mathrm{Hy}-$ pophysis cerebri zusammen.

Hypophysis cerebri(Fig.123. - Fig. $120 \mathrm{Hc}, \mathrm{S} .290$. - Fig. $128 h, \mathrm{~S} .298$ ) ist $5 \mathrm{~mm}$ lang, $3 \mathrm{~mm}$ breit und hoch, besteht aus einem hinteren grauen und einem vorderen, mehr weiß-rötlichen Lappen Fig. $123 v)$.

Chiasma opticum (Fig. 122 Ch). Sein hinterer Rand wird von der Commissura arcuata s. Tractus thalami transversus begrenzt, die nicht dem Chiasma selbst angehört, sondern als weißer querer Markstreifen von einem Corpus geniculatum Fig. 122.

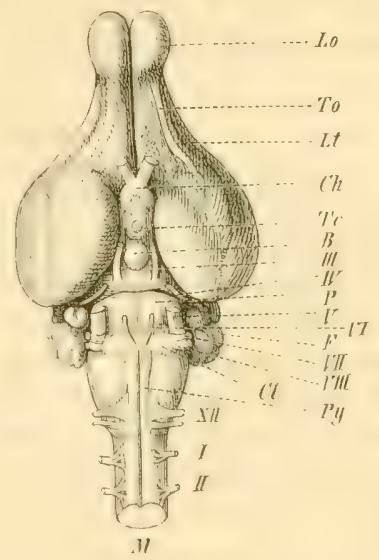

Gehirn von unten, in seiner richtigen Lage, wobei die Lohi olfactorii und das Rückenmark sich gegen den Beschauer erheben. Lo Lobus olfactorius. To 'Tractus olfactorius. $L t$ Lobus temporalis. $C h$ Chiasma opticum mit den beiden Sehnerven. Tc Tuber cinereum, das Infundibulum an dessen oberem Ende ringförmig abgeschnitten. $B$ Bulbus fornicis. $I I I \mathrm{~N}$. oculomotorius. $I I^{\mathrm{N}} \mathrm{N}$. trochlearis. $P$ Pons Varolii. $V$ N. trigeminus. $V I \mathrm{~N}$ abducens. $f^{*}$ Flocculus cerebelli. $V I I \mathrm{~N}$. facialis, VIII N. aeustieus, $C t$ Corpus trapezoides, $P$ P Pramidenstrang. XII $\mathrm{N}$. hypoglossus. I N. cervicalis primus. II $\mathrm{N}$, cervicalis secundus. $M$ Durehschnitt des Rückenmarkes. mediale zum entgegengesetzten zu verfolgen ist (455).

Die Commissura inferior des Chiasma nach Gudden (484, S. 716) liegt am oberen hinteren Rande tes Chitsma, ist nur experimentell nachweisbar, insofern sie nach Exstirpation beider Augäpfel beim neugeborenen Kaninchen persistiert.

In jedem $N$. opticus soll ein gekreuztes und ein viel kleineres ungekreuztes Bündel enthalten sein; ersteres versorgt den oberen, unteren und den medialen, letzteres nur den lateralen Abschnitt der Retina, von diesem aber auch nur etwa den vierten Teil (580 u. 644).

Tractus optici. Sie sind entsprechend der relativen Größe der Augen 
stark entwickelt, nehmen einen großen Teil der Gehirnbasis ein. Der Tractus entspringt rom Corpus geniculatum laterale des Thalamus opticus, sein Hauptzug aber kommt vermittels des Tuberculum posterius thalami, welches diesem Tractus die weiße Farbe seiner Oberfliche verdankt, vom Colliculus anterior eminentiae quadrigeminae. - Der Tractus krummt sich ahwirts, dann nach vorn, umgiebt den Pedunculus cerebri, durchkreuzt sich vollständig mit dem der anderen Seite im Chiasma opticum (Vergl. 705).

Substantiae perforatae laterales s. anteriores. Sie liegen jederseits zwischen dem Chiasma opticum und dem hinteren Ende des medialen Randes des Gyrus rectus.

Trigona olfactoria sind wenig deutlich: am hinteren Ende der Unterfliche des Stirnlappens wurzelt in letzterem jederseits der Tractus olfactorius, (Fig. 122 To S. 293), ein breiter im Sulcus olfactorius des Stirnlappens gelegener weißer Markstreifen (vergl. S. 300).

\section{Innerer Bau des grofsen Gehirues.}

Ventriculus tertius. Derselbe stellt auf dem Durchschnitt eine enge Spalte dar (Fig. $120 \mathrm{~V}$, S. 290).

Th alami optici. Jeder derselben ist $11 \mathrm{~mm}$ lang, seine größte Breite betrigt hinten $9 \mathrm{~mm}$. Die Achse seiner größten Linge ist schrig nach vorn und medianwarts gerichtet. Auf der oberen flache sind hinten das stark entwickelte und hervorragende weiße Tuberculum posterius (Fig. 124. Tp, S. 295) s. Pulvinar s. Corpus geniculatum laterales. posterius (45\%, S. 25), vor demselben das viel kleinere rundliche graue Tuberculum medium s. posterius, welehes den eigentlichen Körper des Thalamus entspricht, und ganz vorn das noch kleinere grauweißliche Tuberculum anterius zu unterscheiden. (Vergl. über die mikroskopisch trennbaren Kerne des Thalamus 5\% 4, S. 6\%0.) Am medialeu Rande der oberen, dieselbe gegen die mediale Flache abgrenzend, verlaufen dicht aufeinander folgend: der Pedunculus conarii, jenen Rand bildend, lateralwirts davon der Nucleus pedunculi conarii und die Taenia thalami optici (s. Conarium, S. 295).

Die stria cornea s. terminalis ist wenig gebogen. Über ihren Zusammenhang mit Fasern des Septum pellueidum vergl. 574, S. 666).

Jeder Thalamus ist mit einem Corpus geniculatum mediale (Fig. 124 Cy S. 295) und laterale ausgestattet.

Die Corpora geniculata mediale und laterale s. internum (45\%) sind klein, mamentlich das erstere, verhalten sich übrigens wie beim Menschen. Sie liegen hinter und unter dem Tuberculum posterius, werden von letzterem iiberragl und stehen dureh die Brachia conjunctiva anterius und posterius mit den Colliculi anterior resp. posterior der Eminentia quadrigemina in Verbindung. maßen an

Die Dimensionen des Thalamus giebt Forel (454, S. 49) in $\mathrm{mm}$ folgender-

Liinge in sagittaler Richtung von der Columna fornicis zum vorderen

Ende der Eminentia quadrigemina

ร, 5 
Länge des lateralen Randes von der Columna fornicis bis zum vorderen Ende des Tuberculum posterius (welches Forel für das Corpus geniculatum laterale hält)

Größte Länge incl. des Tuberculum posterius

Breite von der Commissura posterior bis zur Cauda corporis striati $\quad 6, b$

Größte Länge des Tuberculum posterius $3, \mathfrak{b}$

Breite des Tuberculum posterius $\quad 2,75$

Größte Länge des Corpus geniculatum laterale (welches Forel für das mediale hảlt)

Breite des Corpus geniculatum laterale

Vor dem Thalamus opticus, zwischen demselben und dem Corpus striatum liegt eine Stelle, bei deren Verletzung männliche Kaninchen einen grunzenden Ton, wie sonst in der Brunstzeit, hören lassen (466). Ubrigens geben auch Weibchen in der Brunst einen ahnlichen Ton von sich (467).

Ausschließlich auf Grund experimenteller Untersuchungen (s. Großhirnrinde, S. 303) lassen sich ein vorderer, mittlerer, Jateraler und hinterer Kern unterscheiden (468), außerdem ein Tuberculum posterius s. Pulvinar.

Corpora striata sind bedeutend entwickelt (ahnlich wie bei den Viigeln), nehmen einen großen Teil der Großhirnhemisphiren ein; jedes ist $14 \mathrm{~mm}$ lang, die größte Breite beträgt $5 \mathrm{~mm}$. Uber den Nucleus lentiformis siehe Commissura anterior (S. 296). Derselbe besteht aus nur zwei Gliedern, einem medialen, mebr weiß gefarbten und einem lateralen peripherischen, vorwiegend grauen Abschnitt $(606$, S. 206).

Uber einen sog. Nucleus cursorius im Streifenhügel s. 606.

Commissura posterior s. posterior inferior ist wenig entwickelt.

Conarium s. Gl. pinealis (Fig. 124C) ist graubriunlich, von zylindrischer, an vorderen Ende ein wenig zugespitzter Gestalt, 7, $0,5 \mathrm{~mm}$ breit und dick; enthält keinen Hirnsand (646). Dasselbe erfüllt die Furche zwischen den Colliculi anteriores eminentiae quadrigeminae, liegt längs der V. cerebri magna, gewöhnlich an der rechten Seite derselben, besitzt zwei stark entwickelte Pedunculi conarii s. GI. pinealis s. Tractus recti (453). Dieselben hängen hinten "durch eine Commissura pedunculorum conarii s. posterior superior thalami (453) in der Medianebene zusammen. Von da erstrecken sie sich nach vorn, um sich in der vorderen Gegend des Stratum zonale thalami optici zu verlieren. Laterahwarts werden sie jederseits von der etwas gebogen von vorn nach hinten und lateralwärts verlaufenden Taenia thalami optici s. Tractus lateralis begleitet, die hinten mit der Commissura pedunculorum zusammenfließt. Die

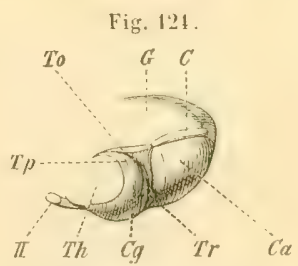

Hinterer Teil der rechten Groß. hirmhälfte nebst Mittelhirn, nach Behandlung mit $H$. Müller'seher Flüssigkeit und Alkohol. $C \mathrm{Co-}$ narium. \& Großhirnhemisphäre. To T'aenia thalami optici, ' $T$ 'p Tuberculun posterius thalami optici. II Rechter N. opticus. T' $h$ Sehnittfäche des Thalamus. Cq Corpus geniculatum mediale. $T r$ Tractus peduncularis transversus. $C a$ Colliculus anterior quadrigeminae eminentiae. Taenia wird vom Pedunculus durch einen schmalen Streifen graucr substanz, Nucleus pedunculi conarii s. Ganglion habenulae getrennt.

Taenia thalami optici, der Nucleus pedunculi conarii und der Pedunculus conarii zusammen sind als Eminentia medialis s. Tuberculum internum thalami optici $(455)$ bezeichnet worden. - Das Haubenbiindol des Ganglion habe- 
mulae von Meynert oder das Meynert'sche Bündel von Forel (iSO) entspringt in der Substantia perforati media (S. 293), verlïuft schräg nach oben zum Ganglion pedunculi conarii. Cber die Faserkreuzung der Columnate fornicis und die Radix descendens fornicis oder das sog. Vicq' d'Azyr'sche Bündel, s. 574, S. 660, 691, 694 u. 695 .

Das Conarium enthält doppeltkonturierte Nervenfasern und brïunliches Pigment.

Luys $(470)$ hat den Querschnitt der Pedunculi conarii für das nach seiner Angabe parrig vorhandene, resp. aus zwei getrennten II:ilfen bestehende Organ genommen, letzteres selbst aber ganz übersehen. Nach Tiedemann (471), dem Longet (472) folst, wire das Conarium klein und rund. Jedenfalls tömnen diese Autoren das Organ niemals gesehen haben.

Commissura mollis nimmt fast die Hälfte des dritten Ventrikels ein.

Commissura anterior ist stark entwickelt, erscheint als weiBer Strang an der vorderen oberen seite der Laminat terminalis des Tuber cinereum, geht in horizontaler Richtung nach beiden Seilen lateralwirts fort, um dann nach kurzem Verlaul durch die am meisten nach der Mediancbene hin gelegenen Teile des Corpus striatum mit ihrer Ilatuptmasse in einem nach oben stark konkaven Bogen nach der (iehirnbasis abzubiegen. Dort weichen die Fasern allmahlich mehr auseinander, gelingen aber sammllich in den Lohus olfactorius und kleiden die Wandung seines Ventriculus aus. Schon vorher jedoch, so lange die Commissura anterior als rundliches Bündel in dem Corpus striatum verlanft, zweigt sich ein feiner, ebenfalls rundlicher Arm von der Ilauptmasse der Commissur ah, der als isoliertes Bündel dureh den Nucleus lentiformis (corporis striati) zu verfolgen ist, welcher Teil des Corpus striatum unterhalb einer michtigen weißen Fasemasse liegt, die der Corona radiata angehört. Dieses Bundel zicht damn in der Richtung gregen den Lobus temporalis cerebri, in den es von vorn her eintritt; hier scheint es sich jenen großen Fasermassen anzuschließen, welche die laterale, ordere und hintere Wand des Seitenventrikels bilden (469. - Vergl. 574, S. 655. u. 575 sovie 576.

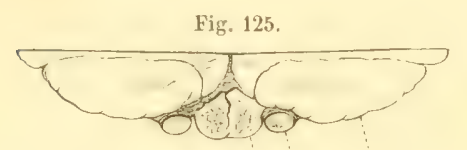

$\because \quad \dot{B} \quad$ III $\quad \dot{P}$

Bulhi fornicis auf lem senkrerhtin Durehschnitt. von varn resehen. Yerur. 2, a kleine Arterie. $B$ Bulbi fornicis, in der Mediau liniw durch eine +twas kliffende spalte grtrennt. III N. oculomotorius. $P$ Pedunculus cerebri.
Fornix. Derselbe bildet ein Dreieck, dessen Basis nach hinten sieht.

Die Radix descendens fornicis oder dessen aufsteigender Schenkel nach Meynert wird auch als Vicq' d'Azyr'sches Bündel bezeichnet $(480)$.

Bulbi fornicis s. Corpora mamillaria (Fig. $123 B$ ). Sie liegen dicht neben der Medianlinie und sehen, so lange die Pia mater nicht entfernt ist, wie ein ein-

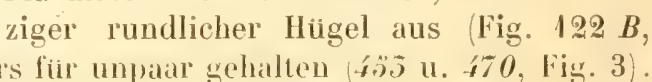

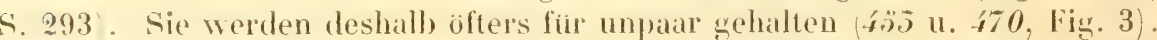
(Cher den mikroskopischen Bau des Bulluus fornicis s. 37\%, S. 692, und 642).

sept $11 \mathrm{~m}$ pellucidum ist wenig entwiokelt, der Tentriculus septi pellucidi 7 mm lang. Ther den Verlauf der Fasern des Septum vergl. 57.4, S. 660.)

Corpus callosum. Der Balken ist $13 \mathrm{~mm}$ lang, reicht nicht weit nach hinten (Fig. 120 Cc, S. 290 ), hesteht aus zwei Schichten von Fasern, welche 
gegen die Großhiruhemispharen aufsteigen, resp. zum Gorpus striatum und Thalamus opticus sich abwarts wenden.

Loewe (455) lieferte eine detaillierte Beschreibung eines schrägen Gehirndurchschnittes, in welcher jedoch der Balken nicht erwähnt wird, auch die $\mathrm{Ab}$ bildung (455, Fig. 4) läßt keine weiteren Aufschlüsse entnehmen.

Ventriculi laterales sind weit, das untere Horn und das Corm Ammonis (Fig. 126.4) stark entwickelt, letzteres $10 \mathrm{~mm}$ breit; das hiutere Horn fehlt; das vordere setzt sich in den Ventriculus lobi olfactorii fort.

Öfnet man den Seitenveutrikel. so fillt hinterwirts das kolbig aussehende Cornu Ammonis (Fig. 126 A) in die Augen; ror demselben liegt der Streifenhugel. Die graue Substanz der Fascia dentuta setzt sich lings der Fimbria resp). des Crus fornicis fort und erreicht die Medianlinis sog. Ganglion Tarini). - Eine detaillierte Beschreibung der Zusammenrollung des Ammonshornes s. 455; iber den Faserverlauf in der Fascia dentata 57 f, S. 636.

Corpora medullaria (hemisphär. cerebri). Über den Faserverlaufs. 574, S. 649.

\section{Oberfliche der Hemisphiren des grofsen Gehirnes.}

Das große Gehirn ist hinten hreit, liuft nach vorn beiuahe spitz zu, was demselben eine ausgesprochene Ähnlichkeit mit dem Vogelgehirngiebt, die auch an dem Schädel hervortritt (s. allgemeine Osteologie S. 136). Von der Seite gesehen erscheint das Gehirn von oben her stark abgeplattet. Die Hemisphären sind annahernd kegelförmig; ihre Oberfliche ist glatt, zeigt kaum Spuren von Windungen. Ebenso sind an ihrer Masse keine bestimmt abgegrenzten Lappen unterscheidbar. Man kann dieselben jedoch zur besseren Orientierung in drei Hauptlappen teilen.

Lobus frontalis s. anterior. Stimlappen, Frontallappen oder Vorderlappen (Fig. 126). Der Stirnlappen ist nach vorn zugespitzt, stellt die Spitze des Kegels dar, welchen das Großhirn bildet, endigt etwas oberhalb und hinter einer Linie, welche die beiden Pupillenmittelpunkte verbindet, und reicht bis an die Einschnurung, welche das hintere in den Tractus olfactorius übergehende Ende des Bulbus olfactorius darstellt. Auf der. unteren

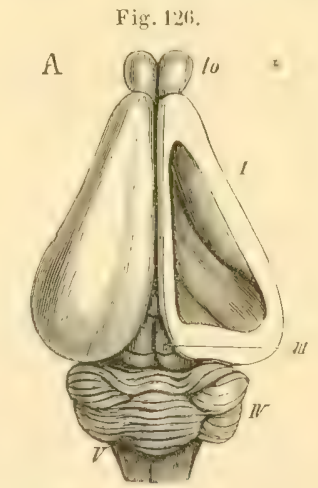

Gehirn nach Gegeubaur (570). A. von oben. $l_{0}$ Lobi olfactorii. I Vorderhirn. III Mittelhirn, IV Hinterhirn. $V$ Nachhirn. Der Seitenventrikel ist rechterhand geöfinet, . vorn erscheint das Corpus striatum, dahinter der Fornix mit dem Cormu Ammonis. Fläche verläuft in sagittaler Richtung ein Sulcus olfactorius, worin der Tractus olfactorius ruht (Fig. 122 To, S. 293). Medianwirts vou letzterem erstreckt sich ebenfalls in sagittaler Richtung der Gyrus rectus, lateralwarts vom Tractus der Gyrus frontalis medius. Dieser wird lateralwarts von einem sagitalen Sulcus frontulis begrenzt, der in den Sulcus collateralis nach hinten sich fortsetzt, den vorderen Teil der V. collateralis cerebri enthailt und den Sulcus triradiatus s. cruciatus des Menschen vertritt. Lateralwärts folgt auf 
den Suleus frontalis der Gyrus frontalis inferior, der aber nur auf der unteren Flache des Stirnlappens zu erkennen ist. Denn die Fossa Sylvii beschränkt sich auf eine flache Grube, welche auf die obere Flache des Stirnlappens als

Fig. 127.

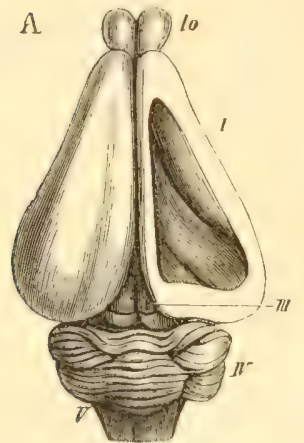

Gehirn nach Gegenbaux (570). A. von oben. lo Lobi olfactorii. I Vorderhirn. III Mittelhirn. IV Hinterhirn. $V$ Nachhirn. Der Seitenventrikel ist rechterhand geöffinet, vorn erscheint das Corpus striatum, dahinter der Fornix mit dem Cornu Ammonis.

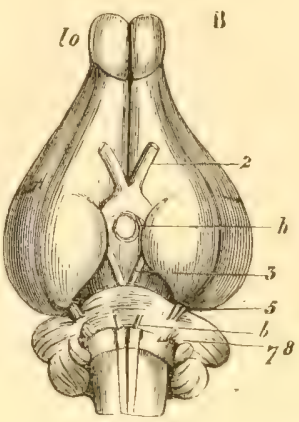

B. Gehirn von unten. lo Lobi olfactorii, $2 \mathrm{~N}$. opticus. $h \mathrm{HF}$ pophysis cerebri. $3 \mathrm{~N}$. oculomotorius. $5 \mathrm{~N}$. trigeminus. $b \mathrm{~N}$. abducens. $7 \mathrm{~N}$. facialis. $8 \mathrm{~N}$ acusticus. Unter dem Pons Varolii erscheint das Corpus trapezoides als helles Querband. leichte Einkerbung hinüberreicht (Fig. 128); im übrigen ist die letztgenannte Fläche glatt. Jener Fossa fehlt also ihr Ramus anterior (des Menschen); sie markiert indessen die Grenzlinie des Stirnlappens nach hinten.

In den Gyri rectus, frontalis medius und inferior sollen drei sog. Uroder Ringwindungen wiederzufinden sein $(455)$; vergl. jedoch über letztere 59, S. 813 .

\section{Lobus olfactorius}

s. Processus mamillaris cerebri ragt als kolbiger Vorsprung (Fig. 122 Lo, S. 293. - Fig. 127 lo. - Fig. 128 Lo), unter der Spitze des Stimlappens nach vorn, innerhall des Os frontis. Sein hinteres Ende liegt unter dem oberen Ende des Sinus frontalis. Im Innern findet sich eine mit den Seitenventrikeln in Verbindung stehende Hähle: der V'entriculus lobi olfactorii.

Vom hinteren Ende des Lobus zieht der Tractus olfactorius nach hinten s. S. 300 .

Derselbe kamn sich ausnahmsweise fast sogleich nach seinem Anfang in die Hirnrinde verkriechen (477).

Über den feineren Bau des Lobus olfactorius beim Kaninchen s. 478.

Bulbi olfactorii accessorii sind $2 \mathrm{~mm}$ lange Nebenbulbi (484), die zwischen der Basis des Bulbus olfactorius und dem vorderen Ende der Großhirnhemisphïe jederseits gelegen sind.

Lobus temporalis. Schlifelappen, Temporallappen. Ist noch am deutlichsten abgegrenzt (Fig. 122 Lt, S. 293), ragt nach abwarts. Lateralwarts neben seinem vorderen Ende wurzelt das hintere Ende des Tractus olfactorius; iiber seine untere Fliche zieht der sulcus collateralis, welcher sich nach vorn auf den Stirnlappen erstreckt und die V. collateralis cerebri enthalt. Durch den Sulcus zerfaillt die Unterflache des Schlifelappens in zwei Abteilungen. Die mediale ist der Gyrus hippocampi, IJakenwindung, die Jaterale entspricht dem vorderen Teile der vereinigten Gyri oceipitotemporalis medialis s. lingualis und occipitotemporalis lateralis s. fusiformis des Menschen $(453)$.

Bei der Betrachtung von der lateralen Seite her erscheint der vom Sulcus collateralis medianwärts begrenzte laterale Teil des Stirn- und Schläfelappens als 
ein kontinuirlicher, hinten kolbig angeschwollener Lappen, der Lobus pyriformis genannt worden ist (Stieda, 5899, vergl. 484).

Lobus parietalis s. posterior. Scheitellappen oder Hinterlappen. Ohne irgend eine Grenzlinie gehen Stirnlappen und Schlifelappen in den windungslosen Scheitellappen über. Derselbe liegt über dem Lobus temporalis, bedeckt nach hinten den Colliculus anterior eminentiae quadrigeminae, dessen hintere Partie jedoch, am herausgenommenen Gehirn von oben gesehen, frei liegt (Fig. 128); der Scheitellappen endigt unter dem hinteren Rande des Os parietale.

Der Lobus posterior stellt die Hauptmasse des Großhirnes dar und entspricht der letzteren beim Menschen.

Am hinteren medialen Ende desselben markiert sich durch eine flache, auf der oberen und hinteren Fläche des Lappens sichtbare Furche die Abgrenzung von dem rudimentären Hinterhauptslappen.

Lobus occipitalis. Hinterhauptslappen. Occipitalhirn. Ein eigentlicher Hinterhauptslappen fehlt dem Kaninchen ebensowohl wie das Cornu posterius des Seitenventrikels.

Wenn man in dem Hinterhauptslappen des Menschen die centralen Endigungen des N. opticus sucht, so harmoniert dies wenig mit dem relativ kolossal großen Auge des Kaninchens. Hiermit stimmen wenigstens die experimentellen Resultate von Goltz (479) am Hundegehirn überein. Eher wäre die geringe Intelligenz des Tieres damit in Verbindung zu bringen.

\section{Betrachtung des Gehirnes von oben.}

Als zwei kolbenförmige Anschwellungen ragen an der Spitze der Stirnlappen die beiden Lobi ol-

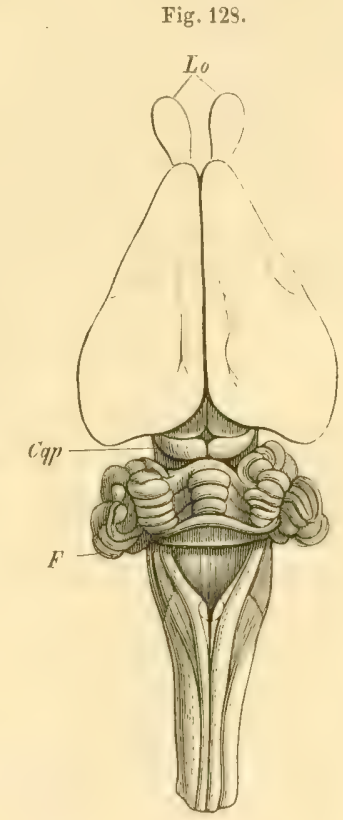

Gehirn und Medulla, oblongata von oben. Lo Lobi olfactorii des großen Gehirns. Cqp Colliculi posteriores quadrigeminae. $F$ Floceulus cerebelli, der in der Fossa mastoidea oss. temporum sich befindet. $O$ Noeud vital (s. S. 258). factorii (Fig. $128 \mathrm{Lo}$ ), hervor. Parallel der Fissura longitudinalis cerebri verliuft auf der ubrigens windungslosen Großhirnhemisphare der Sulcus longitudinalis cerebri in sagittaler Richtung. Der laterale Rand jeder Ilemisphäre zeigt eine leichte hintere Einkerbung, welche der Fossa Sylvii entspricht und den Stirnlappen vom Schlifelappen abgrenzt. Die vordere Einkerhung bezeichnet ungefaibr die Grenze zwischen der vorderen und hinteren Halfte des Stirulappens. Der mediale Rand jeder Ilemisphare ist geradlinig, am Hinterrande zeigt sich medianwarts der Lohus occipitalis als eine leichte, den Colliculus anterior eminentiae quadrigeminae iblorlagernde Hervorragung. Am hinteren Ende der Fissura longitudinalis erscheinen die von vorn her größtenteils úberdeckten Colliculi anteriores, dahinter in Verkurzung die Colliculi posteriores der Eminentia quadrigemina; in der die beiden vorderen Hügel trennenden Sagittalfurche liegt das Conarium. Auf den hinteren Rand der Colliculi posteriores lagert sich das vordere 
Ende des Vermis superior. Die Längsachsen ter Kleinhirnhemisphären sind etwas schrigg medianwarts und nach vorn gerichtet; ihre vorderen Enden springen daher ein wenig vor und es korrespoudieren die Lobi superiores anteriores der Kleinhirnhemisphiren dem leichten Einschnitt, welcher die laterale Grenze des Ilinterhauptshppens gegen den Schlifelappen markiert; zwischen GroB- und Kleinhirn schiebt sich jedoch das Tentorium cerebelli. Am weitesten nath hinten und lateralwirts gelegen, sind die oberen Flachen der Floceuli am Ilinterande des Cerehellum sichthar, zwischen denselben erstreckt sich das Velum medullare posterius.

Dic Rautengrube liegt nach Wegnahme der Tela chorioidea frei zu Tage. Man unterscheidet das untere, nicht sehr spitze Jinde oder den Calamus seriptorius. Ferner neben der Medianlinie jederseits den unteren Teil der Lamina cinerea sowie das Corpus restiforme nebst den medianwarts von letzterem aufsteigenden Funiculi cuneatus und gracilis.

\section{Betrachtung des Gehirnes von unten.}

Das vordere Ende bilden die keulenförmigen Lobi olfactorii Fig. 127 lo, S. 298, von welchen sich die michtigen weiBen Tractus olfactorii nach hinten fortsetzen; sie endiwen an der L'nterfliiche der Spitze des Schlifelappens. Lateralwarts vor letzferer liegt eine flache Vertiefung, die Fossa Sylsii. Yom vorderen zum hinteren Inde der Großhiruhemisphire verlauft ein weuig lateralwarts honvex gebogen der Sulcus collateralis, welcher eine V. collateralis rerebri (S. 27) enthäl. Der Sulcus hegrenzt den lateralen Rand des Grus hippocampi sowie den medialen Rand des (i) rus temporalis, welcher der dritten Schlafewindung des Vensehen korrespondiert (45,5, S. 9). An der unteren Flache des Stimlippens setzt sich der Sulcus als Sulcus frontalis fort, lateralwirts von und parallel dem Sulcus resp. Tractus olfactorius; dasellost sind die (iyri recelus, frontalis medius und inferior sichthar. In Mitfelteil des großen Gehirnes zeigt sich worn an der lateralen Seite des Chiasma opticum jederseits die Substantia perforata lateralis und am hinteren Rande des Chiasma die Commissura areuali. Ilinter dem letzteren folgt das Tuber cinereum mit dem Infundibulum und der Ilypophysis, dann die Bulbi fornicis und hinter denselben die Substantia perforata media, aus welcher die X. oculomotorii herauskommen. Sie erscheinen hetrichtlich nach vorn vom vorderen Rande des Pons. am hinteren Rande des letzteren die No. abducentes, am lateralen Briackenrande weiter nach vorn jederseits die Nn. trochlearis und trigeminus, dithinter die No. facialis und arousticus. Ilinter und unter der Brücke liegt das Corpus trapezoides, dessen Mitte yon den Prymidenstriingen eingenommen wird; an dasselbe schließt sich die Medulla oblongala mit den lateralwirts austretenden Xn. glossopharyngei, vagi, arcessorii. Das obere Ende der Vedulla oblongata wird durch den Beginn der am lateralen Rande des Pyranidenstranges jederseits in langer Reihe entspringenden Wurzelfiden der No. hypoglossi markiert (Fig. 122 XII, S. 293).

Mikroskopische Anatomie des Gehirnes (u. Rückenmarkes). Eine detaillierte Darstellumg der makroshopischen und mikroskopischen Anatomie der nervisen Zentralorgane des Kaninchens hat Stieda $(589)$ geliefert. Aul die- 
selbe ist zu verweisen und nur einige Hauptdifferenzen im Vergleich zum Menschen sowie einzelne Mlessungsresultate werden hier hervorgehoben.

Riickenmarl. Die großen multipolaren Ganglienzellen der Vordersäulen (Untersäulen, Stieda, 1870) haben 0,04-0,056, selten 0,08 mm Durchmesser. Ganglienzellen mittlerer Größe haben $0,02-0,0$ ', die kleinsten, welche überhaupt vorkommen, $0,004-0,02 \mathrm{~mm}$ Durchmesser.

Im Bereich des ganzen Dorsalteiles des Rückenmarkes, auch wohl noch an den obersten Partieen des Lumbalteiles, häutig jedoch nur im mittleren Abschnitt des Dorsalteiles, zeigen sich entsprechend den Nervenwurzeln leichte Anschwellungen; die höchstens $1 / 1 j$ der Breite des Rückenmarkes betragen. Hiernach zerfällt das Rückenmark in Seymente, was auch durch die histologische Untersuchung bestatigt wird $(601)$. - Vergl. über die Details der mikroskopischen Anatomie des Rückenmarkes $599,600,601$.

Medulla oblongata. Die Pyramidenstränge sind wenig entwickelt, die untere Olive (Nucleus basalis medullae oblongatae, Stieda liegt jederseits größtenteils medianwärts von den Wurzelbiindeln des N. hypoglossus. In Seitenstrange findet sich ein aus zerstreuten Zellen mittlerer Größe bestehender hern Nucleus lateralis medullae oblongatae, Stieda). Weiter nach oben, nachdem der Zentralkanal sich in die vierte Hirnhöhle geölfnet hat, zeigen sich zahlreiche zerstreute Ganglienzellen neben der Raphe (Kern der Raphe, Stieda) und ein großer, schairfer begrenzter Zellenhaufen, Nucleus ambiguus unterer Teil des Nucleus facialis, Stiedat lateralwärts davon. Vergl. 726. - Das Respirationsbündel ist leicht zu konstatieren, seine Durchschneidung hemmt die Respiration (727, vergl. $37,5.412)$.

Pons. In der Gegend des Corpus trapezoides liegt die gut entwickelte obere Olive Nucleus dentatus partis commissuralis, Stieda). Ein Nucleus pontis Kern des hinteren (Querwulstes, Stiedil) liegt lateralwärts neben den Wurzelbündeln des N. abducens. Der Abducenskern ist vom Facialiskern scharf geschieden, das Knie und der ganze Verlauf der Facialisw urzel leicht zu erkennen. Das Tuberculum acusticum zeigt zerstreute Ganglienzellen; Striae medullares der hinteren Acusticuswurzel fehlen. Der mediale liern der vorderen Acusticuswurzel lateraler heru der vorderen oder unteren Acusticuswurzel, Stieda) besteht aus multipolaren Ganglienzellen der größten Art ron 0,04-0,06 mm Durchmesser, Wïhrend diejenigen des lateralen Kernes der vorderen Acusticuswurzel nur $0,02-0,024 \mathrm{~mm}$ messen. Im motorischen Trigeminuskern sind dic Ganglienzellen $0,04 \mathrm{~mm}$ groß, ebenso groß im oberen sensiblen Trigeminushern (Trochleariskern, Stiedi) und im Oculomotoriuskern.

Übrigens sind die Homologieen der einzelnen Kerne u. s. w. in der Medulla oblongata und dem Pons keinesweges überall sichergestellt. Die Form der genannten Teile ist so charakteristisch, daß man an jedem (querschnitt auf den ersten Blick erkennt, derselbe riihre jedenfalls nicht vom Henschen, sondern von irgend einem (kleinen) Säugetiere her.

Eminentia quadrigemina. Die der Substantia nigra entsprechenden Ganglienzellengruppen sind nicht pirmentiert, sie haben $0,012-0,016 \mathrm{~mm}$ Durchmesser. In jedem Colliculus anterior ist schon mit freiem Auge auf dem Querschnitt ein der Oberliache paralleler weißer streifen bemerkbar, der langsanfende Vervenfasern und kleinste Ganglienzellen von 0,008-0,012 mm Durchmesser enthält. Nach vorn rücken die Nervenfasern an die Oberlläche, sie gehören ohne Zweifel dem N. opticus an.

Cerebellum. Die Ganglienzellen des Nucleus cerebelli messen $0,04 \mathrm{~mm}$.

Corpora striata. Ihre Ganglienzellen messen 0,008-0,012 $\mathrm{mm}$. 
Gehirn.

Großhirnrinde. Eine helle Randzone hat 0,0 , die graue Rinde $1-1,5 \mathrm{~mm}$ Dicke; die größeren Pyramidenzellen sind 0,04 $\mathrm{mm}$ lang, 0,02 mm und mehr dick. - Vergl. a. 714.

Cornu Ammonis. Über den Bau desselben vergl. 590.

Lobus olfactorius. Die Ganglienzellen haben ungefähr 0,016 mm Durchmesser.

Pathologische Anatomie. Fettige Degeneration der Blutgefäßwandungen des Gehirnes ist bei alten Tieren beobachtet $(485)$.

Pathologische Anatomie der Großhirnrinde. Setzt man Kaninchen stundenlang in einem Kasten Luftströmen aus, denen Dïmpfe von Chloroform oder Äther oder Anylnitrit beigemengt sind, so sterben sie rasch, wobei die Temperatur bis auf $44-45^{\prime \prime}$ steigt. Die Großhimrinde zeigt öfters Blut-Extravasate und koustant zahlreiche Leukocyten (57, S. 463) in den perivaskuliren und pericelluliren (57, S. 463, u. 58, S. 120) Räumen der Großhirnrinde, sowie im Protoplasma der Ganglienzellen $(509)$.

Parasiten des Gehirnes (und Rückenmarkes): Coenurus cerebralis (24, S. 407 ).

Exstirpation der Großhirnhemisphären. Bei circa 3 Monate alten Tieren öffnet man den Schïdel mit der Säge: die Blutung wird nach Abtragung der Hemisphären durch kaltes Wasser gestillt. Es tritt ein Zustand analog wie bei operierten Tauben ein $($ 186).

Andere Operationen am Großhirn etc., die nach Aufsägung des Schädels vorgenommen werden, beruhen auf einfacher Priijaration der abzutragenden Teile und finden keine weitere Berücksichtigung.

Blutlauf im lebenden Gehirn. Um ein Glasplättchen in eine Schädelöffnung einzukitten ( 187 ), legt man bei einem breitköpfigen Kaninchen die Sutura sagittalis durch einen Kreuzschnitt bloß, löst das Periost von dem trocken erscheinenden Knochen, zeichnet den Umriß eines elliptischen Uhrglasstückes von 11 mm Länge und einer Breite, die vorn $8 \mathrm{~mm}$, hinten $9 \mathrm{~mm}$ beträigt, längs desselben mit Bleistift auf den Knochen, löst das Knochenstück mit Säge und Knochenzange aus und paßt die an ihrer oberen Fläche mattgeschliffenen Rinder des Gliischens genau in die Knochenwunde. In demselben Umfange wird die Dura mater geöffnet, die Blutung durch Zunder oder das Glaspläitchen selbst gestillt und letzteres gereinigt. Ist das Gehirn etwas eingesunken, so bringt man einen Tropfen Wasser auf die Stelle, setzt das Gläschen auf, streut feines Gummipulver in die Lücken zwischen Glasplättchen und Knochen und fährt mit einem kleinen, geknöpften, rotglühenden Eisen nach, um rasch zu trocknen; entfernt auch den Überschuß des Gummipulvers. Dann wird dasselbe Verfihren mit Schellakpulver wiederholt. Ist der Verschluß luftdicht, so sinkt das Gehirn nicht ein, wenn man vorher die A. subclavia sinistra an ihrem Ursprung unterbunden hat und nun den Truncus anonymus konprimiert (s. Unterbindung des Truncus anonymus S. 247). Hört die Kompression auf, so treten Luft und Wasser aus etwa vorhandenen undichten Stellen des Verschlusses, die man ausbessert. Bei luftdichtem Verschluß sind keinerlei Bewegungen des Gehirns wahrnehmbar; wird der Truncus anonymus komprimiert, so wird das Gehirn blaß, die Venen der Großhirnhemisphären werden sichtlich enger; hört die Kompression auf, so wird das Gehirn rosenrot, mehr Gefaße werden sichlbar, die Venen schwellen an. Man kann also bei geschlossener Schädelkapsel den Blutgehalt des Gehimes ändern (488).

Operationen an der Großhirnrinde. Um ganz zirkumskripte Partieen zu zerslören, umwichelt man das sitzende Tier mil einem Ilandtuch, macht einen kleinen 
Hautschnitt, durchbohrt die Schädeldecke mit einer dünnen, ganz kurzen Nadel mit hölzernem Griff und spritzt mittels einer Pravaz'schen Spritze einen kleinen, etwa den vierten Teil eines Tropfens konzentrierter Chromsïure ein (606); die Hautwunde wird durch Naht geschlossen. Es entsteht ein grïner harter Herd, die Tiere sterben nach einigen Tagen oder Wochen. Man kann auch trepanieren und das Glïheisen anwenden $(607$ - über elektrische Reizung vergl. z. B. 782). Bei Verletzung eines $12-16 \mathrm{~mm}$ hinter dem Lobus olfactorius auf der oberen Fläche der Großhiruhemisphäre, etwa mm lateralwärts von deren medialem Rande gelegenen Partie gestattet das sitzende Kaninchen, daß man ihm den entgegengesetzten Vorderfuß ausstreckt, den ein gesundes Tier sogleich zurückzieht.

Sowohl auf dem Wege elektrischer Reizung (481, 482 u. 757), als durch Exstirpation einzelner Rindenpartieen beim neugeborenen Tiere und späterer Untersuchung des Gehirnes bei den herangewachsenen Kaninchen ( 68 ) hat man versucht, einerseits besondere motorische oder sensible Zentren in der Großhirnrinde wie bei anderen Tieren nachzuweisen, andererseits bestimmte Stellen der Rinde mit einem lateralen Kern des Thalamus opticus in Beziehung zu bringen (468). Stärkere elektrische Ströme veranlassen Extravasate (482); auf die Exstirpation einzelner Rindenpartieen folgen vielfache Entwickelungshemmungen in verschiedenen Nervenbahnen des Zentralorganes.

Uber Gefrierenlassen und Wiederaufthauen des lebenden Großhirnes vergl. 694; über die Exstirpation desselben und des Corpus striatum 845.

Über den Einfluß des Großhirnes, der Eminentia quadrigemina u. s. w. auf die Atembewegungen vergl. 845 .

Uber einige Operationen am Gehirn neugeborener haninchen s. 485, namentlich Verschließung einer Nasenöffnung; Entfernung eines N. olfactorius nebst (oberer) Muschel und Labyrinth des Os ethmoideum; Exstirpation eines Bulbus olfactorius, nach Entfermung beider Bulbi verhungern die Tiere. Abtragung des oberen Teiles einer Gehirnhemisphäre, oder Exstirpation einer ganzen llemisphäre. Exstirpation der Augen mit Verschließung beider äußeren Gehörgänge. Dauernde Verschließung der Lider eines Auges. Exstirpation eines Colliculus anterior der Eminentia quadrigemina.

\section{Hainte des Gelrirnes und Riickenmarkes.}

Sie sind sämmtlich recht dünn, namentlich die Pia mater, was bei Operationen zu berücksichtigen ist $(57$, S. 464), - s. auch Vermis, S. 294.

Die Dura mater trägt eine einfache Endothellage auf ihrer Innenfliche $(640)$. - Uber die Aufnahme von Tuschekörnchen in Lymphkörperchen des Gehirnes vergl. 57, S. 463 ; ïber reflektorische Erweiterung der Blutgefäe der Pia mater 757. - Über angebliche Ganglienzellen (Tastzellen) der Arachnoidea an der Konvexität der Großhirnhemisphären und der medialen Seite des Bulbus olfactorius s. 612 .

Entleerung von Cerebrospinalfliissigkeit. Hautschnitt in der Medianlinie des Nackens von der Protuberantia occipitalis externa abwärts; das Ligamentum obturatorium posterius wird freigelegt und eingeschnitten. Dann kann man eine feine Glasröhre in den Ventriculus quartus einführen $(1.58)$, die Cerebrospinalllüssigkeit aufsaugen und abwechselnd Luft einblasen (1 33 ), ohne Nystagmus oder Kopfbewegungen hervorzurufen (weil hierbei die Crura cerebelli ad medullam oblongatam wenig tangiert werden, S. 182). 
Der mittlere Druck im Subduralraum betriggt durchschnittlich $20-40 \mathrm{~mm}$ Wasser, mit Respirationsschwankungen von $2-5 \mathrm{~mm}$, Pulsschwankungen von $0,5-1 \mathrm{~mm}(711)$. - Über den Arachnoidealraum s. 850,851 u. 852.

\section{Peripherisches Nervensystem.}

\section{Hirnnerven.}

\section{N. olfactorius.}

Von dem Lobus olfactorius ausgehend verlaufen zahlreiche feine Zweige mit Ïstchen der A. ethmoidalis posterior in die Nasenhöhle zu den Conchae posteriores.

Auch an der medialen Außenwand des Marsupium nasale verzweigt sich ein oberer X. olfactorius, und ein unterster Zweig geht zum Jacobson'schen Organ.

Durchschneidung der Nn. olfactorii. Hautschnitt in der Medianlinie längs der Sutura frontalis zwischen beiden Augen von $1,5 \mathrm{~cm}$ Länge. Eröllnung des Schädels mittels einer Trepankrone von $7 \mathrm{~mm}$ Durchmesser, im mittleren Teile der Pars frontalis oss. frontis, ohne Blutung. Zerstörung der Lobi olfactorii mittels des Skalpells, dessen Schneide nach links und rechts gewendet wird. Die Tiere hïnnen zuweilen lingere Zeit am Leben bleiben; sie beschnülfeln tote Kaninchen nicht mehr $(490)$.

\section{N. opticus.}

Verlïuft dicht neben dem Nerven der anderen Seite nach vorn zum Foramen opticum, daun lateralwirts in der Orbita, trill etwas nath vorn von der optischen Augenachse in den Bulbus.

Vor seinem Eintritt in den Bulbus nimmt sein Durchmesser von $2,2 \mathrm{~mm}$ auf $3,3 \mathrm{~mm}$ zu. Er hesteht danu aus zwei innig vereinigten Schenkeh und ist auf der oberen Fläche konvex, auf der unteren konkav; an letzterer findet sich eine $1 \mathrm{~mm}$ breite sehr dünne Stelle in seiner Hülle (491).

Durchschneidung des N. opticus.

A. In der Schäidelhöhle. Einstich mittels des Neurotomes wie bei der Durchsechneidung des X. ophthalmicus (s. 309', Führung des Xeurotomes entlang der hinteren Fläche der Ala magna oss. sphenoidei posterioris nach vorn und medianwärts. Die Operation mißlingt sehr häufig. - Vergl. a. 758.

B. In der Orbita. Man durchbohrt mit dem Neurotom die Conjunctiva zwischen Bulbus und oberem Augenlide am hinteren Ende des Processus supraorbitalis posterior oss. frontis, geht längs der hinteren Wand der Orbita medianwärts und nach vorn und durchschneidet den N. opticus vor dem lioramen opticum. Mitverletzung der A. ophthalmica hat keine störenden Folgen (492).

Nach einer anderen Methode (495) wird das Kaninchen in der Bauchlage auf ein Brell gebunden, der Kopf von einem Gehilfen fixiert, der zugleich die Augenlider auseinander zieht. Mit Schere und Pinzette macht man die Tenotomie 
des M. rectus superior, dann der darunter gelegenen Fasern des M. retractor bulbi. Man durchsehneidet dann den N. opticus entweder mit einer spitzen geraden oder mit einer auf das Blatt gebogenen Schere oder mit einem besonders zu diesem Zwecke konstruierten Neurotom (W. Krause, 195). Nlan muß sich hüten, den Bulbus zu verletzen. Nach der Durchschneidung des Sehnersen bleibt die Pupille anfangs gewöhnlich eng und unbeweglich hontrahiert. "Tötet man nach etwa drei Wochen das Tier durch Erhängen, so zeigen sich die Blutgefiiße der Retina gut gefüllt, die Stäbchen- und Zapfenschicht vollkommen unverändert (495, - vergl. 644). - Man kann den Sehnerv ganz dicht am Bulbus durchtrennen (759).

Auch kann man nach Tenotomie des M. rectus superior in den Sehnerv Flüssigkeiten injizieren, z. B. in $0,75 \%$ iger Chlornatriumlisung aufeeschwemmte Aspergillussporen, welche Neuritis und Perineuritis optica erzeugen, die sich auf den N. opticus des anderen Auges fortzupflanzen pflegen $(81 \tilde{3})$.

Kaninchen, denen beide Nn. optici durchschnitten worden sind, lassen sich wegen der Unbeweglichkeit der Pupille vortrefflich zu ophthalmoskopischen Studien für Anfänger verwenden $(865)$.

\section{N. oculomotorius.}

Erscheint am Pedunculus cerebri, am oberen Rande des Pons Varolii (Fig. 122 III, S. 293) ror dem Ursprunge der A. profunda cerebri, verliuft oherhalb der Sella nach vorn, durchbohrt die Inra mater am Processus clinoideus posterior, geht durch den oberen Winkel der Fissura orbitalis in die Augenhöhle; unterhall, des N. trochlearis, oberhall, des X. abducens, medianwarts von dem stäkeren $\mathbf{N}$. ophthalmicus. Teilt sich im Hintergr'und der Orbita in einen $R$. superior, welcher Zweige zu den Mm. rectus oculi superior und levator palpebrae superioris entsendet, und in einen $R$. inferior. Letzterer giebt zuerst die sehr kurze Radix brevis ganglii ciliaris ab (Fig. 129), dann einen Ast-(Fig. $129 r t$ ) fair den M. retractor bulbi (vergI. S. 312) und spaltet sich in die Zweige für die $\mathbf{M m}$. rectus oculi inferior, obliquus inferior und rectus medialis $(506$ u. $80 \%)$.

\section{Durchschneidung des N. oculomo-}

Fig. 12!.

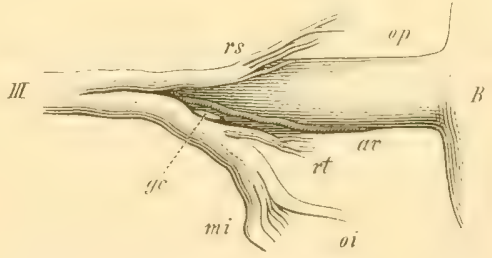

Rechtes Auge in natürlicher Kopfhaltung (Fig. 1, S. \$), von hinten, Vergx. 5. B Bulbus. op N. opticus. a. $v$ A. ophthalmica superior. $r t$ Ast des N. ocnlomotorius zum M. retractor bulbi. o $i$ Ast zum M. obliquus inferior. $m i$ Ast zum M. rectus anticus $g$. internus. $g c$ Ganglion ciliare. $I I I \mathrm{~N}$. oculomotorius. is Ast zum N. rectus superior. torius.

A. Mit Eröffnung des Schädels. Chloroformierung, Abtragung des Schädeldaches mittels der Sige oder Knochenzange, Entfernung der Großhirnhemisphären. Querer Schnitt durch die Lobi olfactorii, Durchschneidung der Nn. optici, Aufheben des Gehirnes. Durchschneidung des N. oculomotorius. Eventuell Spaltung der oberen Wand des Sinus cavernosus, Stillung der Blutung durch Schwämme binnen einiger Ninuten. Soll das Auge unbewegt bleiben und nur die Wirkung von Reizungen des Nerven auf die Binnenmuskeln des Auges untersucht werden. so macht nan vor der Eröffnung des Schïdels die Tenotomie der Mm. recti oculi 
anticus, superior, inferior und obliquus inferior. Nach Bloßlegung des N. oculomotorius werden auch die drei Augenlider weggenommen, die sich bei Erregung desselben regelmäßig schließen (494).

B. Ohne Eröffnung der Schädelhöhle innerhalb derselben. Einstich mittels des Neurotomes wie bei der Durchschneidung des N. trigeminus (S. 309), Führung desselben medianwärts, bis man den Keilbeinhörper fühlt, Senkung des Grifles, Vorschieben des Neurotomes um 1-2 mm, wobei der Nerv (Fig. 132) durchschnitten wird. Leicht kann man die A. carotis interna im Sulcus caroticus verletzen, wodurch tötliche Blutung und Krämpfe entstehen (492, S. 657). Oder man dringt hinter dem Processus condyloideus maxillae inferioris nach oben zur Sella vor $(780)$.

\section{N. trochlearis.}

Erscheint am Velum medullare anterius, windet sich (Fig. 122 IV, S. 293) um den Pedunculus cerebri unter dem vorderen Teil des medialen Randes des Tentorium cerebelli, tritt am lateralen Rande des Crus cerebelli ad eminentiam quadrigeminam oberhall, des N. trigeminus hervor, gelangt in ein Kanälchen der Dura mater, unter der lateralen Kante des Processus clinoideus posterior verlaufend, und dureh die Fissura orbitalis oberhalb des N. oculomotorius in die Augenhohle. Verlauft alsdann oberhally und lateralwirts von letzterem Nerven zum M. oblicquus superior.

\section{N. trigeminus.}

Ist anBerordentlich stark entwickelt, ibertriflt an Masse alle anderen Ilimneren zusammengenommen, rscheint (Fig. 122 V, S. 29:3) an der lateralen Seite des Crus cerebelli ad pontem; seine Portio major und Portio minor treten in das foramen lacerum, verlaufen lateralwarts vom hinteren lateralen Rande des Corpus oss. sphenoidei posterioris in dem Sulcus sphenoidalis nach vorn, von der Dura mater bederkt, gelangen zum Ganglion Gasseri, welches lateralwarts vom Sinus cavernosus in dem Sulcus sphenoidalis gelegen ist, am medialen Teile der Ala magna oss. sphenoidei. Unter dem Ganglion Ciasseri und dem N. maxillaris inferior verliuft die Portio minor. Aus dem ersteren gehen die Nn. ophthalmieus, maxillaris superior, maxillaris inferior hervor; die Portio minor verschmilzt mit dem X. maxillaris inferior.

Die Portio major entspringt in der Medulla oblongata etwas oberhalb des unteren Endes derselben $(460,5.389)$.

N.s. R. ophthalmicus verbiuft dureh die Fissura orbitalis lateralwarts von den Yn. trochlearis, oculomotorius und abducens, sowie etwas oberhalb des letztren. Der N. ophthahmicus ist bedeutend stirker, der X. trochlearis viel schwither als die genannten anderen beiden Nerven; das Lageverhiltuis ist von oben nach unten:

\section{Trochlearis \\ Oculomotorius Ophthalmicus \\ Abducens}

Der N. ophthalmicus giebt dicht vor der Fissura orbitalis superior inmerhalb 
der Augrenhöhle den $\boldsymbol{N}$. palpebralis inferior ab, weleher unterhalb des M. rectus inferior, oberhalb der Membrana orbitalis und der Gl. infraorbitalis nach vorn liaft und sich im unteren Augenlid verteilt. Ferner giebt der N. ophthalmicus im Ilintergrunde der Orbita den $N$. lacrymalis ab. Letzlerer erstreck sich am hinteren oberen Rande der Augeuhöhle nach vorn, gelangt als N. suprorbitulis mit der A. supraorbitalis durch die Incisurat suprarbitalis posterior zur Haut des yorderen Teiles des oberen Augenlides.

Über die (nicht gelingende) Reizung des N. lacrymalis s. $495^{\circ}$.

Alsdamn geht der N. ophthalmicus oberhalb des N. opticus an die vordere Wand der Augenhöhle und teilt sich oberhalb des M. rectus oculi anticus in die Nn. frontalis und nasociliaris.

Der $N$. frontalis geht anfangs in Begleitung des N. trochlearis, dann oberhalb des 41 . obliquus superior nach vorn, gelangt mit der gleichnamigen Arterie durch die Incisura supraorlytalis anterior zum vorderen Teile der Haut des oberen Augenlides.

Der N. frontalis kann mit dem N. trochlearis eine Strecke weit in derselben Scheide eingeschlossen verlaufen. Eine Anastomose beider Nerven in der Form, wie sie Bernard 496) abbildet, würde physiologisch unerklärlich sein; es kann aber der Schein eines solchen Faseraustausches durch nicht-injizierte Arterienzweige, namentlich die Aa. ethmoidalis und frontalis hervorgebracht sein.

Der $N$. nasociliuris giebt die Radix longa ganglii ciliaris, sowie zwei Nn. ciliares longi al) und spaltet sich in die Nn. ethmoidalis und infratrochlearis. Der $N$. ethmoidalis geht mit der A. ethmoidalis anterior durch das Foramen ethmoidemm und verhreited sich in der Nase. Der $N$. infratrochlearis verlaiuft mit der 1 . ophthalmica an der vorderen Wand der Augenhöhle und giebt Äste an den vorderen Augenwinkel.

N. maxillaris superior verläuft anfangs mit dem N. ophthalmicus vereinigt und wird daher bei der Durchschneidung desselben (S. 309) mit getroffen. Da das Foramen rotundum fehlt, oder vielmehr mit der Fissura orhitalis superior verschmolzen ist, so verliß der $\mathrm{N}$. maxillaris superior durch letztere die Scharlelhöhle, verlauft nach vorn, lateralwirts langs der Pars nasalis oss. palatini, giebt die Nn. subcutaneus malae, sphenopalatinus und dentalis superior posterior ab, setzt sich im Sulcus infraorbitalis als $N$. infraorbitalis fort.

N. subcutaneus malue trennt sich vom N. maxillaris superior im Ilintergrunde der Augenhöhle, rerläuft an der lateralen Seite der Alveolen des sechsten his dritten oberen Backenzahmes, gelangt in den Canalis zygomaticus, tritt aus demselben durch das Foramen zygomaticofaciale auf der lateralen Flache des Os zygomaticum in das Gesicht, verzweignt sich in der Itaut der Wangengegend und dem vorderen Teile des unteren Augenlides.

N. sphenopalatinus entsteht von der unteren Fläche des N. maxillaris superior, verläuft nach vorn, ist nur kurz, geht in das Ganglion sphenopalatinum über, welches medianwirts neben dem N. maxillaris superior gelegen ist.

Aus diesem Ganglion kommen die Nu. petrosi superficiulis und profundus majores (s. S. 347 u. 348 ) und Äste fur die Pharynxschleimhaul, ferner vom unteren Winkel des dreieckigen Ganglion die. In. nasales sphempala- 
timi, welche durch das Foramen sphenopalatinum zur Schleimhaut der Nasenhöhle gelangen, und der $N$. nasopalatimus. Derselbe ist stark entwickelt, geht durch das Foramen sphenopalatinum, enthilt zugleich die Fasern der Nin. nasales posteriores des Menschen, welche er abgiebt und dann medianwirts an der lateralen Wandung des Labyrinthes aufwirts steigend an das Septum varium gelangt. Am unteren Rande des letzteren verliuft derselbe bogenfirmig nach vorn, damn an der oberen Wand des Ductus nasopalatinus der Schleimbaut desselben $\mathrm{A}$ ste gebend abwirts zur Schleimhaut des Gaumens hinter den Schneidezihnen.

Aus dem unteren Winkel des Ganglion sphenopalatinum gehen endlich die Nin. palatini hervor. Zwei $\mathrm{Nn}$. palatimi posteriores schlagen sich hinter dem Foramen palatinum um die Wurzel des Processus pyramidalis oss. palatini und gelangen zu den Muskeln und der Schleimhaut des lateralen Teiles des Gaumens. Der $\mathrm{N}$. palatimus anterior gelangt lateralwairts rom Foramen sphenopalatinum mit der $\Lambda$. pterggopalatina durch das Foramen palatinum zum harten Gammen und verläuft unter demselben gerade nach vorn, dessen Schleimhaut versorgend.

I. dentulis superior posterior versorgt mit mehreren Ästen den hinteren Teil der Par's alveolaris des Oberkiefers.

$N$. infraorbitulis ist die Fortsetzung des N. maxillaris superior, rerlauft im Sulcus infraorbitalis an der medialen Seite der Alveolen des fünften bis dritten oberen Backenzahnes nach vorn. oberhalb der A. plerygopalatina, unterhalh der $\Lambda$. infraorbitalis, welche er begleitet. Giebt den $N$. dentalis medius für die vorderen Backenzilnme und den $N$. dentalis anterior ab. Letzterer verliaft entlang dem medialen Raude der Alveolen simmtlicher oberen Backenzihhe, in einem Knochenkanialcheu der medialen Seite der Pars alveolaris oss. maxillaris superioris nach vorn und versorgt den großen und kleinen oberen Schneidezahn. Darauf tritt der $\mathrm{X}$. infraorbitalis dureh das Foramen infraorbitale auf die Vorderseite des Gesichts, lïst sich in Rr. palpebrales inferiores, nasales und starke Rr. labiales superiores auf.

Durchschneiding des $N$. ophthalmicus (inkl. des N. maxillaris superior).

A. Bei geölfneter Schädelhöhle. Verfahren anfangs wie bei der Durchschneidung des N. oculomotorius. Das Gehirn wird etwas stärker in die Höhe gehoben, der N. ophthalmicus schimmert durch die Dura mater, welche man in größerer Ausdehnumg ahpräparieren, oder oberhalb des N. ophthalmicus spalten kamm. Derselbe ist stärker als die Nn. trochlearis, oculomotorius, abducens. Der N. trochlearis verliuft in der (iegrend vor dem Ganglion Gasseri lateralwäts und nach oben vom N. ophthalmicus. Der N. oculomotorius liegt medianwärts (Fig. 132, S. 310 ) und etwas nach oben von dem letzteren, der N. abducens medianwärts und nach unten. Weiter nach vorn ändert sich das Lageverhältnis: in der Fissura orbitalis liegt der $\mathrm{N}$. trochlearis oberhalb des $\mathrm{N}$. oculomotorius, dann folgt der N. abducens, alle drei liegen medianwiirts vom N. ophthalmicus (S. 306), der N. abducens zugleich etwas unterhalb des letzteren. Die isolierte Erregung des N. ophthalmicus ist schwierig $(494, \mathrm{~S} .130)$.

B. Ohne Eröffnung der Schädelhöhle. Man benutzt ein Neurotom (Fig. 130) von dreieckiger (restalt mit seharfer Schneide (Hagendie). Der Handgriff ist dureh einen weißen Punkt an einer Stelle markiert, um über die Lage der Schneide innerhalb des Schädels während der Operation keinen Zweifel zu lassen. 
Man fühlt nach dem vorderen Rande des linken Meatus auditorius extermus osseus, durchbohrt vor demselben (Fig. 131, S. 310) mit dem Neurotom die Ilaut und die Pars squamosa oss. temporum, führt das Instrument in horizontaler und transversaler Richtung medianwärts, während die Schneide nach vorn gerichtet ist. Am besten benutzt man halberwachsene Kaninchen, deren Schläfenbein sich leichter durchbrechen läßt. Man fühlt am vorderen Ende der Pars petromastoidea oss. temporum den Widerstand, welchen die Dura leistet; nach Longet (497) kann man auch eine Vorrichtung an dem Neurotom anbringen, welche dasselbe in einer bestimmten Länge einzuführen gestattet (s. Durchschneidung des Crus cerebelli ad pontem, S.291), und diese vorher an einem mazerierten Schädel abmessen. Sobald man den N. ophthalmicus berührt, schreit das Tier heftig, sonst nicht; man wendet alsdann die Schneide nach abwärts, hebt den Griff des Neurotomes und zieht dasselbe lateralwärts durch den N. ophthalmicus - wenn man die Schneide stärker nach unten driickt auch durch den N. maxillaris superior - und in derselben Weise, wie es eingeführt wurde, aus dem Schädel heraus. Während es noch darin ist, kann man bereits prüfen, ob das korrespondierende Auge unempfindlich ist, resp. ob bei Berührung desselben die Lider nicht mehr geschlossen werden.

Zufälle während der Operation sind: Verletzung der V. temporalis superficialis, wenn man allzu nahe vor dem Meatus auditorius einsticht. Verletzung des Lobus temporalis cerebri ist beinahe unvermeidlich, macht aber keine Störung weiter und gefïhrdet auch das Leben nicht. Kommt man zu weit nach vorn (Fig.132, S. 310 ) an der Sella oss. sphenoidei, so öffnet man den Sinus cavernosus; auch die A. carotis interna kann verletzl werden und eine tödliche Blutung bedingen. Nach hinten verletzt man den Pedunculus cerebelli ad pontem und eine Zwangsbewegung um die Längsachse des Körpers ist die Folge. Dies ist der am häufigsten begangene Fehler. $\mathrm{Zu}$ weit nach oben verletzt man den Pedunculus cerebri und es tritt Manègebewegung (S. 292) ein. Führt man den Schnitt zu tief, so wird auch der N. maxillaris superior durchschnitten. Bei Anwendung großer Gewalt kann die Pars petromastoidea oss. temporum zerbrechen, wobei die Nn. acusticus und facialis durchrissen oder gequetscht werden: Verlust des Gehöres und Lähmung der Gesichtsmuskeln auf der entsprechenden Seite sind die Folgen. Hat man den N. trigeminus rückwärts vom Ganglion Gasseri getroffen, so entzündet sich das Auge nicht (498). Man hat daraus schließen wollen, daß die Verletzung sympathischer, in der Bahn des $\mathrm{N}$. ophthalmicus verlaufender Fasern die Augenentzündung bedinge und Meißner (499) vermuthete, daß die Nervenfasern, deren Durchschneidung die Augenentzündung bedingt, an der medialen Seite des N. ophthalmicus verlaufen. Ohne Zweifel ist jedoch letztere traumatisch.

Durchschneidung des $N$. infraorbitalis. Hautschnitt vom

Fig. 130 .

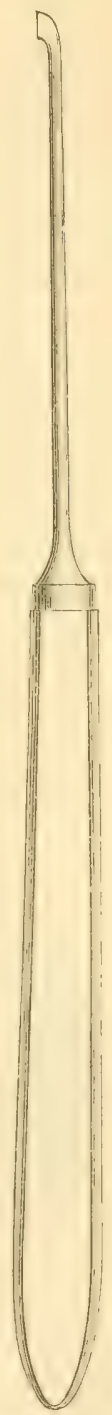

Neurotom zur Durehschneidung tes N. trigeminus in der Schädelhöhle. vorderen Ende des Arcus zygomaticus, den man durchfühlen kinn, beginnend, nach dem oberen Ende des Nasenloches, ca. $2 \mathrm{~cm}$ lang. Durchschneidung des M. levator labii superioris. Man hommt auf die rïliche Gl. facialis (5. 282), ober- 
halb und medianwärts verlïuft längs derselben der N. infraorbitalis, von den Vasa infraorbitalia begleitet.

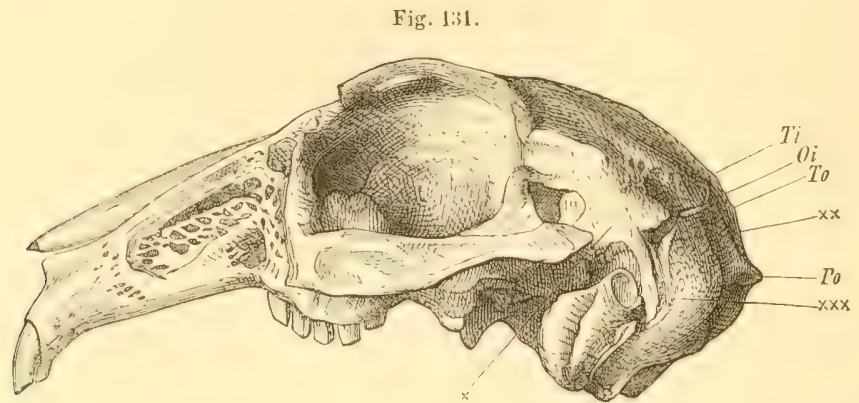

Suhädel von der Seite. $T i$ Tuberculum interparietale. $\quad 0 i$ os interparietale. To Tuberculum occipitale. $\times$ Einstichstelle fur die Durehschneidung des N. trigeminus. Po Protuberantia oceipitalis externa.

N. maxillaris inferior geht durch den vorderen Teil des Foramen lacerum, weleher das foramen ovale reprisentiert, giebt sogleich drei Iste ab: die Rr. pterygoideobuceinatorius, massetericotemporalis und den N. auriculotemporalis; verliuft an der medialen und vorderen Seite der A. maxillaris interna und teilt sich in die $\mathrm{Nn}$. lingualis und mandibularis.

R. pterygoideobuccinatorius geht durch das Foranen sphenoidale medium in der Wurzel des Processus pterygoideus oss. sphenoidei posterioris nach aufwirts, gielnt $\mathrm{Aste}$ an die Mm. pterggoidei externus und internus, lauft oberhally des $\mathbf{H}$. pterygoideus externus, dann zwischen letzterem und dem M. pterygoideus internus nach vorn und ver-

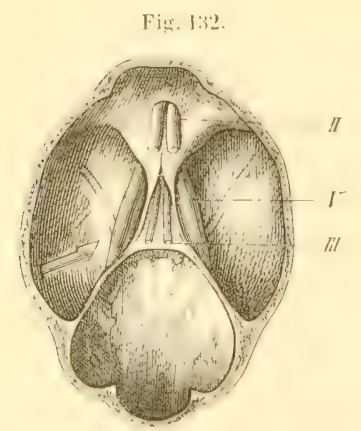

Das Sehädeldarh ist durch einen horizontalen Sägesthnit troffnet. Inrehsehneidung des $\mathrm{N}$. trigeminus. $11 \mathrm{~N}$. opticus. $V \mathrm{~N}$, trigeminus. III N. oculomotorius. Der R. massetericotemporalis des N. maxillaris inferior schimmart durrh die dumm sinhstanz der Ala magna oss. sphenoidei posterioris. Linkerseits ist an der rirhfigen Strlle das Neurotom zur Durhschneidung des $\mathrm{N}$. trigeminus durch den Knochen gefüht. sorgt die Mundschleimhaut über dem M. buccinator $(500)$.

R. massetericotemporalis geht durch das Foramen sphenoidale posterius in der Wurzel des Processus pterygoideus oss. sphenoidei, verläuft an der Vorderfläche der Pars superior der Ala magna oss. sphenoidei posterioris in dem Sulcus massetericotemporalis nach oben, indem er durch diesen diinnen Knochen in die Schädelhöhle hinein durchschimmert (Fig. 132), hinter dem M. pterygoideus externus; geht dann vor dem maxillae inferioris lateralwarts und spaltet sich in die No. temporalis und massetericus.

I. anriculotemporalis ist stark entwickelt, verlauft lateralwarts vor der Bulla tympani nach oben, hinter dem Condylus maxillae inferioris, verbindet sich innerhalb der GI. parotis mit Ästen des $\mathrm{N}$. facialis, gelangt zur A.

temporalis superfocialis in der Gegend der Abgangsstelle der A. transversi faciei, steigr ror dem lleatus audilorius externus osseus mil der genannten 
Arterie aufwarts, giebt einen R. auricularis ab und geht zur IIaut der Schliafengegend.

Der $\boldsymbol{R}$. auricularis verzweigt sich in der Haut des vorderen Teiles der medialen Außenflache des Heatus auditorius externus cartilagineus und erstreckt sich bis zur Incisura intertragica. - Über die Durchschneidung und Reizung des Nerven vergl. 255 und 695.

$N$. lingualis verlauft an der medialen Seite des M. pterygoideus internus, medianwarts rom oberen Ende des M. mandibulae, nimmt die Chorda tympani auf, geht dann oberhalb der Gl. submaxillaris, lateralwaits von dem N. hypoglossus nach vorn, dicht unter der Schleimhaut; gieht Äste zur Schleimhaut des Zungenruckens, verbreitet sich hauptsächlich an den seitenrindern und der Unterfliche der Zungenspitze, mit Zweigen des N. hypoglossus Anastomosen eingehend.

Durchschneidung des $N$. lingualis. Hautschnitt in der Medianlinie rom Kinne rückwärts bis zu einer die Anguli maxillae inferioris verbindenden Linie. Ablïsung des M. mandibulae vom unteren Rande des Unterkiefers; an seinem hinteren Ende findet sich der N. mylohyoideus, weiter aufwärts der stiirkere N. lingualis.

$N$. mandibularis verlauft hinfer dem $N$. lingualis und lateralwirts von demselben, an der medialen Flache des unteren Ansatzes des M. plerygoideus externus, giebt den $\mathrm{N}$. mylohyoideus ab, tritt von hinten her mit der A. alveolaris inferior in den Canalis maxillaris, gielnt Äste an die Zibme des Unterkiefers, kommt zum Foramen mentale heraus und verzweight sich als N. mentalis in der Haut des Kinnes und der Unterlippe mittels der Rr. labiales inferiores.

Durchschneidung des $N$. mandibularis. Hautschnitt bei $2-3$ Monate alten Tieren, 0,75 cm lang, am Unterhieferrande längs dessen mittleren I ritteiles vor dem vorderen Ende des M. masseter und der $\Lambda$. maxillaris esterna. Eröifnung des Canalis maxillaris mittels Messer oder Meißel und Resehtion des Nerven. Nach 3-4 Tagen bilden sich Geschwüre an der Unterlippe gegenüber dem Schueidezahn, die nach ca. 14 Tagen heilen, ohne Wiederkehr der Sensibilität (824).

N. mylohyoideus verliuft an der medialen Seite des II. pterygoideus internus, giebt $\mathrm{A}$ ste an dew hinteren Teil des Bauches des M. mandibulae, an den M. mylohyoideus, ferner den N. submentalis. begleited die $\mathrm{A}$. maxillaris externa, giebt $\ddot{A}$ ste an den $\mathbf{~ I . ~ m a n d i h u l a e ~ u n d ~ v e r i s t e l t ~ s i c h ~}$ in der Haut des lateralen Teiles der Unterlippe.

Varietat. Der N. mylohyoideus biegt sich vor dem unteren vorderen Ansatzpunkt des M. masseter an den Unterhiefer in das Gesicht, verbindet sich durch eine Schlinge mit dem N. subcutaneus maxillae inferioris aus dem N. facialis. Aus dieser Schlinge gehen feine Äste, um den vorderen Rand des Unterkiefers sich biegend, zur lateralen Seite des M. mandibulae.

Da der N. mylohyoideus motorische Fasern enthält, so läßt sich nichts darüber aussagen, ob die den vorderen Teil des M. mandibulae versorgenden Äste jener Schlinge aus dem N. facialis oder aus dem N. maxillaris inferior stammten. [Auch beim Menschen wird der vordere Bauch des M. digastricus maxillae inferioris ausschließlich vom N. mylohyoideus versorgt (s. W. Krause, fo, S. 331)).

N. submentalis verlauft an der lateralen Seite des M. mandibulae, 
zwischen dem letzteren und dem Unterkieferbein nach vorn, ziemlich nahe der Medianlinie, und giebt Äste an die Unterkinngegend und Unterlippe.

\section{N. abducens.}

Erscheint am unferen Rande des Pous Varolii am Vereinigungswinkel des lefzteren mit dem Pyramidenstrange (Fig. 122 IT S. 293), verlauft durch den Sinus cavernosus und die Fissura orlitalis in die $\Lambda$ ugenhöhle, giebt Äste in den M. rectus oculi posticus.

Bei vielen Såugetieren wird der M. retractor bulbi wie beim Kaninchen (S. 305 vom N. oculomotorius versorgt; bei der Katze (50S) und dem Kalbe ist aber der N. abducens die Quelle der Nervenfasern für denselben (was Foltz, 502, und Chatureau ebenfalls angeben'. - Bei dem letztgenannten Tier entspringen sowohl der M. retractor bulbi als der M. rectus oculi externus vom Körper des vorderen Keilbeines (W. Krause).

Durchschneidung des $N$. abducens.

A. Innerhalb der Schädelhöhle. Zuerst wird der N. trigeminus innerhalb des Schiidels durchschnitten /s. Durchschneidung des N. ophthahmicus, S. 309) und von einem Gehilfen die Unemptindlichkeit der betrellenden Gesichtshälfte konstaliert. Das so lange im Schaidel belassene Neurotom wird medianwirts und nach unten mit auf die Schidelbasis senhrecht stehender Schneide vorgeschoben. Dabei ham die Medulla oblongata und die Wurzel des $\mathrm{N}$. trigeminus verletzt werden, wie iiberhaupt das Experiment gewöhnlich nicht gelingt $(501$, S. 30$)$.

B. In der Augenhöhle. Man schiebt ein Messerchen entlang der hinteren Wand der Orhita und durchschneidet nebst dem Nerven einen Teil der Augenmuskeln. Die Folge der Operation ist Exophthalmos und Lnbeweglichkeit der Palpebra tertia $(502)$.

\section{N. facialis.}

Erscheint am oberen Rande der Medulla oblongata (Vig. 122 VII, S. 293), unterhall, des Pons Varolii, verläuft oberhall) des $\mathrm{N}$. arusticus zum Meatus auditorius internus, geht duroh den Canalis facialis, das Gunglion geniculi bildend, welches den $\mathrm{N}$. petrosus superficialis major entsendet (S. 347), giebt den Nervulus stapedius und die Chorda tympani ab, nimmt Verbindungsweige rom R. auricularis des $\mathrm{X}$. vagus auf (Fig. 133, S.315), tritt aus dem Foramen stylomastoideum, wendet sich nach rorn, giebt gleich nach seinem Austritt den N. auricularis profundus posterior, sowie Rr. auriculares anteriores ab, ferner vor dem foramen stỵlomastoideum einen starken R. temporalis, die Rr. auriculares profundus anterior und superficiales, den R. stylohyoideus und den X. subcutaneus colli superior. Der kurze Stamm des N. facialis spaltet sich dann in mehrer" nath rorn gehende Zweige, die an der lateralen Flache des $\mathbf{M}$. masseter den Pes anserinus $\mathbf{n}$. facialis bilden.

Aus letzterem gehen zwei Ilatuptiste hervor, welehe unterhab und lings der A. transversa faciei gerade nach vorn an der lateralen Seite des M. masseter verlaufen. Der ohere Ast ist der stirkere, kreuzt sich am vorderen Ende des Arrus \% 
gelangt an der lateralen Seite des M. bucoinator zu dem letzteren Muskel, giebt auch Aste: Rr. zygomatici und huccales, zu den Mm. zygomatici, subcutaneus faciei, levator labii superioris u. s. w. Der untere $\Lambda$ st giebt die $\mathbf{N}$. subcutanei maxillae inferioris zu den betreffenden Hautmuskeln (s. letztere, S. 136 u. 170$)$.

Chorda tympani verläuft bogenförmig durch die Paukenhöhle, zwischen dem Crus longum incudis und Manubrium mallei hindurchgehend, tritt durch die Aperfura canalis chordae tympani in die Fissura Glaseri, verlauft vor dem oberen Teile des vorderen Randes der Bulla tympani s. 177 absteigend und nach vorn; geht nach abwirts, hinter dem N. maxillaris inferior, damn hinter dem $\mathrm{X}$. lingualis und in die Scheide des letzteren eingeschlossen zum Ganglion linguale.

Durchschneidung der Chorda tympani. Man dringt mit einem geraden, spitzen, scharfen Messerchen durch das Trommelfell in die Paukenhiohle, wendef die Schneide nach oben und zieht das Messer mit einiger Kraft zurück (41).

N. curicularis profundus posterior ist stark entwickelt, steigt am hinteren Rande des Meatus auditorius externus osseus in die Höhe, gelangt an die mediale Außenflache des Meatus auditorius cartilagineus und versorgt die Mm. cerviroscutularis, cervico-auricularis, vertico-auricularis, occipito-auricularis, scutulo-auriculares anticus und posticus.

Fig. 133.

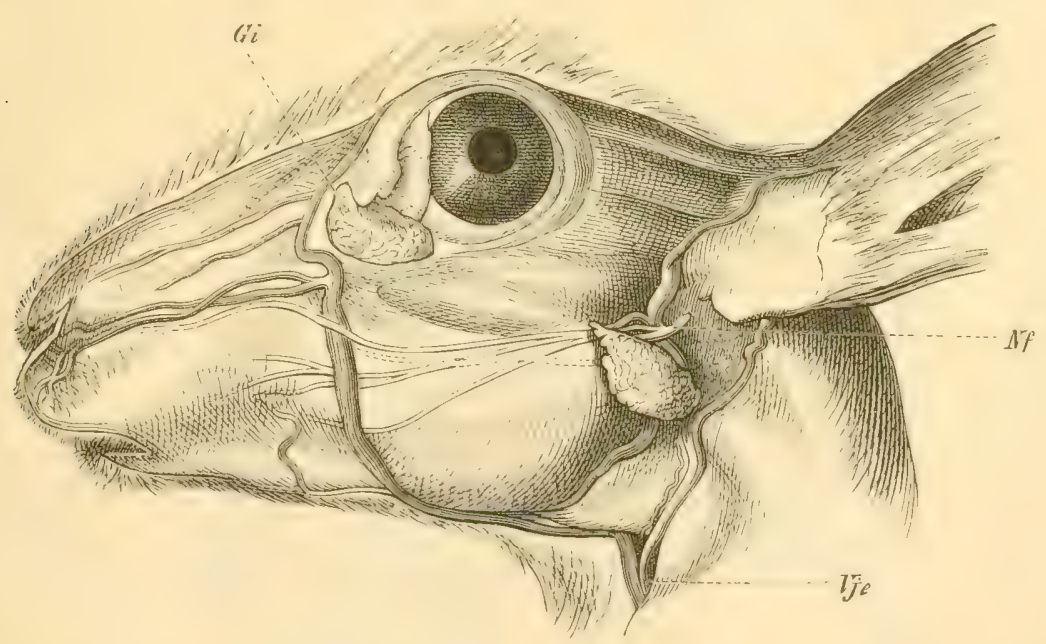

Gesicht von der Seite. If N. facialis. If $e$ V. jugularis externa. $G i$ Gl. infraorbitalis. Die Gl. parotis ist nach unten und zur Seite geschlagen, um den Austritt des $\mathrm{N}$. facialis aus dem Foramen stylomastoideum zu zeigen. Der Ductus parotideus ist punktiert. Die Venen injiziert.

R. anricularis profundus anterior ist stark, entspringt etwas vor dem Foramen stylomastoideum, verlauft vor dem Meatus auditorius extermus osseus, an der Vorderseite des Meatus auditorius cartilagineus, hinter der V. facialis posterior aufwarts, gelangt zwischen Tragus und H. tragicus major und giebt. Zweige zu den Mm. tragici und helicis superior et inferior. 
Rr. anriculures superficiales (R. externus, 505$)$ entstehen dicht vor dem N. auricularis profundus anterior, versorgen die Mm. helico-occipitalis, frontoseutularis, parotideo-auricularis anticus und posticus; geben auch liaden zum M. orbicularis palpebrarum.

N. subcutameus colli superior verliuft gerade abvairts, binter dem Ramus maxillae inferioris, an der medialen Seite der V. jugularis externa; gelangt in der Mitte des Ilalses vor der Vene auf ihre laterale Seite und den M. platysma versorgend bis zur Höhe der Clavicula.

Durchschneidung des $N$. facialis.

A. Innerhalb des Schådels - s. Durchschneidung des N. acusticus.

B. Unterhalb des Foramen stylomastoideum oder Ausreißung aus dem letzteren. Der Kopf des in der Rückenlage befestigten Tieres wird seitwärts gewendet und gehalten. Hautschnitt in horizontaler Richtung, g $\mathrm{cm}$ lang, dicht unterhalb des unteren Randes des Meatus auditorius esternus osseus, den man schon durch die Iaut fühlen hamn. Durchschneidung des M. parotideo-auricularis anticus, dann der Gl. parotis ebenfalls in horizontaler Richtung. Der N. facialis wird durchschnilten oder mit der Pinzette gefaßt und aus dem Foramen stylomastoideum (Fig. 133, S. 313) ausgerissen. Kommt man zu weit nach hinten, so erscheint der N. auricularis magnus in der Wunde. Die Operation ist für gelungen zu halten, sobald Cerebrospinalthissigheit atus dem Foramen stylomastoideum hervordringt (\#0). Das Gesicht erscheint nach der gelahmten Seite verzogen, infolge der natiirlichen Hasenscharte. Eine (nicht wohl verstïndliche) Erklïrung des Mechanismus hierbei s. $460, \mathrm{~S} .391$. - Uber die Folgen der Operation für das Auge s. 781. - Über nachträgliche Veränderungen am Kopf junger Kaninchen vergl. 577 .

\section{N. acusticus.}

Erscheint am lateralen Rande der Medulla ololongata Fig. 129 IIII, S. 293), dicht unterhalb des Pous Varolii, verlauft unterhalb des N. facialis, mit welchem er durch die Portio intermedia in Verbindung steht.

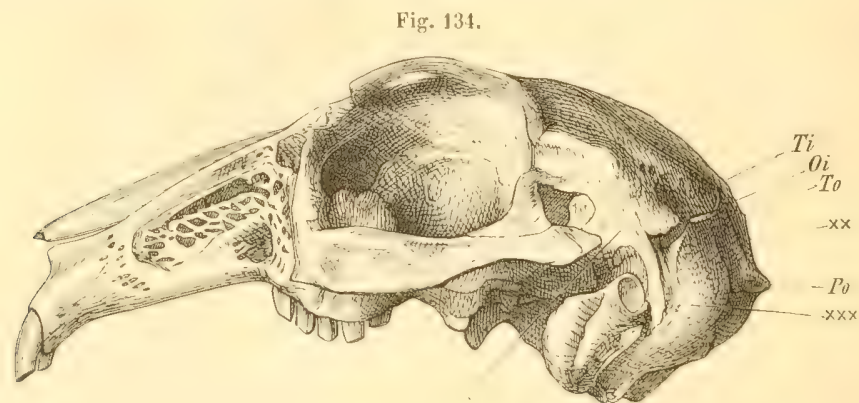

Schädel von der Seite. $T i$ 'T'uberculum interparietale. $O i$ os interparietale. To Tuberculum occipitale. Po Protuberantia occipitalis externa. $\times$ Einstichstelle fur die Durchschneidung des N. trigeminus. $X \times$ Einstichstelle fur den Diabetesstich. $\quad \times \times \times$ Einstichstelle in die Fossa mastoidea oss. temporum zur Durchschneidung
der Nn. facialis und acustieus.

Durchschneidung des N. acusticus. Ohne den Schädel zu erö̈fnen. Hautsehnilt hinter dem :iuBeren Olıre. Nan geht mit einem schmalen Neurotom unmittelbar oberhalb und am oberen und hinteren WVinkel des außeren Ohres durch den Kno- 
chen (Fig. 134) in die Fossa mastoidea oss. temporum ein, durchbohrt den darin liegenden Flocculus cerebelli und führt das Instrument vorsichtig medianwïrts und nach vorn zum Neatus auditorius internus. Der Nerv ist unempfindlich. Der Sinus transversus, die Kleinhirnhemisphäre und die Seitenteile des Pons Varolii können verletzt werden. $(501$, S. $32 .-460$, S. 399.)

Uber andere Methoden der Acusticusdurchschneidung s. $41 \mathrm{u} .160$; und über die Mitverletzung der Canales semicirculares 689 .

\section{N. glossopharyngeus.}

Erscheint am mittleren Strange der Medulla oblongata, dicht oberhalb des $\mathrm{N}$. vagus, geht dureh den vordersten Teil des Foramen jugulare, enthitt ein Ganglion petrosum, entsendet einen Ast zum R. auricularis n. vagi (Fig. 135), ferwer den R. tympanicus, der im Sulcus tympanicus des Promontorium (S. 178) verläuft, vor der Fenestra ovalis einen Verbindungsast vom Plexus caroticus internus: $N$. petrosus profundus minor aufnimmt, durch die Fossa muscularis tympani major sich fortsetzt, die Paukenhöhle verläßt und im Ganglion oticum endigt (s. Kopfteil des sympathischen Nervensystemes, S. 347).

Der N. glossopharyngeus verläuft dann an der medialen Seite der A. carotis interna, erst hinter, dann vor, dann oberhalb derselben in schräger Richtung sich mit ihr kreuzend, an der medialen Seite des M. stylopharyngeus, welchem er einen Ast giebt, zwischen den Aa. carotis interna und externa, vor dem $\mathrm{N}$. vagus.

Ausreifung des $N$. glossopharyngeus. Am leichtesten nach $\Lambda \mathrm{rt}$ der Freilegung des N. auricularis magnus (Fig. 142, S. 321); von der Vorderseite des Halses her (s. N. hypoglossus, S. 322) ist die Operation schwieriger (41, S. 515). Vergl. a. S. 201.

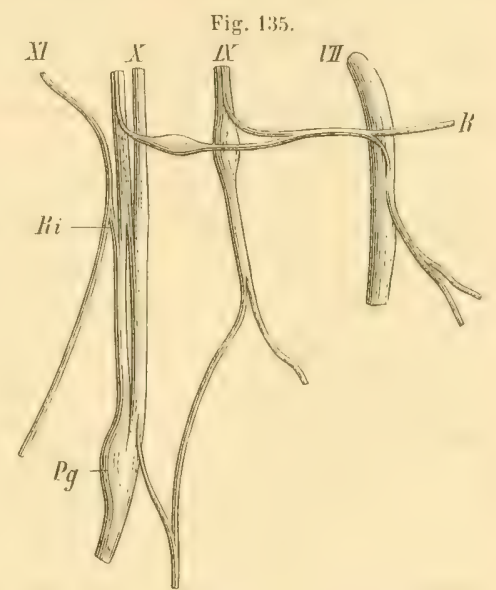

Verbindungen des siebenten, neunten bis elften Hirnnerven untereinander, nach Ludwig (514). VII $\mathrm{N}$. facialis, ter einen $\mathrm{A}$ st rom $\mathrm{R}$. auricularis $\mathbf{n}$. vagi anfuimmt umi den N. auricularis profundus posterior abgiebt. IX N. glossopharyngeus, mit dem Ganglion petrosum, derselbe gielit einen Verbindungszweig zum $\mathrm{R}$. auricularis $\mathrm{n}$, vagi. $I \mathrm{~N}$. vagus. $P g$ Plexus ganglioformis n. vagi. $R$ $\mathrm{R}$, auricularis $\mathrm{n}$, vagi. $X I \mathrm{~N}$, accessorius, dessen $\mathbf{R}$, internus sich mit dem $\mathbf{N}$. vagus vereinigt, $R i$ Ramus internus $n$. accessorii.

Nachdem der N. glossopharyngeus sich mit der A. carotis interna gekreuzt hat, entsendet er einen $R$. pharyngeus, welcher nach vorn liuft und mit den Rr. pharyngei des N. vagus sich verbindet, sowie Äste zum Velum palatinum und setzt sich dann als $\mathbf{R}$. lingualis fort.

Der R. pharyngeus führt keine motorischen Fasern (501, S. 38).

R. lingualis verlaiuft an der medialen Seite des M. stylopharyngeus, oberhalb und parallel mit dem N. hypoglossus nach abwirts und vorn, an der medialen Seite des Cornu minus oss. hyoidei, giebt Äste an die Seitenwand des Gaumens, der Tonsillengegend und der Zungenwurzel und den starkeren Endast: $R$. ad papillam circumvallatam. 
Alle diese Äste enthalten Ganglienzellen in ihrem Verlauf eingelagert. Durchschneidung des N. glossopharyngeus. S. N. hypoglossus S. 322.

\section{N. vagus.}

Entspringt mit 5-6 Wurzeln von der Lamina cinerea (S. 286) auf dem Boden des vierten Ventrikels, etwa 3 mm oberhalb des unteren Endes des letztereu; greht unter dem X. ylossopharyogeus lateralwarts und etwas nach abwäts. Nach einem Verlauf von kamm 2 mm vereinigen sich die Wurzeln im Foramen jugulare zu einem Stamme, welcher hinter dem X. glossopharyngeus, vor dem N. accessorius liegt. Von den hinteren Wurzelfasern entspringt der R. auricularis (s. Fig. 135, S. 315). Am Stamme des N. vagus sind an dieser Stelle in der Regel zwei sehr hleine, dicht aneinander liegende Ganglia jugularia $n$. ragi befindlich, an welchen ain kleineres Wurzelbindel, ohne sich zu beteiligen, vorbeigeht (s0); . Fon dem Foramen jugulare an verlauft der N. vagus nach abwirts, unterhalh des uach vor'm und unten ziehenden X. hypoglossus, nimmt noch oberhalb dieser Kreuzungsstelle den R. internus n. accessorii auf, der fast ebenso dick ist, wie der Iauptstamm des N. Vagus selbst. Etwa $3 \mathrm{~mm}$ unterhalb dieser Stelle sitzt an der hinteren Seite des $\mathbf{N}$. vagus der rundliche, graurobliche Plexus ganglioformis n. vagi s. Ganglion nodosum, (Fig. 144 14, S. 325. - Fig. 14638 , S. 329), welcher etwa 2 mm Längè, $1,5 \mathrm{~mm}$ Breite und $1 \mathrm{~mm}$ Dicke hat.

In der Ilohe der Teilungsstelle der $\Lambda$. carotis communis entspringt der X. Jaryngeus superior, sowie der R. cardiacus, etwas obcrhalb des ersteren die Rr. pharyngei. Dimn liuft der N. vagus an der hinteren lateralen Seite der A. carotis communis am Ilalse abwirls (Fiw. 144. S. 325 . - Fig.146x, S.329) bis zur oberen Apertur des Thorax. Daselbst hiegt sich der N. vagus dexter am unteren Ende der A. carotis commmis dextra ror der $\Lambda$. subclavia dextra Jateralwirts. giebt den X. lar ngęeus inferior ab, verlauft an der rechten Seite des Oesophagus in der Brusthöhle, grieht Rr. pulmonales zum Bronchus dexter, sowie einen Verstirkungszweig zum X. vagus sinister (j//), und gelangt auf die hintere $\mathbb{W}$ and des Magens. Der N. vagus in is ter verlauft an der lateralen Seite der A. carotis sinistra, hinter dem unleren Ende der V. jugularis externa sinistra und der $V$. cava superior sinistra, vor dem linken Ende des Areus aortae, wiebt den N. laryngeus inferior ab, gelangt dann an der medialen Seite dep V. cava superior sinistra vor die Aorta deseendens thoracica und lateralwirts rom Bronchus sinister oberhalb der V. pulmonalis sinistra herabsteigend, woselhst Rr. pulmonales entspringen, zum Oesophagus. In der Höhe der miltleren Ritckenwirbel kreuzt sich der $\mathrm{X}$. vagus sinister, ror dem Oesophagus verlaufend, mit letzterem und gelangt auf die vordere Flache des Magens.

An den Ästen des N. vagus zum Oesophagus und in der Magenwand sah Remak $\ddot{3} / 2$ ) mikroskopische Ganglien; auch sind Teilungen der Nervenfaseru am letztgenannten Orte bekannt $(515)$.

Ebenso finden sich in den Plexus pulmonales an der hinteren Wand der Bronchien mikroskopische Ganglien (5/1). 
R. auricularis entspringt (Fig. 142, S. 321) hoch oben im Foramen jugulare aus einem Ganglion jugulare, nimmt eine Wurzel vom N. glossopharyngeus (Fig.135, S. 345) auf, tritt durch den Canaliculus mastoideus in der oberen hinteren Wand der Paukenhöhle zum Canalis facialis, kreuzt sich mit dem $\mathrm{X}$. facialis, welchem er einen Ast, R. communicans, zusendet, tritt aus dem lateralen Ende des Canaliculus mastoideus, an der oberen Flache des Meatus auditorius externus cartilagineus hervor. Damn verliuft er, mit dem R. auricularis profundus posterior des $\mathbf{X}$. facialis sich kreuzend, zwischen der medialen und vorderen Außenflache der Pars posterior helicis und der Pars superior tubi, durchbohrt das Ligamentum auriculare annulare superius und verhreitet sich mit feinen Zweigen an die Ilat der konkaven Flache der Concha.

$\boldsymbol{R}$. communicans des $\mathbf{R}$. auricularis verlauft eine Strecke in der Scheide des N. facialis eingeschlossen, trennt sich von letzterem im Foramen stylomastoideum, gelangt unterhalb der Spina helicis posterior, das Ligamentum auriculare annulare inferius durchbohrend, zur Haut der konkaven Fläche der Concha - s. 514.

N. laryngeus superior (Fig. 137 ns.-Fig. $138 n s$, S.318. - Fig. 14416, S. 325). Entspringt in der Höhe des oberen Endes der A. carotis communis, verläuft an der medialen Seite der A. laryngea superior nach vorn, giebt einen R. cardiacus (Fig. 136) ab, der sich mit dem R. cardiacus $n$. vagi verbindet, geht durch die Membrana thyreohyoidea oder durchbohrt die Cartilago thyreoidea (S.208) und verzweigt sich mit der A. laryngea (superior). Versorgt die Schleimhaut des Kehlkopfes und den M. cricothyreoideus.

$R$. cardiacus s. $N$. depressor (Fig. $136 R c$. Fig. 14.6 36, S. 329). Entspringt in der Höhe des unteren Randes der Cartilago thyreoidea, wie auch der $\mathbf{N}$ laryngeus superior, nimmt den R. cardiacus des letzteren auf (Fig. 136), gelangt an die laterale Seite des N. sympathicus, dann vor demselben an seinen medialen Rand, lauft in der Scheide des N. sympathicus, hinter dem N. vagus und medianwärts von demselben am Halse abwarts zur oberen Apertur des Thorax. Er ist dúnner als der N. sympathi-

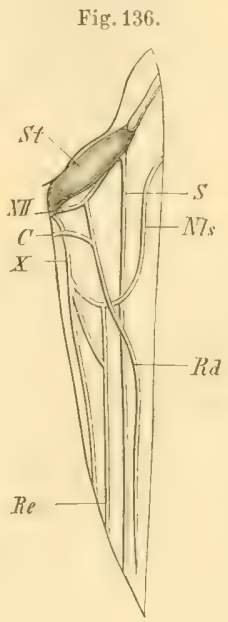

Ursprung des $R$. cardiacus n. vagi, schematisch, nach Ludwig (516). Die Hautrănder des an der rechten Seite des Halses geführten Längsschnittes sind angedeutet. St II. stylohyoideus major, sich an das Cornu majus oss. hyoidei inserierend. $\mathrm{X} I I \mathrm{~N}$, hypoglossus, nach unten den $\mathbf{R}$. descendens $R d$ abgebend. $C$ Wurzel des $\mathbf{R}$. descendens aus dem N. cervicalis III. $X$ N. vagus. $N l s$ N. laryngeus superior. $R c$ Ramus eardiacus n, vagi, der eine zweite Wurzel aus dem N. laryngeus superior erhält. $S \mathrm{~N}$. sympathicus. cus. Alsdann geht der R. cardiacus rechterseits hinter dem Ursprunge der A. subclavia dextra und hinter der Aorta adscendens, linkerseits an der lateralen Seite der A. carotis sinistra und hinter dem Arcus aortae abwarts zum Plexus cardiacus $(\not 3 / 0$ u. $3 / 6$; eine Abbildung s. a. 628$\}$.

Der N. laryngeus superior versorgt nach experimentellen Ermittelungen (702) die Schleimhat der Epiglottis, der Plicae ary-epiglotticae und die Cartilagines Santorinianae. - Über seine Endigung im Stimmbande vergl. 870 , s. a. 40 S. 71. 
Varietät. Der R. cardiacus des N. laryngeus superior oder derjenige des N. vagus fehlt: letzteres ist häufiger. Einmal unter 40 Kaninchen verlief der R. cardiacus in der Mitte des Halses eine Strecke weit in der Scheide des N. vagus, mit demselben Fasern austauschend $(5 / 6)$. Der R. cardiacus ist linkerseits doppelt vorhanden; beide entspringen aus dem $\mathrm{N}$. vagus $(517)$, oder derselbe entspringt-mit zwei Wurzeln aus dem N. laryngeus superior; der Zweig aus dem N. vagus fehlt $(628)$.

$N$. laryngeus inferior s. recurrens. Rechterseits wendet sich der $\mathbf{N}$. laryngeus inferior (Fig. $139 \mathrm{n}$ i) hinter dem Ursprunge der $\mathrm{A}$. subclavia dextra

Fig. 137.

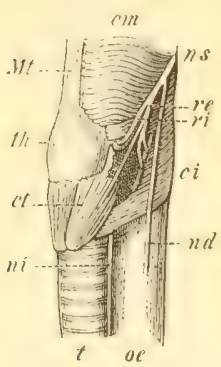

Muskeln und Nerven an der Außenseite des Kehlkopfes. Nach Schneider (250). cm M. constrietor pharyngis medius, $n s$ N. laryngeus superior. re Ramus externus desselben, welcher die AIm. ericothyreoideus ( $c t$ ) und constrictor pharyngis inferior $(c i)$ versorgen, $r i$ Ramus internus des $\mathbf{N}$. laryngeus superior. $c i$ M constrictor pharyngis inferior. nd Ramus cardiacus $n$. vagi $(N$. depressor), oe Oesophagus. $t$ Trachea. $n i \mathrm{~N}$. laryngeus inferior. ct MI. cricothyreoideus, $t h$ Cartilago thyreoidea. If $t$ Membrana thyreohyoidea.

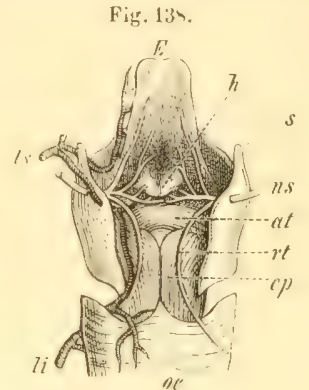

Muskeln, Arterien und Nerven im Innern des Kehlkopfes, von hinten. Vergr. 2. Nach Sehneider (250). E Epiglottis, h Hamulus epiglotticus. $s$ Cornu superius cartilaginis thyreoideae. ns $\mathrm{N}$. laryngeus superior internus. Sein erster Ast geht zur Epiglottis $(\boldsymbol{E})$, ler zweite unterhalb des Hamulus epiglotticus (h) zur Glottisschleimhaut, der dritte (rt) steigt abwärts, mit dem N. laryngeus inferior anastomosierend. $a t$ M. arytaenoideus transversus, $r t$ Drittor Ast des N. laryngeus !superior internus. $c p$ I. cricoarytaenoideus posticus. of Oesophagus. $l i \Lambda$. laryngea inferior, welche mit der A. laryngea superior anastomosiert. ls A. laryngea (superior).

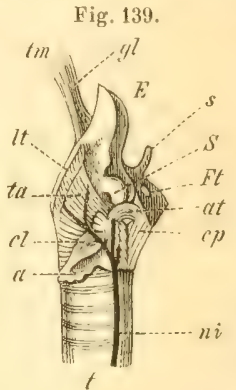

Muskeln des Kehlkopfes und der $\mathrm{N}$, laryngeus inferior, von der Seite. Nach Schmeider (250). Die Lamina lateralis der Cartilago thyreoidea ist weggenommen. $t$ m Lig. thyreohyoideum medium. $g l$ M. glosso-epiglotticus. $E$ Epiglottis. s Cornu superius dextrum eartilaginis thyreoideae. $S$ Cartilago Santoriniana. Ft Foramen thyreoideum. a $t$ H. arytaenoideus transversus, $c p$ M. cricoarytaenoideus posticus, $m i \mathrm{~N}$. laryngeus inferior, dessen Zweige die IIm. crico-arytaenoidens posticus $(c p)$, arytaenoideus transversus (at), crico-arytaenoideus lateralis $(c l)$ und thyreo-arytaenoideus $(t a)$ versorgen. $t$ Trachea. a Arcus cartilaginis cricoldeae. cl M, crico-arytaenoideus lateralis, ta M. thyreo-arytaenoideus. lt Schnittraud der Lamina lateralis sinistra cartilaginis thyreoidene.

aufwarts, verlåuft hinter der A. carotis communis dextra in die Höhe zum lateralen Rande der Trachea. Linkerseits liuft der N. laryngeus inferior (Fig. 146 31, S. 392 ) unterhall, des linken Endes des Areus artale, lateralwirts vom Ductus arteriosus nach hinten, steigt hinter dem ersteren und dem Anfange der $\Lambda$. subclavia sinistra aufwarts zur Luftrobre.

Alsdann verlizuft der $\mathrm{X}$. laryngeus inferior jeder Seite hinter dem lateraleu Raude der Trachea, in der Furche zwischen demselben und dem Oesophagus atufirts zum kehlkopf. Der $\mathrm{N}$. laryngeus inferior sendet nahe seinem $\mathrm{Ur}$ sprunge alowarts verlaufende $R r$. cardiaci zum Plexus cardiacus, in seinem Verlate zahlreiche $R r$. oesophagei und İste fur die Muskeln des Kehlkopfes mit Ausnahme des M. cricothyreoideus ab.

Durchschneidung des $N$. vagus.

A. Am Halse.

Unterbindung der $\Lambda$. carotis communis, der V. jugularis interna. Durch- 
schneidung des R. descendens $n$. hypoglossi, der Nu. vagus, sympathicus, des R. cardiacus n. vagi (Fig. $140 \mathrm{u}$. 141).

Der Kopf wird vom Gehilfen stark nach oben gewendet oder durch eine um die großen Schneidezähne des Oberkiefers gelegte Schlinge fixiert, so daß die Scheitelgegend das Brett berührt, aut welchem das Tier befestigt ist.

Hautschnitt in der Medianlinie des Halses, unterhalb der Cartilago thyreoidea beginnend, $2-3 \mathrm{~cm}$ lang. Die Haut wird nach rechts oder links verschoben, der vordere Rand des MI. sternomastoideus mit der Hohlsonde vom $\mathbf{M}$. sternohyoideus abgelöst. Die A. carotis communis erscheint als weißlicher, pulsierender Strang, lateralwärts der $\mathrm{N}$. vagus, hinter der $\mathrm{A}$. carotis communis die V. jugularis interna, die sehr fein ist und vom Truncus lymphaticus jugularis be-

Fig. 140.

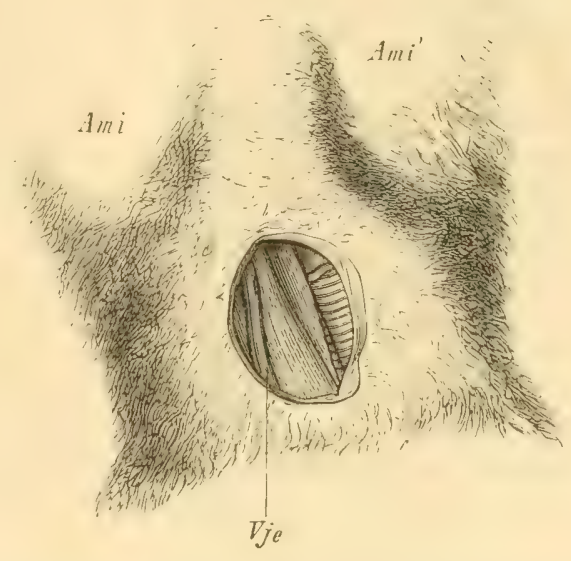

Rechte Soite des Halses, die durehschnittene Fascia cervicalis ist am medialen Rande des Hautschnittes sichtbar. Neben der Medianlinie erscheint die 'Traehea und Cartilago cricoidea. Vje V. jugularis externa. Ami $A m i^{\prime}$ Anguli maxillae inferioris. gleitet wird. Das tiefe Blatt der Fascia cervicalis umhüllt diese Teile, vor demselben verlïuft der $\mathrm{R}$. descendens n. hypoglossi. Die Faszie wird gespalten, der N. vagus von der A. carotis communis isoliert, ersterer nach der lateralen, oder letztere nach der medialen Seite gezogen. Dadurch kommen die in derselben Scheide der Faszie befindlichen N. sympathicus und R. cardiacus $n$. vagi zur Anschauung. Ersterer ist von matterem Aussehen.

Zur Durchschneidung des N. laryngeus superior muß der Hautschnitt etwas höher angelegt werden; der N. laryngeus inferior ist lïngs des lateralen Randes der Trachea leicht aufzufinden.

B. in der Bauchhöhle.

Medianschnitt, am Processus xiphoideus beginnend, $5 \mathrm{~cm}$ lang durch Haut, Muskeln und Peritoneum. Der Magen wird hervorgezogen, der Bauchteil des Oesophagus ist verhältnismäßig lang. Der

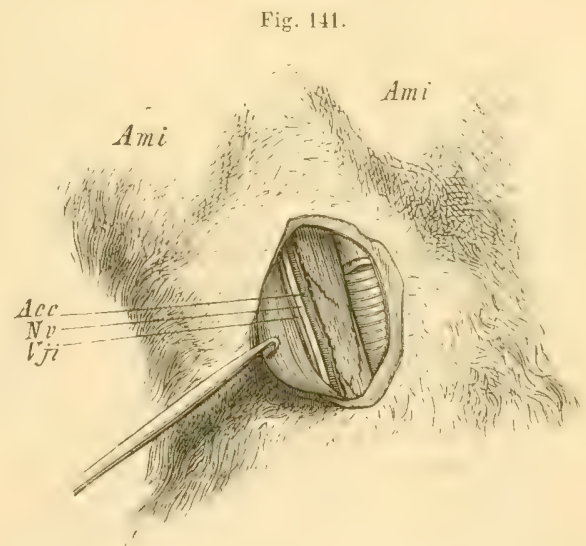

Dasselbe Objekt; der MI. sternomastoideus nebst der V. jugularis externa (s. Fig. 140) ist durch einen Haken lateralvärts gezogen. In der Medianlinie erscheint die Trachea, lateralwärts lägs derselben der $\mathbf{M}$. sternohyoideus, auf welchem der $R$. descendens $n$. hypoglossi geschlängelt $a b-$ wärts läuft und diesem Muskel einen Zweig giebt. Acc

A. carotis communis. $\boldsymbol{N} v \mathbf{N}$. vagus. $\quad V_{j} i \mathbf{V}$. jugularis interna. Ami A mi Anguli maxillae inferioris. $\mathrm{N}$. vagus dexter liegt mehr an der hinteren, der sinister an der vorderen Seite des Oesophagus. 


\section{N. accessorius.}

Erscheint mit etwa 10 Wurzelfiden an den Seitenstringen der Medulla spinalis und oblongata bis zum Lrsprunge des N. cervicalis V abwarts; die von der Hedulla oblongata stammenden Wurzeln sind sehr dün. Verlauft anfangs im Camalis vertebralis, der lateralen Flache der Medulla spinalis anliegend aufwarts, gelangt durch das Foramen magnum in die Schadelhöhle, geht, dicht an den Stamm des $\mathbf{N}$. vagus geheftet, hinter demselben durch das Foramen jugulare; giebt unterhalb des letzteren einen starken R. internus ab. Alsdamn verlauft der $\mathrm{N}$. aceessorius nach hinten und unten, oberhalb des $\mathrm{X}$. hypoglossus sich mit demselben kreuzend, vor der $\Lambda$. occipitalis, hinter dem oberen Teil der Mm. sternomastoideus und cleidomastoideus, woselbst er einen Ast, der sich in zwei Zweige für die genannten Muskeln teilt, absendet. Weiter abwirts geht der X. accessorius (Fig. 14. XI, S. 325) schrig durch den oberen Teil der Fossa suprachavicularis und nach hinten an der vorderen Fläche des M. cucullaris, in welchem er sich verästelt.

V arietät. Der N. accessorius teilt sich schon innerhalb des Foramen jugulare in seine Äste.

R. intermus wendet sich schrig aufwirts, um in den N. vagus einzutreten (Fig. 135, S. 315), ist ebenso slark als der letztere; enthalt die motorischen Fasern der Schlund- und Kehlkopfmuskeln sowie des Ilerzens, welche genannten Fasern iu der Bahn der Rr. pharyngei, Nn. laryngei superior und inferior, R. cardiacus $n$. vagi verlaufen $(5 / \&)$.

Durchschneidung des $N$. accessorius. Man wählt halberwachsene Tiere, vermeidet die französischen Kaninchen (S. :3). Ler Kopf wird durch eine Schlinge um die oberen großen Schneidezïhne bei Rückenlage des Tieres fixiert. Hantschnitt in der Medianlinie $3-3,5 \mathrm{~cm}$ lang, dessen Milte von einer die Anguli maxillae inferioris verbindenden Linie gekrenzt wird. Das untere Ende der Gl. parotis (Fig. 14439, S. 325) wird von der hinteren Fläche der Gl. submaxillaris mit Pinzetten abgelöst, nach oben und lateralwärts geschlagen. Man sieht das Cornu majus oss. hyoidei, an dessen hinterem Ende den Ansatz des M. stylohyoideus, parallel dem Cornu und lateralwärts von demselben den weißen stamm des N. hypoglossus. Weiter abwärts liegt im unteren Wundwinkel die Gl. cervicalis profunda (S. 282), welche die A. carotis communis und den N. vagus verdeckt; ïher ihren lateralen Rand ragt der M. sternomastoideus. Die genannte Lymphdrüse wird medianwärts, der Muskel lateralwärts gezogen; in den letzteren tritt der N. accessorius. Mittels eines Häkchens wird letzterer aufgehoben und mit der Pinzette bis zum Foramen jugulare isoliert. Man faßt ein möglichst langes Stiich des N. acressorius der Länge nach zwischen die gerifften Spitzen einer Pinzette, zieht, leise rotierend, anfangs schwach, dann stiirker, bis mit einem leichten Rucke das Neurilem reißt. Ohne Widerstand folgt dann ein $2-3 \mathrm{~cm}$ langes, zum Teil aus einzelnen Wurzelfaden bestehendes Stück des N. accessorius, wie man unter Wasser bemerkt. Diese Operation des Ausreißens des N. accessorius aus dem Foramen jugulare (vergl. Fig. 142) ist schmerzhaft; daher man den Kopf des Tieres gut fixieren muß. Die Blutung ist nicht bedeutend; doch kann namentlich bei französischen Kaninchen die V. jugularis interna im Foramen jugulare in größerer Ausdehnung zerrissen werden, an deren vordere Wand der 
N. accessorius sich anlegt. Durch die Operation werden die vom N. accessorius innervierten Keblkopfmuskeln gelähmt $(5 / 8)$.

Außerdem kann man durch mikroskopische Untersuchung der im Text genannten Äste des $\mathrm{N}$. vagus nach eingetretener fettiger Entartung darthun, daß

Fig. 142 .

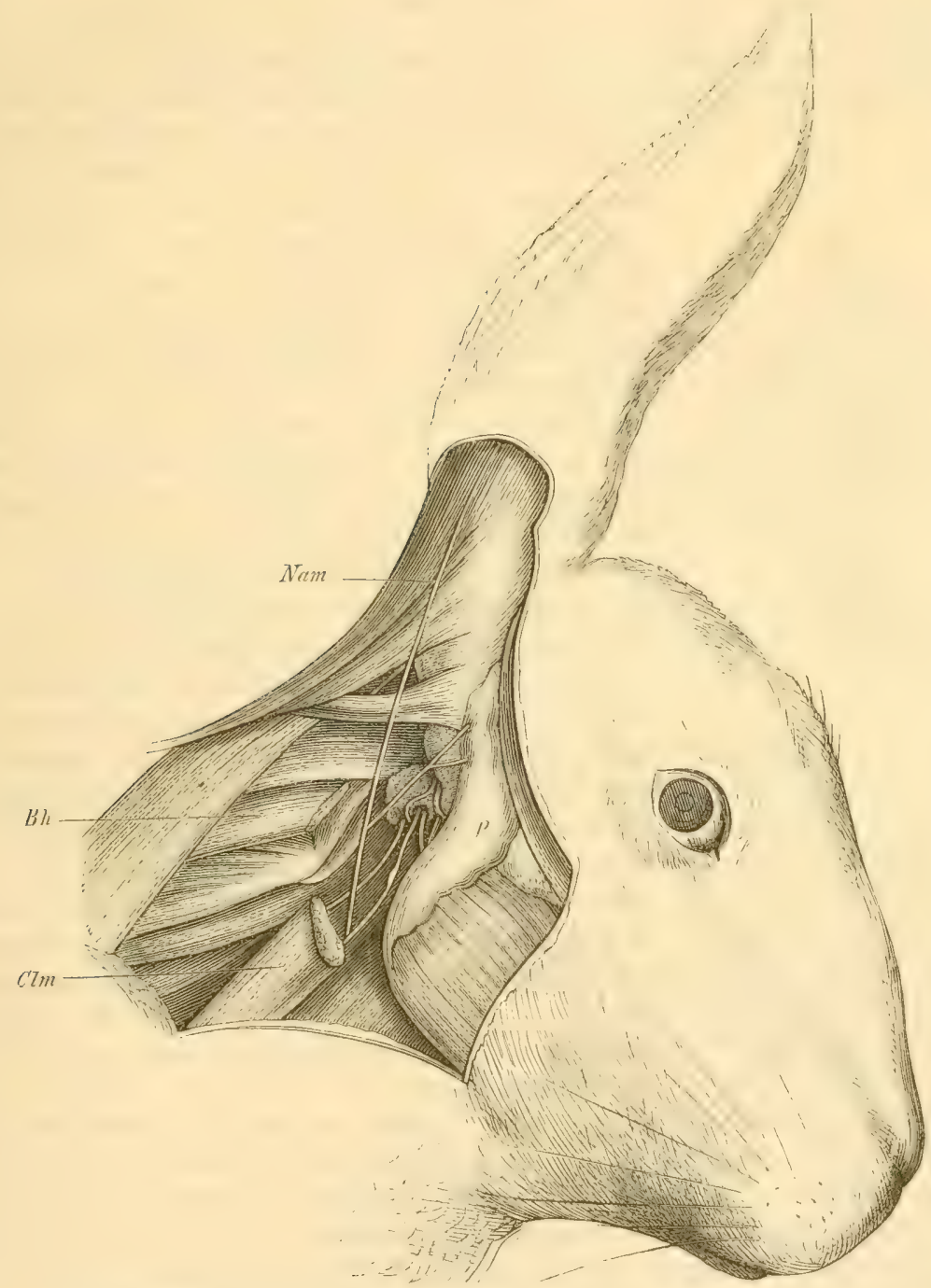

$N a m$ N. auricularis magnus. In der Tiefe ist das 0 s temporum auf einer Sägeschnittfläche sichtbar; nach Ludwig (514). Vorn erscheint der N. facialis, einen Ast nach unten absendend, dann der N. glossopharyngeus, der N. vagus mit seinem Plexus ganglioformis und dem R. auricularis, hinter dem N. vagus der N, accessorius.

$B h$ M. basiohumeralis durehschnitten. $C l m$ M. cleidomastoideus durchschnitten. $P$ Gl. parotis.

dieselben ihre motorischen Fasern von dem R. intermus des N. accessorius erhalten $(5 / 8)$.

Ausreißung der Nn. accessorii hat öfters einen mehrere Stunden andauernK ra use, Anatomie des Kaninchens. 2. Auflage. 
den, intensiven Diabetes zur Folge $(5 / 9)$. Über eine andere Methode für die erstere s. 41, S. 516. Taf. XIV. Fig. 2. - Nan kann auch das Ligamentum obturatorium posterius (S. 111) durchschneiden, und den N. accessorius an der Medulla oblongata aufsuchen (Bischoff, s. 41, S. 515).

\section{N. hypoglossus.}

Der zwäfte Ilimnery erscheint am lateralen Rande des Py ramidenstranges mit mehreren Wurzelfiden (Fig. 122 . $I I$, s. 223), die, in zwei Stamme ver-

Fig. 143.

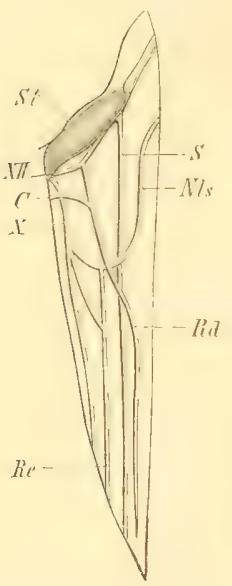

Ursprung des $\mathbf{R}$, descendens $\mathbf{n}$. hy poglossi (s. Fig. 136, S.317). Die Hautränder des an der rechten Seite des Halses gefuhrten Längsschnittes sind angedeutet. St M. stylohyoideus major, sich an das Cornu majus oss. hyoidei inserierend. $X I I N$. hypoglossus, nach unten den $\mathrm{R}$, descendens $R d \mathrm{ab}$. gebend. $C$ Wurel des $\boldsymbol{R}$. descendens aus dem N. cervicalis III. $X$ $\mathrm{N}$, vagus. $R c$ Ramus cardiacus n. vagi, der eine zweite Wurzel aus dem N. laryngeus superior erhält. $N l s \mathrm{~N}$. laryngeus superior. $S \mathrm{~N}$. sympathicus. einigt, durch die Foramina condyloidea superius und inferius die Schädelhöhle verlassen. Verläuft anfangs unter dem $\mathrm{N}$. accessorius, oberhalb des $\mathrm{N}$. vagus und mit beiden sich kreuzend, biegt sich an der lateralen Seite der A. carotis interna nach vorn, zwischen letzterer und der A. occipitalis, giebt einen Ast zum Ganglion cervicale superius ab, welcher erweiternde Fasern für die Iris enthält (459), verläuft dann an der medialen Seite der Ursprungssehne des M. mandibulae, beschreibt einen Bogen unterhalb des M. stylohyoideus major an dessen medialer Seite (Fig. 144 XII, S. 325. - Fig. 146 XII, S.329), lateralwärts von der $\mathrm{V}$. jugularis interna und der A. carotis interna sowie dem Anfange der A. carotis externa, giebt den R. descendens ab, gelangt medianwärts von der Insertion des M. stylohyoideus major an die Spitze des Cornu majus oss. hyoidei an den hinteren Rand desselben, von vorn her bedeckt vom M. cleidomastoideus und der V. facialis anterior. Verläuft alsdann an der lateralen Seite des Cornu minus oss. hyoidei und oberhalb des Cornu majus, parallel demselben an der lateralen Seite und in Begleitung der A. lingualis nach vorn zwischen $\mathbf{M}$. styloglossus und M. geniohyoideus, dann zwischen den $\mathrm{Mm}$. styloglossus und genioglossus' und verzweigt sich in sämmtlichen Zungenmuskeln. Ist der stäkste Zungennerv.

R. descendens (Fig. 144, 36, S. 325. - Fig. 146, 3\%, S. 329) verliuft an der lateralen Seite der A. carotis communis, schräg abwärts steigend, verbindet sich mit dem X. ligus und dem N. cervicalis III (rig. 143), gelangt an die vordere seite der $\Lambda$. (arotis communis, gicht $\ddot{A}_{\text {ste }}$ an die Mm. sternothyreoideus, thyreohyoideus und sternohyoideus (Fig. 144, S. 325).

Die motorischen Fasern für die Zunge sind ausschließlich in der unteren Wurzel des N. hypoglossus enthalten (501, S. 59).

Die Erregung seiner Wurzel innerhalb des Schädels kann leicht an einer isolierten Kopfhälfte eines eben dekapitierten Tieres bewirkt werden $(520-\mathrm{s}$. Gl. parotis, S. 204 ).

Durchschneidung des $N$. hypoglossus (oder des $N$. glossopharyngeus). Haut- 
schnitt in der Medianlinie, zwischen den Anguli maxillae inferioris beginnend, ca. $3 \mathrm{~cm}$ lang. Mit der Pinzette geht man an der Vorderseite der Seitenwand der Cartilago thyreoidea in die Höhe, findet an deren oberem Rande, ein wenig lateralwiirts von letzterer, die Spitze des Cornu majus oss. hyoidei. Lateralwïrts von demselben liegt die A. carotis externa, welche die $\mathrm{A}$. lingualis nach vorn absendet. Letztere verliuft parallel dem Cornu majus; oberhalb derselben liegt der $\mathrm{N}$. hypoglossus (Fig. 88. .II, S. 207), damn folgt weiter lateralwäts die glinzende Selıne des M. mandibulae; medianvärts von den Aa. carotis externa und lingualis liegt der verhältnismäßig sehr schwache N. glossopharyngeus.

Oder man geht an der medialen Seite des Cornu majus in die Höhe und gelangt oberhalb der A. lingualis auf den N. glossopharyngeus.

\section{Rückenmarksnerven.}

Man unterscheidet nach den Abteilungen der Wirbelsiule: 8 Nn. spinales cervicales, 12 dorsales, 7 lumbales, 4 sacrales und 6 coccygei. Die Nn. spinales haben $R r$. anteriores und $R r$. posteriores. Letztere sind mit Ausnahme derjenigen der In. cervicales I und II schwicher, manchmal sehr betrichtlich schwacher als die Rr. anteriores; sie verlaufen ríckwarts und versorgen, jeder in der seiuem Ursprunge ungefihr entsprechenden Höhe, die Haut und die Muskeln, welche hinter der Wirbelsäule liegen. Da die latztere Region keinerlei praktisches Interesse darbietet und Alles sich mutatis mutandis wie beim Menschen verhiilt, so ist die spezielle Beschreilung der Rr. posteriores, mit Ausnahme derjenigen von den Nn. cervicales I und II, ganz unterlassen.

Die Rr. anteriores der Rückemmarksnerven, mit Ausnahme der Nn. dorsales III-XII, verbinden sich untereinander zu Plexus, die als Plexus cervicalis, brachialis, lumbalis, sacralis, coccygeus unterschieden werden. Die ersten Vereinigungsstellen von je zwei Ruckenmarksnerven werden Ansae genamnt, die in der Weise bezeichnet werden, daß z. B. die von den Nn. cervicales I und II gebildete Ansa cervicalis I genamnt wird. Aus den Ansae gehen Zweige hervor, die untereinander wiederum Fasern austauschen können, und diese Zweige setzen sich damn in die besonders benanuten Nervenstimme des Körpers fort. Zu bemerken ist, daß sehr oft ein Vervenstamm schon mit IIülfe des Messers in seinem Hauptzuge rückwarts bis zu den aus einem bestimmten Intervertelsalloch hervortretenden Rückenmarksnerven verfolgt werden kann. Damit ist jedoch nicht ausgeschlossen, daß demselben Nervenstamm sich nicht Fasern beimischen, die durch ein anderes loramen intervertebrale den Wirbelkanal verlassen haben, was auf experimentellem Wege, namentlich mil Uilfe von Nervendurchschmeidung und nachfolgender fettiger Degeneration untersucht werden muß. Nur in dem ersteren, rein anatomischen sinne ist es zu verstehen, wenu in Folgendem von dem $\mathrm{Lr}^{\top}$ sprunge eines Verven aus einem bestimmten Rückenmarksnerven die Rede ist. Die mit Hilfe des Experimentes gewonnenen Resultate beschranken sich auf die obere Extremitit und sind in einer Tabelle der Bechreibung des Plexus brachialis beigefügt; ihre Zuverlassigkeil wird, soweit es sich um Emilteluug 
der fettigen Degeneration handelt, als größer auzusehen sein, gegenüber den auf rein experimentellem Wege gewonnenen Resultaten.

Varietät en des Nervenursprunges sind in betreff einzelner Wurzeln nicht selten (602 - Untersuchung von 11 Kaninchen).

Die Spinalganglien lassen drei Gruppen von Ganglienzellen unterscheiden, zwei sind lateralwäts, eine medianwärts gelegen, die Nervenfasern der hinteren Wurzeln sollen an den Zellengruppen vorbeizichen, während sich die in den Ganglien entspringenden Fasern den Bündeln der ersteren beimischen (585). Theilungen doppelthonturierter Nervenfasern sind hiufig (652); sie kommen auch nahe an den Ganglienzellen vor (Tubes en T, s. 655).

\section{Plexus cervicalis.}

Der Plexus cervicalis entsteht aus den vorderen Ästen der Nn. cervicales I-VIII, dem oberen Aste des N. dorsalis I und einem feinen Zweige des N. dorsalis II, dex an medialen hinteren Ende des ersten Interkostalraumes durch letzleren aufwirts steigt. Derselbe liegt lateralwarts vor den Processus transversi der Ilalswirhel, resp. den Mm. scaleni und setzt sich aus den Ansae cervicales I-VIII zusammen. Die Ansa cervicalis I wird von den No. cervicales I und II gebildet $u$. s. w. Die Ansa cervicalis VIII vom N. cervicalis VIII, X. dorsalis I und dem erwahnten feinen Faden des N. dorsalis II. Aus den Ansae gehen die Nerven in der gleich anzugebenden Ordnung hervor, wobei zu hemerken isı, daß die an der Seitengegend des Ilalses liegenden Muskeln durch $\ddot{A}$ ste aus den in ungefihr entsprechender Ilohe Jiegenden Ansae versorgt werden. Die Mn. scaleni z. B. erhalten von den Ansae cervicales VI und VII feine Zweige.

Nach Peyer (109) werden die Mm. scaleni vom N. cervicalis VII versorgt.

Man unterscheidet im Plexus cervicalis zwei Abteilungen: den Plexus cervicalis im engeren sinne, welcher von den Ansae cervicales I-IV gebildet wird, und den Plexus brachialis.

Der Plexus hrachialis wird von den Ansae cervicales V-VIII gebildet und liegt ror den Mm. scaleni anticus, medius mol posticus. Derselbe zeigt eine auBerordentlich komplizierte Durchkreuzung von Faserbindeln, welche meist unter spitzen Winkeln stattfindet. Daher lißt sich mur auf experimentellem Wege ermitteln, an welchen llautstellen und in welchen Muskeln die Fasern eines jeden N. cerricalis am Arm endigen. Im Allgemeinen laßt sich daribber aussagen, daß weiter nach der Haud hin gelegene Partieen der oberen Extremitiat ihre Nervenfasern aus Wurzeln erhalten, die naher dem unteren Ende des Rickenmarkes entspringen. Dieses gilt sowohl für sensible als motorische Vervenfasern. Die ahsolut langsten Nervenfasern kommen aus dem X. cervialis VIII und versorgen die Itaut des ersten bis dritten nebst der Radialseite des vierten fingers; dann folgen die im N. dorsalis I austretenden Fasern, von denen die Ilaut der Inarseite des vierten und des ganzen fiunften Fingers innerviert wirl. In Muskeln, welche mehrere Sehmen aussenden, werden die zu jeder einzelnen Sehne gehörenden Muskelfasern von besonderen Vervenstammen versorot. Die letzteren kömnen aus verschiedenen Riickenmarksmerrenwurzeln ihren Ursprung nehmen. Weiter unten (S. 331) ist eine label- 
Iarische Ühersicht der auf experimentellem Wege ermittelten Nervenverhreitung an der oberen Extremitit gegeben, wie sie in ähnlicher Vollstindigkeit von keinem anderen Körperteil irgend eines Säugers vorliegt. Ilier folgt zu-

Fig. 144.

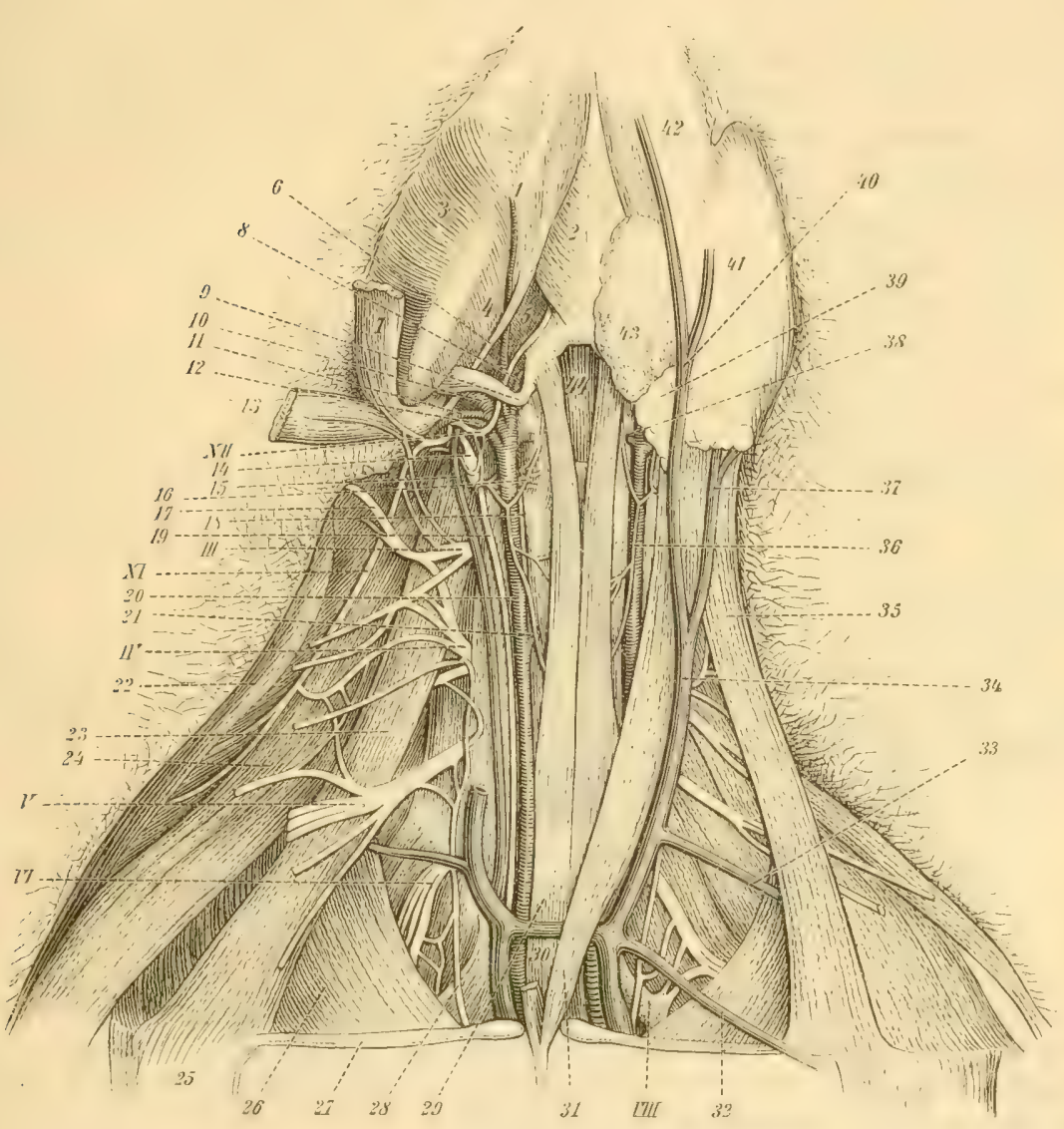

Ansicht des Halses von vorn, mit injizierten Arterien und Venen. Nach Schneider (250). Rechterhand oberflächliche Schicht, linkerhand tiefe Schicht. 1 A. maxillaris externa, 2 M. mylohyoideus, 3 M. masseter. 4 II. pterygoideus internus. 5 M. styloglossus. 6 Sehne des M. mandibulae. 7 Oberes Ende des M. sternomastoideus, abgeschnitten. 8 A.lingualis. 9 Cornu majus oss. hyoidei, an welches sich der $\mathbf{M}$. stylohyoideus major inseriert. $10 \mathrm{~A}$. carotis externa, nach Abgabe der Aa. occipitalis etc. $11 \mathrm{~A}$. occipitalis. $12 \mathrm{~A}$. carotis interna. 13 Oberes Ende des $\mathbf{I I}$. cleidomastoideus, abgeschnitten, $\quad$ III N. hypoglossus. 14 Plexus ganglioformis des $\mathrm{N}$. vagus. $15 \mathrm{~V}$. jugularis interna. $16 \mathrm{~N}$. laryngeus superior. $17 \mathrm{~N}$. auricularis magnus, $18 \mathrm{~N}$. sympathicus. $19 \mathrm{~N}$. vagus. $I I I \mathrm{~N}$. cervicalis tertius. $X I \mathrm{~N}$, accessorius. $20 \mathrm{~A}$. carotis communis. $21 \mathrm{~A}$. thyreoidea superior. IV N. cervicalis quartus. $20 \mathrm{M}$. cucullaris, $23 \mathrm{M}$. basiohumeralis dexter 24 II. levator seapulae major. $V$ N. cervicalis quintus. VI N. cervicalis sextus. 25 M. deltoideus. 26 M. pectoralis minor. 27 Clavicula. $28 \mathrm{~N}$. phrenicus. 29 M. sternohyoideus, $30 \mathrm{~V}$. jugularis transversa. 31 II. sternomastoideus (linkerhand abgeschnitten). VIII N. eervicalis oetavus. 3:" sulkutaue Vene der oberen Extremitat (Varietit) $33 \mathrm{~V}$ transversa scapulae, abgeschuitten, $34 \mathrm{~V}$. jugularis externa, $35 \mathrm{ML}$, basiohumeralis sinister. $36 \mathrm{R}$ descendens $\mathrm{n}$. hypoglossi. $37 \mathrm{~V}$. facialis posterior. $38 \mathrm{~A}$. laryngea (superior). 32 Unterer Teil der Gl. parotis. $40 \mathrm{~V}$. facialis anterior. $41 \mathrm{~V}$. maxillaris externa, abgeschnitten. $42 \mathrm{~V}$. submentalis, in die linke V. faeialis anterior mündend. $43 \mathrm{GI}$. submaxillaris. 44 Membrana lyothyreoidea.

nitchst die Aufzahlung der Ansae cervicales und die spezielle Beschreibung der einzelnen Nerrenstamme; die in den letzteren Abschnitten enthaltenen Angaben iiber den Lrsprung der betreffenden Yervenstamme beziehen sich, 
wie schon erwïhnt, nur auf die mit dem Messer darstellbaren IIauptzüge und schließen die Beimengung kleinerer, aus anderen Nn. cervicales herstammenden Faserzüge nicht aus. In Übrigen ist auf die in der allgemeinen Neurologie erwahnte Monographie (W. Krause, 55), sowie auf eine Arbeit von Peyer (109) zu verweisen. Bei der erstgenamnten Publikation war der feine Faden noch nicht gefunden, der rom N. dorsalis II zur Ansa cervicalis VIII verlïuft (S. 336). Die Feinheit dieses Fiddchens lißßt jedoch vicht bezweifeln, daß die Resultate der experimentellen Untersuchungen iber die Vervenverteilung in der oberen Extremitit durch die Existenz jener Verbindung in keiner Weise in Frage gestellt werden können.

Ansa cervicalis I liegt vor dem Processus transversus des Atlas, s. Nn. cervicales I und II.

Ansa cervicalis 1I: N. occipitalis minor.

Ansa cerviculis III: Äste zum oberen Teile des M. longus colli, N. auricularis magnus, $\mathbf{N}$. subcutaneus colli inferior.

Ansu cerviculis $\mathrm{I}^{\mathrm{r}}$ : $\mathrm{X}$. phrenicus, $\mathrm{Yn}$. supraclaviculares, Rr. musculares zum .1. rhomboideus cervicalis, die schraig abwirts und rückwairts laufen.

Ansa cerviculis $V: \mathrm{N}$. suprascapularis, Nn. thoracici zum Teil.

Ansu cerviculis VI: Nn. (horacici zum Teil, Nn. subseapulares, perforaus brachii, axillaris, radialis, medianus.

Ansa cervicalis VII: Nn. perforans brachii, radialis, medianus.

Ansa cervecalis VIII: No. ulnaris, medianus, radialis, cutaneus brachii minor, culaneus brachii major, longissimus pectoris; Verbindungsfaden zum Ganglion cervicale inferius.

\section{Plexus cervicalis.}

\section{N. cervicalis I.}

Erscheint zwischen Os oceipilis und hinterem Teil des Atlas; sein $R$. posterior ist beträchtlich starker als der vordere. biegt sich unter der $\Lambda$. vertebralis rückwirts, verzweigt sich an den N. rectus capitis posticus major und die anderen eigentlichen Kopfmusheln. sowie den M. rectus rapitis lateralis.

Der R. anterior (Fig. 146 I. S. 329) giebt einen Verbindungsast zum N. vagus, verliaft zwischen den $\mathrm{Mm}$. rectus capitis anticus und rectus capitis lateralis, denselben $\ddot{\Lambda}$ ste zusendend, sowie einen Ast zur Ansa cervicalis I abgebend.

\section{N. cervicalis II.}

Der R. posterior ist der stirkere. giel» $\ddot{\Lambda}$ ste an die tiefen Rückenmuskeln, liault als Y. occipitulis major reickwärts, damn hogenförmig aufwäls, durchbohrt den .I. cucullaris und verästeh sich in der Ilaut des Ilinterkopfes. Der" $R$. anterior giobt hauptsichlich den $N$. occipitalis minor ab. Dersellse verliuft. an der hinteren seite des Processus transiersus des Atlas, gelangt aufsteigend 
hinter den Processus mastoideus, giebt Äste zur IIaut des Hinterkopfes, verbindet sich mit dem N. occipitalis major, lateralwairts von letzlerem verlaufend. Durchbohrt den hinteren Teil des Seutulum und den M. scutulo-auricularis superior posticus, steigt am vorderen Rande des Tubus (hinterer Ohrnerv,

Fig. 145.

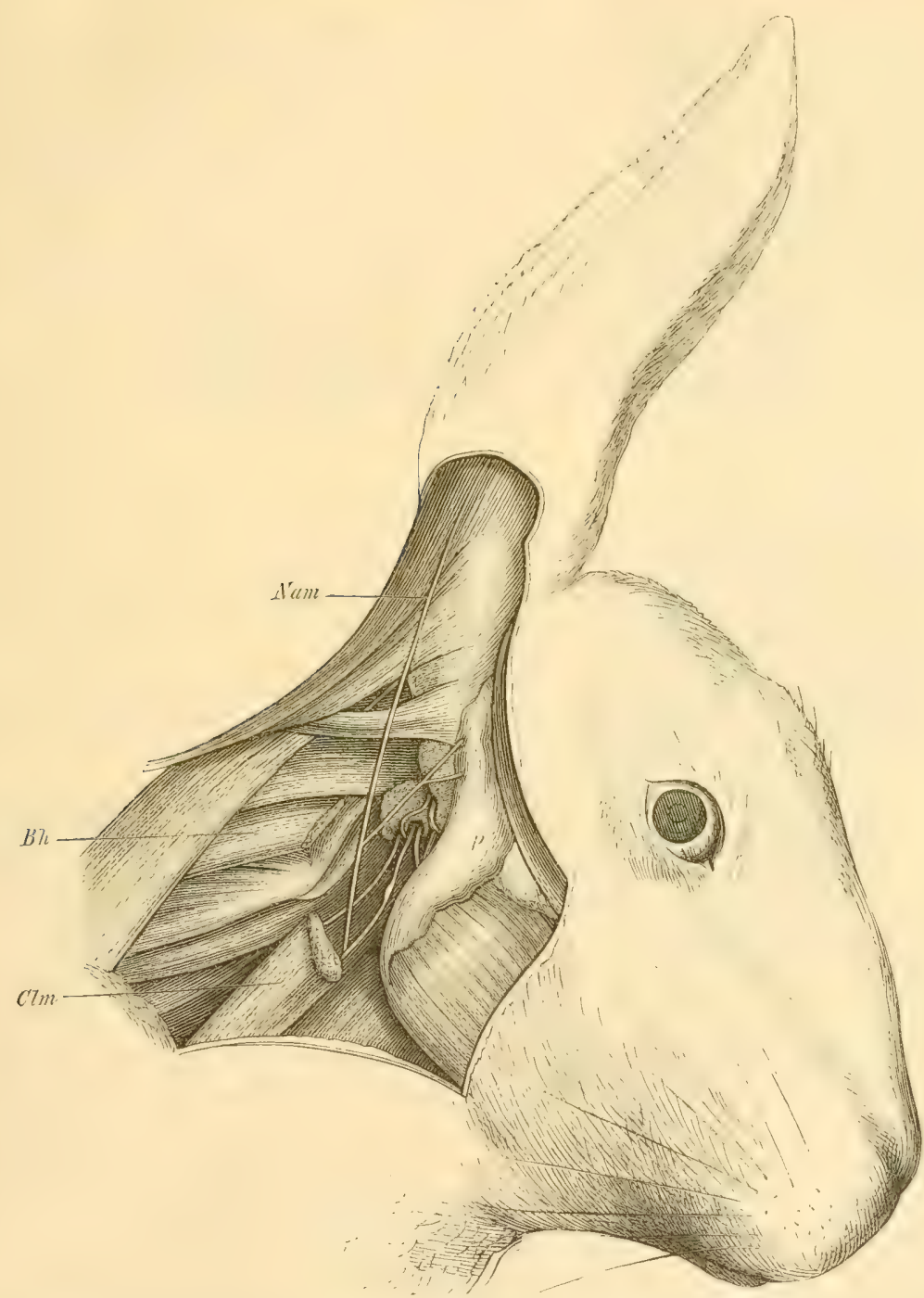

$N$. $N$, auricularis magnus. In der Tiefe ist das Os temporum auf einer Sägesehnittfläche sichtbar; nach LudVicular mager

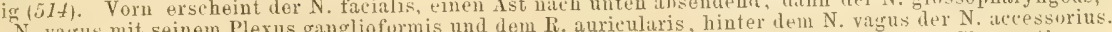
$B h$ II. basiohumeralis durchschnitten. Clm M. cleidomastoideus durchschnitten. $P$ Gl. parotis.

3/4) dicht vor der gemeinschaftlichen Sehne der Mm. scutulo-auricularis superior anticus und frontoscutularis aufwärts, versorgt den vorderen Teil der Haut der Concha. 


\section{N. cervicalis III.}

Beteiligt sich an der Bildung der Ansie rerricales II und III, gieht hauptsächlich den $\mathrm{N}$. auricularis magnus al, und $\mathrm{A}$ ste zum oberen Teil des M. Longus colli. - S. a. Fig. 443, S. 322.

N. auricularis magnus (Fig. 144, 17, S. 325. - Fig. $145 \mathrm{Nam}, \mathrm{S} .327$. - Fig. 146,8$)$ entsteht vom N. cervicalis III, verlauft aufwäts hinter der hinteren flache des Processus transversus des Atas, an der medialen Seite und damn hinter dem hinteren Rande des M. (Pleidomastoidens, unmiltelbar bedeckt von der Fascia cervicalis, gelangt an die hintere Geite des R. medius der V. auricularis posterior, wahrend an dessen vorderer Seite der R. medius der A. auricularis posterior verlauft, und veristelt sich mit mehreren Zweigen an der medialen Flache des iuBeren ()hres in der Haut desselben, sendet auch einen Ast auf die laterale Fläche des hinteren Teiles der Scapha.

Man kann die Nn. auricularis magnus und occipitalis minor auch am lebenden Tiere nach Anleitumg der Fig. 145 (S. 325) aufsuchen und reizen (́), S. 199$\}$.

\section{N. cervicalis IV.}

Der N. cervicalis IV (Fig. 147 IV, S. 335) bildet die Ansae cervicales III und IV, giebt den N. subcutaneus colli inferior hauptsichlich ah, ebenso die Nn. supraclavicularis posterior und phrenicus.

Varietät. Der N. cervicalis IV giebt einen Faden zur Ansa cervicalis VI. Die darin enthaltenen Fasern gelangen in der Bahn des N. axillaris zum M. deltoideus $(109$, S. 70 . - 55, S. 21).

N. subcutaneus colli inferior s. cervicalis superficialis entsteht aus dem N. cervicalis IV, verläuft an der medialen Seite des M. cleidomastoideus, sehligy sioh um dessen hinteren hand und steig̣t ron da, an seiner hateralen Seite, mit dep l. lacialis sich rechlwinklig̣ kreuzend und lateralwirts von derselhen zum V. platysma und der llaut des Lnterkiefers aufwarts. Giebt den $N$. subcutaneus colli medius zur Haut der lateralen AuBenfläche des Halses.

Nn. supraclaviculares. Die posteriores entstehen von dem N. cervicalis IV, latufen am hinferen lande des $M$. cleidomastodeus in der Fossa supractaricularis abwarts, versorgen die Ilaut der oheren Thorax-Partic an der Rubckenfliahe, die Mm. lesalor seapulate major, basiohumeralis. levator anguli seapulare, rhomboidens dorsalis und den vorderen Teil des II. cucullaris. Der $\boldsymbol{N}$. supraclavicularis medius stammt rom $\mathrm{N}$. cervicalis $\mathrm{V}$, lituft zur Haut, die den M. deltoideus bedeckt; der N. supraclavicularis anterior, ebenfalls vom $\mathbf{N}$. cervicalis V alostammend, geht dureh die Fossa supfordavicularis abwarts, vor der Mitte der Clavicula zur IIaut der oberen Brustgegend.

N. phrenicus entsteht (Fig. 147, S. 335) hauptsichlich von dem N. cervicalis IV, verläuft abwarts vor dem M. scalenus anticus (Fig. 146, 18), dann hinter dem Anfang der V. subclavia in die Brusthöhle (Fig. 144, 28, S. 325). Hier liegt der N. phrenicus dexter am hinteren lateralen Rande der 
V. cava superior dextra, vor einer V. spinalis, die in das Foramen intervertebrale dorsale II eintritt, gelangt an die rechte Seite des Atrium dextrum, geht vor der Lungenwurzel, hinter dem rechten Ventrikel zur rechten Seite des Centrum tendineum, wendet sich lateralwärts, und verbreitet sich im muskulösen Teil des Diaphragma. Der N. phrenicus s in ister geht am lateralen Rande der V. cava superior sinistra, vor der linken Lungenwurzel, hinter dem Atrium sinistrum und dem Ventriculus sinister zur linken Seite des Centrum tendineum und verbreitet sich analog dem N. phrenicus dexter. Beide Nn. phrenici wer'den von den $V_{v}$. phrenicae superiores dextra und sinistra begleitet.

Durchschneidung des N.phrenicus.

A. Oben am Halse. Operation wie bei Durchschneidung der Nn. cervicales V und VI (s. Durchschneidung des Plexus brachialis S. 335). Der N. phrenicus erscheint zwischen den Nn. cervicales IV-VII.

B. Unten am Halse, Hautschnitt in der Medianlinie, vom oberen Rande des Sternum beginnend, nach oben, einige cm lang. Aufsuchung des lateralen Randes der Insertionen der $\mathbf{M m}$. sternomastoideus und cleidomastoideus, Freilegung des oberen hinteren Randes der ersten Rippe; medianwärts neben derselben am Halse in dem Winkel, den die Vv. jugularis externa und subclavia bei

Ansicht des Halses von vorn, Arterien iujiziert. Nach Schneider (250). I A. maxillaris externa. 2 II. mandibulae. $\mathrm{X} I I \mathrm{~N}$. hypoglossus. 3 Ursprungssehne des M. mandibulae. IX N. glossopharyngeus. $4 \mathrm{~A}$. occipitalis. 5 Oberes Ende des M. sternomastoideus, abgeschnitten. $6^{2}$ Oberes

Ende des M. cleidomastoideus, abgeschnitten. I N. cervicalis primus. $y$ MI. rectus capitis lateralis. $\delta$ N. auricularis nagnus. II N. cervicalis secundus. III N. cervicalis tertius. IV N. cervicalis quartus. 9 Rand des II. cucullaris, io M. levator scapulae uajor. FI N. cervicalis sextus, 11 M. basiohumeralis. VII N. cervicalis septimus. VIII N cervicalis octavus, $12 \mathrm{~A}$. subclavia sinistra, welche die $\Lambda$. vertebralis nach oben entsendet. $13 \mathrm{~N}$. dorsalis primus. 14 Ganglion cervicale inferius. 15 Ansa subclavialis. 16 Querdurchschnitt der dritten Rippe, daruber die Durchschnitte der zweiten und ersten Rippe. 17 Ganglion dorsale primum. $78 \mathrm{~N}$. phrenicus. $19 \mathrm{~V}$. cava superior sinistra. 20 Aorta descendens thoracica. 21 Linke Lunge. 22 Linker Herzventrikel. 23 Linkes Herzohr. $\mathrm{I}$. varus, 24 Rechtes Herzohr. $25 \mathrm{~V}$. cava superior dextra. 26 Aorta adscendens. 27 Rami cardiaci, welehe aus dem Ganglion cervicale inferius stammen. 28 Truncus anonymus. 29 Oesophagus. 30 Trachea. $31 \mathrm{~N}$. laryngens inferior. $32 \mathrm{M}$. longus colli. $33 \mathrm{~V}$. thyreoidea inferior. 34 Im. sternolyoidei. $35 \mathrm{~N}$. sympathicus. $\quad \vec{N}$. cervicalis quintus. $36 \mathrm{R}$. cardiacus n. vagi (N. depressor). 37 $\mathrm{R}$, descendens $\mathrm{n}$. hypoglossi. 38 Plexus ganglioformis n. vagi. 39 Ganglion cervicale superius. 40 Membrana thyreohyoidea. 41 Cornu majus oss. hyoidei, an welches sich der M. stylohyoideus major inseriert. 42 I. styloglossus. 43 M. mylohyoideus. 
ihrem Zusammenfluß zur V. cava superior bilden (521), wird der Nerv durchschnitten. Die Operation gelingt leicht $(501, \mathrm{~S}, 60)$.

\section{Plexus brachialis.}

\section{N. cervicalis V.}

Derselbe bildet die Ansae cervicales IV und V (Fig. 144 V, S. 325. Fig. $147 \mathrm{~V}$, S. 33:3), giebt die Nn. supraclaviculares medius und anterior (s. N. cervicalis IV) ab, sowie einen Faden zum N. phrenicus. und VII.

Nach Peyer (109) erhält das Diaphragma Fasern aus den Nn. cervicales VI

N. suprascapularis. Entsteht von der Ansa cervicalis V, läuft abwärts durch die Fossa supraclavicularis, giebt einen $\Lambda$ st zu dem oberen Teile des M. subseapularis, biegt sich um das Collum scapulae in die Fossa supraspinata, versorgt den M. supraspinatus; gelangt dann abwairts dicht an der Wurzel des $\Lambda$ eromion und medianwarts vou demselben, das Ligamentum transversum scapulae durchbohrend, in die Fossa infraspinata zu dem M. infraspinatus, in welchem sich seine Eudäste verzweigen.

$\mathrm{N} n$. thoracici posteriores entspringen von den Ansae cervicales V und VI, durchbohren den II. scalenus medius, versorgen die Mm. rhomboidei cervicalis und dorsalis.

N. thoracicus longus entsteht von den Nn. cervicales VI und VII, lauft abwirts ibber die erste Rippe; rereinignt sich in ler Höhe der dritten Rippe mit der $\Lambda$. thoracica longa, geht zum 11 . seralus anticus major, die genannte Arterie begleitend.

Nach Peyer (109) wird der Halsteil des M. serratus anticus major vom N. cervicalis VI, der Brustteil von den Nn. cervicales VII und VIII aus versorgt.

$\mathrm{N}$. thoracici anteriores entspringen von der Ansa cervicalis VI, senden $\ddot{\Lambda}$ ste zu den $\mathrm{Mm}$. pectorales superficialis, major und minor. Der erstere $\Lambda$ st kommt wahrscheinlich aus dem $\mathrm{N}$. cervicalis VII, wendet sich um den oberen Rand des Mushels in der Mitle seiner Lange nath vorn und giebt auch eiuen Faden zur lateralen Partie des $\mathbf{H}$. pectoralis major ab.

Vn. subseapulare's entstehen aus der Ansa rervicalis VI, haupt sichlich vom N. eervicalis VII; die oberen versorgen den unteren Teil des M. subscapularis und den I. teres major; der untere geht als $\mathrm{N}$. thoracicodorsulis, den R. thoracicodorsalis der $\Lambda$. subscapularis begleitend, zu dem M. latissimus dorsi.

\section{Verbreitung des Plexus brachialis.}

Die Verbreitung der in den Plexus brachialis eintretenden No. cervicales erhellt aus folgender Übersicht. 
Verbreitung der in den Plexus brachialis eintretenden Nervenwurzeln, auf experimentellem Wege ermittelt (109).

\begin{tabular}{|l|l|}
\hline $\begin{array}{l}\text { No. cer- } \\
\text { vical. u. } \\
\text { dorsal. }\end{array}$ & MIuskeln \\
\hline IV & $\begin{array}{l}\text { Deltoideus } \\
\text { Deltoideus } \\
\text { Gleno-ulnaris }\end{array}$ \\
\hline
\end{tabular}

\section{Pectoralis superficialis}

Pectoralis minor

Abductor brachii inferior

VI

Deltoideus

Supraspinatus

Infraspinatus

Subscapularis

Teres minor

Pectoralis superficialis

Pectoralis major

Pectoralis minor

VII

Supraspinatus

Infraspinatus

Teres minor

Subscapularis

Teres minor

Extensor antibrachii par- Palmaris

vus

Anconaeus longus

Anconaeus lateralis

Anconaeus medialis

Anconaeus minimus

Flexor carpi radialis

Flexor digitorum profundus

Flexor digitorum sublimis

Extensor antibrachii parvus Flexor carpi ulnaris

Anconaeus longus

Anconaeus lateralis

Anconaeus medialis

Anconaeus minimus

Pronator teres

Flexor carpi radialis

Flexor digitorum profundus

Flexor digitorum sublimis

Palmaris

\section{Coracobrachialis}

Gleno-ulnaris .

Brachialis internus

Extensores carpi radiales

Serratus anticus major (Brustteil)

Abductor brachii superior

Abductor brachii inferior

Anconaeus lateralis

Anconaeus medialis

Pronator teres

Flexor carpi medialis

Extensores carpi radiales

Flexor carpi ulnaris

Extensor digiti quarti proprius

Extensor digitorum communis

Extensor pollicis

Abductor pollicis

Extensor digiti quarti proprius

Extensor digitorum communis

Abductor pollicis

Flexor digiti minimi

Lumbricales

Interossei
Haut

Vordere mediale Seite des Schultergelenkes

Uber der Clavicula

Untere laterale Gegend des Halses bis zur Mitte zwischen Schulter und Unterkiefer

Vordere Seite des Oberarmes bis zum unteren Dritteil

Über dem oberen Ende der $\mathbf{M m}$. anconaei longus und lateralis bis zum Schulterblatt

Über der lateralen Seite des Schultergelenkes

Über dem Ansatzende des M.pectoralis superficialis

Vordere Fläche des Vorderarmes bis iber die Mitte hinunter

Ellenbogenbeuge

Über dem unteren Teil des M. anconaeus lateralis

Über dem unteren Ende des M. anconaeus longus bis $z$. Olecranon

Mediale Seite des Oberarmes und Vorderarmes

Vordere laterale Seite des Vorderarmes

Über der Sehne des M. flexor carpi radialis

Volarfläche der Hand

Volar- und Dorsalfläche des Daumens

Volar- und Dorsalfläche des zweiten Fingers

Volar- und Dorsalfläche des dritten Fingers

Radialseite des vierten Fingers

Hintere Seite des Vorderarmes.

Gegen die Hand hin an derUlnarseite

Ulnarseite der Hand

Ulnarseite des vierten Fingers.

Volar- und Dorsalfläche des fünften Fingers 
N. cutaneus brachii minors. medialis minor entsteht von der Ansa cervicalis VIII, verliuft mit einer Wurzel des $N$. radialis, geht zur hinteren und medialen Seite des Oberarmes.

N. cutaneus brachii major s. medialis major entspringt von der Ansa cervicalis VII, verlinft am Oberarm, an den N. ulnaris geschmiegt, gelangt in dessen Mitte unter die Fascia brachialis, veriistelt sich, die V. basilica begleitend, in der Haut der medialen Seite des Oberarmes und der ulnaren des Vorderarmes mit langen $\ddot{A s t e n . ~ E i n e r ~ d e r s e l b e n ~ w e n d e t ~ s i c h ~ u n t e r l u a l b ~ d e r ~}$ Ellbogengrube $u m$ den M. flexor carpi ulnaris in querer Richtung dorsalwirts und verliuft dann auf der Dorsalfliche des Vorderarmes an dessen ulnarer Seite bis zur Hand.

N. perforans brachii s. musculocutaneus ist wenig entwickelt, stammt von den Nn. (•ervicales VI und VII, namentlich von einem Bundel des X. cervicalis VII, welches sich in den $\mathrm{V}$. medianus fortsetzt, rerliuft an der medialen filiche und dem unteren Rande der Sehne des M. latissimus dorsi, sowie an der lateralen seite der : In. medianus und radialis, durchbohrt den II. coracolnachialis, versorọ den letzteren Muskel und den oberen Teil des ir. gleno-ulnaris an seiner medialen Seite.

Die fehlenden Muskeläste des N. perforans brachii werden vom N. medianus, seine fehlenden Hautäste vom $R$. superficialis $\mathrm{N}$. radialis ersetzt.

N. axillaris s. circumflexus brachii entspringt aus der Ansa cervicalis VI, hauptsichlich vom Y. cervicalis V', verlauft hinter der A. brachialis, gelangt hinter das Gollum humeri, grebt den X. cutaneus hrachii posterior Jateralis al); trill damn, das Collum humeri umwindend, vor dem II. anconateus longus auf die laterale Seite des Oberarmes, verzwrigl sich in den IIm, deltoideus, teres minor und den $\mathbf{M m}$. abductores brachii superior und inferior.

Der $N$. cutaneus brachii posterior lateralis s. Iateralis verläuft zwischen II. deltoideus und II. antonaeus lateralis, tritt mit der V. cephalica durch die Fascia brachialis unter die Haut und rersorent die letztere an der lateralen Seite des Oberarmes mitlels eines Zwoiges, der den obersten Teil der V. cephalica am Oberarm hegleitel. Mittels anderer Zweige, die nach oben und lateralwirts ansstrahlen, versieht der N. cutaneus brachii posterior lateralis die Haut, welche die Scapula bedeckt.

V. medianus entspringt mit einem unteren Bündel aus der Ansa cerviralis VIII, mit einem oberen aus der Ansa cervicalis VII; verlauft anfangs unter der $\Lambda$. brachialis, an den oberen zwei brilleilen des Oberarmes ror derselhen, gelangt weiter abwirts, an der medialen seite der Arterie vorbeiyehend, hinter die letztere. An der Grenze des oberen und mittleren Drittteiles des Oberarmes entsendet der X. medianus einen abwirts steigenden h. muscularis fiur die Mm. gleno-ulnaris und brachialis internus, der die fehlenden entsprechenden Aste des X. perforans hrachii ersetzt. In der Ellenbogenwlube liegl der X. medianus, bedecht von dem oberflichlichen Sehneufaszikel des .II. Gleno-ulnaris an der radialen Seite der Arterie und weiter abwarts an der ulnaren seile der $A$. radialis. Vou der Ellenbogengrube an abwarts liuft der X. medianus zwischen den Mm. pronalor teres und flexor carpi radialis, giebt Rr. musculares fur die Im. pronator teres, flexor carpi radialis, flexor 
digitorum sublimis, palmaris, sowie den $\mathrm{N}$. interosseus antibrachii volaris al, und spaltet sich in zwei $\mathrm{A}$ ste, einen radialen und einen ulnaren. Dioselben verlaufen mit der $A$. radialis und sind zwischen dem Radius nebst den Sehmen des M. flexor carpi radialis einerseits, den Mm. palmaris nebst flexor digitorum sublimis andererseits gelegen. Sie gelangen volarwarts bedeckt rom Ligamentum carpi volare proprium zur Hohlhand. deren Volarflache sie mit versorgen.

Der radiale Ast giebt den $N$. digitalis volaris pollicis radialis, sowie die $\mathrm{N} n$. interossei metacarpi rolares $I$ und $I I$ fir die Ulnarseite des ersten und die Radialseite des zweiten Fingers, sowie für die Unarseite des zweiten und die Radialseite des dritten Fingers ab.

Der ulnare Ast spaltet sich in zwei Zweige, von denen der radiale für die Volarflichen der ulnaren Seite des dritten und der radialen Seite des vierten Fingers bestimmt ist und als $\mathrm{V}$. interosseus metucarpi volaris $I I I$ bezeichnet wird, wihrend der ulnare Zweig den N. interosseus metacirpi volaris IV aus dem N. ulnaris verstärkt.

$N$. interosseus antibrachii colaris verliuft an der volaren seite des oberen Endes der Llna und im Inferstitum interosseum antibrachii abwarts, versorgt den II. flexor pollicis longus und die radialwaits gelegenen Bündel des M. flexor digitorum profundus.

Durchschneidung des $N$. medianus. Hautschnitt an der medialen Seite im mittleren Dritteil des Oberarmes, $2-3 \mathrm{~cm}$ lang, in der Längsrichtung, parallel dem medialen Rande des $\mathbf{1}$. gleno-ulnaris. Durchschneidung der Faszie; der N. medianus liegt vor der A. brachialis und dem N. ulnaris, ist stärker als letzterer Nerv.

Resektion des N. medianus kann mit Vorteil benutzt werden, um die fettige Entartung der Terminalfasern innerhalb der motorischen Endplatten z. B. im II. flexor carpi radialis zu studieren (522 и. 872).

N. ul naris entsteht hauptsichlich von der Ausa cervicalis VIII, rerlauft an der oberen Halfte des Oberarmes, an der hinteren Seite der A. brachialis, an der vorderen der $\mathrm{V}$. brachialis, gelangt in einger Entfermung hinter der Arterie herabsteigend an der medialen Seite des M. anconaeus medialis, $\quad$ on der $A$. collateralis ulnaris inferior begleiter, hinter den Condylus medialis humeri, ror dem Olecramon in der Rinne zwischen beiden und dem M. anconaeus minimus. Dann wendet sich der N. ulnaris am oberen Teil der ITna rolarwärts, gelangt zwischen Llna und den beiden köpfen des M. flexor carpi ulnaris an die Uhnarseite der A. ulnaris, welche er begleitet, zwischen den Mm. flexor digitorum profundus, flexor earpi ulnaris und der Uha verlanfend. Er versorgt den M. flexor carpi ulnaris und den uluaren Teil des M. flexor digitorum profundus. giebt den N. ulnaris dorsalis ab und gelangl, an der Volarseite der A. ulnaris verlaufend, bom Ligamentum carpi colare transversum volarwirts bedeckt, zwischen letzterem und dem ligamentum carpi volare proprium, an der ulnaren Seite der Sehue des M. flexor digitorum sublimis für den vierten Finger und an der ralialen Seite der Sehne des M. flexor carpi ulnaris als $\mathrm{N}$. ulnaris coluris zur Jlohlhand. In der IJohlhand versorgt der $\mathrm{X}$. ulnaris volaris die Inat der Ulnarseite und den M. Hexor digiti minimi und teilt sich dann in den $R$. digitalis volaris digiti minimi ulnaris und den 
$N$. interossens melacarpi rolaris 11 , welcher einen Zweig vom N. medianus aufnimmt und sich in die Nn. digitales volares digiti V radialis und digiti IV ulnaris spaltet.

N. ulnaris dorsalis windet sich am unteren Ende der Ulna um deren ulnaren Rand zur Dorsalfliche der IIand und gielt den N. interossens metıcarpi dorsulis $I V$ ab, welcher die Nn. digitales dorsales digiti IV uluaris und digiti $V$ radialis entsendet; sowie auch den $N$. digitalis dorsalis digiti mimimi ulnaris.

Der N. ulnaris (sowie der N. tibialis) ist zu Experimenten über Degeneration und Regeneration von Nervenfasern benutzt worden (78.), ersterer oberhalb des Ellenbogengelenkes, letzterer in der Kniekehle.

N. radialis entsteht mit drei Wurzeln von den Ansae cervicales V-VIII, giebt aus seiner Wurzel vom N. cervicalis VIII einen N. subscapularis, verlänt hinter der A. axillaris, an der medialen Seite des M. anconaeus longus, giebt unterhalb der Sehne des M. latissimus dorsi einen Ast zum M. anconaeus longus, der anfangs aufwarts steigt, einen anderen für den II. anconaeus medialis, dann den R. collateralis (W. Krause), der in Begleitung der A. collateralis ulnaris media zum $\mathbf{H}$. extensor antibrachii parvus herabsteigt. Der $\mathbf{N}$. radialis verliuft damn hinter dem Ilumerus, zwischen letzterem und dem $M$. triceps hrachii und teilt sich in die Rr. superfeialis und profundus. Beide verlaufen zwischen M. anconaeus medialis und der lateralen Portion des M. brachialis internus in Begleitung der A. collateralis radialis.

Der R. superficialis verliuft am Oberarm und Vorderarm in Begleitung der V. cephalica, dann zwischen Haut und Fascia antilorachii an der ulnaren Seite des M. extensor carpi radialis brevis, und weiter abwirts zwischen den Sehnen der Mm. extensor digitorum communis und extensores carpi ladiales. Der R. superficialis teilt sich schon in der Nitte des Vorderarmes in drei Äste, welche zwischen IIat und dem Ligamentum carpi dorsale zum Handrücken gelangen und als $N$ n. interossei metacarpi dorsales $I-I I I \mathrm{zu}$ den Fingern sich erstrecken. Der am meisten ralialwirls grelegeve verliuft an der uhnaren seite der Sehne des M. abductor pollicis, versorgt die Haut des Handrückens an der Radialseite und entsendet als $\mathrm{N}$. interosseus metacarpi dorsalis I die Xn. digitales dorsales digiti primi radialis, ulnaris und digiti secundi radialis. Die Nn. interossei metacarpi dorsales II und III geben die Nu. digitales dorsales digiti secundi ulnaris, digiti tertii radialis, resp. digiti tertii ulnaris und digiti quarti radialis ab.

Der N. interosseus metacarpi dorsalis I repräsentiert die fehlenden Hautäste des N. perforans brachii mit. - Über den R. collateralis ulnaris beim Menschen s. W. Krause $(55)$. - Die Vater'schen Körperchen der Extremitäten haben beim Kaninchen $0,75-1 \mathrm{~mm}$ Länge auf $0,5-0,75 \mathrm{~mm}$ Querdurchmesser $(555)$, s. auch allgemeine Neurologie (S. 71).

Der R. profundus giebt den $N$. cutaneus untibrachii lateralis ab, welcher die Fascia hrarhialis durchbohrt und in Begleitung der $\mathrm{V}$. cephalica sich in der llaut der lateralen Seite der Dorsalfliche des Vorderarmes veriistelt, ferner einen R. muscularis für den M. anconacus lateralis. Der R. profundus gelangt dann in die Ellenhogengrule, veristelt sich in die Mm. anco- 
naeus minimus, extensor digitorum communis, extensores carpi radiales, extensores proprii digiti quarti und minimi, extensor carpi ulnaris; giebt den $N$. interosseus antibrachii dorsulis für die Mm. abductor pollicis und extensor pollicis ab.

N. longissimus pectoris entsteht von der Ansa cervicalis VIII, biegt sich an unteren Ende der $\Lambda$ chselgrube riickwirts, durchbohrt den M. pectoralis major, läuft auf dessen vorderer Fliche schriig abwiirts und medianwarts und erstreckt sich in Begleitung der V. abdominalis an deren medialer Seite bis zum Nabel, den M. cutaneus maximus versorgend.

Nach Peyer (109) wird der M. cutaneus maximus vom Plexus cervicalis aus durch den $\mathrm{N}$. cervicalis VIII versorgt.

\section{Durchschneidung des Plexus brachialis.}

A. der Nn. cervicales V und VI sinistri.

Rückenlage; die zu operierende obere Extremität wird von einem Gehilfen etwas abwärts gezogen, der zugleich Kopf und Ilals des Tieres nach der entgegengesetzten Seite wendet. Hautschnitt in einer Linie, die von der äußeren Offnung bis zu dem durchzufühlenden Processus hamatus scapulae reicht, $4 \mathrm{~cm}$ lang; die Nitte des Schnittes trift auf die Mitte der beschrichenen Linie. Durchschneidung des M. levator scapulae major und der Pars superior des M. cucullaris nach der Längsrichtung ihrer Fasern. Die Wunde wird von einem zweiten Assistenten mit stumpfen Haken auseinandergezogen. Man sieht vor den Mm. scaleni anticus und medius den $\mathrm{N}$. cervicalis $\mathrm{V}$, der einen starken Ast nach vorn und unten zum M. basiohumeralis absendet. Man fühlt die Processus transversi der Halswirbel, um sich zu orientieren. Der N. cervicalis V (Fig. 147) sendet einen Faden nach unten zur Ansa cervicalis V, der vor dem M. scalenus medius und vor dem glänzenden sehnigen Ursprunge desselben von dem Processus transversus des sechsten Halswirbels herabsteigt. Für die Untersuchung der Verbreitung des N. cervicalis V an der oberen Extremität selbst genügt es, diesen Faden zu durchschneiden. Den $\mathrm{N}$. cervicalis VI reseziert man in derselben Weise. Derselbe verliiuft etwas weiter abwärts und weniger senkrecht absteigend als der $\mathrm{N}$. cervicalis $\mathrm{V}$. , Zu Versuchen, welche ein längeres Leben des Tieres nicht erfordern, kann man auch die Nn. cervicales VII und VIII und den $\mathrm{N}$. dorsalis I in derselben Weise bloßFig. 147.

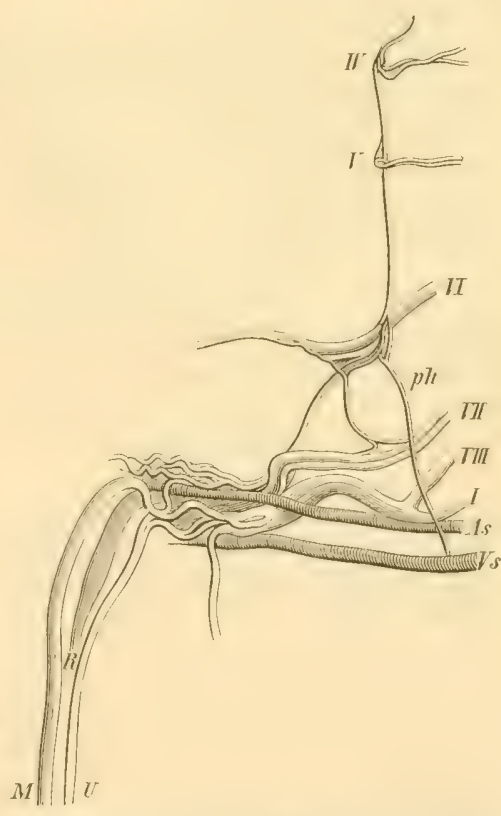

As A. subclavia dextra. Vs V. subclavia dextra. $I V-V I I I \mathrm{Nn}$. cervicales quartus-octavus. $p h \mathrm{~N}$. phrenicus. $I \mathrm{~N}$, dorsalis $1 . \quad R$ N. radialis. $U \mathrm{~N}$. ulnaris. $M \mathrm{~N}$. medianus. legen. Will man aber das Tier erhalten, so ist es schwer, an den N. cervicalis VII olne anderweitige Verletzungen zu gelangen. Die N. cervicalis VIII und dorsalis I durchschneidet man nach einem anderen Verfahren. 
B. Der Nn. cervicalis VIII und dorsalis I dextri.

Rückenlage; llautschnitt in der Medianlinie $3 \mathrm{~cm}$ lang, am oberen Rande des Sternum beginnend. Mblösung der Mm. pectorales superficialis, major und minor von ihren Ansiitzen am Sternum in entsprechender Ausdehnung. Mit einer Hohlsonde wird das dünne Bindegewebe getrennt, welches zwischen den Brustteil des M. serratus anticus major und den Mm. intercostales externi sich befindet. Unmittelbar ïber der ersten Rippe findet man die in horizontaler Richtung lateralwärts verlaufende V. subclavia, über derselben die A. subclavia. Beide werden mit cinem stumpten Haken nach oben gezogen. Weiter rückwïrts und aufwärts liegt vor dem M. scalenus anticus der aus den $\mathrm{Nn}$. cervicalis VIII und dorsalis I hervorgehende gemeinschaftliche Stamm, welcher die Fasern fiir simtliche Nn. digitales enthält, die nach einer Resektion desselben fettig entarten.

\section{Nervi dorsales.}

I)ie vorderen $\mathrm{A}$ ste der Nu. dorsales I-XII verlaufen zwischen den Mm. intercostales externi und interni unterhall, der zugehorigen Rippe und lings des unteren Randes der A. intercostalis nach vorn und heißen hier $N$ n. intercostales. Der $\mathbf{N}$. interoshalis XII verlauft unterhalb der zwöften Rippe; die In. intercostales IX-XII erstrecken sich anfangs hinter dem M. quadratus lumborum.

Der $\mathrm{X}$. dorsalis I nimmt mit einem stirkeren oberen Ast (Fig. 147 I, S.335) an der Bildumg der Ansa rervicalis VIII Teil; der $\mathrm{N}$. dorsalis II sendet einen. feinen, im ersten Interkostalramm aufwarts steigenden Faden zu derselben Ansa. Die Nu. intereostales geben Rr. cutanei ab, welche die llaut der Brust und des obren Teiles des Bauches rersorgen. Sie veristeln sich in den Mm. intercostales interni und externi die In. intercostales VHI-IX beteiligen sich an der Innorvation der Bauchmuskeln. Die Nu. intercostales II-CV greben außerdem Zweige ab, welche nahe der Axillarlinie die Seilenwand des Thorax durchbohren, indem sie dureh die Interstitia interoostalia II-CV zum M. (•ulameus maximus gelangen. Jer Vl. puadratus lumborum wird von den vorderen Isten der No. intercostales VIII-XII und der No. lumbales I-VII) rersorgt.

Bei Embryonen von $3 \mathrm{~cm}$ Länge färben sich die motorischen Fasern intensiver mit Karmin als die sensibeln, und zwar liegen im vorderen Ast die letzleren an der Außenseite der motorischen, im hinteren Aste dagegen an deren Innenseite $(775)$.

\section{Plexus lumbalis.}

Die vorleren Äste der No. lumbales IV-VII bilden ein Geflechr, welches zwischen den Mm. psoas major und quadratus lumborum vor den Processus transrersi der Lendenwirbel gelegen ist und Plexus lumbalis genannt wird. Die vorderen Aste der Nn. lumbales I- III hilden keinen Plexus, sondern rerlatufen laleralwiats ganz nach Art der Nu, infereostales. Narch unten hingl der Plexus lumbalis mit dem Plexus sitcalis zusammen. Jerselbe enthäl drei Ansale lumbales, deren erste von den $\mathrm{Nn}$. lumbales IV und $\mathrm{V}$ gebildet 
wird u. s. w. indem jeder N. lumbalis sich in einen oberen und unteren $\Lambda$ st teilt. Der untere Ast des X. lumbalis VII geht in die Ansil sacralis I über.

Die $\mathrm{Nu}$. Iumbales $\mathrm{V}$ - VII nehmen $\mathbf{c}$ om ersten bis zum letzten an Stirke zu. Die No. lumbales I-VI beteiligen sich an der Innervation des M. quadratus lumborum (s. Nn. dorsales).

Die Nn. Iumbales I-IV durchbohren den M. quadratus Iumborum. Die Nn. lumbales I-VII geben Äste zu dem V. psoas major; am meisten entwickelt ist unter diesen der Ast vom $\mathrm{N}$. lumbalis $\mathrm{V}$; der $\mathrm{M}$. psoas minor wird von den $\mathrm{Nn}$. lumbales IV-VII versorgt.

Der N. lumbo-inguinalis des Menschen wird von dem N. cutaneus femoris anterior lateralis ersetzt; der N. ilio-inguinalis rom N. genitocruralis. Man kam die Verteilungsweise auch so auffassen, daß man annimmt, der N. genitocruralis werde von den anfangs gemeinsam verlaufenden Nn. ilio-inguinalis und spermaticus externus gebildet.

$N n$. lumbales $I-I I I$ verlaufen anfangs hinter den $\mathbf{M r m}$. psoas major und quadratus lumborum, damn vor dem letzteren unmittelbar hinter der Fascia transiersa abdominis lateralwärts und abwärts, unterhall, der Processus transtersi des niichsten weiter alwirls gelegenen Lendenwirbels und reristeln sich in den Bauchmuskeln, sowie in der llaut des Bauches.

Die Verteilung der übrigen In. lumbales erhellt aus folgender Chersich. wobei zu bemerken ist, daß die in der speziellen Beschreibung angegehenen Ursprünge der peripherischen Nerven aus bestimmten No. spinales sich hier (wie auch bei den Nn. sacrales) nur auf die Resultate der anatomischen Pritparation bezichen. Das analoge Verfahren mit den Nn. cervicales ist bei letzteren bereits ausführlicher erläutert worden (S. 325).

Ansa lumbalis I: Nn. iliohy jogastricus, genitocruralis, spermaticus externus, cutaneus femoris lateralis:

Ansa lumbalis II: Nn. eruralis, obturatorius.

Ansa lumbalis III: Nn. obturatorius zum Teil, gluteus superior, gluteus inferior, cutaneus femoris posterior, ischiadicus.

\section{N. Iumbalis IV.}

Derselbe gieht Äste zu den Xlm. psoas major und minor; welehe mit den vom $\mathrm{X}$. Lumbalis $\mathrm{V}$ zu diesen Muskeln alugegebenen Zweigen anastomosieren; ferner auch $\ddot{A}$ ste zu dem 11 . quadratus lumborum, den Bauchmuskehn, sowie die Nn. iliohypogastricus und cutaneus femoris lateralis.

$N$. iliohypogastricus verlauft lateralwärts in gleicher Weise wie die No. lumbales I-III, durchbohrt den $\mathbf{M}$. quadratus lumborum, erstrecht sich in der Batuchwand zwischen den $\mathbf{M m}$. obliquus internus und transversus abdominis lateralwirts, nach unten und rorn und giebt Äste zu den Bauchmuskeln, sowie zur Haut oberhalb des Annulus inguinalis.

N. cutaneus femoris lateralis $\mathrm{s}$. anterior lateralis entsteht aus den Nn. lumbales IV und V, rerlauft anfangs in der Substauz des II. psoas major, dann vor demselben hinter der Fascia transversa alydominis, gelangl zur Bauchwand etwas unterhall, der spina anterior superior oss. ilium, durchbohrt die erstere dicht oberhalb des Liğamentum inguinale, verlauft vor den 
A. und Yiliolumbales und etwas unterhall, derselben sich abwirts biegend zur Haut des Oberschenkels an dessen vorderer und lateraler Seite, vor dem II. rectus femoris.

\section{N. Inmbalis $\mathrm{V}$.}

Derselhe steiget schriag abwirts und vorwirts, verbindet sich mit dem $\mathrm{N}$. lumbalis IV. dureh einen anderen Faden mit dem X. cutaneus femoris lateralis, durch aimen dritten mit der Ansil lumbalis III, gieht starke, nach vorn, ab)Wirls und aufwirts verlaufende Aste zum M. psoas major (Fig. 148), ferner den N. genitocruralis, einen Ast zum N. obturatorius, der nach unten zur

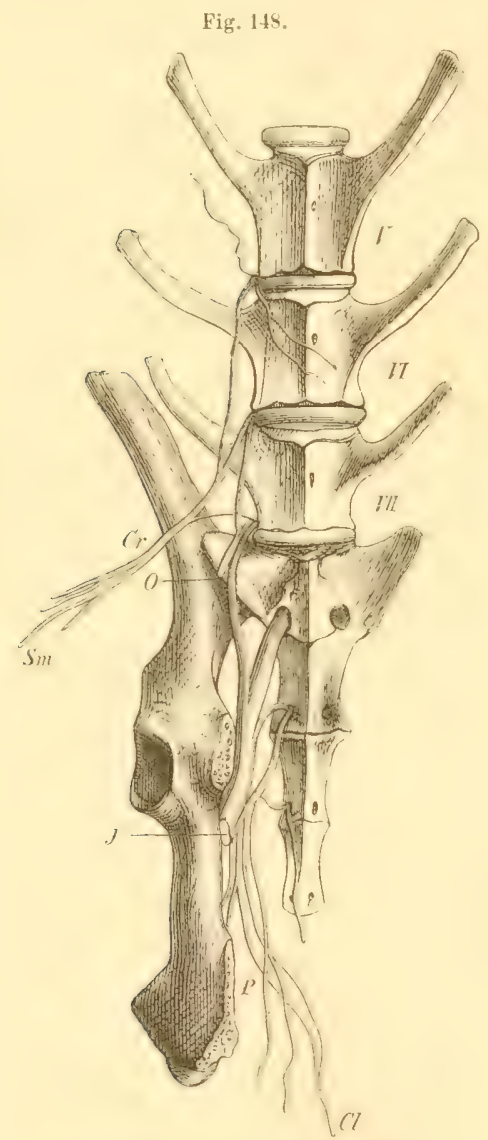

Plexus Inmbalis und sacralis. VVI VII Die drei untersten der sieben Lendenwirbel, welche sich an das ans vier Wirbeln bestehende Os sacrum anschließen. $C_{r} \mathbf{N}$. cruralis. $S m$ N. saphenus major. $0 \mathrm{~N}$. obturatorius, $J$ N. ischiadiens. $P$ ¿. pulnmlus, ans drui Fumdeln zusammengesetzt. Cl N, clitoridis.

Wurzel dieses Nerven aus dem N. lumbalis VI verlauft; nimmt weiter nach vorn einen stirkeren Ast des N. Iumbalis VI auf und bildet mit demselben den N. cruralis (Fig. 148). Es sind also eigentlich zwei Ansae Iumbales II jederseits vorhanden; eine weiter vorwårts und aufwiirts gelegene für den $\mathbf{N}$. cruralis und eine weiter abwärts und rückwär's gelegene für den $\mathrm{N}$. obturatorius.

N. genitocruralis entsteht vom N. lumbalis V, durchbohrt den M. psoas minor, verlauft schrig vor der A. iliaca externa absteigend, gelangt oberhalb der V. iliaca externa zu dem Annulus inguinalis, giebt den N. spermaticus externus ab, setzt sich beim Mannchen längs der A. und $V$. spermatica interna fort, tritt aus der vorderen Öfnung des Leistenringes hervor und verästelt sich in der Haut oberhalb der Symphysis pubis ; gelangt auch zur Haut des Hodensackes. - Beim Weibchen verläuft der N. genitocruralis lägs des Ligamentum uteri rotundum zur Haut der Labia.

Obolensky (554) machte einen Hautschnitt in die Skrotaltasche und durchschnitt die am Samenstrang verlaufenden Nerven, worauf Atrophie des Hodens eintrat. Vergl, auch S. 232.

N. spermaticus externus entspringt und verliuft anfangs gemeinschaftich mit dem $\mathrm{N}$. genitocruralis, geht als ein Ast desselben medianwirts von der V. cruralis duroh den Annulus cruralis und reristelt sich in der Ilaut des Oberschenkels medianwirts von der $V$. cruralis. 
N. cruralis entsteht hauptsichlich aus dem N. Iumbalis V (Fig. 148), giebt gleich an seinem $\Lambda$ fang $\Lambda$ ste zum M. iliacus, verlauft schriag nach vorn hinter der Fascia iliaca zum Annulus cruralis, tritt aus demselben an der lateralen Seite der $\Lambda$. cruralis hervor, teilt sich am unteren Rande der medialen Seite der Insertion des .II. iliopsoas in zahlrearhe Iste. Der stirkste ist der $\mathrm{N}$. saphenus major (Fig. 148, S'm), damn folgl der R. muscularis für den II. rectus femoris, welcher sich an der rorderen Seite des R. muscularis der A. circumflexa femoris lateralis in dem genannten Muskel veristelt. Die lateralwirts abgegebenen Rr. musculares versorgen die Mm. vastus medialis, rruralis, vastus lateralis: die medianwarts verlaufenden gehen zu den Mm. pectineus und sartorius, außerdem entsendet der N. eruralis Rr. cutanei, welche den Mr. sartorius durchbohrend zur Haut der medialen Seite des Oberschenkels gehen.

Fig. 149 .

Fig. 150.
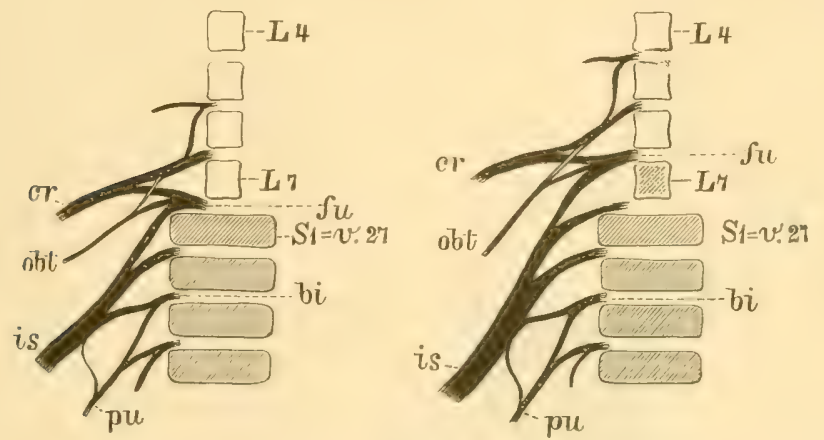

Schema der Plexus lumbalis und 'sacralis nach v. Jhering (535). Fig. 149 stellt die Norm dar (vergl. Fig. 14S), Fig. 150 eine Varietät. $L 4$ Vierter Lendenwirbel. $L 7$. Siebenter Lendenwirbel. $f u$ N. lumbalis VII s. triradiatus s. furcalis; der siebente Lendenwirbel ist in Fig. 150 postfarcal und deshalb schraffiert. S1 Erster Sacralwirbel oder 27. Wirbel vom Schädel an gezählt. bi N. sacralis II s, biradiatus s, bigeminus, $p u$ N. pudendus. is $\mathrm{N}$. isehiadieus. obt $\mathrm{N}$, obturatorius. $c r \mathrm{~N}$, cruralis.

V a rietät. In der Norm $(70 \%, 555)$ geht der N. lumbalis VII hauptsächlich in die Nu. ischiadicus und obturatorius über, giebt aber auch einen Ast (Fig. $149 f u j$ zum N. cruralis ab. Daher wird dieser N. lumbalis VII als N. triradiatus $(59$, S. 740$)$ oder N. furcalis $(555)$ bezeichnet. Im Anschluß daran ist der $\mathrm{N}$. sacralis II als $N$. biradiatus $(59$, S. 740) S. N. bigeminus (555) untersehieden worden (Fig. $1496 i)$. Als Varietät erscheint der N. lumbalis VI als N. triradiatus (Fig. $150 f u$ ). Uber die Details der Varietäten dieser Nervenwurzeln S. 555; die Differenzen werden aus solchen der Rückenmarkswurzeln (602) zu erklären sein (W. Krause).

Durchschneidung des $N$. cruralis. Hautschnitt von $3 \mathrm{~cm}$ Länge, senkrecht auf die Richtung des Ligamentum inguinale; an der Stelle beginnend, wo man dicht unterhalb des Ligamentes die A. cruralis pulsieren fühlt. Durchschneidung der Fascia lata und des M. sartorius nach dessen Längsrichtung. Die A. cruralis liegt in der Mitte (Fig. 154, S.340), die V cruralis medianwirts, der N. cruralis lateralwïts von der Arterie. Man isoliert den Nerven mit einer Hohlsonde, die man, mit der konvexen Seite gegen die A. cruralis gekehrt, zwischen letztere und den N. cruralis einschiebt (s. auch Angiologie, Unterbindung der $A$. cruralis, S. 265$)$. 
N. saphenus major verliuft anfangs an der lateralen Seite der A. cruralis, gelangt damn oberhalb des Durchtrittes der letzteren durch den M. adAuctor magnus an die laterale Seite der A. saphena magna, die Fascia lata durchbohrend. Verlauft mit der $\Lambda$. saphena magna an deren lateraler Seite und vor derselben am Oberschenkel mol Interschenkel abwirts, giebt IIautaste zur Vorderflache des Lnterschenkels; rersorgt die mediale Seite desselben und die Haut vor dem M. tibialis anticus mit Zweigen, die bis zum Malleolus medialis hinabreichen.

Durchschneidung des N. saphenus major s. Unterbindung der A. Saphena magna (S. 267).

\section{N. Inmbalis VI.}

Dersellue giebt zu den No. (ruralis und obturatorius starke Wurzeln ab. N. obturatorius entsteht aus den Nn. lumbales V und VI, verlauft an-

Fig. 151.

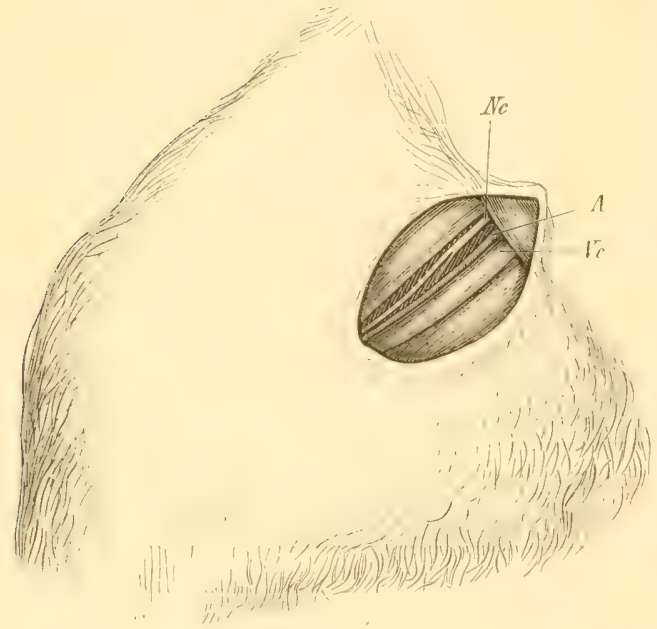

Nc N. cruralis. A A. cruralis, unterhalb des Ligamentum inguinale hervortretend. Vc V. cruralis. fangs in der Substanz des M. psoas major, tritt aus demselben nach vorn heraus, steigt an der hinteren Seite des M. iliopsoas in das kleine Becken hinab, lauft nach vorn ziemlich parallel dem R. superior oss. pubis und hinter dem M. obturator internus, dem letzteren Äste gebend, zum oberen Rande des Foramen obturatorium, an der lateralen und vorderen Seite der A. obturatoria; tritt am oberen Rande desselben aus dem Becken und grelot Iste an die Mm. obturator externus, gracilis, adductores brevis und Iongus.

Nach Durchschneidung des N. Lumbalis VI oder nach Verletzung des Rückenmarkes in der Gegend des Austrittes seiner Nervenwurzeln bleibt der Sehnenreflex an der Patella (Kniephänomen) aus (844).

\section{N. Inmbalis VII.}

Dieser unterste ist der stirkste N. lumbalis, geht größtenteils in den $\mathrm{N}$. ischiadions ibor, giebt anen Ast zum N. ohturatorius, eineu sehwacheren zum X. couralis Fig. 148, \$. 338) und den N. gluteus inferior hauptsichlich $a b$.

N. gluteus superior ist ein starker Nerv, entsteht gemeinschaftlich mit dem X. ischiadicous ete. von der Ansa Lumbalis III. Tritt an der hinteren 
Seite der A. glutea oberhall) des M. pyriformis durch die Incisura ischiadical major, giebt einen Ast an den M. pyriformis, einen zweiten zum oberen Teile des M. gluteus medius, wendet sich zwischen M. gluteus minimus und der lateralen Flache des Os ilium nach vorn, versorgt den M. gluteus minimus und endigt im M. tensor fasciae latae.

N. gluteus inferior kommt von der Ansa lumbalis III, und zwar vom N. lumbalis VII; trennt sich vom N. ischiadicus in der Incisura ischiadica major, verliuft an die vordere Flarhe des 1. pyriformis geschmiegr, wendet sich, den unteren Rand desselben durchbohrend, nach rickwirts und reristelt sich im M. gluteus maximus.

N. cutaneus femoris posterior entsteht aus der Ansa lumbalis III, gelangt unterhalb der $\mathbf{M m}$. pyriformis und gemellus superior aus der Incisura ischiadica major heraus, giebt in derselben einen Ast ab, der den II. pyriformis durchbohrt und zum unteren Teile des 11 . gluteus medius gelangt; begleitet die A. und V. ischiadicae nach abwirts. Verläuft hinter dem R. superior oss. ischii und dem Tuber ischii. an der medialen Seite der I. ischiadica und hinter dem M. semimembranosus, von zwei Blattern der Fiscia lata eingeschlossen und gieht $\ddot{\Lambda}$ ste an die mediale Seite der hinteren Fliche des Oberschenkels, mit laugen llautisten bis zum unteren Ende des letzteren hinabreichend.

N. ischiadicus entsteht (Fig. 148, S. 338) hauptsächlich vom N. lumbalis VII und $\mathrm{N}$. sacralis I, mit feineren Wurzeln von den Nn. Iumbalis VI; sacrales II und III. Gieht einen noch aus der Ansa lumbalis ItI entstehenden Ast zu den Mm. gemelli superior, inferior und quadratus femoris, einen anderen zum M. gluteus minimus. Verlauft, aus der Incisura ischiadica major unterhall, des $\mathbf{H}$. pyriformis lateralwairts und riickwirts ron den $\Lambda$. und $V$. ischiadicae heraustretend, erst hinter dem M. quadratus femoris, medianwirts vom zweiten Kopf des M. biceps femoris, Lateralwirts vom M. adductor magnus in der Furche zwischen beiden am Oborsehenkel abwirts. Er giobt Ẍste an die $\mathbf{M m}$. tensor fasciae latae. gluteus medius, weiler abwirts an den ersten, zweiten und drillen Kopf des II. biceps femoris sow ie an den M. fensor fasciae cruris, ferner an die Mm. semimembranosus, semilendinosus und adductor maguus. endlich einen oder mehrere Nn. cutanei cruris posteriores. Schon am oberen Dritteil des Oberschenkels tremul sich der $\mathrm{N}$. ischiadicus in zwei parallele nebeneinander abuirts steigende starke stimme: die Nn. peronaeus und tibialis.

Durchschneidung des $N$. ischiadicus. Befestigung in der Bauchlage, Hautschnill am hinteren kande des Oberschenkels, von der Knickehle beginnend gerade aufwärts, $3 \mathrm{~cm}$ lang, Durchschneidung der Faszie; die V. ischiadica bleibt medianwirts. Eindringen mit der Hohlsonde in die Tiefe zwischen den Mm. biceps femoris und semimembranosus. Der ausgeschnittene Nerv bleibt (bei 40 $45^{\circ}$, Valentin) eine Stunde lang leistungsfihig und zur Demonstration von elektrischęn Erscheinungen am Nerven geeignet. Wenn nach etwa drei Wochen fettige Degeneration des peripherischen Teiles der durchschnittenen Nervenfasern eintreten soll, so schneidet man bei der Operation ein $1 \mathrm{~cm}$ langes Stück heraus.

- Die Operation wurde schon von Arnemann (825) ausgeführt.

Als weitere Folgezustande der Operation werden beschrieben . .56 ) : blasse, 
frockene, sich leicht ablïsende Haut, später Ulzerationen derselben, Brüchigkeil und Ausfallen der IIaare, der Zehennägel, Entbïßung der Phalangenknochen und Nekrose derselben. Die Blutgefaße neigen zu IÏ̈morrhagieen und angeschnitten zu starken Blutungen in Folge fettiger Degeneration ihrer Wandungen. Vernarbungen und Ileilung dieser Ernährungstörungen begannen zugleich mit Wiederherstellung der Sensibilitit und des Muskel- und Nervengewebes. - Endlich Epilepsie, die erblich sein soll (750 - vergl. jedoch S. 292).

N. cutaneus cruris posterior trennt sich vom N. ischiadicus am oberen Teile des Oberschenkels, liuft zwisthen dem zweiten liopfe des M. biceps femoris und dem .I. tensor fasciae eruris rickwirts, durchbohrt oberhalb der Kniekehle die Faszie und veristelt sich an der hinteren Seite des Unlerschenkels mil langen Ilautisten, lateralwirts von den Nn. cutaneus femoris posterior und saphenus minor.

V. peronueus stammt hauptsachlich aus dem $\mathrm{N}$. Iumbalis VII, ist mit dem X. tibialis muterhall, des oberen Iritteiles des Oberschenkels durch lockeres Bindegewelor vereinist, liuft parallel demselben abwirts an der medialen Seite des .I. bicepts femoris, nahe an dessen Ansalz zwischen lefzterem und dem V. gastrocnemius lateralis, durchhohrt die an weitesten nach vorn gelegene Lrsprungsstelle des II. gastrornemius lateralis rom oberen Ende der Tihia: gelang unter dem Capitulum fihulae auf die Vorderflache des Unterschenkels zwischen die Mm. peronaci longus und brevis, hinter welchem, und ilen II. peronaeus tertius, vor welchem er liegr. Gieht medianwarls verIatufende Rr. musculares an die Inn. tibialis anticus und extensor digritorum pedis longus; voliant abwirts an der vorderen Seite des Unterschenkels, am lateralen Rande des M. extensor digitorum pedis longus, an der medialen Seite des M. premaneus longus, fihularwirts von der A. tibialis anterior und von der V'. libialis anterior und dem 11 . peronaeus quartus und gieht Rr. mus•uhares an simmfliche Mn. perouaei. Oherhalh des knöhelgelenkes gieht der X. peronaeus einen Ast zur Ilaut des liuBriuckens, ferner den $N$. digitalis dorsulis digiti $I V$ fibuluris ah. Alsolamn tritt der N. peronaeus am fibubaren Rande des Lig̣mentum rouris. resp. an der fibularen Seite der Sehnen des M. extensor digrtorum pedis longus, an der tibialen seite der V. tibialis anterior auf

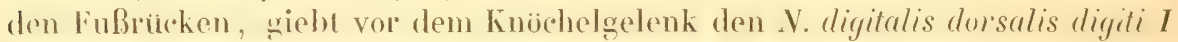
libialis al), und spaltet sich in die Nu. interossei dorsales metatarsi I-III. Der erstere entsendet die Nn. digitales dorsales digiti l tibularis und digiti ll tibialis. der $\mathbf{N}$. interossens dorsulis metatarsi II die $\mathrm{N} n$. dieritales dorsales digriti II libularis und digiti III tibialis, der $\mathrm{V}$. interossens dorsalis metatursi III die Nn. digitales dorsales digiti III fibularis und digiti IV tibialis.

Durchschneidung des $N$. peronaeus. Hautschnitt an der vorderen Seite des Fußgelenhes; die Topographie s. im Text. Reizung des zentralen stumpfes bewirkt Erweiterung der A. saphena magna (b̆/4, S. 13).

N. tibialis lïßt sich mit den Rr. musculares des N. ischiadicus bis zur Ansi lumbalis III verfolgen. Verlault, am Oberschenkel mit dem N. peronaeus rereinigt, in der Kniekohle (s. N. ulnaris, S. 334 ) hinter der A. poplitea, efwas weiter rilchwirts als letztere, zwischen den Mun. adductor magnus, semimembranosus, die medianwirls liegen. und dem M. hiceps femoris, der lateralwärts herablault. Der $\mathrm{X}$. (ibialis tritt zwischeu die Lrspriange der Mm. gastrocnemii 
lateralis und medialis, zwischen letzteren und dem M. plantaris; schlägl sich an der medialen Seite des hopfes des M. plantaris anf dessen vordere Fliche. Giebt den N. siphenus minor ab, sowie Rr. musculares, die schon am Oberschenkel zu einem besonderen Bündel vereinigh sind, an die Mm. popliteus, gastrocnemii lateralis und medialis und plantaris; weiter ahwarts an die Mm. soleus, extensor digiti primi pedis proprius, flesor digitorum pedis longus. Alsclann gelangt der $\mathrm{N}$. tibialis weiter abwirts hinter letzterem Muskel und vor der vorderen Flache des M. plantaris, dann an der hinteren Seite der $\Lambda$. tibialis posterior, welche letzlere am hinteren Rande des M. extensor digiti primi pedis proprius verlauft, unter dem Malleolus medialis in die Fußsohle.

Durchschneidung des $N$. tibialis (587).

A. Etwas oberhalb des Malleolus medialis. Hautschnitt hinter dem letzteren, der Nerv liegt hinter der $\Lambda$. tibialis posterior, zwischen den Mm. flexor digitorum pedis longus und plantaris; er soll mit dem an der Dorsalseite verlaufenden $\mathrm{N}$. peronaeus (S. 342) verwechselt werden können (41).

B. Etwas höher zwischen den $\mathbf{M m}$. gastrocnemius lateralis und plantaris um die genannte Verwechselung zu vermeiden (41).

C. Am unteren Dritteil des Oberschenkels zwischen den $\mathbf{M m}$. semimembranosus und biceps femoris, lateralwärts neben der A. poplitea (41).

In der Fußsohle teilt sich der $\mathbf{N}$. tibialis unter der Basis oss. metacarpi 1 und der Sehne des M. flexor digitorum pedis longus zur ersten Zehe in vier Äste. Der erste, am meisten tibialwirts gelegene, versorgt die Ilaut am tibialen Rande des Os metatarsi I und wird zum V. digitalis plantaris digiti I tibialis. Der zweite ist der $\mathrm{V}$. interossens metatarsi plantaris I, welcher die Nu. digitales digiti I fibularis und digrili II tibialis absendet. Der dritte: $N$. interosseus metatarsi plantaris II entsendet die No. digitales digiti Il libularis und digili III tibialis. Der vierte, an meisten fibularwirts gelegene giebt den . V. digitalis plantaris digiti IV fibuluris ab, setzt sich als $\mathrm{V}$. interossens metatursi plantaris III fort und spaltet sich in die Nir. digitales plantares digiti lll fibularis und digiti IV tibialis.

N. saphenus minor entspringt vom N. tibialis unterhalb der Incisura ischiadica major, liuft in dessen Scheide eingeschlossen am Oberschenkel abwirts, tremnt sich vom $\mathrm{N}$. tibialis nahe oberhalh der Kniekehle, verläuft hinter dem M. gastrocnemius lateralis schriag abwarts und nach rorn, an der hintereu Seite der V. saphena parra, giebt Ïste zur Iaut an der hinteren Fläche des Unterschenkels.

\section{Plexus sacralis.}

Aus den Foramina sacralia anteriora treten die vorderen Äste der Nn. Sacrales I-IV hervor und bilden auf der vorderen Flähe des Os sarem den Plexus sacralis, der aus den Ansae sacrales I-IV besteht (Fig. 152, S. 344). An der Bildung der Ansa sacratis I beteiliegt sich der $\mathrm{X}$. Iumbalis VII, an der Ansa sacralis IV der N. coceygeus I. Aus den Ansae sacrales gehen folgende Nervenstämme hervor :

Ansa sacralis I: N. ischiadicus, N. pudendus zum Teil (vergl. S. 344). 
Ansa sacralis II: N. pudendus zum Teil, Nn. haemorrhoidales medii. inferior.

Ansa sacralis III: No. dorsales penis resp. clitoridis, haemorrhoidalis

Ansa sacralis $1 V$ : Nn. coccygei.

\section{N. sacralis $\mathbf{I}$.}

Derselbe erscheint zwischen den Mor. pyriformis und abluctor catudae anticus, giebt einen starken Ast zum N. ischiadicus resp. zur Ansa lumbalis III, einen schwächeren zur Ansa sacralis I.

\section{N. sacralis II.}

Der zwoite sacralnem (X. hiradiatus, S. 339) durchbohrt den N. abductor

Fig. 152.

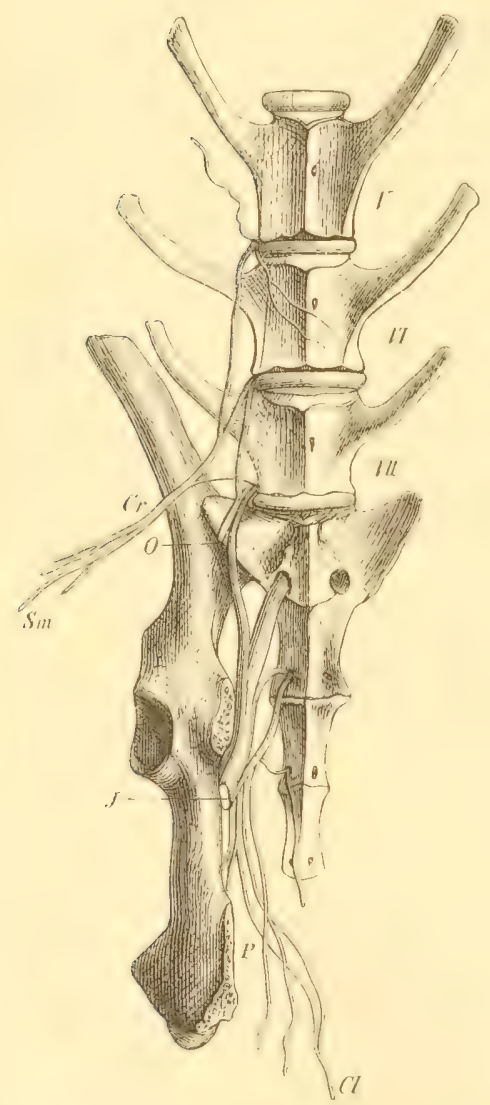

Plexus lumbalis und sacralis. Y VI VII Die drei untersteu der sieben Lendenwirbel, welehe sich an das aus vier Wirbeln hestehende os sacrum auschließen, $\quad C r$ N. cruralis, Sm N. saphenus major. $O \mathrm{~N}$. obturatorius. $J \mathrm{~N}$. ischiadieus. $P$ N. pudendus, aus drei Bündeln zusammengesetzt. $C l$ N. elitoridis. caudae anticus, sendet einen Zweig zum $\mathrm{N}$. ischiadicus, einen anderen zum N.pudendus, wahrscheinlich einen Faserzug zum N. dor'salis penis resp. clitoridis.

N. pudendus entsteht von der Ansa sacralis II, erhält auch Fasern aus der Ansa sacralis I; hauptsächlich vom N. sacralis II (Fig. 15\%). Verlauft hinter dem M. abductor caudae anticus abwärts, an der oberen Seite der A. pudenda interna, anfangs in Begleitung des N. cutameus femoris posterior. Wendet sich daun, lateralwarts von der Spina ischii verlaufend, unterhalb derselben bogenförmig von oben nach unten und vorn, an der lateralen Seite des unteren Teiles des M. abductor caudae anticus sich erstreckend, biegt sich damn nach oben und gelangt in Begleitung der A. pudenda interna an der medialen Fliche des $R$. inferior oss. ischii und des R. inferior oss. pubis bis unterhalb die Symphysis pubis. Giebt Äste an die Gl. Cowperi, Rr. scrotales zum hinteren Teile des Scrotum, resp. Rr. labiales ab, setzt sich als $\mathbf{N}$. dorsalis penis, resp. clitoridis fort.

N. dorsalis penis resp. clitoridis stammt mit drei Wurzeln aus der Ansa sacralis II, dev Nn. sacrales III und IV ab. Verläuft von der Symphysis pubis nach vorn auf dem Rücken des Penis, resp. der Clitoris, unterhalb der V. dorsalis penis, an der lateralen Seite der A. penis. 
Genitalnervenkörperchen (Fig. 153) oder Wollustkörperchen (55\% u..$; 8)$. Die Nervenfasern in der Schleimhaut der Glans clitoridis endigen wie beim Menschen in Genitalnervenkörperchen. Sie sind ellipsoidisch, meist mit zwei oder drei Einschnürungen versehen und bis $0,15 \mathrm{~mm}$ groß; am häufigsten sind sie in der Glans penis $(571)$. - Die Vater'schen Körperchen der Clitoris haben 0,18 mm Länge, $0,07 \mathrm{~mm}$ Breite und Dicke $(559 ;$ s. auch Plexus vaginalis, $S .356$ ).

\section{N. sacralis III.}

Erscheint zwischen den Mm. abductor caudae anticus und flexor caudae, entsendet die Yn. haemorrhoidales, resp. vesicalis inferior, uterinus und

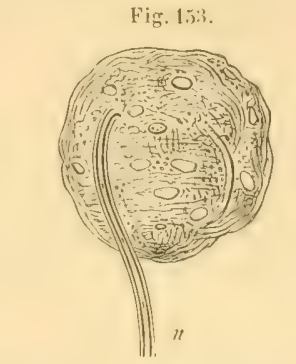

Genitalnervenkörnerchen aus der Clitoris des Kaninchens nach Bense (jill). Frisch mit vertumnter Natronlange, $n$ Nervenfaser. eine Wurzel des $\mathbf{N}$. dorsalis penis resp. clitoridis.

Nh. haemorhoidales medii. Mehrere diinne Zweige entspringen aus den Ansae sacrales II und III, gehen als Nil. vesiceales zur Ilarnblase, als No. haemorrboidales zum Rektum, als Vh. uterini heim Weihohen auch zum Ltepus. Letatere steigen an der lateralen Außenwand des Rektum und der Vagina in die Hähe, gehen vor dem Lreter, den Aa. resicalis superior und vaginalis superior aus der A. uterina zu den Mesometria, bilden dort Ganglienführende Plexus und verästeln sich an den IIörnern des Uterus.

\section{N. sacralis IV.}

Der vierte Sacralnerv enthält eine Wurzel des $\mathrm{N}$. dorsalis penis, resp. clitoridis, giebt den N. haemorrhoidalis inferior ab.

X. huemorrhoidalis inferior s. rectoraginalis $(724)$ verlauft unterhalh und medianwirts von der spina oss. ischii, durchbohrt die (il. analis, gelanget zur lateralen Außenwand des Rektum und der Itaut des Anus; heim Weibehen auch zur lateralen Außenwand des unteren Teiles der Vagina, seine Iste enthalten hier viele mikroskopische Ganglien.

\section{Plexus coccygeus.}

Die vorderen Äste der Nn. coccygei I-VI sind sehr dün und nehmen

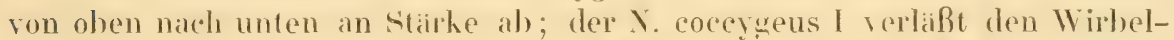
kanal zwischen dem ersten und zweiten Schwanzwirhel, der X. coecrgeus VI zwischen dem sechsten und siehenten. Der erste heteilight sich an der Bildung der Ansa sacralis $\mathrm{N}$; die abrigen bilden untereinander ein zartes Geflechl: Plexus cocoygeus, welches sich aus den lusae coccygere I-I zusammensetzt. Aus dem X. coecrgeus I entstoht ein ahwiats laufender Faden. welcher hauptsichlich von dem N. coceggeus II verstairkt wird. Derselbe verliuft als $N$. coccygeus lateralis langs der lateralen vorderen Seite des Schwanzes und durch 
Anastomosen mit diesem Nerven bildet sich der Plexus coceygeus, aus welchem dimn feine Zweige zu den Muskeln und der Haut der unteren und lateralen Flächen des Schwanzes hervorgehen.

\section{Sympathisches Nervensystem.}

\section{Kopfteil des sympathischen Nervensystemes.}

Ganglion ciliare. Liegt unter dem N. opticus, ist oval und abgeplattet, erscheint bei der wewöhnlichen Kopfhaltung des lebenden Kaninchens dem

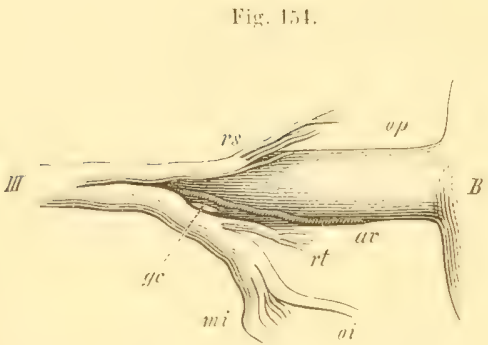

Rechtes Auge in natürlicher Kopfhaltung (Fig. 1, S. 8), von hinten, Vergr. 5. B Bulbus, op N. opticus. av A ophthalmica superior. it $\Lambda$ st des N. oculomotorius zum MI. retractor bulbi. o $i$ Ast zum M. obliquus inferior. $m i$ Ast zum M. rectus anticus s. internus. gc Ganglion ciliare. III N. oculomotorins. $r s$ Ast zum M. rectus superior.

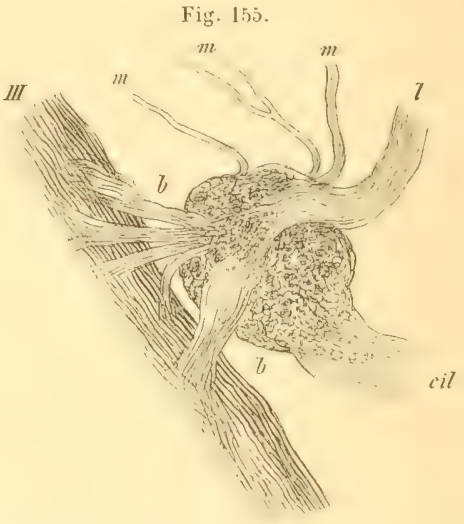

Ganglion ciliare nach 24 stündiger Behandiung mit $30{ }_{0}$ iger Essigsäure. Vergr, 35. III N. oculomotorius, b Radix brevis ganglii ciliaris, in zwei fäden geteilt. $m, m$ Radix media, ebenfalls in mehrere Füden geteilt. $l$ Radix longa. cil Nervenbündel, aus welchem die Nn. ciliares hervorgehen.

freion Juge als gelbrötliches Pounhtchen am unteren hinteren beim Menschen unteren lateralen Rande des Sehmerven (Fiw. lig gc). Seine Lange betragt $0,4-0.5 \mathrm{~mm}$, im Mittel 0.45 , Jeim Ilasen 0,35$) \mathrm{mm}$, seine Breite $0,2-0,3 \mathrm{~mm}$, im Mittel 0,25 beim llasen $0,38 \mathrm{~mm}$. Lis enthialt mehr als 100 Gamglienzellen. Die doppelte Radix brev is (Fign. 155 b) ist der erste Zweig des R. inferior

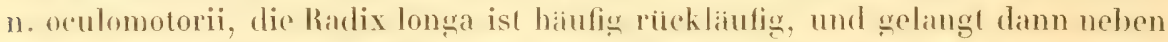
der Austriltsstelle der heiden Vn. ciliates hreves zum lateralen beim Menschen hinteren Ende des Gianglion oder ist in mehrere feine Vervenfaden geteilt $(\mathrm{Fig} .155 \mathrm{~m})$. Das Ganglion entsendet $\mathrm{Nn}$. ciliares.

Das Ganglion ist fast mikroskopisch; es ist mir seit 1852 aus eigener Untersuchung bekannt. Seine Exstirpation am lebenden Tiere dürfte wertvolle Aufschlüsse über die Funktion der Ganglien überhaupt liefern, weil ein so fein organisierter Apparat wie das Auge als ein empfindliches Reagens auf Störungen angeselien werden kann. 
Varietät. Die Radix brevis ist sehr kurz, das Ganglion liegt dann gewöhnlich an der Abgangsstelle des Zweiges für den M. rectus anticus. Nach Schwalbe

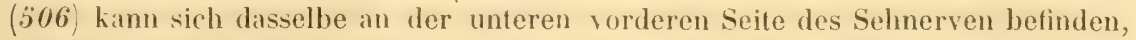
und wandständig am Endzweig des N. oculomotorius für die Mm. rectus inferior und obliquus inferior sitzen.

Es ist zuweilen (einmal, 507) ein kleineres Ganglion ciliare accessorium vorhanden, welches die Radix brevis und Radix media aufnimmt. Dasselbe dïrfte dem Uculomotoriusganglion niederer Wirbeltiere homolog sein. Denn das Ganglion ciliare der Siuger überhaupt ist aus zwei ganz verschiedenen, aber riumlich verbundenen Bestandteilen zusammengesetzt. Bei weitem der größere Teil repräsentiert das letzte sympathische Grenzganglion am Kopfe, welches der Entwichelungsgeschichte zufolge als Ausläufer des Ganglion Gasseri entsteht und dem N. trigeminus angehört. Ein hleiner Teil aber ist ein den Spinalganglien homologes Stammganglion einer (dorsalen oder) sensiblen Wurzel des Oculomotorius, das sehr rudimentiir und für gewöhnlich mit jenem obersten sympathischen Ganglion untrennbar vereinigt ist. Der N. oculomotorius ist ein echter segmentaler Schidelnerv, das Oculomotoriusganglion der niederen Wirbeltiere aber nicht dem Ganglion ciliare der Sïuger, sondern nur wenigen mit der Radix brevis in direktem Zusammenhange stehenden Zellengruppen desselben homolog.

Zahlreiche Ganglienzellen eines angeblichen Plexus ophthalmicus (76.i) mögen Fettzellen gewesen sein.

Durchschneidung der Nn. ciliares. Uber die Folgen derselben s. 805.

Ganglion sphenopalatimum (s. X. sphenopalatinus, S. 30\%) ist dreieckig, liegt unter dem X. nasopalatinus, nimmt außer anderen Ästen, die es entsendet, den $\mathrm{N}$. petrosus superficulis major auf. Derselbe tritt in den hinteren oberen Winkel, wendet sich im Sulcus Vidianus am hinteren und orderen Rande der medialen Pache der Lamina medialis des Processus pterygoideus oss. sphenoidei rückwarts und lateralwarls zum Foramen lacerum; verliuft im Hiatus eamalis facialis, vom Ganglion geniculi kommend. Ferner entsendet das Ganglion sphenopalatinum den $\mathrm{N}$. petrosus profundus major, welcher im Sulcus Vidianus den X. petrosus superficialis major begleitet und damn unterhalb der Bulla tympani sich mit Fiden, die vom Ginglion cervicale superius kommen, verbindet. Endlich Äste zu dem Plexus maxillaris internus, der die gleichnamige Arterie begleitet.

Gunglia otica. Das anterius liegt an der unteren Flähe des X. maxillaris inferior, ist rundlich, von 1,̋̈ mm Durchmesser. Das Gunglion oticum posterius liegt efwas weiter ruckwirts, ist Iinglich-oval und nur $0,5 \mathrm{~mm}$ lang und steht mit dem anterius durch den $\mathrm{N}$. petrosus superficialis minor in Verbindung. Letzterer verlauft mit dem X. petrosus superficialis major im Iliatus canalis facialis und remittelt zw ischen den Ganglia otica und dem X. facialis, sowie dem Plexus t!mpanicus die Verbindung. Ferner gieht das Ganglion oficum posterius den I. musculi mallei und einen Faden zu dem I. auriculotemporalis; das anterius Verbindungszweige zu den Rr. pterygoideobureinatorius und massetericotemporalis ab.

Arnold $(\not 35)$ entdeckte das Ganglion oticum beim Kaninchen. Breschet ( 359$)$, Bendz $(\ddot{360})$, der den IIaseu untersuchte, $1 . \Lambda$. kennen nur das größere Ganglion oticum anterius. Die Prïparation mit Wegnahme der Bulla fympani von unten her ist sehr leicht. - Schiff $(561)$ exstirpierte das Ganglion oticum anterius.

Vergl. a. 562 . 
Durchschneidung der Nn. petrosi superficiales major und minor. Verfahren wie bei der Durchschneidung des N.ophthalmicus (S.308 B), sobald letzterer berührt wird und das Tier schreit, soll das Neurotom um I mm zurückgezogen, die Schneide mit kraft an die Schidelbasis gedrückt und dann gegen den Rand des ()s petrosum angedrücht aus der Schïdelhöhle herausgezogen werden, wobei wenigstens der N, petrosus superficialis minor getroflen werden kann (Schiff, s. Af, S. 514$)$.

Die vom N. facialis kommenden Sekretionsnerven der Gl, parotis scheinen in der Bahn des $\mathrm{N}$. petrosus superficialis minor zum Ganglion oticum, von letzterem zum N. auriculotemporalis und ron diesem in die Parotis zu gelangen Heidenhain, s. Gl. parotis, S. 204 ).

Ganglion maxillare liegt unterhall, des X. lingualis, lateralwäls von der Gl. submaxillaris, stell einen Plexus dar, der die Chorda tympani aufnimmt und Äste zur GI. submaxillaris entsendet.

\section{Halsteil des sympathischen Nervensystemes.}

Ganglion intercaroticum ist ein kleines Knötchen, welches in dem Teilungswinkel der $\Lambda$. carotis communis gelegen ist. Dasselbe enthatt auBer Ganglienzellen gew andene und kolbig umgehogene Gefiße und Vervenstammchen, die mit denen der Plexus carotici commmis, externus und internus zuSammenhängen.

Die Injektion gelingt leicht von der A. carotis communis aus (b41).

Ganglion cervicale superius (Fig. 157, 39, S. 350) liegt in der Höhe der Cartilago rrivoidea hinter dem $\Lambda$ fange der $\Lambda$. carotis externa, an der medialen seite des Anlinges der $A$. carotis inferna. Aus demselben gehen Fiden zu den Aa. carotis interna und rarotis externa und deren Xsten (s. auch Gangl. sphenopalatinum, S. 347).

N. sympalhicus. Aus dem unteren Ende des Ganglion cervicale superius entspringt nur der $\mathrm{X}$. sympathicus Fig. 157, 35. S. 330 , weleher hinter der $\Lambda$. carotis commmis, an der medialen Seite des X. vagus, von demselhen durch lockeres Bindegewobe getremt - aber vom R. cardiacus n. ragi dicht begleitet, der einen X. cardiatus superior aus dem X. sympathicus aufnimmt, — abwärts zum Ganglion cervicale inferius veriauft.

Exstirpation des Ganglion cervicale superius. Operation wie bei der Unterbindung der A. carotis communis (s. N. vagus, S. 318). Nach Bloßlegung der A. carotis communis wird dieselbe sammt dem N. vagus und der V. jugularis interna mit Ilaken medianwirts gezogen. mit stumpfen Pinzellen der N. sympathicus nach oben verfolgt, woselbst der $\mathrm{N}$. vagus mehr von hinten herkommt, und ersterer Nerv freigelegt, der M. stylohyoideus major durchschnitten, der N. hypoglossus nach oben gezogen und das Ganglion ausgerissen oder mit der Schere entfernt. Blutungen finden nicht statt (492, S. 138$)$.

Bè Albinos ist nach Exstirpation des Ganglion cervicale superius eine stirkere Injektion der Iris sichtbar (542); auch wurte Injektion der Chorioidea und Temperaturerhöhung des Auges um 0,9-2, $4^{0}$ beobachtet (709).

Durchschneidung des N. sympathicus am Halse. S. Durchschneidung des N. vagus, S. 318$)$. 
Ganglion cervicale inferius s. stellatum (Fig. 156 Gci) liegt vor der Wirbelsiule, lateralwarts rom Oesophagus an der medialen Seitedes Lrsprumges der $\mathrm{A}$. vertebralis oberhall der A. subclavia; ist circa $4 \mathrm{~mm}$ lang. Das Ganglion nimmt außer dem $\mathrm{N}$. sympathicus von oben her éine Radix longa auf, welche aus mehreren Fäden besteht, die von den oberen Wurzeln des Plexus brachialis herstammen und durch die tiefen Halsmuskeln verlaüfen $(545)$. Ferner eine Radix brevis s. vertebralis, die mit der A. vertebralis verläuft (s. Fig. 156, rechterhand), und Äste vom Hals- und Brustteil des N. vagus. Das Ganglion entsendet mehrere Fäden, welche die A. subclavia und deren Äste begleiten, auch $R r$. cardiaci s. Nn. accelerantes zum Plexus cardiacus.

Exstirpation des Ganglion cervicale inferius. Hautschnitt in der Medianlinie des Halses, am oberen Ende des Sternum beginnend, nach aufwårts. Verfahren übrigens wie bei Durchschneidung des N. vagus am Halse, S. 318 . Man findet das Ganglion (Fig. 157, 14, S. 350 ), indem man den $N$, vagus nach abwärts bis zur A. subclavia verfolgt, medianwärts neben dem Ursprunge der A. vertebralis. Linkerseits muß man die Einmündungsstelle des Ductus thoracicus an der V. subclavia sinistra wegnehmen, um das graue Ganglion neben dem Oesophagus vor der Wirbelsäule zu finden. Isolierte Reizung der Radix brevis (s. vertebralis) bewirkt Vermehrung der Pulsfrequenz um $25 \%$ diejenige der Radix longa um ca. 7 -

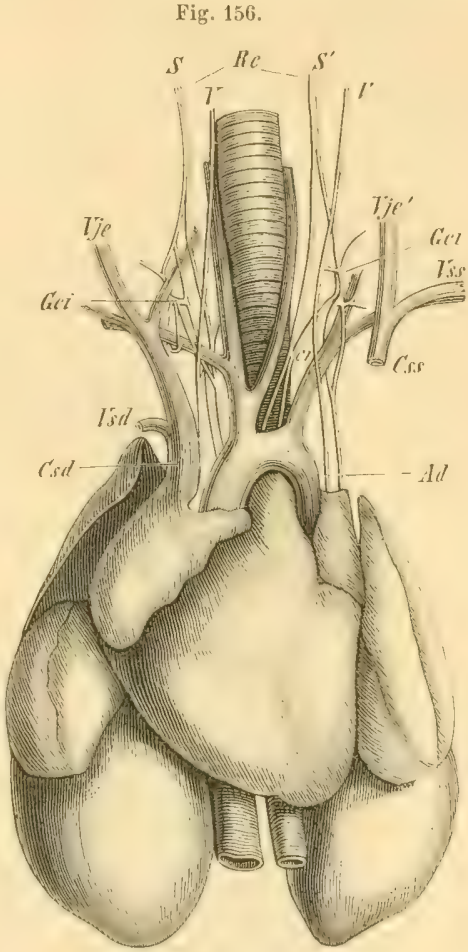

Gangliou cervicale inferius. Nach Ludwig (99). $C s d$ V. cava superior dextra. $C s s \mathrm{~V}$. cava superior sinistra, abgeschnitten. $V s d \vec{V}$. subclavia dextra, Vss V, subclavia sinistra. Vje Vje $V_{\nabla}$ jugulares externa dextra und sinistra. $G$ Ganglion cervicale inferius. Rechterhand zeigt sich die Radix brevis mit der $A$. vertebralis, dem Aste der A. subclavia sinistra (s. Fig.157, 12; S.350) verlaufend, $c \eta$ Ganglion cardiacum. $S S^{\prime}$ Nn. sympathici dexter und sinister. $h c \mathrm{Rr}$. cardiaci n. vagi dextri und sinistri mit den $\mathrm{Nn}$, sympathici verlaufend. $\quad \boldsymbol{V} V^{\prime} \mathbf{N} n$, vagi dexter und sinister.

14\%. Die Vv. jugulares externa, transversa, cava superior und subclavia sinistrae werden vorher successive doppelt unterbunden und durchschnilten ( ̈̈ í). Man kann auch den N. sympathicus bis zum Ganglion dorsale II mit entfernen. Unter drei Versuchen waren zwei gelungen ( 545$)$.

Das Ganglion cervicale inferius horrespondiert mit dem medium des Menschen; das inferius des Menschen ist das dorsale I des Kaninchens. Ludwiz 11 . Thiry 9!); bezeichnen das G. cervicale inferius, Cyon (41, S. 172) dagegen das Ganglion dorsale s. thoracicum primum als G. stellatum. Letzterer hat die Operation sehr genau beschrieben. Man kann das Sternum dabei mittels Ilaken, Sohnur und eines iber eine Rolle laufenden Gewichtes von der Wirbelsäule entfernen.

Der stamm des N. sympathicus ist ron dem Ganglion cervicale inferius an doppelt, bildet eine Schlinge, Ansu subcluciulis s. Vieussenii, um die $\mathrm{A}$. subclavia, senkt sich in das Ganglion dorsale I. 


\section{Brustteil des sympathischen Nervensystemes.}

Ganglia dorsalia s. thoraciea I-XII. Vor den Capitula costarum liegen

Fig. 157.

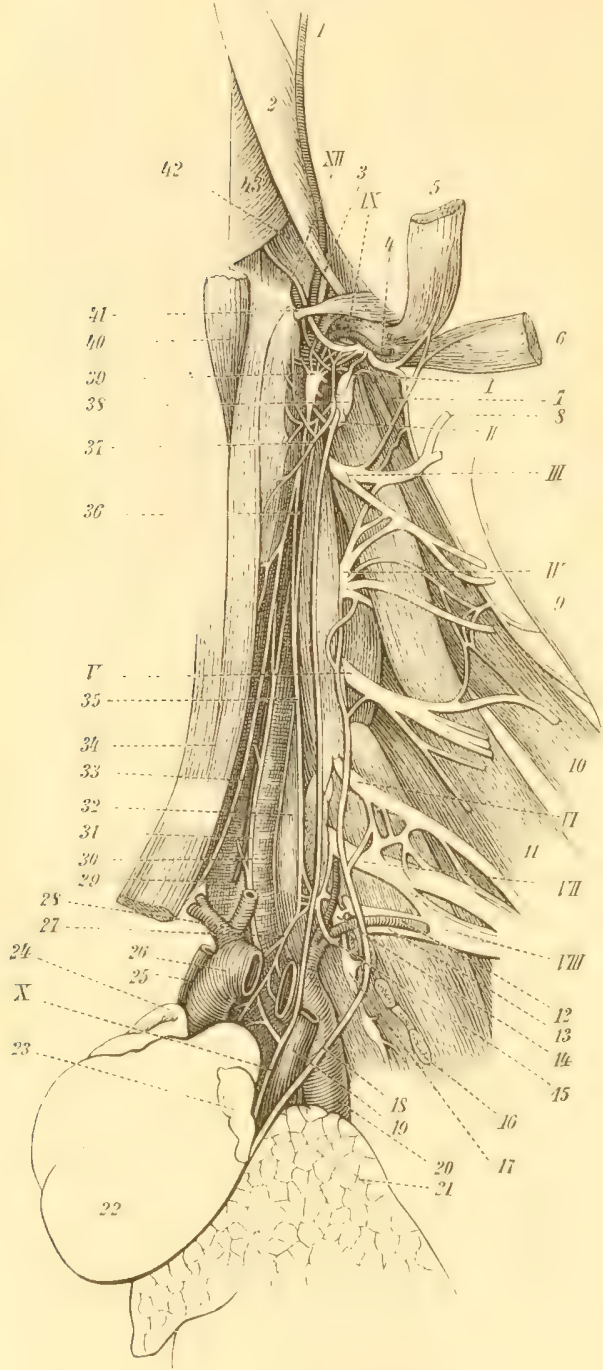

die Ganglia dorsalia, welche durch den Stamm des $N$. sympathicus in Verbindung gesetzt werden. Das I (Fig. 157, 17) giebt Füden zum Plexus cardiacus; von den unteren entsteht vom achten oder neunten Ganglion dorsale an abwärts mit ebensoviel Wurzeln der N. splanchnicus.

Die Ganglia dorsalia sind wie beim Neerschweinchen $(546)$ leicht zu präparieren. Abbildung $\mathrm{s}$. in 816 .

Varietat. Das Ganglion dorsale s, thoracicum I s. stellatum nimmt sehr häufig einen Ast vom N. vagus oder dem $\mathrm{N}$. laryngeus inferior auf (544, S. 253, Taf. VIII). - Es ist ein N. splanchnicus minor (vergl. S. 352) vorhanden, der aus dem Ganglion dorsale XI stammt. Zugleich zeigt sich hinter der linken Nebenniere ein kleines accessorisches Ganglion, in welchem zivei Äste des N. splanchnicus sinister zusammentrelfen $(547)$.

Plexus cardiacus liegt zwischen Aorta adscendens und A. pulmonalis. Erhält linkerseits Zweige aus dem kleinen unpaaren Ganglion cardiacume, welches oberhalb des Areus aortae zwischen A. cárotis sinistra und $\Lambda$. subclavia si-

Ansicht des Halses ron roru, Arterien injiziert. Nach Schneider (250). 1 A. maxillaris externa. 2 M. mandibulae. XII N. hypoglossus. $3 \mathrm{Ur}$ sprumgssehne des M. mandibulae. IX N. glossopharyngeus. 4 A. occipitalis. 5 Oberes Ende

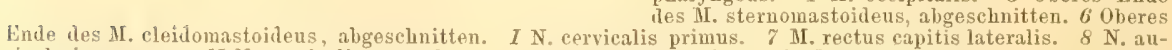
ricularis magnus. II N. cervicalis seeundus. III N cervicalis tertius. IV N. cervicalis quartus. 9 Rand des M. cueullaris. 10 M. levator seapulae major. VI $\mathrm{N}$. cerviealis sextus, 11 II basiohumeralis. VII $\mathrm{N}$, cervicalis septimus. VIII N. cervicalis octavus, $12 \Lambda$. subelavia sinistra, welehe die $\Lambda$. vertebralis nach oben entsendet. $13 \mathrm{~N}$. dorsalis primus. 14 Ganglion cervicale inferius. 15 Mnsa subelavialis. 16 Querdurchsehnitt ler dritten Rippe, darüber die Durchschnitte der zweiten und ersten Rippe. 17 Ganglion dorsale primum. $18 \mathrm{~N}$. phrenicus. $19 \mathrm{~V}$. cava superior sinistra. 20 Aorta descendens thoracica. 21 Linke Lunge. 22 Linker Herzventrikel. 23 Linkes Herzohr. $\mathrm{X}$ N. vagus, 24 Rechtes Herzohr. 25 V. cava superior dextra. 26 Aorta adscendens. 27 Rami cardiaci, welche aus dem Ganglion cervicale inferius stammen. 2S Truneus anonymus. 29 Oesophagus. 30 Trachea. $31 \mathrm{~N}$. laryngeus inferior. $32 \mathrm{M}$. longus colli. $33 \mathrm{~V}$. thyreoidea inferior. 34 IIm. sternohyoidei. $35 \mathrm{~N}$. sympathicus. V N. cervicalis quintus, $36 \mathrm{R}$. cardiacus $\mathrm{n}$. vagi (N. depressor). 37 R. descendens n. hypoglossi. 38 Plexus ganglioformis n. vagi. 39 Ganglion cervicale superius. 40 Membrana thyreohyoidea. 41 Cornu majus oss. hyoidei, an welches sich der I. stylohyoideus major inseriert. 
nistra vor dem linken Raude der Trachea liegt und den R. cardiacus n. vagyi sinistri, sowie einen Ast aus dem Ganglion cervicale inferius aufnimmt (Fig. 156, S. 349). Ferner rechterseits die rereinigten Zweige, Rr. cardiaci (Fig. 157, 27), des Ganglion cervicale inferius und den R. cardiacus u. vagi dextri. Außerdem Rr. cardiaci von beiden Nn. laryngei inferiores. Aus dem Plexus cardiacus gehen Äste hervor zu den Plexus pulmomales dexter und sinister, an die $V_{v}$. cavae superiores und $V_{V}$. pulmonales, zu dem Plexus aorticus thoracicus und die Plexus coronarii cordis dexter u. sinister für die Herzsubstanz selbst.

Die Muskelfasern des Herzens erhalten motorische Endplatten (S. 244). Die

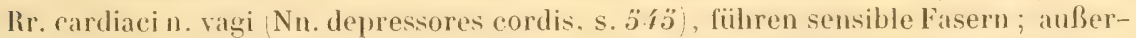
dem enthatten sie aus dem Ganglion cervicale superius abstammende Fasern, und es reprïsentieren die Nu. depressores cordis jederseits die vereinigten R. cardiacus n. vagi und $\mathrm{Nn}$. cardiaci superiores des Menschen (s. auch 548). Die motorischen Fasern, deren Erregung das Herz zum Stillstande bringt, kommen aus dem N. accessorius, welcher der eigentliche Hemmungsnery des Herzens ist (579); sie stammen aus den Wurzeln des $\mathrm{N}$. accessorius von der Medulla spinalis, und gelangen mittels des R. internus vom N. accessorius und des N. laryngeus inferior zum Plexus cardiacus.

Uber die Ganglienzellen des Plexus cardiacus s. 787.

Exstirpation des Plexus cardiacus. Die Zerstörung des Plexus cardiacus bewirkt man am lebenden Tiere durch Galvanokaustik $(\$ 40)$.

\section{Bauchteil des sympathischen Nervensystemes.}

N. sympathicus. Der Stamm des N. sympathicus geht nahe der Wirbelsäule zwischen den Urspriungen des M. psoas major ron den unteren Rỉckenwirbeln und Lendenwirbeln abwäts.

Aufsuchung des N. sympathicus in der Bauchhöhle. Erölfnung der letzteren durch einen vom Processus xiphoideus bis zur Symphysis pubis reichenden Schnitt in der Medianlinie. Nötigenfalls Durchschneidung der Bauchwand in transversaler Richtung, nach doppelter Unterbindung der Aa. epigastricae inferiores. Die Därme werden nach oben, der untere Teil des Colon stark nach rechts gezogen. Die Aorta abdominalis und V. cava inferior werden z. B. oberhalb des Ursprunges der A.spermatica (interna) sinistra nach rechts geschoben; in der Tiefe zwischen den medialen Rindern der Mm. psoas verlaufen sehr dicht neben einander die beiden Nn. sympathici (Fig. 158, S. 352). Der linke ist am zugänglichsten. Reizung desselben unterhalb des Ganglion lumbale V bedingt gleichseitige Bewegung des Vas deferens und der Vesicula prostatica $(418$, S. 20).

Unterhalb, nicht aber oberhalb der Gegend des fünften Lendenwirbels bewirlit Erregung des N. sympathicus Bewegungen der Harnblase, der Tubae FalIoppiae, der Vasa deferentia, sowie des Rektum $(550)$.

Ganglia lumbalia I-VII liegen nahe den Austrittsstellen der Nn. lumbales aus den entsprechenden Foramina intervertebralia und stehen mit dem N. sympathicus in Verbindung.

N. splanchnicus löst sich in der Brusthöhle am VIII oder X Ganglion dorsale vom I. sympathicus ah, rerliaft ror dem M. psoas major abwirls, 
nimmt von hinten herkommende Zweige aus den unteren Ganglia dorsalia IX oder XI-XII atuf; gelang jederseits in der Höhe des zehnten Rückenwirbels an die laterale srite der Aorta descendens thoracio: lauft neben derselben abwirts. Msdann tritt der $\mathrm{X}$. splanchnicus, die Pars lumbalis des Diatphragua durchlohenend, in die Batchhöhle; der dexter etwas rechts von der Aorta descendens abdominalis, der sinister dicht neben derselhen an ihrer linken seite. Der dexter gelangt rechts von der Aorta vor der rechten vebenniere zur rechlen Spilze des Ganglion coeliacum superius. Der sinister verliult an der linhen $\mathbb{W}$ and der Aorta deseendens abdominalis und gelangt vor der-

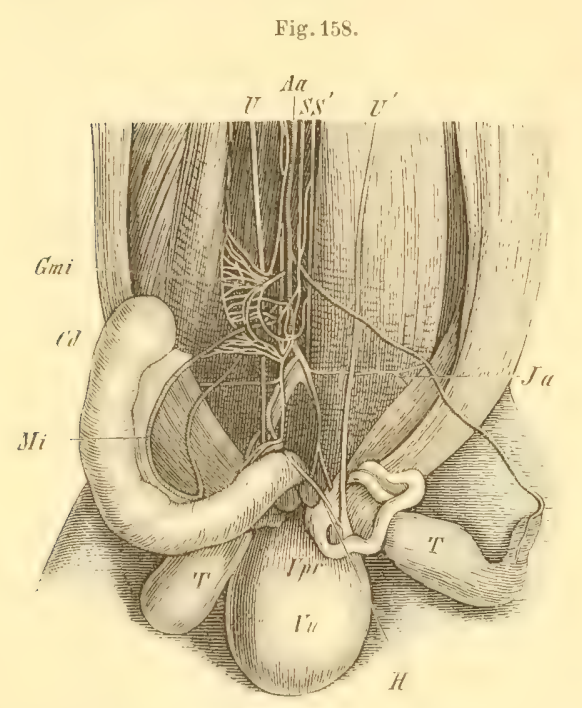

Nn. sympathici in der Bauchhöhle. Vu Haxublase. Ip Cornua vesiculae prostaticae. $C d$ Colon descendeus. $P U U^{\prime}$ Rechter und linker Ureter. A $a$ Aorta abdominalis. Nach

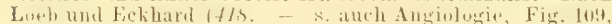
S. 262). $S S^{\prime}$ Nn. sympathici dexter und sinister. Zwischen beiden ist in ihrem oberen Teile auscheinend ein Terhindungsat wohatmen, wolcher den Bewegungen der Vasa deferentia rorsteht. Ja A. iliolumbalis sinistra. I $i$ A. mesenterica inferior. Gi i Ganglinn mesentericum inferius. $H$ Ende des N. hypogastricus, sich an dem Vas deferens sinistrum verlierend. Der $\mathrm{N}$. hypogastricus verläuft abwäts vor den $\Lambda$. und $V$. iliacae communes. selben zu dem Ganglion coeliacum superius. Beiderseits teilt sich der N. splanchnicus in zwei oder drei Äste, von denen der' $R$. posterior parallel der Aorta hinter der Nebenniere zum Plexus renalis geht. Dieser R. posterior repräsentiert den N. splanchnicus minor des Menschen, welcher dem Kaninchen fehlt. Der $\boldsymbol{R}$. anterior verlảuft mit einem oder zwei ' Zweigen linkerseits vor der Aorta abdominalis, rechterseits vor der rechten Nebenniere zu den Ganglia coeliaca.

Der N. splanchnicus erhält auch von verschiedenen $\mathrm{Nn}$. intercostales Zweige, namentlich vom $\mathrm{N}$. intercostalis V $(55 \%)$. - Tergl.S. 300 .

Varietat. Der N. splanchnicus sinister verläuft ungeteilt bis hinter die linke Nebenniere und sendet von dort seine Zweige zu den Ganglia coeliaca (547, S. 8).

Durch.schneidung des N. splanchnicus sinister. Hautschnitt in der Linea alba, 6-8 cm lang, am Processus xiphoideus beginnend. Blutungen werden gestillt, dann erst das Peritoneum in derselben Ausdehnung eröffnet; die Darmschlingen zurïckehalten, sie dïrfen nicht erkalten. Man sieht ohne weiteres, eventuell nach Einschneidung der Pars lumbalis des Diaphragma, bei mageren Tieren den N. splanchnicus sinister (Fig. 158) links neben der Aorta descendens abdominalis, zerreißt olne Blutung nit P'inzetten die Hinterwand des Peritoneum und reseziert den Nerven. Die Operation gefährdet das Leben nicht, der Harn wird öfters nach einigen Tagen für mehrere Tage zuckerhaltig. Man kann auch den peripherischen Teil des durchschniftenen Nerven durch Induktionsströme veranlassen, die Bewegungen des Dünndarmes zu hemmen (552).

Die Durchschneidung des N. splanchnicus dexter ist schwieriger. Operation wie bei Unterbindung der A. renalis dextra (S. 261). Der N. splanchnicus dexter erscheint unterhalb und an der lateralen Seite der rechten Nebenniere $(555)$.

Die Durchschneidung in der Brusthöhle geschieht nach Eröllnung des Thorax, 
Resektion der Rippen, Unterbindung von Blutgefißen in der Ilöhe des foten bis I1ten Rückenwirbels (595).

Elektrische Reizung des zentralen Stumples des durchschnitlenen N. splanchnicus hemmt die Athembewegungen bei Erschlatfung des Diaphragma und krïftiger Kontraktion der Bauchmuskeln; die Ilemmungslisern gelangen im 1 llen bis I 2 ten N. dorsalis in das Rückenmark und reichen bis zur Medulla oblongata (682).

Durchschneidung beider Nn. splanchnici hindert den Erfolg des Zuckerstiches (S. 287 - s. 705 ).

Ganglia coeliaca. Das superius (Fig. 159) liegt oberhalb des Ursprunges der A. mesenterica, ist dreicekig und meistens sind on demsellen noch mehrere kleinere Ganglia coeliaca superiora accessoria abgesondert. Das inferius ist retortenförmig, liegt mit seiner Spitze nach vorn, unterhalb der A. mesenterica superior. Das Ganglion coeliacum superius sendet Zweige zum Magen resp. zur Leber, auch Äste, die mit dem Ganglion coeliacum inferius die A. mesenterica superior begleiten.

Über Ganglienzellen mit zwei Kernen vergl. 57, S. 475.

Exstirpation der Ganglia coeliaca s. Durchschneidung des N. splanchnicus (S. 352). Die Ganglien werden ohne Blutung mit einer auf das Blatt gebogenen Schere entfernt. Die Operation erfordert 30-40 Minuten Zeit. Die Tiere sterben unter Temperaturabnahme nach 24 Stunden $(554)$.

Plexus coeliacus und Plexus mesentericus superior begleiten die entsprechenden Arterien und ihre Äste.

Plexus renalis liegt zwischen der A. und V. renalis und hinter beiden, erhiilt den R. posterior des N. splanchnicus (fig. 159 ), welcher aus dem Ganglion dorsale XI stammt, sendet Zweige zur Nebenniere.

Exstirpation des Plexus renalis s. Unterbindung der A. renalis (S.261). Abbildung s. 555 .

Nicht nur die A. renalis führt sympathische Nervenplexus, sondern solche verlaufen auch in der Adventitia der V. renalis $(869)$. - Die Nierennerven fïhren nur sensible und gefäßrerengernde Fasern, wenigstens ist cine tonische Innervation der Nierengefüße unter normalen Verhältnissen nicht bewiesen und ebensowenig eine solche durch den N. splanchnicus. Reizung des zentralen Stumpfes des letzteren durchschnittenen Nerven bewirkt starke Kontraktion der Nierengefißße auf beiden Seiten, Reizung des peripherischen stumpfes ehensolche auf der gleichnamigen Körperhälfte. Reizung des zentralen Stumpfes des N. ischlitt- 
dicus, ferner Erstickung, Strychninvergiftung bedingen Kontraktion der Nierengefäße und dadurch Verkleinerung des Volumens der Niere, welche an dem in (iner Melatlkapsel (Nierenplethysmometer) eingeschlosienen Organ direkt gemessen werden kann $(869)$.

Plexus spermaticus. Entsteht aus Fiden, die vom Ganglion mesentericum (inferius), sowie vom Plexus aorticus herstammen. Verliuft als I. spermaticus intermes zwischen $\Lambda$. und V. spermatieat, rersorgt mit foinen Zweigen beim Minnchen den Hoden, beim Weibehen das Ovarium, die Tuba Falloppiae und das Gormu uteri. Die Iste für das $O$ arrium veraufen dichter an die $A$. spermatica geheftet.

Die Plexus spermatici bestehen zum Teil aus doppeltkonturierten Nervenfasern $(556)$. Ihre Durchschneidung (gleichzeitig mit anderen Nerven) ist versucht worden (3i; , s. N. genitocruralis, s. 338 und Aufsuchung des Vas deferens, S. 233$)$.

Plexus anrlicus abdominalis. Die $\Lambda$ ortal descendens abdominalis wird ron zahlreichen sympathisehen Stimmehen umsponnen. Die aus dem Ganglion mesenterioum (inferius) stammenden verlaten 1 or der $\Lambda$ orta abdominalis nach abwirts; heim Weibchen zwischen den beiden Platten des Mesometrium. Sie sind zu zwoi sehr dicht zusammenliegenden IIauptstringen vereingegt, welehe aurh fidlen zu den Plexus spermatici ahegeben und den unteren Teil, Plexus andicus, hamptsibhlich konstituieren. J)ie vereinigten Itauplstringe sind ra.

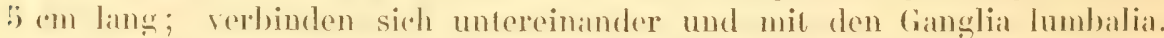
Etwa 7 cm unterhall, der Teilumgsstelle der Aorta abdominalis trennen sich die beiden Jamptstrimge des Plexus aorlicos abdominalis von einander und verlaufen als l'lexus hypoustriei dexter und sinister vor dem unteren Ende

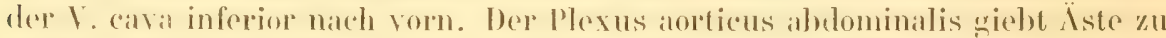
dem Plexus mesentericus inferior und den N. mesentericus inferior ab.

Exstirpation des Plexus aorticus abdominalis. Hautschnitt in dem mittleren Teil der Linea alba, mindestens $6 \mathrm{~cm}$ lang. Aufsuchung der Aa. mesentericae superior und inferior. Die zwischen den Ursprüngen beider Arterien vor der Aorta abdominalis verlaufenden Fiden des Plexus aorticus abdominalis werden entfernt $(557)$

Ganglion mesentericum (inferius) ist unpar, ca. $7 \mathrm{~mm}$ lang, $3 \mathrm{~mm}$ breit, '2 mm dick, eckigr, gefißreich. liewt zwischen den Platten des Peritonem, chas oberhalb des Lrsprumes der $\Lambda$. mesenterica inferior aus der Aorta abdominalis (Fig. 160), vor der letzteren. Erhailt liaden aus dem Plexus rodiatus und von den fimglia lumbalia. Entsendet nach oben Zweige zum Colou descendens, nach unten und vorn zom Plexus mesentericus inferior, nath rechts und links zum Plexus spermatieus internus dexter und sinister. Dir stirksten Zweige laufen nach abwits zum Plexus aorticus abdominalis.

Beim Hannchen erhilt das Ganglion mesentericum (inferius) einen in dessen unfores Ende sich einsenkenden, bogenfirmig verdafenden, etwa in

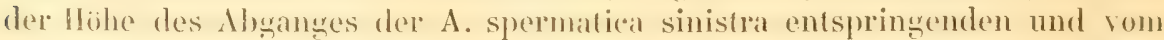
$N$ stmpathious abstammenden Vervenzweig. bas Ganglion entsendet anch

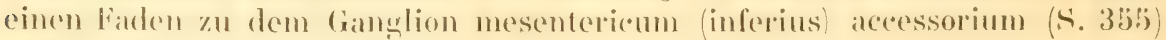
und zahlreiche Zweige zu dem Ganglion hypogastricum. 
Varietät. Das Ganglion mesentericum zerfillt (einmal unter 150 Faillen) beim Weibchen in zwei Ganglien (556, S. 72).

Exstirpation des Ganglion mesentericum. Medianschnitt in der Linea alba. Anziehen des Mesenterium, wodurch das oberhalb der Abgangsstelle der A. mesenterica inferior vor der Aorta gelegene Ganglion von letzterer abgehoben und dann mit Schere und Pinzelte exstirpiert wird (585, S. 388).

Ganglion mesentericum (inferius) accessorim. Ist sehr klein, Jinglich, liegt (beim Mannchen) dicht unterhalb des Ursprunges der $\Lambda$. mesenteriea inferior, vor der Aorta abdominalis. Hiangt durch zwei die Wurzel der A. mesenterica inferior ungreifende, schlingenförmig angeordnete fïilen mit dem Ganglion mesentericum (inferius) zusammen. Erhailt einen vom Ganglion lumbale $\mathrm{V}$ sinistrum en(springenden, zwischen deu beiden Nn. sympathici albwïrls steigenden, mit bloßem Auge kaum sichtbaren Vervenfaden. Entsendet einen Faden zum Ganglion hypogastricum.

Plexus mesentericus inferior. Die aus dem Ganglion mesentericum (inferius) stammenden Zweige vereinigen sich zu zwei dünnen Stämmchen, welche die A. mesenterica inferior begleiten; sie teilen sich weiter abwärts dichotomisch und senden beim Weibchen jederseits Äste zu dem Ganglion uterinum. Der $N$. mesentericus (inferior) entsteht jederseits aus dem Hauptstrang des Plexus aorticus abdominalis, etwa $7 \mathrm{~mm}$ unterhalb des Ganglion mesentericum (inferius), verliuft mit demjenigen der anderen Seite vereinigt zwischen den Platten des Mesocolou descendens, parallel der A. mesenterica inferior und hinter derselben einen kleineren Bogen bildend. Senkt sich beim Weibchen mit zwei $\ddot{A}$ sten in den Plexus hypogastricus dexter und sinister; verbindet sich auch mit dem Plexus aorticus abdominalis an der Lrsprungsstelle der Plexus hypogastrici. Del Plexus mesentericus inferior, sowie der

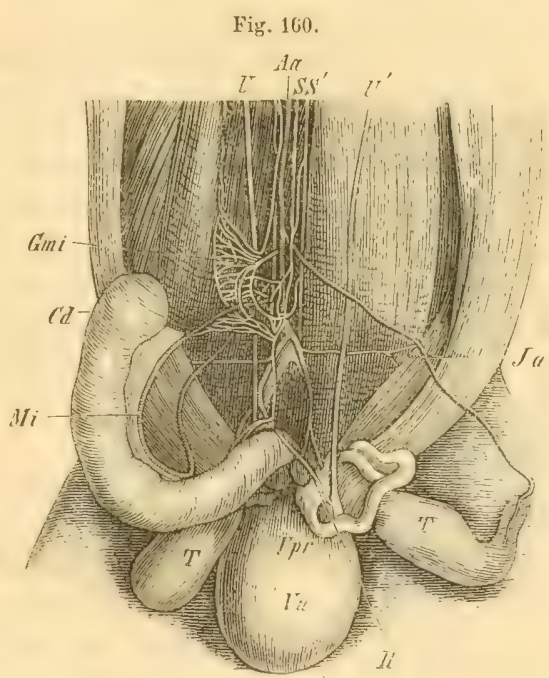

N. hypogastricus nach Ioeb und Eckhard (418. - s. a. Fig. 106. S. 2(i2). In Harnblase. Tpr ('ornua vesiculae prostaticate. C'd C'ulon descendens. $U E$ Rechter und linker Ureter. Aa Aurta aludominalis. SS $S^{\prime \prime} \mathrm{N} n$. symuntlici dexter und sinister. Zwischen beiden ist in jhrem oboren Teile anseheinend fin Verbindungsist rurbanden, weleher den Bewegungen der Vasa deferentia vorsteht. I $A$ A. iliolumbalis sinistra. Mi A. mesenterica inferior. Fimi tranglion mestenterieum inferins. $/ 1$ Ende les N. hypogastriens, sich an dem Vas deferens sinistrum verlierend. Der $\mathrm{N}$. hypogastricus verliaft abwarts vor den 1 . und $V$, iliacae communes.

N. mesentericus (inferior) geben zahlreiche, zum Treil mikroskopische Zweige zum Colon descendens.

Plexus hypogastrici senden beim Weibchen zahlreiche, an der hinteren Platte des Mesometrium rerlaufende Zweige zu dem oberen Teile des Plexus vaginalis und zum Ureter, namentlich auch zum Ganglion ulerinum. Beim Mannchen sind ein unpalares Gangliou hypogastricum und ein unpaarer $\mathrm{N}$. hypogastricus (Fig. 160) vorhanden. 
Ganglion hypoyastricum ist unpaar, linglich, liegt vor der $\Lambda$. iliaca communis dextra, hingt durch zahlreiche Fiden mit den Ganglia mesentericum (inferius) und mesentericum (inferius) accessorium zusammen, entsendet zahlreiche, mit der $\Lambda$. mesenteriea inferior verlaufende Zweige zum Plexus mesentericus inferior, und aus seinem unteren Ende den $\mathrm{N}$. hypogastricus.

$N$. hypogastricus (Fig. 160, S. 355) ist unpaar, besteht aus zwei dicht aneinander gehefteten Fiden, die nach unten auseinander weichen; steigt im Mesorektum vor der $\Lambda$. iliaca communis dextra, dann an der medialen Seite der $\lambda$. iliaca interna dextra, vor der $Y$. iliaca interna dextra, abwirts in das kleine Becken, hinter dem Rektum demselben zahlreiche Äste, Nn. haemorrhoidales superiores, gebend, seine Endverzweigung findet an der Vesicula prostatica und dem unteren Teile der beiden Vasa deferentia statt.

Aufsuchung des N. hypogastricus. Operation wie bei der Aufsuchung des N. sympathicus in der Bauchhöhle (S. 351). Der N. hypogastricus (Fig. $160 \mathrm{H}$, S. $355)$ verlïuft vor der $\mathrm{V}$. iliaca interna medianwärts von der $\mathbf{A}$. iliaca interna, wird mit zwei Pinzetten isoliert.

Reizung des N. hypogastricus beelingt Kontrahtionen der Vesicula prostatica und beider Vasa deferentia , 58 , S. 17), auch Erektion (725) oder doch Blutfüllung des Bulbus urethrae (4, S. ;49) beim Minnchen, sowie Uterusbewegungen bei trächtigen oder trïchtig gewesenen Weibchen (Scherschewsky, s. 11, S.550).

Ganglion uterinum liegt jederseits an der lateralen Vorderflache des Rektum, in der Itöhe des unteren Endes des rom Peritonem bekleideten oberen Treiles der Vagina. Es ist hallnmondförmiğ, nach vorn konkav, ca. 2 mm lang; crhailt Fäden aus den Plexus hypogastricus, mesentericus inferior und steht durch den Plexus haemorrhoidalis mit den Nn. sacrales III und IV in Verbinduug. Von dem Ganglion verlaufen feine Zweige zum Plexus vaginalis, welchem es überhaupt angehört.

Plexus vaginalis. Erstreckt sich mit zahlreichen

Fig. 161.

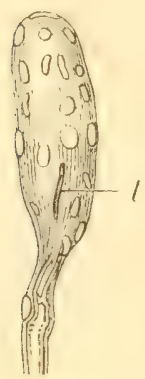

Endkolben aus der Scheidensobleimhant mit zahireichen Kernen in der bindegewebshülle und piner zutretenden, doppeltionturierten Nervenfaser. Nach melirtägiger Behandlung der Vagina mit etwa $30 / 0$ igerEssigsäure. Vergr. 300 , $t$ Rest der Terminalfaser.

\footnotetext{
Körperchen von $0,27 \mathrm{~mm}$ Länge auf $0,11 \mathrm{~mm}$ Breite $(565$, s. auch 564$)$; sie finden sich auch in der Haut des äußeren Ohres s. 57, S. 542.
} zelne größere Ganglien eingelagert enthalten, im Bindegervebe des nicht vom Peritoneum über'zogenen Teiles der Vagina, namentlich am mittleren Dritteil der letzteren, sowie zwischen Vagina und dem Rektum. Der nach hinten und oben gelegene Teil, welcher das Ganglion uterinum enthailt, sendet feine Nerven zum Uterus ab. Dieselben verlaufen längs der A. vaginalis superior oder direkt durch das Mesometrium zur A. uterina, die außerdem noch von nur mit der Lupe zu erkennenden Zweigen aus dem Plexus aorticus abdominalis oder direkt aus dem N. sympathicus stammenden Fiden begleited wird. Die Nerven des übrigen Teiles des Plexus vaginalis versorgen die Vagina.

Die Nerven der Schleimhaut der Scheide endigen 
Die früher mebrfach $(36 \ddot{3}, 566$ u. 36 i) beschriebenen Ganglienzellen im submuhösen Bindegewebe der Scheide homntr ich nicht finden (Erste Auflage, S. 269 — s. auch 585,367 u. 368$)$. Neuerdings (5s.j, S. 390) wurden sie ebenfalls nur an den angegebenen Orten (S.356): abwärts bis zum Aufhören des mehr lockeren Bindegewebes (S. 356, Erste Aufl. S. 176) und zwischen den oberflächlichen Mushelbündeln der Vagina angetrollen. Die Ganglienzellen, welche isoliert in Nervenstïmmchen gesehen werden, fand Polle (56. $)$ bipolar. - Über die Selbstindigheit der Uterusganglien vergl. $\$ 02 .-$ Dembo fand sehr heine Ganglienzellengruppen in der oberen vorderen Wand der Vagina (802).

Plexus cavernosus ist wenig entwickelt.

Plexus haemorrhoidalis. Verlauft an der Lateralen $\Lambda$ ußenlliche des Rekum, erhitt Zweige aus den No. sacrales III und IV, sowie aus dem fianglion uterinum, versorgt das Rektum (s. Plexus sacralis, S. 345).

Ganglia sacralia $I-I V$ liegen nahe der Medianlinie, in der Hibe dor vier Foramina sarelalia anteriora und stehen miteinander durch den stamm des X. sympathicus in Verbindung.

Ganglia coccygea $I$ u. II liegen jederseits vor dem ersten und zweiten Schwanzwirbel, das unpare Ganglion coceygenm infimm vor dem drillen Schwanzwirbel, sammtlich hinter der $\Lambda$. und V. sarcalis media. Auf beiden Seiten zusammen sind also fünf Ganglia coceygea vorhanden. I)as Ganglion coceygeum infimum ist homolog dem Ganglion coceggemm des Menschen, rundlich, $0,5 \mathrm{~mm}$ groß. Es sendet den Plexus secrulis medius aus, welcher die Arterie hegleited. Die Nervenstimmchen in der Nachbarschaft der Ganglia cocygea enthalten Gruppen von Ganglienzellen. 


\section{Literatur - Verzeichmis.}

Die Nr. jedes Citates ist im 'Text des Werkes ohne weitere Bezeichnung kursiv in Kilammern gesetzt, z. B. (18, S. 90). - Das Verzeichnis maeht selbstverständlich keinen Anspruch auf Vollständigkeit.

1. Carus u. Gerstäcker, Handbuch der Zoologie. Bd. I. 1868.

๖. Pennant, British Zoology. 1768. Vol. I. S. 94.

3. B is choff, Entwickelungsgeschichte des Kanincheneies. 1842. S. 41.

4. Blätter fiir Kaninchenzucht, herausgegeben von Ka s ch. Hildesheim. 1875. S. 50.

5. Heiden hain, Studien des physiologischen Institutes zu Breslau. 1865. Bd. III. S. 4 .

6. Kußmaul u. T'enner, Moleschott's Untersuchungen. 1857. Bd. III. S. 43.

7. We iske, Blätter für Kaninchenzucht. 1875. S. 58 u.63. Aus der Versuchsstation der landwirthschaftlichen Akademie zu Proskau.

8. Ch. Darwin, The variation of animals and plants under domestication. 1868. Vol. I. S. $103-130$.

9. W a terliouse, Natural History of the Manmalia. Vol. II. 1848.

10. Amoretti, Osservazione sull accopiamento fecondo d'un Coniglio e d'una Lepre in Opuscoli scelti sulle scienze e sulle arti. 1780. T. III. S. 258. Mitgeteilt vou BrownSéquard s. unten, ferner in Noll's Zoologischem Garten 1873. Jahrg. XIV. S. 434, sowie von Hochstetter, Das Kaninchen. 1873, und vonv. Nathusius, Über die sogenannten Leporiden. 1876. S. 7. - Proceedings of the Committee of the zoological Society. 1830-31. P. I. S. 66. Vergl, von Nathusius s. Nr.14. - B row n-Sé quard, Journal de Physiologie. 1859. T. II. S. 374. - Ga yot, Comptes rendus. 1868. T. XLVII. S. 987. Journal d'agriculture pratique. 1868. T. XXXII. P. II. S. 658. Vgl. Österreichisch-ungarische Blätter für Geflügel- und Kaninchenzucht. 1880. S. 326, und Blätter für Kaninchenzucht. 1876. S. 79. - Vergl, ferner Sanson, Annales des sciences naturelles. 1872. Zoologie. 'T. XV. und von Nathusius s. Nr. 14. sowie in Noll's Zoologischem Garten. 1879. Jahrg. XX. S. 129 - und Guer rapain s. Allgemeine Forst- und Jagdzeitung. 1867. S. 164, oder Österreichische Blätter für Geflugel- und Kaninchenzucht. 1850. S. 311. - Co n r ad, Annalen der Landwirthschaft in den Kigl. Preußischen Staaten. Wochenblatt. 1869. Jahrg. IX. Nr. 17. S. 164. - Vergl. Z ürn, Zoopathologische und zoophysiologische Untersuchungen. 1872. S. 93. Blätter für Kaninchenzucht. 1875. S. 37, 71, 87. Zum Streit über die Leporiden. Weimar, 1876. - Ostereichisch-ungarische Blätter für Geflügel- und Kaninchenzucht. 1882. S. 146. - Schuster, s. daselbst und Landwirtschaftliche Zeitschrift für Elsaß-Lothringen. - Schlegel, Blätter für Kaninchenzucht. 1876. S. 87 .

11. Proceedings of the zoological Society of London. 18:7. S. 159.

12. Vergl. von Nathusius s. Nr, 14. - Dorner, Blätter für Kaninchenzucht. 1875. S. 33. - Pigeaux (s. Nr. 13). 
13. Pigeaux, Bulletin mensuel de la Société impériale d'Acclimatation. 1866. 'T. III, Nr. 7. Annals of Natural history. 1867. Vol. XX. S. $7 \%$.

14. von Nathusius, Uber die sogenannten Leporiden. 1876.

15. Z ürn, Zoopathologische und zoophysiologische Untersuchungen. 1872. S. 93. - Der Freundlichkeit von Herrn Hofrath Haeckel in Jena verdanke ich die Übersendung mehrerer Skelette von Kaninchen aus der Conrad'schen (Nr. 10) Zucht, deren Untersuchung zu dem im Text angefuhrten Resultat führte. Es wird hierfür der herzlichste Dank abgestattet.

16. Z ü rn, Blätter für Kaninchenzucht. 1875. S. 37, 71, 87.

17. Blătter für Kaninchenzucht. 1876. S. 70 .

18. Huperz, Die Geflugel- und Kianinchenzucht. 1881.

19. Arloing, Journal de l'anatomie et de la physiologie. 1868. S. 449.

20. Crisp, Proceedings of the zoological Society of London. 1861. S. 86. Vergl. Nr. 8, S. 126.

21. Zürn, Zum Streit über die Leporiden. 1877. S. 26.

22. Bronn's Klassen und Ordnungen des Tierreiches. Bd. VI. Abth. V. Mammalia von Gi e bel. Liefg. 1-25. 1874-79.

23. Hochstetter, Blätter für Kaninchenzucht. 1874. S. 46.

24. Max Schmidt, Deutsche Zeitschrift für Tierheilkunde u. s. w. 1876. Bd. II. S. 29 u. 395 .

25. Seefisch, Blätter für Kaninchenzucht. 1875. S. 79. Betrifft das Kind des Architekt Banten in Köpenick bei Berlin. 1875.

26. Lanceraux, Traité historique et pratique de la Syphilis. 1874. S. 594.

27. Il ánsell, Archiv für Ophthalmologie. 1881. Bd.27. Abth. III. S. 93.

28. Bollinger, Archiv für pathologische Anatomie. 1874. Bd. 59. S. 341.

29. Lieberkühn, Archiv für Anatomie und Physiologie. 1854. S. 7 .

30. Hake, Treatise on varicose capillaries, as constituting the structure of carcinom of the hepatic ducts. 1839.

31. Reinhard, Archiv für pathologische Anatomie. 1852. Bd. IV. S. 86.

32. Zürn, Blätter für Kaninchenzucht. 1874. S. 33.

33. Kölliker, Archiv für Anatomie und Physiologie. 1843. S. 39. - Nasse, daselbst S. 209. - Remak, Diagnostische und pathologische Untersuchungen. 1843. S. 239. - Kle bs, Archiv für pathologische Anatomie. 1859. Bd. XVI. S. 188. - V u l pian, Gazette médicale de Paris. 1859. S. 161. - Colin, Bulletin de la Société impériale de médecine vétérinaire. 8. Mai 1862. Recueil de médecine vétérinaire. 1862.4e Sér. T. IX. S. 692. — Leisering, Bericht über das Veterinärwesen im Königreich Sachsen. 1862. S. 18. - Keferstein, Götinger gelehrte Anzeigen. 1862. S. 1608. St i ed a Archiv fuir pathologische Anatomie. 1865. Bd. 32. S. 132. Taf. 11. - R e in cke, Nonnulla quaedam de Psorospermis cuniculi. Diss. Kiel. 1866. - Frey, Histologie und Histochemie. 1867.S. 108. - W a l de n burg, Archiv für pathologische Anatomie. 1867. Bd.40. S. 435.- W. Krause, Anatomie des Kaninchens. Erste Aufl. 4868. S. 158. - Roloff, Archiv für pathologische Anatomie. 1868. Bd.43. S. 312. - V irchow, dasélbst S. 548. - Lang, daselbst, 1868. Bd. 44. S.202. - Zürn, Dic kugel- und eiförmigen Psorospermien als Ursache von Krankheiten bei Haustieren. 1878.

34. Welcker, Zeitschrift für rationelle Medizin. 1858. Bd. IV. S. 167.

3:. Gscheidlen, Physiologische Methodik. 1877. S. 337.

36. Custor, Archiv für Anatomie u. Physiologie. 1873. S. 478.

37. W. Ki rase, Allgemeine und mikroskopische Anatomie. 1876.

38. W. Krause, Nachträge zur allgemeinen und mikroskopisehen Anatomie. 1881.

39. W. Ki ause, Spezielle und makroskopische Anatomie. 1879.

40. W. Krause, Handbuch der menschlichen Anatomie. Bd. III. 1880. Varietäten, Homologie der Extremitäten u. s. w. 
41. Gyon, Methodik der physiologischen Experimente und Vivisektionen. Mit Allas. 1876.

4. Gseheidlen, Physiologische Methodik. 1876.

43. L ud wig, Zeitschrift für rationelle Medizin. 1849. Bd. VII. S. 216. - Kölliker, Archiv für pathologische Anatomie. 1856. Bd. IX. S. 336.

44. Traube, Allgemeine medizinische Zentralzeitung. 1862. S. 297.

43. Rajewsky, Medizinisches Zentralblatt. 1870. S. 212.

46. Gscheidlen, Physiologische Methodik. 4879. S. 537.

47. Czermak, Molescholt's Untersuchungen zur Nalurlehre des Menschen. 1860. Bd. VII. S. 357. Sitzungsberichte der kaiserlichen Akademie der Wissenschaften zu Wien. Math.-naturw. Kl. 1859. Bd. 35. S. 418; 1869. Bd. 59. S. 235. - Vergl. Ranvier, Traité technique d'histologie. 1875. S.52. u. G scheidlen Nr.42. 1876. S. 316 .

is. Kußmaul u. Tenner, Moleschott's Untersuchungen zur Naturlehre des Menschen u. s. w. 1833. Bd. III. S: 70.

49. Milne Ed wards, Todd's Encyclopaedia of anatomy and physiology. Vol. 1. 1836. S. 412.

;0. Kußmaul u. Tenner, Moleschott's Untersuchungen zur Naturlehre des Menschen u. s. w. 1857. Bd. I. S. 105.

:3. Gscheidlen, Physiologische Methodik. 1876. S. 88. Fig. 76.

:3ะ. Tiegel, Über die fiebererregenden Eigensehaften des Microsporon septicum. 1871. S. 18.

33. M a nassëin, Archiv für Physiologie. 1874. Bd. IV. S. 287.

34. Eden huizen, Zeitschrift für rationelle Medizin. 1863. Bd. XVII. S. 35.

3i. W. Kr ra use, Beiträge zur Neurologie der oberen Extremität. 1865. Taf. II. Fig. 2 u. 3.

:36. W. Krause, Zeitschrift für rationelle Medizin. 1863. Bd. XXI. S. 78. Taf. VI. Fig. 1.

:37. W. Krause, Beiträge zur Neurologie der oberen Extremität. 4863. S. 24.

38. W a terhouse, Annals and Nagazine of natural history. 1842. Vol. X. S. 199.

59. Bronn's Klassen und Ordnungen des Tierreiches. Bd. VI. Abt. V. Mammalia von Giebel. Liefg. 1-25. 1874-79.

fio. Wild $t$, Úber die Zusammensetzung der Knochen der Kaninchen. Diss. phil. Leipzig, 1872.

61. Lotze, Archiv für Anatomie u. Physiologie. 1876. S.301. - Taf.VII. Fig. 5.

6ะ. Ollier, Comptes rendus. 1858. II. S. 905. - De la production artificielle des os etc. 1859. - Journal de la pliysiologie par Brown-Séquard. 1859. Janv. - B u chholz, Archiv für pathologische Anatomie. 1862. Bd, 26. S. 78. Taf. IV.

6i3. Ollier, De la production artificielle des os. 1859. S. 8.

64. Ranvier, Archives de physiologie par Brown-Séøuard. 1874. S. 1.

63. E. Me yer, Archiv für Anatomie u. Physiologie. 1875. S. 217. Taf. VI. - Kleine chemische Unterschiede zwischen den roten und weißen Kaninchenmuskeln hat Dan ilewski (Zeitschr. für physiol. Chemie. 1882. Bd. VII. S. 124) gefunden, insofern die ersteren mehr Myosin im Verhältnis zur übrigen Substanz des Muskels aufweisen.

66. Stöver; Blătter für Kaninchenzucht, 1875. S. 59.

67. G. Cuvier, Anatomie comparée, recueil de planches de Myologie par Laurillard et Mercier. 1849. Pl. 232-236.

68. Archiv für Naturgeschichte. Bd. 26, Abt. 2, S. 138. - Vergl. Nr, 24, S. 411.

69. Langhans, Übertragbarkeit der Tuberkulose auf Kaninchen. 1868.

70. Il yrt1, Das Gehörorgan. 1845. S. 129.

71. Crampe, Archiv für Anatomie u. Physiologie. 1879. S. 697.

7ః. Cuvier, Leçons d'anatomie comparée. 2e édit. T. IV. P. II. 1835. S. 191.

7i. Oken's Isis. 1825: S. 467.

74. Cha uveau, Traité d'anatomie comparée des animaux domestiques. 1857. S. 382.

7.j. Custor, Über die relative Größe des Darmkanales u. s. w. Diss. Berlin. 1873. Archiv für Anatomie u. Physiologie. 1873, S.478. Vergl. Brümmer, Deutsche Zeitschrift fur Tierheilkunde- 1876 . Bd. II. S. 161. 
76. A s ler, Blätler für Kaninchenzucht. 1876. S. 7.

77. Heiden, Blätter für Kaninchenzucht. 1876. S. 8 .

78. W. Krause, Die Varietäten der Arterien und Venen in Hente's Handbuch der systematischen Anatomie. Bd. III. 1867. S. 378. - Zweite Aufl. 1876. S. 399.

79. Collard de Martign y, Journal de la physiologie. T. VIII. S. 176.

80. Heiden hain, Disquisitiones criticae et experimentales de sanguinis quantitate in mammalium corpore exstantis. Hal. 1857. Archiv für physiologische Ileilkunde. 1857. S. 507 .

81. Welcker, Zeitschrift für rationelle Medizin. 1858. Bd. IV. S. 157.

S2. Gscheid Ien, Physiologische Methodik. 1877. S. 337.

83. Nasse, R. Wagner's Handwörterbuch der Physiologie. Bd. I. 1842, S. 82.

84. Poggiale, Comptes rendus. T. XXV.

8.;. Prevost et Dumas, Annales de chimie. 'T. XXIII.

86. Kölliker, Mikroskopische Anatomie. Bd. II b. 1854. S. 581.

87. Vierordt, Archiv für physiologische Heilkunde. 1852. Bd. XI.

ss. Frey, Handbuch der Histologie und Histochemie. 1876. S.122.

s9. Welcker, Zeitschrift für rationelle Medizin, 1863. Bd, XX, S. 279.

90. IV a grner, Göttinger Nachrichten. 1856. Nr. 13.

91. Milne Edwards, Todd's Encyclopaedia of anatomy and physiology. Vol, I. 1836. S. 312. - Reid, daselbst. Vol. II. 1839. S. 610.

92. Vierordt, Erscheinungen und Gesetze der Stromgeschwindigkeiten des Blutes. 1858. - Archiv für physiologische Heilkunde. 1858. Bd. II. S. 527. - Grundriß der Physiologie. 1862. S. 123. - Vergl. Welcker (Nr. 89, S. 287).

93. Birkner, Das Wasser der Nerven. 1858.

94. von Bibra, Annalen der Chemie u. Pharmazie. Bd. 91. S. 1.

93. W. K rause u. Telgman n, Die Nervenvarietäten beim Menschen. 1865. - Vergl. $\mathrm{Nr} .40$, S. 196-220.

96. W. Krause, Beiträge zur Neurologie der oberen Extremilait. 1865.

97. W. Kra use, Die terminalen Körperchen d. einfach sensibeln Nerven. 1860. Tabelle 1.

98. Peyer, Zeitschrift für rationelle Medizin. 1854. Bd. IV. S. 60.

99. Ludwig. u. Thi ry, Sitzungsberichte der k. Akademie der Wissenschaften zu Wien.. Math.-naturw. Kl. Bd. 49. 1864.

100. Cuvier, Leçons d'anatomie comparée. 1837. T. II. S. 477.

101. Löwe, Beiträge zur Anatomie der Nase. 1878.

102. Hilgendorf, Monatsberichte der k. Akademie der Wissenschaften zu Berlin. 1865. S. 673. - (S.106) Burme ister, Ersch u. Gruber, Encyclopädie. Art. Felis, 1846.

103. Giebel, Abhandl. d. naturw. Vereins zu Halle. 1857. Bd. I. S. 37. Bronn's Klassen und Ordnungen des Tierreiches. Bd. VI. Abt. 5. Mammalia. S. 237.

104. Giebel, Abhandlungen des naturwissenschaftl. Vereins in Halle. 1857. Bd. I. S. 37.

105. Stannius, Archiv für Anatomie u. Physiologie. 1848. S. 397.

106. Retzius, Archiv für Anatomie u. Physiologie. 1849. S. 403.

107. E. H. We ber, Archiv für Anatomie u. Physiologie. 1827. S. 272.

108. Ma yer, Archiv für Anatomie u. Physiologie. 1834. S. 273.

109. Pe yer, Zeitschrift für rationelle Medizin. 1853. Bd. IV. S. 53.

110. M. J. W e ber, Die Skelette der Haussäugetiere u. S. W. 1824. Taf. VII. Fig. 1.

111. Me k el, System der vergleichenden Anatomie. Bd. II. T.2. 1825. S. 391.

112. W. Krause, Medizinisches Zentralblatt. 1876. S. 817. - Handbuch der menschlichen Anatomie: Bd: II. 1879. S. 117. Bd. III. 1880. S. 41.

113. Gegen b a r, Morphologisches Jahrbuch. 1868. Bd. II. S. 83.

114. Le che, Gegenbaur's Morphologisches Jahrbuch. 1880. Bd. VI. S. 597.

115. Cuvier, Leçons d'anatomie comparée. $2^{\theta}$ édit. T. I. 1835. S. 477.

116. Kehrer, Beiträge zur vergleichenden u, experimentellen Geburtshunde. 1875. H.5. 
117. Hesse, Disquisitio anatomica de musculis leporis limidi. Diss. Rostock. 1847. S. 19.

118. Theile, Archiv für Analomie u. Physiologie, 1839. S. 122.

119. Strauß-Dürkheim, Anatomie du Chat. 1845. T. I1.

120. Günther, Die topographische Myologie des Pferdes, 1866. S. 273.

121. Welcker, Archiv für Anatomie u. Physiologie. Anat. Abt. 1878. S. 32.

122. WV. Gruber, Archiv für pathologische Anatomie. 18s1. Bd. 86. S. 484.

123. W. K ra use, Zeitschrift für rationelle Medizin. 1862. Bd. XX. S. 1.

124. Seuffert, Würzburger naturwissenschaftliche Zeitschrift. 1862. Bd, III. S. 137.

12.). von Bijora, Annalen der Chemie u. Physik. Bd. 96. S. 295.

126. von Gorup-Besanez, Annalen der Chemie u. Physik. Bd. 66. S. 321.

127. Odenius, Archiv für mikroskopische Anatomie. 1867. Bd. II. S. 436.

12s. Jantzen, Blätter für Kaninchenzucht. 1874. S. 42. - Gerlach, Über Krätze u. Räude. 1857. S. 153.

149. Pagenstecher, Zeitschrift für wissenschaftliche Zoologie. 1862. Bd. XI. S. 156. Taf. XVII. - Von der Literatur der Kaninchenräude sind noch zu erwähnen: Go hier, Mémoires et observations de Chirurgie et de Médecine vétérinaire. 1813. Recueil de Médecine vétérinaire. 3e Sér. V. XXI. T. I. S. 432.

130. Eden huizen, Zeitschrift für rationelle Medizin. 1863. Bd. XVII. S. 35.

1:31. Boll, Archiv für mikroskopische Anatomie. 1871. Bd. XI. S. 276.

133. Ranvier, Archives de physiologie. 1869. S. 470.

133. Adickes, Zur Histologie des Bindegewebes. Diss. Göttingen. 1872. S. 12.

134. Henle, Canstatt's Jahresbericht für Medizin. 1851. Bd. I. S. 24. - Jahresbericht der Anatomie für 4869. S. 29.

133. Bill roth, Beiträge zur pathologischen Histologie. 185s. S. 17. Taf. I. Fig. 4.

136. Soltmann, Uber einige physiologische Eigentümlichkeiten der Muskeln und Nerven des Neugeborenen. Diss. Breslau. 1877. S. 17.

137. Laskewitseh, Archiv für Anatomie u. Physiologie. 1868. S. 61.

138. Valentin, Archiv für plyssiologische Heilkunde. 1858. Bd. Il. S. 433.

139. C. Lang, Folgen der kiinstlich unterdrickten Ilautatmung bei Tieren. Diss. Göttingen. 1871 .

1'0. Erythropel, Zeitschrift für rationelle Medizin. 1865. Bd.24. S. 214. Taf. VII. Fig. 2.

1:1. Heidenhain, Studien des physiologischen Institutes zu Breslau. 1868. Bd. IV. S. I.

142. A. Heidenhain, Uber die acinösen Drüsen der Nasenschleimhaut etc. Diss. Breslau. 1870 .

13. von Eb ner, Die acinösen Drüsen der Zunge. 1873.

14. Heidenhain, Lermann's Ilandbuch der Physiologie. Bd. V. 1880.

143. Cohnstein, Archiv für Gynäkologie. 1881. Bd. XV111. S. 384.

146. Rymer Jones, Todd's Encyclopaedia of anatomy and physiology. Vol. IV. 1852. S. 368 .

1:7. Schweigger-Seidel in Cyon, Nerven des Peritoneum, Ludwig's Arbeiten aus der physiologischen Anstalt zu Leipzig. 1868.

148. Hannover, De cartilaginibus, musculis, nervis auris externae. Havn. 1839.

149. W. Krause, Götinger gelehrte Anzeigen. 1861. S. 1466. - H a ase, Zeitschrift für rationelle Medizin. 4865. Bd. 24. S. 95. Taf. II. Fig. 4.

130. Erb, Archiv fuir pathologische Anatomie. 1865. Bd.34. S. 151.

151. Cuvier, Legons d'anatomie comparée. 2e édit. T. IHI. 1845. S. 553-559.

152. Z Zü r’n, Deutsche Zeitschrift für Tierheilkunde etc. 1875. Bd. I. S. 278.

153. Bollinge r, Deutsche Zeitschrift für Tierheilkunde etc. 1876. Bd. II. S. 79.

154. Samuel, Moleschott's Untersuchungen zur Naturlehre etc. 1865. Bd. IX. S. 654.

153. Fanny Berlinerblau, Archiv für Anatomie u. Physiologie. 1875. S. 177. Taf.V A.

1:36. J. Gruber, Anatomisch-physiologische studien über das Trommelfell etc. 1867. S. 24. Tat. 11. Fig. 2. 
137. A. Meckel in Meckel's Archiv f. Anatomie u. Physiologie. 1827. S. 356. 'Taf. V. Fig. 14. 155. Höggyes, Archiv für Physiologie. 4881. Bd, 26. S. 558.

159. Baginsky, Archiv für Anatomie u. Physiologie. Physiol. Abt. 1881. S. 201. Biologisches Zentralblatt. 1881. S. 438.

160. Cy on, Recherches expérimentales sur les fonctions des canaux sémicirculaires et sur leur rôle dans la formation de la notion de l'espace. Thèse. Paris. 1878.

161. Vietor, Zeitschrift für nationelle Medizin. 1865. Bd. 23, S. 243, Taf. XII, Hig. 6.

162. B 1 u m berg, Ủber die Augenlider einiger Haussăugetiere. Diss. Dorpat. 1867. S. 38.

163. W. Krause, Die terminalen Körperchen der einfach sensibeln Nerven. 1860. S. 144.

164. W. Krause, Anatomische Untersuchungen. 1861. S. 146.

163. Foltz, Journal de la physiologie. 1862. T. V. S. 232.

166. Reinhard, De viarum lacrymalium etc. Diss. Leipzig. 1840.

167. Walzberg, Über den Bau der Thränenwege etc. 1876. Taf. II. Fig. 8.

168. Ranvier, Comptes rendus. 1879. T. 88. S. 979. - Leçons d'anatomie générale. Cornée. 1881. S. 398 .

169. Schalyge n, Archiv für Ophthalmologie. 1866. Bd. XII. Abt. 1. S. 83.

170. Eberth, Archiv für pathologische Anatomie. 1876. Bd.67. S. 526. Taf. XVIII. Fig. 2. - Vergl. Nr. 38, S. 29, sowie Vossius, Archiv für Ophthalmologie. 1881. Bd. 26. Abt. I11. S. 225.

171. Valentin, Zeitschrift für rationelle Medizin. 1844. Bd. I. S. 232.

172. Brozeit, Archiv für Physiologie. 1870. Bd. V. S. 353.

173. Grünhagen, Zeitschrift für rationelle Medizin. 1866. Bd. 28. S. 176. 'Taf. IX u. X, u. 1868. Bd. 31. S. 403, - Archiv für mikroskopische Anatomie. 1873. Bd. IX. S. 286 u. 726 .

174. Merkel, Zeitschrift für rationelle Medizin. 1868. Bd. 31. S. 136. Taf. II.

17i. Henle, Eingeweidelehre. 1866. S. 635.

176. Adickes, Zur Histologie des Bindegewebes. Diss, Göttingen. 1872. Fig. 4.

177. W. Krause, Die Membrana fenestrala der Retina. 1868. Taf. II. Fig. 38.

178. Kölliker, Mikroskopische Anatomie. 1854. Bd. II. b. S. 639. Fig. 388 . Geweloelehre. 1867. S. 667.

179. Grünhagen, Berliner klinische Wochenschrift. 1867. S. 288. - Archiv für mikroskopische Anatomie. 1883. Bd. 22. S. 369. Taf. XIV.

180. J. Arnold, Archiv für pathologische Anatomie. 1863. Bd. 27. S. 345 . Taf. VIl.

181. Gray, Annals and Magazine of natural history. 1867. Vol. XX. S. 219.

182. Von Möllendorf, Praktische Anleitung zur Erlernung der hochchinesischen Sprache. 1881.

183. Schuster, Landwirtschaftiche Zeilschrift für Elsaß-Lothringen. S. Nr. 10.

184. Lavdowsky, Archiv für mikroskopische Anatomie. 1876. Bd. XIII. S. 281. Taf. XXIV. Fig. 13.

183. Klein, Quarterly Journal of microscopical science, 1882 . Nr. 86. S. 154.

186. O. Nasse, Zur Anatomie u. Physiologie der quergestreiften Muskelsubstanz. 1882. S. 69 u. 71 .

187. Schwalbe, Sitzungsberichte der physikalisch-ökonomischen Gesellschaft zu Königsherg. 1882. Bd. XXIII.

188. Kühne, Archiv für pathologische Anatomie. 1865. Bd. 33. S. 82.

189. Kronecker u. Stirling, Arch. f. Anat.u. Physiol. Physiol. Abt. 1878. S. 1.

190. Von Mojsisovics, Sitzungsberichte der k. Akademie der Wissenschaften zu Wien. Math.-naturw. Kl. 1878. Bd. 46. Abt. I. S. 503. Mit Taf.

191. Trautvetter, Archiv für Ophthalmologie. 1866. Bd. XII. Abt. 1. S. 119.

192. Budge, Zur Bewegung der Iris. 1855.

193. Grünlı gen, Zeitschrift für rationelle Medizin. 1867. Bd. XX1X. S. 34. - Salkowski, daselbst. S. 167. 
194. Cuvier, Legons d'anatomie comparée. 2e édit. T. III. 1845. S. 400.

19:5. Nunnely, Quarterly Journal of microscopical science. 1858. Bd. VI. S. 136.

196. Setschenow, Archiv für Ophthalmologie. 1859. Bd. V. Abt. 2. S. 205.

197. Flem ming, Archiv für mikroskopische Anatomie. 1868. Bd. IV. S. 365. - Vergl. noch G. Me yer, Archiv für pathologische Anatomie, 4865. Bd. XXXIV. S. 396.

198. II. Sehultze, Archiv für mikroskopische Anatomie 1866. Bd. II. S. 197 u. 250.

199. W. Krause, Zeitschrift fül rationelle Iledizin. 1861. Bd. XI. S. 176. Taf. VII. B. Fig. 3 u, 4.

200. Vergł. W. Krause, Nachträge zur allgemeinen und mikroskopischen Anatomie. 1881. S. 54 .

201. Kühne, Untersuchungen aus dem physiologischen Institut zu Heidelberg. 1877. Bd. I. S. 78. Taf. I. Fig. 1.

202. W. Kra use, Die Membrana fenestrata der Retina. 1868. S. 30.

203. II. Schultze, Arehiv für mikroskopische Anatomie. 1866. Bd. II. S. 219. Taf. XIV. Fig. 8 .

204. Rosow, Sitzungsberichte der k. Akademie der Wissenschaften zu Wien. Math.naturw. Kil. 1864. Bd. 49. Abt. 1. S. 431. - Leber, Archiv für Ophthalmologie. 1865. Bd. XI, Abt. 1. S. 4.

205. Kölliker, Ilandbuch der Gewebelehre. 1867. S. 663.

206. Nichel, Archiv für Ophthalmologie. 1881. Bd. XXVII. Abt. 2. S. 194. - Vergl. Michel, Die histologische Struktur des Irisstroma. 1875.

207. Bendz, Archiv für Anatomie u. Physiologie. 1841. S. 196.

208. W. Krause, Zeitschrift für rationelle Medizin. 1863. Bd. XVIII. S, 136.

209. Cuvier, Leçons d'anatomie comparée. 1845. T. III. S. 57.

240. Blu mberg, Über die Augenlider einiger Haussäugetiere. Diss. Dorpat. 1867. S. 38.

¿11. C zermak, Moleschott's Untersuchungen zur Naturlehre des Menschen u. s. w. 1860. Bd. VII. S. 379 .

212. Guvier, Leçons d'anatomie comparée. $2^{e}$ édit. T. III. 1843. S. 457.

213. Trapp, Symbolae ad anatomiam et physiologiam organorum bulbum adjuvantium. Diss. Turici. 1836, S, 30 u. 36 . Fig. XXVI.

214. W endt, Über die Harder'sche Drüse der Säugetiere. Diss. Straßburg. 1877.

213. Joh. Müller, De glandularum secernentium structura penitiori. 1830. S. 51. Taf. V. Fig. 7.

216. Cohn heim, Archiv fuir pathologische Anatomie. 1867. Bd.40. S. 65.

217. Klein, Quarterly Journal of microscopical science. 1884. Vol. 21. S. 549.

218. Rosenthal, 'Treviramus' Untersuchungen über die Natur des Menschen ete. 1827. Bd. H. S. 298.

219. Stenson, De musculis et glandulis. Amst. 1664. S. 37. - Mangeti Bibliotheca anatomica. 1685 . T. II. De narium vasis.

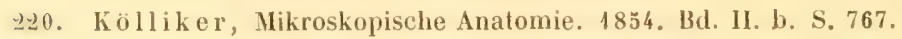

221. Walter, Archiv für patholog. Anatomic, 1861. Bd. 22. S. 257.

222. W. Krause, Göttinger Nachrichten. 1867. 18. Sept.

223. Bollinger, Deutsche Zeitschr. f. Tierheilkunde. 1876. Bd. II. S.88. - von Wys (1864), daselbst, S. 89. - Sieg mund, Correspondenzblatt f. Schweizer Ärte. 1873. S. 603 .

224. Z ürn, Blätter für Kaninchenzucht. 1874. S. 33.

22:5. You att s. Deutsche Zeitschrift für Tierheilkunde etc. 1876. Bd. II. S, 396.

2296. Hassenstein, Blătter für Kaninchenzucht. 1874. S. 29.

2y7. C. Schmidt, Die mykotischen Erkrankungen der Haustiere und speziell die der Kaninchen. Diss. (Göttingen). 1877. - Vergl. Karsten, Deutsches Archiv für Tiermedizin. 1875. Bd. I. S. 24. 
228. Briggs, Sitzungsberichte der k. Akademie der Wissenschaften zu Wien. Math.naturw. Kl. 1879. Bd, 79. Abt. 3.

229. Schoeler, Archiv für Ophthalmologie. 1879. Bd. 25. Abt. 3. S. 88-99.

230. Owen, Odontography 1840-45. Pl. 104. S. a. Rymer Jones, Todd's Encyclopaedia of anatomy and physiology. 1852. Vol. IV. S. 385. Fig. 269. - M. Schmidt, Deutsche Zeitschrift für Tierheilkunde. 1876. Bd. II. S. 38.

231. Carus u. Gerstäcker, Handbuch der Zoologie. Bd. I. 1868. S. 94.

232. H i gend orf, Monatsberichte der k. Akademie der Wissenschaften zu Berlin. 1865. S. 673 .

233. W aterhouse, Natural History of the Mammalia. Vol. II. 1848. S. 4.

234. von Nathusius, Über die sogenannten Leporiden. 1876. S. 20.

235. F. Guvier, Sur les dents des Mammifères. 1821. S. 152.

236. Tomes, Philosophical transactions. 1850. P. II. S. 560. Pl. 46. Fig. 50-52.

237. Lavagna, Rifless. sopra la carie dei denti elc. e la riproduzione dei denti negli animali rosicanti. 1812. - O u d et, Journal de physiologie. 1823. S. 1. 1824. S. 70.

23s. O we n, Odontography. 1840-45. Pl. 104. Fig. 5.

239. Gi ebel, Bronn's Klassen u. Ordnungen des Tierreiches. Bd. VI. Abt. V. 1875. S.152.

240. Legallo is, Nouveau Bulletin des sciences philomathiques. 1809. T. I. S. 397.

241. Oudet, Comptes rendus. 1855. T. 41. S. 266.

242. von Nathusius, Zoologischer Garten. 1879. S. 134.

243. II ensel s. Nr. 242.

244. von Wyss, Archiv für mikroskopische Anatomie. 1870. Bd.VI. S. 238. Taf. XV.

24:. C. M a yer, Neue Untersuchungen aus dem Gebiete der Anatomie u. Physiologie. 1842. S. 25 . Fig. 6.

246. Schiff, s. W. Krause, Anatomische Untersuchungen. 1861. S. 63.

247. Szabad-földy, Archiv für pathologische Anatomie. 1867. Bd. 38. S. 177.

248. Schwalbe, Archiv für mikroskopische Anatomie. 1867. Bd. III. S. 508.

249. Braun, Zeitschrift für rationelle Medizin. 1865. Bd. 24. S. 113.

2ّ0. Schneider, Topographische Anatomie des Vorderhalses beim Kaninchen und der Kehlkopf desselben. Diss. Berlin. 1867.

2:31. Kehrer, Zeitschrift für rationelle Medizin. 1867. Bd. 22. S. 88.

252. B ernard, Leçons de la physiologie. 1856. T. II. S. 94. Fig. 14 u. 15.

253. Naw rocki, Heidenhain's Studien des physiologischen Instituts zu Breslau. Heft 4. 1868. S. 144.

254. Bernard, s. Nr. 252, S. 57.

25:5. von Wittieh, Archiv für pathologische Anatomie. 1866. Bd. 37. S. 95.

256. W. Krause, Zeitschrift für rationelle Medizin. 1864. Bd. 21. S. 92.

257. R a h n, Zeitschrift für rationelle Medizin. 1851. Bd. I. S. 285.

258. Bermann, Medizinisches Zentralblatt. 1877. S. 897. - Über tubulöse Drüsen in den Speicheldrüsen. Diss. Würzburg. 1878. - Sitzungsberichte der physikalischmedizinischen Gesellschaft zu Würzburg. 15. Juni 1878. - Über die Zusammensetzung der Gl. submaxillaris aus verschiedenen Drüsenformen u. s. w. 1878.

259. Reichel, Gegenbaur's Morphologisches Jahrbuch. 1882. Bd. VIII.

260. Beyer, Die Glandula sublingualis. Diss. Breslau. 1879.

261. W. Kra us e, Zeitschrift für rationelle Medizin. 1864. Bd. 21. S. 92.

262. W. Krause, Zeitschrift für rationelle Medizin. 1864. Bd.23. S.52. Taf. VI. Fig. 6 u. 7.

263. Rahn, s. Nr. 257, S. 292.

264. Bernard, s. Nr. 252, S. 34 .

265. Wolff, De organo vocis mammalium Diss. Berol. 1812. S. 19.

266. M e ckel, System der vergleichenden Anatomie. 1833. Bd. VI. S. 521.

267. Cuvier, Leçons d'anatomie comparée. 20 édit. T. VIII. 1846, S. 790.

26s. Leydig, Lehrbuch der vergleichenden IIistologie. 1857. S. 374. 
269. John Bishop, Todd's Encyclopaedia of anatomy and physiology. 1852. T. IV. S. 1491. Fig. 904 .

270. H enle, Beschreibung des Kehlkopfes. 1839. S. 69.

๖71. Sandström, Upsala läkareförenings förhandlingar. 1880. XV. S.441. Schmidt's Jahrbücher der Medizin. 1880. Bd, 187. S. 114. Schwalbe's Jahresbericht der Anatomie für 1880. S. 225.

279. H off ert, Blätter für Kaninchenzucht. 1876. S. 78.

273. Czermak, Moleschott's Untersuchungen z. Naturlehre u. S. w. 1860. Bd.VII. S. 354.

274. A eby, Der Bronchialbaum des Menschen und der Säugetiere. 1880. S. 30.

275. Kollma n n, Zeitschrift für wissenschaftliche Zoologie. 1860. Bd. X. S. 413.

476. Wundt, Archiv für Anatomie u. Physiologie. 1855. S. 269.

277. Villemin, Comptes rendus. 1866. T. 63. S. 730. - Gazette médicale de Paris. 1865. S. 787.

27S. Edenhuizen, Zeitschrift für rationelle Medizin. 1863. Bd. 17. S. 41.

279. Lehmann, Verhandlungen der k. sächsischen Gesellschaft der Wissenschaften zu Leipzig. 1846. S. 472.

2s0. Schiff, Archiv für physiologische Heilkunde. 1850. S. 652.

2S1. Le uckart, Die menschlichen Parasiten. Bd. II. 4867. S. 106.

282. Hirsehman n, Archiv für pathologische Analomie. 1866. Bd. 36. S. 339.

253. Block, Verhandlungen des Vereins für innere Medizin zu Berlin am 5. Juni 1882. Deutsche medizinische Wochenschrift, 1882. Nr. 44. - Vergl. Mosler, Über Lungenchirurgie. 1883. S. 70.

284. F. Arnold, Die physiologische Anstalt zu Heidelberg. 1858.

285. Rosenthal, Die Atembewegungen. 1862.

286. Vierordt, Archiv für physiologische lleilkunde. 1856. S. 274.

287. Milne Edwards, Todd's Encyclopaedia of anatomy and physiology. Vol. I. 1836. S. 412 .

28s. Ernst, Die Anordnung der Blutgefäße in den Darmhäuten. Diss. Zürich. S. 3.

299. E d. W eb e r', Wagner's IIandwörterbuch der Physiologie. 1846. Bd. III. Abt. 2. S. 30.

30\%. Ghauveau, Journal de la physiologie. 1862. T. V. S. 224. - Jolyet, Essai sur la terminaison des nerfs, qui président aux mouvements de l'oesophage. Thèse: Paris. 1860 .

301. Remak, Archiv für Anatomie u. Physiologie. 1858. S: 190.

30さ. Ki $11 \mathrm{mann}$, Zeitsehrift für wissenschaftliche Zoologie. 1860. Bd. X. S. 413.

303. Baßlingex, Moleschott's Untersuchungen zur Naturlehre. 1860. Bd. VII. S. 359.

304. G. Retzius, Archiv für Anatomie u. Physiologie. 1857. S. 74.

30 3. Kölliker, Mikroskopische Anatomie. Bd. II. 2. 1854. S. 143.

306. Remak, Amtlicher Bericht über die Naturforscherversammlung zu Wiesbaden. 1852. Archiv für Anatomie u. Physiologie. 1856, S. 190.

307. Hemmer, Über die Wirkung faulender Stoffe. 1866. S. 85.

308. Frey, Handbuch der Histologie u. Histochemie. 1876. S. 522 U. 529. - Zeitschrift für wissenschaftliche Zoologie. 1863. Bd. XIII. S. 55.

309. F. E. Schulze, Archiv für mikroskopische Anatomie. 1867. Bd. III. S. 215.

310. Manz, Die Nerven und Ganglien des Säugetierdarmes, 1859. S. 6.

311. A uerbach, Über einen Plexus myentericus. 1862.

312. W. Kr rase, Anatomische Untersuchungen. 1881. S. 64.

313. Frey, Handbuch der Histologie u. Histochemie. 1867. S. 542.

314. Billroth, Archiv für Anatomie u. Physiologie. 1858. S. 148.

315. Küchenmeister, Archiv für physiologische Ileilkunde, 1850. Bd. IX. S. 166.

316. Heusinger, Recherches de pathologie comparée. 1847. T. I. S. 75.

317. Funke, Zeitschrift für wissenschaftliche Zoologie. 1856. Bd. VII. S. 323.

31s. van der II ulst, s. Deutsche Zeitschrift für Tierheilkunde. 1876. Bd, II. S. 48. 
319. St. C y r, Journal de médicine vétérinaire, publié à l'école de Lyon. 1869. T. XV.

320. Thom. Bartholinus, Acta Hafniensia, Leporis anatome. S. 278-282. Fig. 1. u. 2. - S. auch Thom. Bartholin i patris) Hlistoria anatom. rarior. Hafn. 1654.

Cent. II. S. 324. Leporis anatome, Nr. 86. S. 324-326.

321. Vulpian, s. Davaine, Traité des entozoaires. 1860. S. 260.

322. Virchow, Archiv für pathologische Anatomie. 1860. Bd. 18. S. 528.

323. Oidtmann, Die unorganischen Bestandteile der Leber und Milz. 1858.

324. Daubenton s. Buffon, Histoire naturelle. 1749-1804.

325. Meckel, System der vergleichenden Anatomie. 1829. Bd. VI. S. 646.

3z6. M e ißner, Zeitschrift für rationelle Medizin. 1858. Bd. II. S. 320.

327. Schönfeld, De functione lienis. Diss. Groningen. 1855.

32s. Langerhans, Beiträge zur mikroskopischen Anatomie der Bauchspercheldrüse.

Diss. Berlin. 1869.

329. Saviotti, Archiv für mikroskopische Anatomie, 1869. Bd. V. S. 404 ,

330. Iloggan, Journal of anatomy and physiology. 1881. Vol. XV. S. 475. PI. XXIV.

331. W. K ra use, Zeitschrift für rationelle Medizin. 1864. Bd. 23. S. 54.

332. Klein u. Burdon-Sanderson, Medizinisches Zentralblatt. 1872. S. 32.

333. Paw low, Archiv für Physiologie. 1878. Bd. 14. S. 124.

334. Bernard, Leęons de physiologie. 1856. T. II. S. 271.

335. Schiff, Moleschott's Untersuchungen zur Naturlehre des Menschen u. s. w. 1857. Bd. II. S. 346 .

336. von Recklinghausen, Archiv für pathologische Anatomie. 1862. Bd. 26. S. 172.

337. Dy bkowsky, Ludwig's Arbeiten des physiologischen Instituts zu Leipzig vom Jahre 1866. S. 50 .

3:38. Hassall, The microscopic anatomy of the human body. $4846 \sim 49$.

339. He r bst, Göttinger Nachrichten. 1850. S. 205.

340. Ml a yer, Archiv für Anatomie u. Physiologie. 4817. S. 141. - Klebs, Archiv für pathologische Anatomie. 1865. Bd. 33. S. 535. - Kaschewarowa, daselbst. 1869. Bd. 47. S. 400.

341. Dohrn, Archiv für pathologische Analomie. 1861. Bd. 21. S. 249.

34. W. Krause, Schuchard's Zeitschrift für praktische Heilkunde für Norddeutschland. - 1864. S. 2.

343. Perroncito, Annali della R. Accademia d'Agricoltura di T'orino. Vol. XVII. Deutsche Zeitschrift für Tierheilkunde. 4876. Bd. I. S. 434.

344. Valentin, De functionibus nervorum. 1839. S. 148.

345. Schachowa, Untersuchungen über die Nieren. Diss. Breslau 4876.

346. Hy rtl, Denkschriften der k. Akademie der Wissenschaften zu Wien. Math.-naturw. Ḱlasse. 1872, Bd. XXXI. S. 122.

347. W. Krause, Göttinger Nachrichten. 1863. S, 341. - Zeitschrift für rationelle Medizin. 1865. Bd. 25. S. 216.

348. Erythrope1, Zeitschr. für rationelle Medizin. 1865. Bd. 24. S. 220. Taf. VII. Fig. 1. 349. Erythropel, daselbst. Fig. 2 u. 3.

350. Saikowsky, Archiv für pathologische Anatomie. 1866. Bd. 37. S. 346.

351. W. Krause u. G. F is ehe r, Zeitschrift für rationelle Medizin. 1866. Bd. 26. S. 316.

359. Frankenhäuser, Jenaische Zeitschr. f. Med. u. Naturw. 1866. Bd. II. S. 6 s.

353. M e ißner, Zeitschrift für rationelle Medizin. 1858. Bd. II. S. 346.

354. von Wittich, Königsberger medizinische Jahrbücher, 1861. Bd. IlI. S. 52.

3\%:. Vauquelin, Annales de chimie. Bd. 82. S. 197. - W. Arnold, Treviranus' Zeitschrift für Physiologie. 1829. Bd. III. S. 129.

356. Vulpian, Gazetle médicale de Paris. Paris. 3e Sér. Vol. IX. S. 67.

357. Holm, Silzungsberichte der k. Akademie der Wissenschaften zu Wien. Math.naturw. Ki. 1866, Bd, 53, S. 314. 
358. Lo e b, Bewegungen der Samenleiter etc. Diss. Gießen. 1866. S. 9.

359. Valentin, Zeitschrift für rationelle Medizin. 1863. Bd. 18. S. 220. Fig. 2.

360. Leeuwenhoek, Opera omnia. 1722. T. Ib. S. 168.

361. Frerichs, Todd's Encyclopaedia of anatomy and physiology. 1852. T. IV. S. 506.

362. Ley dig, Lehrbuch der vergleichenden Histologie. 1857. S. 502.

363. Cuvier, Leçons d'anatomie comparée. 2e édit. T. VIII. 1846. S. 164.

364. Husch ke, Sömmerring's Eingeweidelehre. 1844. S. 411.

365. E. H. W eber, Abhandlungen der k. Sächsischen Gesellschaft der Wissenschaften zu Leipzig. 1846. S. 383. Taf. V. Fig. 1-3. - W a hIg re n, Archiz für Anatomie u. Physiologie. 1849. S. 691. - Rymer Jones, Todd's Encyclopaedia of anatomy and physiology. 1852. Vol. IV. S. 393. Fig. 284.

366. Ley dig, Zeitschrift für wissenschaftliche Zoologie. 1830. Bd. V. S. 27 u. 46.

367. Budge, Zeitschrift für rationelle Medizin. 1864. Bd. 23. S, 78.

368. W. Krause, Anatomische Untersuchungen. 1861. S. 109.

369. Bis ch off, Entwickelungsgeschichte des Kanincheneies. 1842.

370. De Graaf, De mulierum organis generationi inservientibus tractatus novus. 1672. Cap. XVI. S. 307.

371. Haighton, Philosophical transactions. 1797.

372. Kilian, Zeitschrift für rationelle Medizin. 1849. Bd. IX. S. 8. Taf. I. Fig. 97.

373. Reichert, Archiv für Anatomie u. Physiologie. 1848. S, 78.

374. Segallois, Journal hebdomadaire etc. 1829. T. III. S. 166.

375. Klebs, Archiv für pathologische Anatomie. 1865. Bd. 33. S. 538.

376. Blundell, Medico-chirurgical transactions. 1819. Vol. X. S. 246.

377. Bourgery et Jacob, Traité complet de l'anatomie de l'homme. Paris 1854. T. VIII. Pl. 5 (nach Coste).

37s. Grumme1, Blätter für Kaninchenzucht. 1876. S. 6. - Nr. 24, S. 66.

379. Fo cke, Blätter für Kaninchenzucht. 1874.S.51. - Me y er, daselbst. S. 74. - II a s I, daselbst. 1875. S. 27. - Grebe, daselbst. 1876. S.43. - Oesterreicher, daselbst. S. 7 .

380. Schenk, Embryologisehe Mitteilungen. 1878. Heft I1. S. 107.

381. Hensen, Archiv für Anatomie und Entwickelungsgeschichte. 1875. Bd. I. S. 213.

3\$ษ. Bary, Philosophical transactions. 1843. S. 33. - Meißner, Zeitschrift für wissenschaftliche Zoologie. 1854. Bd. VI. S. 246. - R. Wagner, Zeitschrift für rationelle Medizin. 1854. Bd.IV. S.404. - B is ch off, Bestatigung des Eindringens der Spermatozoiden in das Ei. 1854. - Weil, Medizinische Jahrbücher der $k$. Gesellschaft der Ärzte zu Wien. 1873.

3\$3. Cohnstein, Archiv für Gynäkologie. 1881. Bd. XVIII. S. 384.

384. Cyon, Methodik der physiologischen Experimente und Vivisektionen. 1876. S. 424. 385. Hensen, Medizinisches Zentralblatt. 1869. S. 403 . - Auf S. 239 der ziveiten Aufl. bedeutet diese Nr.: E. H. We ber, Abhandlungen der k. sächsischen Gesellschaft der Wissenschaften zu Leipzig. Math.-phys. KJ. 1846. S. 382.

386. Remak, Archiv für Anatomie und Physiologie. 1840. S. 349.

387. Pappenheim, Archiv für Anatomie und Physiologie. 1840. S. 346 . Taf. IX und X.

388. Frankenhảuser, Jenaische Zeitschrift für Medizin. 1866. Bd. II. S. 60. Taf. III. Fig. 9 und 10 .

389. Remak, Archiv für Anatomie und Physiologie. 1841. S. 446.

390. Rudolphi, Abhandl. der k. Gesellschaft der Wissenschaft. zu Berlin. 1831. S. 342.

391. W. Kra use, Zeitschrift für rationelle Medizin. 1863. Bd. 20. S. 15. - Archiv für Anatomie und Physiologie. 1870. S. 1. Taf. I. Fig. 1.

392. Ranvier, Leçons d’anatomie générale. 1880. S. 179.

393. Bricke, Sitzungsberichte der k. Akademie der Wissenschaften zu Wien. Math.naturw. Kl, 185\%. Bd. 14, S. 373. 
394. Czermak, Moleschott's Untersuchungen zur Naturlehre des Mensehen. 1860. Bd. VII. S. 368 .

395. Eberth u. Belajeff, Archiv für pathologische Anatomie. 1866. Bd. 37. S. 126.

396. Albanus, Archiv für pathologische Anatomie. 1861. Bd. 21. S. 99.

397. Flourens, Gazette médicale de Paris. 1854. S. 395.

39s. M ol es ch ot t, Untersuchungen zur Naturlehre dẹs Menschen. 1860. Bd. VII. S. 408.

399. R. W a gn er, Neurologische Untersuchungen. 1854. S. 234.

400. Vlacovich u. Vintschgau, Sitzungsberichte der k. Akademie der Wissenschaften zu Wien. Math.-naturw. Kl. 1864. November.

401. Bamberger u. Kölliker, Archiv für patholog. Anatomie. 1856. Bd. IX. S. 328.

402. Hyr 11, Die Selbststeuerung des Herzens. 1855. S. 9. - Vergl. Nr. 438.

403. Legallois, Bulletin de la société de médecine. 1800. S. 99.

404. K u $3 \mathrm{maul}$ u. Tenner, Moleschott's Untersuchungen zur Naturlehre des Menschen u. s. w. 1857. Bd. 1II, S. 12.

405. W. Krause, IIenle's IIandbuch der systematischen Anatomie. Bd. III. 1. Varielaten der Arterien. 1868. S. 221. Fig. 113-116. - 1876. S. 229. Fig. 113-116.

406. K $\mathrm{u} ß \mathrm{maul}$ u. Tenner, Moleschott's Untersuchungen zur Naturlehre des Menschen u. S. w. 1857. Bd. I. S. 104.

407. Kußmaul, Verhandlungen der physikalisch-medizinischen Gesellschaft zu Würzburg. 1856. Bd. VI. S. 16.

408. Samuel, Archiv für pathologische Anatomie. 1867. Bd. 40. S. 218.

409. Ku Bmaul, Archiv für pathologische Anatomic.. 1858. Bd. 13. S. 294.

410. Stannius, Archiv für physiologische Heilkunde. 1852. Bd. XI. S. 4.

411. Du Bois-Reymond, Archiv für Anatomie und Physiologie. 1860. S. 639.

412. II eißner, Jahresbericht der Physiologie für 1860. S. 429.

413. B rown-Séquard, Comptes rendus. 1854. T. 32. S. 855.

414. Cohn, De embolia. Diss. Vratislaviae. 1856. S. 47.

41:3. Von Wittich, Königsberger medizinische Jahrbücher. 1863. Bd. III. S. 52.

416. Peipers, De nervorum in secretiones actione. Diss. Berlin. 1834. - s. Joh. Miiller, Handbuch der Physiologie. Bd: I. 1844. S. 384. - Experimente an Schafen und Hunden.

417. Blessig, Archiv für pathologische Anatomie. 1859. Bd, 16. S. 123.

418. Loeb, Beitrảge z. Bewegung der Samenleiter u. der Samenblase. Diss. Gießen. 1866.

419. Frankenhäuser, Jenaische Zeitschrift für Medizin, 1866. Bd. II. S. 74.

420. J. Arnold, Archiv für pathologische Anatomie. 1866. Bd. 35. S. 222.

421. J. Arnold, Archiv für pathologische Analomie. 1867. Bd. 39. S. 505.

422. Lo vén, Ludwig's Arbeiten des physiologischen Institutes zu Leipzig. 1867. S. 12.

423. Hartman n, Archiv für pathologische Anatomie. 1855. Bd. VIII. S. 11 3. Taf. III u. IV.

424. W. Krause, Henle's Handbuch der systematischen Anatomie des Menschen. Bd. III.

1. Varietäten der Venen. 1868. S. 374. - 1876. S. 395.

42.. W. Gruber, Mémoires de l’académie impériale des sciences de St. Pétersbourg. 1862. 7. Sér. T. VII. Nr. 2.

426. W. Krause, s. Nr.424. - 1868. S. 379. - 1876. S. 401.

427. Kußmaul u. Tenner, Moleschott's Untersuchungen zur Naturlehre des Menschen u. s. w. 1857 . Bd. III. S. 108.

42S. Otto, Lehrbuch der pathologischen Anatomie. 1830. S.348. S. Nr.424. 1868. S. 392. - 1876. S. 413.

429. Miescher, Ludwig's Arbeiten des physiologischen Institutes zu Leipzig. 1871. V. Jahrg. S. 174.

430. W. Krause, s. Nr. 424. - 1868. S. 376 u. 388. - 1876. S. 397 u. 409.

431. Goltz, Amtlicher Bericht über die Naturforscherversammlung zu Königsberg. 1861. S. 139. 
432. Hönle in, Descriptio anatomica systematis venae portarum in homine et quibusdam brutis. 1808.

433. Kle in, Medizinisches Zentralblatt. 1871. S. 594. - Quarterly Journal of microscopical science. 1872, Vol. XII. S. 123.

434. Ku Bmaul u. Tenner, Moleschott's Untersuchungen zur Naturlehre des Menschen u. s. W. 1857. Bd, III. S, 59.

435. Sanders, Geleidingsbanen in het ruggemerg etc. 1866. Nit Abbildungen.

436. Schiff, Lehrbuch der Physiologie. 1858. S. 229-299.

437. Miescher, Ludwig's Arbeiten des physiologischen Institutes zu Leipzig. 1871. Jahrg. V. S, 172. Mit Holzschnitt.

438. Lud wig u. Thiry, Silzungsberichte der k. Akademie der Wissenschaften zu Wien. Math,-naturw. KI. 1864. Bd. 49. S, 32 ,

439. Budge, Bewegung der Iris. 1855 (mit Angabe der Operationsmethoden).

440. Budge, Archiv für pathologische Anatomie. 1858. Bd. 15. S. 115.

141. Salkowski, Zeitschrift für rationelle Medizin. 1867. Bd. 29. S. 190.

442. Bernard, Lecons de physiologie. 1855. T. I. S. 291. - Leçons sur la physiologie du système nerveux. 1858. T. II.

443. J. u. K. Wenzel, De penitiori structura cerebri, 1812.

444. Serres, Anatomic comparée du cerveau. 1824. T. I. S. 430.

44:5. Deiters, Untersuchungen über Gehirn und Rückenmark. 1865. S. 275 u. 288.

446. S chiff, Untersuchungen über die Zuckerbildung in der Leber. 1859. S. 117.

447. Becker, Zeitschrift für wissenschaftliche Zoologie. 1854. Bd. V.

is.. von Graefe, s. A. Krause, Annotationes ad diabelem. Diss. Hal. 1833.

449. Bernard, Societé de biologie. 23. Febr. 4849. - Leçons de physiologie. 1855. Bd. I. S. 290. Fig. 14-17. - Leçons sur la physiologie du système nerveux. 1858. T. I. S. 347. Fig. 48-64. - Schrader, Göttinger Nachrichten. 20. Febr. 1852.

450. Bernard, Leçons sur la physiologie du système nerveux. 1858. T. I. S. 392. Flo ure ns, Comptes rendus. 1858. T. 47. S. 803 . Mit Abbildungen.

451. J. u. K. Wenzel, De penitioni structura cerebri. 1812. - Serres, Anatomie comparée du cerveau, 1826. T. II. S. 424.

452. Cuvier, Lecons d'anatomie comparée, 1845. T'. III. S. 81.

453. Löwe, Beitrige zur Anatomie und zur Entwickelmogsgeschichte des Nervensystems. Bd. I. 1880.

434. Forel, Sitzungsberichle der k. Akademie der Wissenschaften zu Wien. Math.naturw. Kl. 1872. Bd. 66. Abt. HI. S. 49.

455. Albertori, Moleschott's Untersuchungenz. Naturlehre u. s, w. 1881. Bd. XII. Heft5.

456. von Bibra, Vergleichende Untersuchungen über das Gehirn u.s. W. 1854. - Annalen der Chemie und Pharmazie. Bd. 91. S, 1.

457. Carus, Darstellung des Nervensystems. 1814. S. 250-u. A.

458. Huschke, Verhandlungen der k. sächsischen Gesellschaft der Wissenschaften zu Leipzig. Math.-physik. KI. 1853. II. S. 151.

459. Longet, Anatomie et physiologie du système nerveux. 1842. T. I. S. 434. T. II. S. 158 .

460. Schilf, Lehrbuch der Physiologie. 1858. S. 353.

461. Stieda, Archiv für Anatomie und Physiologie. 1864. S, 407.

462. Cuvier, Leçons d'anatomie comparée. 2e édit. T. III. 1845. S. 78.

463. Orth, Gursus der normalen Histologie. 1881. S. 299. Fig. 103.

464. Gudden, Archiv für Psychiatrie und Nervenkrankheiten. 1870. Bd. II. S. 365. Taf. 11. Fig. 4 u, 2.

465. Inzani e Lemoigne, Sulle origine e sull" andamento di varii fasci nervosi del cervello. 4861 .

466. Schiff, Lehrbuch der Physiologie. 1558. S. 349. 
467. Bisch off, Entwickelungsgeschichte des Kanincheneies. 1842. S. 41.

468. Von Monakow, Archiv für Psychiatrie und Nervenkrankheiten. 4881. Bd. XI. S. 141. Taf. II.

469. Sander, Archiv für Anatomie und Physiologie. 1866. S. 752.

470. L uy s, Recherches sur le système nerveux. 1865. S. 260. Pl. 39. Fig. 2.

471. Tiedemann, Anatomie und Bildungsgeschichte des Gehirns. 1816. S. 133.

472. Longet, Anatomie et physiologie du système nerveux. 1842. T. I. S. 488.

473. Brown-Séquard, Mémoires de la société de biologie. T. V. S. 167.

474. Budge, Zeitschrift für rationelle Medizin. 1864. Bd. 21. S. 177.

475. Budge, Medizinisches Zentralblatt. 1864. S. 525.

476. Czermak, Jenaische Zeitschrift f. Medizin u. Naturwissenschaften. 1866. Bd. III. S. 8. 477. Gudden, Archiv für Psychiatrie und Nervenkrankheiten. 1870. Bd. II. S. 365. Taf. II. Fig. 3 .

478. Walter, Archiv für pathologische Anatomie. 1861. Bd.22. S. 241. Taf. III u. IV.

479. Goltz, Über die Verrichtungen des Großhirns. 1881. S. 169. - Archiv für Physiologie. 1881 .

480. For e l, Archiv für Psychiatrie und Nervenkrankheiten. 1877. Bd. VII. S. 393. Taf. IX. Fig. 27 (Sagittalschnitt des Mittelhirns)..

4\$1. Ferrier, Die Funktionen des Gehirns. 1879.

4\$2. Fürstner, Archiv für Psychiatrie und Nervenkrankheiten. 1876. Bd. VI. S. 749.

483. Gudden, Archiv für Psychiatrie und Nervenkrankheiten. 1870. Bd. II. S. 693.

484. Gudden, Archiv für Psychiatrie und Nervenkrankheiten. 1870. Bd. II. S. 693.

Taf. VI. Fig. 2.

48:5. Vulpian, Gazette médicale de Paris. 1865. 3e Sér. T. XX. S. 80.

486. Schöps, Archiv für Anatomie und Physiologie. 1827. S. 373.

487. Donders, Nederlandsch Lancet. 1850. Schnidt's Jahrbücher der gesamten Medizin. Bd, 69.

4ss. Kußmaul u. Tenner, Moleschott's Untersuchungen zur Naturlehre des Menschen u. S. IV. 1857 . Bd. III. S. 44-49.

4\$9. The Veterinarian. XVIII. S. 419.

490. Valentin, De functionibus nervorum. 1839. S. 11. - Lehrbuch der Physiologie. 1844. Bd. II. S. 634 .

491. Barkow, Disquisitiones neurologicae. Lipsiae. 1836.

492. Valentin, Lehrbuch der Physiologie. 1844. Bd. II. S. 655.

493. W. Krause, Die Membrana fenestrata der Retina. 1868. S. 36. Taf. II. Fig. 42 u. 43.

494. Trautvetter, Archiv für Ophthalmologie. 1866. Bd. XII. Abt. 1. S. 121.

49:. Herzenstein, Beiträge zur Physiologie der Thränenorgane. 1868. S. 13.

496. Bernard, Leçons sur la physiologie du système nerveux. 1858. T.II. S. 202. Fig. II.

497. Longet, Anatomie et physiologie du système nerveux. 1842. T. II. S. 138.

498. M ag endie, Journal de physiologie expérimentale. 1824. T. IV. S. 303. - s. a Nr. 497.

499. Me ißner, Zeitschrift für rationelle Medizin. 1867. Bd. 29, S, 96. Taf. II.

500. Eckhard, Experimentalphysiologie des Nervensystems. 1867. S. 172.

501. Valentin, De functionibus nervorum. 1839. S. 30.

502. Foltz, Journal de la physiologie. 1862. T. V. S. 236.

303. Hannover, De cartilaginibus etc. auris externae. Hauniae. 1839.

504. Rahn, Zeitschrift für rationelle Medizin. 1851. Bd. I. S. 287.

505. Remak, Froriep's Notizen. 1837. Nr. 42.

306. Schwalbe, Jenaische Zeitschrift f. Naturwissenschaft. 1872. Bd. 13. Taf. XII. Fig. :3.

307. W. Krause, Gegenbaur's Morphologisches Jahrbuch. 1881. Bd. VII, S. 43. Taf. V. Fig. 3 u. 5.

508. W. Krause, Zeitschrift für rationelle Medizin. 1863. Bd. 18, S. 136.

509. Pop off, Archiv für pathologische Anatomie. 1882. Bd. 87. S. 39. Taf. 1. Fig. 3. 
310. Popoff, Archiv für pathologische Anatomie. 1882. Bd. 87. S. 66. Taf. I. Fig. 4.

511. Ko IImann, Zeitschrift für wissenschaftliche Zoologie. 1860. Bd. X. S. 413.

512. Remak, Amtlicher Bericht ïber die Naturforscherversammlung zu Wiesbaden. 1852. - Archiv für Anatomie und Physiologie. 1858. S. 190.

513. Eeker, R. Wagner's Handwörterbuch der Physiologie. 1846. Bd. III. S. 462.

;14. Lovén, Ludwig's Arbeiten des physiologischen Institutes zu Leipzig. 1867. S. 8. Taf. 1. Fig. 1 u. 2.

:3:. L. L I w ig u. Thiry, Sitzungsberichte der k. Akademie der Wissenschaften zu Wien. Math.-naturw. Kl. 1864. Bd. 49.

:j6. Cyon u. Ludwig, Ludwig's Arbeiten des physiologischen Instilules zu Leipzig. 1867. S. 129. Nit 'Taf.

:17. Röver, Untersuchungen des Nerven-Einflusses auf die Erweiterung und Verengerung der Blutgefäße. 1869. S. 63.

518. Heidenhain, Studien des physiologischen Institutes zu Breslau. 4 S65. II. III S. 113.

519. Schiff, Untersuchungen über Zuckerbildung in der Leber ete. 1859.

5ュ0. Czermak, Moleschott's Untersuchungenz. Naturlehre u.s. w. 1860. Bd. ViI. S. 377.

521. Budge, Zeitschrift für rationelle Medizin. 1861. Bd.21. S. 273.

722. W. Krause, Göttinger Nachrichten. 1863. Nr. 18. - Zeitschrift für rationelle Medizin. 1864. Bd. 21. S. 77. Taf. IV. Fig. 1 u. 2.

333. Rauber, Untersuchungen über die Vater'schen Körper. 1867. S. 22.

:34. Obolensky, Medizinisches Zentralblatt. 1867. S. 497.

:335. von Jhering, Das peripherische Nervensystem der Wirbeltiere. 1878. S.153-157.

;36. Laborde u. Leven, Gazette médicale de Paris. 1870. Meißner's Jahresbericht der P'hysiologie für 1870 . S. 215.

637. W. Krause, Zeitschrift fiir rationelle Medizin. 1866. Bd. 28. S. 86 .

i3s. Finger, Zeitschrift für rationelle Medizin. 1866. Bd. 28. S. 222. Taf. XIII. Fig. 8.

339. Rauber, Untersuchungen iber die Vater'schen Körperchen. 1867. S. 22.

540. Lud wig u. Thixy, Sitzungsberichte der k. Akademie der Wissenschaften zu Wien. Math.-naturw. Kl. 1864. Bd, 49. Abt. 2. S. 450.

.341. Pförtner, Untersuchungen über das Ganglion intercaroticum. Diss. Göttingen. 1868. Fig. 3 .

5.2. Gri n hagen, Zeilschrift für rationelle Medizin. 1867. Bd. 29. S. 33 .

i43. Bever, Wirzburger medizinische Zeitschrift. 1867. Bd. VII. Heft 4. S. 240.

5:4. von B ezold, Untersuchungen aus dem physiologischen Laboratorium in Würzburg. 1867. Ileft 2. S. 235 . - Bever, daselbst, S. 249. Taf. VIII.

\#45. Ludwig u. Cyon, Ludwig's Arbeiten des physiologischen Institules zu Leipzig. 1867. S. 134.

546. Freuler, Monographia caviae porcelli zoologica. Diss. Götting. 1820. V tab. S. 42. 5i7. Ploch, Diabeles nach Durchschneidung des N. splanchnicus. Diss. Gießen. 1863.

5'tS. M. U. E. Cyon, Archiv für Anatomie und Physiologie. 1867. S. 412.

:349. Heiden hain, Studien des physiologischen Institutes zu Breslau. 1865. H.III. S. 117.

5:j0. Bu d ge, Zeitschrift fur rationelle Medizin. 1864. Bd.21. S. 184.

:3.51. Rüdinger, Rückenmarksnerven der Baucheingeweide. 1866 S. 23.

5:3.. Pflüger, Das Iemmungsnervensystem für die Gedärme. 1857. S. 33.

:..3. Von Gra efe u. A. Kra use, Annotationes ad diabetem. Diss. Halae.1853. - Ploch, Diabetes nach Durchschneidung des N. splanchnicus. Diss. Gießen. 1863. - Vergl. Ni. ;17. S. : $; 7$.

:34. Budge, Nova acta academiae Leopoldino-Carolinae naturae curiosorum. 1860. Bd. 27. S. 267. Mit Abbildungen. - La ma nsky, Zeitschrift für rationelle Medizin. 1866. Bd. 28. S. 61 .

3ii.i. Bernard, Lecons de physiologie. 1855. T. 1. S. 322.

356. Franken hảuser, Jenaische Zeitschrilt für Medizin. 1866. Bd. II. S. 78. 
:37. Pincus, Experimenta de vi nervi vagi et sympathici. Diss. Vratislaviae. 1S56. S. 20. 558. F. Arnold, Ueber den Ohrknoten. 1828. S. 27.

559. Breschet, Répertoire d'anatomie et de physiologie pathologiques. 1828. T. VI. S.92. 560. Bendz, Dissertatio de anastomosi Jacobsonii. 1833. S, 24.

561. Schiff, Lehrbuch der Physiologie. 1858. S, 396.

562. Prévost, Archives de physiologie. 1868. Bd. I. S. 1 u. 207.

563. W. Krause, Göttinger Nachrichten. 1863. S. 275.

564. P’olle, Die Nervenverbreitung in den weiblichen Genitalien. Preissehrift. Göttingen. 1865. S. 12 u. 20.

565. Kehrer, Beiträge zur Geburtskunde. 1864.

366. Spiegelberg, Monatsschrift für Geburtskunde. Bd. 24. S. 12 u. 13.

567. Frankenhäuser, Jenaische Zeitschrift für Medizin. 1S66. Bd. II. S. 61-\$3. Tal. Il u. III.

56s. R. Koch (Entdecker der Tuberkelbakterien), Uber das Vorkommen von Ganglienzellen an den Nerven des Uterus. Preisschrift. Güttingen. 1865.

569. Köllner, Geologische Entwickelungsgeschichte der Säugetiere. 1882. S. 84.

;70. Gegenbaur, Grundriß der vergleichenden Anatomie. 1874. S. 532. Fig. 237.

571. Bense, Zeitschrift für rationelle Medizin. 1868. Bd. 33. S. 1. Taf. II. Fig. 11.

572. Ziegler, Lehrbuch der pathologischen Anatomie. 1882. Bd. 1 S. 336 .

573. Rie B, Archiv für Anatomie und Physiologie. 1872. S. 248.

374. Ganser, Gegenbaur's Morphol. Jahrbuch. 1882. Bd. V11. S. 591. Taf. XXIX, Fig. 8. 57:;. 'Ganser, Archiv für Psychiatrie und Nervenkrankheiten, 1878. Bd. IX. S. 286. Taf. II. Fig. 5b $6^{\mathrm{b}}, 7^{\mathrm{b}}$. - Über die vordere Hirnkommissur der Säugetiere. Wuirzburger Diss. Berlin. 1878.

376. Gudden, Archiv für Psychiatrie und Nervenkrankheiten. 1870. Bd. H. S. 693.

577. Schauta, Sitzungsberichte der k. Akademie der IVissenschaften zu WVien. Math.naturw. Kl. 1872. Bd. 65. Abt. III. S. 105. Mit Taf.

:3:S. Arloing, Journal de l'anatomie et de la plyysiologie. 1868. Ve Ann. S. 449.

:379. Hofmeister, Sitzungsberichte der k. Akademie der Wissenschaften zu Wien. IIath.-naturiv. Kl. 1872. Bd.65. Ablh. III. S. 92.

5so. Bumm, s. Gudden, Archiv für Ophthalmologie. 1879. Bd. 25. Abt. I. S. 49. Taf. I. Fig. 3 -u. Nr. 644 .

5\$1. R anvier, Leçons d'anatomie générale. 1880. S. 364.

jsz. Kl a $\mathrm{B}$ ner, Studien über die Huskelanordnung am Pylorus der Vertebraten. 1880. S. 14. Taf. X. Fi心. 3 .

:is:3. Lu chsinger, Archiv für Physiologie. 1882. Bd. 28. S. 78.

584. NuBbaum, Archiv für mikroskopische Anatomie. 1882, Bd.21. S. 308. Taf. XV und XVI. Fig. 1, 2, 11, 21. - Vergl. Langley and Sewall, Journal of physiology. 1879. Vol. II. S. 281.

385. Raw itz, Archiv für mikroskop. Anatomie. 4882. Bd. 21. S. 284. Taf. XIV. Fig. 24. 586. Adamkiewicz u. Jacobson, Medizinisches Zentrablatt. 1873. S, 483.

:87. Woroschiloff, Ludwig's Arbeiten des physiologischen Institutes zu Leipzig. 1874. S. 248 .

iss. Klug, Archiv für Anatomie und Physiologie. Physiolog. Abt. 1881. S. 267.

:39. Stieda, Studien uber das zentrale Nervensystem der Wirbeltiere. 1870. S. 46. Fig. 26-34. Zeitschrift f. wissenschaftl. Zoologie. 1870. Bd. 20. Taf. XVII-XX.

590. G. Kupfer, De structura cornu Ammonis disquisitiones. Diss. Dorpat. 1859.

391. Stieda, Studien über das zentrale Nervensystem der Vögel und Säugetiere (Maus). 1868. S. 72. Zeitschrift für wissenschaftl. Zoologie. 1868. Bd. 19. Taf. III. Fig. 52.

392. vou Bezold, Untersuchungen aus dem physiologischen Laboratorium in Wiirzburg. 1867. Heft Il. S. 261. 
593. Gegen baur, Untersuchungen zur vergleichenden Anatomie der Wirbeltiere. 1864. Heft 1. S. 50. Taf, III. Fig. 4.

594. Owen, On the Archetype etc. S. Nr. 593, S. 49.

595. Bever u. von Bezold, Untersuchungen von Bezold's aus dem physiologischen Laboratorium in Würzburg. 1867. Heft II. S. 319.

;96. J. Ranke, Die Blutverteilung und der Thätigkeitswechsel der Organe. 1871.

597. von Sehlen, Archiv für Anatomie und Physiologie. Anat. Abt. 1882. S. 33.

5:s. Hirschberg, Archiv für Anatomie und Physiologie. Physiol. Abt. 1882. S. 91.

399. NI a yser, Archiv für Psychiatrie und Nervenkrankheiten. 1877. Bd. VII. S. 539. 1879. Bd. IX, S. 108 .

600. Stieda, s. Nr. 589 . S. 318 .

601. Lüderitz, Archiv für Anatomie und Physiologie. Anat. Abt. 1881. S. 445. Taf. XVIII. Fig. 4 .

602. Hilbert, Zur Kenntnis der Spinalnerven. Diss. Königsberg. 1878. S. 35-47. Durch ein Versehen ist diese Dissertation (Nr. 40, S. 204. $\mathrm{nm}$. 3) als von Hinrichsen herrihrend zitirt worden.

603. Gudden, Archiv für pathologische Anatomie. 1876. Bd, 66. S. 55. Taf. III.

604. Bentkowski, Schwalbe's Jahresbericht der Anatomie für 1876. S. 303.

60;. Platen, Archiv für pathologische Anatomie. 1877. Bd. 71. S. 33.

606. Nothnagel, Archiv für pathologische Anatomie. 1873. Bd. 57. S. 184. Taf. IV. Fig. 1-4. - Daselbst 1876. Bd. 68. S. 33.

607. Iloeli, Archiv für patholog. Anatomie. 1879. Bd. 76. S. 475. Taf. VIII. Fig. 1-3. 608. J. Arnold, Archiv für pathologische Anatomie. 1878. Bd. 73. S. 136.

609. J. Arnold, Archiv für patholog. Anatomie. 1880. Bd.80. S.315. Taf.IX. Fig.1.u. 2. 610. Hoyer, Archiv für mikroskopische Anatomie. 1576. Bd. 13. S. 603. Taf. XXXVIII. Fig. 1, 2, 3. Taf. XXXIX. Fig. 6.

611. Gerster, Zeitschrift für Anatomie und Entwickelungsgeschichte. 1876. Bd. II. S. 49. Taf. IV. Fig. \& II. ").

619. Löwe, Archiv f. mikrosk. Anatomie. 1879. Bd. 16. S.614. Taf. XXIX. Fig. 11 u. 12. 613. Löwe, Archiv f. mikrosk. Anatomie. 1878: Bd. 15. S. 542. Taf. XXXIV-XXXVI.

614. Pfitzner, Gegenbaur's Morphologisches Jahrbuch. 1882. Bd. VII. S. 726.

615. Löwe, S. Nr.613, S. 396. Taf. XXXVII.

616. Gliappuis, Archiv fuir Anatomie u. Entwickelungsgeschichte. 1876. Bd. II, S. 290.

617. Schwalbe, Archiv für Anatomie und Entwickelungsgeschichte. 1876. I3d. II. S. 134 u. 137.

618. Andreas lleyer, Archiv für mikroskopische Anatomie. 1879. Bd. 17. S. 324. Taf. XXXI u. XXXII.

619. His, Archiv f. Anatomie u. Physiologie. Anat. Abt. 1880. S. 230. Taf. VIIl. Fig 8.

6э0. Angelucci, Archiv für Anatomie und Physiologie. Anat. Abt. 1878. S. 377. Taf. V. Fig. 22-25.

621. von Vintsehgau, Archiv für Physiologie. 1880. Bd. 23. S. 1.

62ّ. Von Mihalkovics, Ludwig's Arbeiten des physiologischen Institutes zu Leipzig. 1873. S. 7 .

623. E. Cyon, Archives de physiologie. 1869. Bd. II. S. 555.

624. H. M üller, Zeitschrift für wissenschaftliche Zoologie. 1856. Bd. VIII. S.94.

(jæ5. Engelman n, Stricker's Hand\}uch der Lehre von den Geweben. Bd. II. 1872. S.823. 6ə6. Golgi, Sui nervi del tendini. 1880.

6๖7. Hällsten u. 'I'igerstedt, Nordiskt Medicinskt Arkiv. 1877. Bd. IX.

6џS. Finkelstein, Archiv für Anatomie und Physiologie. Anat. Abt. 1880. S. 247. Taf. IX. Fig. 4.

62!). Magendie, S. Dönhoff, Archiv fuir Anatomie und Physiologie. Physiol. Abt. 1880. S. 432. - Salkowsky, Medizinisches Zentralblatt. 1881. S. 155. 
630. Pinner, Archiv für Anatomie und Physiologie. Physiol. Abt. 1880. S. 241.

631. Wo roschiloff, Berichte der k. süchs. Gesellschaft der Wissenschaften zu Leipzig. Math,-phys. Ki. 1874. S. 248. Taf. I-XVII.

632. G. Retzi us, Archiv für Anatomie und Physiologie. Physiol. Abt. 1880, S. 382.

633. Ranvier, Comptes rendus. 1875. T. 81. - A. Key u. G. Retzius, Studien in der Anatomie des Nervensystems, 1876. Zweite Hälfte. Abt. 1. Taf. III. Fig. 12.

634. Falck, Beiträge zur Physiologie etc. 1875. Bd. I. S. 129.

635. Ruge, Archiv für pathologische Anatomie, 1870. Bd. 49. S. 246.

636. Kölliker, Handbuch der Gewebelehre. 1867. S. 437. Fig. 310.

637. Frey, Handbuch der Histologie und Histochemie. 1876. S. 663.

638. von Ebner, Rollett's Untersuchungen aus dem physiologischen Institut in Graz. Heft I. 4870. S. 57.

639. Hering, Stricker's Handbuch der Lehre von den Geweben. Bd. I. 1871. S. 435.

640. Boh m, Archiv für pathologische Anatomie. 1869. Bd. 47. S. 223.

641. Von Gudden, Archiv für Psychiatrie und Nervenkrankheiten, 1881. Bd. XI. S. 415. Taf. VI. Fig. 1-5.

64. Von Gudden, daselbst. S. 428. Taf. VII. Fig. $8-18$.

643. von Gudden, daselbst. S. 424. Taf. VI. Fig. 6 u. 7.

644. B u mm, Archiv für Psychiatrie und Nervenkrankheiten. 4884. Bd. XI. S. 264 u. 265.

643. af Schulten, Arch. f. Anat. u. Physiologie. Physiol. Abt. 1882. S. 285. Taf. VII.

646. Hagema nn, Über den Bau des Conarium. Diss. Göttingen. 1872. S. 24.

647. Schwalbe, Archiv für mikroskopische Anatomie. 1876. Bd. 12. S, 509. Taf, XX. Fig. $9-11$.

6is. II. Virchow, Verhandlungen der physikalisch-medizinischen Gesellschaft zu Würzburg. 1881, Bd. 16. Taf. V. Fig. $3 \mathrm{~A}$.

649. Cohnheim, Vorlesungen über allgemeine Pathologie, 1877. Bd. I. S. 610.

630. Losen, v. Pitha u. Billroth's Ilandbuch der Chirurgie. Bd. II. Abt. 2. Liefg. 4. 1882. S. 118-121.

631. Bidder, Archiv für klinische Chirurgie. 1878. Bd. 22. S. 156. - Vogl, Berliner klinische Wochensehrift. 1875. S. 473.

639. Jukes, Beiträge zum .histologischen Bau der Labdrüsen. Diss. Götlingen. 1871.

653. Ebstein, Archiv für mikroskopische Anatomie. 1870. Bd. VI. S. 516 u. 518.

634. Kölliker, Mikroskopische Anatomie. 1854. Bd. Il b. S. 143.

65... Damsch, Über die pathologisch-anatomischen Prozesse in den Lungen bei Fütterungstuberkulose. Diss. Berlin. 1880, - O rth, Berliner klinische Wochenschrift. 1881. Nr. 42.

656. Ehrlich, Medizinisches Zentralblatt. 1881. S. 753.

657. Cohn heim, Archiv für pathologische Anatomie. 1866. Bd. 38, S. 343.

638. Petermöller, Zeitschrift für rationelle Medizin. 1868. Bd. 34. S. 88. Taf. VIIl u. IX.

659. N y yerstein, Zeitschrift für rationelle Medizin. 1864. Bd. 23. S. 63.

660. Finka m, Über die Nervenendigungen im großen Netz. Diss Göttingen. 1873. Vergl. W. Krause, Nr. 38. S. 98. Fig. 51.

661. Sa melsohn, Medizinisches Zentralblatt. 1880. S. 305 u. 322.

66. Deutschman n, Klinische Monatsblätter für Augenheilkunde, 1880.

663. Reinert, Zeitschrift für rationelle Medizin. 1869. Bd, 34, S. 203.

664. Cohnheim u. von Schultheß-Rechberg, Archivfür pathologische Anatomie. 1881. Bd. 85 . S. 503.

665. Frey, Handbuch der Histologie und Histochemie. 1867. S. 131.

666. Roßba ch, Medizinisches Zentralblatt: 1882. S. 81.

667. G. Retzius, Nordiskt Medicinskt Arkiv. 1871. Bd. III. Fig. 4.

668. Gruber, Deutsche Vierteljahrsschrift für öfentliche Gesundheitsptlege. 1882. Bd. 14. S. 168. 
669. Baginsky, Mrchiv fïr Anatomie und Physiologie. Physiolog. Abt, 1881. S. \$60.

650. Bochefontaine, Revue internationale des sciences naturelles, Bd. VIII. Nr. 10. Biologisches Zentralblatt. 1882. S. 767.

671. R. Koch, Ủber die Milzbrandimpfung. 1882. - Medizinisches Zentralblatt. 1883. S. 250 .

672. von Werra, Archiv für pathologische Anatomie, 1882. Bd. S8. S. 197.

673. Grawitz u. Is rä̈l, Archiv für pathologische Analomie. 1879. Bd. 77. S. 333:

674. Ribbert, Archiv für pathologische Anatomie. 1882. Bd. 88. S. 11.

670. Gins burg, Archiv für pathologische Anatomie. 1882. Bd, 88. S. 277.

676. Kupffer, Arehiv für mikroskopische Anatomie. 1875. Bd. 12. S. 355. - Vergl. Rothe, Uber die Sternzellen der Leber. Diss. Müchen. 1882.

677. Kühne u. Lea, Untersuchungen aus dem physiologischen Laboratorium zu Heidelberg. 1882. Bd. II. S. 448. Taf. II-VI.

678. Fürst, Retzius' Biologische Untersuchungen. 1881. S. 67. Taf. VIII-IX.

679. Hortolès, Archives de physiologie. 1881. S. 861.

6so. Jungersen, Bitrag lil Kundskaben om det Jacobsonske Organ. Kjöbenhavn. 1881.

6si. Klein, Quarterly Journal of microscopical science, 1881. Vol. 21. S. 379.

682. Campbell Graham, Archiv für Physiologie. 1881. Bd. 26. S. 379.

683. Kandarazki, Archiv für Inatomie und Physiologie. Anat. Abt. 1881. S. 7.

6s'. W. Krause, Die Membrana fenestrata der Retina. 1868. Taf. II. Fig. 23.

6S:). W. Krause, Archiv für mikroskopische Anatomie. 1876. Bd. 12. S. 776. - Vergl. Nr. 38. S. 60 .

686. Heidenhain, Archiv fuir mikroskopische Anatomie. 1870. Bd. VI. S. 392. $\mathrm{Nu}$ B b a um, daselbst. 1877. Bd. 13. S. 743.

687. Paneth, Silzungsberichte der k. Akademie der Wissenschaften zu Wien. Math.naturw. KI. 1876. Bd. 74. Abl. III.

685. Brissaud, Archives de physiologie. 1880. S. 769.

6s9. Löwenberg, Archiv für Ohren- und Augenheilkunde. 1872. Bd. III.

690 Gscheidlen, Untersuchungen aus dem physiologischen Laboratorium zu Wiirzbrg. 1868. Heft 3. S. 141.

691. Tieffenbach, Uber die Existenz der glykogenen Funktion der Leber. Diss. Königsberg. 1869.

692. Schiff, Lecons sur la physiologie de la digestion. 1868. Bd. II. S. 419.

693. Correnti, Studi critici e contribuzioni alla patogenesi dell' albuminuria. Firenze. 1868 .

694. Walther, Medizinisches Zentralblatt. 1868. S. 450.

695. Sch iff, Lecons sur la physiologie de la digestion. 1868 . Bd. I. S. 239.

696. Frisch, Sitzungsber. d. k. Ak. d. Wissensch, zu Wien. Math.-naturw. Kl. 1869. Bd. 58.

697. Engelmann, Archiv für Physiologie. 1869. Bd. II. S. 243.

6!s. Fleischer, Archiv für Physiologie. 1869. Bd. II. S. 432.

699. Krieger, Zeitschrift für Biologie, 1869. Bd. V. S. 476.

700. Oehl, Gazett. lombard. 1868. Nr.9 u. 10.

701. Krishaber, Archives de physiologie. 1869. S. 559.

70ษ. Waller et Prévost, Comptes rendus. 1869. T. II. S. 480.

703. Knol1, Eckhard's Beiträge zur Anatomie u. Physiologie. 1869. Bd. IV. S. 111.

704. Brozeit, Archiv für Physiologie. 1870. S. 373.

70.;. Eckhard, Beiträge zur Anatomie und Physiologie. 1867. Bd. IV. S. 1.

706. A fan asieff, Wiener medizinische Wochenschrift. 1870. Nr.9-12.

707. Lott, Rollett's Untersuchungen aus dem physiolog. Laboratorium in Graz. 1871. Helt. 2. s. 252 .

708. Eckhard, Beiträge zur Anatomie und Physiologie. 1871. Bd. VI. S. 33.

709. Sinitzin, Medizinisches Zentralblalt. 1871. S. 161. 
710. Riegel, S. Meißner's Jahresbericht der Physiologie fix 1871. S. 317.

711. Jolly, Untersuchungen iber den Gehirndruck u. iiber die Blutbewegung im Schiidel. 1871.

712. Oser u. Schlesinger, Medizinisches Zentralblatt. 1871. S. 817.

713. Hoуer u. Stravinsky, Zeitschrift für wissenschaftliche Zoologie. 1872. Bd. 22. S. 302 .

714. Rindfleisch, Archiv für mikroskopische Anatomie. 1872. Bd. 8. S. 4 33.

715. Pop off, Schwalbe's Jahresbericht der Anatomie fül 1872. S. 153.

716. Heller, Beriohte der k. sächsischen Gesellschaft der Wissensehaften. 1872. S. 165.

717. Bock u. Hoffmann, Archiv für pathologische Anatomie. 1872. Bd. 56. S. 204.

718. Ma yer, Medizinische Jahrbücher der k. Gesellschaft der Arzte zu Wien. 1872. S. 132.

719. Kupressow, Archiv für Physiologie. 1872. Bd. VI. S. 291.

720. Malas sez, De la numération des globules rouges du sang. 1873.

721. Nicoladoni, Medizinische Jahrbicher der k. Gesellschaft der Ärte zu IVien. 1873. S. 401.

722. Duval, Journal de l'anatomie et de la physiologie. 1873. S. 30.

723. Steinberg, Archiv für Physiologie. 1873. Bd. VII. S, 101.

724. Frankenh äuser, Jenaische Zeitschrift für Medizin etc. 1866. Bd. I1. S. 77.

72:3. Eckhard, Beiträge zur Anatomie u. Physiologie. 1873. Bd. VII. S. 67.

726. Dittmar, Berichte der $\mathrm{k}$. sächsischen Gesellschaft der Wissenschaften zu Leipzig. Math.-phys. Kl. 1873. S. 449.

727. Gierke, Archiv für Physiologie. 1873. Bd. VII. S. 583. Taf. VILa.

728. Curschmann, Deutsches Archiv für klinische Medizin. 1873. Bd. XII. S. 356.

729. Mokritzky, Schwalbe's Jahresbericht der Analomie für 1873. S. 480.

730. As p, Berichte der k. sächsischen Gesellschaft der Wissenschaften zu Leipzig. Phys.math. Kl. 1873. S. 482.

731. Reich, Archiv für Oplithalmologie. 1873. Bd. XIX. Abt. III. S. 38.

732. Gayat, Klinische Blätter für Augenheilkunde. 1873. Bd. XI. S. 453. - Comptes rendus. 1876. T. 81 . S. 483 .

733. Legros, Journal de l'anatomie et de la physiologie. 1874. S. 137. Pl. III.

73\%. Win kler, Jahresbericht der Gesellschaft fur Natur-u. Heilkunde in Dresden. 1874. 733. von Brunn, Göltinger Nachrichten. 1874.

736. We il, Medizinische Jahrbücher der k. Gesellschaft der Arzte zu Wien. 1873.

737. Schüller, Deutsches Archiv für klinische Medizin. 1874. Bd. 14. S. 566.

738. Holmgren, Upsala läkareföreniugs förhandlingar. 1874. Bd. 9. S. 578.

739. Leber, Graefe u. Sämisch, Handbuch der Augenheilkunde. Bd. II. 1874. S. 302.

740. Cohnheim, Neue Untersuchungen über die Entzündung. 1873. S. 52.

741. Picot, Comptes rendus. 1874. T. 79. S. 62.

742. Fr. Darwin, Quarterly Journal of microscopical science. 1874. S. 109.

743. Gudden, Experimentaluntersuchungen über das Schädelwachsthum. 1874. Mit Taf.

744. Toe I, Die Ranvier'schen Schnürringe markhaltiger Nervenfasern. Diss. Zürich. 1875.

745. Bogoslovsky, Archiv für pathologisehe Anatomie. 1875. Bd. 65 . S. 359.

746. Gonjaew, Archiv für mikroskopische Anatomie. 1875. Bd. XI. S. 479.

747. Klein, The anatomy of the lymphatic system. T. II. 1875.

748. Kondratow icz, Schwalbe's Jahresbericht der Anatomie für 1875. S. 269.

749. van Beneden, Bulletins de l'Acarémie Royale de Belgique. 1875. T.40. Nr.12. Journal de Zoologie. 4876 . Bd. V. S. 10.

730. Obersteiner, Medizinische Jahrbücher der k. Gesellschaft der Ärte zu Wien. 1875. S. 179.

751. Owsjannikow, Berichte der k. sächsischen Gesellschaft der Wissenschaften zu Leipzig. Math.-phys. Kl. 1874. S. 457.

752. Schultze.u. Fürbringer, Medizinisches Zentralblatt. 1875. S. 929. 
7.3.3. H e ekel, Comptes rendus. 1875. T. 80, S. 1608.

7.;. Eliseher, Medizinisches Zentralblatt. 1876. S. 884.

755. Gohnheim u. Litten, Archiv für pathologische Anatomie. 1876. Bd.65. S.99.Köster, Sitzungsberichte der niederrheinischen Gesellschaft für Natur- und Heilkunde in Bonn. 21. Febr. 1876.

7:36. Weil, Medizinische Jahrbücher der k. Gesellschaft der Ärzte zu Wien. 1873. Il ensen, Archiv für Anatomie u. Entwicklungsgeschichte. 1875. Bd. I. S. 228. Rein, Archiv für mikroskopische Anatomie. 1883. Bd.22. S. 235 u. 236.

7.:7. Albertoni u. Michieli, Lo Sperimentale. 1876. Vol. 37. S.136. - Fürstner; Archiv für Psychiatrie u. Nervenkrankheiten. 4876. Bd. VI. S.719. - Eulenberg u. L a ndo is, Archiv für pathologische Anatomie. 1876. Bd. 68, S. 245. - Balog h. Schwalbe u. Hofmann's Jahresbericht der Physiologie für 1876. S. 39.

758. Holmgren, Upsala lảkareförenings förhandlingar. 1876. Bd. 11. S. 231.

739. A. Budge, Berichte der k. sächsischen Gesellschaft der Wissenschaften zu Leipzig. Math.-phys. Kl. 1875. S. 161. Mit 1 Tafel.

760. von Win iwarter, Sitzungsberichte der k. Akademie der Wissenschaften zu Wien. Math.-naturw. KI. 1876. Bd. 74. Abt. III. Mit 1 Tafel.

761. Drasch, Sitzungsberichte der k. Akademie der Wissenschaften zu Wien. Math.naturw. Kl. 1877. Bd. 76. Abt. III. S, 79.

762 . Davis, Archiv für mikroskopische Anatomie. 1877. Bd. 14. S. 163.

763. Schwalbe, Sitzungsberichte der Jenaischen Gesellschaft für Medizin u. Naturwissenschaften. 1878.

76). Peschel, Giornale della Accademia di Medicina di Torino. 1878. Vol, II. Nr. 8.

$76 ; 3$. Wendt, Medizinisches Zentralblatt. 1878. S. 260.

766. Löw e, Archiv für mikroskopische Anatomic. Bd. 15. S. 41.

767. Ditlevsen, Nordiskt Medicinskt Arkiv. 1878. Bd. X.

76s. Formad, American Journal of the medical sciences. 1878. Vol.75. S. 93.

769. II. Für bringer, Beitrag zur Kenntnis der Kehlkopfmuskulatur. 1875. S. 37. (Untersuchung von acht Kehlköpfen.)

770. Henry u. Wollheim, Arehiv für Physiologie. 1877. Bd. 14. S. 437.

771. Tarch anow, Schwalbe u. Hofmann's Jahresbericht der Physiologie fuir 1878. S. 34.

779. Valentin, Archiv für Physiologie. 1878. Bd. 17. S. 255.

773. Löwe, Medizinisches Zentralblatt. 1879. S. 337. Vergl. Nr. 433.

77 i. Arens, Ein Beitrag zur Anatomie des Lig. ileofemorale. Diss. Gießen. 1879.

773. Langley, Journal of Physiology. 1879. Vol. II. S. 261. Mit Taf. - Proceedings of the Royal Society of London. 1879. S. 377.

776. Leopold, Archiv für Gynäkologie. 1879. Bd. 15. S. 258.

777. Nuel, Recherches microscopiques sur l'anatomie du limaģon des mammifères. 1878.

77 s. Ott, Journal of physiology. 1879. Vol. II. S. 42.

779. F゙ilehne $u$. Pentzoldt, Medizinisches Zentralblatt. 4879.

$7 \times 0$. Laborde, Gazette hebdomadaire. 1879. S. 480.

isı. Il öggyes, Archiv für experimentelle Pathologie u. Pharmakologie. 1879. Bd. 11. S. 258.

7s. Bessau, Die Pupillenenge im Schlafe u. s. w. Diss. Königsberg. 1879. - Vergl. Grii nhagen, Berliner klinische Wochenschrift. 1879. S. 407 u. 649.

7\$3. Rigal et Vignal, Comptes rendus. 1879. T'. 90. S. 1218.

784. Neumann, Archiv für mikroskopische Anatomie. 1880. Bd. 18. S. 302. Taf. XVI.

78:i. Marchi, Atti della Accademia delle scienze di Torino. 1881, - Vergl. Nr.38. S. 44.

786. Golgi, Sui nervi del tendini. 1880.

is7. Vignal, Gazette médicale de Paris. 1880. S. 651. - Archives de physiologie. 1881. S. 694 U. 910 .

iss. Klose, Beitrag zur Kenntnis der tubulösen Darmdrüsen. Diss. Breslau, 1880.

784. Kossowski, Schwalbe's Jahresbericht der Anatomie für 1880. S. 213. 
790. Veraguth, Archiv für pathologische Anatomie. 1880. Bd. 82, S. 238. Taf. VII.

791. Pautynski, Archiv für pathologische Anatomie. 1880. Bd. 79. S. 392.

792. B rissaud, Archives de physiologie. 1880. '1. VII. S.847. - Vergl. Nr. 38, S. 77.

793. Leopold, Archiv für Gynäkologie. 1880. Bd. 16. S. 24.

794. Wassilief, Schwalbe's Jahresbericht der Anatomie für 1880. S. 268.

79\%. Jakowski, Schwalbe's Jahresbericht der Anatomie für 1880. S. 275.

796. Deutschmann, Archiv für Ophthalmologie. 1880. Bd. 26. Abt. III. S. 117. Vergl. Ulrich, daselbst. S. 35, u. Schoeler, daselbst, Bd. 25. Abt. IV. S. 65.

797. Fürst, Nordiskt Medicinskt Arkiv, 1880, Bd, 12. Nr. 19.

798. Langenbacher, Österreichische Vierteljahrsschrift für wissenschaftliche Veterinärkunde. 1880. Bd.53. S. 121.

799. Leydig, Zeitschrift für wissenschaftliche Zoologie. 1859. Bd. II. S. 1.

soo. Schneidemühl, Deutsche Zeitschrift für Tiermedizin u. vergleichende Pathologie. Bd, VI. S, 329. Fig. 11.

801. Cash, Archiv für Anatomie u. Physiologie. Physiol. Abt. 1880. Suppl. S. 150.

s0y. Rein, Schwalbe u. Hofmann's Jahresbericht der Physiologie für 1880. S. 85. De mbo, Annales de Gynécologie. 1883. T. XIX. S. 81.

s03. Stein er, Verhandl. d, naturhist.-med. Ver. z. Heidelbg. 1880. Bd. II. S. 283. Taf. VIII.

s04. Lassar, Archiv für pathologische Anatomie. 1880. Bd. 79. S. 168.

s05. Redard, Recueil d'ophthalmologie. 1880 u. 1881. - Poucet, Zentralblatt für praktische Augenheilkunde. 1880. Bd. IV. S. 321.

806. Demant, Zeitschrift für physiologische Chemie. 1880. S. 384.

s07. Balbiani, Zoologischer Anzeiger. 1881, S. 637 u. 662.

s08. Razumowski, Schwalbe's Jahresbericht der Anatomie für 1881. S. 232.

809. Broca, Revue d'Anthropologie. 1881. T. IV. S. 193 u. 385.

s10. Kölliker, Entwickelungsgeschichte des Menschen u. s. w. 1879. S.981.

811. Langen b a cher, Archiv für mikroskopische Anatomie. 1881. Bd, 20. S. 92.

812. Rein, Archiv für mikroskopische Anatomie. 1882. Bd. 20. S. 433. Taf. XXIX.

813. Deutschmann, Archiv für Ophthalmologie. 1882. Bd. 28. Abt. II. S. 291.

814. Henle, Eingeweidelehre. 1862. S. 56. - 1873. S. 61.

815. Gotthard, Vollständiger Unterricht in der Wartung und Pflege der Ziegen und Kaninchen. 1806, S. 179.

816. Owen, Comparative anatomy of vertebrates. Vol. I-III. 1866-1868.

817. Pfliuger, Die Eierstöcke der Säugetiere und des Menschen. 1863.

818. Hilgendorf, Briefliche Mitteilung. - Dr. Hilgendorf hat die große Freundlichkeit gehabt, eine beträchtliche Anzahl sehr wertvoller Notizen, Bemerkungen und Berichtigungen, zum Teil ganz neue Beobachtungen enthaltend, dem Verf. zur Verfügung zu stellen, wofür hier der herzlichste Dank abgestattet wird. Sie sind sämtlich als Nr. 818 charakterisirt.

819. W. Gruber, Mémoires de l'académie impériale des sciences de St. Pétersbourg. T. XVl. 1870

820. Hagen-Torn, Archiv für mikroskopische Anatomie. 1882. Bd. 24. S. 623 u. 649. 821. Hyrtl, Sitzungsberichte der k. Akademie der Wissenschaften zu Wien. Math.-naturw. Kl. 1879. Bd. 61.-Derselbe, Handbuch der praktischen Zergliederungskunst. 1860. - Lehrbuch der Anatomie. 1878. S. 1041.

822. W. Krause, Archiv für pathologische Anatomic. 1881. Bd. 86. S. 370.

823. Arnemann, Versuche über die Regeneration. 1787. Bd. I. S. 104.

824. Stood, Über trophische Nerven nebst einigen einschlägigen Versuchen an Kaninchen. Diss. Halle. 1881, S. 42.

825. Simons, Vorläufige Mitteilungen über eine neue Genese der Temperaturerniedrigung. Diss. Bonn. 1870 .

826. Gluck, Berliner klinische Wochenschrift. 1881, Nr.44. - Vergl. Deutsche medi- 
zinische Wochenschrift. 1881, Nr. 49, und Arehiv fïr klinische Chirurgie. 1882. Bd. 28. S. 605 .

827. Ruickert, Der Pharynx. 1882. S. 6.

828. Du Bois-Reymond, Untersuchungen über tierische Elektrizität. Bd. II. Abt. 2. 1860. S. 340 U. 344 .

829. Langhans, Die Übertragbarkeit der Tuberkulose auf Kaninchen. Habilitationsschrift. Marburg. 1868 .

\$30. O. Rosenbach, Über artifizielle Herzklappenfehler. Diss. Breslau. 1878.

\$31. René, Gazette des llôpitaux. Paris. 1882.

832. A, Bidder, Medizinisches Zentralblatt. 1882. S. 897.

833. Deutschmann, Archiv für Ophthalmologie. 1882. Bd. 28. Heft 3. S. 241.

834. L. Bruns, Zeitschrift für vergleichende Augenheilkunde. 1882. Bd. II. Taf.V. Fig. 4 u. 5.

835. G. Retzius, Biologische Untersuchungen. 1883. Bd. II. S. 103. Taf, VII u. VШI.

836. Schottelius, Archiv für pathologische Anatomie. 1883. Bd. 91. S. 150.

837. II. Fiseher, Die septische Nephritis. Breslau, 1868.

838. Lukjanow, Archiv für Physiologie. 4882. Bd. 30. S. 82.

839. Schlesinger, Medizinische Jabrbücher der k. Gesellschaft der Ärzte zu Wien. 1873. Bd. I.

840. Mauth ner, Sitzungsberichte der k. Akademie der Wissenschaften zu Wien. Math.naturw. K1. 1873. Bd. 67. Abt. HII. Nit Taf

841. Hänsell, Archiv für Ophthalmologie. 1879. Bd. 25. Abt. IV. S. 1.

842. Deutschmann, Archiv für Ophthalmologie. 1879. Bd. 25. Abt. IV. S. 280.

843. Christiani, Monatsberichte der kgl. Akademie der Wissenschaften zu Berlin. 1881. Biologisches Zentralblatt. 1881. Bd. I. S. 214. - Danilewsky, daselbst, 1882. S. 694 .

844. Prévost, Revue médicale de la Suisse romande. 1881. Schwalbe u. Hofmann's Jahresbericht der Physiologie für 1881. S. 29.

845. Christiani, Monatsberichte der k. Akademie der Wissenschaften zu Berlin. 1881. S. 487.

846. Rubner, Zeitschrift für Biologie. 1881. Bd. 17. S. 214.

847. Riegel, Deutsches Archiv für klinische Medizin. 1882. Bd. 31. S. 1.

S48. Dobson, Journal of anatomy and physiology. 1883. Vol. 17. P. II. S. 159. PI. VI. Fig. 10 .

849. Ka mocki, Biologisches Zentralblatt. 1883. S. 709.

850. Schwalbe, Archiv für mikroskopische Anatomie. 1870. Bd. 6 S. 1. Taf. II u. III.

851. A. Key u. G. Retzius, Studien in der Anatomie des Nervensystemes. I. Hälfte. 1875. S. 71. Taf. XXXVII.

532. Schwalbe, Medizinisches Zentralblatt. 1869. S. 466.

853. Joh. Miiller, Zur vergleichenden Physiologie des Gesichtssinnes. 1826. S. 145.

854. Pot Diss. Göttingen. Ohne Jahreszahl (ca. 1875). S. 71 .

855. Körner, Abhandlungen der Senckenlergischen naturforschenden Gesellschaft. 1883.

856. Schütz, Tageblatl der Naturforscherversammlung zu Eisenach. 188\%. S. 229.

S57. Pasteur, Deutsche Vierteljahrsschrift für öffentliche Gesundheitspflege. 1883. Bd. 15. S. 204.

858. Grassi, Gazetta medica Italiano-Lombardia. 1878. Nr. 48.

839. Leuckart, Berichte der k, sächsischen Gesellschaft der Wissenschaften zu Leipzig. Math.-phys. Kil. 1882 (12. März 1883).

860. W. Krause, Die terminalen Körperchen der einfach sensibeln Nerven. 1860. S. 119. Tabelle IV.

861. Cizermak, Moleschott's Untersuchungen z. Naturlehre U. s. w. 1860. Bd. VII. S. 377.

862. Neuman n, Archiv für mikroskopische Anatomie. 1866. Bd. II. S. 512. 
863. A utun. s. B. Sch midt, v. Pitha u. Billroth's Handbuch der Chirurgie. Bd. III. Abt. 2. Liefg. 3. 1882. S. 201.

864. Lebedeff, Archiv für Physiologie. 1883. Bd. 31. S. 34.

865a. von $\mathbf{M l o j}$ is ovics, Leitfaden bei zoologisch-zootomischen Präparierübungen. 1879. S. 82. - Zitirt auf S. 221.

865b. Bech terew, Archiv für Physiologie. 1883. Bd. 31. S. 64. - Zitirt auf S. 305.

866. Nicolaides, École pratique des hautes études de laboratoire d'histologie. 1882. S. 221 .

867. 'Bruch, Untersuchungen über die Entwickelung der Gewebe. Aus den Abhandlungen der Senckenbergischen naturforschenden Gesellschaft. Bd. IV u. VI. 1868, S. 249.

868. von Schklarewsky, Göttinger Nachrichten. 1872. Nr. 15. S. 301.

869. Cohn heim u. Roy, Archiv für pathologische Anatomie. 1883. Bd. 92. S. 424.

870. Simanowsky, Göttinger Nachrichten. 1883. S. 188.

871. Frommel, Zeitschrift für Geburtskunde u. Gynäkologie. 1882. Bd. VIII. S. 205.

872. W. Krause, Deutsches Archiv fuir klinische Medizin. 1883. Bd. 33. S. 435. 


\section{Verzeichnis der Operationen.}

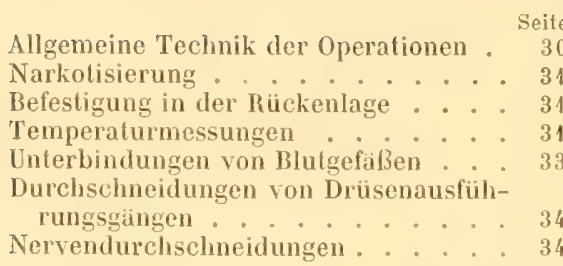

\section{Splanchnologie.}

Überziehen der IIaut ....... 172

Eröffnung des Vestibulum .... 181

Verletzung der Canales semicirculares 181

Durchschneidung der Hornhautnerven 186

Atzung der Cornea ........ 186

Anlegung einer Thranenfistel ... 186

Aufsuchung des Ductus parotideus . . 204

Aufsuchung des Ductus submaxillaris 207

Tracheotomie ......... 212

Exstirpationen der Lunge ..... 214

Eröffnung der Pleurahöhle . . . . 215

Unterbindung des Oesophagus . . . . 216

Anlegung einer Magenfistel .... . 217

Injektionen in den Magen . . . . 217

Exstirpation von Stücken der Leber - 222

Anlegung einer Gallenfistel . . . . 223

Aufsuchung des Ductus choledochus . 222

Exstirpation der Milz ........ 224

Aufsuchung des Ductus pancreaticus . 225

Injektionen in die Bauchhöhle . . . . 227

Exstirpation der Nieren s. Unterbindung der Aa. renales .......

Unterbindung der Ureteren s. Unterbindung der Aa, renales .......

Exstirpation der Nebennieren ... .

Kastration...........

Aufsuchung des Vas deferens ...

Fxstirpation des Ovarium . . . . .

Reizung des Uterus. . . . . . . .

Verschließung eines Cornu uteri ..

Exstirpation eines Cornu uteri . . .

Verschließung einer Stelle der Vagina

Exstirpation eines Stuckes der Vagina

\section{Angiologie.}

Seite

Herz.

Einfülırung einer Nadel in das Herz . 245

Bloßlegung des Herzens. . . . . 245

\section{Arterien.}

Unterbindung des Truncus anonymus der A. carotis communis s. Durchsch, d. N. vagus der A. subclavia . . . der A. mammaria interna der Aorta thoracica. . der Aorta abdominalis . der A. coeliaca . . . (I. A. hepatica s. Aufsuch. des Ductus choledochus d.A. mesenterica superior der Aa. renales .... der A. iliaca communis . der A. iliaca externa . (ler A, uterina..... der A. cruralis . . . . der A. saphena magna. der A. nutritia tibiae. .

\section{Venen.}

Unterbindung der V. mammaria interna s. Unterb. der A. mammaria interna Unterbindung der $\mathrm{V}$, jugularis interna s. Durchschmeidung des $\mathrm{N}$, vagus . Unterbindung der V. jugularis externa Unterbindung der Vv. renales s. Unterbindung der Aa. renales . . . .

Unterbindung der V. cruralis s. Unterbindung der A. cruralis . . . . $26:$; Unterbindung der V. portarum . . . 280

\section{Neurologie.}

Riickenmark. markes. 
Zerstörung des Lumbalteiles Seite

Reizung des Cervikalteiles .

Ge h i r n.

Zuckerstich ......... 287

Noeud vital......... 288

Durchschneidung d. Pyramidenstränge $28 s$

Durchschneidung des Pons Varolii . . 289

Zerstörung der Flocke des Cerebellum 290

Exstirpation des Cerebellum . . . 291

Durchschneidung des Crus cerebelli ad pontem . . . . . . . .

Durchschneidung des Pedunculus cerebri ...........

Manègebervegung-Operation ... 292

Epilepsie .......... 293

Exstirpation der Großhirnhemisphären 302

Blutlauf im lebenden Gehirn .... 309

Operationen an der Großhirnrinde . . 302

Entleerung von Cerebrospinalflüssigkeit 303

\section{Hirnnerven.}

Durchschneidung des N. olfactorius .

-
-
-
-
-
-
-
-
des N. opticus. des N,oculomotorius des N. ophthalmicus des $\mathrm{N}$, infraorbitalis des $\mathrm{N}$. lingualis . . des $\mathrm{N}$. mandibularis des $\mathrm{N}$. abducens. . der Chorda tympani des N. facialis.. . des $\mathrm{N}$. acusticus.

Ausreißung des N. glossopharyngeus . Durchschneidung des N.glossopharyngeus ................

Durchschneidung des $\mathrm{N}$. vagus. . . des $\mathrm{N}$, laryngeus superior s. N. vagus ....... Durchschneidung des R. cardiacus s. N. vasus
Durchschneidung des $\mathrm{N}$. laryngeus inferior $\mathrm{S}$. N. vagus . . . . 319

Durchschneidung des R. descendens des N. hypoglossus. . . . . . 319

Durchschneidung des $\mathrm{N}$. accessorius. 320 des N. hypoglossus . 322

\section{Rii ckenmarksnerven.}

Durchschneidung des N. phrenicus . . 329

- des N. medianus . 333

- des Plexus brachialis 335

- des N. cruralis. . 339

- des N. saphenus ma-

jor s. Unterb.der A. Saphenamagna 267

Durchschneidung des N. ischiadicus . 341

- des N. peronaeus. . 342

- des N. tibialis . . 343

Sympathisches Nervensystem.

Durchschneidung der Nn. petrosi superficiales....... . . . 348

Exstirpation des Ganglion cervicale superius . . . . . . . 348

Durchschneidung des $\mathrm{N}$. sympathicus am Halse s. N. vagus. . . . .

Exstirpation des Ganglion cervicale inferius. 349

Exstirpation des Plexus cardiacus . $\quad 3 \$ 9$

Aufsuchung des $\mathrm{N}$. sympathicus in der Bauchhöhle . . . . . 3 3

Durchschneidung des $\mathrm{N}$. splanchnicus 3.5

Exstirpation der Ganglia coeliaca . . 353

Exstirpation des Plexus renalis S. Unterbindung der Aa. renales

Exstirpation des Plexus aorticus abdominalis............

Exstirpation des Ganglion mesentericum $3: 3:$

319 Aufsuchung des N.hypogastricus. . . 350 



\title{
DIE
}

\section{ANATOMIE DES KANINCHENS}

\author{
IN
}

TOPOGRAPHISGHER UND OPERATIVER RÜCKSICHT

BEARBEITET

VON

W. KRAUSE

DR. MED. ET ZOOLOG. PROFESSOR IN GÖTTINGEN.

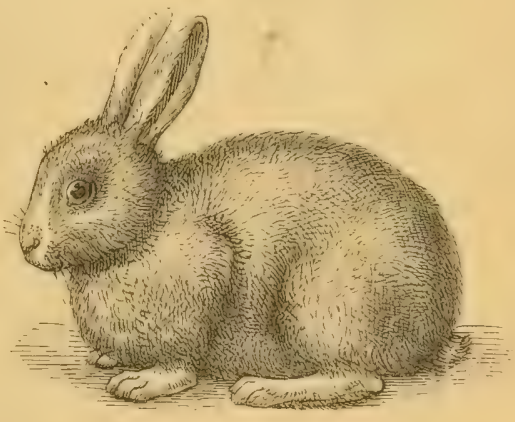

ZWFITE ADFLAGE.

MIT 161 FIGUREN IN HOLZSCHNITT.

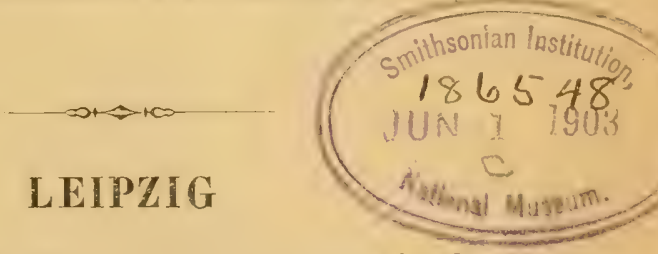

VERLAG VON WILHELM ENGELMANN 1884. 






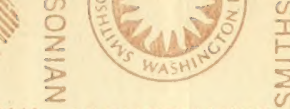

(2)
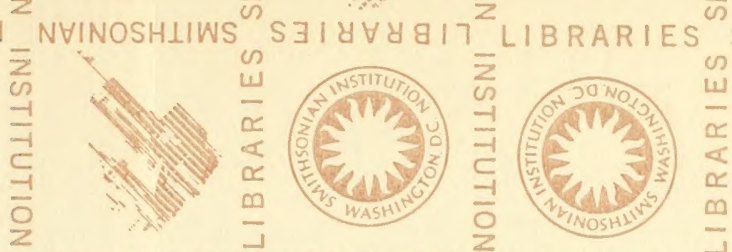

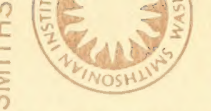

$\sum_{\frac{2}{2}}^{0} \% \frac{\mathrm{N}}{\mathrm{E}}$
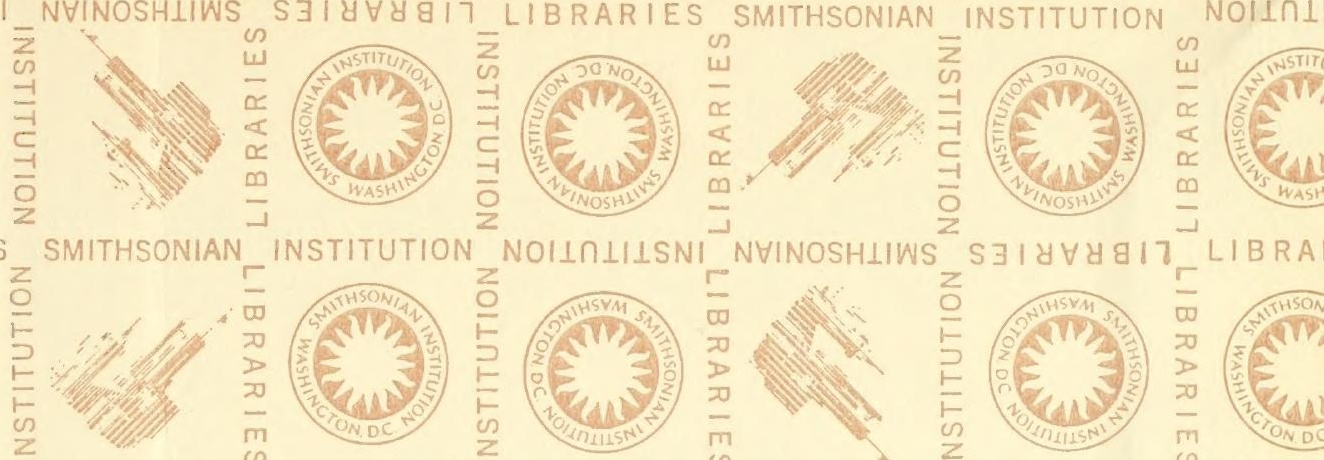

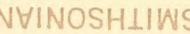
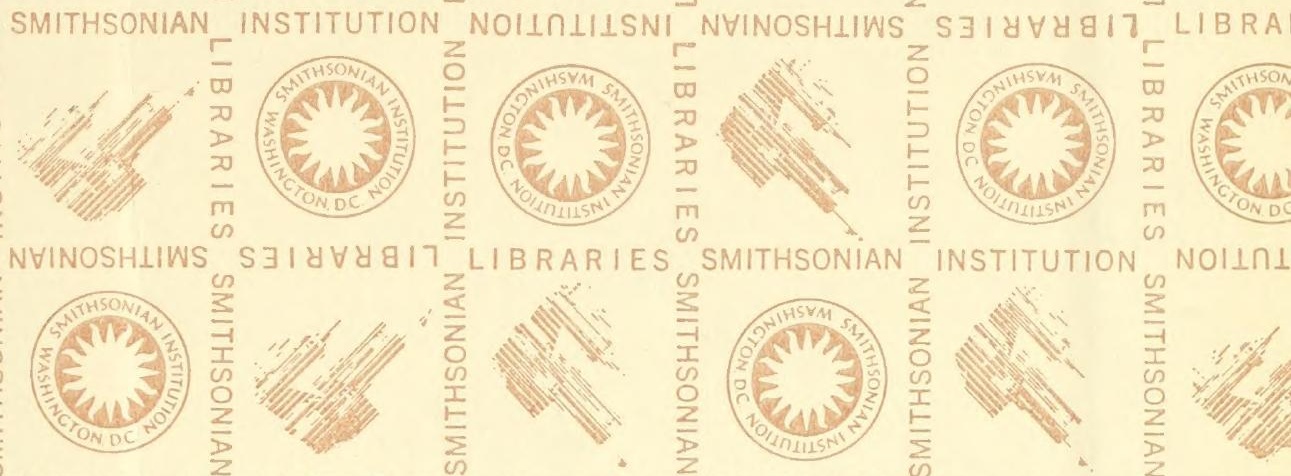

Nolın!
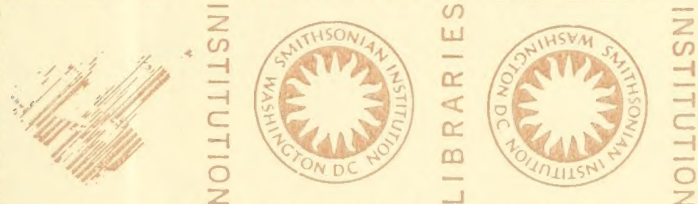

NHINOSHLIWS

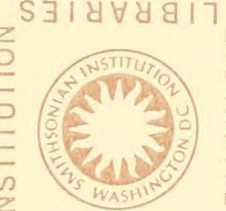

L I B
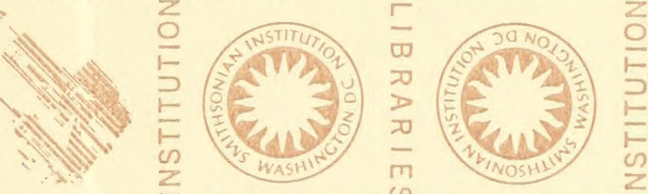

NVINOSHLIWS
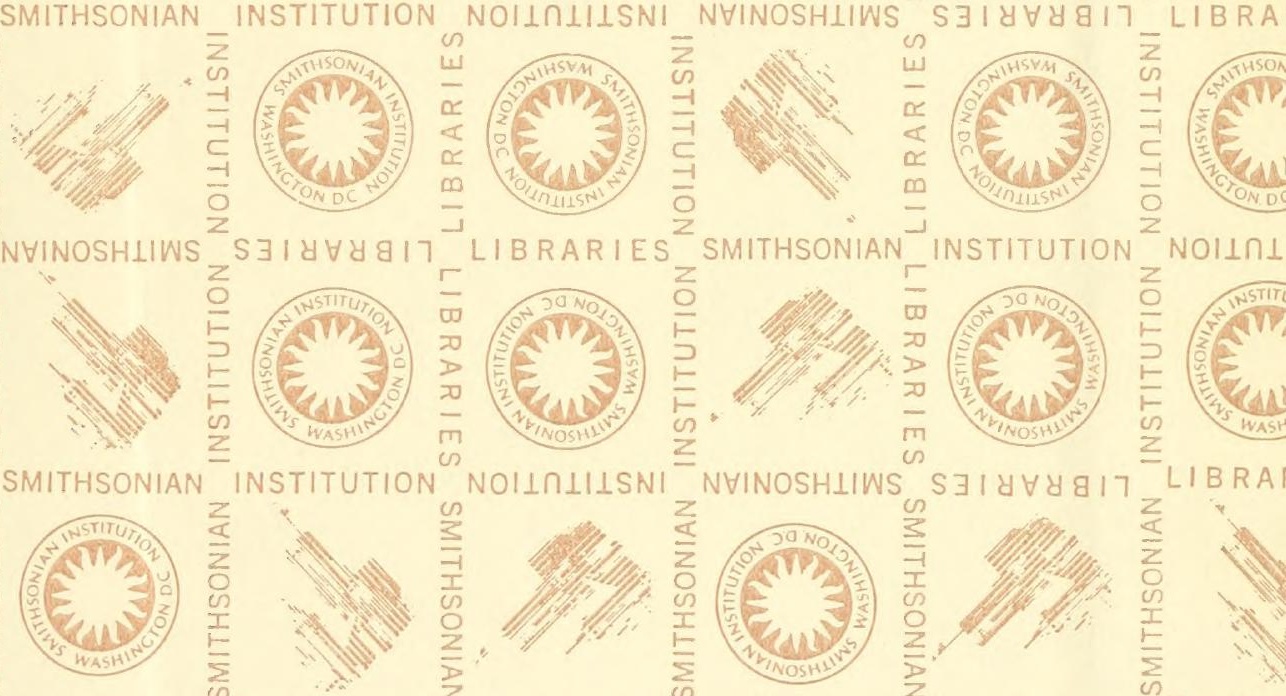

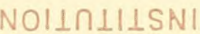
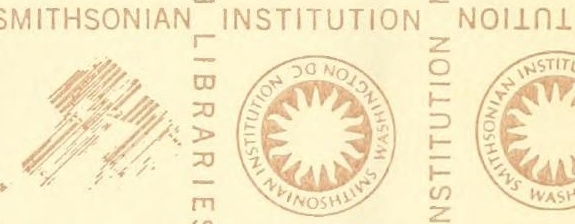

NVINOSHIIWS
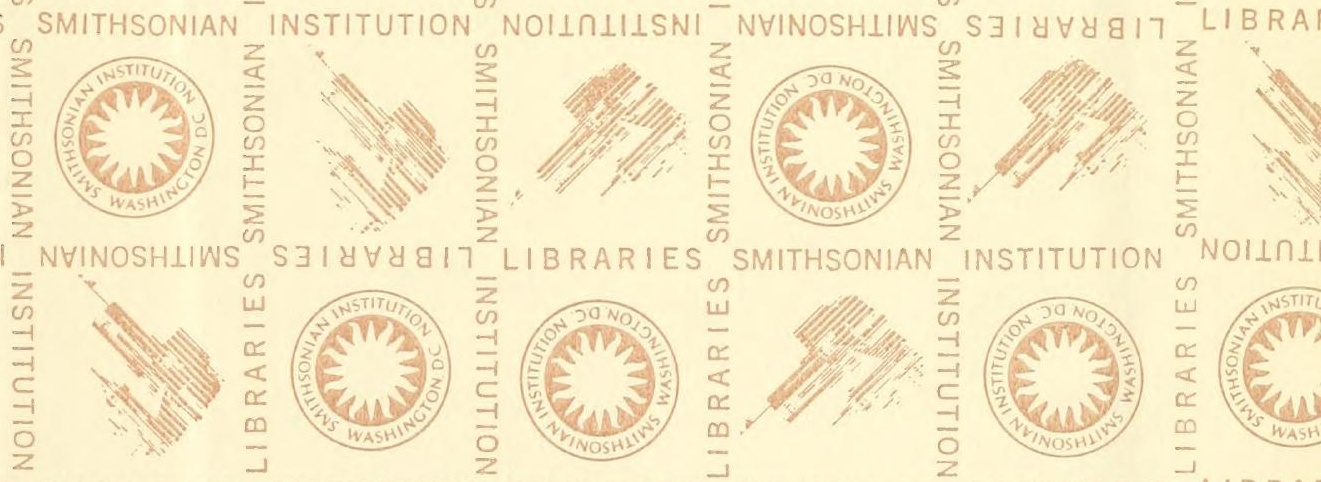

NOIL 1

政
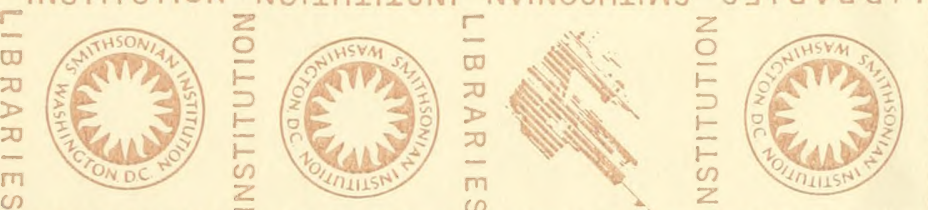

LIBRAF

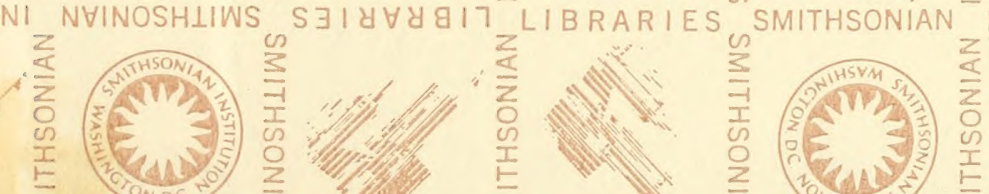

年

INSTITUTION
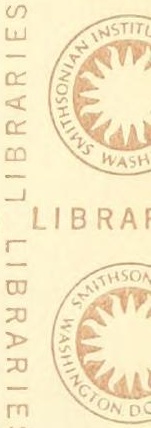

NOIInI 
